UC-NRLF

C 2 962 585

CARCINOMA OF THE THYROID IN THE SALMONOID FISHES : : : : By Harvey R. Gaylord and Millard C. Marsh

Publications from STATF INSIITUTE FOR THE STUDY OF MAI.IGNANT DISFASE

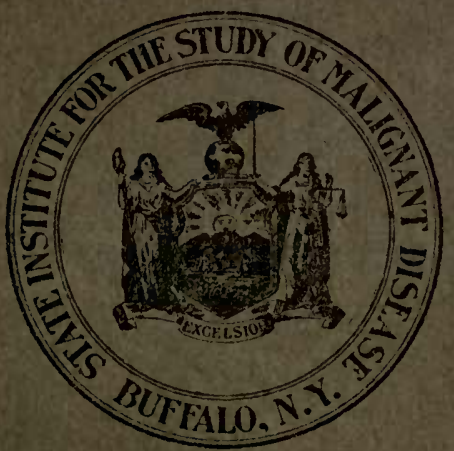




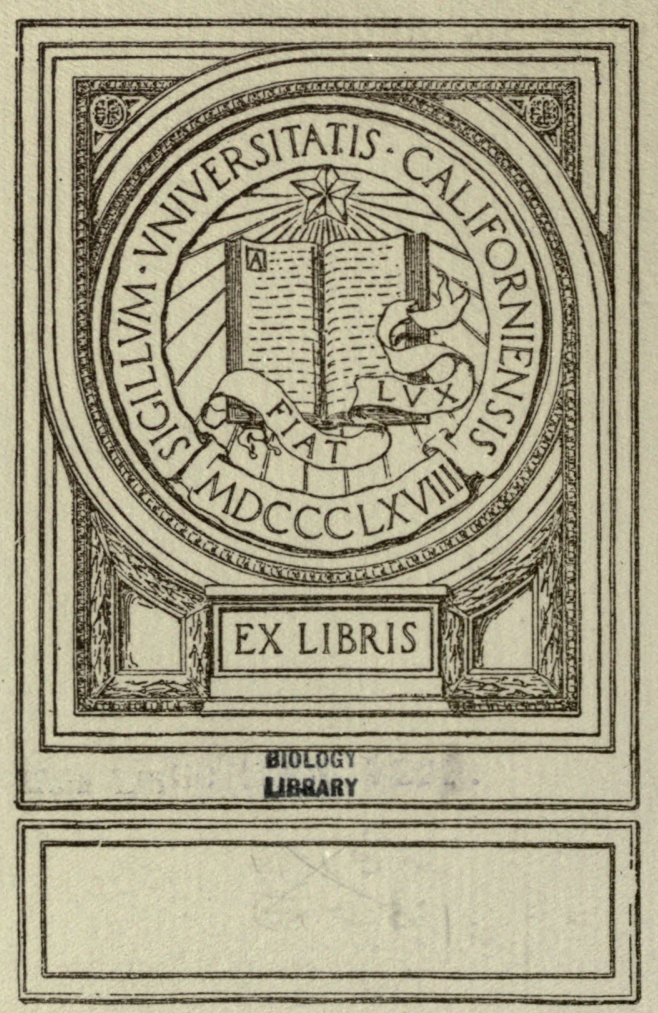


19t: 



\section{CARCINOMA OF THE THYROID IN THE SALMONOID}

FISHES : : : : By Harvey R. Gaylord and Millard C. Marsh

Publications from STATE INSTITUTy For THE STUDY OF MALIGNANT Disease

Serial No.99 $\quad: \quad: \quad: \quad: \quad: \quad: \quad$ Issued April 22, 1914



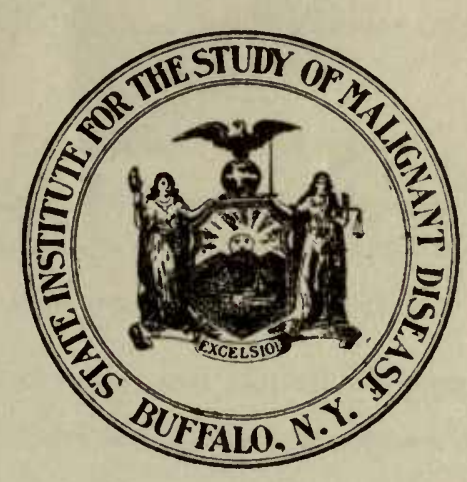


$\mathrm{SH} 173$

C 3 G 3

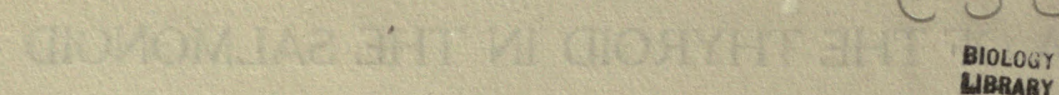

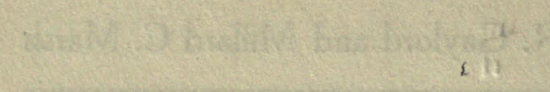




\section{CARCINOMA OF THE THYROID IN THE SALMONOID FISHES}

An investigation and experimental study conducted jointly by the Gratwick Laboratory of the State Institute for the Study of Malignant Disease, Buffalo, N. Y., and the United States Bureau of Fisheries

\section{By Harvey R. Gaylord, M. D.}

Director, State Institute for the Study of Malignant Disease, Buffalo, N. Y.

AND

\section{Millard C. Marsh}

Biologist, State Institute for the Study of Malignant Disease, formerly Scientific Assistant, United States Bureau of Fisheries

WITH THE COLLABORATION OF

Frederick C. Busch, M. D., Internist, and Burton T. Simpson, M. D., Pathologist State Institute for the Study of Malignant Disease 


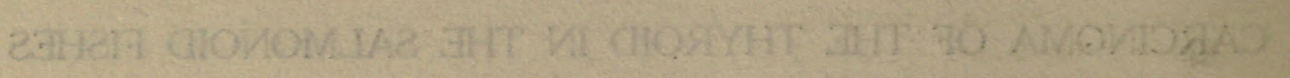

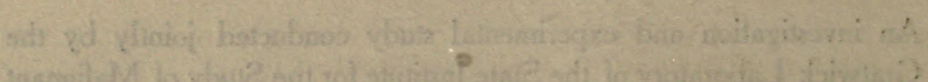

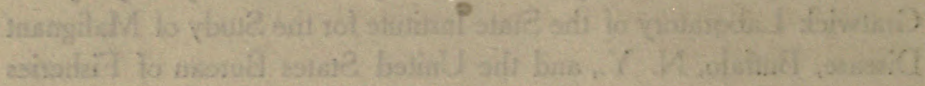

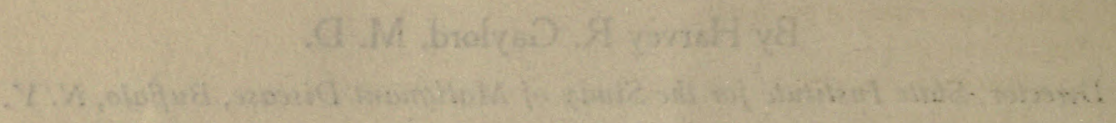

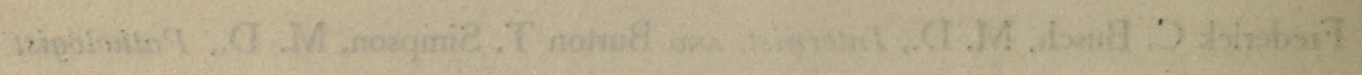




\section{CONTENTS.}

Introduction

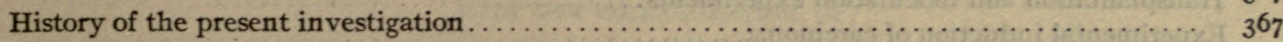

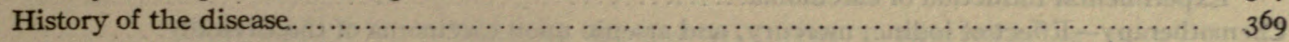

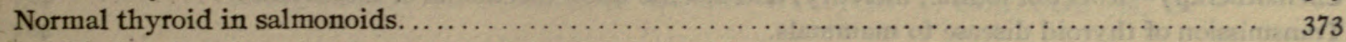

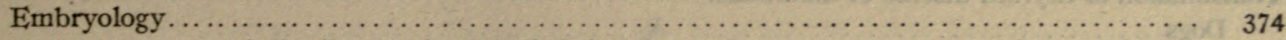

Gross anatomy and distribution in the adult brook trout. . . . . . . . . . . . . . . 376

Anomalous deposits of thyroid $\ldots \ldots \ldots \ldots \ldots \ldots \ldots \ldots \ldots \ldots \ldots \ldots \ldots \ldots \ldots \ldots \ldots \ldots \ldots \ldots \ldots \ldots \ldots \ldots \ldots \ldots$

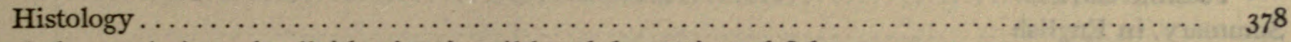

Simple hyperplasia and colloid goiter in wild and domesticated fish $\ldots \ldots \ldots \ldots \ldots \ldots \ldots \ldots \ldots \ldots, 379$

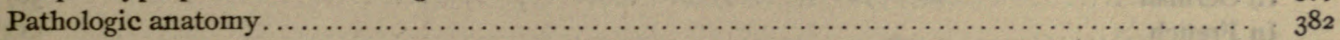

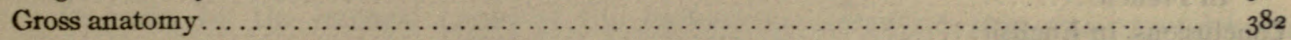

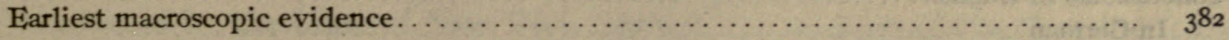

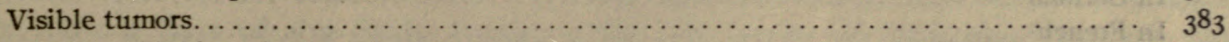

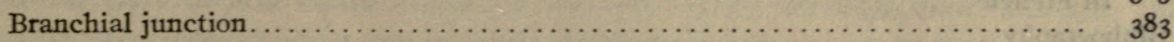

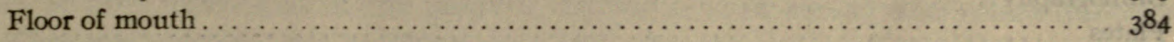

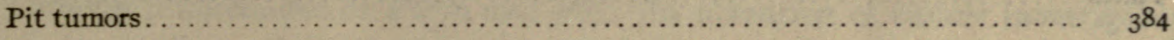

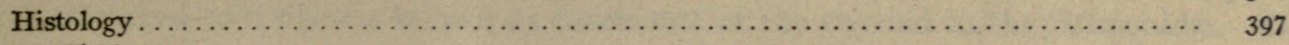

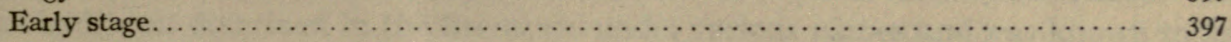

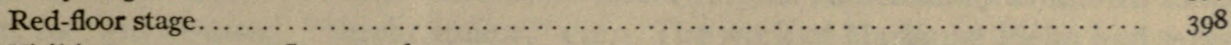

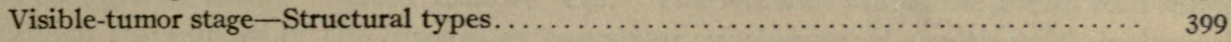

Infiltration. . . . . . . . . . . . . . .

Bone and cartilage; vessel wall; muscle; skin................... $40 \mathrm{I}-402$

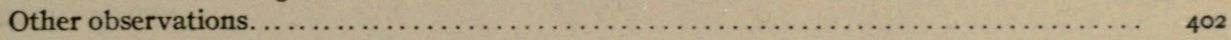

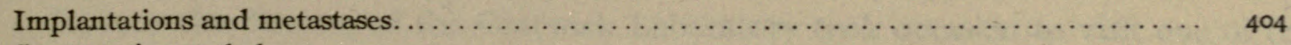

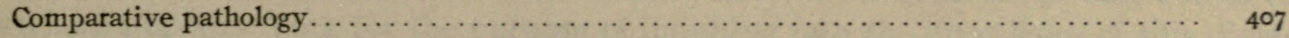

Occurrence of the disease under wild conditions. .................... 4 II

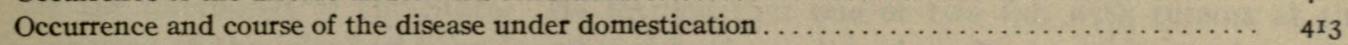

Distribution of the disease in United States hatcheries......................... ${ }_{41} \mathrm{I}_{3}$

Names of species and hybrids. . . . . . .

Geological formation at fish hatcheries. . . . . . . . . . . . . .

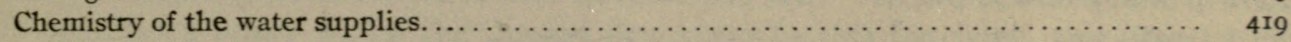

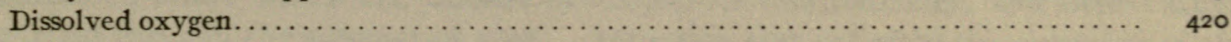

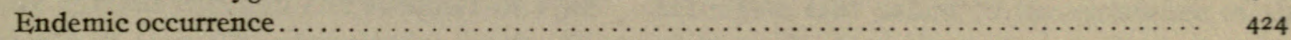

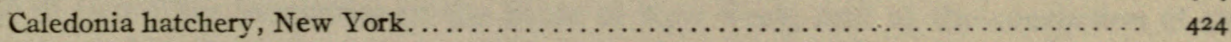

Craig Brook station: Conditions at the beginning of the investigation $\ldots \ldots \ldots \ldots \ldots \ldots \quad 425$

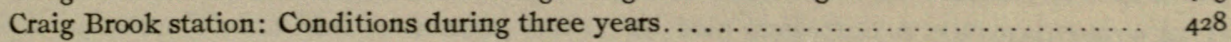

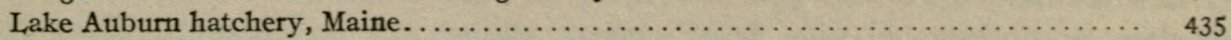

Private hatchery in the State of Washington...................... 436

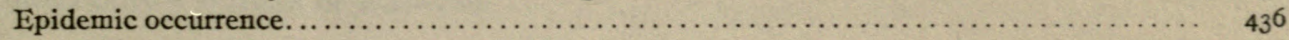


Occurrence and course of the disease under domestication-Continued.

Hybridization

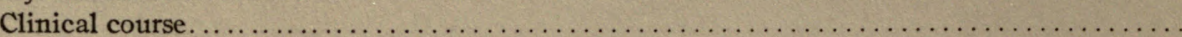

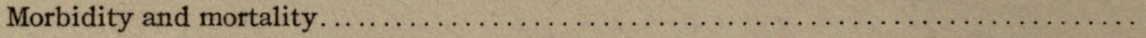

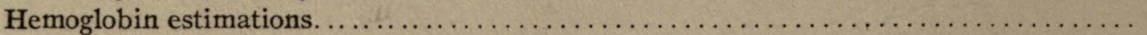

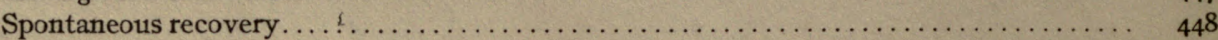

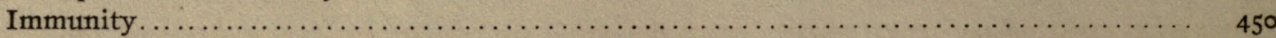

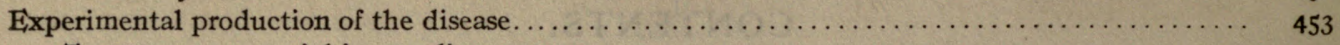

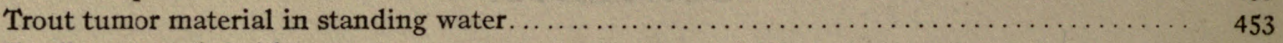

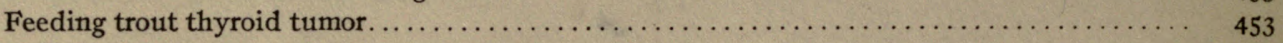

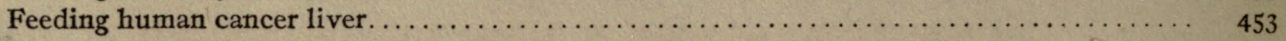

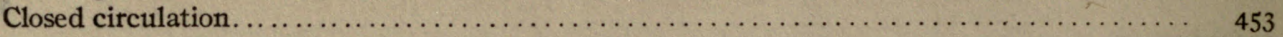

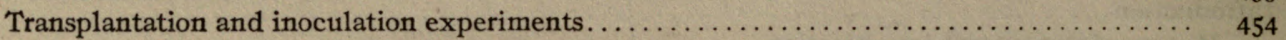

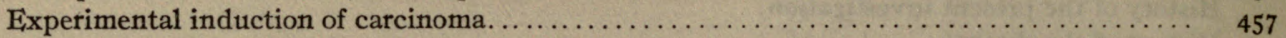

Chemotherapy-Effect of iodine, mercury, and arsenic upon carcinoma of the thyroid ....... 463

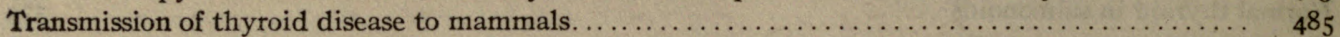

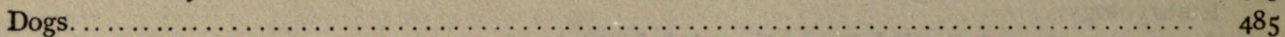

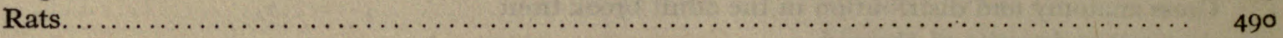

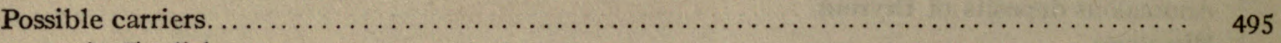

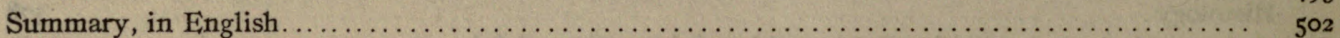

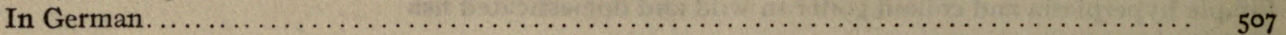

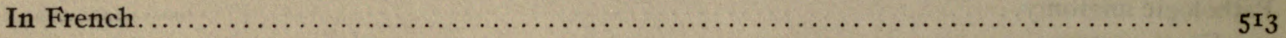

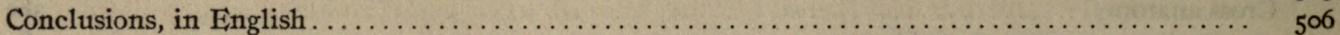

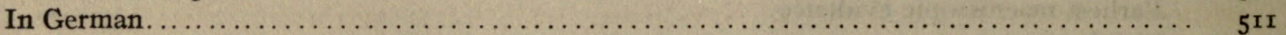

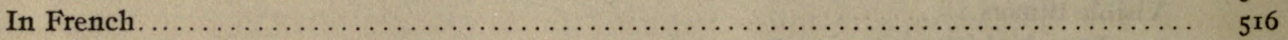

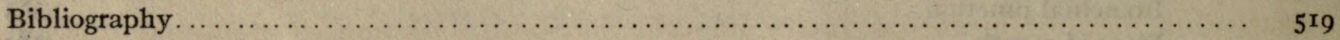

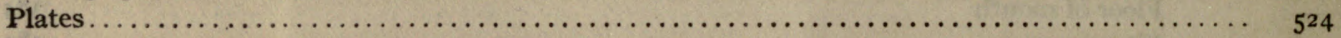




\title{
CARCINOMA OF THE THYROID IN THE SALMONOID FISHES.
}

\author{
$*$ \\ BY HARVEY R. GAYLORD, M. D., and MILLARD C. MARSH \\ WTTH THE COLLABORATION OF \\ FREDERICK C. BUSCH, M. D., and BURTON T. SIMPSON, M. D. \\ INTRODUCTION.
}

HISTORY OF THE PRESENT INVESTIGATION.

In 1907 , by the natural trend of the general investigation into cancer which was being conducted by the State of New York through the medium of the Gratwick Laboratory, now a part of the State Institute for the Study of Malignant Disease, that institution became interested in the possible distribution of cancer and allied affections in fish. Through publications of Plehn and Pick the attention of cancer investigators was attracted to a disease known as carcinoma of the thyroid in the Salmonidæ. The disease had been described in the literature under various names and was known to fish culture as "gill disease," "throat tumor," etc. The work of Marianne Plehn had served to establish the nature of the disease as cancer or carcinoma of the thyroid, intimately associated with enlargement of that organ of a more simple nature which might be considered goiter.

In 1907 the director of the Gratwick Laboratory took occasion to visit one of the hatcheries in New York for the purpose of inquiring into the prevalence of this disease in the hatcheries of the State. He learned that one or two fish with tumors at the junction of the gills had been found and in the spring of 1908 a report came from this hatchery that an epidemic was in progress, and an examination made on the spot revealed the presence of visible tumors in some 700 fish. Attempts were made to study the conditions under which the disease developed in this hatchery, and observations were carried through the summer of 1908 . Attention was called to the existence of the disease in two other hatcheries in the State of New York, and at the conclusion of the summer's work it became apparent that the great extent of the disease, the existence of which in other States had been reported to us, was such that a comprehensive investigation could probably be successfully accomplished only in cooperation with the United States Bureau of Fisheries. 
For this reason, in February, 1909, the results obtained and the importance of the subject were laid before President Roosevelt, who decided that a joint investigation between the Gratwick Laboratory and the Bureau of Fisheries should be undertaken. The Commissioner of Fisheries, Hon. George M. Bowers, detailed Mr. Millard C. Marsh as the representative of the Bureau to cooperate with the State. Facilities were at once afforded for a detailed investigation at one of the Government fish hatcheries where the disease was endemic.

The first summer's work was carried out by Dr. Gaylord at this Government hatchery. In the winter of I909-1o Mr. Marsh, working at the Gratwick Laboratory in Buffalo, in conjunction with Dr. Gaylord, carried out a series of experiments on feeding, crowding, vitiation of water, etc. The summer of 1910 was again spent by Dr. Gaylord and Mr. Marsh at the Government hatchery in question. The winter of I910-I I Mr. Marsh continued the work in Buffalo. In July, I911, Mr. Marsh was detailed for service in Alaska and Dr. Frederick C. Busch, of the State Institute for the Study of Malignant Disease, took up his part of the work. In the pathologic histologic part of the work Dr. Burton T. Simpson contributed largely, having studied many hundred sections and recorded important facts. The experimentation at the Government hatchery has been conducted to a point where it is now possible to make the first report on the studies thus far conducted into this disease.

In this report we have attempted to determine the nature of this affection, to present a well-defined picture of the disease as it occurs in hatcheries under conditions of practical fish culture, to determine as nearly as possible the factors which predispose to the development of the disease, and to present certain conclusions regarding its nature. Identification of the agent which causes this disease we have left for future investigation. How important to fish culture and how significant to cancer research future studies in the more sharply defined field to which this report is an introduction will prove, may be easily seen from the significant facts thus far adduced.

In our investigations and in the preparation of this report we have had assistance from many persons to whom we wish here to acknowledge our indebtedness. The joint investigation was begun during the incumbency of Hon. George M. Bowers as Commissioner of Fisheries, and the resources and facilities of the Bureau were freely used by him in furtherance of the mutual undertaking. Likewise, Dr. Hugh M. Smith, who as Deputy Commissioner interested himself keenly in the encouragement of the work, has since his recent appointment to the commissionership continued in every way to give indispensable support and cooperation. The members of the fish-cultural and scientific staffs of the Bureau in Washington, and superintendents and employees of stations, have given much time and effort in various ways. Of the latter, Mr. C. G. Atkins, superintendent of Craig Brook station, has been our chief dependence.

The Commissioner of Forest, Fish, and Game of the State of New York, Mr. James S. Whipple, and the State Fish Culturist, Dr. T. H. Bean, have furnished valuable assistance by placing at our disposal facilities and material at certain of the State hatcheries. The superintendents and employees at the hatcheries at Bath, Caledonia, and Cold Spring Harbor gave much direct assistance. 
The excellent plates in color and most of the other drawings are the work of Miss E. S. Carrington, of Louisville, $\mathrm{Ky}$.

Dr. F. W. Baeslack, formerly of the Gratwick Laboratory, autopsied a portion of the tumor-fish material. Of the present force of the laboratory the work of Mr. Damon Averill deserves special mention. He has had to do with the fish material from the beginning of the investigation, has done a part of the histological work and all the extensive photography involved; to the photomicrographs particularly, on which the value of this report largely depends, he has devoted much pains and skill.

Miss C. A. Maclay, secretary of the State Institute, has had charge of many details concerned in the investigation, has prepared much of the manuscript for the printer, and taken part in the proof reading.

The translations of the summary and conclusions into German and French we owe to the skill of Dr. Max Breuer and Dr. Charles van Bergen, both of Buffalo.

\section{HISTORY OF THE DISEASE.}

The existence of this disease was first noted in 1883 by a German investigator, R. Bonnet, who published in the Bavarian Fisheries Journal the description of a peculiar epidemic occurring among the lake trout (Trutta lacustris) at the fish hatchery in Torbole on the Gardasee, and, between the middle of February and the end of June, killing no less than 3,000 fish. All of these fish had tumors at the junction of the gills.

Bonnet did not recognize that this disease was cancerous in its nature. The first to recognize the tumor as carcinoma was Scott (1891). The full text of his "Note on the Occurrence of Cancer in Fish" is as follows:

The fish afficted with this disease were all specimens of the American brook trout (Salmo fontinalis) kept in confinement in one of the ponds at Opoho belonging to the Dunedin Acclimatization Society. Males and females were alike affected and the diseased fish never recovered. Through the kindness of Mr. Deans, the manager, I was able to examine several specimens showing the disease in various stages of advancement, and the following is a short account of the naked-eye and microscopic appearances of the growth.

In the earliest stages the ventral wall of the pharynx in the middle line, a short distance behind the tongue, is seen to be somewhat roughened and raised in low irregular swellings. At this stage nothing is to be seen unless the mouth is opened widely. As the tumor grows, however, not only does it involve more and more of the pharyngeal floor, spreading also to a slight extent laterally, and involving the ventral ends of the gill arches, but it ultimately shows itself externally as a rounded pink lump on the isthmus in the angle between the diverging branchiostegal rays.

A microscopic section of the tumor shows all the stages in the development of a carcinomatous growth. In parts a purely glandular structure is seen-the glands, apparently, of the acinotubular type. Elsewhere, owing to the proliferation of the cells, the gland acini have become distended and irregular in form (adenoma stage), while in large areas these overdistended acini have burst, as it were, and the liberated cells, making their way into the stroma, infiltrate it, and all gland structure is lost (carcinoma stage).

Of the two figures which accompany this note, the first (Fig. I) shows the floor of the mouth and pharynx, as seen from above, of a fish suffering from the disease. The nodular character of the tumor is clearly seen. The second shows a small portion of a section as seen under the microscope. A distended acinus is seen liberating a stream of cells into the gland stroma (Fig. 2). 
The occurrence of cancer in the lower animals has been frequently noted of late years, and it is by no means so rare among them as it was at one time thought to be. I have, however, been unable to find any mention of it having been noted in fish.

A report on this disease in trout appeared in 1902 in the General Fisheries Magazine (German), by Marianne Plehn, who recognized it as a disease of the thyroid gland. L. Pick reported fully on the subject in a paper entitled "Carcinoma of the Thyroid in the Salmonidæ," describing ro fish affected with the disease, which, in agreement with all other authorities, he concludes, is genuine cancer. He refers especially to the epidemics of the disease, descriptions of which are found below.

In the reports of the New Zealand Department of Agriculture, Division of Veterinary Science, $190 \mathrm{I}-2$, is a report by Gilruth entitled "Epithelioma Affecting the Branchial Arches of Salmon and Trout." Gilruth describes a specimen, a 5-year-old salmon (Salmo salar) from the Clinton ponds, which had a growth on the third branchial arch and "its gill ray." It was the first specimen which had been found there. His description is as follows:

Macroscopical examination.-Growth appeared about the size of a marble, situated on the center of the third branchial arch, affecting laterally the first and third and implicating the branchiæ. The gill cleft was distended, but until forcibly opened the tumor was not visible.

Later he received three rainbow trout (Salmo irideus).

In each specimen the tumor was about the size of a large walnut projecting on both sides of the gill cleft. (Fig. 3.) Each tumor appeared to have started at the apex of the second branchial arch, about the base of the branchiæ, which they had implicated almost to their terminal points, only leaving a faint fringe of what were the branchiæ. The first and second arches, with their branchiæ, were also affected. The growth did not affect the apex of the the arch externally, but passed on the internal surface through to both sides. The external surface of the tumor was faintly pink. On section the tumor was found to be homogeneous, pale in color, and soft in consistency.

Microscopical examination.-Fibrous capsule, covered by several layers of squamous epithelium, from which the fine fibers forming branching and anastomosing trabeculæ pass inward, inclosing more or less irregular alveoli. These alveoli are lined by an irregularly disposed layer of columnar cells, the center of each alveolus being filled with cubical cells more or less degenerated. The smaller alveoli are lined with columnar or cubical cells, and have the appearance of tubules cut transversely, the central area only containing one or two degenerated cells. Blood vessels with thin walls and wide lumina are found traversing the fibrous capsule and the fibrillar network within. Frequently hemorrhage is met with where the slender walls of the blood vessels have ruptured. In many portions of the tumor the branching fibrillæ with columnar cells on either side show an appearance recalling somewhat the fronds of the common fern. Taking into consideration the histology of the branchiæ with the above description, it would appear that the only pathological classification, at least from the mammalian standpoint, which this would come under, is epithelioma (as distinguished from carcinoma).

Gilruth gives a letter from L. F. Ayson, Chief Inspector of Fisheries, New Zealand, who states:

This gill disease was first noticed there [Masterton hatchery] among the American brook trout (Salvelinus fontinalis) in 1890 , when three diseased fish were taken out that spawning season. The disease was peculiar to this species until the rainbow trout (Salmo irideus) were introduced, among which it made its appearance when they were over 3 years old. I have never found any of the brown trout ( $S$. fario) affected, but took out three diseased fish from a thousand 3 and 4 year old Loch 
Leven ( $S$. levenensis) during the spawning season of 1896 . In 1898 about 2 per cent of the American brook trout over 3 years old would be affected and about $x$ per cent of the rainbow trout over that age. I have no record of ever finding any diseased fish under 3 years old.

With regard to the diseased specimens of rainbow trout which I brought to you recently, I visited the Masterton hatchery on June $x 6$, when the manager was engaged in shifting his 3 -year-old rainbow trout from their summer ponds into the spawning races, where they were sorted out, i. e., the male fish were separated from the females and the ripe female fish from the unripe; the ripe fish being stripped, and the unripe females and male fish being put into separate races. I assisted with the separating and stripping that day, when $x, 200$ fish were handled. From this number 29 fish affected with this gill tumor were taken out; these (with the exception of the specimens taken to your laboratory) were knocked on the head and buried.

At the Otago Acclimatization Society's Opoho and Clinton trout hatcheries the American brook trout are, I believe, the only fish affected with this disease, but at Christchurch hatchery I understand that it is common among both the American brook and rainbow trout. If it is of any interest to you I will get particulars from the Otago and Canterbury Acclimatization Societies with regard to this matter, and will also inquire whether this disease has made its appearance at the Aukland Society's hatchery at Okoroire, where only rainbow trout are kept.

Gilruth quotes Ayson further as the authority for the statement that at Masterton he was present at the handling of 3,000 or 4,000 pond-spawning fish (1902) and that, from these, roo fish affected similarly to those described were taken out and killed; also that the manager of the Aukland Society's rainbow trout hatchery stated that 7 per cent of the mature pond fish at that hatchery were affected.

Marsh in 1903 first reported the disease in the United States as an occasional occurrence known to fish culturists, affecting yearling as well as older trout, and noted the occurrence of marked anemia in affected fish.

In the Third Annual Report of the Imperial Cancer Research Fund (English), I 908 , in an article on the zoological distribution of cancer in fishes, occurs the following:

Since the first authentic case of carcinoma in a fish, viz., of the thyroid gland in a trout, was submitted to us in February, 1903, by Mr. Gilruth, over 2,000 additional cases have been reported to us from the same and other hatcheries. * * We have been unable to approach this extremely interesting and important subject from the fact that up to the present we have been unable to find any evidence of its occurrence in the hatcheries in this country at the present time, the last epidemic of the disease appear. ing in $\mathrm{x} 888$ in Scotland.

At a meeting of the Lyon Medicale in 1908 Jaboulay reported having had in his laboratory for study six trout affected with malignant tumors of the thyroid gland. These were sent to him in November by M. Crettiez, inspector of waters and forests of Thonon. The disease had existed at the establishment at Thonon for three years and had been first noticed by M. Crettiez in salmon hatched from eggs received from Germany. He had recently observed the disease in sea salmon, ombres-chevaliers (Salvelinus alpinus), and in the offspring of one hybridization formed by crossing the common female trout with the male ombres-chevaliers, to which he had given the name Salmo thononensis. To Crettiez the disease appeared to be clearly hereditary and at the same time contagious and always fatal, although any elaboration of his grounds for these conclusions is not given by Jaboulay. Jaboulay considers the tumor an adeno-carcinoma of the thyroid, which he says invades the thyroid region and the neighboring tissues and in its last stages generalizes in the various organs. 
In the United States the disease has been known to fish culture for some 40 years, but has escaped mention, so far as we have been able to find, in the several treatises on fish culture which have been written in this country, and has not until recently been the subject of any particular study.

From time to time during the progress of this investigation we have made preliminary statements before the American Association for Cancer Research. These brief summaries are here reprinted in order to show the development of the investigation along the lines originally indicated.

\section{AN EPIDEMIC OF CARCINOMA OF THE THYROID GLAND AMONG FISH $a$}

Dr. Harvey R. Gaylord, Buffalo: This paper is a continuation of a preliminary report made before the society a year ago. It gives details of two epidemics in different parts of the country, and refers to two others. The epidemic referred to last year, which resulted in the loss of 3,500 brook trout, had, during the summer of 1909 , begun to involve the brown trout and adult rainbows, so that heavy losses continued during this summer. Among the fish preserved from this epidemic was one with a tumor on the lower jaw, which on section was found to be either an implantation of the thyroid tumor or a metastasis, as the fish so affected had a primary tumor of the thyroid. From this observation it is plain that this tumor may, under given conditions, metastasize, or that it is implantable. In an epidemic in a second hatchery, an analysis of the course of the disease again showed that where fish occupied ponds which received water from ponds containing infected fish, these fish may become infected; and, furthermore, the rate at which the fish become involved increases progressively as the contents of ponds containing infected fish are added to the water which supply the fish. Another observation of importance is the discovery that lots of fish are immune. This is particularly shown in hybrid fish, in which one lot of hybrid salmon I year old were reduced from I, 043 in April to 44 sound fish remaining in August, whereas another lot of yearling hybrid salmon, although badly exposed by being placed in ponds into which the water from infected ponds ran, remained free from the disease throughout. Three lots of Scotch sea trout remained immune, although badly exposed. The only lot of brook trout 2 years old which were free from the disease was found on a careful analysis of their position throughout their entire life history in this hatchery, never to have been placed where the water from infected troughs or ponds flowed to them. They were placed in the uppermost pond and remained free from the disease throughout the epidemic. These observations on immunity in hybrid fish, in the light of those made by Tyzzer in inoculation of Japanese waltzing-mouse tumor, in hybrids from immune and nonimmune parents, serve to accentuate the similarity of this disease in fish to cancer in warm-blooded animals.

The disease is found to affect very small fish. A brook trout of the hatch of 1909,3 inches in length, was shown with a tumor of considerable size from which it had died. This was the first affected fish from the hatch of 1909 , and it had occupied from May until September one of five troughs which had the previous summer contained infected fish. From this it would appear that the contagion can be localized, even to given, small wooden troughs, and that these troughs can retain their infectivity from year to year. In all the epidemics thus far described, occasionally large fish, when expossed, acquire the disease. A landlocked salmon 8 years old, measuring 24 inches in length, developed large tumors, and in two other hatcheries during the past year epidemics have broken out involving considerable numbers of adult rainbow trout and large adult brook trout. Among the large fislı epithelioma of the tongue or the region of the mouth is not uncommon. Carcinoma of the thyroid produces the most rapid destruction among young fish, frequently diffusely infiltrating the gills and also growing to great relative size in the small fish. The tumor erodes bone, destroys cartilage, and infiltrates the muscular structure. The tumor presents varying characteristics, frequently retaining the alveolar type with colloid, again of a strictly adenomatous type, but in all cases with areas of complete malignant degeneration and assuming the characteristics of solid soft carcinoma.

a American Association for Cancer Research, meeting of Nov, 27, 1909, Journal American Medical Association, Jan. I5, 1910. 
In the study of this interesting form of cancer, the discovery of metastasis formation, the evidences of immunity, and the influence of blood relationship to susceptibility show the practical identity of this affection to cancer in warm-blooded animals. The apparent absence of metastasis formation as a criticism was long since applied to mouse cancers and to-day falls to the ground in this affection. The evidence of infectivity and contagion appear to the observer to be conclusive, and when correlated in the evidence of infectivity in cancer in warm-blooded animals should prove the greatest support to the parasitic theory we have yet encountered. The marked evidence of infectivity and contagion found in carcinoma of the thyroid in fish appears to be an accentuation of similar evidence of a less convincing character found in other species. Its accentuation in this disease can be largely explained by the environment and the conditions under which fish are artificially propagated.

\section{AN EPIDEMIC OF CANCER OF THE THYROID IN BROOK TROUT IN A FISH HATCHERY $a$}

Dr. H. R. Gaylord, Buffalo: This is a preliminary report on the investigation of a fish hatchery in which an epidemic of carcinoma of the thyroid in 2-year-old brook and brown trout exists at the present time. In this hatchery the water supply is from a spring coming out of a hillside, which runs into a basin or pond, from which it is piped to a small reservoir and then through a series of tanks which draw their supply directly from the reservoir. Carcinoma of the thyroid was discovered in a fish in the basin on the hillside two years ago. One year ago this basin was emptied and restocked with young fish and feeding was practiced for the first time in this upper pond. Of the tanks fed from the water passing through this pond, one tank containing 3,700 brook trout 2 years old, hatched from eggs brought from a hatchery in an adjoining State where the disease is not known to exist, showed 700 fish in various stages of the disease. The outbreak occurred in the early autumn and fresh cases are continually developing. In an adjoining tank, which has no connection whatsoever with the tank in question, are 200 brown trout reared from eggs hatched on the premises. Between 3 and 4 per cent of these fish show disease. The infected fish at no time have come in direct contact with the fish in the upper pond where the disease is known to have existed; neither at any time have the brook trout and the brown trout been in contact with each other. I believe that the state of affairs found in this fish hatchery points very strongly to the infectious nature of this form of cancer and that the contagion is water-borne. It is possible that feeding liver into the waters of the fish hatchery has some relation to the outbreak in this case. I know of a second fish hatchery where the disease was endemic for a number of years and where the feeding of liver has been changed to the feeding of chopped sea fish and in the last three years the disease has disappeared. I also know of two other fish hatcheries in which the disease is endemic, and I am undertaking a systematic and careful study of a number of fish hatcheries for the purpose of further determining the conditions under which the disease occurs.

\section{NORMAL THYROID IN SALMONOIDS.}

The thyroid in fishes has given rise to a not inconsiderable literature, beginning with Simon's paper (1844) on the comparative anatomy of the gland, in which he first identified the thyroid in fishes. The detailed studies of its histology belong to a much later period. Most of the work has been upon genera outside the Salmonidx, and especially upon the lower forms of fishes. Maurer (1886) described and illustrated the development of the thyroid in a trout, and the location of the thyroid follicles in the adult, with a semidiagrammatic drawing of the histology of the adult follicles. In 1910 and I9I Marine and Lenhart published photomicrographs of normal thyroid in the brook trout in illustration of studies of enlargement of the gland. Thompson in Igr I published a paper on the thyroid and parathyroid of vertebrates, with Amiurus as the only teleost

\footnotetext{
- American Association for Cancer Research, meeting of Nov. 27, I908, Journal of American Medical Association, Jan. $30,1909$.
} 
representative. In I9I I Gudernatsch, in the most extended study of the fish thyroid that has yet appeared, diagramed the distribution of the follicles in 22 genera of teleosts including 4 genera and 5 species of salmonoids, and showed the minute structure in several genera including 2 species of salmonoids, viz., a Pacific salmon and the American brook trout (Salvelinus fontinalis). He was the first to emphasize, in a preliminary statement before the American Society for Cancer Research (Nov. 27, 1909), the lack of a capsule in the thyroid of teleosts.

It is thus seen that a number of studies having to do with normal fish thyroid have been made, and are widely scattered among the many and diverse genera of this great class. Not until recently has any particular attention been focused upon the Salmonidæ. The amount, distribution, and structure of the gland may be said to have been shown for individuals whose source and history and the conditions under which they had been living are not well known or are not stated, but which are presumptively normal and show no obvious pathologic changes. If, however, one limits the normal to the minimum of the thyroid exhibited by adults from streams far from and unaffected by civilization, where the fish are obviously living strictly in a state of nature, there is yet but a meager exposition of the normal thyroid in the salmonoids. We believe that the final comparison is to be against a norm set up by such individuals, and that most trout from aquariums, markets, fish-cultural establishments, and from artificially stocked streams and lakes or unstocked streams or lakes close to civilization or much frequented by people, have either abnormal thyroids or are not to be judged by criteria obtained from strictly wild trout.

In our specimens of wild brook trout we are unable to find the thyroid distributed as widely and in such quantity as shown by Gudernatsch (191 I, a, p. 753 and pl. II) for this species. He finds it extending into the gill arches, infiltrating muscle bundles and in places completely filling the available thyroid spaces. We find these conditions in domesticated fish, but not in our wild specimens. His material was in part obtained from aquarium fish, and in such we would expect such a distribution. It may even occur in specimens from some streams or lakes. We would infer that all fish exhibiting it may be presumed to have been under influences foreign to those usually obtaining in strictly wild natural conditions, but they may perhaps be considered to represent a normal for trout under a modified régime without presumption of any definite pathologic change. The minimum quantity of thyroid and its more restricted distribution appear to us as affording a more representative picture of the ultimate normal. Maurer, while not mapping in detail the distribution in the adult, describes a condition which speaks for the more confined arrangement of thyroid tissue (fig. 5 and 6 ).

\section{EMBRYOLOGY.}

Maurer (1886) has described the development of the thyroid in trout. According to his observations, about the twenty-seventh day after fertilization, the embryo being 6 millimeters long, an unpaired median evagination arises from the ventral epithelium of the pharynx (fig. 7). This is the earliest differentiation of thyroid. It lies in front of the heart in the bifurcation of the heart tube into the hyoid arteries, and consists 
of several layers of cubical cells. At this time no cartilage is differentiated, but the hyoid arch is well developed and the true gill arches are indicated, the brain vesicles and mouth opening are present, while the only macroscopic vessels of the region are the S-shaped heart tube and the two hyoid arteries.

The primary evagination lies close but not attached to the arterial wall, from which it is separated by connective tissue. At 32 days it has become spherical, has a lumen of its own, its epithelium is single layered and is connected with the mother cells only by a slender pedicle. (Fig. 8.) At 35 days it has completely separated (fig. 9), is about 0.04 millimeter in diameter, and lies exactly in the fork of the heart tube, which is 0.1 millimeter in diameter before the bifurcation. The four pairs of true gill arteries are now visible.

During the next six days the vesicle becomes somewhat elongated and changes its position. It now measures about 0.03 by 0.06 millimeter and has been pressed back of the bifurcation and lies ventral to the gill artery trunk, or ventral aorta (fig. ro). Colloid is now present and the vesicle begins to put out buds which rapidly develop a lumen filled with colloid and quickly separate. These multiplying buds grow around the aorta to the dorsal side and keep pace with its increase in length until, at 77 days or 3 weeks after hatching, that portion of the aortic trunk from the last branchial arteries forward to the bifurcation is surrounded by thyroid follicles. Finally, thyroid growth failing to keep pace with the lengthening of the ventral aorta, the adult condition is approached when the thyroid mass breaks up into irregular deposits or clusters of follicles which remain in the vicinity of the ventral aorta.

In the adult trout the greater portion of the thyroid is dorsal to the aorta. Maurer's description therefore requires that it migrate, from its origin dorsal to the heart tube, to the ventral side of the aorta and then back again to the dorsal side, and this view is confirmed by our specimens.

While colloid no doubt appears very early in the embryo and before the latter leaves the eggshell, Maurer's statement that it appears about the forty-first day of incubation is indefinite, since incubation proceeds over a considerable range of temperature and is much more rapid in the warmer water. The stage of incubation may be accurately stated in temperature units when both time and temperature are known. From the facts at hand, however, it may be expected that all normal trout embryos have developed colloid as soon as the hatching stage is reached.

In our specimens of hatchery brook trout still in the sac stage, but some days hatched, colloid is plainly visible (fig. I3) in many follicles. The amount and location of thyroid tissue is even at this early stage subject to considerable variation. The follicles are, however, always relatively few. In three examples the total number of distinct follicles recognizable by serial sections throughout the floor of the mouth was 24,27 , and 33 , respectively. In other cases there appears to be a smaller number. In distribution two more or less distinct deposits are recognizable, besides scattered follicles. One of these is at or in front of the level of the epithelial invagination which is to become the jugular pit, a region which will be shown later to be the seat of thyroid deposits in the adult. At this stage it is already a very definite infolding. The follicles 
are here in close relation to and not infrequently lic in actual contact with (fig. ro) the cells of this invagination, and thus illustrate the probable origin of pit tumors. One or more of the thyroid follicles can be easily dragged away from their neighbors with the growth of the pit region and come to lie immediately beneath the pit epithelium, as has been remarked in the discussion of distribution (fig. 14). When the thyroid later proliferates abnormally, an independent tumor begins to occupy the jugular pit.

In the adult scarcely any thyroid is located so far forward as in these recently hatched fry, where in the neighborhood of the pit it is to be found cephalad of the first arch and of the bifurcation of the aorta. The other deposit or aggregation of follicles centers in the region occupied by the adult thyroid, or in the vicinity of the second arch. They are not arranged with any regularity, were not observed in any case to extend laterally upon the gill arches but scatter along directly beneath the mesal bridge, and reach in a few cases as far back as the beginning of the fourth arch. Between the follicles about the jugular pit and those in the vicinity of the second arch, a gap usually intervenes in which no thyroid occurs. The limits of variation in amount and position of thyroid tissue can not be defined here, but from the material examined it appears that either of the chief groups of follicles as just described may in some specimens be entirely wanting, and that the adult gland may develop from one of these groups alone.

\section{GROSS ANATOMY AND DISTRIBUTION IN THE ADULT BROOK TROUT.}

While the thyroid is not a definite gland unit and on account of its small size, separation into discrete aggregates, and lack of encapsulation can not be extirpated, or dissected free in its entirety, it is nevertheless macroscopic in adult trout. On medisection of the floor of the mouth, delicate small masses of tissue may be seen about the ventral aorta near the first and second arches between the vessel and the cartilages and bone of the mesal bridge into which the gill arches unite. These masses contain the chief aggregates of thyroid follicles, and consist in large part of connective tisșue. They are likely to be found close to the second gill arch, and more likely to lie opposite the interspaces between the arches than opposite the arch itself. Under a hand or dissecting lens the individual follicles may be recognized embedded in the mass. Only the massed follicles are to be seen with the naked eye and therefore the outlying small deposits are not demonstrable save on microscopic section. The macroscopic thyroid masses in wild fish will only be found close to the middle line and at or just in front of or behind the second arch. Such masses closely resemble in appearance the fatty and areolar tissues which contain no thyroid, and can not be recognized with certainty as thyroid without a lens.

The exact location of thyroid follicles in the adult is variable. Perhaps every fish gives a recognizably distinct distribution pattern. To understand the location of the thyroid some consideration of the anatomy of the skeletal and other parts of the floor of the mouth is necessary. There are five pairs of branchial arches, of which only the cephalic four bear gills. Each arch save the fifth is composed of several bones, of which the ventral, or hypobranchial, is united with its fellow of the opposite side by the mesal unpaired basibranchial, and by cartilaginous copulæ which thus form the links 
between the right and left halves of each pair of arches. The basibranchials are connected with each other by these same cartilaginous copulæ, so that a solid mesal bridge is formed on the floor of the mouth, continuous with the tongue and reaching back to the fourth arch. The basibranchials lie opposite the interspaces between the arches, while the copulæ lie opposite the arches themselves. The first and second basibranchials are well ossified, the third less so, and the fourth is mostly cartilage.

Immediately beneath this bridge runs the ventral aorta. The bulbous aorta is located deeper, well beneath the floor of the mouth and somewhat back of the fourth arch. From it the ventral aorta runs dorsocephalad to a point just under the third arch. Here are given off the two trunks which soon bifurcate into the third and fourth branchial arteries supplying the corresponding gills. Thence the ventral aorta runs cephalad and slightly ventrad. Near the caudal margin of the second arch the second pair of branchial arteries is given off, supplying the second pair of gill arches. Finally the ventral aorta, just as it reaches the first arch, bifurcates into the first pair of branchial arches. A certain amount of space is left about the ventral aorta between it and the parts which inclose it. This space is greater dorsal to the vessel, and especially at the origins of the first and second pairs of branchial arteries. It contains the normal thyroid and its supporting tissues.

Figures 15 and 16 illustrate the lateral, longitudinal, and dorsoventral distribution of normal thyroid. They represent the condition in no single fish, but show compositely a probable average from a number of individuals. Two chief masses of thyroid may usually be recognized, the follicles clustering at and back of the first and second pair of branchial arteries, with usually a definite space between them in which but few and scattered follicles occur. Occasionally three masses or groups are recognizable, and the masses themselves present irregularities in the arrangement and number of follicles. Exact medisections show less thyroid than those slightly sagittal on account of the extension of the copulæ and basibranchials to the aorta at the second and third arches on the mesal line.

We have not found in the normal wild fish studied by us any lateral extension of thyroid structure along the branchial arches. Most of it, in fact, hardly reaches the lateral margins of the mesal bridge. The most cephalic extensions rarely reach the first basibranchial, and on the mesal line scarcely to the first copula. The extreme caudal extension is to the fourth arch, but usually there are but few follicles either at or behind the third pair of branchial arteries. Follicles are present in bone spaces, but in normal wild trout we have never found them among the muscle bundles. They are frequently embedded in the fatty tissue network or lie loosely attached to the vessels or other tissues, but never show any invasive tendency, nor do the follicles occupy more than a part of the apparently available space of the thyroid region.

\section{ANOMALOUS DEPOSITS OF THYROID.}

In a quantitative sense all the thyroid of importance is confined to the immediate vicinity of a portion of the ventral aorta. As the thyroid is a somewhat diffuse organ

$$
8207^{\circ}-14-2
$$


one might expect to find instances of remotely placed deposits. We are therefore surprised to find the sharp delimitation to the region already described which appears to exist in our wild specimens, with one marked exception, i. e., the jugular pit to which reference has already been made. It has been assumed by some writers that aberrant thyroid deposits in some region's might be frequently expected. This has been due to the development of tumor nodules in regions beyond the normal and usual seat of distribution, such as the lower mouth parts and gill arch region. The only outlying tumors of this sort which may be inferred with certainty to arise from original deposits of thyroid are the so-called pit tumors.

In the adult trout there occurs on the ventral side of the head between the dentary bones a median irregular depression or blind pit open to the exterior. It is the region where the muscles between the dentaries and those of the branchiostegals become common. The skin dips into its ramifications with many plications and infoldings. It is an entirely superficial and exterior landmark, and though independent of and well removed from the thyroid region in the adult, is of some importance in thyroid pathology, since at an early stage it is in closely apposed relation to the thyroid region, and is the occasional seat of detached thyroid follicles and of independent thyroid tumors. This much branched and partitioned cavity may be designated as the jugular pit (fig. II). It may be recognized at or soon after the hatching of the embryo. Normal thyroid has been several times observed immediately beneath the pit epithelium in wild brook trout (fig. 14), where its presence may be readily explained by the mechanics of development of the parts (fig. 12). Since of 9r trout with tumors, 25 showed pit tumors, one may conclude that more than one-quarter of all brook trout have normally some thyroid follicles in the region of the pit.

Occasionally detached tumors develop in the gill arches. We have never actually seen thyroid follicles on the free portions of the gill arches, and there is little embryological presumption in favor of such deposits, notwithstanding the relation of the gill arches with the thyroid region. The tip of the lower jaw has even much less anatomical relation to the thyroid region, rendering it an unlikely place for stray follicles. The examination by serial sections of the tips of the lower jaws of about 25 trout failed to show any thyroid here. The region is called into question as a seat of normal thyroid deposit on account of the rare cases of a thyroid tumor occupying this site. The actually observed occurrence of normal thyroid in the pit and the incidence of tumors here make it extremely probable that no other extralimital deposits occur with any frequency, else such would declare themselves in tumor formation.

\section{HISTOLOGY.}

A closed alveolus is the unit of the thyroid gland. These alveoli are apparently independent of each other save as they are more or less bound together by the vascular framework and connective tissue stroma. Their lumina have no connections with each other and each alveolus independently discharges its secretion into the circulation. Many alveoli are quite isolated from their kind and lie, loosely in the tissue, whether connective, muscle, bone, cartilage, or fat. In the simplest adult condition (fig. I $4^{-2}$ I) 
they are typically spherical, subspherical, or slightly elongated, and consist of a single layer of flattened epithelium, with a large lumen completely filled with homogeneous colloid readily stainable by cytoplasmic stains. The cells of this epithelium are polyhedral, very flat, with very deeply staining slightly vesicular nuclei, lying parallel with the longer dimensions of the cell. The nucleus is longer than wide, about as thick as the short diameter of the cell, but its other dimensions are shorter than those of the cell. In size, alveoli show wide variation, the smallest measuring as little as 0.02 millimeter, or even less, in diameter. From these all sizes are to be found up to plainly macroscopic follicles at least 0.75 millimeter across. Perhaps even larger ones occur. Most of the alveoli of course fall well within these extremes. Only the largest are visible to the naked eye.

There is thus a promptly recognizable similarity between the structure and appearance of the thyroid unit in the trout and that of man and other mammals. The entire gland in these groups is similarly comparable in location, function, and perhaps in size, though it is impossible to weigh the trout thyroid and difficult to estimate its weight or bulk. The chief difference between the gland in fish and mammals lies in the absence from the fish thyroid of even a suggestion of a capsule, which in man is a definite and important structure which completely delimits the thyroid from the neighboring tissues and confines its units as a definite gland organ. The trout thyroid lies in the various tissues beneath the floor of the mouth without any very definite interstitial tissue of its own.

For the normal structure of the thyroid we have examined trout taken from natural waters of the country, such as streams and lakes in wild and unsettled regions. From these it is apparent that there is no inconsiderable variation in the thyroids of adult fish in their natural habitat. This variation certainly depends largely upon age and season, is no doubt in part individual, and is in our opinion also a function of other causes among which is the nature of the waters inhabited, whether shallow, rapidly flowing streams or the more quiet and deeper lakes. These natural conditions react with the metabolism of the fish.

The simplest condition of the thyroid, as described above, was seen in wild brook trout taken in January from the Au Sable River in Michigan. (Fig. I7.) The same species taken in June from streams in Wisconsin differ in showing somewhat higher epithelium, which may be regarded as cuboidal. Our specimens from these two sources show the simplest or lowest epithelium, in most cases flattened and never higher than cuboidal. Specimens taken in May from a lake in Algonquin National Park, Ontario, Canada, show a further advance. The epithelium is distinctly higher and the general character of the thyroid picture seems to us to separate these fish from the other groups of wild fish discussed above and to justify their consideration under the heading of simple hyperplasia.

\section{SIMPLE HYPERPLASIA AND COLLOID GOITER IN WILD AND DOMESTICATED FISH.}

The picture of the normal thyroid in the wild Salmonidæ is extremely characteristic, and although, as described, considerable variations are found in the size of the alveoli, 
there is but a very limited range of change in the epithelial cells. So characteristic is this picture that it is possible to recognize the condition of simple hyperplasia of the thyroid, although the exact relation of simple hyperplasia to the function of the organ is not clear. We have encountered a condition of the thyroid in specimens of brook trout taken from the Algonquin National Park in Ontario, Canada, where the change is sufficiently marked to constitute, in our opinion, a condition of simple hyperplasia in fish living under wild conditions. (Fig. 18.) The specimens were taken in the regular course of angling on several days in Little Island Lake in the park. The picture presented by the thyroid of these fish is sufficiently characteristic to permit the description of the thyroid of any one specimen to serve for the rest. As compared with the thyroid structure of Wisconsin and Michigan wild brook trout, the alveoli lie more closely packed and present much more the appearance of a definite organ than in the strictly normal condition. The alveoli are of much more irregular shape, presenting irregular forms and protrusions, smaller pouch-like additions to the typical spherical or oval alveolar structure, and evidences of budding. The epithelium is high cuboidal, stains more deeply, and the long axis of the deeply stained nucleus is usually perpendicular to the circumference of the alveolus. The colloid is diminished in amount, many of the smaller alveoli containing little or none. It stains less deeply than in the normal structure. There are evidences of hyperæmia in the stroma and the stroma is much richer in small cells than in the normal. The total number of alveoli seems to be increased. We have not seen any evidences of karyokinetic figures in the cells. The epithelium never reaches the high columnar and bizarre shapes found in the early stages of carcinoma. The entire thyroid structure is more uniform in type.

Simple hyperplasia of the thyroid has been described by Marine and Lenhart (1910) as occurring in fish obtained from Lake Erie. Pike and bass, according to these authors, are commonly affected; sheepshead and herring more rarely. They also report an example of spontaneous colloid goiter in the pike which they consider the terminal stage of hyperplasia that has undergone resolution.

A simple hyperplasia of this type undoubtedly occurs in fish under domestication. It is impossible to distinguish simple hyperplasia in fish hatcheries from the first stages of carcinoma of the thyroid, a difficulty which is common to the diagnosis of all malignant tumors. We have been fortunate in having for study at Craig Brook a variety of the Salmonidæ which possesses natural immunity to carcinoma of the thyroid. These fish are the Scotch sea trout (Salmo trutta Linnæus). The original stock was obtained from abroad as eggs, hatched in the hatchery, carried through its various troughs, and the adult fish ultimately came to occupy the ponds lying in a position where they received the water from ponds above, in which carcinoma of the thyroid in brook trout was extremely prevalent. The facts bearing on the evidences of immunity in this connection will be considered later. The eggs taken from these domesticated sea trout have been again hatched in the hatchery, maintained in the outside smaller troughs, and we have thus had an opportunity to study the offspring of the adult fish at various stages, as well as the condition of the thyroid in the larger fish. We have never found macroscopic evidence of even the earliest stages of carcinoma of the thyroid in the younger of these 
fish. The examination of specimens of the offspring of the older fish at the fingerling stage reveals the thyroid of occasional specimens in a state of simple hyperplasia (fig. 20), perhaps slightly more marked than that found in the wild fish from Algonquin Park. (P. 75.)

In these small fish the thyroid is not markedly increased in amount and is largely localized about the great vessels, but occasional groups of alveoli are found somewhat more widely removed from these structures than normal, and occasional small groups in the infoldings of the cartilage or bone or between the muscle bundles. The alveoli are not unusually large, the epithelium is high cuboidal and low columnar, the long axes of the nuclei perpendicular to the circumference of the alveoli. Both protoplasm and nucleus stain more deeply than normal. The colloid is diminished in amount and stains less well than in the normal specimens. (See fig. 20, which may be compared with a similar photograph at the same magnification of a Scotch sea trout from the same lot, $2050 \mathrm{~A}$, fig. 19, in which the thyroid structure presents a characteristic normal appearance, and both may be compared with a fish of similar size taken in the wild state from the Au Sable River, Mich., fish I99 A, fig. 19, of which an illustration at similar magnification is provided.) The thyroid gland of the adult Scotch sea trout, when viewed in the light of the conditions found in the smaller fish, in which occasional examples show simple hyperplasia and the larger proportion strictly normal thyroid tissue, reveals a similar division in character of the thyroid in the adults. A larger proportion of the adult Scotch sea trout presents strictly normal thyroid tissue. (Fig. 2I.) There does not appear to be an increased amount of thyroid for the size and age of these fish. The minority of the fish, however, presents microscopically a condition of the thyroid which may be spoken of as colloid goiter. (Fig. 22.) In them the alveoli are greatly increased in size, the total amount of thyroid is also increased, the walls of the alveoli are very thin, the epithelium pressed very flat, and the lumina compactly filled out with large masses of colloid.

From a careful study of the Scotch sea trout, it is clear that although, as will be shown later, they are almost perfectly immune to carcinoma of the thyroid, a certain proportion of them are affected by a process of simple hyperplasia which terminates by resolution in colloid goiter. It will be shown later that spontaneous recovery of carcinoma of the thyroid in the Salmonidæ produces an entirely different terminal picture from that of colloid goiter. In the instance above described of the Scotch sea trout, the transformation of hyperplasia into colloid goiter has been brought about by a process which has been termed resolution. In carcinoma the disappearance of the tumors in spontaneous recovery is brought about by a process of regression, a part of which may be referred to as resolution; that is, the epithelium undergoes changes of type, colloid reappears, but the bulk of the tumor literally retrogrades. Many of the alveoli totally disappear and large areas are frequently removed so rapidly as to require extensive repair by connective tissue. All of the characteristic appearances found in regression of malignant mammalian tumors, such as the frequency of large areas of hemorrhage followed by repair, the formation of pseudogiant cells by coalescence of the epithelium, great increase in the connective tissue stroma especially at the margins of 
the tumor, deposition of pigment and final clearing up of these phenomena with total disappearance of the tumor, leaving only a small residue of approximately normal functionating thyroid alveoli, presents a picture which can be readily distinguished from the characteristic appearance of colloid goiter, as found in the Scotch sea trout. From the evidences obtained from the fish from the Algonquin National Park, we are of the opinion that trout in the wild state may also suffer from simple hyperplasia of the thyroid, which also, no doubt, would terminate by resolution in colloid goiter, although we have not been fortunate enough to secure such specimens from the wild state. As the majority of the Scotch sea trout under the conditions we have studied present both in the small fish and in the adults a preponderance of strictly normal thyroids, it is obvious that this condition is not the direct result of domestication, the existence of simple hyperplasia in wild fish making this deduction obvious.

Whether simple hyperplasia leading to colloid goiter in the Scotch sea trout is a process with distinctive etiology, possibly the result of unusual physiological demand upon the organ, or a greatly modified type of carcinoma of the thyroid occurring in an immune species, can not at present be determined. The observation in one or two of the older fish of red floors, and one or two reported tumors which we did not see, may indicate that further material may be secured which will throw light upon this question. For the present we would recognize a simple hyperplasia not associated etiologically with carcinoma of the thyroid.

\section{PATHOLOGIC ANATOMY.}

\section{GROSS ANATOMY.}

\section{EARLIEST MACROSCOPIC EVIDENCE.}

The first evidence of thyroid proliferation visible to the unaided eye is the so-called red floor (fig. 23 and 23a). It is a faint reddening or flushing of the median area of the floor of the mouth usually opposite to or in the neighborhood of the second gill arches. It is caused by the increasing blood supply of the main thyroid deposit and by hyperemia of adjacent tissues, which show through the epithelium. Its first appearance is sometimes a mere streak, more often a circular or irregular diffuse reddening. It usually soon spreads more widely, reaching a little out on the arches and tending to spread forward toward the first pair of arches, and is, of course, variable. At the angles between the arches the color is often heightened and very distinct. The color picture illustrating the red floor shows a well developed process scarcely prior to visible swelling, and not the very earliest flush of hyperplasia. The color changes rapidly under examination on account of the excitement of the fish due to removal from water and the vigorous handling necessary. The red flush pales rapidly under these conditions and often almost disappears in less than a minute, due to the inhibition of the circulation from nervous shock, the area taking on a dirty gray color.

The red-floor stage is not sharply demarcated from the succeeding stages. It proceeds gradually and is succeeded by or merged with visible tumor formation, the color persisting and spreading in various degrees over the subsequent swelling. 
Fish which are without any clinical evidence of thyroid disease, either in externally visible swelling or the inflamed and flushed condition of the floor of the mouth, are for brevity referred to in this report as clean or clinically clean.

It is the increased vascularity associated with increased thyroid that causes the red floor, and an increased amount of hyperemic thyroid tissue of normal type sometimes makes a visible flush on the floor of the mouth so that the red floor is not an absolute and infallible sign of thyroid hyperplasia. The wild brook trout held in confinement in cement tanks and fed natural food showed after two years a number of cases of red floors. (See table virr.) Microscopically the thyroid was considerably increased in amount but not otherwise definitely changed from the normal type. Likewise the adult Scotch sea trout show occasional red floors referable to the microscopical condition of colloid goiter. Such cases of red floors are evidently to be separated from those in which the flush is caused by the early stage of carcinoma.

\section{VISIBLE TUMORS.}

Branchial junction.-Whereas evidence of beginning growth of thyroid tissue in the affected fish is first shown by a more or less distinct reddening of the floor of the mouth, the growth of tumor tissue in the spaces about the aorta and in the muscular structure of the isthmus may proceed to a very considerable extent before the growth gives other macroscopic evidence of its presence. The illustrations of visible tumors in the literature usually depict growths appearing at the branchial junction. Because of the resistance offered to the growth of the tumor by the bony and cartilaginous structures forming the floor of the mouth, it is natural to expect that the region at the junction of the first pairs of gills with the isthmus, representing the line of least resistance, would be the first and most frequent site of the visible outgrowths. This median region we refer to as the branchial junction.

In an analysis of 91 tumors carefully classified (table I), we find that the branchial junction alone is the site of the visible tumors in but 4 cases, but where the growth of tumor tissue is sufficiently extended to protrude in other directions it is found to be the site of visible outgrowths in combination with one or the other, in 67 cases. The branchial junction is therefore one of the most common sites for the early evidence of tumor growth. In many cases the first macroscopic evidence of the disease is found in the appearance of small protrusions with smooth surface, of rose color, often not larger than a grain of rice or smaller, on each side of the isthmus exactly at the branchial junction. This evidence of tumor formation is almost always associated with the evidences of reddening of the floor of the mouth and means that the avaliable space below the branchial arches and about the aorta is filled with tumor mass and that the conditions favoring the growth downward of the tumor have determined its first protrusion in this direction. Tumors making their first appearance at the branchial junction on one or either side of the isthmus may rapidly develop into large growths in this region. As they increase in size they become more readily recognizable, push the gill covers apart and ultimately present themselves as obvious growths protruding into the gill spaces on either side. 
In the diagrams of the 48 analyzed tumors here presented, great irregularity of outline, size and form of these outgrowths on the inferior aspect of the fish may be easily studied. The freedom afforded by the spaces between the gill covers and the isthmus permits of the growths of tumors of enormous size. Figure 27 represents a 2 -year-old brook trout with a tumor of such magnitude that practically the entire gill space is filled by one tumor mass, which has pushed the isthmus downward and practically occludes the entire gill space. In some cases tumors of great size may develop in such a way as to push the isthmus to one side and present the appearance of a unilateral tumor. In all these cases, however, the tumor tissue is found to extend from the median region about the aorta, which is the site of the normal thyroid tissue from which all these tumors spring. Occasionally tumors extend downward and make their first appearance through the substance of the isthmus, indicating the exquisite infiltrative character of the growth, and in one instance, the first macroscopic evidence of tumor (fig. 4) was found at the base of the isthmus in the solid muscular structure of the breast of the fish.

Floor of the mouth.-Although the lines of least resistance for the growth of tumor tissue springing from the thyroid region are obviously downward, a large proportion of all tumors give evidence of their existence in the floor of the mouth. In an analysis of $9 \mathrm{r}$ fish taken at random, visible evidence of tumor growth in the floor of the mouth was found in 70 instances. The reddening of the floor of the mouth, which is the first evidence of tumor growth, is replaced by infiltration through the structures of the floor of the mouth, developing either by uniform bulging upward of the floor or the protrusions of masses between the branchial junctions; or one or more rounded masses of large dimension may become prominent. (Fig. 26 and 29.) Not infrequently, besides the upheaval of the floor, the tumor tissue breaks through the elastic structure of the underlying mucosa and produces minute papillary growths. These are usually of shiny appearance, small or rounded, irregularly shaped, and present the appearance of vegetations scattered over the floor of the mouth. (Fig. 30.)

Pit tumors.-Early in our investigations Marsh called attention to the fact that the jugular pit often contained a tumor which was entirely independent of the thyroid enlargement originating in the thyroid region. (Fig. 24.) Of the 9r tumors analyzed, in 5 the only macroscopic evidence of tumor growth was in the jugular pit. In combination with other regions the jugular pit was the site of tumor growth in 20 other examples, and in the entire 9I it was the site of tumor growth in 25. As has been shown in the chapter on embryology, we were able to demonstrate the existence of deposits of normal thyroid tissue in the immediate vicinity of this so-called jugular pit. The frequency of tumors in this region strongly indicates that deposits of thyroid in this region are not uncommon, and in determining the limitation of distribution of the thyroid in normal fish, the frequency of displacement of occasional follicles in this region must be recognized. As will be seen from the diagrams, the jugular pit may be the site of outgrowth of tumor tissue of very considerable extent, and of various forms. They are usually subspherical, or hemispherical, may be slightly flattened or considerably elongated, and occasionally vegetate irregularly and take on bizarre forms. They vary greatly in size, from bare visibility to masses having a diameter of 17 millimeters or even more. 

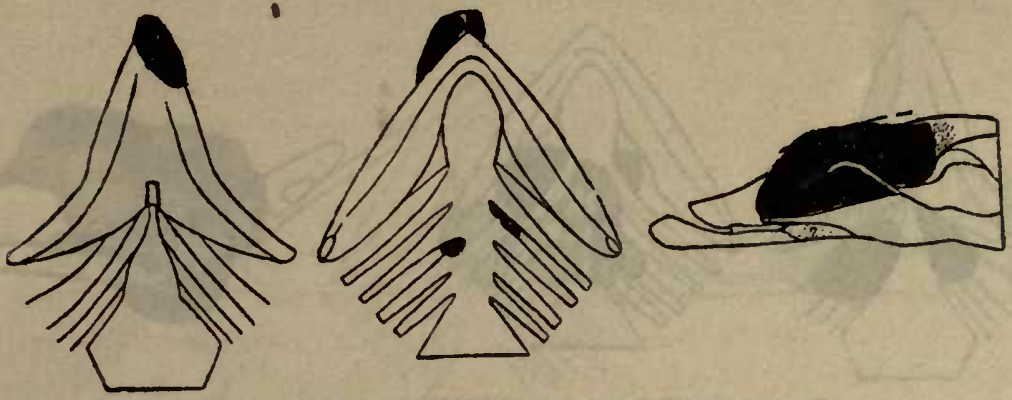

DIAGRAM x.-Fish 6r, S. fontinalis, length $20 \mathrm{~cm}$; type alveolar.
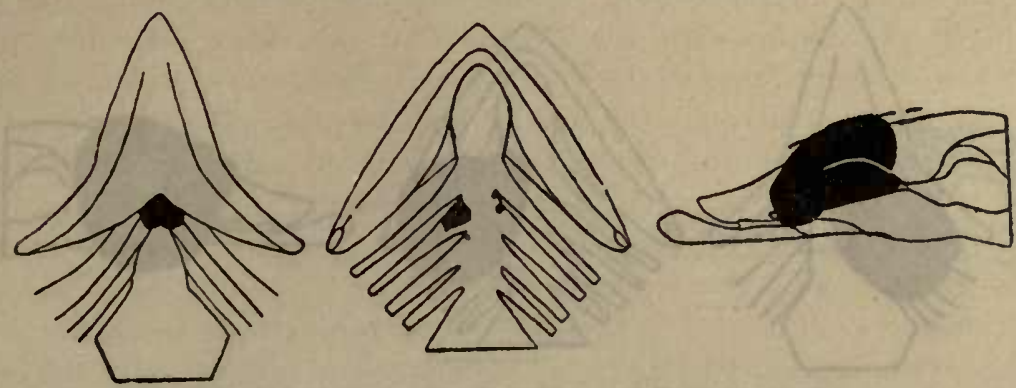

DIAGRAM 2.-Fish 72, S. fontinalis, length $26.5 \mathrm{~cm}$; type alveolar.
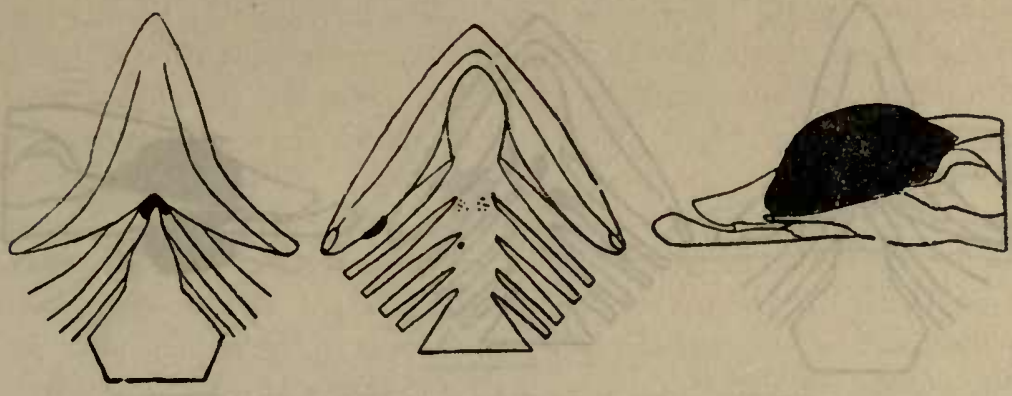

DIAGRAM 3,-Fish 73, S. fontinalis, length $22 \mathrm{~cm} . ;$ type alveolat.
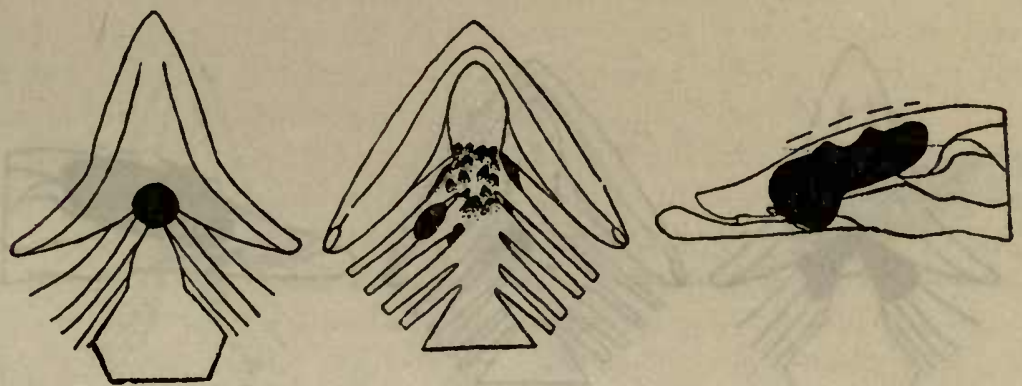

Diagram 4.-Fish $75^{-1} 57$. S. fontinalis, length $26.4 \mathrm{~cm}$.; type tubular. 

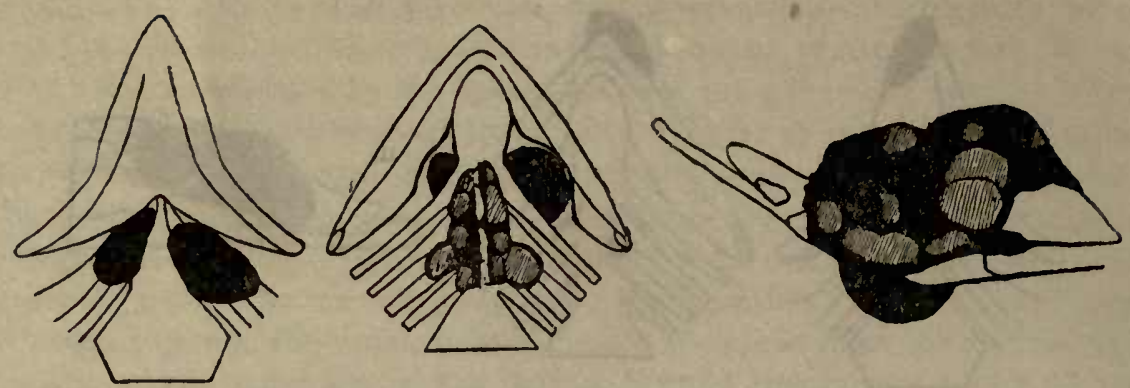

Diagram 5.-Fish 92, rainbow, length 28.5 cra.; type papillar.
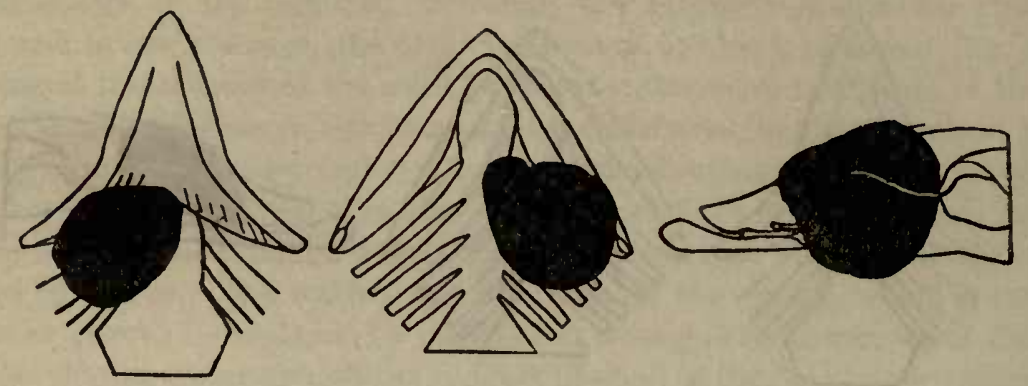

DLaram 6.-Fish 93, rainbow, length $29 \mathrm{~cm}$.; type alveolar.
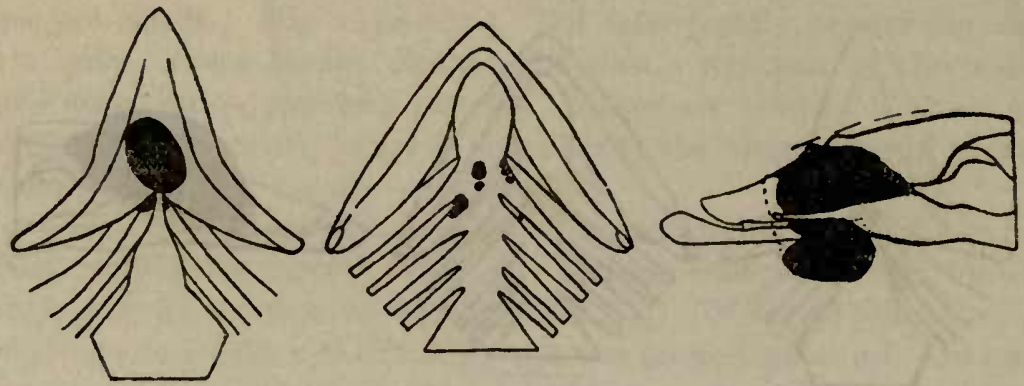

Dingram 7.-Fish 94, rainbow, length 33 cra.; type papillar.
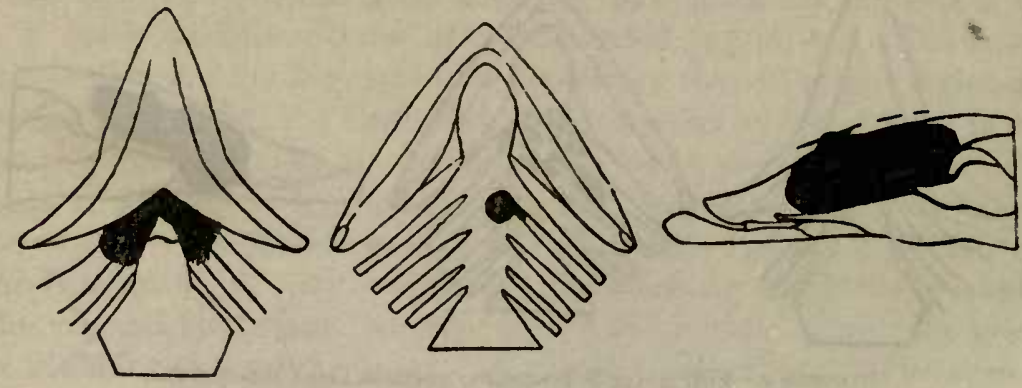

Diagram 8.-Fish 96, S. fontinalis, length $25.3 \mathrm{~cm}$.; type alveolar. 


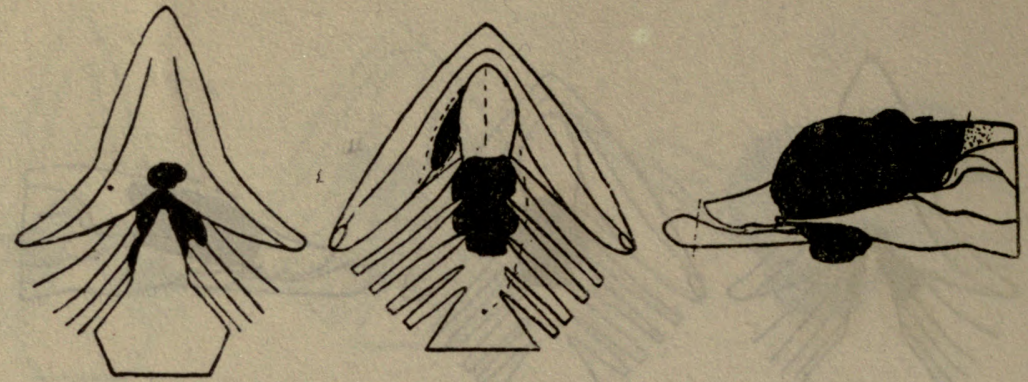

DIAGRAM I3.-Fish 120, S. salar sebago, length $14.7 \mathrm{~cm}$.; type alveolar.
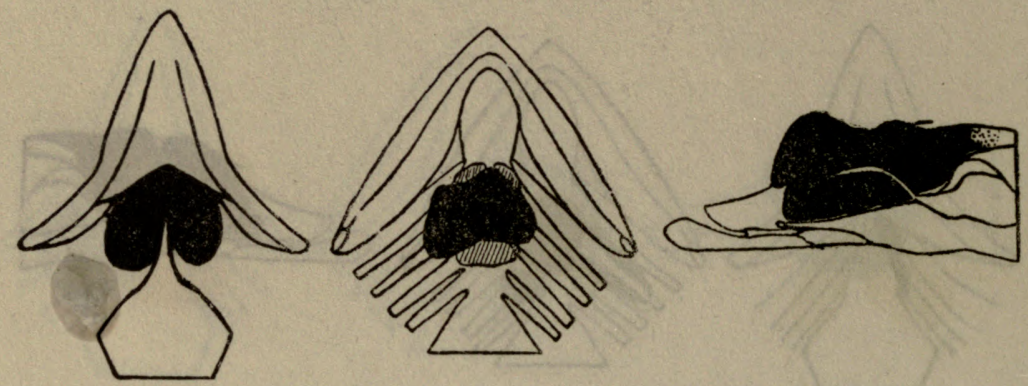

DIAGRAX I4.-Fish I24, humpback, length $14.7 \mathrm{~cm}$; type alveolar.
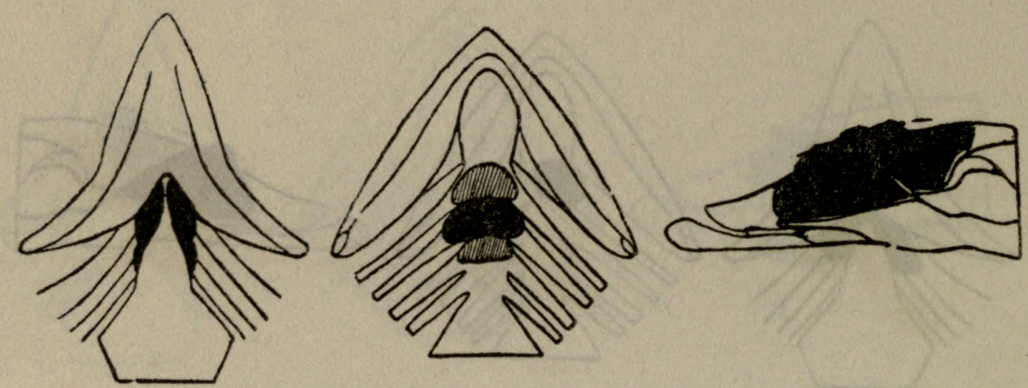

DIAGRAM 15.-Fish 125 , humpback, length $14.8 \mathrm{~cm}$; type alveolar.
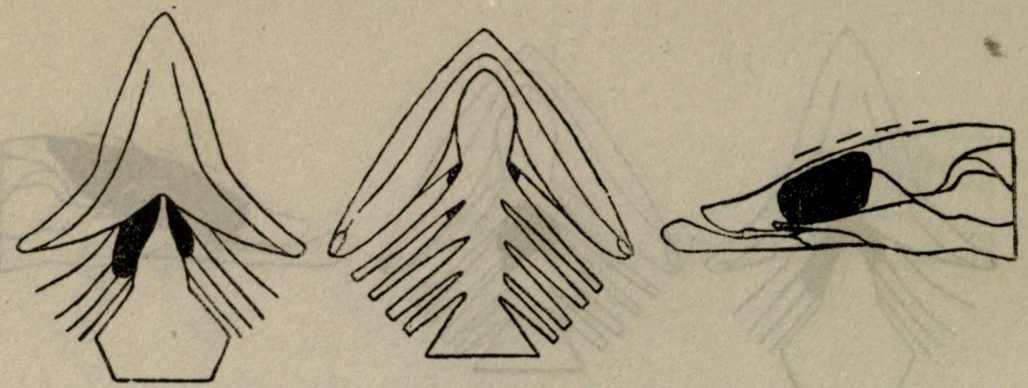

DIAGRAM I6.-Fish I 3 r, Coregonus, length $60 \mathrm{~cm}$; ;ype solid. 

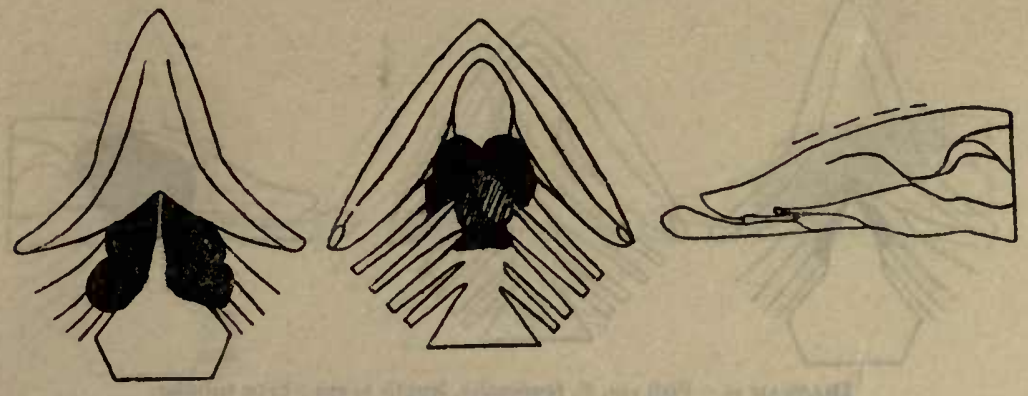

DiagraM $\times 7,-$ Fish $\times 33$, humpback, length $\times 4.4 \mathrm{~cm}$.; type alveolar.
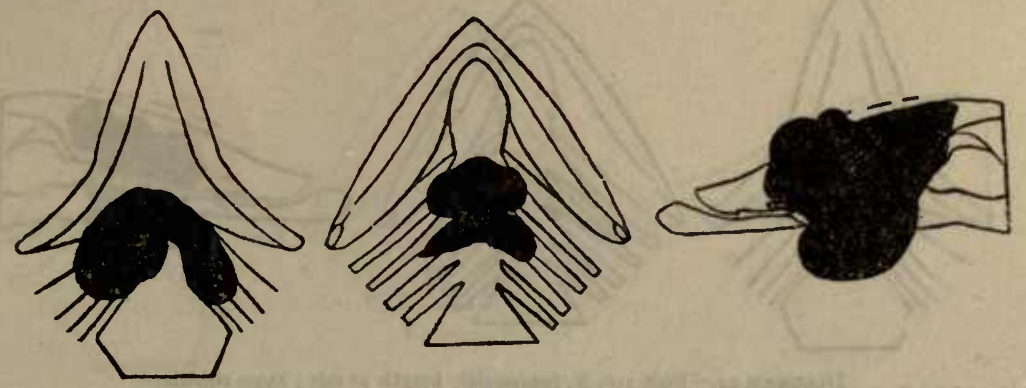

Diagrax 18.-Fish x39. Salmo hybrid, length $10.7 \mathrm{~cm}$. ; type alveolar.
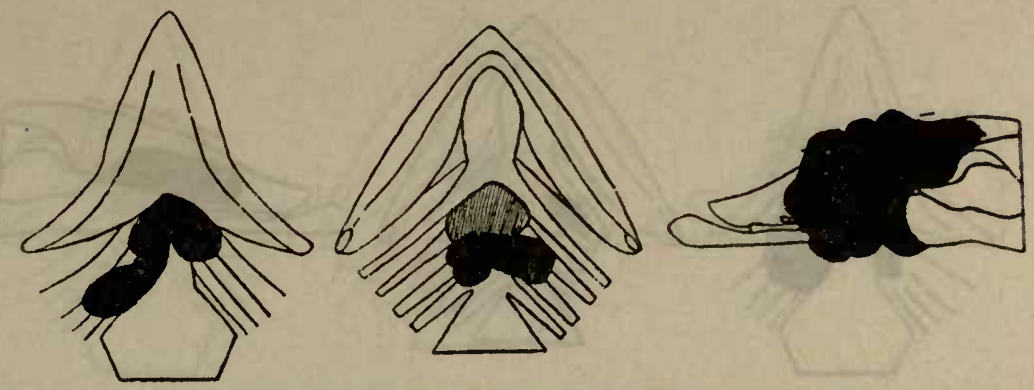

Diagram x9.-Fish x40, Salmo hybrid, length $8.7 \mathrm{~cm}$.; type solid.
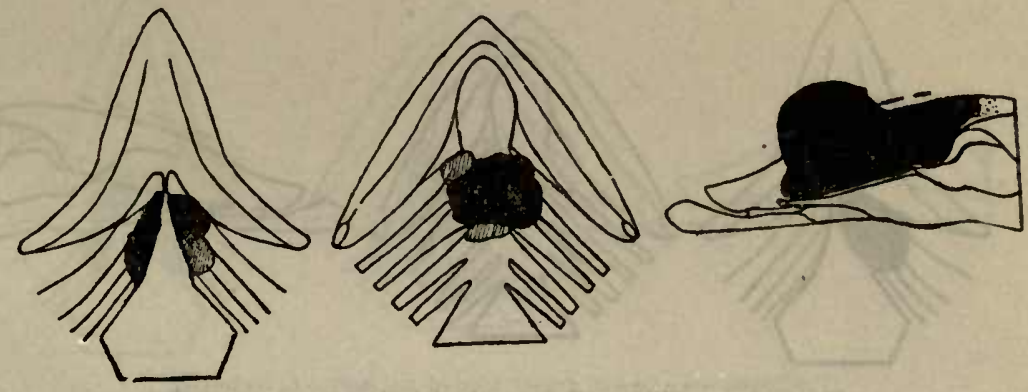

DUGRAM 20.-Fish 15r, S. fontinalis, length $22 \mathrm{~cm}$.; type tubular. 

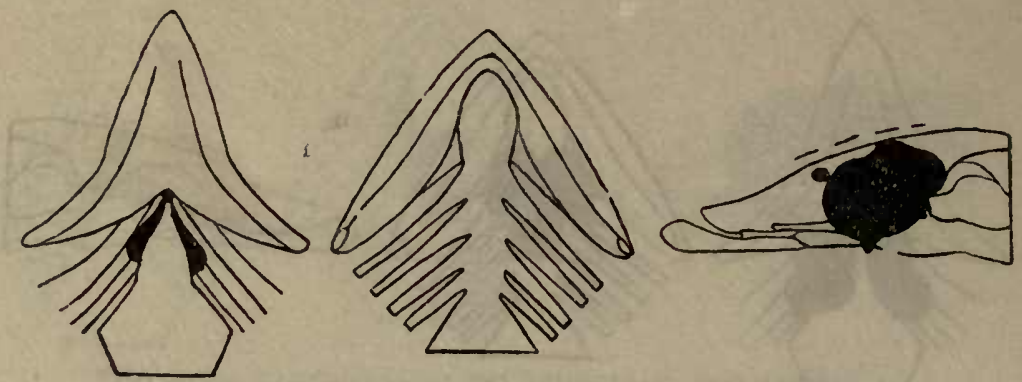

Diagrax 21. - Fish 152, S. fontinalis, length $19 \mathrm{~cm}$.; type tubular.
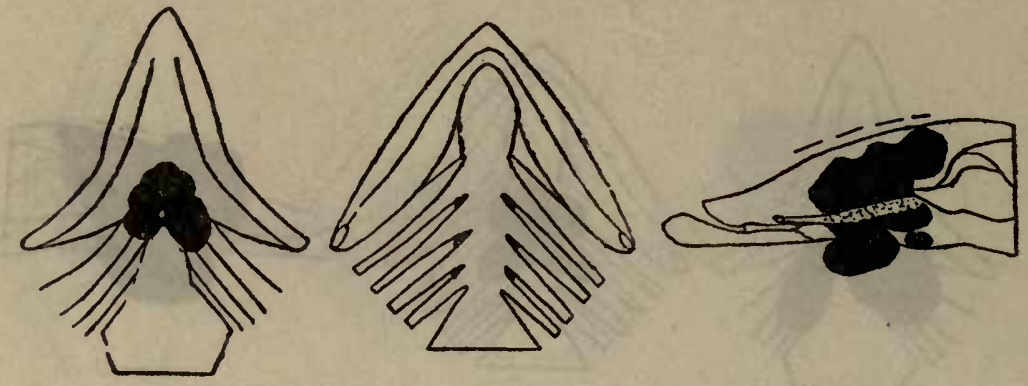

DiAGRaM 22.-Fish 156 , S. fontinalis, length $18 \mathrm{~cm}$.; type tubular.
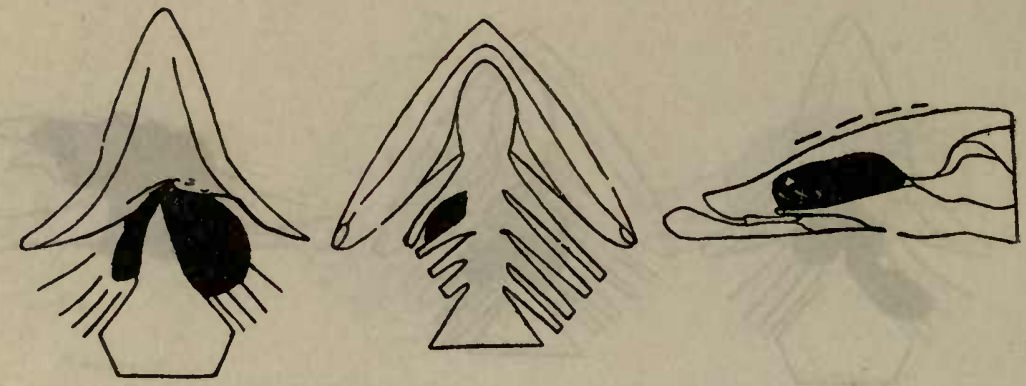

DIAGRaM 23.-Fish x72, S. fontinalis, length $x 7 \mathrm{~cm}$.; type solid.
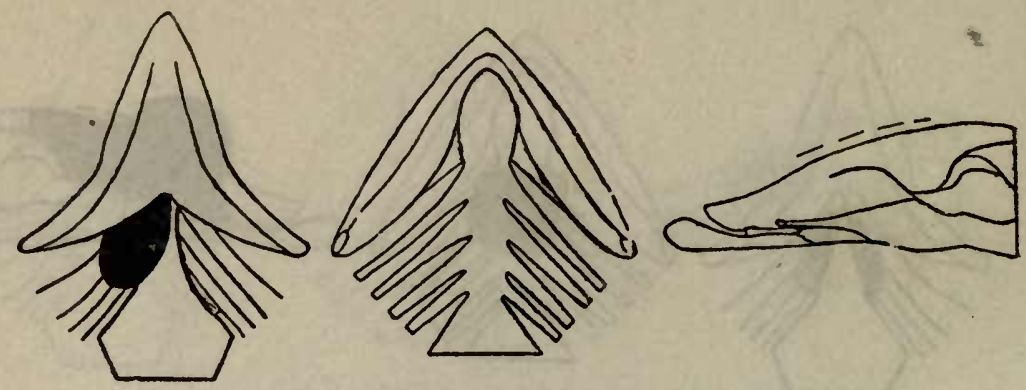

Diagrame 24.-Fish $\times 74$, S. fontinalis, length $20 \mathrm{~cm}$.; type papillar. 

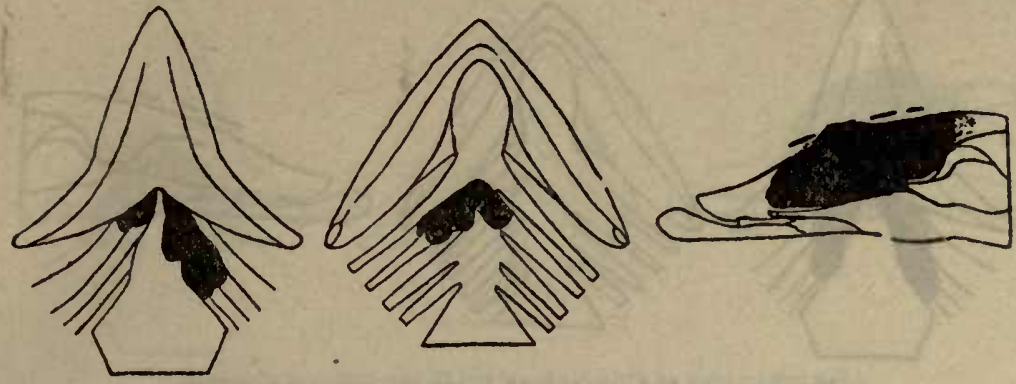

DIAGRAM 25.-Fisb $18 \mathrm{x}$, landlocked salmon, length $35 \mathrm{~cm}$.; type alveolar.
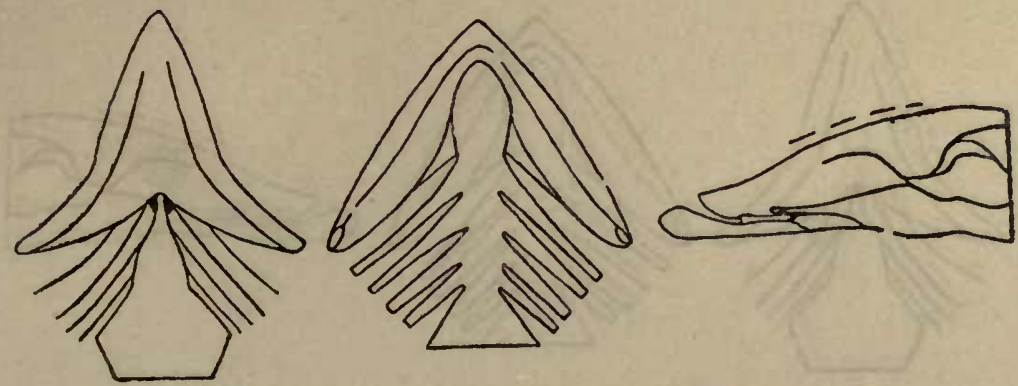

Diagram 26.-Fish $18_{3}$, S. fontinalis, length $15.9 \mathrm{~cm}$.; type alveolar.
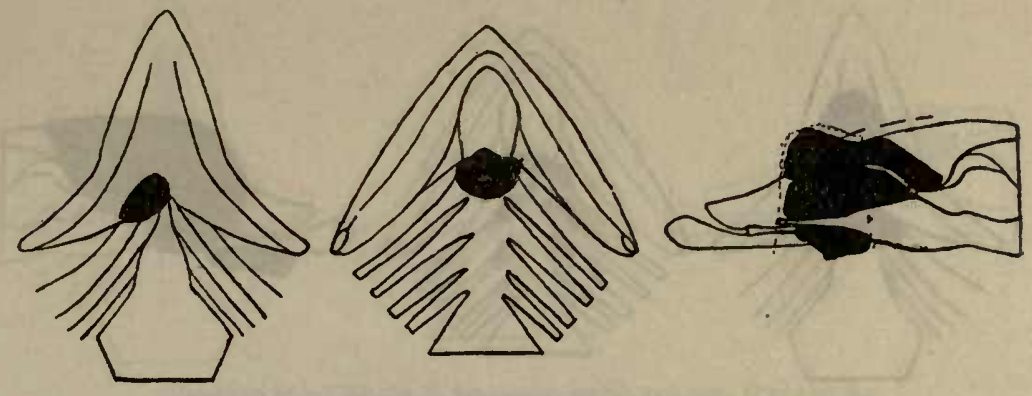

Diagram 27,-Fish 205, hybrid, length $17.6 \mathrm{~cm}$; type papillar.
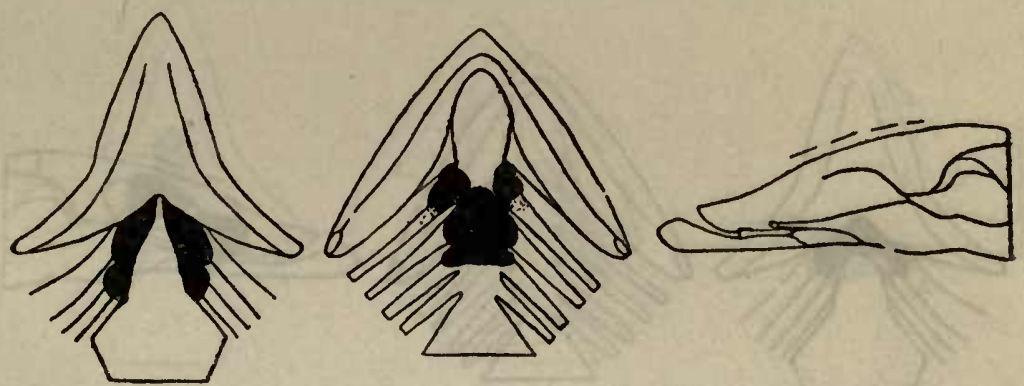

Diagrax 28.-Fish 208, hybrid, length $16 \mathrm{~cm}$.; type papillar. 


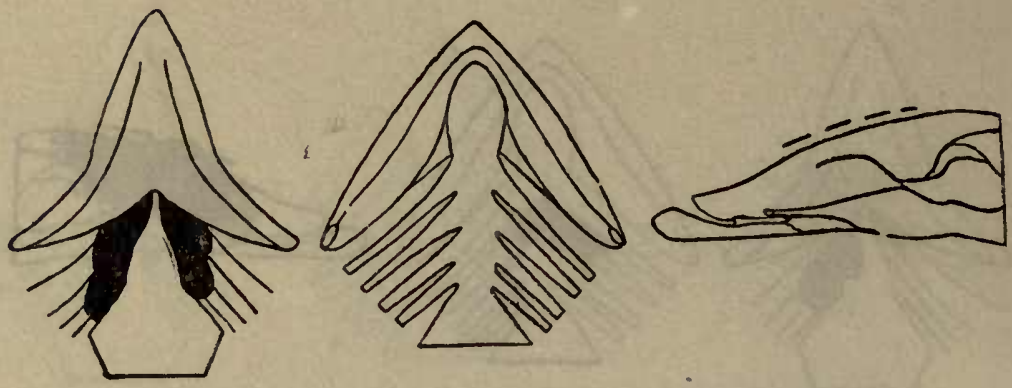

DiagraM 29.-Fish 209, hybrid, length $16.3 \mathrm{~cm}$.; type papillar.

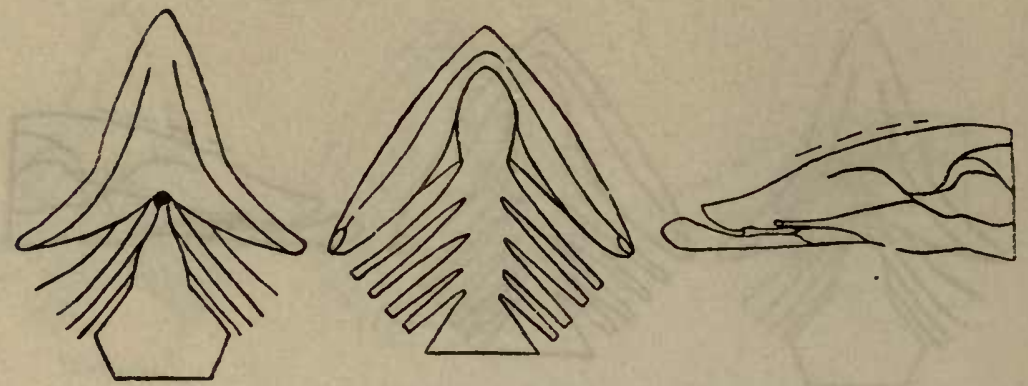

DiAgram 30.-Fish 217 , S. fontinalis, length $9.9 \mathrm{~cm}$.; type alveolar.
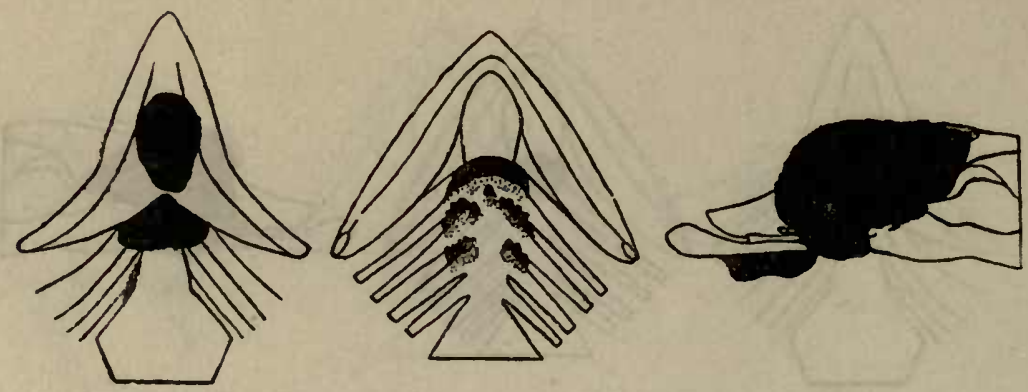

DLagram 3r.-Fish ror, $S$. fontinalis, length $2 \mathrm{x} .5 \mathrm{~cm}$.; type papillar.
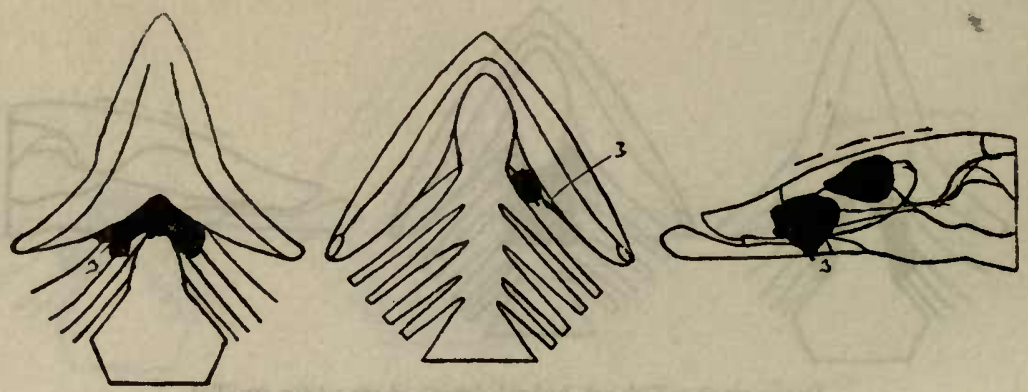

Dugras 32. Fish II\%, S. salar sebago, length $14.5 \mathrm{~cm}$.; type papillar. 

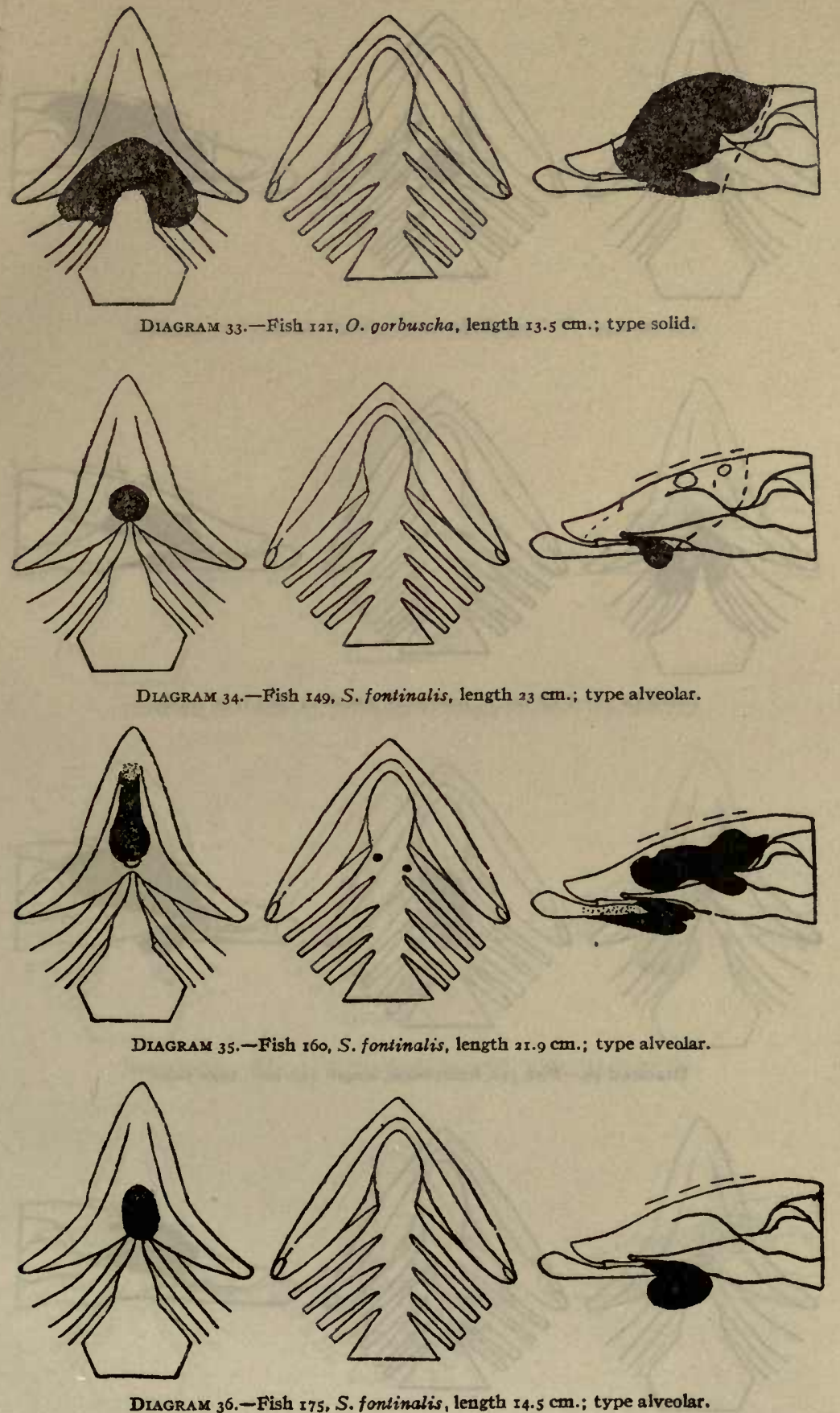

$8207^{\circ}-14-3$ 

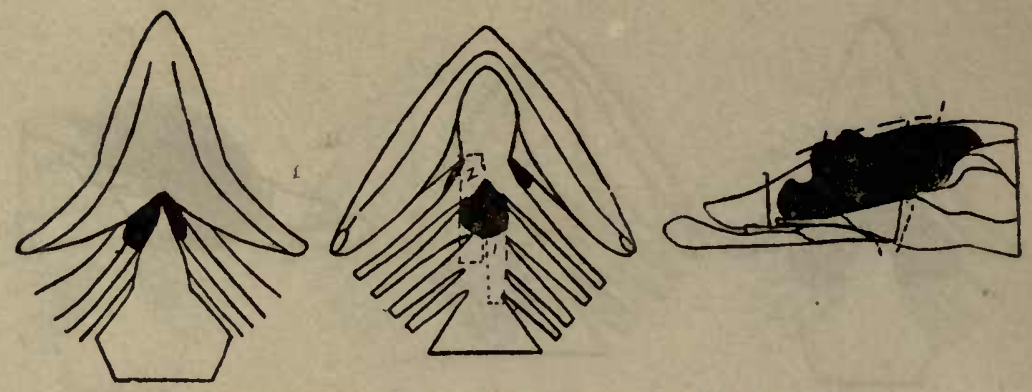

Dugray 37.-Fish 100, S. fontinalis, length $24 \mathrm{~cm} . ;$ type papillar.
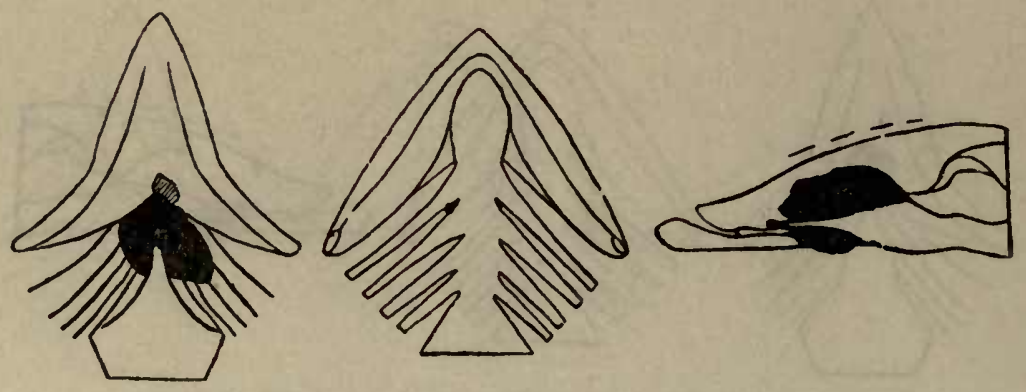

DIAGRAM 38.-Fish 103, S. fontinalis, length $24 \mathrm{~cm} . ;$ type papillar.
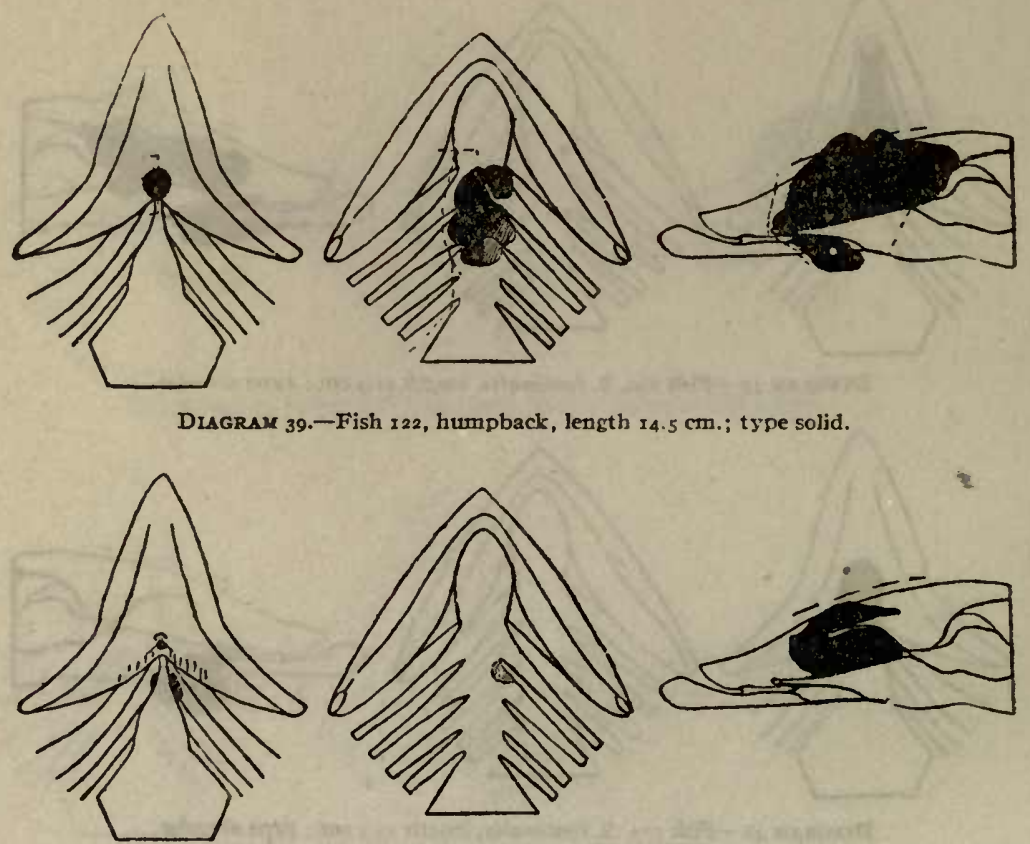

DIAGRAM 40.-Fish I12, S. salar sebago, length $15.5 \mathrm{~cm}$.; type alveolar. 


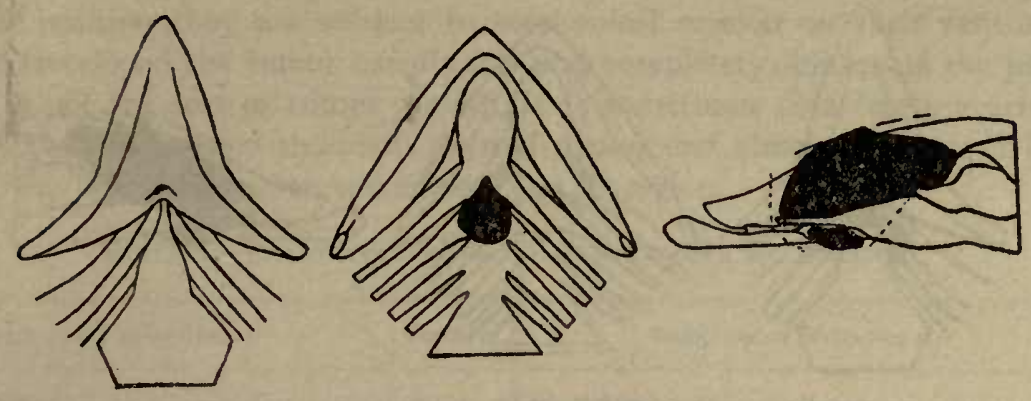

Diagram 41 , Fish $\times 50, S$. fontinalis, length $16.5 \mathrm{~cm} . ;$ type papillar.
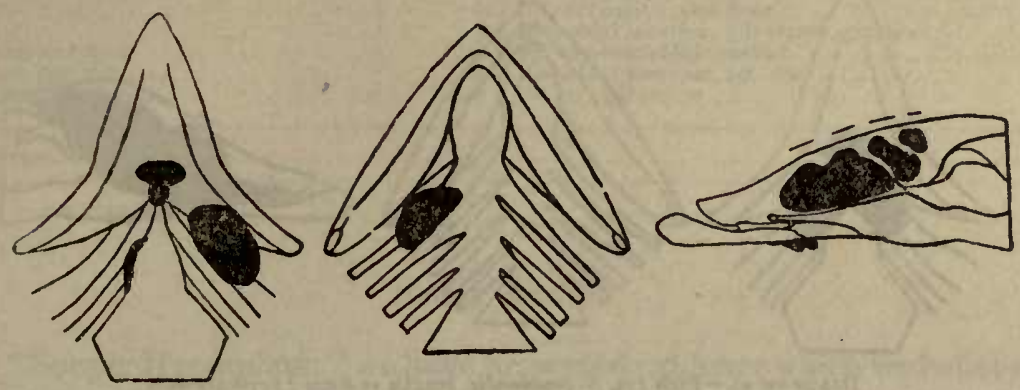

DIAGRAM 42.-Fish 153, S. fontinalis, length $24.3 \mathrm{~cm}$; type alveolar.
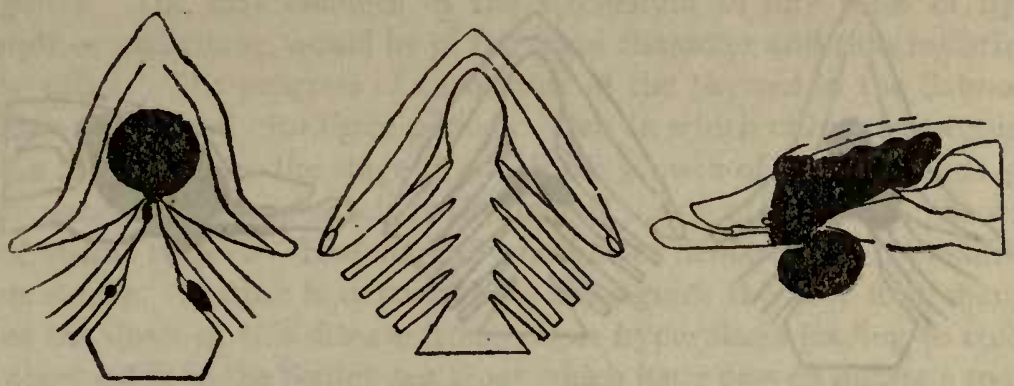

Diagram 43.-Fish ${ }_{54}$, S. fontinalis, length $18.7 \mathrm{~cm}$; type alveolar.
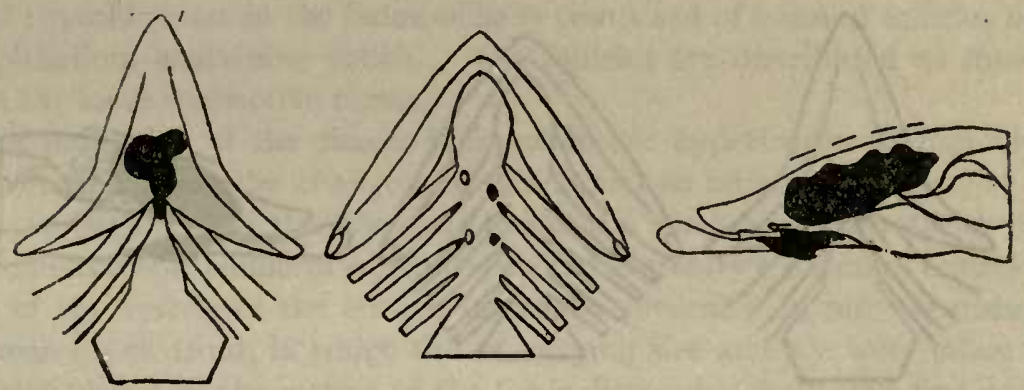

DIAGRAM 44.-Fish 155 , S. fontinalis, length $24 \mathrm{~cm}$; ; type alveolar. 


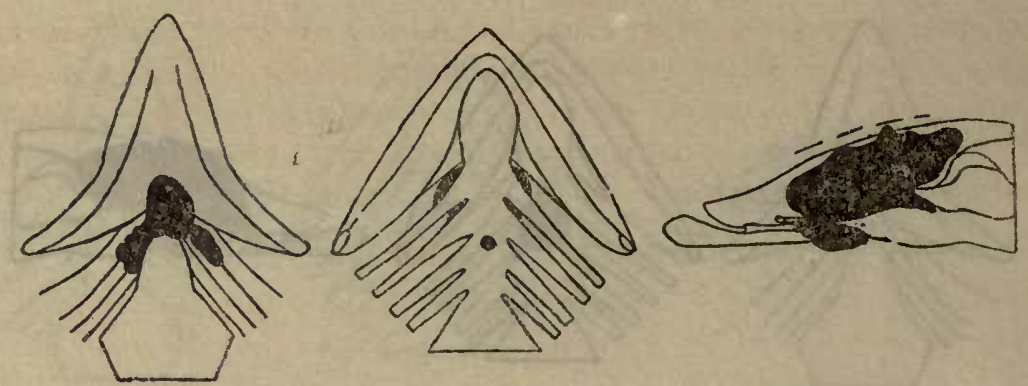

Diagram 45.-Fish $\times 58$, S. fontinalis, length $18.6 \mathrm{~cm}$.; type alverlar.

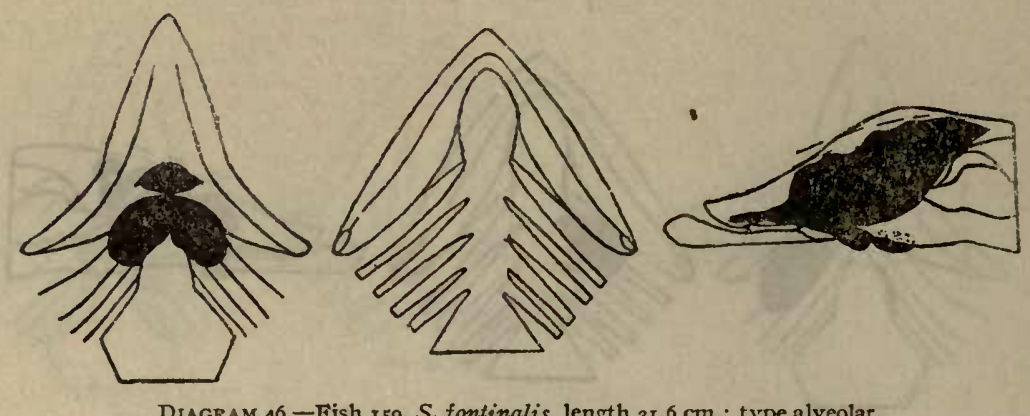

DiAgram 46.-Fish $\times 59$, S. fontinalis, length $21.6 \mathrm{~cm}$; t type alveolar.

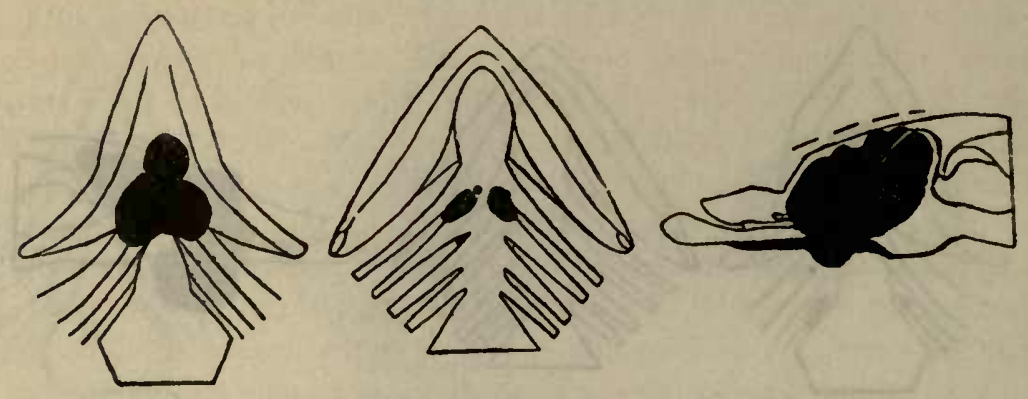

DiAgram 47.-Fish r62, S. fontinalis, length $23 \mathrm{~cm}$.; type mixed.

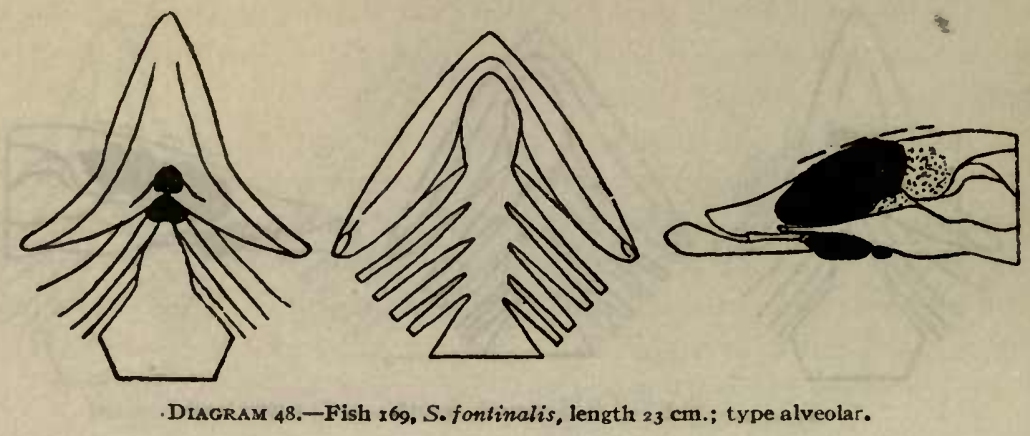


From their position they are subject to mechanical erosion on their ventral surface. When well developed the tumor usually fills and completely obliterates the pit. When the latter is not the seat of tumor growth, it is sometimes completely everted by the pressure of the tumor from the main thyroid region, and almost all trace of it lost, the surface of the skin being stretched smooth in this region.

TABLE I.-Classification of Visible Tumors by Location.

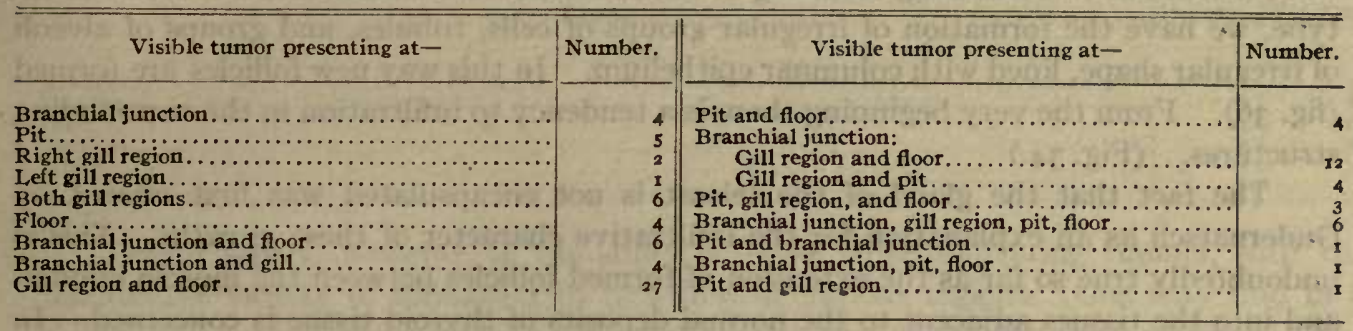

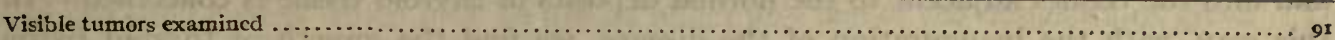

HISTOLOGY.

EARLY STAGE.

Under "Simple Hyperplasia" we have presented evidence which we believe indicates. that there occurs in wild and domesticated fish a type of simple hyperplasia which leads to colloid goiter. The first changes in the epithelium in any form of hyperplasia, whether simple or malignant, would be of the same character and thus indistinguishable. one from the other. The progress of carcinoma of the thyroid in the Salmonidx may for convenience be divided into three periods: That in which only microscopic evidence of hyperplasia is discernible; the stage in which the growth of tissue extends sufficiently to produce hyperæmic changes visible in the floor of the mouth-i. e., red floor; and then the period of visible tumors. Histologically no line of demarcation is possible between these various stages. Neither is it possible to distinguish the very first changes in the epithelium at the onset of this disease from simple hyperplasia leading to colloid goiter as we have observed it in the Scotch sea trout which have proven immune to carcinoma of the thyroid.

Normal thyroid tissue in the Salmonidæ is composed of isolated follicles lined with flattened epithelium containing colloid. The follicles are distributed as shown about. the aorta in the loose connective tissue.

The first indication of the disease is found in the hypertrophy of individual cells; in a given follicle usually the change affects one or two adjacent follicles, or the only evidence of the beginning of the disease is found in a small group of follicles lined with cubical or columnar epithelium in which the colloid is greatly reduced or entirely absent. Hyperemia of the vessels of the stroma is usually present. In our experiments with wild Wisconsin brook trout, in which fish of varying size and age were taken from the wilderness and placed in the waters of the Craig Brook hatchery, the first evidence of 
the disease was found in changes like those above described and affected individual or small groups of follicles lying adjacent to the large arteries. (Fig. 40.) One or two seleeted protocols of fish in which the disease was experimentally induced and properly controlled show that the action of the agent causing the disease is clearly focal. Budding of the wall of the follicle is early in evidence, presenting an appearance much like that found in the embryo, where the formation of secondary follieles is in progress. But here, instead of this budding, resulting in the formation of isolated follicles of the usual type, we have the formation of irregular groups of cells, tubules, and groups of alveoli of irregular shape, lined with columnar epithelium. In this way new follicles are formed (fig. 36). From the very beginning there is a tendency to infiltration in the surrounding structures. (Fig. 34.)

The fact that the gland of the teleost is not encapsulated was first offered by Gudernatsch as an explanation for the infiltrative character of these growths. This is undoubtedly true so far as the extension of formed follicles between the muscle bundles and into the tissues adjacent to the normal deposits of thyroid tissue is concerned. In this way, with the inauguration of the disease, we find the growth of thyroid tissue into the surrounding structure. Such growth follows in the first instance the lines of least resistance and is in our opinion quite distinct from the phenomenon of the infiltration of adjacent cell structures by individual cells - a phenomenon which is frequently found with the very first evidence of the disease. The cells of the alveoli in this stage have changed from flattened to high columnar, with deeply staining protoplasm, basilar nuclei often vesicular and frequently with many karyokinetic figures. Where the follicles have simply grown between the muscle bundles or against opposing structures, such as bone and cartilage, they are frequently flattened, usually of small size, and closely grouped. Where the follicles are broken through, and groups of individual cells infiltrate the surrounding structures, there is frequently marked proliferation of the interstitial connective tissue. Even in the early stages great variation in the arrangement of the cells is apparent. They form long, narrow tubules, the alveoli more or less irregular in shape, with solid masses of cells and large irregular spaces. The follicles may or may not contain colloid. In the early stage there is generally a marked diminution in colloid. (Fig. 36.)

\section{RED-FLOOR STAGE.}

In this stage the extent of proliferating thyroid is such as to be visible as a slight flush on the floor of the mouth. Histologically the spaces surrounding the vessels are filled with tumor tissue. Bone, cartilage, and muscle are invaded, and the tumor tissue extends toward the gill arches and backward toward the heart. A characteristic of this stage is that the tumor tissue does not seek the paths of least resistance, but infiltrates in other directions. (Fig. 37.) The arrangement is tubular or alveolar in most instances; the epithelium is high and deeply staining. Only occasional follicles with colloid are encountered. There is a well-defined connective tissue reticulum. Karyokinetic figures are numerous and are found in most tumors. (Fig. 35 and 36.) 
VISIBLE TUMOR STAGE-STRUCTURAL, TYPES.

In the larger tumors one finds a remarkable variation in the histologic picture. The fundamental types may be divided into four - alveolar, papillar, tubular, and solid. In occasional tumors one of these three types definitely predominates. In the roo tumors selected for study these types occur in the following proportions:

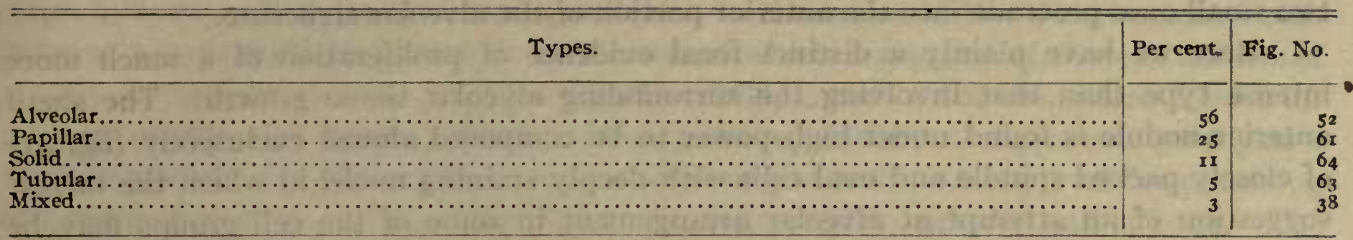

One is struck, however, in the study of these large infiltrating tumors, with the remarkable variety of formation to be found in various regions. One may find in a single tumor areas which may be placed under any one of the designations given. The action of the stimulus upon the thyroid tissue in these tumors appears not only to work irregularly, as will be shown by the advent of nodules of active proliferation and areas simulating hyperplasia, but appears to throw the entire thyroid tissue into such a riot of proliferation that a definite type for the entire tumor is seldom accomplished. The epithelial cells forming the tumor present the greatest possible variety of form and size. The nuclei are usually vesicular, in entire areas of a tumor the cells may present a typical spindle form, thus simulating sarcoma, and in some instances areas of the tumor are made up of a background of spindle cell tissue, through which are scattered small but definite alveoli containing colloid. (Fig. 38.)

In such a tumor we have a picture analogous to the so-called mixed tumor of the thyroid encountered in man. Occasionally tumors may be met in which a large proportion of the tumor is made up of large alveoli packed with solid masses of large cells, deeply staining protoplasm and vesicular nuclei, and frequent karyokinetic figures, presenting the picture of proliferating struma. (Langhans.) (Fig. 39.)

Again, the general predominating type of a tumor may be distinctly papillary, in which large vegetations covered with columnar epithelium and deeply stained nuclei are found projecting into irregular spaces, usually free from colloid. The tendency to papillary formation may be found in almost all of these tumors. Occasionally these papilliform areas are of nodular form, in which case the cells forming the papillary nodule are more deeply stained than the surrounding tubular or alveolar type, which gives them a distinct focal character. (Fig. 45.) This marked tendency to focal or nodular development within the tumors occasionally produces growths in which we have a large mass of tubulo-alveolar structure, with nodules of solid, closely packed areas of intensive proliferation. In figure 40 we have a low-power picture of such a tumor. The tumor mass involves the entire area between the base of the tongue and the pericardial space and extends between the arches to the floor of the mouth, where it projects in a series of large protrusions, has pushed down the muscular structure of the isthmus, protrudes in 
the median line at the branchial junction and extends forward into the areolar tissue at the base of the tongue, and presents visible evidence of erosion of the large mass of cartilage at the base of the tongue. The superior, anterior, and protruding posterior portions of this tumor are composed of a network of large alveoli, free from colloid, in which are embedded a number of dense nodular growths. One of these protrudes into the floor of the mouth, a group of larger ones forms the central portion of the tumor, and one or two small ones protrude into the anterior portion of the alveolar structure.

Here we have plainly a distinct focal evidence of proliferation of a much more - intense type than that involving the surrounding alveolar tissue growth. The small anterior nodule is found under high power to be composed almost exclusively (fig. 4I) of closely packed spindle and oval cells with deeply staining nuclei in which the merest suggestion of an attempt at alveolar arrangement in some of the cell groups may be traced. In the distinct nodule lying in the floor of the mouth the alveolar structure is more apparent, and figure 42 shows a small, distinct nodule of adenomatous type. The margins of these more or less solid nodules in this tumor gradually merge into the loose alveolar structure forming the remainder of the tumor. In some tumors, however, we have found small nodules of closely packed alveoli, the cells of which stain deeply, with closely packed, deeply staining nuclei, the nodule embedded in a reticulum of more open alveolar structure, the cells of which are not in so active a state of proliferation and do not stain so deeply. In many of these nodules expansive growth is evidenced by compression and displacement of the alveoli of the tumor tissue surrounding the nodule. (Fig. 43.)

\section{INFILTRATION.}

In another aspect of the nodule one finds definite evidence of infiltration of surrounding thyroid tumor tissue by individual alveoli of the more malignant type. (Fig. 44.) We have here definite evidence of infiltration of thyroid tissue by a nodule of malignant degeneration of more active type. The importance of this finding is that the infiltration in this instance does not deal with anatomical landmarks or adjacent structures but represents a true infiltration, by a more malignant and rapidly growing portion of the thyroid tissue, of surrounding thyroid structure.

A nodular development in the tumors indicates a more intense focal action of the stimulus causing these tumors. It has been suggested that proliferation of the thyroid in these growths in the Salmonidæ is due to a reaction of the tissue to physiological demands. A marked characteristic of physiological hyperplasia is the uniformity with which the entire organ is affected. One of the most prominent characteristics of these growths in the thyroid in the Salmonidæ is intensive local stimulation, which leads not only to nodules within the tumor masses, but gives the visible growth a marked lobulated appearance. If these tumors represented a response to physiological demands, we should expect a more uniform character of the hyperplastic tissue. We should expect all of the thyroid tissue to be affected. In this connection the section of fish 158 is significant. Here we have an extensive tumor (diagram 45, p. 36) involving the entire region between the isthmus and the floor of the mouth, appearing at the branchial 
junction and in the gill spaces on both sides, protruding between the first and second branchial arches, and penetrating the floor of the mouth in the median line at the junction between the second and third branchial arches.

Microscopically, this extensive growth is found to infiltrate the surrounding structures, bone, cartilage, and muscle. It may be classified as alveolo-tubular type. In many regions it presents a characteristic solid structure. Only in occasional areas do a few follicies contain poorly staining colloid. In the region of the third branchial arch is found a cross section of bone, in the lumen of which is a group of thyroid follicles of strictly normal appearance. (Fig. 47.) The follicles are of the usual size filled with homogeneously and deeply staining colloid, the epithelium is flattened, protoplasm small in amount, the nuclei stain deeply and homogeneously. A study of the preceding and succeeding serial sections fails to show any opening through the wall of bone. The tumor tissue is in immediate contact with the shell of bone for a considerable extent of its circumference, the remainder is covered with periosteum and dense connective tissue.

The significance of this finding is that here we have a large tumor of tubulo-alveolosolid type infiltrating the surrounding structures, while lying within the medullary space of the bone structure and included in the tumor tissue is a deposit of normal thyroid tissue which by its appearance, and the presence of deeply stainable colloid, must be in physiological continuity with the metabolism of the fish. That the deposit of normal thyroid within the bone has remained unaltered because it was protected from an agent working from without by being inclosed within the bone is probable, but no less important is the fact that it shows clearly that portions of the thyroid structure in the Salmonidæ may undergo malignant change, while other portions of the thyroid tissue remain strictly normal in appearance and retain their physiological function until, it may be said, as this tumor was very advanced, the last stages of the disease.

A great deal has been said about the significance of the capsule of the thyroid in mammals. Here the evidence of malignancy consists in a breaking through the capsule and infiltration of the surrounding structures. As the thyroid structure of the teleost has no capsule, such a criterion can not be applied, and some have ascribed the infiltrative characteristics of these tumors to the isolated character of the follicles and lack of a delimiting capsule. One of the best evidences of malignancy in the mammalian thyroid is the development of isolated nodules of malignant character within the structure of an enlarged thyroid, and here the evidence of infiltration has not to do with a capsule, but the infiltration of surrounding thyroid structure. A determination of exactly analogous conditions in our tumors indicates that we have in the proliferation of the tumor tissue in the Salmonidæ an expression of genuine malignancy.

Infiltration of bone and cartilage.- The growth of these extensive tumors naturally leads to the crosion and destruction of cartilage and bone. The mere presence of thyroid tissue within the bone spaces of the branchial arches is in itself of no significance. Deposits of normal thyroid tissue are often encountered in the open spaces of both bone and cartilage. The shape of the bony and cartilaginous structure in the floor of the mouth in the teleost is frequently such that the thyroid tissue grows in through small openings in the base of the arches. In many instances, however, we 
find total destruction of cartilage and bone and marked evidences of infiltration of the bony and cartilaginous structures by individual cells and groups of cells. (Fig. 48 and 49.)

Infiltration of vessel walls - Genuine infiltration of vessel walls will serve much the same purpose as infiltration of the capsule in mammals, as deposits of thyroid tissue within the media of the larger vessels has never been encountered. Figures 33 and 50 show a section of the aortic wall stained with orcein, in which the elastic lamellæ of the media are split up and spread out into the adjoining tumor mass as the result of the penetration between the elastic lamellæ of the alveoli of an infiltrating tumor. The aortic wall at this point is reduced to about half the thickness of the uninfiltrated remainder of the circumference. We have here genuine infiltration of the media of the aorta.

Infiltration of muscle.-Besides the growth of the alveoli of tumors between the muscle bundles (fig. 37), we frequently encounter infiltration of individual muscles cells by tumor cells. In these cases the sarcolemma sheath is broken through and we find the isolated cells of the tumor displacing the muscle fiber. (Fig. 5I.) The tumor tissue in many instances has lost its alveolar structure, the cells being closely packed together without definite form. There are many instances of genuine infiltration by individuals or groups of cells in the muscle fibers.

Infiltration of the skin.-This is usually best observed in the floor of the mouth. It has been suggested that the breaking through of tumor masses of the outer integument was due largely to pressure, that the epidermis became greatly thinned and ultimately eroded. This is in many instances true where large masses of tumor protrude into the floor of the mouth or where protuberant growths extend downward or outward. In the floor of the mouth, however, we frequently find that the elastic structure of the skin and the epithelial strata overlying it are punctured by small vegetations. Figures 31 and 32 show such growths. Frequently growths penetrating the floor of the mouth will be found to have split up and destroyed the elastic structure of the epidermis without any appreciable thinning whatsoever, the entire thickness of the elastic structure suddenly disintegrating without any evidence of stretching or thinning. (Fig. 46.) It is therefore evident that besides expansive growth, carcinoma of the thyroid in the Salmonidæ presents indisputable evidence of genuine infiltration, such as we encounter in malignant growths in other species.

OTHER OBSERVATIONS.

In 1905, L. Pick published a comprehensive article entitled "Carcinoma of the Thyroid in the Salmonidæ," with I 5 illustrations. It is by all means the most important publication on this subject dealing with the histology of these tumors. Pick's material consisted of ro brook trout obtained from a hatchery, we are led to believe, in the United States. He illustrates five of these fish, one of which exhibited a large infiltrating tumor involving the entire region below the floor of the mouth and the muscular structure of the isthmus (Pick, 1905, fig. I). Figure 3 shows a small tumor at the branchial 
junction. Figure 4 , a view from above downward, shows a vegetating tumor in the floor of the mouth. Figure 2 illustrates an isolated tumor in the jugular pit, and figure 5 a tumor in the jugular pit and one at the branchial junction.

Pick's paper is particularly excellent in the thoroughness with which he deals with the histology of these tumors. In fish I, with the large infiltrating tumor in the floor of the mouth, he recognizes the variegated character of the epithelial structure, distinguishing an adenomatous portion and a follicular portion, both of which he closely describes. He points out the absence of any evidence of a capsule and describes fully and accurately the infiltrating character of the tumor tissue. He notes the extension of the tumor in the lymph spaces of the neighboring muscular fascia, which he describes as being destroyed by the infiltration. Strands of tumor cells which widen into follicles invade the lymph spaces of the adventitia of the aorta. He describes the invasion and breaking up of the tendon of insertion of the muscle of the isthmus. The epithelium of the tumor invades the loose submucous fatty tissue, and the spaces of the dense connective tissue and the tunica propria of the mucosa of the floor of the mouth. Not only are the softer tissues invaded, but he finds that both cartilage and bone are destroyed. This is accomplished by the tumor surrounding the bone growing into the various infoldings of the branchial arches and the cavities of the bone, opening up the capsule of the cartilage, and invasion of the cartilage tissue proper, infiltration between the periosteum and the bone, thus leading to the death of fragments of bone and the formation of sequestra which through the process of decalcification and fibrillation disintegrate.

In his description of fish 3 he shows, in figure 8 , the invasion of the mucosa of the floor of the mouth by papillary outgrowths which, in the instance illustrated, shows the formation of small cystlike alveoli within the epithelium of the mucosa. In fish 5 he describes and in figure 9 illustrates the solid type of tumor; in figure ro is shown the polymorphic nature of the cells of this tumor. In fish 7 he describes portions of tumor with large cystic alveoli, flattened single layer of epithelium and stainable colloid (struma thyreoidea parenchymatosa colloides). In fish 8 the papillary type of growth is described.

Pick concludes that these tumors are undoubtedly infiltrating epithelial neoplasms, malignant epithelioma, or in the general sense of Orth's definition, carcinoma. He points out that the diffuse deposit of thyroid tissue does not necessarily become diseased in toto; in fact, that it is more often affected at various points, that the growths are pluri-centric. He thinks that these centers of growth originate simultaneously or at different times, that they may grow more or less uniformly and that in some cases outlying extensions of thyroid tissue become involved, these facts explaining the remarkable variety of form of the tumors, the directions in which they infiltrate, whether upward into the floor of the mouth or laterally into the gill spaces, and the fact that they may be bilaterally symmetrical or unsymmetrical.

He points out the absence of a capsule in any of the tumor fish. He recognizes that several of his tumors have retained very definitely the thyroid structure and speaks of these as presenting the character of parenchymatous struma, although in such tumors the infiltrative character and destruction may be very great, these being tumors of 
homotypic character; and that in others the great variation in size of cells and marked deviation from the organal type produce tumors of heterotypic character.

\section{IMPLANTATIONS AND METASTASES.}

It is obviously of the greatest importance in a neoplasm of the character of the carcinoma of the thyroid in the Salmonidx to determine whether or not metastases or possibly implantation may occur. Although infiltrative growth is and will always remain one of the best evidences of malignancy, yet in the last analysis a true neoplasm must present some evidence of metastasis formation or the development of implants. The experimental study of cancer has placed a new significance upon the importance of transplantability. Experimental results with mouse and rat tumors clearly indicate that metastasis formation may be controlled or at least influenced by concomitant immunity, and as the immune phenomena are more outspoken in the more virulent types of cancer, it is not surprising that a neoplasm involving a vital organ like the thyroid, through its early infiltrative growth involving vital structures, might prove the determining factor in the early carrying off of the individual and thus the life of the affected fish might not extend into the period in which metastasis formation more frequently occurs.

The rarity of the occurrence of metastases in any given group of tumors may well be expected. In such a case one or two instances may serve the purpose of definitely fixing the nature of the neoplasm. The occurrence of metastasis in the thyroid carcinomata of fish is certainly rare. The circulation of the fish is not well adapted to the transportation of cells. The region in which transported cells would most easily obtain lodgment would be in the bifurcations of the vessels of the branchial arches, and it is a common occurrence to find isolated growths well away from the median line on these structures, but as deposits of thyroid tissue are located immediately about the aorta many of these growths will be found to be simply outgrowths from the primary mass in the median line. Some of them are, however, so widely displaced from the median mass that they may be looked upon as regional metastases in which the transport of cells would have to be accomplished through the lymph channels. It may be said that growths in this region, however, are not competent to determine the question of true metastasis formation from transport of cells. A region already referred to and one in which the development of tumors is very frequent, occurring in not less than 25 per cent of the studied cases, is the jugular pit. The explanation for these growths is, however, found in the frequent presence of misplaced thyroid tissue. The origin of these deposits has been clearly traced and adequately explained.

Early in our observations we noted that occasional growths upon the tip of the lower jaw were to be seen. (Fig. 28.) This region in the fish is one peculiarly exposed to injury. The fish confined in tanks almost certainly run into the sides of the tanks or the screens and injure the epidermis at this point. These growths at the apex of the lower jaw might be explained by the presence of unusual deposits of thyroid tissue at this point. We have examined, by serial section, this region of the lower jaw in 25 fish, and have never found any trace of normal thyroid in this location. Furthermore, 
a careful study of the development of the thyroid in the embryo gives no indication whatever of the likelihood of thyroid tissue being deposited at this point, and in the careful survey of the distribution of the thyroid in wild fish we have never seen any deposits of normal thyroid tissue even so far forward as the base of the tongue. We must, therefore, conclude that there is no evidence that thyroid tisstie is ever laid down in this locality.

The anatomical structure at this point is also very unfavorable for the deposit of normal thyroid tissue. The symphysis of the dentaries here is covered only by the periosteum, a thin layer of dense subcutaneous connective tissue upon which rests directly the elastic structure and the epidermis of the outer covering. In fish 6r, diagram $r$, we find an extensive growth of thyroid tumor springing from the apex of the lower jaw, entirely distinct and separate from the usual growth of tumor about the aorta and extending up into the floor of the mouth. A microscopic examination of the growth of the tip of the jaw and the primary growth in the substance of the isthmus shows that they present much the same appearance, being both alveolar in type and many of the alveoli containing stąinable colloid. (Fig. 52 and 53.) The similarity in the primary and the detached growth on the tip of the jaw naturally indicate that we have here to deal with a metastasis.

There is, however, a further possibility, and this is that a growth has developed from an implant finding lodgment upon the prepared site of an injury. We have frequently observed that fish with large protruding tumors in the gill region attempt to free themselves of the outgrowths by rubbing the tumor upon the bottom of the pond. This is evidenced by the frequent observation of tumors which have been worn off in this way. It is quite easy to conceive that fragments of such eroded tumors floating in the water of the pond might find lodgment upon the injured apex of the lower jaw. If this was the origin of this outgrowth on the tip of the lower jaw, the similarity between the primary tumor and the secondary tumor would have to be a matter of coincidence. We feel we may safely conclude that the growths on the tip of the lower jaw are true metastases from primary growths in the usual locality, the lodgment of the cells by way of the circulation being favored by reparative processes at this point, or that the growth is a result of implantation through the medium of the water. From the standpoint of determining the true neoplastic character of these tumors, the evidence would be in either case of about equal value.

A case of still greater importance has to do with a 2 -year-old brook trout from the same source, in which a tumor measuring 7 by 8 by 14 millimeters, of pear shape, soft consistency, and dark pinkish color, was found in the lowermost portion of the hind gut or rectum just within the anus. (Fig. 25.) Careful examination shows that the tumor is for the greater part covered by the mucosa of the intestine. It protrudes within the intestinal canal, which is greatly flattened and pushed to one side, and has obviously been obstructed by the tumor. (Fig. 54.) A section made from the wall of the intestine, including the intestinal lumen, well into the tumor, presents on microscopic exam. ination the following conditions: 
The tumor is of alveolo-tubular type, the greater proportion of it solid. It involves the muscularis mucosa of the intestinal wall, bundles of muscles derived from this structure running through its substance. In the more open portions of the tumor, alveoli containing colloid may be found. Under higher power (fig. 57) the epithelium of the tumor both in the alveolar and tubular types consists of large cells generally of high columnar type. The protoplasm is deeply stained; the nuclei are vesicular, of basilar location. In some areas marked variation in size and character of the epithelial cells is evident. Karyokinetic figures are not infrequent. The heterotypic nature of the epithelial cells is best seen in the region where the muscular coat of the intestinal wall is infiltrated. (Fig. 57.)

The larger proportion of the tumor is rather regular in formation, homotypic in character. In many places the epithelium is so closely packed that scarcely any evidence of alveolar structure may be made out. The relation of the intestinal lumen to the tumor growth is of peculiar importance. Carefully scanning the tumor under low power a point may be found where the intestinal epithelium spreads out into a single layer upon the surface of the tumor. (Fig. 55.) There is no evidence of transition from the intestinal epithelium into that of the tumor; in fact the marked columnar character of the intestinal epithelium, with its frequent goblet cells, is clearly distinguished against the background of tumor tissue. Upon the surface of the tumor the single layer of epithelium from the intestinal papillæ extends for a considerable distance upon the surface of the tumor, the uppermost portion of which is, however, eroded. Evidences of occasional hemorrhages upon the surface may be found, the apex of the tumor being covered with a distinct clot. In other portions of the tumor the characteristic appearance of alveoli of irregular shape generally filled with colloid is to be found and in this region the tendency to papillary growths within the alveoli is quite distinct. (Fig. 56.) In this region also the structure of the muscularis mucosa is apparent, and the marked infiltrative character of the tumor is here distinctly evident.

The histologic diagnosis of this tumor is to our mind quite clear, It consists of thyroid tissue presenting the characteristics of the alveolo-tubular type of tumor of the thyroid in the Salmonidæ. It furthermore presents in certain areas that tendency to papillary formation which is so frequent in these tumors. The histological picture and the presence of colloid quite clearly determine the nature of this growth. It is greatly to be regretted that through an unforeseen accident the thyroid region of this fish was not preserved. We have no evidence as to the nature of the primary growth in the thyroid region. Although the fish presented no macroscopic evidence of tumor, yet there is little doubt that a primary tumor in the thyroid region existed. The fish was taken from a hatchery in which one of the most outspoken epidemics of the disease we have yet encountered was in full progress. As all of the brook trout of this age succumbed to the disease in the course of two seasons, and as every specimen taken from the pond in which this fish was found presented macroscopic or microscopic evidence of the disease, there is little reason to doubt that we have here to deal with a metastasis from a tumor originating in the thyroid tissue of this fish. 
We have expressed our reason for holding that the growths on the apex of the jaw and this growth in the wall of the intestinal tract just within the anus are instances of genuine metastasis formation. We believe that a wider understanding of the natural history of carcinoma of the thyroid of the Salmonidæ will show that a case described by Marine and Lenhart (I9IIa, p. 470) is more probably a metastasis than a tumor springing from misplaced thyroid. These authors describe an abdominal goiter in a 29-months-old fish. The thyroid mass was round, circumscribed, and measured one by one-half cubic centimeter, was attached to the cardiac end of the stomach by a connective tissue pedicle and extended into the abdominal cavity. The fish had a large ventral tumor histologically identical with the abdominal growth. Because an examination of the visceral regions showed no such deposits of thyroid tissue, these authors looked upon this specimen as an enlarged aberrant thyroid deposit. They also report having seen growths on the tip of the lower jaw in from 2 to 3 per cent of all fish with visible tumors examined by them, and these they also hold to have sprung from misplaced thyroid deposits.

\section{COMPARATIVE PATHOLOGY.}

The study of hyperplasia and carcinoma of the thyroid in the Salmonidæ, on account of the great similarity in the changes in the organ of the fish to that occurring in mammals, seems likely to throw important light upon the origin of certain structures which have been the subject of extensive study in the thyroid of mammals. Virchow (1863), Wölfler (1883), Hitzig ( 1894 ), and Michaud (I906) have described in the thyroid of man small adenomata, the condition being known as struma nodosa. Virchow held that these nodules developed by proliferation from the follicles of the thyroid. Wolfler held that they developed from misplaced embryonic rests. Hitzig evidently opposed the theory of Wölfler as to the embryonic origin of these nodules and held that they developed by proliferation from the normal tissue of the thyroid, for the reason that in normal thyroids they were never found. Michaud has carefully studied the genesis of these adenomata and agrees with Virchow and Hitzig that they are formed by proliferation from normal structures of the thyroid.

According to Michaud these growths develop by changes in the epithelium of normal follicles, which take on columnar type and through proliferation of the cells form extensions and protrusion of the follicles and finally by budding produce new follicles which become detached from the original. The first changes, which are focal, are restricted by the surrounding stroma, which takes no part in the change. From this point on the nodule grows by proliferation of the structures within it, especially those toward the center. The very first evidence of this change is found by Michaud in the presence in the thyroid structure of long, tortuous clefts or tubes with cubical or columnar epithelium, staining more deeply than the surrounding structures, these tubules having already been noted and described by Hitzig. From these tubules, by the process of budding above described, are developed focal nodules, i. e., struma nodosa.

It will be seen that the description given by Hitzig and Michaud for the development of these isolated adenomata in the mammalian thyroid is exactly like the beginning 
changes leading to carcinoma of the thyroid in the Salmonidæ as we have described it. In figure 84 the change from flattened to columnar type, with deeply staining protoplasm, lengthening and flattening of the tubules, closely resemble those found in the mammalian thyroid by Hitzig and Michaud, and, with the exception of the hyperaemia, which is associated with the more intensive chnges, in the hyperplasia of the thyroid in the Salmonidæ. The advent of isolated nodular growths, sometimes sharply circumscribed (fig. 45), indicates that focal proliferation of the thyroid tissue in the fish frequently leads to the development of nodules presenting the picture of nodular struma in mammals. The structure of the normal thyroid in the Salmonidæ is so simple and its amount so limited, that a careful study of this structure in all age periods of the fisl renders it clear that the advent of tubular structures with columnar epithelium clearly represents a pathological change, and here we are not troubled with the many questions which arise to complicate the study of these structures in the mammalian thyroid. We can, in the thyroid of the Salmonidæ, definitely exclude the idea voiced by Krämer, i 910 , that such tubules in the mammalian thyroid were probably originally the remnants of execretory ducts persisting from an earlier period of development of the mammalian thyroid. It is plainly evident from the study of the normal thyroid in the Salmonidæ and the genesis of hyperplasia, nodular growths and fully developed carcinoma, that the changes in this organ are brought about by the action of some agent working focally upon the epithelium of normal vesicles, and we can clearly exclude all possibility of embryonic rests playing a part in the genesis of circumscribed adenomata or cancer.

The evidence adduced on this subject therefore confirms, so far as the evidence is applicable, the conclusions of Virchow, Hitzig, and Michaud that struma nodosa develops as the result of focal change in the epithelium of normal structures of the thyroid. The production of tubules and irregularly distorted spaces lined with columnar epithelium and the process of development of new follicles by budding, as described and illustrated by Michaud, are repeatedly encountered in our specimens, especially in the earliest stages. (Fig. 36.) The theory that carcinoma of the thyroid develops especially from the adenomata of nodular struma and that endemic goiter is the result of a physiological hyperplasia of normal thyroid tissue, finds no support in our study of carcinoma of the thyroid in the Salmonidæ. The theory of Marine that iodine affects alone physiological hyperplastic changes of the thyroid tissue and does not affect these adenomata, and may thus be used as a means of distinguishing between physiological hyperplasia and cancer, is obviously untenable, as we find that iodine, as well as mercury and arsenic, affect not only fully developed carcinoma of the thyroid but where tumors contain individual adenomata these are likewise affected. Well-developed tumors in the Salmonidæ sometimes closely simulate the structures of nodular struma in the mammal. Figure 65 represents such a tumor and may be compared with figure 66 , struma nodosa in man. The tumors of the fish frequently contain the so-called Wachstum centra of Aschoff. (Fig. 66.)

Although it may not be wise to go too far in the comparison of carcinoma in the Salmonidæ with carcinoma of the thyroid in mammals, yet inasmuch as we will show 
later that at least the first stages of this disease can be induced in mammals through the drinking water, such a comparison at the present time becomes even more profitable than formerly. The final relation of these tumors to tumors in mammals can now be left to experimental investigation; especially the production in mammals of metastasizing tumors would serve to clear up the possible relation between carcinoma of the thyroid in the Salmonidæ and carcinoma of the thyroid in mammals. For the present we consider that we have more firmly established the fact already assumed by Plehn, Pick, and many other investigators, that we are here dealing with carcinoma of the thyroid in fish.

Pick, in his excellent article, after having established the homotypic and heterotypic character of these tumors, compared them with the malignant epithelial tumors of other animals, especially carcinoma of the breast in mice. This analogy of Pick's is well taken and we feel that the progress of experimental cancer research has since demonstrated many other points of analogy, which we shall deal with later. Pick also pointed out that certain degenerative and regressive changes are common both to carcinoma of the thyroid in fish and the epitheliomata of mammals. The impossibility of classifying the different types of carcinoma of the thyroid in fish affords another point of similarity with carcinoma of the breast in mice, where the greatest variety of histological appearance may be found in the same tumor. A still closer analogy, according to Pick, is to be found in the histological character of the growths of the thyroid in fish when compared with similar tumors in man, although from the material at Pick's disposal he had no evidence of metastasis formation, such as we are now able to bring.

One of the most important contributions to our knowledge of the various types of epithelial proliferation of the thyroid structure in man is found in a monograph, based on very extensive material, entitled "On the Epithelial Forms of Malignant Struma," by Langhans (1907), in which this author classifies the various types of malignant growths of the thyroid in man under the following heads:

I. Proliferating struma.

2. Carcinomatous struma, the usual irregular structure of carcinoma.

3. Metastasizing struma.

4. Para struma.

5. Small alveolar, large-celled struma.

6. Malignant papilloma.

7. Squamous epithelioma.

From a comparison of our material with that of Langhans we find that in the fish tumors, areas of proliferation, or in some instances the greater part of the structure of a tumor, may be said to conform to one of three of the six types described by Langhans for man, namely, proliferating struma, carcinomatous struma, and malignant papilloma. Figure 59 illustrates a tumor in which the preponderating type is almost identical in appearance with the type described by Langhans for proliferating struma and may be compared with figure 60 , made at the same magnification from one of Prof.

$8207^{\circ}-14-4$ 
Langhans's original sections which he was kind enough to transmit to us. Carcinomatous struma in man has its analogy in many of the illustrations of fish tumors given. Figure 63 illustrates the papillary type of carcinoma in the Salmonidæ, which may be compared with figure 27 , plate 6 , of Langhans's article, illustrating the type known as struma of Geisslar. Langhans's group 6, malignant papilloma, finds its counterpart in many of the fish carcinomata, papillomatous areas occurring in almost all tumors. Figure 6r illustrates a tumor of almost pure papillomatous type and may be compared with figure 62 from one of Prof. Langhans's sections of malignant papilloma in man and illustrated by him as figure 32 , plate 7 , of his monograph.

Pick was of the opinion from his material that carcinoma of the thyroid in the Salmonidæ was a condition superimposed upon endemic goiter and referred to the occasional observation of malignant growths in man upon the basis of preexisting nonmalignant struma. He suggested that endemic goiter might be distinct from, but was the predisposing factor in, carcinoma of the thyroid in fish.

There is no point at which it is possible for us to draw a line between what might be called endemic goiter in the salmonoid fishes and carcinoma of the thyroid. Whichever interpretation one may desire to put upon this process, endemic goiter and carcinoma of the thyroid in the Salmonidæ are one and the same thing. Viewed in the light of modern cancer research, it appears to us that the term carcinoma is in every respect the more suitable. The first positive results obtained by us in dogs and rats must, for the present, be classed as diffused parenchymatous struma; but as Bircher has already produced nodular struma in his rats, and it is well known that such adenomata of the thyroid develop into what is called cancer of the thyroid, it appears to us quite possible that further experiments may show that in mammals experimental parenchymatous and nodular struma are but the early stages of the process which is called cancer of the thyroid. ${ }^{a}$

a At the meeting of the Freiburger medizinische Gesellschaft June 3, 1912, Prof. Aschoff demonstrated certain preparations of fish and dog thyroids which had been transmitted to him by us. The report of this meeting in the Deutsche Medizinische Wochenschrift, no. 25, June 20, 1912, contains certain inaccuracies. Prof. Aschoff is reported as stating that Marine and Lenhart were the first to produce struma in fish experimentally, and spoke of our work as a repetition of such experiments. In none of the publications of Marine and Lenhart is such a claim made. We do not know of any investigators having had the facilities or opportunity to carry out experiments of the kind detailed in this report, requiring, as they do, wild fish taken from regions frce from the disease and introducing them into a hatchery under conditions with proper controls to demonstrate that they have acquired the disease. As this incorrect report has been quoted by Schittenhelm and Weichardt in their monograph on endemic goiter in Bavaria, it seems desirable to make this statement.

In their quotation of Prof. Aschoff's remarks these authors state that Aschoff emphasized the similarity of our tumors in fish with the pathological findings in Basedow's disease in man, and that he could not support our view that the fish struma was carcinoma. From the protocol of the mecting quoted it does not appear that he expressed himself so positively as this. He demonstrated the similarity of the preparations with Basedow's disease in man, but this must have applied to the sections of the thyroid enlargement in dogs, and not the fish tumors. This report quoted the fact that iodine, as shown by Marine and Lenhart and confirmed by us, when added to the water, influenced the fish tumors, this fact appearing to be opposed to our interpretation that the fish tumors were cancer, and it did not emphasize the fact that sublimate and arsenic produced the same result, as opposed to this interpretation.

In this connection we would state that in March, 1913. Prof. Aschoff spent a day at our institute in Buffalo, and after carefully studying all of the preparations upon which this monograph is based, including the specimens of metastases, stated that he now holds, in accord with us, that the tumors of the thyroid in the Salmonidx are carcinoma. 


\section{OCCURRENCE OF THE DISEASE UNDER WILD CONDITIONS.}

It is through the domestication of trout that attention was first attracted to thyroid disease in fish, and it is from this source that nearly all material and data have been derived, both in this country and in Europe. Nevertheless, the same thyroid process has been identified with certainty among adult fish living in open natural waters.

The most important example of the kind at hand is a whitefish from Lake Keuka, N. Y. This fish, of which the head alone came to our hands, is a member of the genus Coregonus of the Salmonidæ and belongs probably to the common species of whitefish of Lake Keuka, Coregonus clupeiformis. (Fig. 67.) It was reported as about 60 centimeters in length, probably a female, though the sex was not definitely determined, was caught December 3, 1909, in water about 15 meters deep, and was preserved in formalin about two days later. The tumor, which is described in detail below, is of good size and shows the typical structure common to this growth in the other salmonoid species considered.

From the museum of the University of Buffalo has come to us a brook trout ( $S$. fontinalis) having a large thyroid tumor. (Fig. 69.) The fish (diagram 23, p. 30) is a female 17 centimeters in length and was caught by Prof. Herbert M. Hill in 1902 from Hosmers Creek, near Sardinia, Erie County, N. Y. About 3 miles of this stream constituted a fishing preserve of the nature of a wild stream. It had for several years prior to this time been stocked with 5,000 to 10,000 fingerling trout, all obtained from the New York State Hatchery at Caledonia, N.Y. Some fry of the same species were also obtained from the same source and were kept in a pond adjacent to the creek where they were reared to fingerling size and then liberated in the creek. No artificial feeding of any kind was done in the stream and the fish in question was either planted as a fingerling, or possibly as fry from the Caledonia hatchery, or was possibly a descendent of some few wild fish which occupied the stream before systematic stocking was commenced. It is more probable that the fish was originally a fingerling sent from Caledonia. From its size it was probably not under 2 years of age.

The tumor occurring in the wild living whitefish is found on inspection to protrude in both gill spaces and between the first and second gill arches in the floor of the mouth. It infiltrates the structures below the floor of the mouth beneath the first and second branchial arches. (See diagram 16, p. 28, and fig. 67.) Under the microscope the tumor presents areas of vesicular type. The alveoli are small, but few of them contain stainable colloid. The bulk of the tumor is made up of areas of closely packed deeply staining islands of cells, presenting the merest suggestion of alveolar structure. The cells are closely packed, the nuclei vesicular, the protoplasm deeply staining. Throughout the tumor there are evidences of karyorrhexis. The tissue presents the appearance of not having been freshly preserved, but the histological characteristics are sufficiently discernible. The nuclei are vesicular, and nucleoli and karyokinetic figures are quite frequent. In some areas the cells are so closely packed as to present the appearance of spindle-celled tissue. The whole presents the characteristic picture of small alveolar carcinoma. The infiltrative characteristics 
are best observed in the wall of the large vein, where we find the cells in small groups slightly suggesting an alveolar structure where they have penetrated into the media of the venous wall. Shrinkage owing to fixation accentuates the chopped out appearance of the media. (Fig. 68.) In studying the various sections in which this vein is included one finds a point at which the venous wall is greatly thinned, and at this point extensive hemorrhage into the surrounding tumor structure has occurred. In the same section groups of tumor cells are to be found in the venous lumen. (Fig. 69.) We have here penetration of vessel walls by the tumor cells. Unfortunately, owing to the fact that we had only the head of this specimen to study, we do not know whether the viscera contained metastases or not.

In the brook trout from Hosmers Creek, N. Y. (diagram 23, p. 30), the tumor presents itself in the gill spaces on both sides of the isthmus, on one side shaping itself into a mass the size of a hazelnut. Protrusion in the floor of the mouth is visible between the first and second gill arches on the side of the large tumor and in the median section it infiltrates the region below the first and second gill arches. The fish is preserved in alcohol. Fixation, is moderately good. The section of the tumor measures $x \mathrm{I}$ by $9 \mathrm{~mm}$. On macroscopic inspection of the section a deeply staining, sharply defined nodule measuring 6 by $8 \mathrm{~mm}$. is clearly discernible embedded in a more lightly staining tumor mass. Inspection under low power shows that there is a distinct difference in the appearance of the surrounding tumor and the nodule, the nodule being separated from the tumor by a well-defined compression capsule. (Fig. 70.) The outlying portions of the tumor are for the greater part composed of small alveoli, somewhat loosely arranged, with occasional larger alveoli of irregular shape and marked columnar epithelium. Wide venous channels are frequent in this portion of the tumor. Within the capsule of the above-described nodule one finds the whole made up of somewhat loosely arranged islands, strands, and masses of cells. The central portion of the nodule presents wide venous sinuses without delimiting intima and areas, which are no doubt the result of hemorrhage. Under high power one finds the cells in certain portions of the nodule to be so arranged as to suggest small alveoli, but for the greater part, especially in the well-preserved marginal portions of the nodule, the cells present a distinct spindle character, and great variability in size of the nuclei, which are vesicular with one or two nucleoli. The protoplasm of the cells stains deeply, is rather sparse, and karyokinetic figures are very numerous. Certain areas may be found in which the spindle character of the cells is so pronounced as to suggest the diagnosis of spindlecelled sarcoma. (Fig. 7I.) Gradual transitions of such areas into an arrangement of cells clearly showing their derivation from the poorly formed alveoli indicate their character. We have here a nodule of malignant tumor growth in a mass of tumor tissue of less malignant appearance, carcinoma solidum simulating spindle-celled sarcoma.

In June, 1913, a large landlocked salmon ( $S$. sebago) with a large thyroid tumor was caught in Sebago Lake, Me., by Dr. Charles F. Parker, of North Windham, Me. Dr. Parker recognized the nature of the growth and forwarded it to us through Dr. W. C. Kendall, of the Bureau of Fisheries. The fish was about 4 years of age, measured 23 
inches in length and in its rather emaciated condition weighed 4 pounds. A salmon of this length in health should weigh 6 to 8 pounds. A large thyroid tumor involved the whole gill region, vegetating in the floor of the mouth and presenting on the ventral surface several cystic lobes which kept the gills and gill covers well distended. (Fig. 72.)

Sebago Lake is located in the southwestern part of Maine. It has an area of about 45 square miles and a general depth of 316 feet. It has but few shoal places, the depth of water often reaching close to the shores, which are for the most part rocky, save in a few shallow coves. The lake has little aquatic vegetation; the water is regarded as unquestionably pure and is the source of stupply for the city of Portland. While the fish had been living in a wild state for two or three years, it was originally planted from a fish hatchery, where it may have contracted the disease. Microscopic inspection of this tumor (see fig. 75) shows it to be almost entirely of the alveolar type, showing at the center areas of cystic colloid degeneration.

These four tumor-bearing fish were living under wild natural conditions. when taken. All can be related more or less remotely to fish culture. They were taken from waters in inhabited regions, in which fish culture has been practiced for years, and these waters had frequently received the products of hatcheries. The trout inhabited a stocked stream, and was possibly the product of a hatchery and fed artificially, or was descended from fish so treated. The landlocked salmon was probably planted from a hatchery. No whitefish are fed artificially nor reared to maturity in domestication. The product of their artificial propagation is planted soon after hatching. The most that may be said, therefore, as far as the relation of this tumor-bearing whitefish to domestication is concerned, is that it may have been artificially hatched, planted before feeding, and was living in a large lake which received the drainage from a large trout hatchery and breeding establishment at which the thyroid disease was endemic and epidemic. It was taken within 5 miles of the point of entry of this drainage inflow.

In one of the small lakes of the Adirondack Mountains of New York, which have been stocked with trout from hatcheries, anglers occasionally report the taking of fish with visible tumors at the throat.

In Europe Hofer (1904, p. 194) reports the disease in wild lake trout (Trutta lacustris) living in the Mondsee. Dr. Plehn informs us that occasionally trout with thyroid tumors and living under wild conditions in the streams of Bavaria are sent to the Bavarian Fisheries Biological Station for examination.

\section{OCCURRENCE AND COURSE OF THE DISEASE UNDER DOMESTICATION}

\section{DISTRIBUTION OF THE DISEASE IN UNITED STATES HATCHERIES.}

The thyroid tumor among fishes is undoubtedly of wide distribution. We believe it occurs almost universally where trout are made the subject of artificial propagation and rearing under the ordinary conditions of fish culture in the United States. A complete canvass of all the trout-breeding establishments in the country has not yet been made, but such an investigation would beyond question indicate the distribution of the disease as coextensive with trout culture. The following list gives the places 
at which, from an adequate examination of material, the disease is definitely known to exist or to have existed in an advanced stage as expressed by the exhibition of visible tumors.

District of Columbia.

Iowa: Manchester.

Maine: Craig Brook, Auburn.

Michigan: Paris; Northville.

Missouri: Neosho.

Montana: Bozeman.

New Hampshire: Nashua.

New York: Bath; Margaretville and other hatcheries.

\section{NAMES OF SPECIES AND HYBRIDS.}

While the disease primarily and chiefly is found in the brook trout, it has been observed among all the following species and hybrids in the United States. Two of these, the brown trout and Loch Leven trout, are introduced species, and one-the whitefish-belonging to a subfamily of the Salmonidæ, is not the subject of fish culture as an adult and is represented by only one specimen bearing a tumor, this being a wild fish from a lake. It is quite certain that this list will be much extended as fast as other species of salmonoids are brought under domestication. The single species which, though bred artificially, can not yet be included among the species subject to thyroid carcinoma, is the sea trout (Salmo trutta Linnæus), introduced into the United States as the Scotch sea trout.

\footnotetext{
American brook trout; square-tail trout; redspot trout;

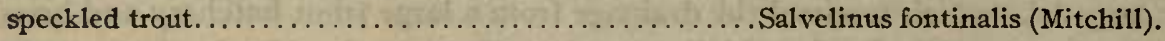

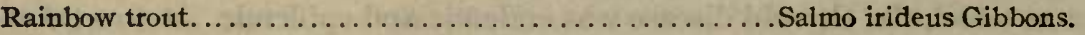

Landlocked salmon; Sebago salmon; Schoodic salmon..... Salmo sebago Girard.

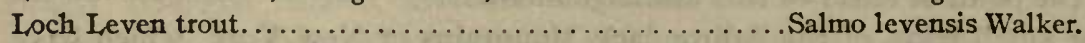

Brown trout; von Behr trout. . . . . . . . . . . . . . . . . . . .

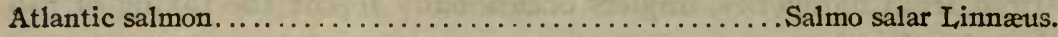

Great Lakes trout; lake trout; Mackinaw trout; namaycush

trout; longe; lunge; togue; Iaker . .................. Cristivomer namaycush (Walbaum).

Humpback salmon............................ Oncorhynchus gorbuscha (Walbaum).

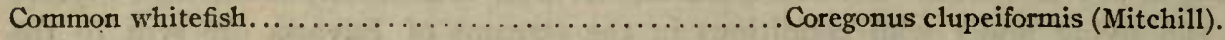

Hybrid salmon:

Female silver salmon..... $\} \ldots$ Oncorhynchus kisutch (Walbaum).

Male humpback salmon.... $\} \ldots \ldots \ldots \ldots \ldots \ldots \ldots \ldots \ldots \ldots \ldots \ldots$ Oncorhynchus gorbuscha (Walbaum).

Female silver salmon..... $\} \ldots \ldots \ldots \ldots \ldots \ldots \ldots \ldots$ Oncorhynchus kisutch (Walbaum).

Male chinook salmon..... $\} \ldots \ldots \ldots \ldots \ldots \ldots \ldots \ldots \ldots \ldots \ldots$ Oncorhynchus tschawytscha (Walbaum).

Female blueback salmon. $\} \ldots . \ldots \ldots \ldots \ldots \ldots \ldots$. Oncorhynchus nerka (Walbaum).

Male humpback salmon... $\} \cdots \cdots \ldots \ldots \ldots \ldots \ldots \ldots \ldots \ldots \ldots \ldots$ Oncorhynchus gorbuscha (Walbaum).

Female humpback salmon. $\quad$ Oncorhynchus gorbuscha (Walbaum).

Male blueback salmon..... $\} \ldots \ldots \ldots \ldots \ldots \ldots \ldots \ldots \ldots \ldots$ Oncorhynchus nerka (Walbaum).

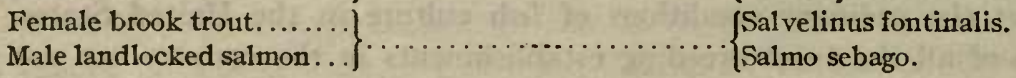

Hybrid trout:

American brook trout........... \{Salvelinus fontinalis.

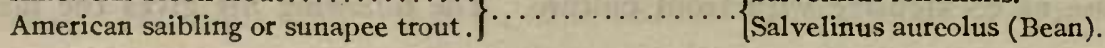


Besides the American brook trout and the rainbow trout introduced into Europe; the following European species, at least, have been observed as the subject of thyroid carcinoma in Europe:

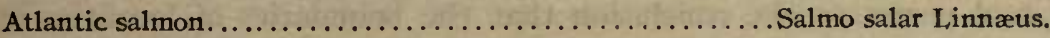

Forelle; Bachforelle; brown trout, yellow trout, brook trout,

river trout, etc. ................................

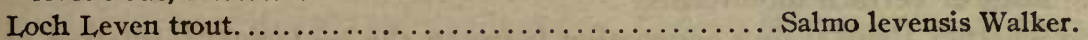

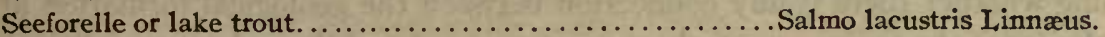

Ombre chevalier, European charr or saibling........... Salvelinus salvelinus (Linnæus). [Salvelinus alpinus (L,innæus) of most aithors.]

\section{GEOLOGICAL FORMATION AT FISH HATCHERIES.}

That the distribution of goiter possesses a definite relation to the geological formation has been repeatedly advanced and denied. McClellan in 1837 pointed out the predisposing quality of the mountainous limestone and the nagelfluhe. The principal exponent of this theory in Europe has been $\mathrm{H}$. Bircher (1883). According to this author the greatest concentration of goiter is found in the Molasse highland. The Tertiary formation also predisposes to goiter, whereas the Jurassic formation and the primary formation of the Alps are free from the disease. Kocher (1889), who with the assistance of 25 of his scholars examined 76,606 school children between the ages of 7 and 15 years, was not able to justify these conclusions of Bircher, as he found that the Jurassic formation was in no way free from goiter, neither was the fresh-water Molasse. Recently Hesse (I III) in a study of the distribution of goiter in the Kingdom of Saxony, was able only in part to confirm the theory of Bircher, as he found next to the highest percentage of the disease in the Eibenstock granite and the highest in the eruptive Muscovite gneiss, both of which are formations that according to Bircher should be free from the disease. Schittenhelm \& Weichardt, in the study of goiter in Bavaria (1912), found that one of the most extensive distributions of goiter in that country was in the Bavarian forest, which lies upon the primary granite formation. These authors conclude that the geological formation is not a primary determining factor in the endemic distribution of goiter, but that the infection of the water supply is. The distribution of goiter in the mountainous southern portion of Bavaria, as well as in Switzerland, they consider to be due to certain conditions depending upon the mountains themselves and not their geological formation as such.

McCarrison in his analysis of conditions in the goitrous regions of Chitral and Gilgit in Northern India finds that the water supply of the Chitral district comes from metamorphic rocks consisting mainly of gneiss and slate and to a lesser extent of liniestone. There are, however, certain large outcrops of limestone, and it is from these that the most goitrous villages derive their water supplies. Likewise the highly goitrous villages of Gilgit are supplied by water from a valley which contains a considerable outcrop of limestone. These results are likewise at variance with the theory of Bircher concerning the influence of geological formation.

Dieterle (1913) after a personal examination of a series of goitrous localities in Switzerland comes to the conclusion that neither the geologic formation upon which 
goitrous regions are located or the geologic formation from which the water supply springs is the determining factor in the incidence of goiter. He has found regions located upon and supplied with water from pure Jura formation, with from 12 to 40 per cent of goiter, and comes to the conclusion that the boundaries of localities in which endemic goiter occurs are purely geographic, such as certain valleys, along certain rivers, or the sides of certain mountains.

To determine whether there is any connection between the geological formation at the various hatcheries of the Government where trout are bred and the endemic conditions existing in most of them, we have obtained from the United States Geological Survey a statement concerning the formation at most of the centers of fish culture throughout the country. All the data are included here, whether the station concerned is engaged with trout culture or not. In some cases only general information is available.

No correlation between geological formation and the occurrence of thyroid disease is at present even suggested from the data at hand, which is here shown for purposes of record in view of its possible future value. Most of the water supplying stations subject to thyroid disease arises among the geological formations of primary order. Only one is secondary (Triassic) and only a few tertiary and quaternary.

\section{ALASKA.}

Yes Bay.-Crystalline schists, probably Carboniferous.

ARKANSAS.

Mammoth Springs.-Probably in Proctor or Potosi limestone. Cambrian system.

CALIFORNIA.

Baird.-Baird formation. Carboniferous system. This underlies a bluff of the Carboniferous McCloud limestone.

Battle Creek. -Tuscan tuff with some lava beds. Tertiary.

Mill Creek.-On border of alluvium of Sacramento Valley, and of Tuscan tuff and lava. Tertiary age. COLORADO.

Leadville.-Crystalline rock; pre-Cambrian age.

GEORGIA.

Bullochville.-Formation not known. Probably granite and gneiss. Archean gneiss. ILLINOIS.

Quincy.-Burlington and Keokuk limestones; Carboniferous age.

Meredosia.-Glacial sand and clay. One hundred feet more or less below the surface is Carboniferous limestone. Same as at Quincy.

IOWA.

Manchester.-Devonian limestone with chert nodules.

Fairport.-At contact of Carboniferous shales on Devonian limestone. 
MAINE.

Boothbay Harbor.-Schists and gneisses with dikes of granite. Age unknown.

Craig Brook (East Orland).-Granite. Silurian or Devonian age.

Grand Lake.-Mica schist. Age unknown. Cut by granite of Silurian or Devonian age.

Green Lake.-Granite. Silurian or Devonian age.

Lake Auburn.-Mica schists. Age unknown. Cut by granite of probable Ordovician age.

Lake Sebago.-Granite and granite gneiss. Probably Silurian or Devonian age.

Portland.-Largely quartzose schist. Age unknown.

York.-Volcanic tuff and lava flows cut by some granite. Age unknown.

\section{MARYLAND.}

Havre de Grace.-Potomac formation. Carboniferous age.

Bryan's Point.-Talbot formation. Quaternary system.

\section{MASSACHUSETTS.}

Woods Hole.-Pleistocene glacial gravels.

Gloucester.-Probably Rockport granite. Carboniferous age.

East Freetown.-Granite. Probably Paleozoic age.

Hartsville.-Stockbridge limestone next to Cheshire quartzite. Canıbrian age.

Plymouth.-Pleistocene glacial gravels and sands.

MICHIGAN.

Northville.-Cold Water shale. Carboniferous age.

Alpena.-Antrim shale. Devonian age. Has a little gas.

Charlevoix.-Antrim shale. Devonian age.

Detroit.-Antrim shale and Traverse limestone. Devonian age.

Sault Ste Marie.-Lake Superior sandstone. Cambrian age.

MINNESOTA.

Lester Park, Duluth.-Lavas of Keeweenawan series. Algonquin age.

Homer.-Immediately underlain by St. Croix sandstone, bluffs to south are St. Peter sandstone, Shakopee limestone, Jordan sandstone, and St. Lawrence limestone. Copious spring waters come from these sandstone formations. The St. Lawrence is of Cambrian age; the other of Ordovician age.

MISSISSIPPI.

Tupelo.-Pleistocene sands resting upon sandy portion of Selma chalk. Cretaceous age.

MISSOURI.

Neosho.-Boone limestone. Carboniferous age.

MONTANA.

Bozeman.-Neocene lake beds. Tertiary age.

NEW HAMPSHIRE.

Nashua.-Sand beds of glacial lake. Quaternary age.

Lake Sunapee.-(East side) Granite; age unknown. Heavy cover of glacial gravel; cuaternary age. (West side.) Formations unknown. 
NEW YORK.

Bath.-Chemung formation. Devonian age.

Buffalo.-Salina formation, Silurian age, and Onondaga limestone and Hamilton shale, Devonian age.

Caledonia.-Onondaga limestone and Oriskany sandstone, Devonian age; Salina shale, Silurian age.

Cape Vincent.-Trenton limestone. Ordovician age.

Chautauqua Lake.-Chemung formation. Devonian age.

Cold Spring Harbor.-Glacial gravel and sand. Quaternary age.

Constantia.-Medina sandstone. Silurian age.

Margaretville.-Catskill fcrmation. Devonian age.

Old Forge.-Mica gneiss. Archean age.

Saranac Lake.-Granite, gabbro, gneiss, and schist. Archean age.

\section{NORTH CAROLINA.}

Edenton.-Sand and clay. Quaternary age.

онго.

Put-in Bay.-Lower Helderberg limestone. Devonian age.

OREGON.

Clackamas.-Volcanic breccia; probably Tertiary agc.

Cazadero.-Volcanic breccia; probably Tertiary age.

Willamette River.-Flood plain sand and clay, Quaternary age; Sandstone, Eocene age.

Rogue River.-Formation unknown.

\section{PENNSYLVANIA.}

Bellefonte.-Trenton limestone. Ordovician age.

Freeland.-Coal measure sandstone and shale. Carboniferous age.

Weissport.-Hamilton shale. Devonian age.

Spruce Creek.-Trenton limestone. Ordovician age.

SOUTH DAKOTA.

Spearfish.-Spearfish formation. Triassic age.

TENNESSEE.

Erwin.-Honaker limestone. Cambrian age.

$$
\text { TEXAS. }
$$

San Marcos.-Del Rio formation. Cretaceous age.

$$
\text { UTAIY. }
$$

Provo Valley.-Mesozoic rocks; mainly shales of Mesozoic age.

VERMONT.

Groton.-West part of town in granite. Age unknown. East part in mica slate; probably Ordovician age.

Sharon.-Mica schist; probably Ordovician age.

St. Johnsbury.--Mica schist; probable Ordovician age, with much glacial gravel of Quaternary age.

Swanton.-Trenton limestone. Ordovician age.

\section{VIRGINIA.}

Wytheville.-Shaly limestone. Cambrian age. 
WASHINGTON.

Baker Lake.-Limestones and schists to the south and volcanic rocks to the north and west. Age unknown.

Birdsview.-Schists partly ferruginous. Age unknown.

Little White Salmon River.-Basalt. Late Tertiary age.

Big White Salmon.-Basalt. Late Tertiary age.

WEST VIRGINIA.

White Sulphur Springs.-Romney shale. Devonian age.

wrsconsrn.

Bayfield.-Lake Superior sandstone, Cambrian age, deeply buried under glacial lake clay. Quater nary age.

Madison.-Madison sandstone, Cambrian age, under heavy cover of glacial gravel.

\section{CHEMISTRY OF THE WATER SUPPLIES.}

There are no very definite chemical standards by which the fish-cultural value of a water may be predetermined without the test of experience with fishes. The ordinary sanitary analysis is of almost no value, the showing with respect to dissolved air gases, which are of primary importance in fish culture, being usually omitted. As for a mineral analysis, it is difficult to interpret it in fish-cultural terms since fishes thrive in waters of such varied chemical content that conclusions can not be drawn from a statement of the inorganic materials dissolved, unless they show the water to be so heavily mineralized that it is no longer fresh, or unless it contains the metals known to be highly poisonous to fishes. Even in the latter case special determinations must be made and large quantities of water used, since some metals, for instance, mercury and copper, are fatal to salmonoids in dilutions far beyond detection in ordinary routine mineral analysis.

In order to lay a foundation for the possible establishment of fish-cultural standards in water analysis, by long fish-cultural experience with waters whose chemical constitution was determined, the Bureau of Fisheries has had analyses made of many waters used to supply its various stations for the propagation of fish throughout the country. These analyses have been made by the Bureau of Chemistry, Department of Agriculture. Since not all these stations engaged in trout propagation whose water supplies have been examined chemically have been thoroughly investigated to determine their status with respect to thyroid disease, it is not possible to divide them into those which are subject to and those which are free from the disease, if, indeed, there are any belonging unequivocally to the latter class. We have therefore shown only the results (table u) for waters supplying such stations as are known to have the trout thyroid disease endemic, save the last two (no. II737 and II738), which supply the State hatchery at Cold Spring Harbor, N. Y., and one of which appears to be at present free from the disease. By a scrutiny of the mineral content of this water at the latter station, nothing distinctive is to be found. It is low in total solids and therefore very lightly mineralized; the chlorids, sulphates, silicates, and bicarbonates of the common earth metals make up the bulk of the residue. These statements apply equally to many of the waters in which 
the disease is developed. It is in our opinion highly improbable that any of the factors in causation of the disease are to be found among the variations of the concentration in which the common earth salts and other matter are found in these waters.

None of the analyses shown in table Ir disclose any trace of iodine or bromine, but only ordinary volumes, as a single liter, were devoted to the reactions for these elements. In order to test further the presence of these elements in the water of the Craig Brook station, where a large part of our data has been obtained, we have had two samples of I 5 liters each used entirely by the Bureau of Chemistry for determining iodine and bromine in two sources of water at the Craig Brook station. The Craig Pond water (no. 5867 ) is the chief water supply of the Craig Brook station. It is slightly augmented, before reaching the fish ponds, by small volumes of spring water not subjected to analysis. The farm-house spring, whose complete content is not shown, is a minor supply arising on the station grounds, and is probably typical of the springs of the immediate neighborhood, such as the lawn spring (no. 5868) whose content appears in table Ir. The Craig Brook water itself is in this way shown to contain I part of iodine to I,310,000,000 parts of water; and I part of bromine to $149,000,000$ parts of water. The farm-house spring showed about the same quantities of each element: of iodine, I part to $1,250,000,000$; of bromine, I part to $142,800,000$. The ratio of iodine to bromine was the same in the two sources, $I$ to 8.7 . As the delicacy of the iodine test detects about one one-hundredth milligram of iodine, the I 5 -liter sample contained a little more than enough for the reaction.

Since thyroid hyperplasia begins in the Craig Brook water and is reduced by iodine in dilutions which, though much attenuated, are yet much richer in iodine than the above, it seems certain that the extreme dilution of iodine found to occur naturally in the water is without appreciable physiological effect. Most brook water will probably be found to contain iodine in quantities comparable to those in Craig Brook.

Dissolved oxygen.-No lack of dissolved oxygen contributes to the thyroid disease at the Craig Brook station. Flowing brooks almost invariably contain all the oxygen the water will absorb from the air. The Craig Brook water was several times titrated for oxygen and was found to be air-saturated. The water at the outlets of troughs and cement tanks containing trout was likewise examined and the amount of oxygen removed by the fish was determined. A cement tank containing about 40 wild trout diminished the oxygen content by 0.13 cubic centimeter per liter. Sixty-eight yearling trout held in a wooden trough removed 0.4 cubic centimeter of oxygen per liter, leaving an oxygen content of 6.8 cubic centimeters per liter at a water temperature of $15^{\circ} \mathrm{C}$., which is barely short of air-saturation.

Spring waters not infrequently emerge from the earth with a considerable deficiency of oxygen. One such was found draining into Craig Brook, holding only 2.39 cubic centimeters per liter at $17.25^{\circ} \mathrm{C}$., which is about 35 per cent of air-saturation. Its volume was insignificant, and no additions of this sort to the stream perceptibly affect its oxygenation.

Lack of oxygenation can be excluded from the consideration of causation. 
CARCINOMA OF THE THYROID IN SALMONOID FISHES.

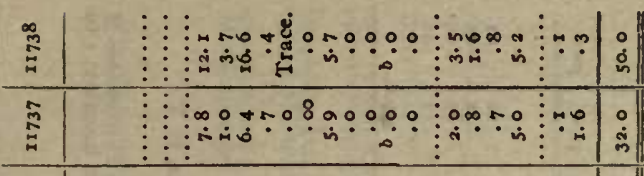

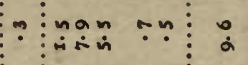

$\stackrel{4}{a}$

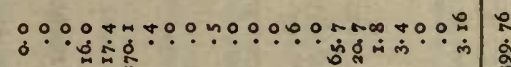

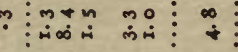

要

$\overline{\mathrm{E}}$

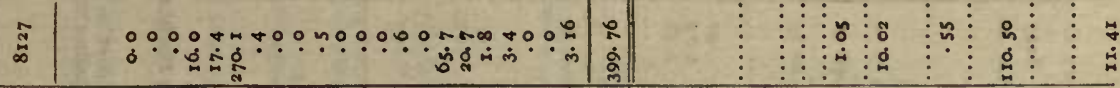

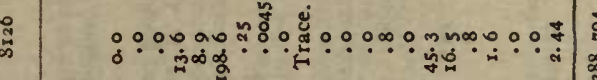

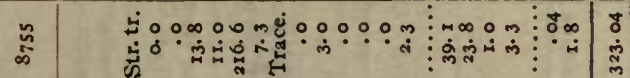

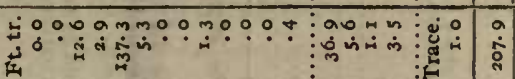

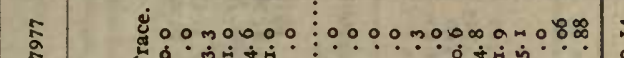

स

웅ำ

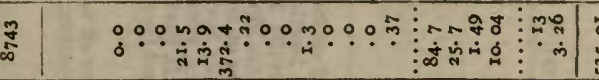

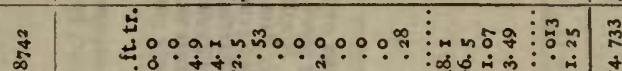

>

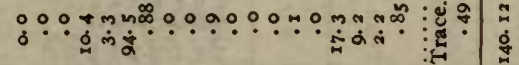

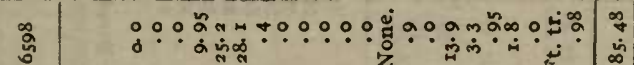

今人

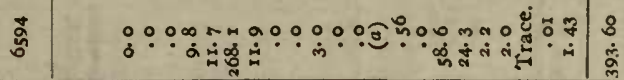

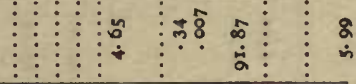

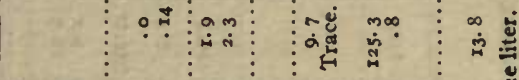

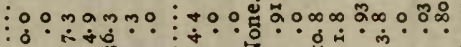

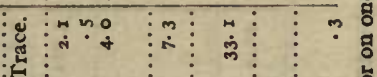

$\therefore$

苋

芯

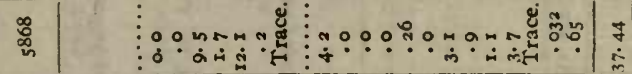

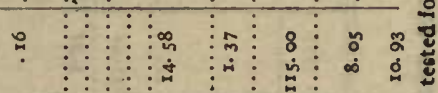

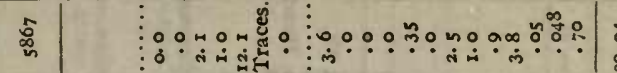

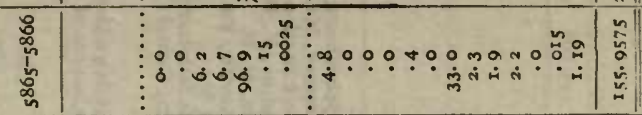

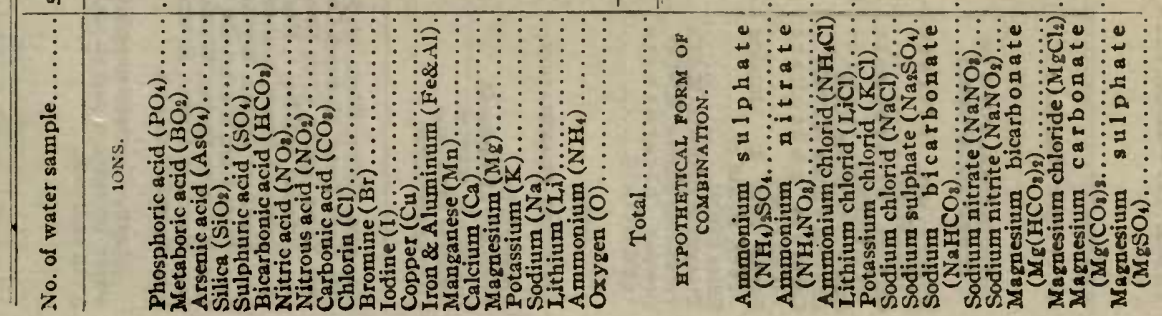




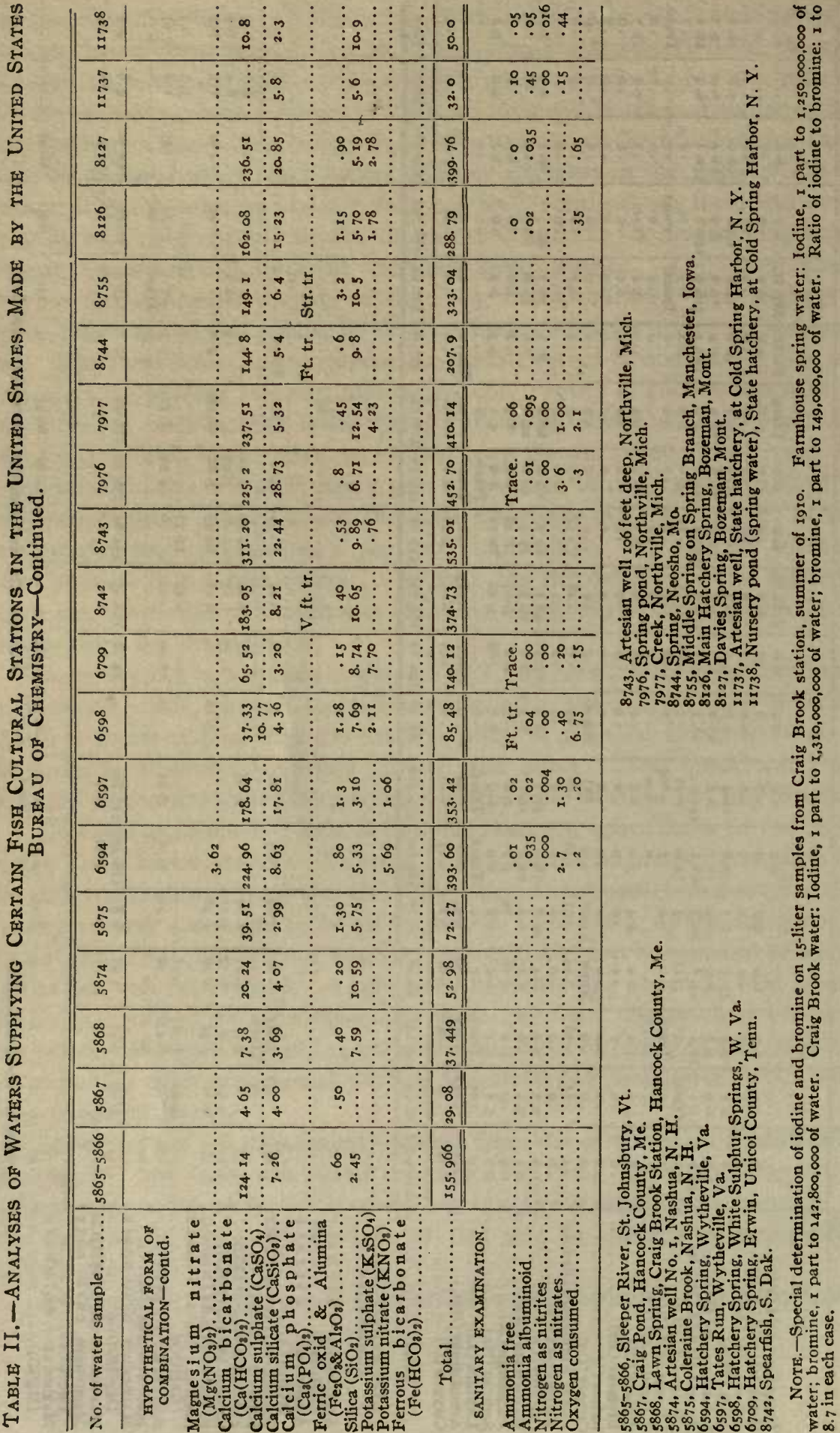


CARCINOMA OF THE THYROID IN SALMONOID FISHES.

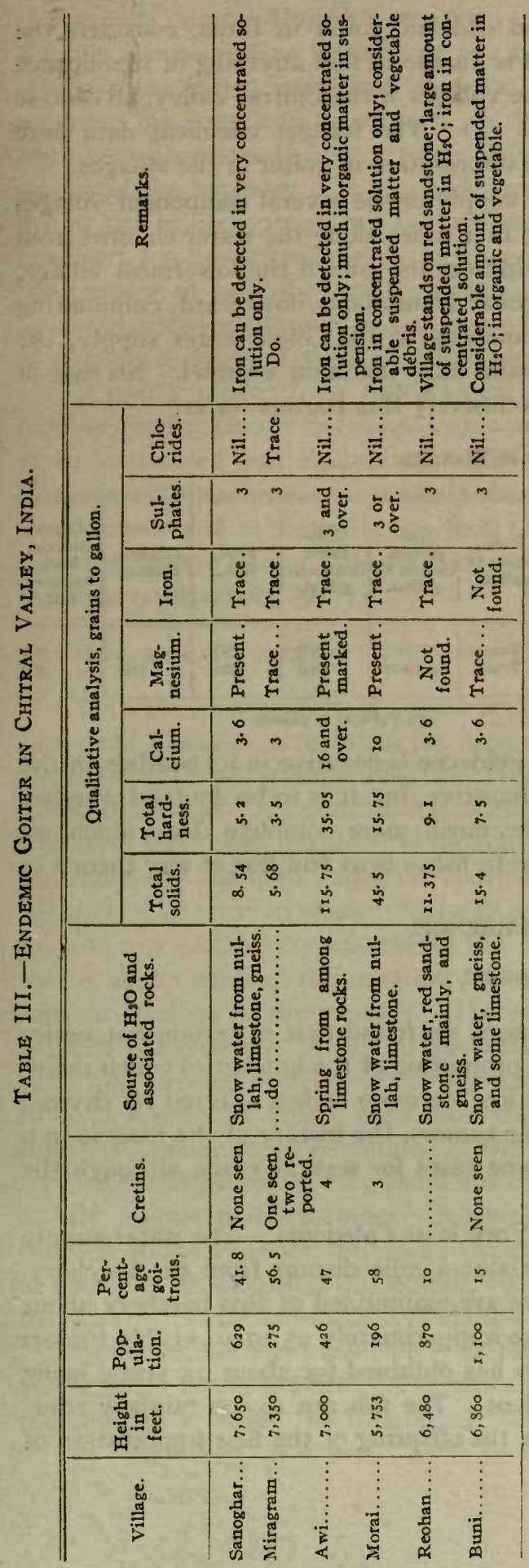


McCarrison, in his observations (1906) on endemic goiter in India, considers the dissolved content of the waters concerned and is unable to find anything of significance in its relation to the amount of goiter. For the villages of the Chitral Valley, all centers of goiter, he gives the foregoing table (table III). The meager chemical data here shown afford no clue to the explanation of the distribution of goiter in the villages.

He gives similar data for the single water supply of the several component villages known collectively as Gilgit, which are located in a series along the water channel from above downward, so that an increasing pollution occurs toward the lowermost village. There is here an increase of the incidence of goiter from above downward, culminating at the lowermost village. In the following analysis of the Gilgit water supply, the Barmis water is an accessory supply which drains into the main channel. No case of goiter has been found among those who use exclusively this Barmis water.

ANal,ysis of Gilgit Waters.

\begin{tabular}{|c|c|c|c|c|c|c|c|c|c|c|}
\hline Supply. & $\begin{array}{c}\text { Total } \\
\text { solids. } \\
\text { Parts per } \\
\text { I00,000. }\end{array}$ & $\begin{array}{c}\text { Total } \\
\text { hardness. } \\
\text { Grams to } \\
\text { gallon. }\end{array}$ & $\begin{array}{l}\text { Calcium. } \\
\text { Grams to } \\
\text { gallon. }\end{array}$ & $\begin{array}{l}\text { Magne- } \\
\text { sium. } \\
\text { Grams to } \\
\text { gallon. }\end{array}$ & $\begin{array}{l}\text { Iron. } \\
\text { Grams to } \\
\text { gallon. }\end{array}$ & $\begin{array}{l}\text { Sul. } \\
\text { phates. } \\
\text { Grams to } \\
\text { gallon. }\end{array}$ & $\begin{array}{l}\text { Chlo- } \\
\text { rides. } \\
\text { Grams to } \\
\text { gallon. }\end{array}$ & $\begin{array}{l}\text { Free. } \\
\mathrm{NH}_{3} \text {. }\end{array}$ & $\begin{array}{l}\text { Organic } \\
\text { matter. }\end{array}$ & $\begin{array}{c}\text { Other } \\
\text { metals, } \\
\text { lead, } \\
\text { copper, } \\
\text { zinc. }\end{array}$ \\
\hline 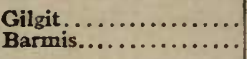 & $\begin{array}{l}a_{30} \\
b \times 9\end{array}$ & $9^{7 \cdot 143}$ & $\begin{array}{r}6 \\
8-10\end{array}$ & $\begin{array}{l}\text { Trace. } \\
\text { Trace. }\end{array}$ & $\begin{array}{l}\text { Trace. } \\
\text { Trace. }\end{array}$ & 3 or over. & $\begin{array}{l}\text { Nil. } \\
\text { Nil. }\end{array}$ & $\begin{array}{l}\text { Nil. } \\
\text { Nil. }\end{array}$ & ${ }^{*}$ Nii. & $\begin{array}{l}\text { Nil. } \\
\text { Nil. }\end{array}$ \\
\hline
\end{tabular}

It is thus seen that McCarrison's chemical evidence is negative in its bearing on the origin of goiter. The analyses are far from exhaustive, but it is to be doubted whether greater detail would be more significant. The much more complete data which we show for waters associated with thyroid disease in fishes is as fruitless of any theory of causation.

\section{ENDEMIC OCCURRENCE.}

\section{CALEDONIA HATCHERY, N. Y.}

Studied from the standpoint of visible tumors, we found that in certain hatcheries the disease is endemic. It is clear that a large proportion of the hatcheries which maintain Salmonidæ under conditions of domestication are more or less affected by thyroid tumors. Studied from the standpoint of visible tumors, the history of the disease in a given hatchery may be traced backward in some cases for several years, although the number of fish observed may be small.

The oldest hatchery in the State of New York is at Caledonia. The water supply of this hatchery comes from springs located about a mile distant from the hatchery. The water supply is unusually ample and there are maintained at this hatchery about 30,000 adult fish. Each year at spawning time approximately 25 to 50 visible tumiors are found in handling the fish. This condition has obtained for about 25 years, being within the memory of the present superintendent. The fish are 10,000 rainbow trout and 20,000 brown trout. The brown trout are the offspring of the first importation of 
this variety into the United States from Germany in the eighties. They have been continually inbred and no fresh stock has been added. The rainbow trout have been in the hatchery for 25 years and have not had fresh stock added to them. Attempts to maintain the American brook trout in this hatchery have been so unsatisfactory as to have been abandoned of late years. This has been partly due to the prevalence in the waters of the hatchery of a copepod parasite (Lernæopoda), which does not affect the brown and rainbow trout, but is very destructive to the brook trout. A few years ago, however, 200 brook trout from the annual hatching were raised to the yearling age for the purpose of exhibition at the State fair. In September, when these fish were $1 / 2$ years old, they were examined, and it was found that every individual, with the exception of possibly a dozen, presented visible tumors, and they were for this reason discarded.

It would appear from this observation that the brown and rainbow trout in this hatchery had gradually developed into a more resistant strain than the native brook trout when introduced and maintained under the conditions affecting the hatchery. That this supposition is perhaps correct is shown by the fact that at the Bath hatchery the adult brown and rainbow trout which came from Caledonia remained practically free from the disease during the course of what may be spoken of as an epidemic outbreak in the latter hatchery (p. 77).

CRAIG BROOK STATION: CONDITIONS AT THE BEGINNING OF THE INVESTIGATION.

With the inauguration of a joint investigation by the Gratwick Laboratory and the Bureau of Fisheries, a report of the presence of thyroid disease in the various hatcheries of the Government was obtained, and from among these Craig Brook, Me., was selected for investigation. An examination at this station made by the superintendent between April and May, 1909, disclosed in the 6,695 fish on hand 376 with well-developed tumors. This hatchery has been under the continuous superintendence of $\mathrm{Mr}$. Charles G. Atkins for a period of some 40 years. It is well equipped and at the time of beginning our investigation was particularly suitable for the work owing to the unusual number of salmonoid species kept there and the fact that it was well known as one of the best conducted fish cultural stations in the country. The scientific accuracy of its management and the unusual completeness of Mr. Atkins's records, which extended back over a period of years and covered nearly every factor which the progress of the investigation suggested to us as worthy of study, gave most unusual advantages for accurate analysis of the conditions under which carcinoma of the thyroid had developed here.

An investigation on the ground was undertaken by Dr. Gaylord, covering the months of July, August, and September. A review of the conditions found at Craig Brook during this first summer is contained in an unpublished report transmitted to the Commissioner of Fisheries under date of November, 1909 , and was reported during the same month at the meeting of the American Association for Cancer Research.

Our attention was immediately attracted to an arrangement of 19 ponds containing yearling and 2-year-old fish. A careful examination of all the fish in these ponds during the summer revealed the interesting fact that the incidence of the diesase increased $8207^{\circ}-\mathrm{x} 4-5$ 
from pond to pond where these ponds communicated with each other. Figure 76 shows the arrangement of the ponds, the general distribution of the water supply, the species of the fish, and the incidence of the disease. The following observations on this diagram were made at the time:

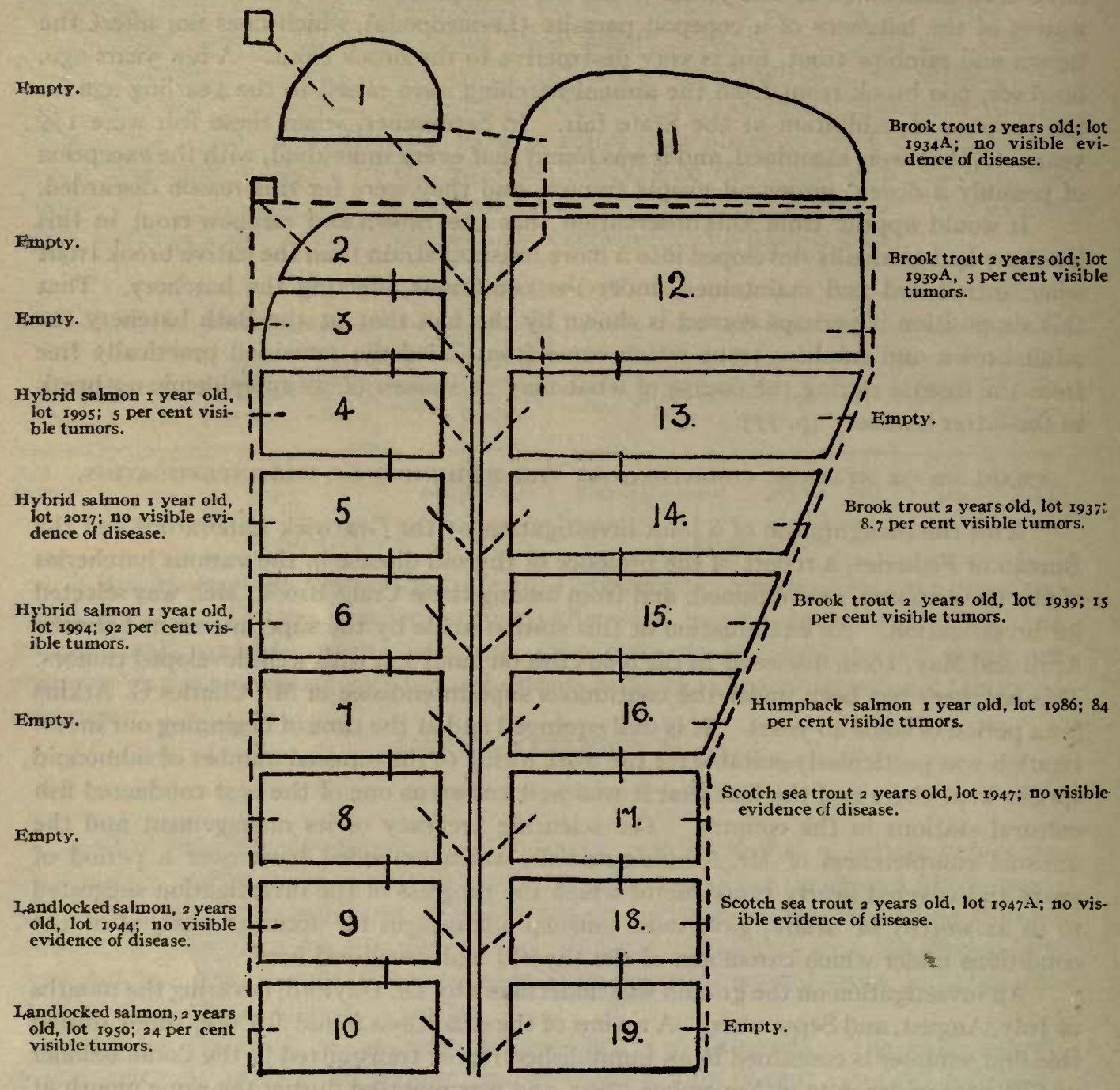

FrG. 76.-Plan of south ponds at Craig Brook station.

The water supply of ponds I to II is from a natural spring on the hillside. The water supply of ponds 2 to 10 and 12 to 19 is from Craig Brook, the water of each pond for the most part flowing into the pond immediately below it, pond I flowing into pond I 2 . As the diagram shows, pond i contained healthy fish. These up to the time of this 
observation had not been fed artificial food but had found a sufficient supply of natural food in the grass-lined pond they occupied. Lot 1939 A, 230 two-year-old brook trout, and lot 1939,132 two-year-old brook trout, were hatched from the same lot of eggs, divided and placed in their respective ponds during the summer of 1908 . They were comparable in every respect except their location in the ponds, the feeding for all the lots being the same, i. e., raw liver. Lot 1939 A occupied pond 12 next to the uppermost pond; I939, pond 15 , three ponds below. The chart shows that 1939 A showed 3 per cent of visible tumors, being the lowest incidence of any lot affected, 1939 i 5 per cent. Between these ponds lot 1937 in pond 14 , also 2-year-old brook trout, gave an incidence of 8.7 per cent. Lot 1986, humpback salmon, were yearling fish and in common with the hybrid salmon, lot 1994 of the same age, showed the highest incidence of any of the lots, namely, 84 and 92 per cent. Lot 1950, two-year-old landlocked salmon in pond 10, were the least favorably placed 2-year-old fish and showed the highest incidence for this age, 24 per cent. (Fig. 4 b.)

Here we may plainly see that the incidence of the disease increases from above downward in the ponds, both in the 2-year-old and the yearling fish. The deduction may also be drawn from the conditions found in these ponds that the incidence of the disease is greater in the yearling fish than in the 2 -year-old, but subsequent observations indicate that other factors, such as the species heredity and hybridization, may so markedly affect the susceptibility that this material is not suitable for such deduction. (See p. 82.)

Perhaps the most striking feature of this diagram is the evidence it affords of immunity in certain species and certain lots. The 2-year-old Scotch sea trout, lots 1947 and $1947 \mathrm{~A}$, were found on examination to present no visible tumors and it was concluded that they were immune to the disease, a fact which microscopic examination and further observation has confirmed. The 2-year-old landlocked salmon, lot 1944, occupying pond 9, although placed below the yearling hybrid lot, 1994, in pond 6, were also free from the disease, although the 2-year-old landlocked salmon, lot 1950, immediately below them in pond 10 , showed the highest incidence of the disease in 2-year-old fish. Yearling hybrid salmon, lot 2017 , were also free from the disease and in accordance with the general scheme, the smallest incidence in susceptible hybrid salmon, lot 1995 in pond 4 , is found in the uppermost pond. The further histories of the hybrid lots and the immune fish are traced in the observations of the succeeding years.

An attempt was made to trace the history of these fish from the time they were hatched in the hatchery through the various troughs which they occupied at different periods up to the time of their final location in these ponds. The records pertaining to the various lots covered the origin of the eggs, the time of hatching, the mortality at every stage of their history in the hatchery, the temperature of the water taken three times daily, and exact data as to the feeding, when first begun, and the amounts fed. While it was impossible to determine the exact troughs in which, or the exact time when, the fish might have contracted the disease, yet our attention was finally fixed upon a 
group of wooden troughs which the records showed had been previously occupied by the fish that were now affected in the ponds. In October, 1909, these troughs were occupied by small fish hatched the preceding spring, and from one of the troughs a small brook trout, a so-called fingerling, was found dead and proved on examination to have a protruding visible tumor in the thyroid region. (See fig. 73.) On microscopic examination this was found to be tubulo-alveolar solid carcinoma, infiltrating the surrounding structures. (See fig. 64.)

These, in the main, are the facts which were impressed upon us by the undisturbed conditions at Craig Brook. The observations of the following summers were carried out on a more extensive basis.

\section{CRAIG BROOK STATION: CONDITIONS DURING THREE YEARS.}

The Craig Brook fish cultural station (fig. 77) of the United States Bureau of Fisheries is located on Lake Alamoosook about I mile from East Orland, Hancock Co., Me. It is but a few feet above tidewater. The station was established in 1879 for the artificial propagation of trout and salmon, though Atlantic salmon eggs were first hatched there in $1871-2$. It is well provided with troughs in hatchery buildings for the incubation and hatching of eggs, with troughs out of doors for the rearing of young fish, and with earthen ponds for holding older fish and adults. Craig Pond drains into Lake Alamoosook through Craig Brook, the whole flow of which is intercepted for fish-cultural purposes. A small quantity of spring water is also available for the station supply.

Fish culture at Craig Brook has been chiefly concerned with brook and rainbow trout, the Scotch sea trout, landlocked salmon, and with hybrid trout and hybrids of some Pacific salmon. Investigations of thyroid disease among the fish were first made in I909, as above stated, and have been continued more or less to date, especially during the summer months. Thyroid carcinoma was immediately found endemic at the station, and affected every salmonoid species or hybrid except the Scotch sea trout, which is almost immune, and the chinook salmon.

The system of outside ponds holding adult fish at Craig Brook station is shown in figure 78 (p. 429), and has been already referred to. A more exact study of the water supply shows that, with two exceptions, these 19 ponds receive brook water and in part discharge into each other from the upper to the lower. Pond I, however, receives only spring water, which is discharged into pond I I and thence drains independently of all others. The rest of the ponds are each supplied in part with fresh brook water and in part with this water after it has flowed through preceding ponds in the series. The ponds are entirely of earth and some have small quantities of higher plant life, besides harboring abundant growths of filamentous green algæ during the summer months. Ponds I and II are best supplied with vegetation. (Fig. 80.) 


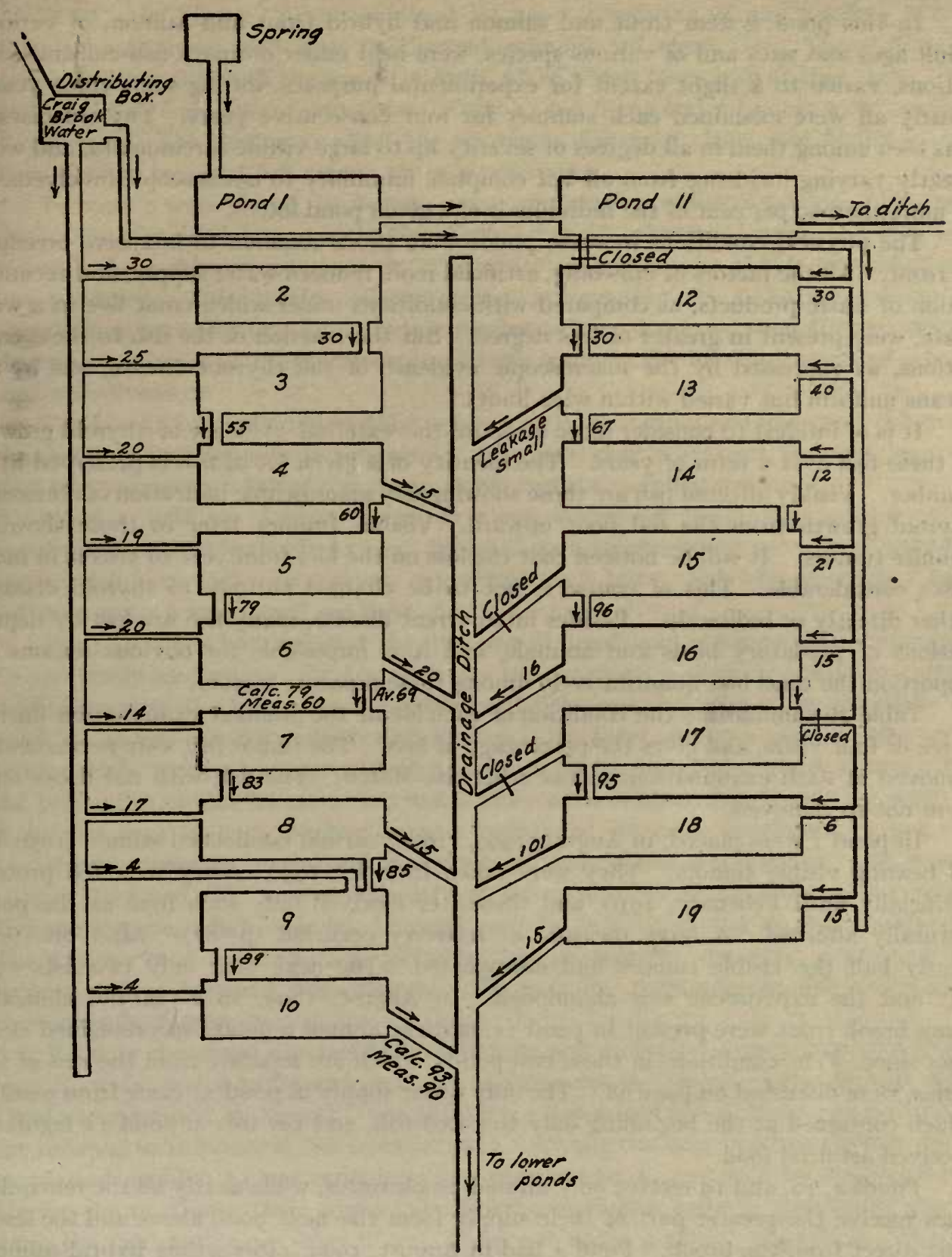

FiG. 78.-Plan of ponds, Craig Brook station, showing water supply. 
In this pond system trout and salmon and hybrid trout and salmon, of various adult ages and sizes and of various species, were held under ordinary fish-cultural conditions, varied to a slight extent for experimental purposes, during some three years. Nearly all were examined each summer for four consecutive years. Thyroid disease was seen among them in all degrees of severity up to large visible carcinomata, and with greatly varying incidence from all but complete immunity to macroscopic involvement of more than 90 per cent of the individuals of a given pond lot.

The physical conditions in these ponds were those common to intensive breeding of trout. All the factors of crowding, artificial food, reduced water supply, and accumulation of waste products, as compared with conditions under which trout live in a wild state, were present in greater or less degree. But the reaction of the fish to these conditions, as expressed by the macroscopic evidence of the thyroid disease, was by no means uniform but varied within wide limits.

It is of interest to consider more in detail the external evidence of thyroid growth in these fish over a term of years. The identity of a given lot of fish is preserved by a number. Visibly affected fish are those showing any macroscopic indication of abnormal thyroid growth from the red floor upward. Visible tumors refer to those showing definite tumors. It will be noticed that the loss on the lots from year to year is in most cases considerable. This of course is not to be charged entirely to thyroid disease, either directly or indirectly. Besides intercurrent disease, many fish are lost by depredations of predatory birds and animals, and it is impossible for obvious reasons to apportion the total loss quantitatively among these separate factors.

Table IV summarizes the condition of each lot at the summer examination during three or four years, and gives the percentage of loss. The tumor fish were permanently removed at each examination, unless otherwise stated. The fish with red floors only were not so removed.

In pond I were placed, in August, I 909, I I 9 2-year-old landlocked salmon (1950 T), all bearing visible tumors. They were taken from lot 1950 . They were fed proteid artificially until February, 1910, and thereafter received only such food as the pond naturally afforded. A large measure of recovery occurred (p. 87). After one year nearly half the visible tumors had disappeared. The next year only two fish were left and the experiment was abandoned. In August, 1909, 28 2-year-old clinically clean brook trout were present in pond $\mathrm{I}$, and the annual remnant has remained clean ever since. The conditions in these two ponds, which are separate from the rest of the series, were discussed on page 68 . The only water supply of pond I I came from pond I, which contained at the beginning only tumored fish, and the fish in pond I r regularly. received artificial food.

Ponds 2, 12, and I 9 receive only unused brook water, while nearly all the remaining ones receive the greater part of their supply from the next pond above and the lesser part direct from the brook. Pond 4 had in August, 1909, 146 yearling hybrid salmon, lot 1995 (female humpback and male blueback) with 5 per cent of visible tumors, which were left with the clean fish. The next year there were 9 per cent and the following year none, though the total affected fish had reached 37 per cent. 
Pond 5 in August, 1909, contained lot 2017, consisting of 729 yearling hybrids (female brook trout and male landlocked salmon), all clean fish. These were the survivors of 1,553 fish of the previous April, all of which were clean at that time. This lot was almost immune for two years. Only 13 red floors and 2 tumors were produced in one year. The next year all of the remaining fish were clean, and finally in 1912 there were ro tumored fish among the 220 remaining.

In pond 6 were placed, in August, 1909, 469 yearling chinook salmon. This pond previously contained lot r 994 , badly affected hybrid salmon. During the two years in which these chinook salmon were kept under observation no visible thyroid process was produced. This species (Oncorhynchus tschawytscha) is a Pacific salmon, an anadromous marine fish. In no adult marine salmon have we seen thyroid disease. Humpback salmon yearlings in troughs of fresh water at the hatchery acquired a heavy tumor involvement.

Ponds 7 and 8 contained in July, 1910, 147 clean yearling rainbow trout (lot $2 \times 33$ ). No visible tumors have been produced. After one year 3 per cent had red floors and after two years only 2 fish of the 31 remaining had the incipient process.

Pond 9 held, in August, r909, 97 clean 2-year-old landlocked salmon. They remained clean during the first year. In July, I9I I, there were ro per cent of red floors, but no visible tumors. In August, 1912, there were but 32 fish left, of which I had a red floor and i a tumor and red floor.

Pond ro is the lowermost of the first row of ponds and is almost entirely supplied by previously used water. In August, 1909, the 673 clean, 2-year-old landlocked salmon remaining after the removal of 219 tumored fish from lot 1950 were placed in this pond. The loss was not excessive on this lot. By July, I9II, 7.7 per cent had visible tumors while 37 per cent were affected, the fish having reached 4 years of age. Thus the tumor fish of this lot recovered under more natural conditions in pond $\mathrm{r}$, while the remainder continued to develop tumors under the intensive conditions of pond 10.

Pond 12 receives 30 gallons per minute of unused brook water only. In August, 1909, 7 tumored fish were removed from the 2-year-old brook trout of lot 1939 A and the 223 clean fish were left in pond 12 . In July, 19ro, but 80 fish remained, of which 5 per cent were affected, including but one tumor. In $19 \mathrm{rr}, 5$ per cent had tumors and 25 per cent were affected. In 1912 the remaining $5^{8}$ fish had a slight increase in both respects.

Pond 13 contained cyprinoid fish, which do not, so far as observed, acquire thyroid tumors or any notable thyroid changes, and are not considered in the present study. Pond 14 contained in August, 1909, 167 clean 2-year-old brook trout remaining after the removal of 16 tumored fish from lot 1937 . During the next year the thyroid process progressed rapidly, 15 per cent acquiring tumors and 31 per cent becoming affected. During the next year there was a very definite regressive process, and during the last year, the fish reaching 5 years of age, there was again a slight progression. Pond 15 had similar susceptible fish, the process continuing slowly at first and then more rapidly.

Ponds 17 and 18 contain Scotch sea trout, which are of especial interest and importance. These ponds receive almost entirely previously used brook water, and the 
essential fish cultural factors are among the most pronounced of all the ponds. The immunity of this species is apparently not quite impregnable. One case of supposed small incipient tumor was lost by accident before a proper examination of it could be made. Several fish with definite red floors have been observed, but these are cases of colloid goiter rather than the hyperplastic stages comparable to those of the susceptible species.

At Craig Brook station many unpainted wooden troughs established out of doors are used for holding and rearing young fish until they are large enough to demand transfer to ponds. They are each about 3.1 meters long, by 32 centimeters wide and 23 centimeters deep. (Fig. 79.) They are supplied by brook water, in part from the hatchery building with water which had flowed through the hatchery troughs, and in part freshly from Craig Brook. The water supply of these outside troughs flows from one trough to the other among some of the series of troughs. Troughs 93 to Io4, however, shown in table $v$, receive water immediately from the hatchery. Fish are not usually held in these wooden troughs beyond the first year, but in those of table $v$ they have been continued beyond the third year for experimental results with thyroid disease in these surroundings. The fish were fed the regular artificial food, chiefly liver, and were in general subjected to the usual artificial conditions, the space available and the water supply being less than the earth ponds of table IV would have afforded. This series of troughs was chosen because they were the containers of the young fish which later showed the most visible tumors, and from one of them (no. 92) was obtained the 5-monthsold brook trout with a tumor of considerable size, the youngest fish yet found with a visible thyroid tumor. Entirely uniform conditions obtained in these troughs. They were of the same size and shape, supplied by the same water, subject to the same régime, and afford the opportunity for comparable experiments.

It is seen that during these three years the brook trout, landlocked salmon, and various hybrids show progressively increasing thyroid growth from year to year. Fish with visibly affected thyroids not reaching to tumor formation are much more numerous from the beginning than those with visible tumors. The latter often appear among the yearlings, but the chief incidence is among 2 and 3 year olds. The Scotch sea trout are exceptional and show a pronounced resistance here as in the earth ponds. No visible tumors appear during the three years. Out of some 300 fish the second year, 2 only show the incipient hyperemia of the floor of the mouth, and in the third year I more. These trout were plainly exposed to exactly the same conditions which result in large percentages of tumor involvement in other species. Their resistance amounts to practical immunity.

In neither the earth ponds nor the wooden troughs are the observations sufficient to establish anything but the general conditions of fish culture or domestication, under which thyroid disease progresses. None of the specific factors of which domestication consists have been or can be isolated in this way. It is plain, nevertheless, that earth ponds are unnecessary to the disease. The wooden troughs are easily kept clean and do not become fouled for long by the accumulation of the products of the fish and 
the unused food. The material of the trough, though water-soaked, affords no permanent lodgment for gross particles of organic matter.

Since thyroid carcinoma in fishes is rare in nature and common in domestication it would seem that some or all of the conditions of domestication-artificial propagation of fish-either by their own direct action cause the disease, predispose to it, or carry its cause to the fishes. That domestication itself, viewed as a single complex whole, is per se the cause of thyroid disease, is a priori highly improbable, and is negatived by the occurrence of thyroid tumors in wild fish. This occurrence, though sporadic and rare, is now established beyond dispute and is a fact of great significance. Domestication predisposes to the disease and carries the causative agent to the fishes, and some one or very few of the constituent factors or conditions of domestication is probably of chief importance in this action. From a study of the conditions at such a station as Craig Brook, while the disease is spontaneous and endemic under the routine of fish culture, it is difficult to fix accurately upon any one of these conditions to the exclusion of others as the prime essential. Feeding is probably more important than any other one factor. The removal of feeding or change to natural food tends toward the recovery of affected fishes, and prevents or delays the initial process. The inevitable reduction in the available unit of water supply per fish and the crowding of fish together in small areas are no doubt factors of next importance. We do not believe that the soluble products of metabolism and of the disintegration of organic matter left from feeding or otherwise play any important part in the origin or progress of this disease, unless as creating more favorable conditions for the development of a causative agent. An unfavorable general hygiene of the fish predisposes to the disease, domestication itself as usually practiced involving a more or less unfavorable hygiene, and in this way these soluble products may enter somewhat into the problem of causation. 
TABLE IV.-Incidench of Thyroid Carcinoma in Dirt Ponds, Craig Brook, zgog-igiz.

[Where there are two entries for August, 1909, under total number of fish, the number before and after removal of tumored fish is indicated.]

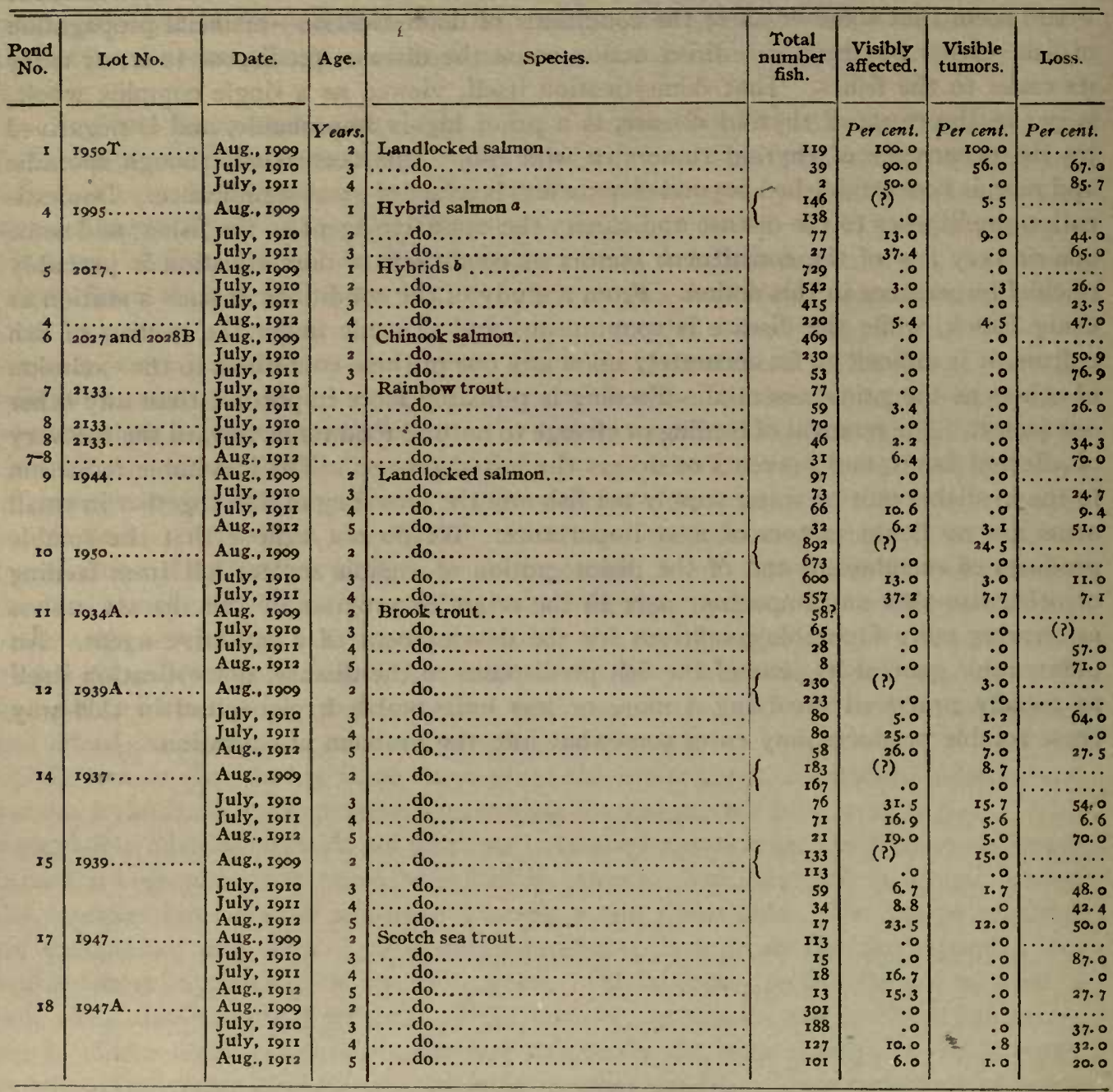


CARCINOMA OF THE THYROID IN SALMONOID FISHES.

Tabli, V.-Incidence of Thyroid Carcinoma in Wooden Troughs, Craig Brook, igio-igiz.

\begin{tabular}{|c|c|c|c|c|c|c|c|c|}
\hline $\begin{array}{c}\text { Trough } \\
\text { No. }\end{array}$ & Lot No. & Date. & Age. & Species. & $\begin{array}{l}\text { Total } \\
\text { fish. }\end{array}$ & $\begin{array}{l}\text { Visibly } \\
\text { affected. }\end{array}$ & $\begin{array}{l}\text { Visible } \\
\text { tumors. }\end{array}$ & Loss. \\
\hline
\end{tabular}

a Many fish used in experiments.

LAKE AUBURN HATCHERY, MAINE.

This is a State hatchery in Androscoggin County. In August, I9ro, an examination of fish for visible tumors was made and the general conditions inspected. Pond $\mathrm{r}$ was a dirt pond fed by two springs of water very cold at its origin, and standing at $\mathrm{II}^{\circ} \mathrm{C}$. in the pond on August 20. The spring water has a very low content of dissolved matter and is said to have about the same analysis as the well-known Poland Springs of Maine. The pond held nearly 400 brook trout of $3 \frac{1}{2}$ years of age, which had occupied the pond since the yearling stage. They had been fed raw beef liver until a year old and raw beef heart ever since. The fish were raised from eggs from the local station and from domesticated eggs obtained from Michigan. They were apparently in fine condition, were feeding well, and had suffered but little loss. One hundred and thirty-one of these trout were examined, of which 20.5 per cent showed visibly diseased thyroids and 5.3 per cent of the $13 \mathrm{r}$ bore visible tumors.

Pond 2 was a similar dirt pond, fed from six independent springs and sometimes by the overflow of pond $\mathrm{I}$. Its water was warmer, being $15.5^{\circ} \mathrm{C}$. It held 4 -year-old brook and brown trout and adult landlocked salmon. A seine haul of fish were examined. Of 66 brook trout, 21.5 per cent had visible tumors and 19.5 per cent red floors; of 15 salmon, $x$ had a red floor and 4 had visible tumors; of 36 brown trout all were entirely clean, without external sign of thyroid proliferation. The food was beef heart. There was no marked mortality rate, but there was a heavy loss on spawn taken from the fish of this pond. 
Of a large number of yearling landlocked salmon held in a small pond, IO2 were examined. Seven fish were affected, three having red floors and four visible tumors.

There is nothing extraordinary about the conditions at Lake Auburn hatchery, which shows rather a typical case of the endemic occurrence of the disease. Here are spring water, dirt ponds, the common proteid foods, liver and heart, and adult fish in excellent condition from the ordinary fish cultural standpoint, and with no unusual mortality rate, but a considerable morbidity in visible thyroid enlargement, with immunity of the brown trout.

At two other State hatcheries similar or greater morbidity has been determined from actual examination, and reports from superintendents of both Federal and State hatcheries indicate the general extent to which these conditions obtain, with some few exceptions, throughout the territory of trout culture in the United States.

PRIVATE HATCHERY IN THE STATE OF WASHINGTON.

At North Yakima, Wash., an interesting and instructive example is afforded of endemic occurrence among young trout at a newly established private hatchery where 30,000 brook trout were held in earth trenches supplied by spring water. The food for the first six months was liver, after that horse meat. The hatchery was started in March. In the following December, before the trout were a year old, thyroid tumors were observed among them, about I per cent being affected. The several specimens we have examined show tumors which, relative to the size of the fish, are among the largest we have seen. One of these was I 3 millimeters in diameter in a trout 8.5 centimeters in standard length. Microscopically the structure shows solid carcinoma, among the most malignant of our examples.

Rainbow trout of the same age and living under exactly the same conditions at this hatchery are not affected with thyroid tumors. The region in this part of the State is said to show a high percentage of goiter among female children and among calves and other domestic animals. Statistical studies, however, have not been made.

This instance shows an unusual acceleration of the thyroid process. Malignant carcinoma of large size developed in trout under I year of age and during the first year of a fish hatchery. Obviously domestication of long duration, either in the individual fish or in the local station where the fish are held, is unnecessary. Something local at this particular fish hatchery seems to be concerned in the unusual result Certainly the general conditions of trout culture as expressed at the numerous stations where trout are bred do not result in the rapid course of disease here shown. Is there merely a local intensification at this hatchery of the essential cause of the disease?

\section{EPIDEMIC OCCURRENCE.}

-The hatchery at Bath, N. Y., referred to in the introduction as having first attracted our attention to this condition, was, up to 1907 , free from visible tumors. From the accompanying diagram (fig. 81 ) it will be seen that the water supply of this hatchery comes from a large pond (A) fed by several springs on land adjoining the hatch- 
CARCINOMA OF THE THYROID IN SALMONOID FISHES.

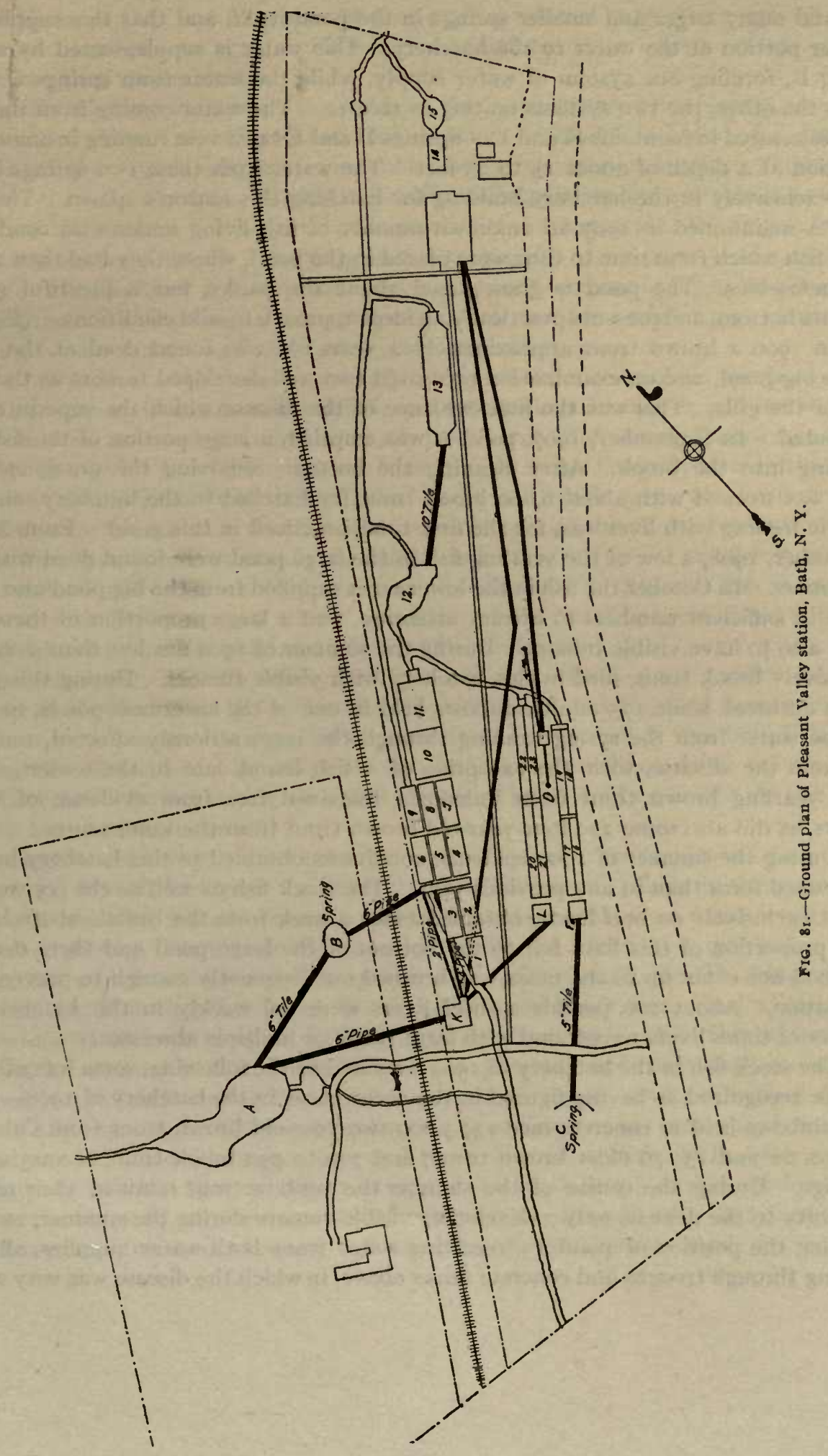


ery, and many larger and smaller springs in the pond itself, and that this supplies the greater portion of the water to the hatchery. This water is supplemented by a large spring B, forming one system of water supply, while the water from springs C and $F$ forms the other, the two systems uniting in race 12 . The water coming from the large pond is aerated in fountains $\mathrm{K}$ and $\mathrm{L}$. Springs $\mathrm{D}$ and $\mathrm{E}$ tap a vein running in a northerly direction at a depth of about 15 to 25 feet. The water from these two springs is now used exclusively in the hatchery building for hatching this season's spawn. The large pond A maintained in 1907 an unknown number of fish living under wild conditions, being fish which from time to time were placed in the pond, where they had then shifted for themselves. The pond is grass-grown about the banks, has a plentiful growth upon its bottom, and presents practically an ideal approach to wild conditions. (Fig. 82.)

In 1906 a brown trout approximately 2 years old was found dead at the outlet of the big pond, and on examination presented two well-developed tumors at the junction of the gills. This was the first evidence of the disease which the superintendent had noted. In September, 1907, pond A was emptied, a large portion of the fish in it escaping into the brook. After cleaning the bottom, removing the grass, etc., the pond was stocked with about 6,000 brook trout fry hatched in the hatchery, and systematic feeding with liver was, for the first time, practiced in this pond. From August to October, 1908, a few of the yearling fish in the large pond were found dead with visible tumors. In October the fish in the lower races supplied from the big pond also began to die in sufficient numbers to attract attention, and a large proportion of these were found also to have visible tumors. During the summer of 1908 not less than 3,000 fish, exclusively brook trout, died in this hatchery with visible tumors. During this period of the outbreak some 175 adult rainbows held in one of the lowermost ponds, to which ran the water from the spring running through the races seriously affected, remained free from the disease, with the exception of $I$ fish found late in the season. Some 4,000 yearling brown trout from Caledonia remained free from evidence of visible tumors, as did also some 220 four-year-old brown trout from the same source.

During the summer of 1909 epidemic conditions obtained in this hatchery in more aggravated form than in any previous year. The stock fish as well as the fry were fed almost exclusively on beef livers, obtained twice a week from the Buffalo abattoirs. A large proportion of this liver fell to the bottom of the large pond and there decayed. The food not eaten up in the races was brushed out frequently enough to prevent contamination. About 200 pounds of beef livers were fed weekly in the hatchery. A number of times livers were found with large single or multiple abscesses.

The stock fish in the hatchery in 1909 consisted of the following, some lots of which may be recognized as having figured in the occurrences in the hatchery of $1908-125$ to 150 rainbows held in concrete race $13 ; 3,000$ two-year-old brown trout from Caledonia in races 22 and $23 ; 76$ older brown trout; and 700 to 750 brook trout of varying size and age. During the course of the summer the rainbow trout retained their relative immunity to the disease, only 7 developing visible tumors during the summer, notwithstanding the position of pond 13 , receiving water from both water supplies, all of it running through troughs and concrete tanks above, in which the disease was very active. 
The remainder of some 200 five-year-old brown trout referred to in the summer of 1908 as free from tumors were again examined closely and found to be in a healthy condition, showing no visible tumors.

A distinct change, however, was found in the 4,000 brown trout from Caledonia, which in 1908 showed no evidences of visible tumors. This lot is described in 1909 as consisting of about 3,000 fish, now 2 years old, from 6 to 8 inches in length. These occupied cement races 22 and 23 . Owing to insufficient help, it was not possible to examine all of these brown trout. However, it was possible to determine that the disease in this lot was now well established. Forty-eight died or were picked out from the lot and found diseased. This does not represent the total number of brown trout affected. Between June and the end of September, among the fish which died from this lot, 43 are recorded as having been examined and all showed visible thyroid tumors.

The brook trout of the hatchery were yearling fish, between 700 and 750 in number, kept in races 10 and $I r$. A number of them were also kept in race 14 and in the large pond. In race 16 , wooden, were 100 brook trout from Cold Spring Harbor hatchery. To these were added 56 wild brook trout from the Old Forge hatchery later in the summer. By the middle of June the epidemic among the brook trout was at its height. These fish were examined a number of times and some of the affected ones were put into the large pond and others into the small pond 15. On June 24 the fish in race ro were examined and 72 affected fish put into the large pond. About $\mathrm{I}$ fish in every 3 was found with visible tumors. Race II contained $1_{42}$ yearling brook trout. Thirty affected fish were found in race $\mathrm{I} I$ and placed in pond 15 .

The remainder, II 2 supposedly healthy fish, were removed to wooden race 18. This race is supplied with the water of springs $\mathrm{C}$ and F, and the Cold Spring Harbor trout kept in this water having remained free from the disease it was hoped that by changing the fish from race II, which did not yet show evidences of visible tumors, they might be saved. On examining these fish in race 18 in September, 107 of the II 2 were found to have visible tumors.

During the summer a large number of the brook trout in the large pond died. One hundred and five of these were found to have visible tumors. Early in the spring the large pond which in September, 1907 , had been stocked with some 6,000 brook trout fry hatched during that season and in which during the summer of 1908 a few dead yearling fish were found with visible tumors, was again cleaned, the fish being temporarily transferred during this time. Some 200 of these brook trout, now 2 years old, were estimated to have escaped with the overflow into the brook. This stream was protected by a screen at the lower end of the hatchery and such fish as escaped remained in the brook during the summer, here receiving no artificial feeding during this time and enjoying conditions of freedom so far as ample space and lack of crowding were concerned. That a large proportion of these fish were affected with visible tumors was shown by the fact that during the course of the summer 105 died of the lot transferred to the big pond, all showing visible tumors, and to determine to what degree they might have recovered under the new conditions an examination was made on Septem- 
ber II. The stream was therefore seined and 48 fish were caught and examined. Of these 31 were found to have visible tumors, many of large size.

Pond 15 had been the receptacle for affected fish taken from the different troughs, tanks, and ponds. There were approximately 450 fish in this pond; 164 of these are recorded as dying during the course of the summer. At the end of September the remainder, all of which still had visible tumors, were killed; the record states 276 in all.

The conditions for observation at the Bath hatchery during the summer of 1909 were unfavorable owing to lack of records as to the origin of many lots of fish, to inadequate help, preventing frequent examination of the various lots, and to frequent changes of the various lots from pond to pond, due to the exigencies of fish culture. The most important observations made were the marked degree to which the water of the big pond and the tanks it supplied were involved in the epidemic; the striking evidences of immunity in the adult rainbow and brown trout from the Caledonia hatchery; the fact that the yearling brook trout exposed to the disease in pond II continued to develop it rapidly although transferred to trough 18 , in which nevertheless the Cold Spring Harbor yearling brook trout in trough 16 , which was supplied by the same source, springs $C$ and $F$, remained free from the disease during the summer; and the lack of evidence of spontaneous recovery in the 2 -year-old brook trout living under conditions of partial freedom without artificial feeding during the summer in the brook; the high incidence of the disease in the large pond, $\mathrm{A}$, where the flow of water and proportionately great area of the pond produced conditions much more favorable from this standpoint than are usual under conditions of domestication; and the rapidity of involvement of the fish by the disease and the great number affected.

As the main activities of this research were, in 1909, transferred to the Craig Brook station in Maine, no further observations were made at the Bath hatchery during r 910 and 1911 , but in the middle of October, 1912 , for the purpose of determining what the condition of this hatchery might then be, an inspection, covering one day, was made. No essential changes have been made in the water supply or other arrangements of the hatchery other than those already described. The hatchery now carries a stock of about 3,000 brook trout hatched in the spring of I9II. With the idea that fish hatched from the eggs of wild fish might prove more resistant to the unfavorable conditions in this hatchery, eggs were obtained from the Ontario Fish and Game Commission in Canada. Approximately $\mathrm{I}, 500$ fish were hatched from these eggs and maintained in a separate trough. The remaining 1,500 fish were hatched from eggs obtained from a private hatchery in Massachusetts, and were also kept in a separate pond. Both these lots of fish showed well-developed examples of the disease ranging from the first evidence of red floor to protruding tumors of 7 to 10 millimeters. Of the 1,500 fish hatched from the wild-fish eggs, some 200 were examined, 9 of which were visibly affected, and 200 examined from the lot of 1,500 hatched from the eggs from the Massachusetts hatchery showed 12 diseased fish. From this inspection it is evident that the disease is still endemic at the Bath hatchery. 
HYBRIDIZATION.

Hybrids of the brook trout with the American saibling (Sunapee trout) and with the landlocked salmon do not differ materially from the pure species in reaction to thyroid disease. Lot 2017, for instance (female brook and male landlocked salmon), as yearlings showed no visible process, and experienced very little involvement during four years. Lots 2036,2037 , and 2038 (brook plus saibling) were little affected as yearlings, but considerably at three years. The appearance and character of the growth is substantially the same as in the brook trout. These crosses, within the genus Salvelinus and the closely related Salvelinus plus Salmo, are more or less successful, and the fish resulting are hardy, and grow to maturity and reproduce.

The hybrids of the Pacific salmon, though all contained in the same genus (Oncorhynchus), are greatly inferior in vigor to their constituent species, and probably could not maintain themselves. They do not do well under fish-cultural conditions, are not hardy, and easily succumb to unfavorable conditions. Hybrids of the silver and humpback salmon are subject from the embryo to deformity of the spinal column in the region of the caudal peduncle. They are readily susceptible to thyroid disease. One of these hybrid lots showed as yearlings the highest incidence of visible tumors yet observed in any large homogeneous brood of fish (p. 67). One lot, however (silver plus humpback, $1988 \mathrm{~A}$ ), consisted at the first examination of but $\mathrm{I} 7 \mathrm{fish}$, all of which were tumored; and all the Pacific hybrids showed a high percentage of tumors. The general gross appearance of these growths is markedly different from that of the trout tumors. The hybrid tumors have a marked symmetry, most apparent on the floor of the mouth. Here the growth as it vegetates into the mouth usually occupies the median bridge, and spreads equally over the arches so that the right and left halves of the tumor are alike, and a distinct and sometimes almost perfect bilateral symmetry appears. The surface of the growth is unusually smooth. The benign impression which results is belied by the structure, which in these growths in hybrid salmon is among the most malignant of the thyroid tumors in fishes. Likewise the cachexia observed among tumor fishes is most extreme in these fish. (Fig. 4a).

\section{CLINICAL COURSE.}

\section{MORBIDITY AND MORTALITY.}

There is no very definite symptom picture among the affected fishes. The disease usually runs a slow chronic course. The earliest external evidences may doubtless occur in very young fish only a few months old, but rarely do fish of this age show any outward signs of disease. The beginning of the process is without clinical symptoms until the red floor or an evident tumor appears. The earliest gross tumor we have seen is in a brook trout about 5 months old. (Fig. 72.) Not many tumors are seen until the fish reach the yearling stage, when the growth is usually still small and not causing much interference. In certain hybrid salmon, however, and occasionally in brook trout, the growths in yearling fish have already reached a relatively great size, sometimes almost their maximum. These hybrids die rapidly and do not grow to maturity. In brook $8207^{\circ}-14-6$ 
and other pure trout species the tumors grow progressively with the growth of the fish to maturity. At the spawning season gravid fish are often thrown out and destroyed on account of the presence of large thyroid tumors, and doubtless eggs from such fish not infrequently find their way into the hatchery. As far as we know they may be fertilized and hatched like the eggs of other trout.

Only the larger tumors are evident to a casual inspection of the fish. To determine whether a fish has a thyroid tumor it is necessary to examine the thyroid region from all sides after spreading wide the gills and opening the mouth. A considerable proportion of the trout in fish-cultural ponds may have developed visible tumors without the knowledge of the fish culturist. By such an examination 3 I per cent of the 2-year-old brook trout at one hatchery were found to have visible thyroid tumors, while 33 per cent showed the red floor indicative of an earlier stage of thyroid disease.

Thus 64 per cent were visibly affected, although the fish culturist knew of the existence of this disease only from having occasionally seen a dead trout with a swollen gill region.

The first obvious effect of the tumor is the mechanical interference with breathing and eating as the tumor grows larger. By filling the mouth it obstructs the passage of food, and by its growth downward and outward it spreads the gill arches, limits their natural movement, and pinches off the vessels until in portions the circulation is stopped. Large tumors often show across their surface a pale atrophied series of nonfunctional gill filaments. Yet the fish succeeds in breathing and eating in spite of a surprising degree of interference.

Tumored trout, like healthy normal trout, ordinarily have the blood sterile to common culture media. This is shown by negative results from numbers of attempts to obtain cultures from the heart blood of freshly killed trout with tumors, and also from tumor trout dead of disease. That tumor trout are more subject to terminal infection than other trout is to be expected and is probably the case, though some meager observations made by us at a State hatchery tend rather to support the contrary view. Terminal blood infection in the living as well as the dead trout has, however, been observed, and of course the tumors are frequently infected. That tumor trout frequently die without showing a general infection, or evidence of intercurrent disease, indicates that the thyroid process itself is fatal in a certain proportion of cases. This intrinsic death rate is probably low, but can not easily be separated from the rate of mortality among tumor fish due to all causes.

Hybridization seems greatly to increase the susceptibility of the salmonoids to the incidence of tumors and to its effect on their bodily economy. In some of these the anemia is readily recognizable by mere inspection, and is so extreme in some individuals that the blood scarcely appears red. A case in point is the lot (no. 1994) of yearling salmon (Oncorhynchus) hybrids of the female blueback with the male humpback. In April they numbered $\mathrm{I}, 043$, of which $\mathrm{I} 6.7$ per cent had visible tumors. By the following August they had suffered a loss of 57 per cent. Of the 594 remaining 92.5 per cent had visible tumors. These showed distinct emaciation, many of them to an extreme 
degree, with the accompanying anemia referred to above. They were constantly succumbing to the disease, and the slightest handling, as during the manipulations incident to transportation, greatly increased the death rate. Before the following summer all were dead. The reaction of the disease in hybrids does not afford a typical clinical picture and is not a criterion from which to infer its virulence or its analogies with other disease processes. Most hybrids are not successful fish-culturally, and the salmon hybrids referred to are especially defective and lacking in vigor.

Restricting morbidity to those showing macroscopic evidence of disease, such as red floors or visible tumors, the morbidity rate is widely variant among the various species and hybrids, and under the various conditions of age and surroundings. Our observations show, for brook trout yearlings, a rate from a minimal one-half of I per cent to 28 per cent; for 2 -year-olds, 20 per cent to 65 per cent; and for older fish from 5 to $9 \mathrm{r}$ per cent. Considering visible tumors only, there appears one-half of I per cent to 7 per cent for yearlings, 3 per cent to $3^{8}$ per cent for 2 -year-olds, and I per cent to 34 per cent for older fish. Landlocked salmon have shown visible evidence of disease in from 2 per cent to 7 per cent of yearlings, and 5 per cent to 37 per cent of older fish. With rainbow trout our experience is very limited, and we have not seen more than 6 per cent of adults affected.

Hybrids of the brook trout and saibling react much like the brook trout, but hybrids of the brook trout and landlocked salmon seem, from experience with one lot only (no. 2017), to have a considerable degree of immunity, showing no involvement until the second year, and at 4 years only 5 per cent were affected. The salmon hybrids of the genus Oncorhynchus usually show extreme susceptibility.

On the other hand, the same hybrid with the sexes reversed (lot 1995, male blueback and female humpback), was much less susceptible. It was held at first under the same conditions, in trough 99, and consisted in April of 312 yearling fish, only 1.2 per cent bearing tumors. In the following August there were 146 fish left, of which 5.5 per cent had tumors. The clean fish were then transferred to pond 4. At 2 years of age there were 77 fish left, of which 13 per cent were affected and 9 per cent had visible tumors. At 3 years of age 27 fish were left, and of these 37 per cent showed red floors without any visible tumors.

The direct and indirect mortality rates can not be stated numerically. The process presumably does not kill, whether directly or indirectly, save in the later stages when the tumor is visible, and the only available data on the loss among fish in any stage of thyroid disease is so complicated with losses from other causes-even causes having nothing to do with disease, that any accurate statement is impossible. The mortality rate is to all appearances not uniform, but varies from a slow fish-culturally unimportant loss to occasional epidemic virulence, as in the active progress of the disease and rapid loss of fish at the State hatchery at Bath, N. Y. Ordinarily and in the common exhibition of the disease the death rate may be said to be low.

In the many studies of the distribution of goiter among human beings none is so striking or apparently so directly comparable to the conditions found in the study of the disease in fish hatcheries, as the observations of McCarrison, 1906, of endemic goiter 
in the Chitral and Gilgit Valleys of north India. McCarrison had the opportunity of studying endemic conditions among the inhabitants of the small villages of this remote region. His observations are of particular value because the people in these small States of northern India are remote from commerce, communication is extremely limited, many of the communities are shut off from communication even with their neighbors, and the conditions which he describes represent the development of the disease under almost fixed conditions. In the Chitral Valley he describes a series of villages lying along the left bank of the Chitral River, each village deriving its water supply from the narrow mountainous valleys at the openings in which the villages lie.

The water supply is in all cases derived from the melting of the snows on the hills above. It comes from the nullah at the mouth of which the village stands, and is the only supply of that village. As a rule the water from the melting snows runs down the nullah as a turbulent mountain stream, taking up what matter it may on its way either in solution or suspension; in other cases it percolates into the soil and appears lower down in the form of a spring, as in the case of Awi. In the summer months the water is invariably gray from the presence of fine sediment. There are no real glaciers in the district under observation; the water is snow water rather than glacier water. There are no wells in the village, and, owing to the slope of the ground and the nature of the soil, water does not and can not stagnate.

The incidence of goiter in these villages varies from ro per cent to $5^{8}$ per cent and appears to be dependent upon the local conditions of the village and its water supply. As compared with the appearance of the disease in the villages of Chitral, McCarrison had observed in Gilgit a remarkable increase of the incidence of goiter in a series of villages scattered along an irrigation ditch where the incidence of the disease increases from above downward.

Gilgit lies between the parallels of latitude $35^{\circ}$ and $37^{\circ}$ and meridians of longitude $74^{\circ}$ and $75^{\circ}$. It is only, however, with Gilgit proper, the capital of the district, and not with the whole of this district that these observations deal. Gilgit is situated on an alluvial fan on the right bank of the Gilgit River, a tributary of the Indus. This fan is roughly ro square miles in extent and has a gentle slope from its apex, in the nullah from which it derives its water supply, to the river. On this extensive fan eight villages are situated; collectively these are known as Gilgit. The remarks which $I$ have made as to the climate and people of Chitral apply equally to Gilgit. The valley runs east and west. The height of the fan above sea level is 5 , ro5 feet. Appended is a rough diagrammatic sketch which shows clearly the water supply of the different villages of the Gilgit fan.

The water comes from a single source and is conveyed to the different villages in open kuls or channels. From the diagram it will be observed that there are two main channels, an upper II and a lower (I). The upper channel has no villages on its banks till it joins the lower kul, at the village of Majinpharri, marked (3). All these seven villages are situated on the banks of this lower kul or are supplied by lesser channels branching from it. Each village in this way receives the drainings of the village or villages above it, till at the last village, Kashrote, the drinking water has been polluted by the six villages above.

The water in these open channels not only supplies the inhabitants with drinking water, but it irrigates their extensive crops, serves as an open sewer, is used for the cleansing of their bodies, household utensils, and wearing apparel. It can readily be imagined, therefore, that considerable organic impurities find their way down to the lower villages; yet, being fed as these channels are by a purer supply, little organic impurity can be detected by qualitative tests.

The water is, during the winter months, at its source clear and sparkling, but at the village of Kashrote (see diagrammatic sketch of water supply and plate Gilgit Valley, western end) invariably gray from the presence of fine sediment and impurities from the villages and lands irrigated by it. During the summer months when the snows are melting it is, of course, much worse. 
If the sketch of the Gilgit water supply is referred to it will be observed that the Barmis spring joins the supply already described at 3 , Majinpharri. This spring does not produce goiter; it is the supply of all the European residents and their servants; there is also a small village on its banks, among the inhabitants of which there is no single case of the disease. It is a very pure water, springs from

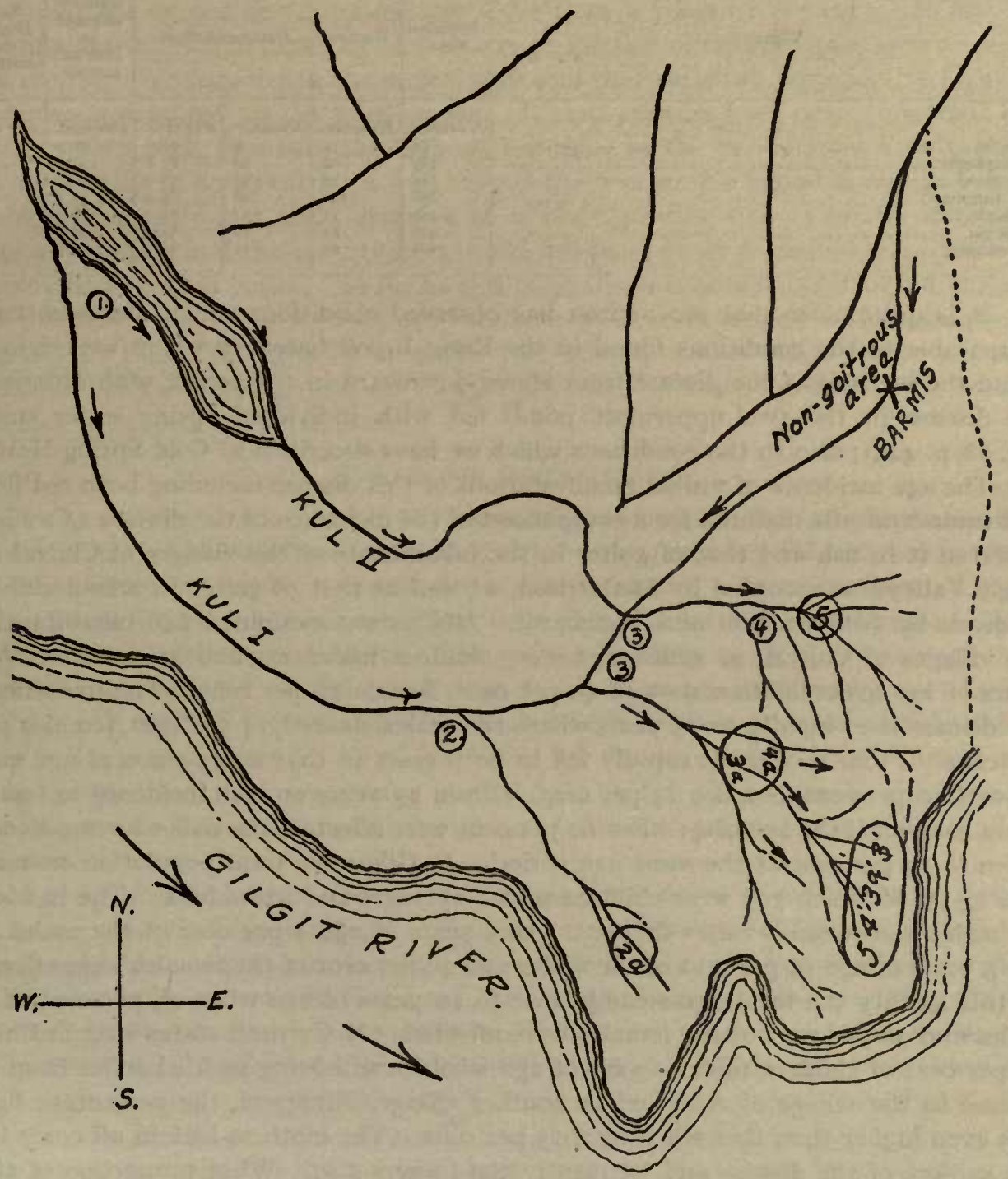

FIG. 83.-Diagrammatic sketch showing water supply of the villages of Gilgit fan, India. After McCarrison.

among rocks, and I have been unable to trace any case of the disease due to the drinking of its water. This is a point of very considerable importance, showing as it does that the other water supply is the vehicle by means of which goiter is produced in the inhabitants of Gilgit. The analysis of this water of Barmis will be found in the table of analyses of Gilgit waters (table Iu). 
In considering the prevalence of goiter in the villages of Gilgit the villages are dealt with in order, from that highest on the water supply to that lowest (see sketch of water supply). The figures are given in the following table:

\begin{tabular}{|c|c|c|c|c|c|c|c|c|}
\hline & Village. & 1 & $\begin{array}{l}\text { Popula- } \\
\text { tion. }\end{array}$ & Houses. & Infected & 1 houses. & \begin{tabular}{|} 
Persons \\
infected \\
in \\
infected \\
houses.
\end{tabular} & $\begin{array}{c}\text { Total } \\
\text { popula- } \\
\text { tion } \\
\text { goitrous. }\end{array}$ \\
\hline $\begin{array}{l}\text { 1. Basin ...... } \\
\text { 2. Umpharis ... } \\
\text { 3. Damyal.... } \\
\text { 4. Majunpharri } \\
\text { 5.6. Kyk....... } \\
\text { 7. Sonyar..... } \\
\text { 8. Kashrote... }\end{array}$ & & 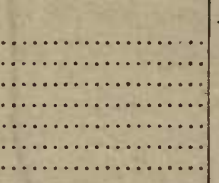 & $\begin{array}{r}\text { Number. } \\
93 \\
385 \\
181 \\
718 \\
229 \\
458 \\
128\end{array}$ & $\begin{array}{r}\text { Number. } \\
15 \\
66 \\
30 \\
108 \\
33 \\
63 \\
24\end{array}$ & $\begin{array}{r}\text { Number. } \\
9 \\
42 \\
20 \\
68 \\
23 \\
52 \\
21\end{array}$ & $\begin{array}{r}\text { Per cent. } \\
60.0 \\
63.6 \\
66.6 \\
63.2 \\
71.5 \\
82.5 \\
87.0\end{array}$ & \begin{tabular}{|r} 
Per cent. \\
21.2 \\
28.3 \\
30.3 \\
24.2 \\
30.0 \\
30.0 \\
36.0
\end{tabular} & \begin{tabular}{|r} 
Per cent. \\
11. \\
20.0 \\
18.8 \\
20.0 \\
26.9 \\
24.5 \\
45.6
\end{tabular} \\
\hline
\end{tabular}

It is quite clear that McCarrison has observed conditions which are remarkably comparable to the conditions found in the Craig Brook hatchery where we originally found the increase of the disease from above downward in the ponds, with absence of the disease in the two uppermost ponds fed with individual spring water supply (fig. 78 , p. 429); also to the conditions which we have described at Cold Spring Harbor.

The age incidence of visible manifestations of this disease including both red floors and tumors affords material for a comparison of the incidence of the disease as we have observed it in fish and that of goiter in the inhabitants of the villages of Chitral and Gilgit Valleys, as recorded by McCarrison, as well as that of goiter in school children as given by Schittenhelm and Weichardt. McCarrison examined 646 inhabitants of the villages of Chitral, of which 277 were children under 15 , and 369 adults. At 5 years of age male children showed 40 per cent, female 22 per cent. The incidence of the disease rises rapidly to 15 years where the males showed 74 per cent, females $591 / 2$ per cent. From this age it rapidly fell in both cases so that at 25 years of age males showed 40 per cent, females 24 per cent. From 25 years on, the incidence in females again rose, until the age of 45 when 62 per cent were affected, the males having steadily fallen to 23 per cent at the same age period. In Gilgit the total population examined was I,533, of which 705 were children under 15 years and 828 adults. The incidence for males and females varies slightly. At 5 years of age 2 per cent of the males and at 15 years of age 16 per cent of the males and 20 per cent of the females were affected. In this locality the incidence steadily rose to 40 years of age when 45 per cent of the males and 36 per cent of the females were affected. McCarrison states that in Chitral 23 per cent of children under I year of age who are still being suckled suffer from this disease in the village of Awi, and in another village, Miragram, the percentage figure was even higher than this, reaching 61.5 per cent. The mothers had in all cases been the subject of the disease and frequently the fathers also. What proportion of these cases were congenital and what acquired he was unable to determine.

Schittenhelm and Weichardt state that in a typical goitrous community in Bavaria the incidence of goiter as expressed by demonstrable enlargement of the thyroid is, from 2 to 6 years of age, 42 per cent; 6 to $9,72.4$ per cent; 9 to $13,89.6$ per cent; and 
that for recruits who have reached the age for military service for the district, 9.22 per cent. From this it would appear that there is a steady increase of goiter in school children up to the age of puberty, with a marked decrease between that age and 20.

Our tables show that for brook trout yearling fish the maximum is 28 per cent, .or 2 -year-olds 65 per cent, and for fish older than 2 years 91 per cent. It may be stated for brook trout in captivity that a large proportion of them at least have acquired their reproductive faculties in the second year and that their full reproductive faculties are certainly acquired by the third season. It thus appears from our figures that fish exhibit a very high, probably the highest, incidence in the period from 2 to 5 years, which in the life of a fish carries it well beyond the comparable period in human beings. We have frequently met with instances of actively growing tumors in the oldest fish under observation and the large tumors in old fish have never presented an appearance comparable to colloid goiter. So far as this comparison is admissible it would indicate that the process in the fish in its age incidence is more in accord with McCarrison's observations than the Bavarian statistics just quoted. Both McCarrison's statistics for man in Chitral and Gilgit and our own for fish reach well into the period of increasing incidence of neoplasms in mammals.

\section{HEMOGLOBIN FSTIMATIONS.}

In the autumn of 1902 , before thyroid carcinoma in fishes had attracted attention in this country, one of us observed, incidental to work upon bacterial infection in trout, an anemic condition among a certain lot of brook trout at a State hatchery at Paris, Mich. These fish were $1 / 2$ years old and were part of a lot of several hundred which had been sorted and segregated from the general hatchery stock on account of their undersized and stunted condition. Except for their small size this lot was in fair condition and most of them would have spawned for the first time some weeks subsequent to these observations. Of this selected lot the percentage having tumors was not determined but there were more normal healthy fish than those bearing tumors. Even the tumor fish with anemia showed no particular emaciation or falling off in condition.

Nine apparently healthy fish without tumors were taken at random from this lot and hemoglobin readings obtained. Nineteen tumor fish from the same lot then had their hemoglobin estimated in the same way. The range of the former was from 30 to 43 , of the latter from almost nothing to 47 , the averages being 37.5 and 21.6 , respectively. The readings were made with a Dare hemoglobinometer; those recorded as 8 are arbitrarily overstated, the samples scarcely showing red and registering much below the lowest scale reading. The fish showing the highest reading (47) had only a very small tumor, in the jugular pit. The largest fish of the series (first of the table) showed one of the lowest readings, and had marked blood changes. The tumors were not measured or accurately compared, but the larger usually gave the lowest readings. A marked poikilocytosis accompanied a low blood count for red cells. The normal red cells numbered 256,000 per cubic millimeter, or 416,000 including the atypical reds of extraordinarily small size. The red cells of normal brook trout blood number about $\mathrm{I}, 000,000$ per cubic millimeter. 
While tumor fish not infrequently have blood infections, plates made from the heart blood of several of these tumor fish remained sterile, save in one case. The hemoglobin readings and other data for each individual are given in the following table:

Table VI.-Hemoglobin Estimations on the Blood of Trout at the State Hatchery at PARIS, MICH, IN OCTOBER, IgO2.

\begin{tabular}{|c|c|c|c|c|c|}
\hline Sex. & Length. & $\begin{array}{c}\text { Hemo- } \\
\text { globin. }\end{array}$ & Sex. & Length. & $\underset{\text { globin.b }}{\text { Hemo- }}$ \\
\hline 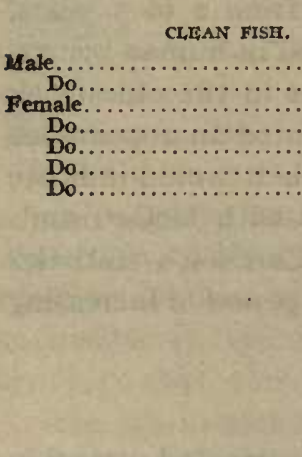 & $\begin{array}{r}\text { Centi- } \\
\text { meters. } \\
\text { I5 } \\
\text { II } \\
\text { II } \\
\text { II } \\
\text { II } \\
\text { I2 } \\
\text { I2 } \\
\text { II } \\
\text { I2 }\end{array}$ & $\begin{array}{l}4 \mathrm{I} \\
38 \\
36 \\
30 \\
43 \\
38 \\
39 \\
4 \mathrm{I} \\
32\end{array}$ & 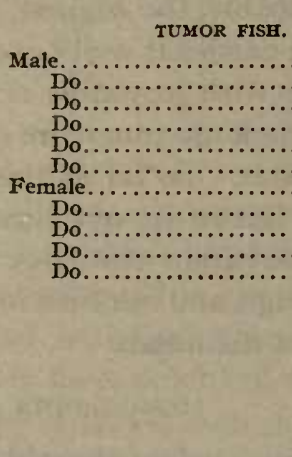 & \begin{tabular}{|c} 
Centi- \\
meters. \\
20 \\
16 \\
16 \\
16 \\
16 \\
15 \\
15 \\
16 \\
18 \\
17 \\
10 \\
11 \\
10 \\
11 \\
11 \\
$1 I$ \\
11 \\
10 \\
11 \\
11 \\
II
\end{tabular} & $\begin{array}{r}12 \\
25 \\
43 \\
43 \\
29 \\
28 \\
8 \\
8 \\
47 \\
19 \\
22 \\
19 \\
11 \\
27 \\
8 \\
8 \\
18 \\
8 \\
29\end{array}$ \\
\hline
\end{tabular}

\section{SPONTANEOUS RECOVERY.}

In the microscopic examination of sections of carcinoma of the thyroid at Craig Brook station during the summer of 1909 , we occasionally encountered what appeared to us to be evidences of regression in certain tumors. We therefore were led to look for evidences of spontaneous recovery. To determine whether a change to more favorable conditions on the part of the fish would increase the number of spontaneous recoveries, in the autumn of 1909 , I I 9 fish with visible tumors, mostly of large size, were selected from a lot of landlocked salmon (lot 1950), and placed in pond I at Craig Brook station. During the winter of r909-10 two yearling brook trout with small thyroid tumors visible at the isthmus were held without food in a glass jar in the cold with occasional changes of water. One died after a few weeks with the tumor still visible. During 44 days the tumor of the other fish disappeared entirely, leaving the entire thyroid region without external enlargement. In the early spring of igro an examination of the I 9 tumor-bearing fish in pond I was made to determine to what extent spontaneous recovery might have affected this advanced lot. The conditions in the pond were more favorable than in the pond below. Here the fish received pure water directly from a spring, had access to natural vegetation, and obtained from their surroundings some natural food while they were fed very little artificial food. Thus they were in a large degree removed from fish culture. During a year the loss was 67 per cent and of the remaining fish only $5^{6}$ per cent showed visible tumors. 
Aside from the actually observed stibsidence of visible tumors under some abatement of the conditions of domestication, trout taken at random from fish-cultural ponds, with clean thyroid region, show the usual microscopic picture associated with thyroid known to have recovered from tumor formation. The wild trout used in feeding experi-

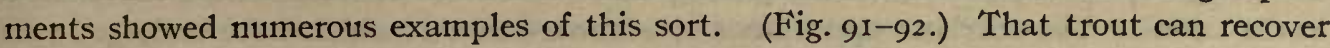
under apparently the same conditions under which they acquire the disease, and under which other trout are showing progressive tumors, seems sufficiently attested by our experience.

Recognition of spontaneous recovery is a necessary factor in studying the controls of fish treated with various metals. It is a remarkable fact that in only three or four instances in a total of 46 controls did we find spontaneous recovery under the conditions selected for these experiments. Regression does not appear to occur until after the disease has continued for some time. The best evidence of regression from moderate hyperplasia is found in the wild Wisconsin brook trout with selected feeding, in tanks I and 2 containing lots 2146 and 2147 . (See table vir, p. roo.)

In this experiment at the end of one year, fish fed upon raw liver and raw ox heart showed marked hyperplasia, whereas those fed upon various other types of food showed no evidence of hyperplasia. At the end of two years the only lots of fish remaining free from evidence of hyperplasia were those fed upon natural food (i. e., live maggots, fresh water and salt water mussels, etc.), whereas those which had from the beginning been fed upon raw liver or raw ox heart in the various experiments, showed a few individuals with well-developed visible tumors and a large number with well-defined evidences of retrograding hyperplasia. A microscopic examination of various fish from these lots will serve to characterize the changes which indicate regression of the earlier stages of the disease. See 2099, 2101, 2103,2104 , on pages 101 and 102.

Summed up, these changes are the evidences of an increased amount of thyroid tissue indicated by the presence of follicles in regions in which they do not normally occur. The follicles are not closely packed as in active hyperplasia, there is no evidence of hyperemia, there is a well-defined stroma, the stroma of ten forming trabeculæ between the alveoli as wide or often wider than the diameter of the follicles. The follicles themselves show great variety in size, a few larger ones are filled with stainable colloid, but the majority of them are small, of irregular shape and free from colloid or are but partly filled with poorly stainable colloid. The epithelium is flattened, of ten definitely atrophic, the protoplasm greatly reduced in amount, so that the cells are composed for the great part of their nuclei, which stain homogeneously and deeply. (Fig. 91.) Frequently evidences of there having been more than one layer of epithelium may be found. The greatest changes are in the peripheral regions, which is characteristic of the regression of all neoplasms. The evidence of the previous branching and irregular tubular type of proliferation, which characterizes the growing tumor, are found in atrophic structures of tubular and branching shape, sometimes reduced to a mere cord of cells. (See fig. 92.)

From a survey of such specimens it is clear that an actual disappearance of thyroid tissue must have taken place. In the earlier stages of regression from large tumors 
evidences of extensive hemorrhage are found, a characteristic which also distinguishes regression following treatment with metals. In such cases organization of the areas of hemorrhage by connective tissue appears. (Fig. Ior.) In the earlier stages of regression the periphery of the tumor will frequently show evidences of round-celled infiltration in the stroma. The scirrhous appearance of advanced tumors which have undergone regression is distinctly characteristic. It will be seen that these changes are distinct from the changes following so-called resolution of hyperplastic thyroid which leads to the stage of colloid goiter, as observed in the Scotch sea trout, where the terminal stage of simple hyperplasia is the large follicles filled with stainable colloid, lined by flattened epithelium. (Fig. 22.) The changes here described as regressive are of the same nature as those encountered in the regression of transplanted or spontaneous carcinoma of the breast in mice. (Gaylord and Clowes, 1906.) The microscopic picture of retrograding large tumors in no way differs from the changes following regression by treatment with iodine, arsenic, or mercury, except that no doubt in the latter instance the changes proceed more rapidly and with less evidence of stroma formation. (Fig. I09.)

\section{IMMUNITY.}

Among marine species it has been remarked that the chinook salmon held at the Craig Brook station until 3 years of age were entirely immune to visible thyroid growth. These fish were nevertheless in poor condition, and did not grow and thrive normally. This fish is anadromous, and under natural conditions the young, being hatched in fresh water, soon find their way to sea. Notwithstanding this, they may survive and grow to maturity when held captive in fresh water. It might be inferred that the immunity which resides in marine species of salmonoids, or the protection which the sea affords them-no marine species having been found in the sea with thyroid enlargement-is transmitted through the eggs and continued during a prolonged sojourn in fresh water. But the humpback salmon is likewise a Pacific marine species, and yearlings of this kind produced at Craig Brook are fine examples of thyroid tumors. Of 319 fish (lot 1986) about I year old, I 4 per cent bore tumors when examined in April. By the following August only 79 fish remained, of which 84.8 per cent had tumors. These resembled the tumors of the Pacific hybrid salmon and showed the same structural evidence of malignancy. Wilkie reported (Gilruth, I902) a thyroid tumor in a 5-year-old Atlantic salmon in fresh water in the ponds of the Clinton hatchery, New Zealand, and we have seen one example at the Craig Brook hatchery in Maine. It is evident that marine species may develop thyroid carcinoma while resident in fresh water.

The best example of species immunity is afforded by the Scotch sea trout, which at Craig Brook is almost completely immune either to visible or microscopic enlargement. One doubtful case of a distinct tumor is recorded and several of red floors, at 3,4 , and 5 years of age. Doubtless trout of this species can not continue indefinitely without affection under the conditions which produce the disease.

While the Pacific salmon hybrids all show a high susceptibility, other hybrids and the brook trout species exhibit various degrees of susceptibility and immunity to tumor formation. The landlocked salmon is about as susceptible as the brook trout, but lot 
1944 showed no visible evidence of thyroid disease until the fourth year, though living under the conditions which produced the disease. Lot 2017, hybrids of the brook trout and landlocked salmon, when it consisted of $\mathrm{I}, 553$ yearling fish, showed not a single fish with a visible process. In the second and fourth years a few visible growths appeared. A lot (2133) of rainbow trout, which develops frequent and large tumors at some hatcheries, were held two years at the Craig Brook station without acquiring any visible tumors and only a small percentage of red floors.

As previously referred to, rainbow trout at the Caledonia hatchery in New York appeared to have a very low incidence of the disease, about one-half of I per cent of the fish each year showing well-developed tumors, this covering a period of approximately 25 years. As stated, no fresh blood during that period was added to this lot of fish. Tumor fish found each year were destroyed and a probable original resistance of the lot was protected and perhaps added to by this form of selection, so that, as we have pointed out, in the epidemic at the Bath fish hatchery covering a period of two years these fish remained practically immune, only I or 2 fish in a lot of 75 adult fish being found with tumors in the course of the two years' epidemic. Exactly the same state of affairs existed in a lot of 20,000 German brown trout which had also been held without the addition of fresh blood at the Caledonia hatchery. These were represented among others by some 200 of their offspring, which as 4 and 5 year old fish went through the epidemic without a single tumor. This was not the case with some 4,000 young German brown trout which were sent from the Caledonia hatchery to the Bath hatchery as young fish, and which toward the end of the epidemic, as 2-year-old fish, developed a considerable incidence of the disease.

That the rainbow and brown trout retained so nany years at the Caledonia hatchery really possessed a definite inmunity against the disease is shown by the fact that during this time attempts to rear brook trout to adult age and maintain them resulted in a high incidence of thyroid tumors in this species. That a given lot of fish from one hatch may possess at a certain age an almost complete resistance to the disease, while another lot from another hatch of the same species and of the same age, kept under the same conditions, may show a high incidence of the disease, is possibly explainable on the basis of blood relationship. The manner in which spawn and eggs are taken and fertilized would easily bring about the presence in any given lot of a large number of fish with the same parents. With the exception possibly of the hybrids, some of the lots of which were small, no lot of fish which we have studied could possibly be entirely of the same parentage; but as a large number of individuals in each lot are certainly of the same parentage it is explainable that the ligh degree of immunity or susceptibility in a giver lot may be due to this fact. Such a supposition is in accord with the now well-known facts of family predisposition in both goiter and cancer in human beings.

The fish offer a remarkable opportunity for the careful study of this phase of immunity. It will be easily possible to obtain in any hatchery in which the disease is endemic, on the one hand from parents both having visible tumors, or, on the other, from parents showing distinct immunity, a sufficient number of eggs to hatch several hundred fish. A number of fish could be reared from such lots sufficient to demon- 
strate clearly in a few generations the exact importance of blood relationship to susceptibility and immunity. To guard against possible accidents obviously a series of such experiments should be carried on at the same time and to this purpose it would be necessary to devote the entire activities of a fish-cultural station for a period of years.

The importance of such an investigation to the question of immunity in goiter and cancer would certainly justify such an undertaking, aside from the possibility of practical results to fish culture. Only in this way can the importance of inbreeding as practiced in fish culture in the production of a general susceptibility among domesticated fish to this disease be properly determined. It is a common assumption that hatchery fish are more or less inbred. We have emphasized this idea in our earlier statements. A marked susceptibility of at least one lot of pure marine salmon species, i. e., the humpback, and in fact the occasional occurrence of the disease in wild fish, indicate that inbreeding as such, except by the perpetuation and accentuation of such susceptibility, may not be considered an important factor and the facts developed in connection with the rainbow and brown trout at Caledonia clearly show that fish-cultural inbreeding may finally develop a markedly resistant strain.

To what extent spontaneous recovery from the disease results in acquired immunity is not easy to state. There are many facts in this investigation which indicate strongly that recovered fish remain immune for a considerable period of time if not indefinitely. An experiment to determine definitely this question, although carried out with too few individuals, failed to realize the development of visible tumors in recovered fish at the end of one year, although placed in one of the lowermost ponds where the incidence of the disease continued to be high.

McCarrison (1906), in his study of endemic goiter in the Chitral and Gilgit Valleys, gives striking examples of family predisposition to goiter and refers to the frequent occurrence of goiter in nursing children where the mother has the disease. Schittenhelm and Weichardt (1912), in their recent monograph on endemic goiter in Bavaria, state that it is easy to trace family predisposition to goiter and append family trees of some 13 families, from which it may be readily seen that certain families show a remarkable incidence of the disease, which is especially marked in children where one or both parents, and especially when both parents and grandparents, are affected by goiter. There are several experimental studies in the lower animals indicating family susceptibility to cancer, the most striking being the breeding experiments of Dr. Maud Slye (1913), and recent statistics emphasize the well-known fact of family predisposition to cancer in human beings. Racial immunity to cancer has been shown by Levin (1910) to be very marked in the American Indians. This fact applies to isolated tribes of Indians living upon reservations extending from the northern to the southern limits of the United States, where the Indians for a period of 20 years have shown almost complete immunity to cancer, whereas the whites living in the immediate neighborhood show the usual incidence of cancer characteristic of the white inhabitants of the country. That such immunity is a special immunity to cancer and not a general resistance to disease is indicated by the fact that the same tribes of Indians show an unusually ligh mortality from tuberculosis. 


\title{
EXPERIMENTAL PRODUCTION OF THE DISEASE.
}

\author{
TROUT TUMOR MATERIAL IN STANDING WATER.
}

The contents of a thyroid tumor of a trout were expressed into tap water and brook trout fry in the sac stage were introduced. About 300 fry were used, distributed in 15 shallow open dishes each with from $I$ to 2 liters of the contaminated water. Eightyfive fry in similar dishes constituted the control. By keeping the dishes in the cold the fry were maintained for 23 days without change of water, or other than spontaneous surface aeration. During this period a loss of 16 per cent occurred on the fish in the tumor water and 11.7 per cent on the controls.

After removal from the tumor water the fry and their controls were held for several weeks in flowing tap water and suffered a gradual mortality. Sections of the thyroid region of these fish show no recognizable difference between the controls and those fed the thyroid material. Figure 13 shows the thyroid of a control fish soon after the food sac had been absorbed.

\section{FEEDING TROUT THYROID TUMOR.}

Fourteen brook trout of yearling age but of small size, reared almost entirely on live fish food, were fed nine times during one month with portions of fresh thyroid trout tumor. The fish were held for 54 days in glass jars, containing each 3 liters of water and two individuals. The water was changed once during this period. The temperature ranged from a little above the freezing point to $17^{\circ} \mathrm{C}$., which made necessary their removal to flowing water. They had received no other food than tumor material. When transferred there was no external evidence of thyroid enlargement. No histological changes in the thyroid tissue were recognized after careful comparisons with the controls.

\section{FEEDING HUMAN CANCER LIVER.}

Under the same general conditions as in the preceding experiment 12 trout were fed five times during 23 days with solid human cancer material from metastatic foci in liver of gastric carcinoma. After 54 days they were transferred to flowing water. All were without externally visible thyroid change and showed microscopically the same early hyperplastic stage as the controls.

\section{CLOSED CIRCULATION.}

In order to experiment further with normal and tumored trout in unchanged water, two independent aquarium systems were established for using the same water over again continuously by means of circulation, aeration, and filtration. Refrigeration was also provided so that the water could be at all times kept at a suitable temperature for trout.

During $5 \mathrm{I}$ days, 16 domesticated brook trout were fed human cancer of the liver on 14 different days, and became reduced to 8 fish in number. The thyroids of 4 of these were affected and 2 had visible tumors, but an accident prevented the controls from covering an equal period, and though the latter, 12 in number, were all clean but one, nothing conclusive is to be inferred. 
Fifty clean domesticated yearling brook trout were placed in the closed circulation with several badly tumored trout. In over four months, during a large part of which the water was aerated artificially, without circulation, we did not succeed in producing any notable thyroid reaction, and none which went beyond the controls. We do not believe tumors can be produced by contact or association with tumored fish in this way, at least not in any reasonable time. (See also feeding experiments p. I0o.).

The experiments in the closed circulation add to those in standing water in glass dishes in showing that the pollution of the water by the fishes themselves and their food refuse plays little if any part in the thyroid reaction. A number of trout were held for I 33 days in a 63-gallon aquarium tank with only four changes of water. Artificial aeration was maintained by a constant air current liberated in minute bubbles at the bottom of the tank. The fish were domesticated yearling trout, but not of a readily susceptible lot, and none of them showed any external sign of thyroid change at the end of the experiment. The fish were fed on liver, ate heartily, and were in good condition thoughout the period.

Most brook trout, however, held in troughs.at the laboratory and supplied with Lake Erie water tended to acquire the red floor of the mouth when fed on liver. Such trout kept in the ice-cold tap water in the winter and fed nothing, or given very low feeding, showed within a few weeks signs of thyroid regression. Further evidence of such regression is afforded by a yearling brook trout with a small but distinct thyroid tumor visible at the isthmus. It was placed in a glass jar with standing water in the cold and kept for 44 days without food. The water was changed several times. The tumor had completely disappeared at the end of this period.

\section{TRANSPLANTATION AND INOCULATION EXPERIMENTS.}

Several attempts to secure a new autonomous growth by implanting portions of visible thyroid tumors in normal trout have been made. Both wild and domesticated trout have been used. In only one fish have we met with partial success in that the graft showed evidence of proliferation and was still alive at the end of three months when examined microscopically.

In December, 1908, a number of supposedly healthy fish were sent to Buffalo from St. Johnsbury, Vt. These were inoculated in the thyroid region with a suspension of thyroid tumors from fish obtained from Bath. The surface of the tumor was carefully sterilized by burning. The greatest precautions were taken to prevent contamination. The center of the soft tumor was carefully scraped out, rubbed up with salt solution, and then injected. Nineteen fish were thus inoculated and later transferred to the Bath hatchery, where they were kept in the troughs of the fish-hatchery building. An examination of these fish in the autumn of 1909 showed that all of them had visible tumors, but the epidemic of 1909 was at that time in full swing, and it was impossible to determine whether the development of tumors was due to the inoculation or to the simple fact that these fish had been placed in the infected water of the Bath fish hatchery.

In a series of fish inoculated at Bath in the summer of 1909 , in most of which the grafts were contaminated and sloughed out, one fish (no. 83), which was inoculated Sep- 
tember I, I909, and killed for examination November 24, 1909, showed at the point of inoculation, which was in the muscular structure of the abdominal wall, just anterior to the left ventral fin, evidence of a small protruding growth the size of a grain of rice. On sectioning this tissue, a slender growth is found extending in what must have been the track of the needle. Under the microscope the growth is made up of a series of nodules, most of them with a not very well-defined connective tissue capsule. The continuity of the epidermis at the point of the small tumor is broken, and we have here a growth of tissue connected with the nodular growths in the deeper structures. This protrudes through the broken continuity of the epidermis. The circumscribed nodules lying between the muscle bundles and the subcutaneous tissue are made up of large spindle and irregularly shaped cells. The centers of the larger nodules contain a certain amount of hyaline detritus. Scattered between the cells of the nodules, particularly toward the center, are many leucocytes. At the outer margins of the nodules the cells are best preserved. The nuclei vary greatly in size, the protoplasm stains, the cell boundaries are not always well defined. The growth is made up of a complex of cells with large vesicular nuclei containing one or more nucleoli. They may be recognized as thyroid epithelium. In a nodule which fills the break in continuity in the epidermis there is a distinct suggestion of tubular arrangement with a definite stroma carrying blood vessels, and at the margin of one or two of the other nodules definite alveoli may be made out.

Toward the centers of the nodules there is distinct evidence of atrophy of the cells, associated with clumps of chromatin and hyaline detritus. There are many cells with very large nuclei. There is generally a great difference in the size and shape of the nuclei. Rarely a karyokinetic figure is found. The cells are closely packed together, but in some nodules there has evidently been a growth of capillaries in attempts at formation of a stroma. From the microscopic picture it is evident that there has been some proliferation in the implanted tissue, and that three months after portions of the graft at least are still alive.

At Craig Brook station in I9ro implants were made directly into the thyroid region of the fish with the aid of a hypodermic needle. It was found that the trout will endure a needle puncture in the floor of the mouth and the injection of one-fifth cubic centimeter of physiological salt solution directly into the tissues containing the thyroid with little reaction. By inserting the needle a little to one side of the median line the ventral aorta is avoided, and most of them show no external bleeding. Some of the fish suffer from shock, due to the puncture, from which they recover within 5 to 20 seconds. Even those which bleed usually do not succumb. Of 76 yearling domesticated trout thus inoculated as controls, only I died as a result of the manipulation. The fish tumor material for inoculation was ground up and mixed with its own volume of physiological salt solution. The difficulty in planting this material in the tissues of the trout lies in the high toxicity of the tumor extract. It is not practicable to place transplants of ordinary size in this vascular region without heavy loss from toxemia. The tumor material varies considerably in toxicity. Domesticated trout endure the mechanical injury incidental to inoculation better than wild trout. 
Of 30 wild trout injected in the thyroid region with 2 minims each of tumor ground with an equal volume of salt solution, about half died from the immediate toxic effect of the injection. At another trial one-tenth cubic centimeter of material made from several tumors was injected into each of 15 domesticated trout. Eleven of them succumbed almost immediatelý. The material was then diluted until it contained 3 volumes of salt solution and 15 more fish were injected, but 12 of these died within 2 or 3 hours. Seven fish were injected subcutaneously near the dorsal fin with one-fifth cubic centimeter of this material, and 5 died within a short time. One cubic centimeter was, however, passed into the stomach of I trout, and one-half cubic centimeter each into the stomachs of 3 others without apparent effect. This particular sample of combined tumor substance was unusually toxic.

The trout dying from the immediate physiological effect of trout tumor substance ground with salt solution showed a fairly characteristic picture of symptoms, ending in tetany. The mechanical effect is little, as shown by the control fish. In the few cases where the shock from trauma is apparent the fish lies on its back or side, scarcely breathing, and recovers in a few seconds. The inoculated fish, however, were evidently poisoned. They became immediately distressed, swam in circles or in short, frantic, and aimless dashes about the trough, then fell greatly weakened upon their sides and lay there with short and rapid breathing until the next paroxysm. Finally they succumbed in tetany, some with gills widely distended and marked opisthotonos. Even the survivors seemed to be much weakened.

Forty-three wild brook trout were inoculated in the thyroid region with small portions of tumor taken directly from the fish without grinding or mixing with salt solution. Pieces were forced through the floor of the mouth by means of trochar, probe, or seeker. 'The material was more or less toxic even in this form, and the mechanical injury and bleeding were greater than with the needle, but 24 of the 43 trout survived.

Ten domesticated brook trout were injected in the thyroid region with one-fifth of a cubic centimeter each of a mixture of one volume of domesticated brook trout blood and three volumes of physiological solution. No loss attended the operation, and the fish have never shown any but the immediate reaction to the inoculation.

In all injections and inoculations the instruments used were sterile, and the tumor material obtained as free from contamination as possible. It is not usually possible to obtain in quantity the thyroid tumor material from fish in a completely aseptic condition.

Mud from one of the fish ponds (no. Io) constantly associated with tumor fish was injected into the stomachs of 25 domesticated trout and of 20 wild trout. The dose was repeated on the former lot after three days. The filtrate of this mud through paper was injected into the thyroid region of 25 domesticated trout and behind the eyeball of 17 domesticated trout. The dose was 2 to $2 \frac{1}{2}$ minims. These fish have shown no results from the inoculations.

Trout tumor material has been ground with sand and filtered through a Berkfeld filter. The filtrate has been injected into the thyroid region of 2-year-old domesticated trout, all manipulations being carried on in the cold. About 0.3 to 0.4 cubic centimeter of filtrate was given each of 9 trout. These were kept under observation for over four 
months, when one thyroid tumor and two red floors had developed among them. The controls had been previously lost from some unknown cause, leaving the result negative.

\section{EXPERIMENTAL INDUCTION OF CARCINOMA. $a$}

In June, I910, about 2,400 wild brook trout of various sizes were collected in the wilderness of Wisconsin by the Bureau of Fisheries and brought to Craig Brook station. They were held in Craig Brook above all fish cultural operations until used in experiments. Several specimens were sectioned from time to time and found to be entirely normal. A series of 16 new cement tanks, 2.7 by I by I meters in size, which had not previously held fish, were used as containers for the experimental lots. (Fig. 79 left.) The depth of water in these tanks was 0.8 meter and the inflow 50 to 60 liters per minute. In July, I 910 , I I lots each of 50 adult wild trout from Wisconsin were placed in II of these tanks and feeding experiments begun with a variety of foods, which were maintained for each lot throughout the experiment without change. The so-called natural food was not all of one kind, but consisted of fresh-water mussels, fresh-water fish, and in the summer maggots of flies. The vegetable food was screenings from miscellaneous grains. In September, 1910, certain of the lots were augmented by smaller wild trout from Wisconsin, which had received food corresporiding to the lots to which they were added, or natural food.

Table virl summarizes these feeding experiments and includes some smaller lots which were inoculated in various ways, and were fed natural food. Such lots were negative, and are in effect controls to the feeding experiments. The inoculated lots are discussed under a separate heading. Lot 2149 was an attempt to crowd the fish by confining them in one-third of the tank. Lot 2155 aimed at excess feeding.

Lots 2150 and 2151 were practically wiped out by the unsuitable food, to which the wild trout could not adapt themselves readily. The wild trout gradually became accustomed to the fish cultural foods, liver and heart, and finally thrived upon them about as domesticated trout do. On examination after four months, and again after one year, all the fish were clinically clean, without any external evidence of thyroid disease. At the examination after one year the thyroid region of from one to three fish from each tank was prepared for microscopic study, and the histology of each is shown below by a description of each section by number (table viII). The diagnoses may be briefly summarized as follows:

In the lots fed raw liver (fig. 84) and heart (fig. 85) a general hyperplasia existed with early carcinoma in a few cases; the two fish from lot 2155 were exceptional, appearing normal. The lot fed cooked liver had remained normal. (Fig. 87.) Those fed marine fish (fig. 88), vegetable food (fig. 89), and natural food (fig. 86) were entirely without hyperplasia. Nearly all remained normal, but a few showed a considerable

a We believe that these experiments, reported at the fifth annual meeting of the American Association for Cancer Research, April 3 and $4, x_{92}$, in Philadelphia, and reported in the Zeitschrift für Krebsforschung, Band 12, Heft 2, 19ז2, p. 436, under the title, "Relation of Feeding to Thyroid Hyperplasia in the Salmonidæ," by H. R. Gaylord and M. C. Marsh, Buffalo, constitute the first instance in which spontaneous cancer has been experimentally induced under properly controlled conditions in the lower animals. They antedate the recent experiments of Fibiger in the production of carcinoma of the stomach and esophagus in rats by feeding them nematodes from cockroaches, for which a similar claim has been made.

$$
8207^{\circ}-\mathrm{I} 4-7
$$


increase in the number of thyroid follicles without elevation of epithelium or other changes from the normal. Lot 2163 was exceptional in that two of three fish showed beginning hyperplasia. They had been inoculated with trout tumor material in the thyroid region, the implant failing to take.

At the examination of June, 1912, two years after the beginning of the experiment, one distinct thyroid tumor (fig. 90) had developed in lot 2146 under the feeding of raw heart muscle. This fish, and one lot 2147 , which was fed raw liver and had developed a red floor, with slight swelling, showed typical thyroid carcinoma. Of the rest many had developed red floors, as shown in table virI. One or more specimens were preserved from each lot, and a description of the histology of the thyroid is given below. The trout fed with marine fish, vegetable, and natural food still remained normal, while carcinoma has definitely developed in two of the sample fish fed raw animal food. Those fed cooked liver have passed through hyperplasia to regression and, in fact, the chief characteristic of the microscopic picture in all the fish on meat diet is the regression indicative of spontaneous recovery. (Fig. 91-92.)

In general, it may be stated that the results obtained by selected feeding are in accord with our experiences in the study of hatchery conditions and that the relation of foodstuffs to the incidence of the disease is contributory and not causative. Thus raw liver and raw ox heart used as a food act as a predisposing factor in the development of carcinoma of the thyroid. Cooking the same food tends to delay the advent of the disease and fish fed upon natural food, marine fish, and vegetable food are able to resist the disease for a considerable period of time, if not indefinitely. One might conclude from these experiments that raw liver and raw heart muscle were the sole cause of the disease, were it not for the fact that we are able to check this observation by an observation made at another hatchery where the conditions are practically reversed. In this hatchery all of the fish are fed upon raw liver and raw ox heart muscle; but the fish kept in one water supply are free from the disease with this type of feeding, whereas those kept in other tanks with a slightly different water supply are uniformly affected by the disease. This state of affairs exists at Cold Spring Harbor, N. Y. The hatchery building is supplied with water from an artesian pipe driven near the building. The overflow from the hatchery, and, of course, from the artesian supply, which is not required for the hatchery building, flow into a series of large earth ponds, and then a series of concrete-lined ponds. The arrangement of the concrete ponds is such that one pond is practically continuous, each division for fish being separated from the one above it by an arrangement of boards over which the water flows. The ponds and concrete tanks are old and at the time of examination were lined with a visible growth of green algae.

Young fish hatched in the hatchery in the artesian water were placed for the most part in the concrete tanks just mentioned, but in a few instances the lots were divided and approximately half were placed in a spring located a distance of several hundred yards from the hatchery building. This spring flowed out from a hillside obviously from the same general supply as the artesian water and the springs near the hatchery. 
In the small brook about roo yards in length wooden divisions and tank-like arrangements had been constructed. In these the young fish were placed and all the fish both in the old concrete tanks and in the spring were fed with chopped raw beef liver and ox heart muscle. An examination of specimens taken from the two sources in the autumn of $19 \mathrm{r}$, of fish respectively 6 and 18 months old, taken from both sources, showed that whereas the fish in the old concrete ponds had well-defined hyperplasia (fig. 93), those kept in the spring water had thyroids exactly like those found in wild fish (fig. 94), although both had been liberally fed upon raw liver and ox heart. From this observation we must conclude that the selective feeding experiments at Craig Brook station indicate that the feeding of raw ox heart and liver produce conditions either in the tanks or in the fish themselves which favor the development of the disease, but that such feeding of raw heart muscle and liver is not the direct cause of the disease. It is hard to understand why fish fed upon cooked liver should have resisted the disease so much longer than those fed upon the uncooked liver, unless it is possible that the agent causing the disease is sometimes or usually transmitted with the uncooked materials, or that cooking the material delays decomposition and thus favors a more hygienic condition in the tanks. The complete resistance of fish fed upon natural food, chopped marine fish, and vegetable food, all of which were obtained from sources entirely different from either the heart muscle or liver, would rather suggest that these sources of food are free from the possible contamination with the agent of the disease; or, again, that they are not so easily decomposed in the tanks and do not therefore contribute to a favorable condition for the propagation or development of the agent in the tanks.

McCarrison (1906) points out that in Chitral where goiter is endemic the people are for the most part poor. Food is plentiful, comparatively speaking, from July to February, after which the people are obliged to live on the poorest grains, dried fruits, and the green stuffs of the spring. Their food is entirely vegetable. Flesh meat is an article of diet far beyond their means, while salt is a luxury to all except the richest families.

That the disease may be introduced into a community where it has not previously been and that in such cases the water supply becomes at once the suspected agent of distribution is shown by McCarrison's remarkable observation in Nagar.

In the village of Nagar goiter was unknown six years ago. Nagar is a small State situated up one of the many side valleys on the left bank of the Gilgit River. It will be remembered as the scene of a smart frontier rising in $\mathbf{1 8 9 3 . ~ I t ~ w a s ~ a f t e r ~ t h i s ~ y e a r ~ t h a t ~ t h e ~ l i t t l e ~ S t a t e ~ o f ~ N a g a r ~ b e g a n ~ t o ~ b e ~ o p e n e d ~ u p ; ~}$ previously, jealous of its independence and at war with its immediate neighbors, it was careful to exclude foreigners. During recent years intercourse with the outside world has become more free, but still there is a decided prejudice against the settling of foreigners in this little hill State.

Some five years ago certain cases of goiter were introduced from without, and since then the disease has begun to gain a footing. It may be as well to indicate clearly that there can be no doubt about the fact that goiter was quite unknown six years ago. The fact that it has gained a footing in his territory is a matter of very considerable anxiety to the present rajah, and through his help I was enabled to go into the matter with great care. All the important men of the State, the rajah himself, councilors, priests, etc., assure me that no case of goiter ever originated in Nagar till within the last six years. 
There is a family at present at Nagar which consists of nine souls; of these three came from Gilgit some years ago, all suffering from goiter. Two, the father and the mother, have no goiters; the father came from Gilgit. The remaining four individuals have never been outside Nagar. Three are highcaste Mohammedan girls ( $16, \mathrm{r}_{5}$, and ro years of age), which makes the statement the more likely to be accurate. The fourth individual is $a_{1}$ boy aged 12 ; he has never been outside Nagar. All of these four developed goiter about two years ago. This family lives in the same house, that is, the same room, eat out of the same vessels, etc. It is to be observed that these, the first victims, are all young.

Another family consists of a man, his wife, and son, aged 2, and the man's brother, aged 2o. The man brought goiter with him from outside five years ago. Two years later his brother developed the disease, though he had not been outside Nagar for five years. The little boy, aged 2, developed the disease one year ago; the wife is free from it. Another man, aged 23, brought the disease from Gilgit one year ago; it is inoreasing in size here.

Twelve children, all under ro years of age, were brought to me having marked enlargements of the gland. There are no other cases of the disease in Nagar. The children were from different houses scattered over the village. The first family to which I referred lives at the head of the spring which supplies the village with drinking water.

The village supply consists of a spring which comes out of the hills; it is not the only supply of the village. The cases I have referred to all drank from this water. This spring is said to have been in existence from time immemorial; the chemical composition of its water has presumably not altered. The conditions of life of the people are the same. The only added factor in the case is the introduction of the disease from without. That it is spreading there can be no doubt, and that the course of the spread is a typically endemic one is equally evident. It is easy to understand why the disease should not have reached Nagar earlier, as it is only within recent years that the communications of Nagar with the outside world have become free.

It appears evident also that it is by means of the spring water that the disease is now spreading, for the 12 children are residents of that part of Nagar supplied by the spring, and their homes are scattered here and there among the houses of the yet unaffected inhabitants. Further, the fact that the first family referred to lives at the head of the spring is of importance, and also that no cases of this disease were observed where water from other sources only is drunk, that is, in the distant parts of the village where the nullah water or the river water is used.

It seems likely, therefore, that some poison, goiter producing in its powers, has been introduced into a water supply which happened to be suitable for the conveyance of this disease.

This case of Nagar can not be explained by any theory which attributes to dissolved ingredients in a water goiter-producing properties; nor can inorganic matters in suspension account for this outbreak; for it can not be supposed that from causes in the water which have existed from time immemorial a disease should suddenly spring. There is, to my mind, only one explanation, namely, the introduction of an organism into the water supply. 
CARCINOMA OF THE THYROID IN SALMONOID FISHES.

TABLE VIII.-FEeding and OTher EXPERIMENTS with WILD BrooK Trout.

\begin{tabular}{|c|c|c|c|c|c|c|c|c|c|c|}
\hline \multirow[b]{2}{*}{ Tank. } & \multirow[b]{2}{*}{ L,ot. } & \multirow[b]{2}{*}{ Fish. } & \multirow[b]{2}{*}{ Food. } & \multirow{2}{*}{\multicolumn{2}{|c|}{ Other conditions. }} & \multirow{2}{*}{$\begin{array}{c}\text { Fish } \\
\text { added } \\
\text { Sept. 21, } \\
\text { rgro. }\end{array}$} & \multicolumn{4}{|c|}{ Clinical condition, June, rgr 2.0} \\
\hline & & & & & & & $\begin{array}{l}\text { Remain- } \\
\text { ing. }\end{array}$ & Clean. & $\begin{array}{l}\text { With red } \\
\text { floors. }\end{array}$ & $\begin{array}{l}\text { With tu- } \\
\text { mors. }\end{array}$ \\
\hline & 2146 & so & Heart, raw. & & & - & ${ }^{2} 39$ & $2 \mathrm{I}$ & 17 & \\
\hline & 2147 & 50 & Liver, raw.. & $\cdots \cdots \cdots \cdots \cdots \cdots$ & & 27 & 34 & 30 & 4 & 0 \\
\hline $3, \ldots \ldots$, & 2148 & 50 & Marine fish.. & & 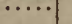 & 5 & I & 0 & 1 & \\
\hline $4 \ldots \ldots \ldots$ & 2149 & 50 & Liver, raw. & Reduced space; crowding. & $\cdots \cdots$ & 24 & 37 & 26 & 11 & o \\
\hline $5 \ldots \cdots \cdots$ & 2150 & 50 & Vegetable... & in presence of tumor fish. & $\cdots \cdot$ & 4 & I & I & 0 & $\circ$ \\
\hline $\begin{array}{l}6 \ldots \ldots \ldots \\
7 \ldots \ldots \ldots\end{array}$ & $\begin{array}{l}215 x \\
2152\end{array}$ & $\begin{array}{l}50 \\
50\end{array}$ & Ziver, cooked. & in presence or tumor usn.. & $\cdots$ & $\begin{array}{r}0 \\
25\end{array}$ & $\begin{array}{r}0 \\
20\end{array}$ & 16 & & \\
\hline $8 \ldots \ldots$ & 2153 & 50 & Iiver, raw... & In presence of tumor fish.. & & 7 & 36 & 28 & $\begin{array}{l}4 \\
8\end{array}$ & 0 \\
\hline $9 \ldots \ldots$ & 2154 & 50 & Naturalfood. & Minimum feeding......... & $\cdots$ & - & (b) & & & \\
\hline 10........ & 2155 & 50 & Liver, raw & Forced fecding. ............ & $\cdots \cdots$ & 13 & 38 & 35 & 3 & 0 \\
\hline II $\ldots \ldots \ldots$ & 2156 & 50 & Natural food. & Controls.................. & . & 26 & 40 & 40 & $\circ$ & $\circ$ \\
\hline $12 \ldots \ldots \ldots$ & 2159 & 25 & ....do........... & $\begin{array}{l}\text { Pond ro thud itu tank..... } \\
\text { Controls for tanks i } 2-16 . .\end{array}$ & $\cdots \cdots$ & $\circ$ & 22 & $2 \mathrm{I}$ & I & $\circ$ \\
\hline 13 upper. & 2160 & 16 & .....do.. & & & 0 & 9 & 5 & 4 & 0 \\
\hline$r_{3}$ lower. . & 2161 & 14 & .....do.. & $\begin{array}{l}\text { Inoculated in thyroid } \mathrm{r} \\
\text { with trout thyroid tumo }\end{array}$ & gion & & 12 & 12 & o & \\
\hline $14 \ldots \ldots \ldots$ & 2162 & 20 & ....do. do. & Pond ro mud in stomachs. & $\ldots \ldots$ & 0 & 16 & 25 & I & ० \\
\hline $15 \ldots$ & 2163 & 22 & .....do. & $\begin{array}{l}\text { Inoculated in thyroid rc } \\
\text { with trout thyroid tumo }\end{array}$ & gion & - & 12 & 9 & 3 & o \\
\hline $16 .$. & 2164 & 17 & .....do. & $\begin{array}{l}\text { Inoculated behind eye wit } \\
\text { trate from pond so mud. }\end{array}$ & fil- & $\circ$ & 4 & 3 & I & \\
\hline Tank. & $\begin{array}{l}\text { Sec- } \\
\text { tions, } \\
\text { rgIr. }\end{array}$ & \multicolumn{3}{|c|}{ Diagnoses, rgri. } & $\begin{array}{l}\text { Sec- } \\
\text { tions, } \\
\text { 1912. }\end{array}$ & \multicolumn{5}{|c|}{ Diagnoses, xgr 2.} \\
\hline $1 .$. & 2000 & \multirow{2}{*}{\multicolumn{3}{|c|}{$\begin{array}{l}\text { A, hyperplasia; } \mathbf{B} \text {, carcinoma } \ldots \ldots \ldots \ldots \ldots \ldots . . . \ldots . \\
\text {, beginning hyperplasia; } B \text {, normal; } \mathbf{C} \text {, carci- } \\
\text { noma. }\end{array}$}} & 2098 & \multirow{2}{*}{\multicolumn{5}{|c|}{$\begin{array}{l}\text { A, tiumor, carcinoma; B, adeno-carcinoma. } \\
\text { A, B, C, regression. }\end{array}$}} \\
\hline & $200 x$ & & & & 2099 & & & & & \\
\hline $3 \ldots \ldots \ldots$ & 2002 & \multicolumn{3}{|c|}{ 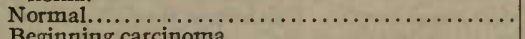 } & 2100 & \multicolumn{5}{|l|}{ Normal } \\
\hline $4 \ldots \ldots$ & 2003 & \multicolumn{3}{|c|}{ 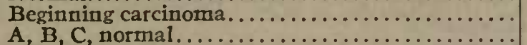 } & $210 I$ & \multicolumn{5}{|c|}{ Regression. } \\
\hline $5 \ldots$ & $\begin{array}{l}2004 \\
2005\end{array}$ & \multicolumn{3}{|c|}{ Normal........... } & $\begin{array}{l}2102 \\
\ldots \ldots\end{array}$ & Normal & & & & \\
\hline $7 \ldots$ & 2006 & \multirow{2}{*}{\multicolumn{3}{|c|}{ 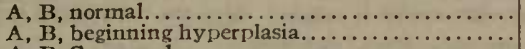 }} & 2103 & \\
\hline & 2007 & & & & $2 \mathrm{IO}_{4}$ & \multicolumn{5}{|c|}{ A, B, regression. } \\
\hline $9 \cdots$ & 2008 & \multirow{2}{*}{\multicolumn{3}{|c|}{$\begin{array}{l}\text { A, } \mathrm{B}, \mathrm{C} \text {, normal } \ldots \\
\mathrm{A}, \mathrm{B}, \text { normal. ..... }\end{array}$}} & $2 I_{3}$ & \multicolumn{5}{|c|}{ Normal. } \\
\hline $10 . \ldots \ldots$ & 2009 & & normal. . & n........... & 2105 & \multirow{2}{*}{\multicolumn{4}{|c|}{ Normal. }} & \\
\hline $\begin{array}{l}11 \ldots \ldots \ldots \\
12 \ldots \ldots \ldots\end{array}$ & 2010 & \multicolumn{3}{|r|}{ 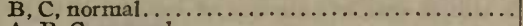 } & 2106 & \multirow{2}{*}{\multicolumn{5}{|c|}{ Increased thyroid of normal type. }} \\
\hline 12....... & $\begin{array}{l}2011 \\
2012\end{array}$ & \multicolumn{3}{|r|}{$\ldots \ldots \ldots \ldots \ldots \ldots \ldots \ldots \ldots \ldots}$, & $\begin{array}{l}2107 \\
2108\end{array}$ & \multirow{2}{*}{\multicolumn{5}{|c|}{$\begin{array}{l}\text { Increased thyroid of normal type. } \\
\text { Normal. }\end{array}$}} \\
\hline $\begin{array}{l}1_{3} \text { toper. } \\
1_{3} \text { lower. }\end{array}$ & $\begin{array}{l}2012 \\
2013\end{array}$ & \multicolumn{3}{|c|}{$\begin{array}{l}\text { A, B, normal. } \\
\text { A, B, normal . }\end{array}$} & $\begin{array}{l}2100 \\
2109\end{array}$ & & & & & \\
\hline$x 4 \ldots \ldots$ & 2014 & Norm & & 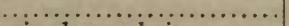 & 2110 & A, norm & nal; $B$, inc & eased thy & roid of nor & mal type. \\
\hline $15 \ldots \ldots \ldots$ & 2015 & A, no & rmal; B, C, begi & nning hyperplasia......... & $2 I I I$ & Increase & ed thyroid & of normal & type. & \\
\hline $16 \ldots \ldots \ldots$ & 2016 & Norm & lal............. & 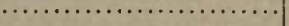 & 2112 & Increase & ed thyroid & f normal & type. & \\
\hline
\end{tabular}

a Examinations of Nov. 30, rgro, and July, rgri, all were clean.

$b$ Transferred to pond ro.

\section{DESCRIPTION OF SECTIONS TO ACCOMPANY TABLE VIII.}

2000 B. Tubulo-alveolar ty pe of carcinoma. Marked infiltration of surrounding areolar tissue. Infiltration of muscle above into bone spaces and infiltration of vessel wall. Invasion of cartilage.

$200 \mathrm{I}$ A. Beginning hy perplastic stage. Certain follicles are lined with columnar epithelium. In many such follicles colloid is absent, in others present but poorly stained. Surrounding this group of follicles are follicles of strictly normal appearance. Ejpithelium flattened, filled with colloid. Beginning of the hyperplasia in this specimen is evidently limited to individual follicles (Fig. 84.)

$200 \mathrm{r}$ B. Most of the thyroid tissue in this specimen is of typical normal appearance, flattened epithelium, follicles filled with stainable colloid.

$200 x$ C. The entire space surrounding the vessel is filled with closely packed alveoli, small sized alveolar structures lined with high columnar epithelium, with decoly staining vesicular nuclei. Colloid is almost entirely absent. Evidently growth of the thyroid tissue which has spread upward into the areolar tissue immediately below the mucosa of the floor of the mouth. Under high power the nuclei present great variability in size, the staining qualities are vesicular with one or two nucleoli. Marked evidence of hyperemia between the follicles. Many tubules are filled with closely packed cells. In some portions of the growth all alveolar structure has disappeared and small islands of closely packed cells are found. Infiltration of dense connective tissue structure, perichondrium and periosteum. Beginning carcinoma of tubulo-alveolar type. 
2002 B. The amount of thyroid tissue surrounding the vessels is very scarce Vesicles small, epithelium flattened, filled with stainable colloid. Normal thyroid.

2003 A. Alveoli small and lined with high columnar epithelium, deeply staining nuclei. Colloid absent. Follicles few in number and poorly staining. Occasional groups of vesicles of normal appearance. Beginning invasion of areolar tissue. Dense connective tissue structure. Growth into bone cavities. Definite alveolo-tubular ty pe beginning carcinoma.

2004 A, B, C. Space about vessels rather well flled with small-sized vesicles relatively uniform in size. Epithelium is flat. tened. Vesicles are filled with stainable colloid. In one small area close to a large vessel are a half dozen follicles in which the colloid is small in amount, the epithelium cubical. Normal thyroid.

2005 A. This is evidently one of the tumor fish introduced into this experiment. Large amount of thyroid tissue. Great variability in the size of the follicles. Large regular shaped follicles lined with flattened epithelium and filled with stainable colloid. I,arge numbers of small follicles with cubical or flattened epithelium. Varying amount of colloid. Large amount of hyaline connective tissue stroma. Obviously a tumor which has undergone regression. Tumor tissue fills the entire space around the vessel, penetrates to the floor of the mouth, and into the bone cavities. It has previously invaded and destroyed large areas of muscle. Contains numerous nematode tubercles, in which no worms are to be found. Spontaneous recovery. See further under that heading.

2005 B. Very few follicles included in this section. Flattened epithelium filled with stainable colloid. Typical vesicles. Normal.

2005 C. Evidently tumor fish introduced into this experiment with spontaneous recovery like 2005 A. Contains two nematode tubercles, in one of which remnants of a worm can be seen.

2006 A, B. Thyroid consists of typical vesicles with flattened epithelium filled with stainable colloid. Normal.

$2007 \mathrm{~A}$. Space around the large vessels contains scattered follicles filled with stainable colloid, lined for the most part with flattened epithelium. There is marked hyperemia, marked engorgement of the vessels between the follicles, and evidence of small extravasation about the follicles. A few follicles are lined with cubical epithelium. Hyperemia of the thyroid, possibly beginning hyperplasia.

2007 B. Tissue badly preserved, evidently overheated in embedding. Shows section of media of aorta around which are areas of closely packed large follicles, lined with cubical epthelium. No colloid. Beginning hyperplasia.

2008 A, B. Small follicles lined with flattened epithelium, filled with stainable colloid. Normal

$2008 \mathrm{C}$. Thyroid tissue in this fish consists of rather compact masses in the region of the large vessels. The epithelium of some follicles is slightly cubical. Follicles are filled with stainable colloid. Some evidence of hyperemia in the vessels between the follicles. Slight hyperemia of the thyroid. Probably normal.

2009 A, B. Follicles oval and spherical, lined with flattened epithelium, flled with stainable colloid. Normal.

20 ro B. Vesicles lined with flattened epithelium, filled with stainable colloid. Normal. Around the large vessels the thyroid follicles are closely packed; the colloid is reduced in amount but stains deeply. Epithelium is small, cubical. Probably normal. Thyroid tissue greatly increased in amount but of normal appearance.

20 ro C. Spherical and oval follicles lined with flattened epithelium filled with stainable colloid. Normal.

2orr A. Follicles lined with flattened epithelium, filled with stainable colloid. Between the follicles hyperemia of the vessels. Some evidence of extravasation. Hyperemia of the thyroid. Probably normal.

$201 \mathrm{r}$ B, C. Spherical and oval follicles lined with flattencd epithelium, filled with stainable colloid. Normal.

2ors B. Closely packed follicles of irregular shape with almost complete absence of colloid. Follicles lined with cubical epithelium. Small groups of detached follicles lying ontside the closely packed area lined with flattened epithelium and filled with stainable colloid. First evidences of hy perplasia. Beginning simple hyperplasia.

20 s C. Between the second and third gill arches the space is filled with loosely arranged follicles, many of which contain stainable colloid and are lined with slightly cubical epithelimin. Between the follicles, marked hy peremia and engorgement of the vessels. Away from this mass in this area of slightly altered thyroid one finds isolated typical normal follicles with deeply staining colloid and flattened epithelium. Again, about the aorta above and below it, one finds one or two aggregates of follicles with slightly cubical epithelium and evidences of hyperemia. The remainder of the thyroid tissue about the large vessels strictly normal. Hyperemia of the thyroid, possibly beginning hyperplasia. Unusual amount of thyroid tissue.

2098 A. Tumor. Typical alveolo-solid carcinoma for the most part, with areas of papillary formation. Infiltration of muscle, bone, and cartilage. Infiltration of wall of vein. Papillary adenoi-carcinoma infiltrating muscle bone and cartilage. Hyaline degeneration of the wall of the media of the aorta. (Fig. 9o.)

2098 B. Beginning adeno-carcinoma of tubulo-alveolar type. Infiltration of areolar tissue, dense connective tissue structures, periosteum of bone and muscle.

2099 A. Examination of this section shows an unusual amount of thyroid tissue about the large vessels, small follicles lined with flattened epithelium, some of them containing stainable colloid, others poorly stained colloid, many of them empty, pushed in flattened strands between the dense connective tissue structures, spreading well forward into the areolar tissue and in the adjacent bone cavities. (Fig. or.) Great increase in the amount of thyroid tissue. Only one or two large follicles filled with stainable colloid. Immediately adjacent to the large vessels a few follicles with high cubical epithelium and no colloid. The whole specimen indicates the previous existence of well-developed hyperplasia followed by regression.

2099 B, C. Presents the same histological characteristics. Increased amount of thyroid tissue. Many isolated groups widcly distant from the large vessels. About the large vessels are many tortuous elongated and brancling alveoli of tubular type, lined with flattened epithelium, free from colloid. (Fig. 92, under " Spontaneous Recovery.") Colloid almost entirely absent. 
2 rox A. Small closely-packed follicles lined with flattened and low cubical epithelium. No colloid. Marked increase in amount of thyroid tissue. Many follicles and flat strands of follicles between the muscle bundles in the areolar tissue, floor of the mouth, and bone cavities. Regression from well-developed hyperplasia.

$2 \mathrm{IO}_{3} \mathrm{~A}$. About the large vessels are individual follicles lined with columnar epithelium, filled with faintly staining colloid. These follicles are irregular in shape. Slight infoldings of the vesicular wall with beginning bud formation. Protoplasm of the cells stains deeply. The nuclei are vesicular, of great variety of size. The long axes of the nuclei are perpendicular to the circumference. Marked hyperemia of the small vessels between these follicles. In the same field by low power may be seen individual follicles of typical normal appearance, flattened epithelium filled with deeply stainable colloid. We have here beginning focal hyperplasia. Certain groups of follicles are lined with flattened epithelium, contain no colloid, are elongate, branching or irregular in shape, and present an appearance suggesting regression of individual follicles.

2104 A, B. Marked increase of thyroid. Follicles closely packed and spherical, some filled with stainable colloid. Some follicles of irregular shape or branching. Widely scattered follicles in the areolar tissue and between the fibers of the dense connective tissue structures. Regression of hyperplasia.

2 II A. Spherical and oval follicles filled with stainable colloid and lined with flattened epithelium. Engorgement of the vessels between the follicles. Slight hyperemia. Normal.

\section{CHEMOTHERAPY ${ }^{a}$}

\section{THE EFFECT OF IODINE, MERCURY, AND ARSENIC UPON CARCINOMA OF THE THYROID.}

The knowledge of the occasional effect of iodine as a remedy in goiter is almost as old as our knowledge of the disease itself. The relation of iodine to the thyroid has been the subject of extensive study by modern chemical methods and by biological experiment. It is well known that the thyroid gland normally contains iodine, and it has been contended that in certain hyperplasias of the thyroid the amount of iodine per gram weight of thyroid tissue is reduced. These facts have led experimenters to hold that the curative effects of iodine upon the hyperplastic thyroid is more due to a restoration of the iodine content to a normal basis than to the specific action of iodine administered as a remedy. In the mammalian hyperplastic thyroid there are frequently encountered small adenomata which are more or less distinct in appearance from

$a$ Themeasures to betaken by fish culturists for the prevention of thyroid carcinoma must await a careful investigation planned specifically with this end in vicw. This we have not been able to undertake. We believe, however, our experiments with wild fish point the way along which efforts should be directed.

The matter of food is undoubtedly the most important aspect of domestication in relation to thyroid disease. The livers af cattle, sheep, and hogs are chicfly relied upon in rearing the salmonoids, and the extent to which this food is varied or replaced by heart, lungs, horse flesh, and other animal proteids apparently does not alter the situation in this respect. Their availability as fish food makes it difficult to displace them, but fortunately they are not inherently necessary to fish culture. Vegetable food made from staple grains, fresh-water and marine fish and mussels, Entomostraca and other Crustacea, live maggots and even living adult insects, have bcen used more or less as foods in practical fish culture. Most of these are not yet available in quantity, and none has displaced entirely the mammalian proteids. Our feeding experiments, however, indicate that such foods would maintain normal thyroid glands in the salmonoid fishes. To devise and prove a composite ration properly balanced for this purpose would scem a fish cultural problem worth while. Perhaps a cooked mixture consisting largely of vegetable meal in which was incorporated fish flesh and a minor portion of one of the foods used commonly at present would promise best. Possibly even small quantities of insects and inscet larva added to this would be an important improvement. Such a food has ever been a prime desideratum in fish culture and affords a measure of protection against most fish diseases as well as against the one now under discussion.

Holding the disease to be an infection, the ultimate problem is largely one of prevention, under which would come a more stringent cleanliness of fish troughs and ponds, possibly the annual painting of wooden containers and in the case of dirt ponds, their occasional emptying with periods of sun-drying, or a change to cement construction. The selection and breeding of resistant strains, or of resistant species like the Scotch sea trout, are obviously indicated.

As for the presumption, which experiments indicate, of remedial possibilities in the use of mercury or iodine, there is no sufficient basis at present for recommending their use on a practical scale. This would involve their administration over considerable periods of time which their cumulative action might render undesirable. Moreover, that they are absolute preventives of the disease process under discussion is not yet demonstrated. The control of this disease can doubtless be brought about by other means than administration of chemical agents. To this end a fish-cultural station handling preferably the brook trout could well be devoted to the extended experiments having to do with feeding and the access of infection to the fish which are necessary both to more exact knowledge of the disease and to its practical relations. 
the surrounding hyperplastic tissue and have been looked upon as developing from embryonic rests, especially rests of the original tubular structure of the fetal gland. From these adenomata the malignant neoplasms of the thyroid are supposed to take their origin.

Marine and Lenhart (1910b, p. 20; 191 1a, p. 22), who have extensively studied the effect of iodine upon the mammalian thyroid, have advanced the theory that hyperplasias of the thyroid including endemic goiter are due to insufficiency of iodine in the diet of the individuals and that the therapeutic effects of iodine are the result of restoring to the thyroid the normal amount of iodine. They state that nodular struma or the adenomas found in strumous thyroids are unaffected by iodine, and that malignant tumors are unaffected by iodine, and they propose that the administration of iodine shall constitute a biological test for the purpose of distinguishing between hyperplasias which they hold to be due to a physiological deficiency of iodine and malignant tumors which they state can not be affected in this way. The evidence of the microscope is no longer to be considered; the final test is to be whether or not a given enlargement of the thyroid responds to iodine. It is obvious that such a test as Marine and Lenhart have proposed is not applicable to malignant tumors other than the thyroid, as it has long been known in experimental cancer research that transplantable mouse cancer is definitely influenced in its growth by many chemical compounds (Clowes, 1908), particularly the heavy metals.

Schoene (1910) showed that for a time regression of advanced implanted mouse cancer could be induced by the intraperitoneal injection of iodine and mercury in the form of $\mathrm{KI}$ and $\mathrm{HgCl}_{2}$. He found the effect of mercury to be much more marked than that of iodine. It was thus known that iodine had an inhibitory effect upon genuine neoplasms and it therefore seemed possible that the action of iodine upon the proliferating thyroid might be due to some specific action upon the tissue, such as these experiments of Schoene's indicated the agent possessed for genuine neoplasms of other organs. Marine and Lenhart reported in 1910 that fish suffering with hyperplasia of the thyroid were favorably affected by adding iodine in the form of Lugol's solution to the water in the troughs in which they were kept, and from these observations applying the theory above stated, concluded that the so-called carcinoma of the thyroid in the Salmonidæ was not carcinoma but simple hyperplasia, distinguishable from true neoplasms by the favorable effect of iodine upon the tissue. The remarkable infiltrative character of these neoplasms, so well described by Scott, Plehn, and Pick, and reported in our first preliminary reports, Marine explains as due to the absence of a capsule. This feature of the case we have dealt with under the appropriate heading and it need not be again referred to here.

The results of Marine and Lenhart in causing regression or, as they term it, involution or reversion, of the hyperplastic thyroid in the Salmonidæ by the administration of iodine through the water, we have been able to confirm. In order to determine whether the action of the iodine was peculiar to this element and might therefore be looked upon as acting upon the thyroid by virtue of its physiological relation to this organ, in repeating the experiments of Marine and Lenhart we decided to control them 
by treating under exactly the same conditions comparable fish with mercury in the form of $\mathrm{HgCl}_{2}$. This gave the further advantage that if mercury should prove to have a similar effect upon the thyroid to that determined by Marine and Lenhart for iodine, the relation of these growths of the thyroid to one of the heavy metals might be determined, mercury already having been shown to have an inhibitory and regressive effect upon genuine neoplasms. The experiments were carried out in the summer of igro with the result, as may be seen by the accompanying tables, that mercury was found to have an effect upon the growing thyroid of the Salmonidæ indistinguishable from that obtained with iodine, with the exception that mercury appeared to produce these results more certainly and more rapidly than did iodine. To further amplify the
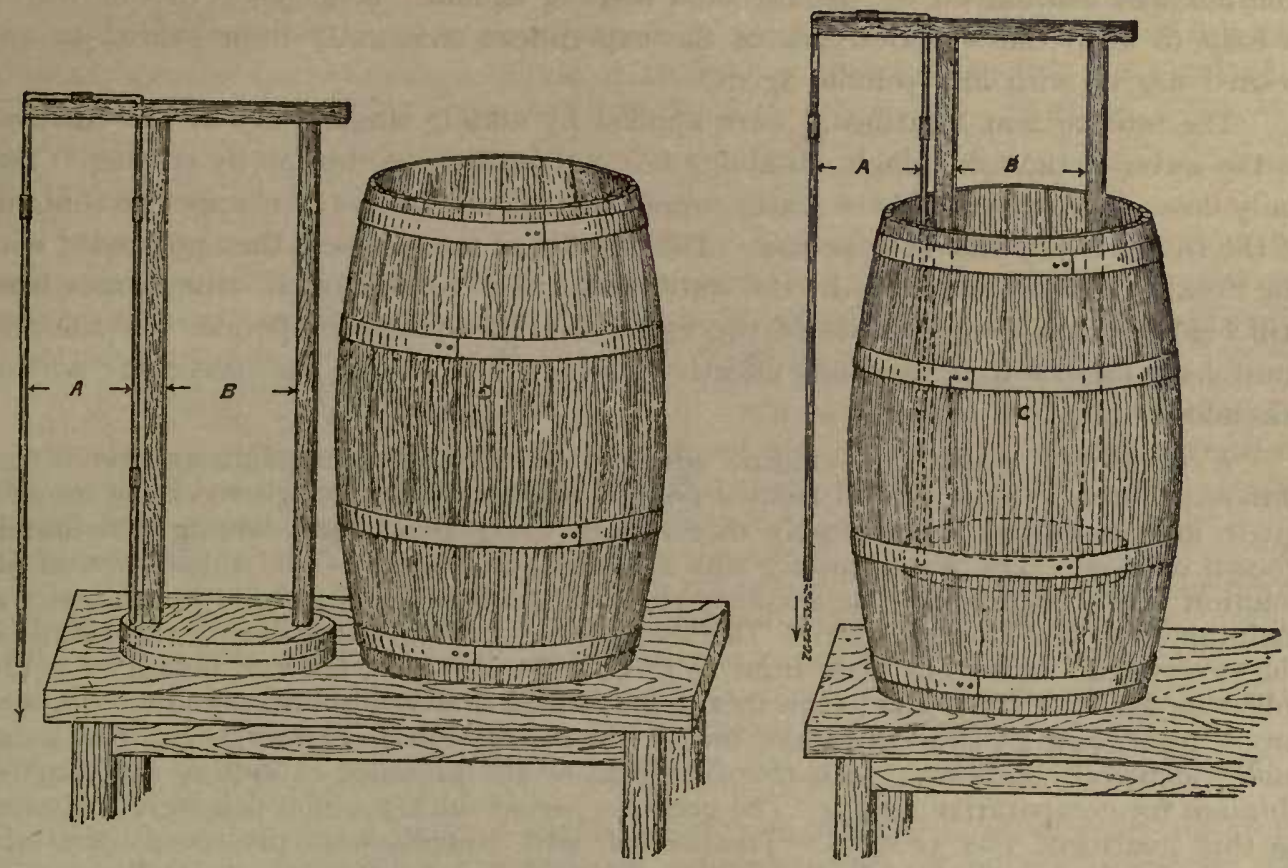

FIG. 95.-Floating siphon. $A$ is the siphon, $B$ the frame, and $C$ the container. The form of the frame is of course not essential, and should be adapted to the container. The illustrations show the glass tubing of much larger size than is necessary or practicable in small siphons. Small tubing is preferable.

comparison, during the summer of I9I experiments with arsenic, an element long known to have a favorable influence upon genuine neoplasms, were carried out, using arsenic in the form of $\mathrm{As}_{2} \mathrm{O}_{5}$. These results are also sufficiently set forth in the tables.

Experiments were begun by determining the toxicity of the iodine to trout when added to the water in the form of the pure element already dissolved in distilled water and then added to the dissolved potassium salt. The uncombined iodine is much more toxic than the potassium iodide. Lake trout fry were killed in less than 20 hours by one part of free iodine added to 400,000 parts of tap water. Dilutions of 1 to $1,000,000$ are safe, perhaps because the iodine is combined before it has time to produce a fatal 
result. At I to 600,000 brook trout yearlings were not killed during three days, but the effect of iodine was seen in coagulating the slime on the bodies of the fish.

In the form of potassium iodide, I part of iodine in 25,000 parts of tap water killed brook trout fry in two to six hours, but $I$ to 50,000 was harmless during a trial of two weeks. Lake trout fry were urinjured by dilutions of $\mathrm{I}$ to 200,000 and weaker.

The administration of the chemical agents has been accomplished in several different ways and in various dilutions. The constant uniform dilutions were maintained by running a solution of known strength continuously into the fish troughs with the measured water inflow at the head of the trough, an intimate mixture being insured. A barrel was used as a receptacle for the solution and a constant head for the flow of solution was maintained by the use of a floating siphon. (Fig. 95.) In this way it is easy to keep the water supply of the experiment constantly impregnated to any desired degree with any soluble agent.

The intermittent treatments were applied by adding single doses of the chemical to the water of the fish trough, obtaining fairly complete distribution by stirring. Two daily doses were given, and the water supply was so adjusted as to change the contents of the trough every four-hour period. The dilution of the chemical then proceeded with the flushing out of the trough by the water flow. The corners of the trough may have still held appreciable quantities of the agent after the four-hour period, but the flow must have diluted it beyond any effective strength long before the succeeding portion was added.

Experiment $\mathrm{I}$ (table Ix).--Iodine administered as potassium iodide and given continuously under constant head from a floating siphon into a trough receiving an adequate and measured water supply direct from Craig Brook and having a definitely known outflow. The water supply was 24 liters per minute. The siphon flow of KI solution was so regulated that a constant concentration of iodine of $1: 5,000,000$ was maintained in the flowing water. The temperature of the water during the course of the experiment varied but little from $19.5^{\circ} \mathrm{C}$. The fish were fed raw beef liver. The following fish were subjected to this treatment: Three tumored hybrid salmon, 6 tumored brook trout, and 15 clinically clean brook trout. An equal number of controls living under identical conditions, with the exception of the presence of iodine, were carried through for comparative study. The greatest period during which fish were subjected to this treatment was 31 days. Treated fish and controls were preserved for study, however, at frequent intervals during the course of the experiment. A brief statement of results is given in table IX. This is self-explanatory. (Fig. 96, 97, 98, 99, 100, I01.)

Experiment 2 (table $\mathrm{x}$ ). - Similar in all respects to experiment $\mathrm{r}$, except for the concentration of iodine, which was much greater, being $1: 300,000$. The fish were fed raw beef liver. The fish subjected to the treatment were as follows: Four clinically clean brook trout, 5 brook trout with pharyngeal discoloration (red floor), and 6 brook trout with various tumors. Parallel controls for all these fish were also studied. The longest period of treatment in this experiment was 17 days. Macroscopic evidence of regression was furnished in some of the red floors and in some of the tumor fish as shown by the disappearance of pharyngeal reddening and reduction of tumor measurement. The results of microscopic study of these specimens, together with their controls, are given in table $\mathrm{x}$.

Experiment 3 (table $\mathrm{xI}$ ). - In this experiment iodine was administered intermittently as potassium iodide, the greatest concentration of iodine in the water at any one 
time being $1: 32,000,000$ parts. From this strength dilution rapidly occurred, reaching infinity in about four hours, the time required for the replacement of the water contents of the trough containing the fish experimented upon. The iodine was administered twice daily, morning and evening, so that there were long periods during which the fish received no iodine. The temperature of the water remained quite constant at $19.5^{\circ} \mathrm{C}$. These fish were fed raw beef liver. The longest period of administration was 30 days. The fish employed were ${ }_{5} 5$ clinically clean brook trout yearlings and 5 small tumor brook trout yearlings. No special controls were employed for this experiment, comparisons being made with the controls for the previous iodine experiment. Here again some macroscopic evidence of regression was furnished by diminution in size of tumors. A brief résumé of the microscopic study is given in table XI.

Experiment 4.-A small number of fish were tested for the toxicity of iodine administered as Lugol's solution into the stomach, and it was found that yearling trout will endure as much as I to $5 \mathrm{mg}$. and adult trout as much as ro $\mathrm{mg}$. A number of fish were treated, some of them during a period of 21 days, with injections into the stomach of Lugol's solution containing from $1.16 \mathrm{mg}$. to $3.75 \mathrm{mg}$. iodine. Some of these died, probably through the cumulative effect of the iodine. Definite reduction of tumors was observed. Microscopic evidence of regression, although in the main not as marked as that occurring in other methods of treatment, is nevertheless definite.

Experiment 5, showing the influence of mercury (table XII). This experiment is comparable with experiment I showing the effect of iodine administration. Mercury was administered as $\mathrm{HgCl}_{2}$, under constant flow, in a dilution of $\mathrm{I}: 5,000,000$ of mercury. The following fish were subjected to this treatment: Fifteen clinically clean yearling brook trout, 5 brook trout showing red floors, and 3 brook trout with tumors. Parallel controls receiving no mercury were employed. Fish were killed and preserved at frequent intervals, the longest duration of treatment being 30 days. The experiment was begun August I3, 1910. The temperature of the water was $20^{\circ} \mathrm{C}$.; feeding, the same as for other experiments. Here, also, macroscopic evidence of regression was furnished by clearing up of red floors and diminution in size of tumors, and in the almost complete clinical disappearance of a tumor $7^{1 / 2} \mathrm{~mm}$. in diameter. A brief summary of the results of microscopic study is given in table xrr. (Fig. 102, 103, 104, 105, 107, 108.) Three days is insufficient to affect tumors. In one case, however, after three days in I $: 5,000,000$ the fish was placed in $\mathrm{I}: 300,000$ and was killed by the mercury in three and one-half hours. The epithelium showed great reduction. (Fig. 106.) Another after three days in $\mathrm{I}: 5,000,000$ and $2.75 \mathrm{mg}$. of $\mathrm{HgCl}_{2}$ introduced into the stomach on the second day showed no reduction.

Experiment 6 (table $\mathrm{xIII}$ ). - Intermittent administration of mercury as $\mathrm{HgCl}_{2}$; camparable to experiment 3 (intermittent administration of iodine). Mercuric chloride was introduced into the water of the trough containing the fish experimented upon in such quantity as to make a solution, for the moment, representing 1 part of mercury in $38,600,000$ parts of water. This was done twice daily, at $10 \mathrm{a} . \mathrm{m}$. and $4 \mathrm{p}$. m. The dilution was estimated to have reached infinity in four hours. Five tumored brook trout and io clinically clean landlocked salmon were subjected to this treatment for periods of 15,31 , and 43 days.

With this high dilution of mercury, even at the end of 43 days there was no definite macroscopic evidence of reduction in size of any of the tumors. The histologic study of the 15 fish of this experiment, together with I tumor and I clinically clean control, appear briefly summarized in table xrrr. Of the 15 fish subjected to treatment, 5 show distinct evidence of regression, either in thyroid hyperplasia or tumor; 2 show slight regression; 2 are doubtful; and 3 show no evidence of change. 
The results, therefore, from mercury in such high dilution and given intermittently, are less marked than with the high iodine dilutions and the less dilute mercury and arsenic. Nevertheless, as compared with controls, even given in these extremely small quantities, there is an undoubted effect from the mercury.

Experiment 7 (table xrv). - Arsenic administered in continuous flow, as $\mathrm{As}_{2} \mathrm{O}_{5}$, delivered constantly, drop by drop from floating siphon, making a dilution equivalent to I part of arsenic in 300,000 parts of water.

Five clinically clean landlocked salmon and five tumored trout were subjected to this treatment. On the fourteenth day of the experiment the following fish were killed and preserved for microscopic examination: One with throat tumor, one with a throat and mouth tumor, and two clinically clean. In addition, two controls, one tumored and one clinically clean, were preserved for comparison.

At the end of the twenty-second day the experiment was discontinued and the remaining fish preserved. These consisted of three originally clean landlocked salmon and three originally tumored brook trout. Of the latter, there was only one visible tumor left and that greatly reduced in size. In another a red floor was the only visible sign of what was originally a fair sized tumor. (Fig. 109.) In a third there was no macroscopic evidence of the former tumor.

Microscopically all the thyroids of the fish subjected to treatment showed distinct evidence of regression. This was most marked in the fish in which treatment had been continued for 22 days. The controls, on the other hand, had undergone no regression. The results of microscopic study are briefly outlined in table XIV.

During the winter of 19 ro, in order to determine whether the results obtained by the administration of thymol in endemic goiter by McCarrison could be duplicated by the administration of this drug through the medium of the water upon fish with carcinoma of the thyroid, the following experiments were carried out: Thymol at I part to 500,000 of water, dissolved by the aid of heat maintained constantly in flowing water for 34 days, was without recognizable effect macroscopically or microscopically upon either visible tumors or the early stage. The temperature of the water ranged from $2^{\circ}$ to $3^{\circ} \mathrm{C}$. A brook trout yearling was killed between the second and third day by thymol at I to 200,000 , indicating that solution of the thymol in the water was attained.

Generally speaking, iodine, mercury, and arsenic produce changes in the proliferating thyroid tissue, both in the early and advanced stages of carcinoma of the thyroid, which are scarcely distinguishable from the changes found in spontaneous recovery. In the early stages the change consists in a reversion of the columnar epithelium to the flattened form, return of stainable colloid, disappearance of hyperemia, and the partial disappearance of the most remote extensions of follicles in the outlying tissues. Where regression occurs rapidly in large tumors the first evidences of regression are found in extensive hemorrhages into the substance of the tumor; in some instances extensive areas of the tumor are the seat of hemorrhage. Such hemorrhages are organized by connective tissue. (See fig. Ior.) The high columnar epithelium, especially in the peripheral portions of the tumor, are changed to flattened and atrophic cells with greatly diminished protoplasm. The retrograde changes are most marked at the periphery, and the entire picture is like that described under spontaneous recovery, except that the process seems to be more rapid and more extensive under treatment with netals. The effect of the metals, particularly mercury, is found as soon as the eighth 
day, and in one instance where a fish with a large tumor (fish I 136 of table XII, fig. 108) was subjected to mercury by immersion for three and one-half hours in water containing a much higher concentration than usual, by which it was apparently poisoned and promptly died, the changes in the tumor were comparable to results obtained only by an exhibition of mercury at $1: 5,000,000$ during a period of not less than 20 days.

Since the experiments above referred to were completed, our knowledge of the action of the heavy metals upon carcinoma in experimental animals has been amplified by the experiments of von Wassermann, who has shown that the intravenous injection of selenium in combination with eosin, when given in large doses, is capable of causing the complete regression of large implanted mouse cancers, followed by clinical cure. In considering the results obtained by ourselves in carcinoma of the thyroid in the Salmonidæ, showing the pronounced effect of iodine, arsenic, and mercury, it became evident to us, after the publication of von Wassermann's results obtained with selenium, that it was highly probable that suitable compounds of any of the heavy metals would prove to have a more or less distinctive effect upon neoplasms. That this is the case is now shown by the publication of Neuberg, Caspari, and Löhe (1912) and the results obtained by the use of colloidal metals by Szécsi (1912), and the favorable, although temporary results obtained by the French observers in the use of colloidal copper in human carcinoma.

All of these experiments, as did the original observations of Schoene, dealt with large doses, in many instances almost a fatal dose of these metallic compounds given intravenously. Lewin ( 1913 ) has recently pointed out that where immediate results are obtained with metals, there is evidence of marked hemorrhage into the tumor, and believes that they are able to affect the tumor by their ability to injure the capillary terminals, this explaining the hemorrhage. Although in our experiments arsenic and mercury were used in very great dilution, we have the same evidence of hemorrhage into the tumors, especially the large ones that are obtained by injecting much larger doses intravenously in animals. It seems highly probable that the results obtained with this great dilution are due to a cumulative action of the metal. It is, however, clear that the results obtained in our experiments are of the same nature as those obtained in neoplasms of experimental animals by intravenous injection. (Gaylord, 1912 a.)

It seems assured that the action of iodine upon the tumors of the thyroid in the Salmonidæ is not due to its physiological relation to the thyroid gland; that its curative qualities are equally possessed by other elements, including the heavy metals, and that it acts by virtue of some quality which it shares in common with the metals; that these metals exhibit the same effect upon true neoplasms in mammals and that the effect of iodine and metals upon the tumors of the thyroid in the Salmonidæ tends to prove their true neoplastic nature, and that the theory of Marine and Lenhart that the action of iodine may be used to distinguish between physiological hyperplasia and true tumor formation is untenable. 


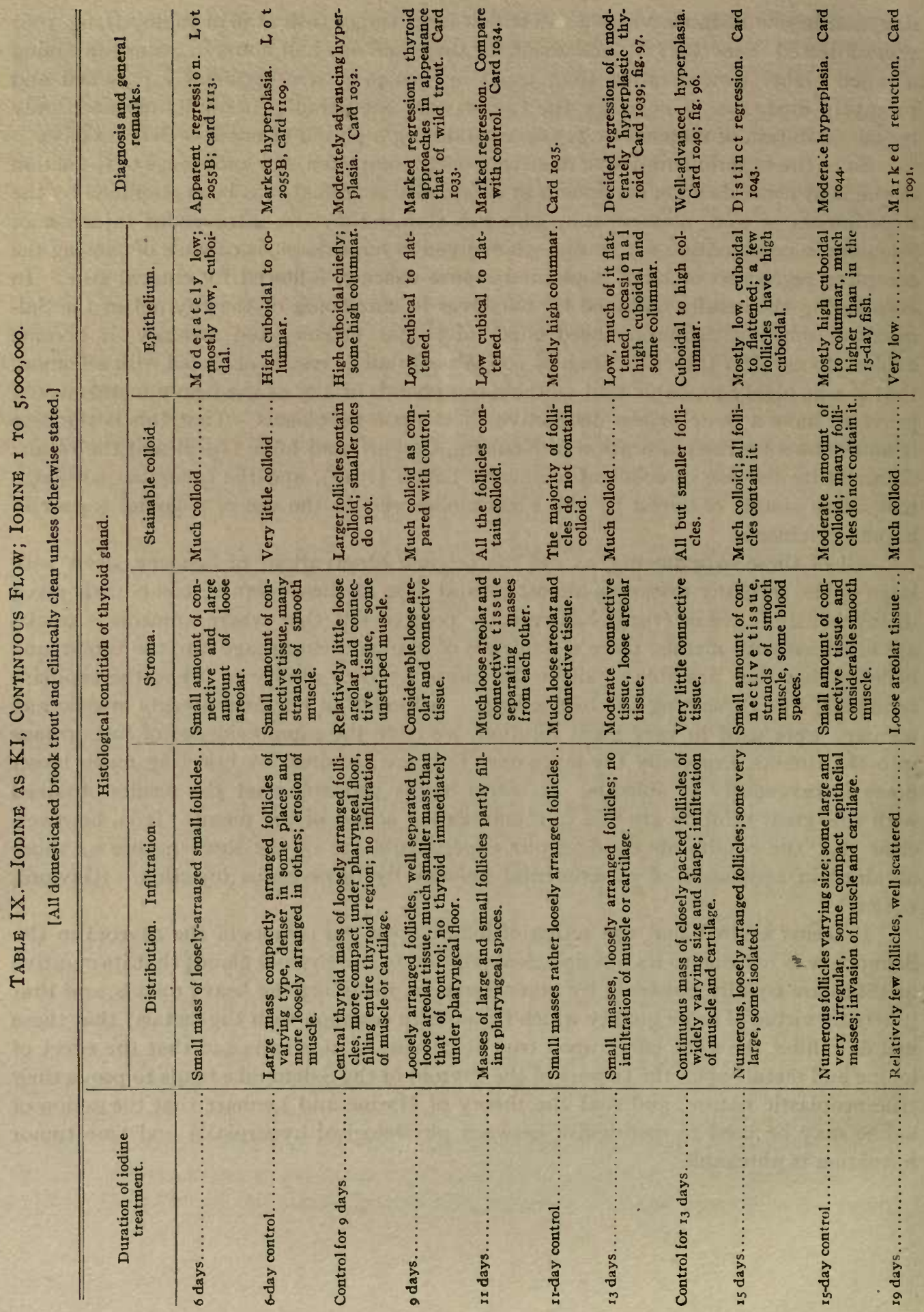


CARCINOMA OF THE THYROID IN SALMONOID FISHES.

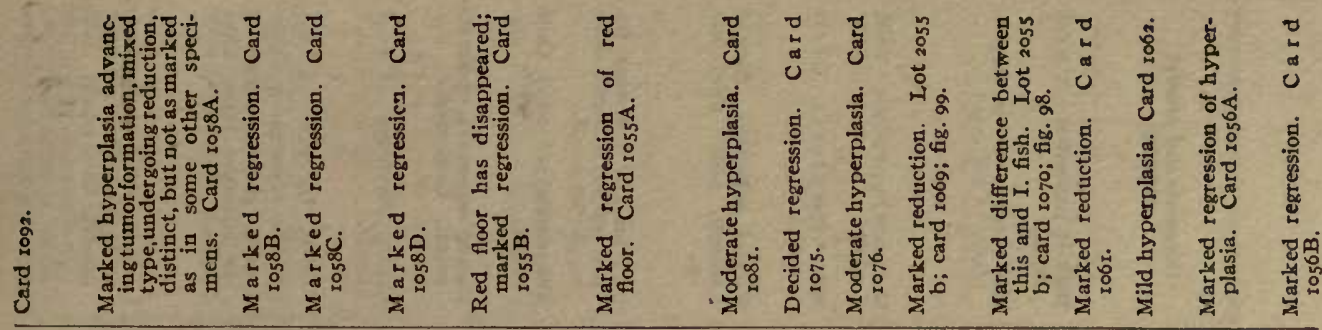

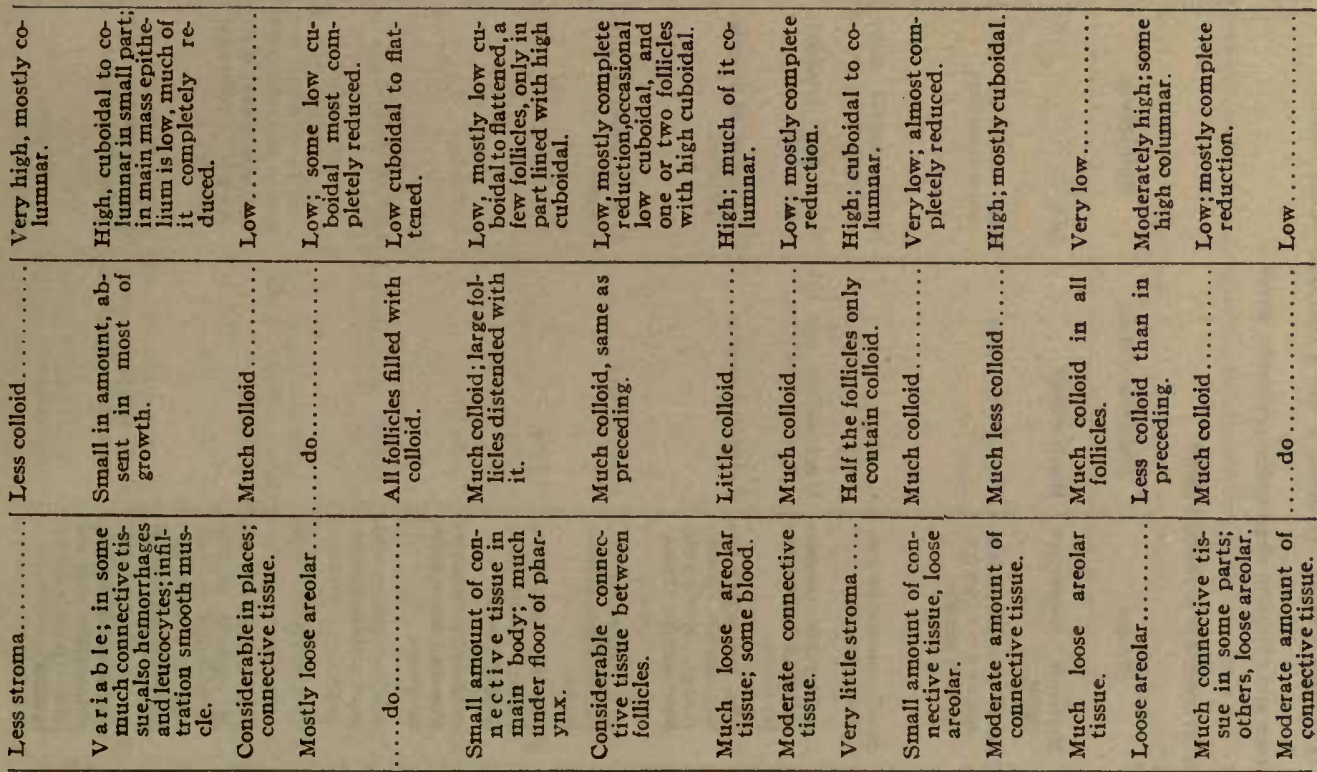

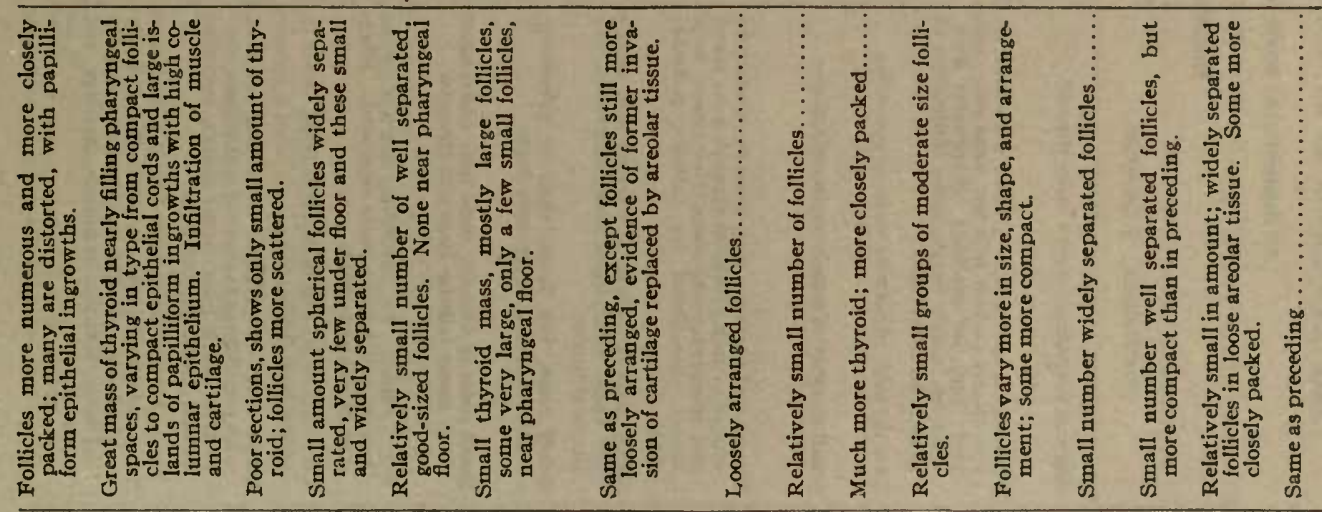

$\frac{1}{2}$

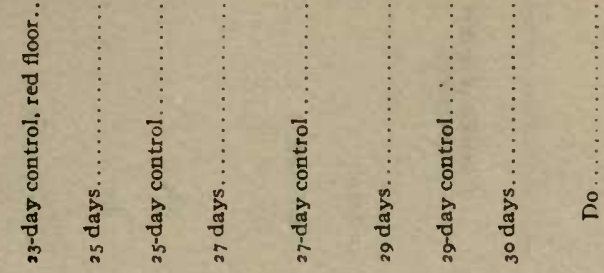




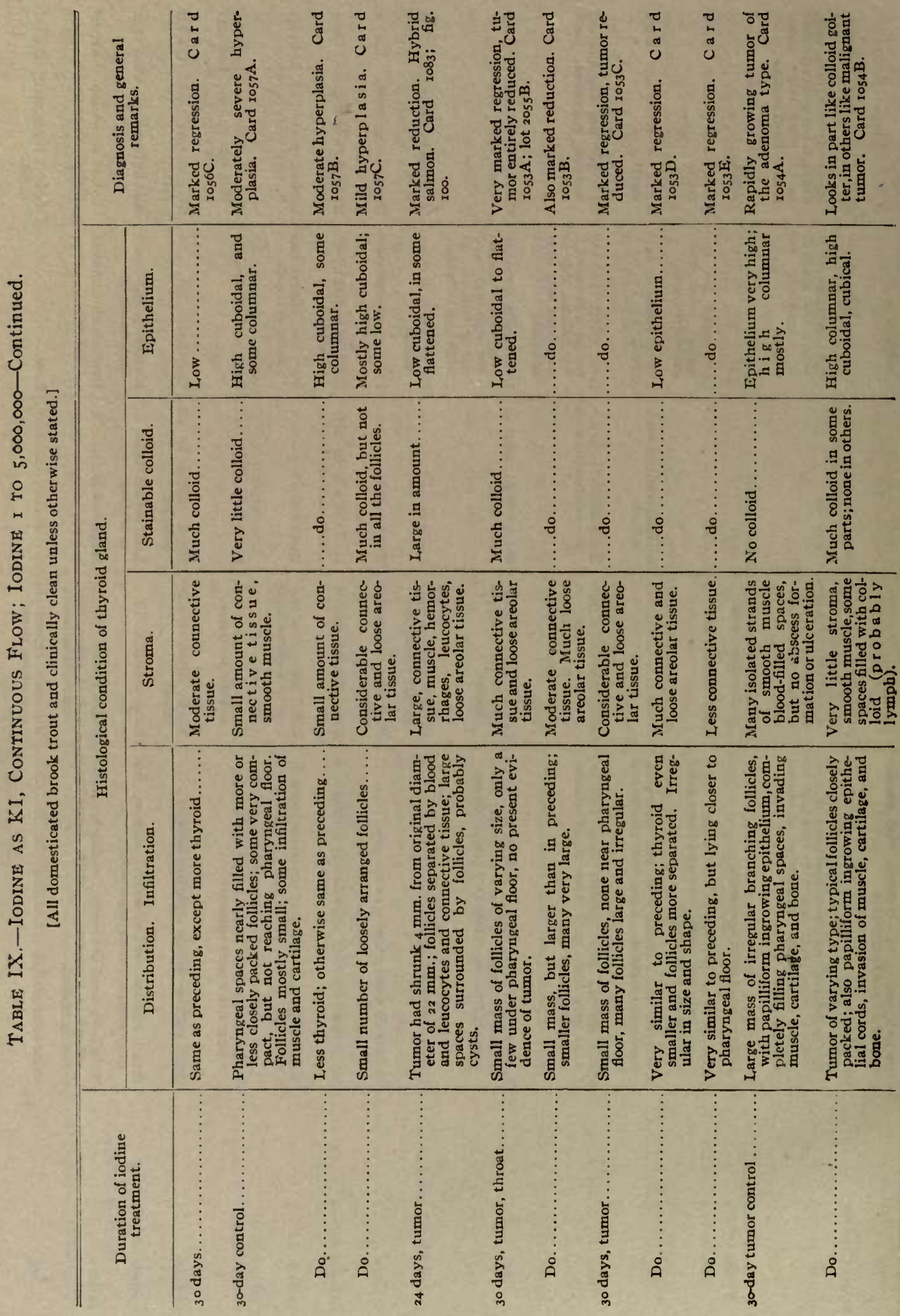


CARCINOMA OF THE THYROID IN SALMONOID FISHES.

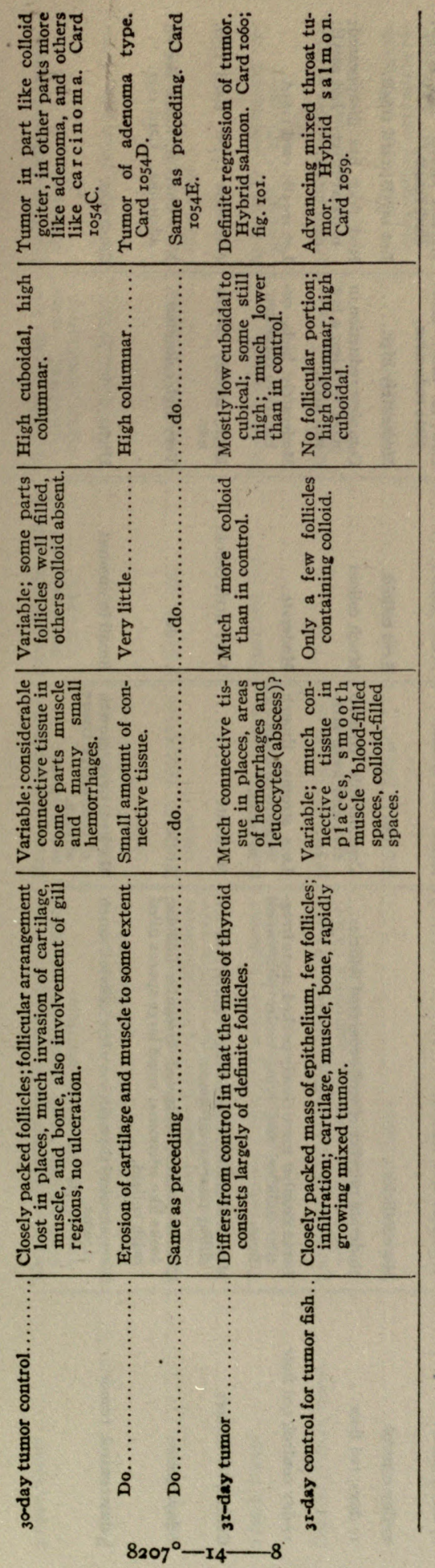


BULLETIN UF THE BUREAU OF FISHERIES.

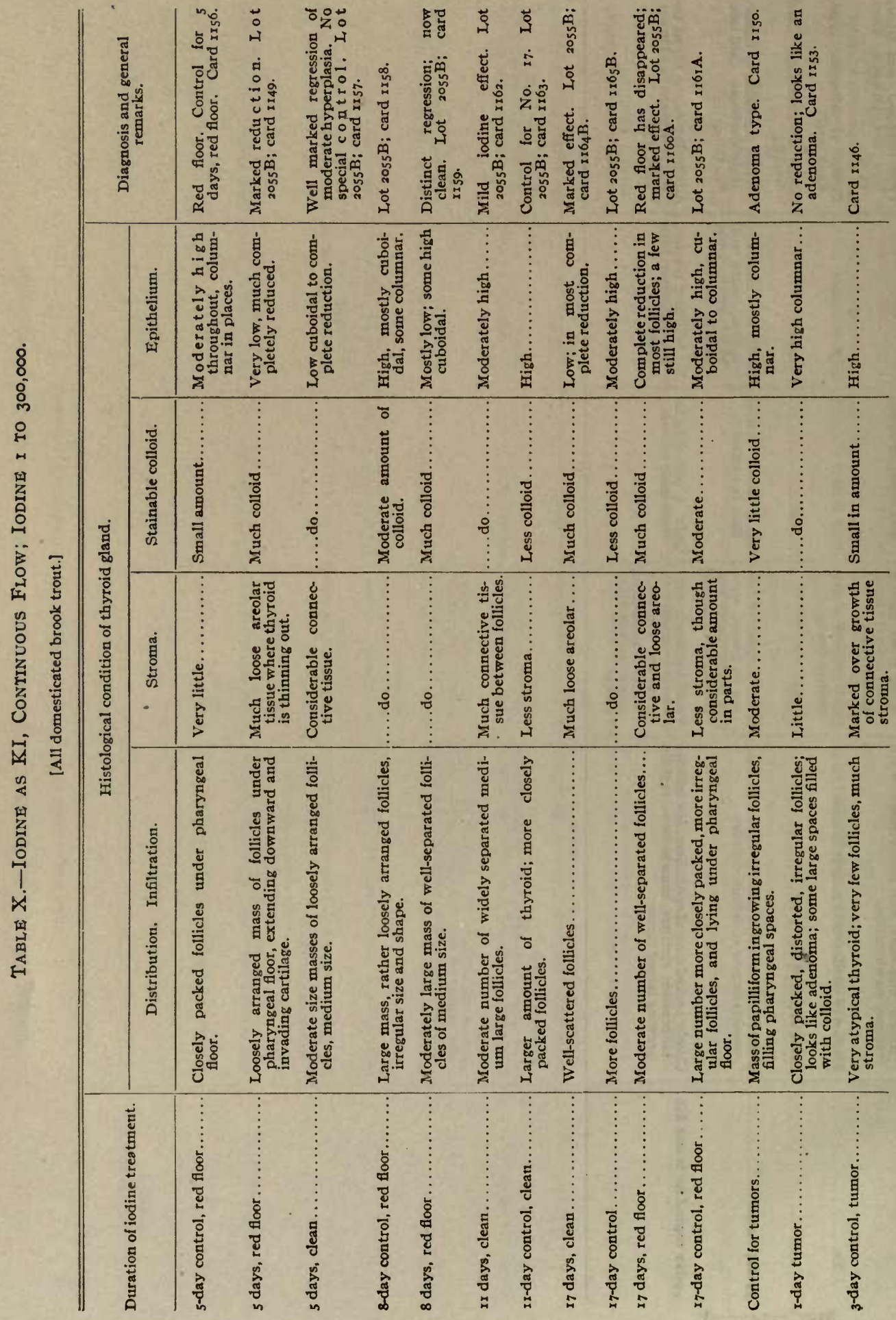



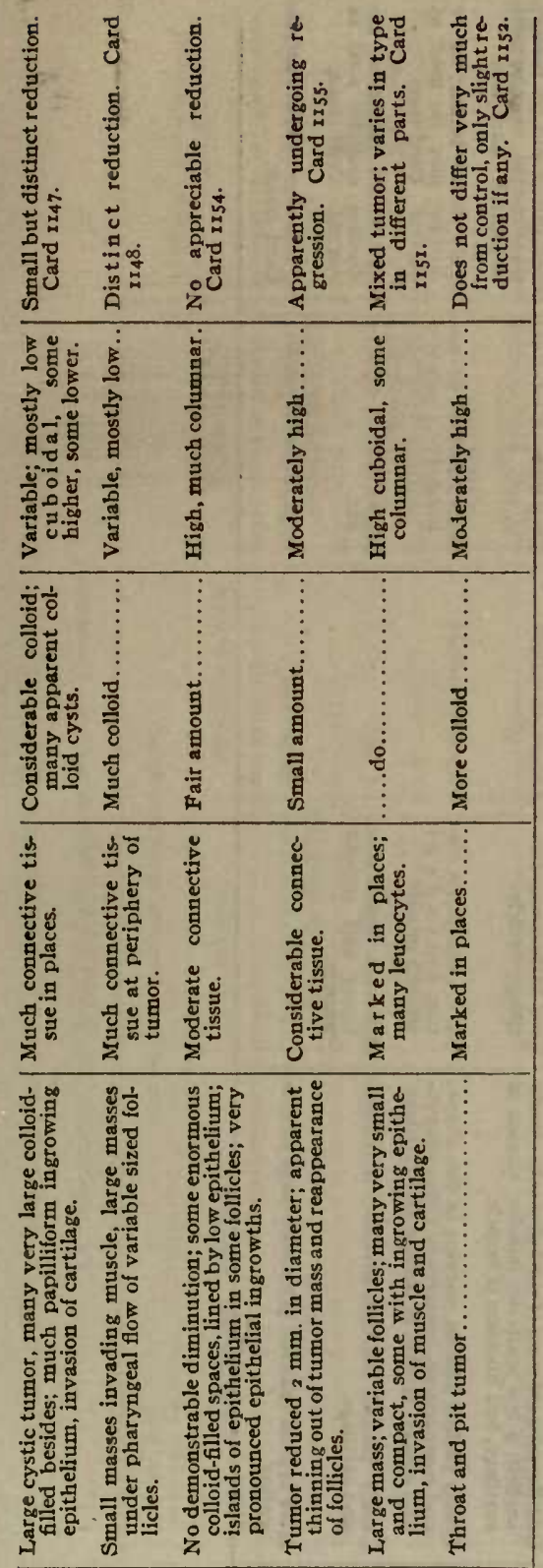

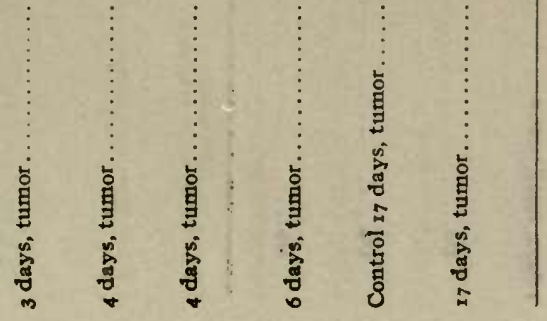




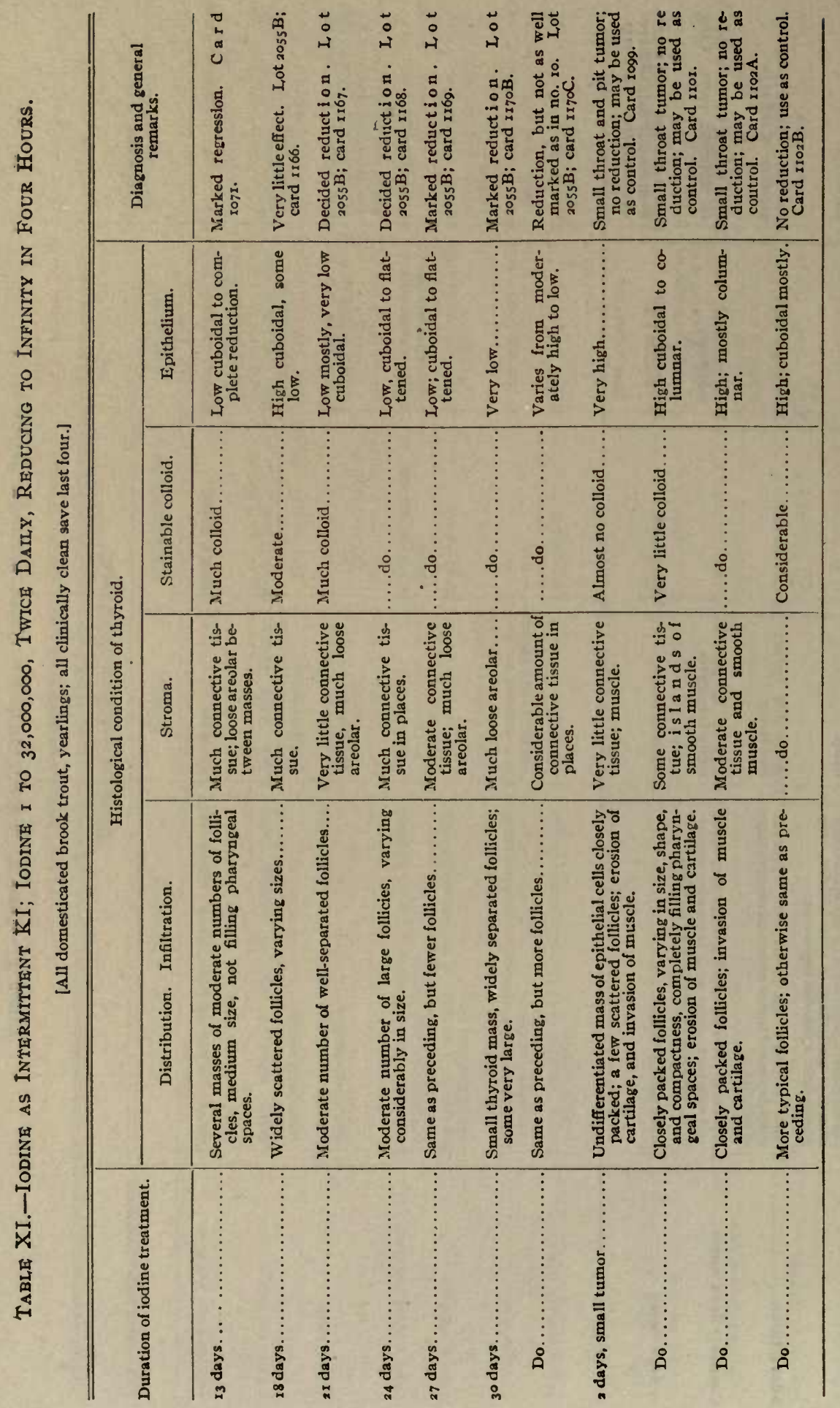


CARCINOMA OF THE THYROID IN SALMONOID FISHES.

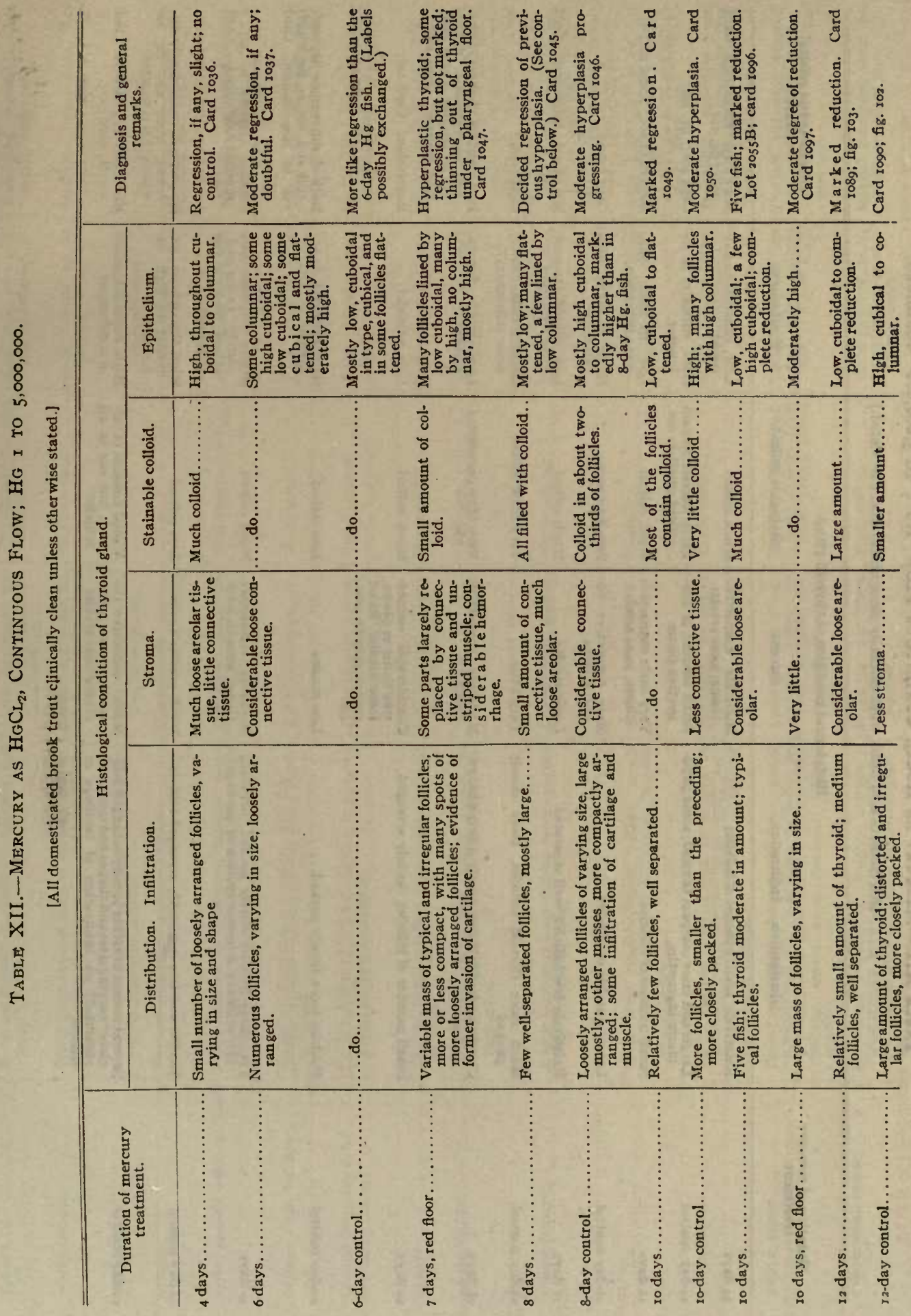


BULLETIN OF THE BUREAU OF FISHERIES.

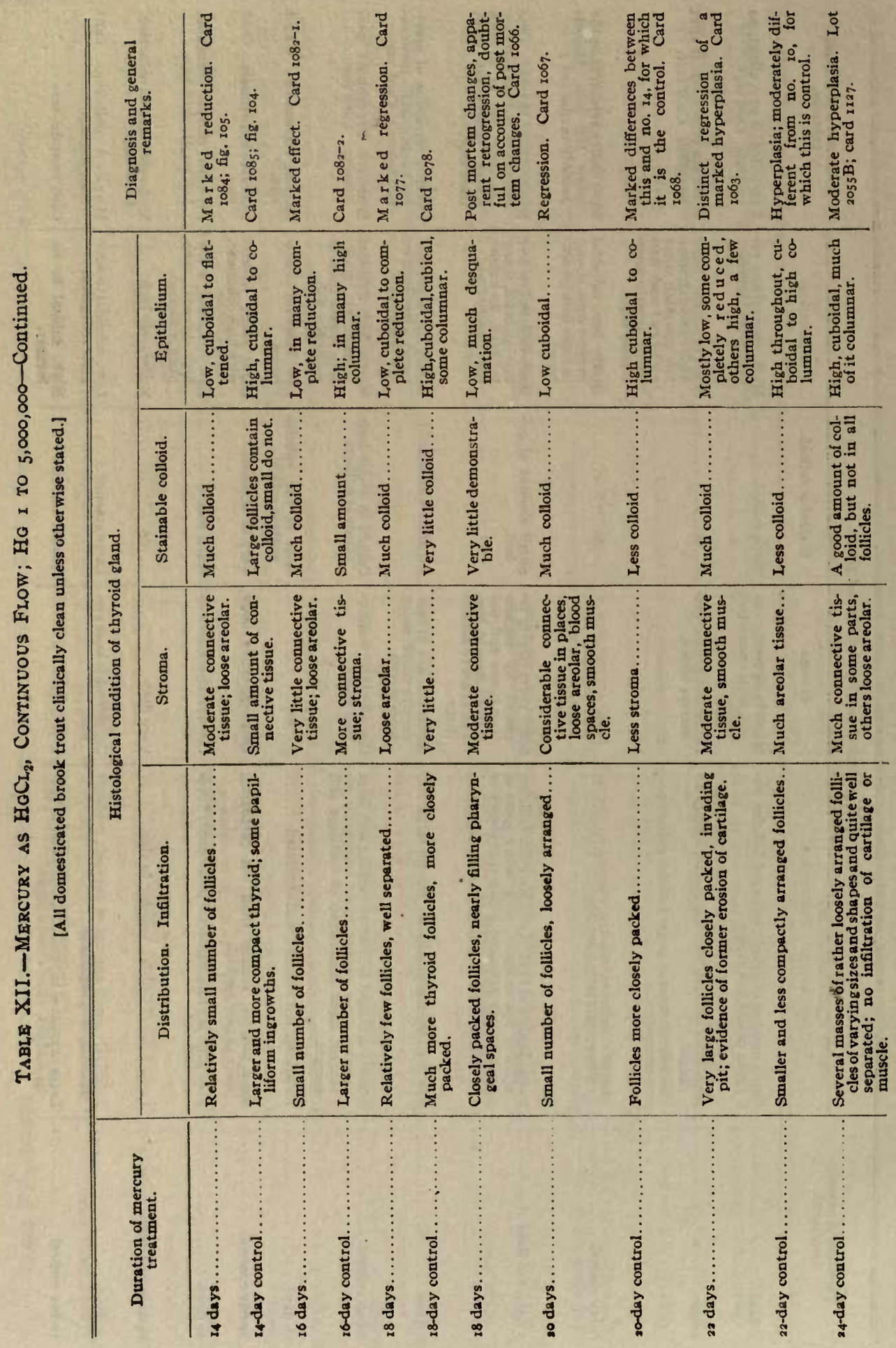


CARCINOMA OF THE THYROID IN SALMONOID FISHES.

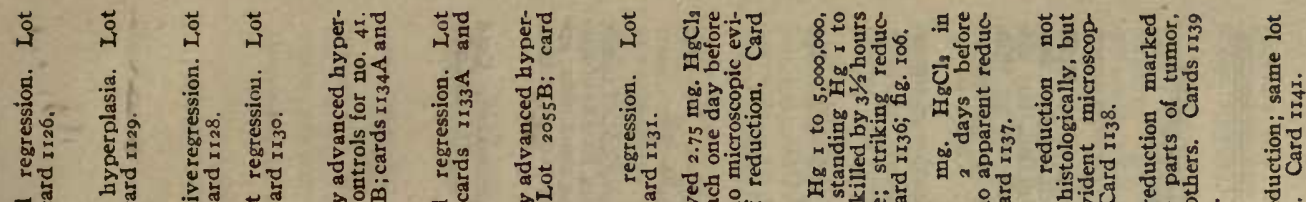

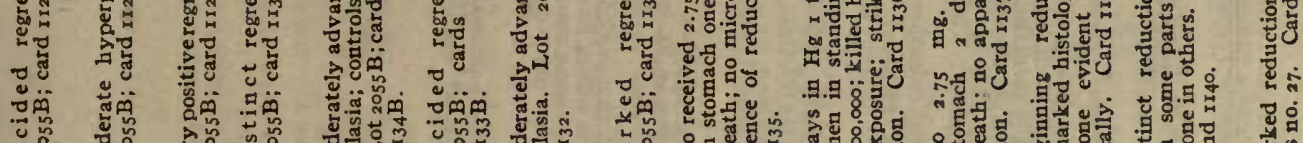

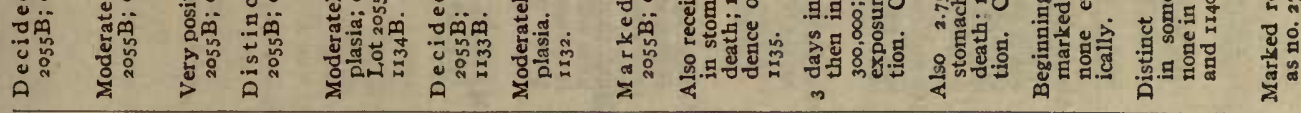

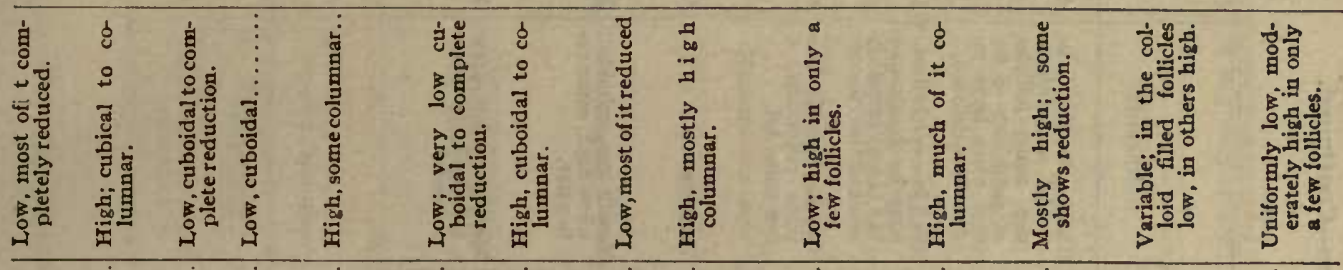

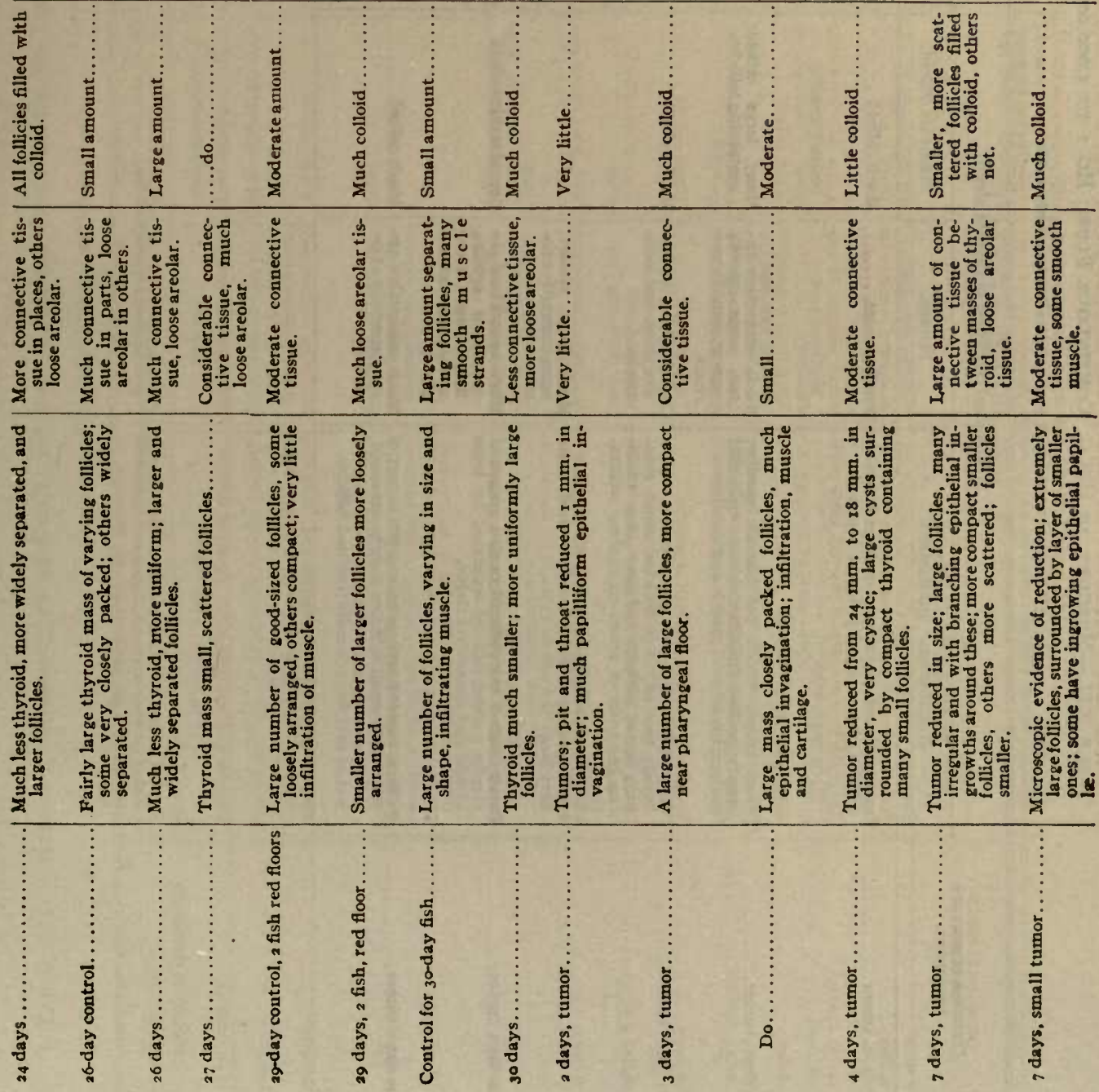


BULLETIN OF THE BUREAU OF FISHERIES.

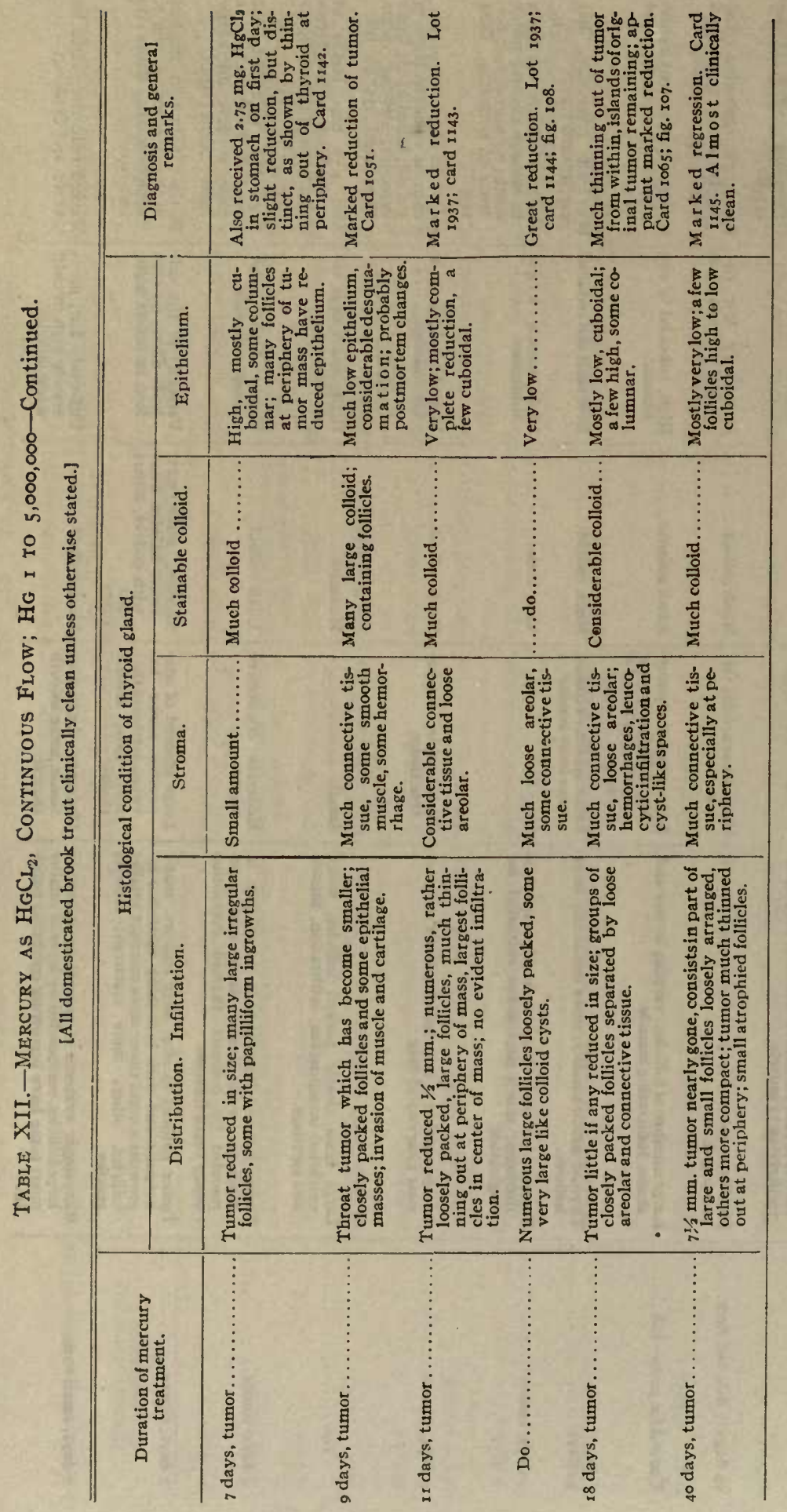


CARCINOMA OF THE THYROID IN SALMONOID FISHES.

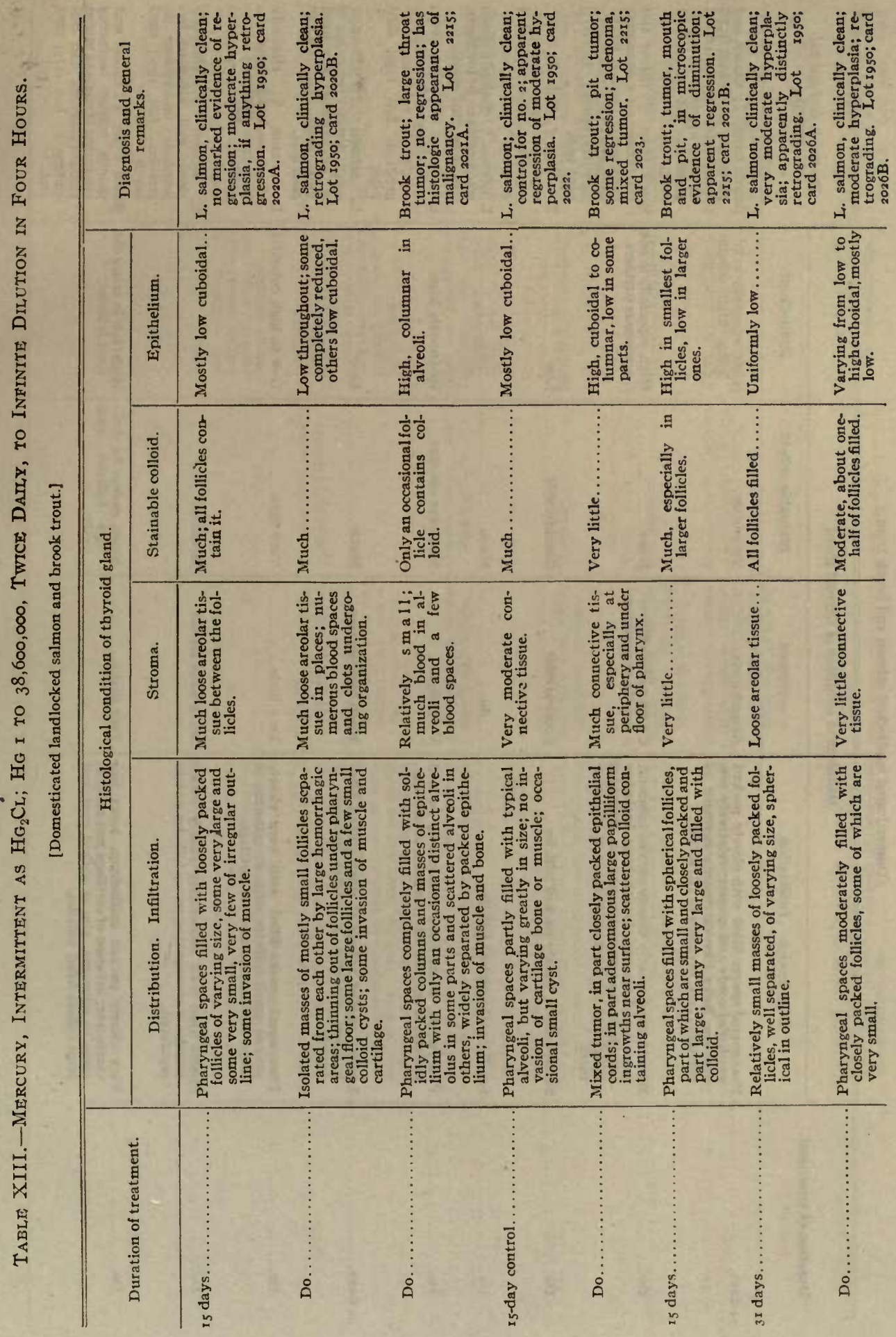


BULLETIN OF THE BUREAU OF FISHERIES.

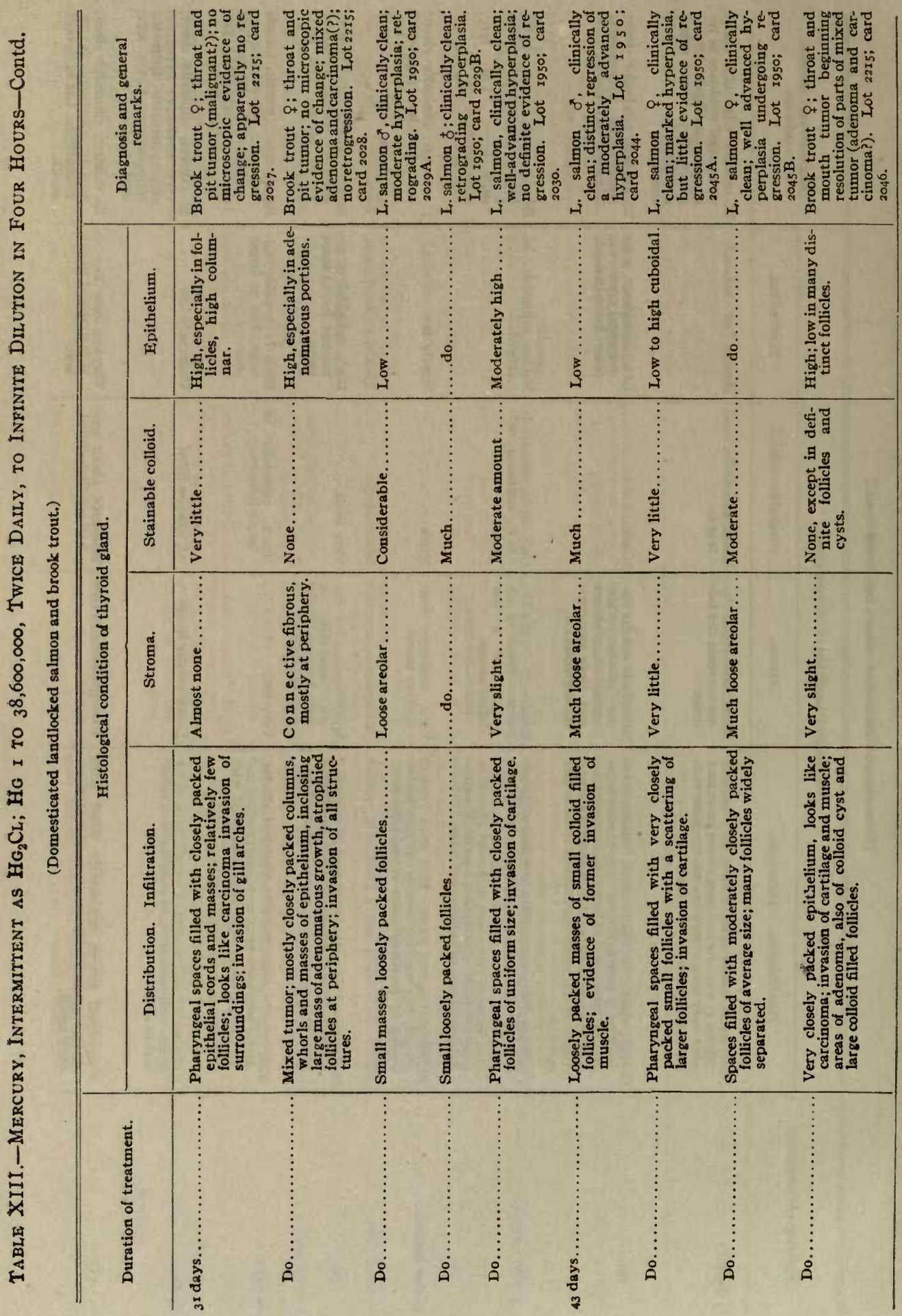


CARCINOMA OF THE THYROID IN SALMONOID FISHES.

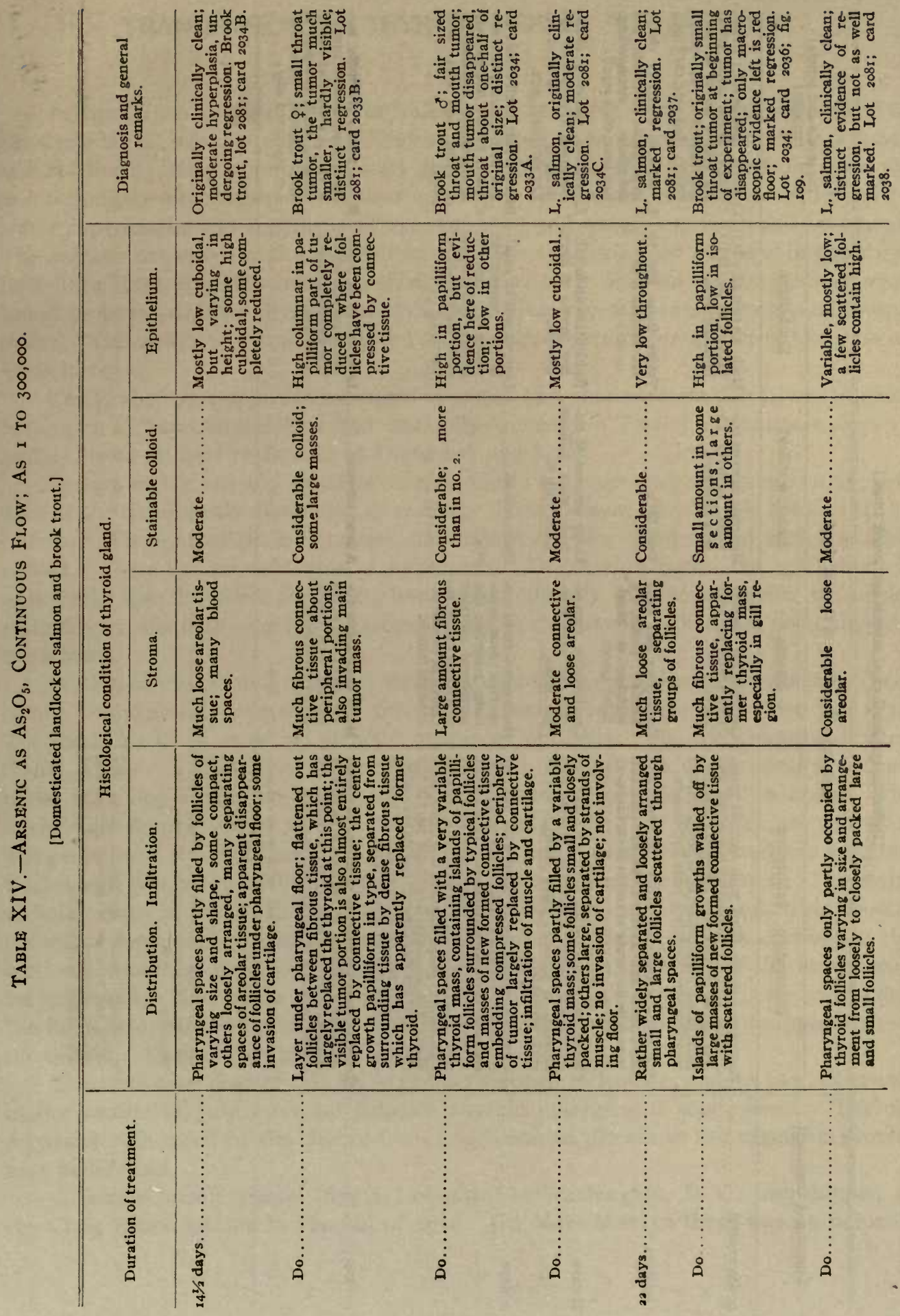




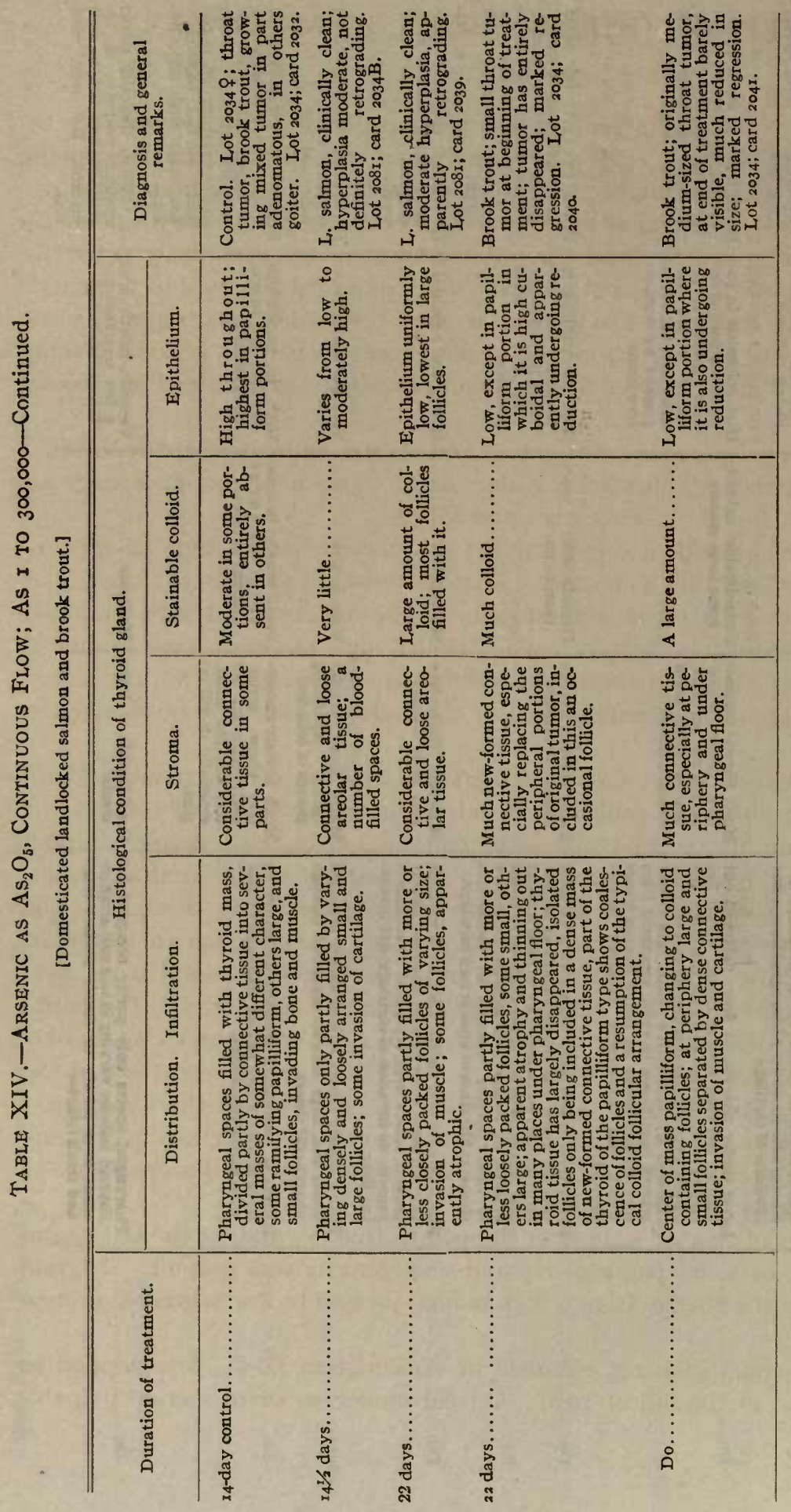




\section{TRANSMISSION OF THYROID DISEASE TO MAMMALS.}

DOGS.

In June, 1910, a dog obtained in Buffalo, and her litter of six young, were taken to the Craig Brook station in Maine. They were placed in an inclosure near the fish ponds and fed liver. They were immediately given to drink constantly water from pond 1o, and beginning with August 20 a pan of mud from the bottom of pond Io with pond-Io water supernatant was supplied to them, the mud and water kept constantly renewed. The animals not only drank the supernatant water but consumed the mud in quantity. Seventeen days after the mud was first placed at their disposal all the puppies were found to have palpable thyroid enlargements, besides greatly enlarged cervical lymph nodes. This result was briefly reported at the Second International Cancer Congress at Paris in 1910.

The food of the puppies was changed to cereal, and upon examination late in November, I910, all the enlargements had markedly decreased. Two of the animals, dogs 14 and I $_{5}$, were shipped to Buffalo in December and killed.

Section of the thyroid gland of $\operatorname{dog} 14$, under the microscope presents an appearance of the tissue easily discernible as normal. There is some variation in the size of the follicles. The epithelium is flattened, the majority of the follicles filled with stainable colloid. There are no evidences of hyperemia. Under high power the epithelium is uniform in size, flattened, the protoplasm stains diffusely with hematoxylin, the nuclei stain deeply, the long axes in the circumference of the lumen. There are no changes in the stroma.

Section of the thyroid of $\operatorname{dog}{ }_{5} 5$ shows a remarkable condition of the tissue. There is but the slightest suggestion of follicular structure in the section. (See fig. II3.) The entire tissue is made up of solid masses of epithelial cells, with deeply staining nuclei. There is absolutely no trace of colloid in any portion of the section. Compared with dog 14 the epithelial cells and their nuclei are distinctly enlarged. The nuclei stain deeply. They vary in size and at some portions of the section are vesicular. The protoplasm stains diffusely with nuclear stain and is distinctly increased in amount. Under high power the outlines of the follicles can be traced by capillaries. The entire alveolar space is filled with irregularly shaped epithelial cells lying somewhat loosely packed in some regions, more compactly in others. In the more open portions of the section a condition suggesting papillary projections into the alveoli of the lumen may be made out. The nuclei are vesicular. Occasional karyokinetic figures are found. We have here intensive proliferation of the epithelium, with complete disappearance of the colloid. Marked parenchymatous struma.

The remaining dogs of this lot were later shipped to Buffalo, and, at the last examination, made in July, I9I I, no palpable thyroid enlargement was present. Thyroid regression influenced by the change from a high animal protein to low vegetable protein may be inferred.

A female brown spaniel (dog 24) obtained in Washington, D. C., was shipped to the Craig Brook station in the fall of 19ro. On November 30 there was no palpable 
thyroid enlargement. A bag of pond-ro mud was now placed in a pail, which was filled with Craig Brook water and placed in the kennel. The mud was not renewed, but fresh water was poured over it from time to time. The dog was fed a meat diet. July $5,191 \mathrm{r}$, the right thyroid gland was found enlarged nearly to the size of a small hen egg. The left gland was palpable but not evidently enlarged. During the next year pond-ro mud and water was supplied to the dog, and on July 1,1912 , she was in good condition, with both thyroid lobes decidedly enlarged. The left lobe was removed and found to weigh 19.3 grams, its dimensions being 5.5 by 3.5 by 2.75 -centimeters. There was no control for this dog.

Under the microscope the thyroid of dog 24 presents follicles of great size filled with stainable colloid, protruding into which are many bud-like processes. The epithelium is columnar in the larger alveoli, the flattened nuclei stain deeply, are oval or spherical, the protoplasm also taking the nuclear stain. The bud-like processes are caused by infoldings of the walls of the alveoli covered with columnar epithelium. The whole presents the appearance of a gland which has been in a state of active hyperplasia, but is at present a colloid gland.

The feeding of these dogs was intended as a preliminary informal trial and was not controlled. Having indicated the probability of positive results in an important field, more accurate experiments were begun with other young dogs.

A bitch with a litter of five pups was obtained from the District of Columbia, a nongoitrous region. These were shipped to the Craig Brook station, in October, r 910. The mother and two pups were supplied until the following summer with a pan of mud from pond io holding pond-ro water supernatant, both kept frequently renewed. The three remaining pups were held as controls and received mud and water from Craig Brook directly, unconnected with fish-cultural conditions. The food for all was shredded wheat scrap and milk until December, when it was changed to dog biscuit with occasional cooked liver, and this continued until spring, when it was again changed to cereal. The two lots of dogs were separately confined in kennels indoors and were exercised and let loose only under proper restrictions.

On palpation in July, $191 \mathrm{x}$, no thyroid enlargement could be detected in any of them. This experiment was now abandoned and a new one instituted with scrapings from the inside of unpainted wooden fish troughs (no. 93), which had long been used to hold domesticated trout and in which thyroid tumors were constantly produced in such trout. (Table III.)

The three pups formerly used as controls were now given to drink Craig Brook water from a pail containing the fish-trough scrapings suspended in a cheesecloth bag. The material was kept cold by standing it continuously in a trough of flowing cold water. A portion of the clear water from the pail was supplied to the dogs each day. The mother and the two pups which had formerly received pond-r o mud and water for several months were now used as controls to the experiment with scrapings. They received water taken from the same pail and boiled. All the dogs were fed liver, cooked and uncooked. The experiment began August I, I9I I, and in January, I9I2, was terminated 
and the dogs shipped to Buffalo. The three which received unboiled water from the scrapings were in poor condition and one of them died just before shipment.

Of these three puppies (dogs 16,17 , and 22) the one which died spontaneously (dog 16 ) and one of the others ( $\operatorname{dog} 17$ ), both had plainly palpable thyroids, from one-third to one-half larger than normal, in gross section, firm and red, approaching spherical instead of normal fusiform shape. In both instances the two lobes were about equally enlarged. The section of the thyroid of $\operatorname{dog} 16$ shows outspoken evidence of hyperplasia. There are no spherical or oval follicles, all the open spaces in the tissue are of irregular shape due to pronounced papillary projections of the epithelial structure into their lumina. Colloid is present in some of the follicles. The greater area of the section is composed of small irregularly shaped follicles many of which contain no colloid; others partly filled with poorly stainable colloid. Under high power the epithelium is found to be high columnar, the nuclei enlarged and often vesicular with one or more nucleoli. There is distinct enlargement of the capillaries in the stroma. In many areas the proliferation has been so intense as to practically fill the alveolar spaces with compact masses of epithelium. Occasional deposits of brown hematogenous pigment are found within the alveoli. There is distinct variability in the size of the nuclei, occasional ones being greatly enlarged and vesicular. Karyokinetic figures are rare. Diagnosis: Marked hyperplasia with great reduction of colloid. (Fig. III, dog 17.) The histological description of dog 16 applies in every way to dog 17 . (Fig. I 12.) Diagnosis: Marked hyperplasia with great reduction of colloid.

Puppy 22 was not operated until March 18 , when the right thyroid was removed. It was about normal in size, measuring 35 by 17 by 12 millimeters, and weighed 3 grams. The dog weighed $7.7 \mathrm{I}$ kilograms. The third puppy (dog 22) presents a histological condition in the thyroid similar to dogs 16 and 17 . The epithelium is high columar, the alveoli of irregular shape, due to plentiful papilliform processes into the lumen. The larger alveoli contain poorly staining colloid. There is some variation in the different portions of the section chosen for study in this case. One portion somewhat remote from the more intensely hyperplastic region presents a somewhat more normal appearance. The alveoli retain a more oval appearance, the papillary processes are smaller. More colloid is present. The epithelium is, however, high columnar. The nuclei stain poorly and more homogeneously than in the other regions where they are of a more vesicular type. Diagnosis: Marked hyperplasia. (Fig. I 15.)

None of the controls (mother and two pups, dogs 19, 20, and 2I) had palpable thyroid enlargements. They were all operated in March, and the left thyroid of each removed. These left lobes were normal in size and appearance and similar in size to the right lobes. The mother dog (19) weighed 10.9 kilograms, the left lobe 2.4 grams; one of the pups $(\operatorname{dog} 2 \mathrm{I})$ weighed 8.6 kilograms, its left lobe 2.05 grams, measuring 32 by I 7 by 9 millimeters. The other puppy (dog 20 , fig. I I 4 ) weighed Io kilograms; its left lobe 6.4 grams, and measured 47 by 22 by 12 millimeters. Histological examination of the thyroid of the mother ( $\operatorname{dog} 19$ ) shows normal thyroid structure for a dog of this age. (Fig. 116.) 
The puppy (dog 21 ) presents a thyroid structure which may be considered normal for a young dog. The alveoli are less spherical and oval, varying in size, filled with stainable colloid. The epithelium is flattened. There are some areas in the thyroid structure in which a slight tendency to budding of the epithelium with a change to columnar may be observed and there are some areas in which there appears to be a somewhat richer stroma than usual. It is, however, only an increase in amount of connective tissue without any evidence of changes in staining characteristics of the cells. As this puppy received pond-Io mud and water for several months previous to the final experiment, it is possible that the very slight changes here noted may be evidence of the first beginnings of a change induced during that period. Diagnosis: Normal thyroid of puppy. (Fig. I IO.)

Section of the left lobe of the thyroid of dog 20 shows follicles of varying size, the oval and spherical type predominating, but some follicles in which there is evidence of beginning bud formation. The lining epithelium of the more simple follicles is flat. The follicles are filled with stainable colloid. In the somewhat more irregular follicles the epithelium forming the budlike projections into the alveoli is cubical. The nuclei are stained deeply and are spherical or oval. The details of the nuclei can not be made out. Intensely stained. There is some slight thickening of the septa here and there through the thyroid tissue. No evidence of hyperemia, no other change except the slight budding. (Fig. I 14.) The thyroid tissue is mostly normal for a young dog; slight evidences indicating the beginning of hyperplasia. As this dog had previously received pond-1o mud and water, as had $\operatorname{dog} 2 \mathrm{I}$, slight evidences of hyperplasia may be due to this previous stage of the experiment. Diagnosis: Areas of slight hyperplasia.

In the same way and beginning at the same time (Aug. I) as in the preceding experiment, a young bull terrier (dog I8) was given to drink water in which was suspended scrapings from another and old fish trough (no. 9 of old hatchery). The water, however, was kept in the kennel and the dog allowed to drink at will. The temperature varied with the weather. In the winter the room was heated somewhat to prevent freezing, but seldom rose above $45^{\circ} \mathrm{F}$., and was often near the freezing point. The control was dog I9, which received the scrapings water after boiling. Neither had thyroid enlargement at the beginning of the experiment. The food was liver and $\mathrm{dog}$ biscuit for both. The bull terrier, after receiving for six months water from the pail in which were suspended the scrapings, showed a marked emaciation, muscular weakness, and a staggering gait. The thyroid was readily palpable. The dog was killed and both lobes found distinctly enlarged, the left lobe being about one-quarter larger than the right and measuring 54 by 28 by 26 millimeters, and both very vascular.

Under the microscope the thyroid gland shows extensive pathological change. The tissue is for the most part made up of a solid adenomatous structure with irregular and narrow spaces representing preexisting vesicles. Under low power whole fields of almost solid compact adenomatous tissue are found. In the irregular clefts and spaces in the more open portions of the tissue, complex and marked papillary processes covered with high columnar epithelium characterize the tissue. This change may be said to be more constant in the peripheral portions of the section of the thyroid tissue. (Fig. 
i 8.$)$ Passing toward the center of the lobe there are marked degenerative processes in the tissue. The clefts become fewer in number, the epithelium stains less irregularly than before, the irregular alveolar openings are fewer, and the whole tissue is composed of a confusion of cells with just a suggestion of the previous clefts representing the old alveoli (fig. I17), which in this region appear to be filled by desquamated and rather poorly staining cells.

At the very center of the lobe the evidences of degeneration are more intense. One finds masses of cell complexes, deeply staining and homogeneous protoplasm. The cell boundaries are destroyed, the nuclei, although still staining deeply, are embedded in the protoplasmic structure with only the most ill-defined suggestion of cell boundaries to the protoplasm. (Fig. I 19.) At the peripheral portion of the lobe where the papillary adenomatous type of tissue is well preserved, no evidences of degeneration are to be found. One finds in various places in the capsule evident invasion of this structure. The capsule is thick, composed of fibrous connective tissue with small, deeply stained connective tissue nuclei. In the dense fibrous structures of this capsule at various points definite alveoli lined with high columnar epithelium are found, extending in some instances to the outermost limit of the thick capsule. Under high power the epithelium of these alveoli and the capsule is found to be high columnar, most of the nuclei staining deeply and homogeneously, but here and there are vesicular nuclei with one or more nucleoli. The epithelium is in some of these alveoli several layers thick; the protoplasm stains deeply with a cytoplasmic stain. Some of the larger nests of cells in the capsule have almost lost their alveolar structure and formed more or less compact islands of cells, with nuclei varying in size, many of them vesicular.

In the margins of such a complex of cells one finds direct invasion of the dense connective tissue structure of the capsule, there being no stroma between the vesicles and no delimiting membrane to them. In fact, individual cells can be found invading the connective tissue fibers. Occasional karyokinetic figures are found and about the larger masses of cells described there are evidences of expansive growth in the arrangement of the immediate encircling fibers of the capsular structure.

Under high power the outer zone of adenomatous proliferation shows great variability in the nuclei of the cells, most of them being vesicular, with one or two nucleoli. They vary in form from elongate to oval and spherical, mostly oval. The smaller nuclei stain more homogeneously than the larger ones, the epithelium covering the papillary projections is high columnar, the protoplasm stains diffusely, and occasional cells are found in this region in which a swollen and cloudy appearance of the protoplasm indicates the first evidence of degeneration. The stroma of the papillae is not well developed. The capillaries are plentiful but do not form a prominent part of the picture.

Approaching the center of the lobe, large irregular clefts, made up by the papillary projections, are less in evidence and large areas are found in which the epithelium presents peculiar forms and a swollen, cloudy appearance of the protoplasm. The cells are of the most bizarre form and shape, often are spindle shaped, and what has previously been the alveolar spaces in the cells are filled with closely packed, desquamated epithelium. The nuclei here still stain well, are vesicular in character, and vary greatly

$$
8207^{\circ}-14 \longrightarrow 9
$$


in size and form. At the center of the lobule where the degenerative changes are most outspoken are found large areas of desquamated cells with cloudy protoplasm, taking the stain deeply. The cell boundaries are not sharply defined, the nuclei generally smaller than in the preceding area, of varying size and deeply stained. Diagnosis: Diffuse hyperplasia of the thyroid gland with degenerative changes at the center and invasion of the capsule at the periphery.

RATS.

In 1910 and 191 I a prolonged attempt was made to affect the thyroid of rats by giving them water to drink from the fish ponds in which the disease was endemic. A barrel of water from pond 10 of the Craig Brook station and a quantity of mud from the same pond were shipped to Buffalo and kept in cold storage. A series of experiments were begun with young rats obtained from Granby, Mass. Each experimental lot consisted of 10 rats. The food was a mixture of corn, oats, sunflower seeds, and dog biscuit. The mud and water was administered daily to the separate lots as follows:

1. Trout-pond mud; small quantities.

2. Trout-pond mud; large quantities.

3. Trout-pond water.

4. Craig Brook water.

5. Trout-pond mud; cooked.

6. Trout-pond water; boiled.

7. Trout-pond water, injected subcutaneously, followed by mud and water feeding.

The feeding of the mud, water, etc., was continued with the same individuals for a period of about six months. A few were killed from time to time during this period for examination of the thyroid. Neither in these nor in those remaining at the close of the experiment were there any thyroid enlargements or any microscopic condition differing materially from the controls.

In the light of Bircher's subsequent observations there are several reasons why these experiments might have failed. Bircher gives the following reasons why water may lose its goiter-producing qualities: (a) Water kept under conditions different from those of its origin for days or weeks; $(b)$ water which before use has been continually shaken or has undergone a long trip by rail; $(c)$ water to which small amounts of chemical agents have been added; $(d)$ that the agent is more active in the water in the summer months and that the source frequently loses its activity in the winter. Three of these reasons bear on the possible negative nature of the above experiments, and as they are all made with water taken from ponds in which the agent is present in dilute form, it is quite clear that the length of time was not sufficiently great to produce positive results. These experiments must therefore be repeated with the animals at the source of water supply and continued over a period not less than 18 months.

The pond water and mud having failed to produce definite changes in rats during six months under the experimental conditions, a quantity of scrapings from one of the wooden fish troughs (no. 102), in which thyroid tumors were constantly developed, was 
brought to Buffalo. The material was kept cold in a thermos bottle during transportation, and on arrival was placed in a cheesecloth bag and immersed in a glass jar of water and kept in the refrigerator. Preliminary trials were made by using this as drinking water for rats on a raw-meat diet. No marked changes occurred during the first month, but at four months one of six rats showed a great enlargement of the thyroid, and nearly all had marked pathological changes consisting of reduction of colloid, increase in height of epithelium, congestion and presence of numerous mitoses. A carefully controlled experiment was now begun with the scrapings water, the diet being changed to dog biscuit and salted lake herrings, the latter for the purpose of increasing thirst and consumption of the water. Twenty-four rats received the scrapings water, and 12 control rats received boiled water from the same source. This experiment is still in progress. The results at the close of this record indicate that the rat thyroids undergo changes similar to those in the dogs, but of a less intensive nature. Figure 120 shows a normal thyroid of the rat from a control; figure $\mathrm{I} 2 \mathrm{I}$, hypoplastic thyroid from a rat from this experiment.

In considering the above experiments, from which it will be seen that a definite enlargement with diffuse proliferation of the thyroid gland may be produced in dogs in a period of five months by giving them to drink the water in which suspended scrapings from wooden troughs in which the fish kept had regularly developed carcinoma of the thyroid, and that the control dogs receiving the same water boiled have in the same time developed no appreciable change in the thyroid gland, it naturally becomes important to determine what is the exact character of the change in the thyroid gland of the experimental dogs.

At the time, I9ro, when the first experiments along these lines were made, we were not aware of the experiments of Bircher and of Wilms in the production of goiter in dogs and rats by giving them water to drink from goitrous wells. From the various publications of $\mathrm{E}$. Bircher it will be seen that in his results obtained in rats $(\mathrm{I} 9 \mathrm{I} \mathrm{I}, \mathrm{b})$ he has produced, in periods varying from 9 to 18 months, distinct enlargement of the thyroid, with pathological changes which he divides into two classes, viz, nodular or adenomatous type and parenchymatous hyperplastic, mostly with degenerative processes. In the nodular hyperplastic form he has produced typical struma nodosa, which, as he points out, is a condition of the mammalian thyroid intimately associated with tumor formation. The parenchymatous hyperplastic type seems to be an expression of a more intensive action of the goiter water, and it is to this type that the changes we have produced in the thyroids of our experimental dogs more closely approximate. In $\operatorname{dog} \mathrm{x} 8$, in which we have the most outspoken change, we find distinctly marked degenerative changes of the protoplasm in the center of the lobe. These changes give, at first glance, the impression of being due to poor fixation of the tissue or to post-mortem change.

Changes of a similar nature have been produced by de Quervain (1904) in the thyroid by the injections of toxic substances. De Quervain's studies indicate that the process is intravital, and for his tumor rats Bircher takes the same position. It is of great interest that Halsted, who originally (Welch, I 888 ) showed that by removing a part of 
the thyroid of normal dogs, the remaining portion would become hyperplastic (1896), has recently $(1913)$ repeated these experiments and now finds that when the present-day aseptic methods are employed, especially the careful sterilization of the skin with iodine, no compensatory hypertrophy results. Although not definitely expressing himself as to the cause of the hyperplasia which followed his original experiments, in the light of de Quervain's production of hyperplasia with the products of organisms, above referred to, Halsted recognizes the possibility that the hyperplasia in the older experiments may have been due to infection.

The experiments of Bircher indicate a very intimate relation between the experimental production of struma in rats and dogs and the etiology of tumors of the thyroid. The fact that he has produced nodular struma in rats, that struma nodosa is generally looked upon as the change from which neoplasms of the thyroid in mammals spring, that the other changes of the thyroid in his experimental rats present intensive parenchymatous hyperplastic degeneration, makes it clear that perhaps the concentration of the agent causing goiter and the method of its administration, the length of time in which it is permitted to work, or the intensity of its action may determine the character of the early changes of the thyroid in these experiments. The changes in our dogs have apparently. developed more quickly and more intensely than those in the experiments made by Bircher. This would probably explain why our results have shown such diffuse and intensive changes in the thyroids of our affected dogs. Dog 18 , the only adult dog so far exposed to the action of the agent in our experiments, presents outspoken degenerative changes at the center of the gland and evidences of infiltration of the capsule. The period of time covered by Bircher's experiments was much longer than those of our own.

We have reported briefly on a few experiments with rats, from which it is clear that hyperplastic changes in the thyroid may be induced in rats under conditions similar to those detailed in the experiments with the dogs. There are many other points of similarity between Bircher's experiments and ours. The agent is in both cases destroyed by boiling and it is not readily transported for a great distance. We have been unable to produce changes in the thyroid of rats with water transported from Maine to the institute in Buffalo. Our prompt and best results have, as with Bircher, been obtained by giving the water from the scrapings freshly to the animals on the ground where the agent is produced. We have not yet been able to carry out extensive filtration experiments, but have such experiments in progress and hope to report on them later.

Bircher, in his experiments, has compared the results obtained in the production of experimental struma in rats with the results obtained by de Quervain and argues therefrom that the agent of goiter as he finds it in Switzerland is probably a parasitic agent. He finds in filtration experiments with moderately fine Berkefeld bougies that intensive general degenerative changes of the nature of cretinism are produced by the residues scraped from the outside of the filters, and infers that possibly it is the toxic products of an organism which pass through the filter. These toxic products tend to produce struma and the unfilterable portions possibly contain the organism that tends to produce general constitutional disturbances of growth, i. e., cretinism. Our dog 18 showed general nutritional disturbances, loss of weight and strength, staggering gait. To deter- 
mine whether or not extensive constitutional disturbances can be produced with the agent which we hold responsible for carcinoma of the thyroid in fish will require extensive experiments with young animals carried over a longer period of time than our experiments have thus far encompassed. It is quite clear from these experiments that there is a most intimate relation between the experimental production of goiter and the development of malignant disease of the thyroid in mammals. The infiltration of the capsule in $\operatorname{dog} 18$ is extremely suggestive. Further experiments with older animals carried over a considerable period of time will be necessary before it can be definitely determined whether or not the agent responsible for carcinoma of the thyroid in trout is capable of producing infiltrating, possibly metastasising tumors in mammals. Bircher's experiments in producing nodular struma in rats makes the outlook in this direction promising.

The first attempts to produce experimental goiter in the lower animals by giving them to drink water from goitrous sources were undertaken by Klebs and $\mathrm{H}$. Bircher (1883?) who, however, did not arrive at successful results. Carle in 1888 and Lustig in 1890 succeeded in producing in both dogs and horses, in regions free from goiter, enlargement of the thyroid as the result of giving them water from goitrous sources over a period of months. The most elaborate and carefully studied experiments are those by E. Bircher, jr., above referred to. Since his observations Répin (I9II) and Breitner (1912) have carried out experiments and confirmed his results especially in rats, dogs, and monkeys, their experiments likewise extending over several months.

Dieterle, Hirschfeld, and Klinger (1913) have repeated the experiments of Bircher, Wilms, Répin, and others, and arrive at the following conclusions: That in regions in which goiter is endemic it is possible to produce goiter in rats by giving them copious amounts of water to drink. Their success ranges from 40 to 70 per cent. Second, the nature of the water which is used in a goitrous locality is without significance. The water may be either fresh or boiled, and goiter may be produced with water which at the point of its origin is not a goiter-producing water. Rats in a goiter-free locality in Zurich which were given goiter water from other localities did not at first develop goiter. Later, however, a few positive results were obtained, but it was felt that contact infection could not be excluded. Because it is possible to develop goiter in rats in goiter regions with water from goiter-free localities, they conclude that the primary character of the water is not the determining factor in the development of goiter. They point out that in goiter localities boiling the water does not protect experimental animals against the development of goiter, but that in goiter-free localities boiling the water destroys the goiter-producing character of such water. They conclude that this indicates that the etiologic agent of goiter must be occasionally transmitted through the water. These experiments conform with the work, as yet unpublished, of Landsteiner, Schlagenhaufer and Wagner, and v. Jauregg, which will show that rats which were given nothing but boiled water from Vienna and kept in a peasant's house in the neighborhood of Rothenthurm in Judenburg, in Steiermark, in which all the inmates of the house were either goitrous or cretinic, developed goiter in a percentage equal to that obtained with rats, using the goitrous water of that locality, whereas attempts to produce goiter in rats in Vienna with the goiter water of Rothenthurm gave only negative results. 
It would thus appear that water is not the exclusive carrier of the etiological agent of goiter, but the giving of large quantities of water to experimental animals in a goitrous region, favors the development of goiter when the agent may find entry in some other way. These observations tend to increase the significance of the finding of nematodes or other possible carriers in connection with the production of experimental goiter in animals.

McCarrison (1909) produced experimental goiter in human beings by giving them residues from the filtered water of Kashrote, where goiter prevails to the extent of 45 per cent of the total population. Experiments were carried out in the nongoitrous village of Barmis so controlled that they were provided with water for drinking, bathing, and other cleansing purposes from the Barmis spring, which is nongoiter producing, but which, as an added precaution, was boiled. Their diet was chiefly vegetable. Of 13 individuals whoconsumed the untreated residue of the goiter-producing water of Kashrote 4 developed a noticeable swelling of the thyroid gland, while 2 others showed an increase in size of the organ, demonstrable by measurement and evident to the touch. In three cases the enlargement was produced early, making its appearance on the thirteenth to the fourteenth day of the experiment. It was not great nor did it appear under the conditions of the experiment to be progressive. Of eight individuals who under the same conditions consumed the boiled residue of the goiter-producing water of Kashrote none developed any swelling of the thyroid gland, and this although three were individuals peculiarly likely to respond to goitrous influences. McCarrison therefore concluded (1) that goiter is due to matter in suspension in the water; (2) that goiter is not due to the mineral but to the living part of the suspended matter; in other words, to a living organism of the disease; (3) that the incubation period of experimentally produced goiter is 13 to 15 days.

An experiment of similar import is reported by Breitner (I9I2) which relates to a family of father, mother, and seven children who, coming from a goiter-free region, drank the water from a goitrous well with the result that all nine individuals developed a great increase in the circumference of the neck with palpable tumors. Upon the advice of Breitner they boiled the water from this source and after a period of four weeks a distinct diminution of the thyroid tumors occurred, but later they disregarded this advice with the result that the thyroid enlargement again progressed. From this well Breitner carried out experiments with rats with the result that in 19 rats 2 developed large visible struma, 2 thyroids two and one-half times as large as normal, ant 4 showed microscopic diffuse enlargement of the thyroid, whereas 20 controls showed no enlargement.

The literature contains many accounts of human beings going from nongoitrous regions into localities in which goiter is endemic and there quickly acquiring the disease. One of the oldest and most striking of those given is that reported by Hancke in 1819 , in which all but 70 young men of a battalion of 300 in the course of a year developed such pronounced goiter that it was found necessary to remove the regiment to a nongoitrous region, where those who were not too far advanced recovered, the enlargement of the thyroid disappearing. Hancke states that in the infected region referred to 
individuals who boiled the water and freed it fron the precipitate which it contained and added thereto wine and sugar very rarely developed goiter. Another striking example of the same kind is that of McClelland (1835) relative to an endemic of goiter in Deoba, India. In this locality the entire population with the exception of the Brahmins had goiter. This higher caste drew their drinking water from a widely distant spring. One or two other castes which had partial access to this source numbered a considerable percentage of goiter cases, and the lowest caste, the Domes, drew their entire water supply from a goitrous well and almost every individual had goiter. The middle caste, Ragpoots, which received partly good and partly infected water from the well were infected to the extent of two-thirds of the individuals. These examples are but one or two from many in the literature. Those who desire to multiply such reports are referred to Hirsch's Handbuch der historisch-geographischen Pathologie (2. Stuttgart I $88_{3}$, bd. 2, p. 83), and Ewald's excellent work on Die Erkrankungen der Schilddrüse, Myxödem und Kretinismus, in Nothnagel's Handbuch der speziellen Pathologie und Therapie (2. aufl., Wien I909, bd. 22).

It is clear both from recorded incidence in man and from experiments both with man and animals that goiter is usually acquired through the drinking water. It has been shown that from the water sources from which man acquires goiter, dogs and rats may be made to develop it. We have shown that with water in which fish develop carcinoma of the thyroid, diffuse parenchymatous enlargement of the thyroid in both dogs and rats may be produced. From these facts inferences may be drawn that there is every reason to believe that human beings also would acquire thyroid disease from the use of such water.

\section{POSSIBLE CARRIERS.}

In a disease like carcinoma of the thyroid in the Salmonidr, which is not transmitted directly from individual to individual but which is transmitted, if at all, from the infected to the healthy by some roundabout method, the idea of carriers for the agent which we believe to be the cause of the disease is very natural. Of the recent experimenters with goiter water, Bircher, as a result of filtration experiments, for some time advocated the view that the agent of goiter was a colloidal toxin, probably liberated by some parasite incapable of passing the Berkefeld filter. The residues scraped from such filters produced in young animals very profound nutritional changes comparable to cretinism. The filterable factor which produces the nodular adenomatous form of goiter, as well as the parenchymatous hyperplastic, will not pass through the membrane of a dialyzer, but the residue upon the dialyzer membrane proved to be particularly active. These observations have led Bircher to the belief that the agent is a colloid, but he recognizes that it may also be a filterable microorganism; or that if the organism itself does not pass the filter it is still the probable source of a filterable toxin.

Many authors have held that endemic goiter is certainly an infectious disease, Ewald being one of the strongest advocates of this theory, and McCarrison holds the same view. Schittenhelm and Weichardt (1912) consider it an infectious disease and 
state that by immunizing rabbits with goiter water which was free from all bacteria or other cultivable organisms, they have gotten with the blood of such immunized rabbits a definite deviation of the complement reaction, as against the suppositious organism in the water. By means of the epiphanin reaction they believe they have demonstrated the existence of an antibody opposed to microorganismal albumin.

Kolle (1909) attempted to test the theory that intestinal parasites bore a relation to endemic goiter. McCarrison (1909) was of the opinion that the agent of goiter was in the intestinal tract, because of the prompt results obtained in his experience by the giving of a single or repeated doses of thymol. He (I9II) tested this hypothesis experimentally by mixing the feces of goitrous men with sterilized soil and he fouled water with this mixture by pouring it through a specially constructed box. In one of these boxes he placed 500 earthworms on the assumption that they might be an intermediary host of the infecting agent. Water from the first box was given to six female goats and from the second with the earthworms to seven female goats. These goats were permitted to consume this highly polluted water for 64 days with the following results: First, loss of weight due doubtless to confinement in a small hut for the 64 days of the experiment; second, many of them suffered from diarrhea; third, 50 per cent of the animals. showed marked enlargement of the thyroid gland, most marked on the right side. The thyroids of three goats showed no enlargement. The enlargements were of various degree. McCarrison gives the average weight of the normal thyroid of the goat of Gilgat as $\frac{1}{10000}$ of the body weight. The enlarged gland of the goats in the experiment weighed from $\frac{1}{4272}$ to $\frac{1}{7000}$ part of the body weight. In both batches receiving the fouled water the results observed were the same.

Microscopical examination of the enlarged organs by McCarrison showed "various degrees of dilatations of the vesicles and no alterations in the connective tissue stroma of the enlarged glands. The hypertrophy was due wholly to the distension of the vesicles with colloid and to the formation of new vesicles from intravesicular masses of cells." He concludes: (I) An hypertrophy of the thyroid gland of goats may be induced by infecting the water supply with feces from sufferers from goiter. It is at present impossible to state whether this hypertrophy is due to the action of the infecting agent of goiter or only to the organic impurity of the water thus contaminated. (2) Earthworms do not appear to be concerned in the spread of goiter. (3) The microscopic appearances described are the earliest changes in the formation of parenchymatous goiter.

One of the most interesting recent discoveries in relation to a parasitic thy roiditis is found in the publication of Carlos Chagas (I9II). This author, cited by Schittenhelm and Weichardt, found in an insect, a Brazilian bedbug (barbeiro, Conochinus megistus), a flagellate which he identified as part of the developmental cycle of Trypanosoma minasense Chagas, which he had discovered in the silky monkey. If the infected bedbugs were allowed to bite this variety of monkey the latter received a blood infection with the organism. The bedbug is therefore the intermediary host and the incubation period after the bite is eight days. Chagas undertook to determine the original host for this organism and found in the State of Minas Geraes, especially in 
children, a flagellate disease which, when the patient was transferred to Rio Janeiro, he was able to transfer to the silky monkey by means of the barbeiro. The characteristic symptoms of the disease in the children were enlargement of the thyroid, the stupefied appearance of the child, and enlargement of the lympahtic glands. He also succeeded in inoculating guinea pigs with the flagellate organism by injecting the blood of the infected children.

He divided the disease into an acute and a chronic form. The chronic form is characterized by hypertrophy of the thyroid affecting one or both of the lobes of the thyroid and frequently the isthmus. Even in young children the enlargement of the thyroid may be very marked. He says that in some regions the disease is very widespread and here infantilism and cretinism are very prevalent. All these individuals presented the characteristic enlargement of the thyroid. The histologic picture of the disease is in part an inflammatory reaction of the stroma of the thyroid with outspoken sclerosis. In such cases the alveoli are small and the lumen reduced. The colloid is usually decreased in amount and stains poorly. In the vesicles there appears to be desquamation and degenerative changes of the epithelium which fill the lumina of the alveoli. The islands of epithelium which normally lie between the vesicles appear to have been increased by proliferation, in some covering extensive areas. Large cysts filled with colloid characterize the last stages of the chronic form, with occasional calcification of the cyst wall.

In cancer of various kinds intermediary carriers have been suspected. The wellknown association of cancer in Bilharzia disease with the important trematode parasite, Distomum haematobium, is classic. Borrel in 1906 reported having found very frequently in mouse cancer, in the immediate neighborhood of or within the tumor, occasional small nematode worms. These, he did not think, were themselves in etiologic relation to the tumors, other than as possible carriers of a specific virus. This theory was strengthened in his mind by finding in the left kidney of a rat, which died of a cancerous. tumor in the right kidney, a small cyst containing a very young cysticcrcus, which was identified as belonging to the Tænia crassicola of the cat. Upon the membrane of this cyst, which was attached to the tissue of the kidney, he found a small tumor of identical structure to that of the larger tumor of the right kidney.

In the second case, furnished him by Laveran, a rat died of a tumor of the liver of the size of an orange, in the exact center of which was found a cyst with a tumor growing out from it in all directions. This cyst contained a cysticercus which was again identified as belonging to the Tænia crassicola of the cat. Microscopically this tumor was a large-celled sarcoma. Bipolar and multipolar karyokinetic figures were very numerous. This tumor proved to be transplantable and had produced large tumors for three or more generations. Borrel felt that the successful transplantation of this tumor strongly indicated that the cysticercus had carried with it a virus which it was possible to propagate with the cells. Finally he called attention to the possible relation of helminthia and cancer and felt that this hypothesis was in accord with the frequent tumors of the digestive tracts and the appendix. He thought that the endemic occur- 
rence of cancer in animals might be explained by the distribution of some nematode or other carrier.

Regaud (1907) reported two rats in one of which he found at autopsy a general sarcomatosis of the peritoneum. At the border of the liver hung a cyst which contained a cysticercus. The neoplasm was a sarcoma with fusiform elements. Inoculation into five rats remained negative. The second, an adult male, having been found dying without known cause, was killed. In the peritoneum a tumor the size of a nut had developed in the large omentum. There were numerous miliary granulations around the tumor. At the center of it was a smooth cavity containing a tapeworm 25 centimeters long and living. Intraperitoneal inoculations made in five rats were negative. The parasites in both cases were identified as cysticerci of the Tænia crassicola of the cat. In common with Borrel, Regaud felt that the cysticerci in these instances were the carriers of a virus, as he had frequently found cysticerci in the liver of rats killed for histological research without accompanying neoplasms.

That a virus of cancer is no longer hypothetical has been shown by the recent demonstration by Peyton Rous in three varieties of sarcoma in chickens of a filterable virus capable of producing type-true neoplasms. This agent passes through a mediumgrade Berkefeld filter. It is preserved by glycerin, has a killing point slightly higher than the cells of the chicken, is not injured by freezing, and is killed at $55^{\circ} \mathrm{C}$. The agent can be preserved by drying the cells and can withstand grinding. After many months the agent can be separated from the dried cells by filtration, or, in common with them, on injection inaugurates at the point of trauma the growth of a malignant sarcoma of the type from which the virus has been taken. Rous has separated the filterable virus from a spindled-celled sarcoma (1910), an osteo-chrondro-sarcoma (1912), and a spindlecelled (intracanalicular) sarcoma (I9I3) with peculiar arrangement of the cells. The virus of the osteo-chondro-sarcoma possesses the remarkable quality of causing the connective tissue with which it comes in contact to proliferate and specialize by forming cartilage and bone. His experiments not only show the existence in these tumors of a filterable virus but the existence for each type of a special virus. It is needless to point out that the agent of goiter is also filterable, which fact should strengthen the theory that the goiter agent is a living organism and not a soluble toxin.

Haaland, Loewenstein, von Wasielewski, and others have found helminthia in mouse cancers.

The theory of Borrel regarding nematodes has recently been experimentally proven by Fibiger (1913). Fibiger found in three rats in his laboratory large papillary growths of the stomach, in all of which were many small nematode worms. These growths he held to be fibroepithelial tumors, probably malignant, an opinion which was strengthened by microscopic examination. The epithelial proliferation was found to have broken through the muscularis mucosa, and the submucosa contained projections and islands of squamous epithelium. To determine how frequent the disease might be in Copenhagen, he examined I,I 44 rats without finding any evidence of the disease. Later his attention was drawn to cockroaches as possible carriers of such nematodes, through an article by Galeb in 1878 , who found nematodes in the stomachs of rats after feeding 
them the cockroaches, Periplaneta orientalis. These he identified as Filaria rhytipleurites of des Longchamps. After examining 61 rats from a locality in Copenhagen which was infested with Periplaneta americana, he found similar worms in the stomachs of 40 , of which 9 had well-developed tumors and 9 inflammatory reaction of the mucosa, which he held to be the beginning or precancerous stage of the disease. Furthermore, he reports that by feeding 57 laboratory rats with Periplaneta americana from the same locality he found the worms in the stomachs of 54 , in 7 of which were definite tumors and 29 of which had the precancerous stage of the disease. Two of these tumors were found certainly to have metastases, probably three. The metastases did not contain the nematodes, and furthermore, Fibiger states that there is no direct relation between the intensity or amount of proliferation and the location of the worms in the gastric mucosa.

The life history of these worms is as follows: They live in the squamous epithelium of the esophagus and stomach of the rat. In rare cases they are found in the epithelium of the tongue and the mouth cavity. Here they reach the reproductive stage and eject eggs which, with the desquamated epithelium, are carried out with the excreta. In the excreta they are taken up by the cockroach Periplaneta orientalis, and in these insects the eggs develop into free embryos, wander into the striated musculature of the prothorax and the extremities. Here they remain for about six wecks or a longer time as trichina-like spirally coiled larvæ. If the cockroaches are consumed by the rats the larvæ are freed from their capsules and wander into the squamous cpithelium of the rat's stomach, occasionally into the esophagus or the epithelium of the mouth or tongue. Here after two months the female begins to deposit eggs. The measurements of these worms in the fully developed stage are, for the male, one-half to I centimeter long, diameter, 0.1 to 0.16 millimeter; females, 4 to 5 centimeters long; diameter, 0.2 to 0.25 millimeter. The eggs are oval, clear, with double contour membrane, at the poles slightly thicker than at the circumference. The eggs measure 0.06 by 0.04 millimeter. They contain a rolled-up embryo with annular divisions of the cuticle. They have been identified as belonging to the genus Spiroptera. The male has a large bursa, with two spicules of different lengths and four preanal, as well as four postanal papillæ, on each side, these characteristics serving to distinguish them from the Spiroptera obtusa, as well as from the Filaria rhytipleurites of Galeb. It is therefore a new nematode.

In the sections of the hyperplastic thyroids in our second series of experimental dogs, we were interested to find in the capsule and in the substance of the thyroid small tubercles measuring usually 0.3 by 0.35 millimeter, of strikingly uniform appearance. At the periphery of these tubercles is a fibrous connective tissue capsule of thin and flattened cells. Within the outer layer of flattened fibrous connective tissue a more cellular structure composes the body of the tubercle. These are large fibroblasts of spindle form with oval, vesicular nuclei. They have a general arrangement, as if perpendicular to the circumference. The center of the tubercle is composed of intercellular substance with usually a zone of leucocytes, and by aid of serial sections, usually in the center of these tubercles, one encounters a cross or oblique section of a small nematode 
worm. (Fig. I24.) Occasional tubercles will be encountered in which either the head (fig. I23) or tail of this worm lies near the periphery, and in some instances a fully formed tubercle has been encountered with cross sections of the worm lying without the connective-tissue capsule usually coiled in undulating fashion. (Fig. 122.) The worms appear to be of the same species. For the purpose of identification, sections of the worms have been submitted to B. H. Ransom, Chief of the Zoological Division of the Bureau of Animal Industry of the United States Department of Agriculture at Washington. We are indebted to Dr. Ransom for the following notes:

After examining the preparations I fail to identify the parasite to which you call attention with any known species. As it is quite different from a hookworm larva it is not Ancylostoma caninum or any other species of hookworm, a possibility which would perhaps first suggest itself, inasmuch as the larval stages of Ancylostoma en route to the alimentary tract are likely to be found in various tissues, though apparently they have not yet been noted in the thyroid gland. As to other possibilities, so far as I have been able to determine, no nematode has been recorded from the thyroid gland of dogs. Furthermore, the form in question does not agree in morphology with any adequately described nematode known to occur in the dog in any part of the body.

The nematodes in this case, which are sexually undeveloped, may be (I) immature stages of some species which occur in its adult stage in the dog and whose larvæ after gaining entrance to the body perform more or less extensive migrations before reaching their final location, and would thus be comparable to Ancylostoma, whose larvæ regularly migrate from the skin to the digestive tract, or to Spiroptera sanguinolenta, whose larvæ, it is stated, sometimes migrate from the digestive tract to the blood vessels and other rather remote locations where development to maturity may occur; (2) they may conceivably belong to some species like Ollulanus tricuspis, whose young, according to Leuckart, may either pass out of the body to become encysted in an intermediate host or penetrate into various tissues of the original host and become encysted in the manner of Trichinella; (3) they may be the larval stage of some species whose adult stage occurs in another host, the dog acting as a true though perhaps unusual intermediate host; or (4) they may be present in the dog as the result of an accidental infection entirely outside the normal life cycle, this case being comparable to that of the infestation of mice and other animals with the larvæ of Spiroptera sanguinolenta to which Seurat (1912, Compt. rend. Soc. de biol., Paris, v. 73, p. 279) has called attention. This author notes that these larvæ which are found in cockroaches, instead of developing to maturity as when fed to dogs, if fed to white mice pass through the wall of the digestive tract and become encapsuled in various organs without undergoing further development. The possibility last suggested (4) is also comparable to that of the migrations of the larvæ of Ancylostoma duodenale, a human parasite, in dogs. The larvæ of this species penetrate the skin of dogs and in course of time may reach the intestine, undergoing a partial development which, however, falls short of maturity.

As a rule when nematodes or other parasites are found in a given host it is to be presumed that the animal is playing the part of a true host and that there is a more or less complete adaptation between the host on one hand and the parasite on the other. The possibility, however, should not be lost sight of that larval nematodes of an unknown species found in a certain host, or of a known species found in an unusual host, may represent individuals which have gone astray so far as the possibility of completing their normal life cycle is concerned. It is apparently true that nematodes which thus go astray usually die before there is any development or any invasion of the tissues of the animal. That is, nematodes entering the digestive tract of an animal which is unsuitable as a host as a rule quickly succumb without doing any damage. This is, however, not the case with all species, for example, Spiroptera sanguinolenta in mice, as noted above. Similarly in the case of nematodes whose normal mode of entrance is through the skin it is to be presumed that they will not even enter the skin of an unsuitable host, but such occurrences may not be very unusual. The case of Ancylostoma duodenale already mentioned, and that of Strongyloides stercoralis, another human parasite, which behaves much 
as $A$. duodenale with reference to dogs, are sufficient to indicate that stray parasites may enter the body through the skin as well as through the mouth, and perform extensive migrations through the tissues and even undergo a partial development before they die. The possibilities as to the amount of damage such stray parasites may do are interesting. They may, for instance, have more injurious effects on the unusual host than on the animal to which they are specifically adapted, much as in the case of various parasitic protozoa which do not injure certain animals considered to be their usual hosts, but are very injurious to others considered unusual hosts. The two cases are of course not strictly comparable as there would be no multiplication, at least no repeated multiplication, in the case of the nematode like that in the case of the protozoan. The introduction of microorganisms by nematode larvæ is another possible source of damage, and this applies not only in the case of stray parasites but in the case of those entering their proper host animals. Many parasitic nematodes have plenty of opportunity during the early stages of their free living existence while they are actively feeding upon the organic materials in the medium, commonly fecal matter which surrounds them, to pick up injurious microorganisms, and these it is quite conceivable may be carried with them on their later migrations and finally deposited where damage will result. Looss (IgII, Rec. Egypt. Govt. School Med., Cairo, v. 4, p. 557), for example, suggests that Ancylostoma larvæ which have developed in feces might retain some bacteria in their intestine and evacuate these as soon as they arrive in the body of their host, and that this if it occurred might have something to do with the skin lesions which accompany Ancylostoma infections.

Returning to the nematodes in the thyroid of the dog, it has not seemed advisable to venture an opinion as to the genus or even the family to which the parasites may belong. In order that they may not be left nameless I have designated them as Agamonematodum gaylordi, thus placing them in a collective group, which is used for convenience of reference to include various immature nematodes, whose sexually mature stage is undetermined. The following brief description is based on an individual the anterior portion of which is present in the sections on a slide labeled " Dog I7. K. I-22-12.20, Nem. 2". (Fig. 123.)

\section{AGAMONEMATODUM GAYLORDI.}

Length uncertain, but apparently less than I millimeter; maximum width $35 \mu$. Head apparently with 3 lips, each supplied with a small papilla. Diameter of head at level of papillæ $20 \mu$, increasing to $24 \mu$ at a distance of $20 \mu$ from the anterior end, then rather suddenly constricted to $20 \mu$, after which the diameter of the body gradually increases, reaching $32 \mu$ at the level of the nerve ring, which is located about $100 \mu$ from the anterior end of the body. Mouth very small, communicating directly, without intervening larynx or mouth capsule, with the esophagus. Esophagus near its anterior end measures about $16 \mu$ in diameter, is then constricted slightly, corresponding with the constriction of the body, and gradually increases again in diameter, attaining a size of about $x \mu$ in the neighborhood of the nerve ring. Length of esophagus uncertain, but exceeds $160 \%$. The anterior end of the body is supplied with narrow lateral cuticular wings, which extend posteriorly an unknown distance beyond the esophageal region.

Host.-Dog (Canis familiaris).

Location.-Thyroid gland in small tubercles.

Locality. -Craig Brook, Me.

The nematodes were not found in the two dogs examined in r9ro, one of which had marked thyroid hyperplasia and the other a nearly normal gland, but serial sections were not available. In all (3) of the puppies which had marked hyperplasia and were given drinking water in which were suspended scrapings ( $\operatorname{dog} 16, \operatorname{dog} 17$, and $\operatorname{dog} 22)$ nematodes are present. In the white mongrel adult dog with the highest degree of diffuse parenchymatous hyperplasia and degeneration ( $\mathrm{dog} I 8)$ they are also present. In the control for this dog, the mother of the puppies, which received boiled water (dog 19), they are not present. In the control puppy no. 21 , which received boiled water, they 
are not present. In the second control puppy, no. 20, they are present. It is this control, no. 20 , which is described as having slight evidence of hyperplasia, but as this dog received before the beginning of the final experinient, as did also the other controls, water from pond $I 0$, it is possible that it acquired the worms at that time. The mother dog, no. 19, and the other control puppy, no. 22 , also received pond ro water and showed no evidence of hyperplasia or nematodes.

There is apparently no direct connection between the hyperplasia of the thyroid and the nematodes. As previously described, the hyperplasia of the thyroid in these experimental animals is diffuse. If the nematodes have any direct relation to the experimental hyperplasia of the thyroid thus produced, it is only as a carrier of the virus of the disease in the manner which Borrel has suggested for tumors in mammals. That hyperplasia can result without nematodes or other possible carriers is shown by the fact that we have not found anything of the sort in the hyperplasia of the thyroid in the rats, induced with water and scrapings from Craig Brook. Bircher or the other authors who have produced experimental goiter in animals have not noted the presence of nematodes. Nematodes in the region of the thyroid in fish are certainly not necessary to the development of the disease in fish. We have in one or two instances found similar tubercles usually lying in the subcutaneous tissue below the floor of the mouth in which coiled-up nematode remains have been found. A portion of the cuticle of such a nematode was sufficiently preserved so that its structure could be clearly made out. (Fig. 126.) There is evidence in the dog thyroids that some of the nematodes perish. The finding of disintegrating tubercles is subject to this interpretation. (Fig. I 25.) It is therefore possible that in the very early stages of the transmission of the disease it will be found that such nematodes act as occasional carriers in this affection and that later they disappear. A careful study of the intestinal contents of the fish and the scrapings from the fish troughs will be included in the next stage of this investigation.

\section{SUMMARY.}

I. The present investigation of thyroid carcinoma among fish was begun by the Director of the Gratwick Laboratory in furtherance of the inquiry of that institution into the nature of cancer in man. Having brought it to the attention of the United States Bureau of Fisheries through the President of the United States, an investigation of wider scope resulted, based upon its interest and importance to fish culture and to cancer research in general, and uniting the Federal and State resources as represented by the Bureau and the Gratwick Laboratory.

Bonnet in 1883 described a gill disease in trout which is undoubtedly identical with the subject of this inquiry, and is thus the first published reference to it, though the nature of the disease was not at that time recognized. Scott in 1891 first identified the disease as carcinoma, without recognizing its relation to the thyroid gland. Its origin in the thyroid was first asserted by Plehn in 1902 , who diagnosed it as adeno-carcinoma. Pick in 1905 published the first extended study of the structure of the growths and insisted on their carcinomatous nature. Gillruth in 1902 described it briefly as an 
epithelioma affecting the branchial arches and showed that it was widely distributed among the hatcheries of New Zealand.

Gaylord began the study of the disease in 1908 and reported evidence pointing to an infectious factor in its causation. Marine and Lenhart, as the result of studies in 1909 and subsequently, hold that the disease is endemic goiter and have failed to find any specimens which they recognize as cancer.

The disease is widely distributed throughout the United States and probably occurs more or less everywhere that artificial propagation of salmonoids is carried beyond the early stages.

II. The normal thyroid follicles in salmonoids resemble those of the mammalian thyroid, but the gland is not encapsulated and not so definitely confined within given limits. In wild brook trout the largest masses of thyroid follicles are faintly macroscopic, and all the thyroid tissue is located in the neighborhood of and chiefly dorsal to the ventral aorta between the first and third gill arches, and does not extend laterally along the arches. The distribution is somewhat more restricted than that indicated by Gudernatsch. Anomalous deposits frequently occur beneath the epithelium of the jugular pit, but are rare elsewhere. The thyroid follicles of wild trout are regular in shape, usually spherical or slightly elongate and in the typical or simplest condition its epithelium is flattened or never higher than cuboidal.

III. Simple hyperplasia of the thyroid is met with in trout living under wild conditions. The follicles are increased in number, are more irregular in shape, the colloid is diminished, and the epithelium is in large part columnar. Such a hyperplasia exists also in domesticated trout and is not to be distinguished from the earliest stages of carcinoma of the thyroid. The immune Scotch sea trout as yearlings occasionally exhibit this simple hyperplasia, and a few adults are found with colloid goiter. Spontaneous recovery from thyroid carcinoma in fish does not result in this picture of colloid goiter.

IV. The first macroscopic evidence of the disease is usually found in an area of hyperemia on the floor of the mouth (red floor). The first evidence of visible tumors may be found at the branchial junction. Tumors may protrude in various directions, at the branchial junction, in the floor of the mouth, or to either side of the gill region. Independent tumors develop in the jugular pit, a region which frequently contains deposits of normal thyroid tissue. The first microscopic evidence of the disease is found to occur in individual follicles, usually those nearest a large vessel. A small group of altered follicles surrounded by normal follicles is frequently found in the early stages. The epithelium is high cubical or columnar, the protoplasm and nuclei stain deeply. Colloid is diminished or absent, the vessels of the stroma hyperemic. Budding of the wall of the follicle next occurs, forming isolated new follicles of irregular type, and papillary projections into the follicles. As the gland is not encapsulated, newly formed tissue grows between the muscle planes and fills in the areolar spaces. At this stage karyokinetic figures are common, the epithelium is high columnar, and frequently there are several layers of epithelium in a single follicle. Proliferation may now have 
reached a sufficient amount to produce the red-floor stage. Bone, cartilage, and muscle are invaded. The growth no longer seeks the paths of least resistance.

In the visible tumor stage there is a remarkable variation in the character of the proliferation. All the various types occur in one tumor. They may be divided into alveolar, tubular, and solid, and combined with papillary and cystic types. Frequently small adenomatous structures of malignant appearance are found invading and infiltrating the surrounding thyroid structure of less malignant appearance. Occasionally islands of normal thyroid tissue have been found in the bone spaces or cavities of the bone where the entire surrounding structure was replaced by thyroid carcinoma. True infiltration of bone, cartilage, vessel wall, muscle, and skin has been demonstrated. Occasionally tumors are met with which present the appearance of so-called sarcocarcinoma of the thyroid in mammals; a background of spindle cells resembling sarcoma with occasional alveoli.

Growths upon the apex of the lower jaw are either implantations or metastases. A marked similarity of the primary tumor in the thyroid region with the growth upon the tip of the jaw in one case studied indicates that this is probably metastasis formation at the site of an injury. An undoubted case of metastasis formation is found in a tumor growing in the intestinal wall at the lower end of the intestinal tract, which infiltrated the muscularis mucosa of the intestinal wall, of characteristic thyroid carcinoma structure, large irregular follicles lined with columnar epithelium, occasionally containing colloid. Portions of the tumor present an appearance closely approximating the least malignant appearing primary tumors. The character of this growth and the region in which it occurred shows conclusively that it is a metastasis.

A comparison of the various types of thyroid carcinoma of the Salmonidx shows that they approximate in type three of the groups made by Langhans for carcinoma of the thyroid in mammals, viz, proliferating struma, carcinomatous struma, and malignant papilloma.

V. Three examples of the disease have been found in wild fish in the United States. One occurred in a brook trout which may have been planted from a hatchery, one in a landlocked salmon, and one in a whitefish. None of the species of whitefishes is fed or reared artificially.

VI. The disease has been observed in 16 species of salmonoids, or in hybrids made among these.

The geological formation at the sources of the water supplies in which the disease occurs has apparently nothing to do with its origin, nor has the dissolved content of the water.

The disease is usually endemic and occasionally epidemic. It occurs in ponds and troughs, of whatever construction, in which fish are held, reared, and fed the ordinary proteid foods of fish culture, viz, raw liver, heart, lungs, and other meats. It shows a tendency to increase from above downward in the course of a given water flow. Hybrids of the Pacific salmon are especially susceptible and show a high incidence. When endemic the course of the disease is slow and chronic, with a low death rate made indeterminate by complication with intercurrent or terminal infection and other causes of death. The incidence of tumors varies greatly and increases with the age of 
the fish. Macroscopically visible growths have not been seen in fish under about five months of age. Anemia and cachexia, sometimes extreme in degree, are a frequent but not constant accompaniment of the disease. Immunity is strikingly exhibited not only among species, as the Scotch sea trout, but with given lots of a susceptible species. Recovery or regression occurs when affected fish are removed from domestication to wild conditions and also in fish in ponds in which the disease was acquired.

VII. Feeding of fish tumors, or of human cancer, to brook trout has not during a period of several months produced the slightest evidence of the disease attributable to this feeding. The intimate association of susceptible trout with trout tumor material in standing water, or with tumor fish in circulating unchanged water, has brought only negative results. The fish tumor has not yet been successfully transplanted, but implants have grown slightly and were alive at the end of three months. The tumor extract is highly toxic to trout when injected into the thyroid region or subcutaneously.

Wild brook trout brought from the wilderness and confined in cement tanks and fed raw heart or raw liver have developed microscopic evidence of the disease by the end of the first year, and visible carcinoma between the first and second year. The feeding of cooked liver retarded the process. Spontaneous regression occurred in a high percentage of the meat-fed fish by the end of the second year. Similar trout fed upon marine fish, vegetable food, or a combination of mussels and live maggots retained their normal thyroids.

VIII. Either of the elements iodine, mercury, or arsenic dissolved as salts in the water in which the fish are living interrupts the progress of the disease and restores the thyroid epithelium to a condition approximating the normal. Recognizable effects are produced within a few days. Visible tumors are markedly affected and may be much reduced in size. Iodine and mercury are effective even when diluted by many millions of parts of water. Iodine is effective when introduced into the digestive tract as well as through the medium of the water. Negative results were obtained with thymol by both these methods of administration.

IX. The administration to dogs of mud and water from fish ponds in which thyroid carcinoma was endemic gave suggestive evidence that the water and mud contained an agent capable of producing marked changes in the thyroid. Scrapings from the inside of old wooden fish troughs in which thyroid carcinoma was constantly produced gave positive results. Four dogs were given for six months water to drink in which these scrapings were immersed. All developed marked thyroid hyperplasia and three of them enlarged thyroids. The thyroids of the three control animals remained of normal size. Two of them were normal in structure while one showed slight evidence of hyperplasia, probably referable to a previous experiment.

Rats given for six months mud and water which had been taken from ponds in which thyroid carcinoma was prevalent and transported several hundred miles gave negative results. Rats given for four months water from the fish trough scrapings, also transported as above, produced results similar to those obtained with the dogs but less marked in degree.

$8207^{\circ}-14-10$ 
$\mathrm{X}$. In the hyperplastic thyroids of three puppies and one adult dog which were given pond mud and water, or water from fish-trough scrapings, minute nematode worms were found immediately beneath the capsule or in the substance of the thyroid. The worms were surrounded by connective tissue tubercles. In two instances only remains of small nematode worms were found in the thyroid region of brook trout with carcinoma of the thyroid undergoing regression. If these worms have any etiological significance it must be merely as carriers of a causative agent.

\section{CONCLUSIONS.}

1. The disease known as gill disease, thyroid tumor, endemic goiter, or carcinoma of the thyroid in the Salmonidæ, is a malignant neoplasm.

2. The disease occurs in fish living under sonditions of freedom in populated areas.

3. When introduced into fish-breeding establishments it becomes endemic with occasional epidemic outbreaks.

4. Normal fish taken from the wilderness may be made to acquire the disease when placed in fish-breeding establishments where the disease is endemic.

5. The feeding of uncooked animal proteid favors and the feeding of cooked animal proteid retards the disease as compared with the uncooked. Feeding alone is not an efficient cause. It must be combined with an agent transmitted probably through the water or food, or both.

6. By scraping the inner surface of water-soaked wooden troughs in which the disease is endemic, an agent may be secured which from its action upon the mammalian thyroid when administered through drinking water is no doubt the cause of the disease in the fish confined in these troughs.

7. The agent is destroyed by boiling.

8. Fish in all stages of the disease are favorably affected in the direction of cure by the addition to the water supply in suitable concentration of mercury, arsenic, or iodine.

9. The effect of mercury, arsenic, and iodine in carcinoma of the thyroid in fish and the subsequent positive experiments with metals in mammalian cancer are probably the expression of a therapeutic relation of these elements to carcinoma.

10. Certain species of the Salmonidæ have an almost complete natural resistance to the disease.

11. Certain lots of fish of susceptible species show a high degree of immunity to the disease.

12. Spontaneous recovery occurs in a considerable percentage of individuals.

13. Removal from ponds in which the disease is endemic to natural conditions, or a change to more natural food, increases the percentage of spontaneous recoveries.

I4. Spontaneous recovery appears to confer a degree of immunity against recurrence.

15. The percentage of spontaneous recoveries in the early stages of the disease appears to be higher than in the later stages of the disease.

16. The incidence of the disease increases with the age of the fish, at least up to five years. 
17. Thyroid enlargement and changes presenting at the end of five months a picture of diffuse parenchymatous goiter were induced in mammals by giving them water to drink in which had been suspended scrapings from troughs in which the disease is endemic. Control animals which receive the same water boiled failed to develop thyroid changes. That these enlargements and changes are the first stages in mammals of the same disease which occurs in the fish inhabiting the troughs from which the scrapings were obtained, is an inference which we believe further experiments will justify.

I 8. The disease is endemic in a very high percentage of all trout hatcheries in the United States.

19. The occurrence of the disease in wild fish, its introduction into fish-cultural stations, its localization in certain troughs or water supplies, the method of its spread, its transmission to mammals, the efficacy of three well-known inorganic germicides in the treatment of the disease, the destruction of the agent by boiling, the phenomena of spontaneous recovery and immunity, strongly indicate that the agent causing the disease is a living organism.

20. No evidence has yet been produced to indicate the direct tranismission of the disease from individual to individual.

$2 \mathrm{I}$. In many of its phases the disease is identical with endemic goiter. As there is no line of demarcation between what is called endemic goiter and what we believe we have clearly shown is cancer of the thyroid, we hold that endemic goiter and carcinoma of the thyroid in the Salmonidæ are the same disease.

\section{ZUSAMMENFASSUNG.}

I. Die gegenwärtige Untersuchung des Schilddrüsen-Krebses unter den Fischen wurde von dem Leiter des Gratwick-Laboratoriums eingeleitet zwecks Foerderung der Untersuchungen dieses Institutes betreffs der Natur des Krebses beim Menschen. Nachdem durch die Vermittlung des Praesidenten der Vereinigten Staaten das Interesse unserer Central-Bureaus fuer Fisch-Zucht gewonnen war, nahm die Untersuchung eine beträchtliche Ausdehnung gestützt auf die Wichtigkeit derselben fuer die Fisch-Zucht und für die Krebs-Forschung im Allgemeinen. So wurden fuer den Zweck die Huelfskraefte des Landes (Centralbureau fuer Fisch-Zucht) und des Finzel-Staates (Gratwick Laboratorium) vereinigt.

Bonnet beschrieb im Jahre 1883 eine Kiemen-Erkrankung der Forelle, welche zweifellos mit dem Gegenstand unserer Untersuchungen identisch ist, und dies ist die erste diesbezuegliche Mitteilung, wenn auch die Natur der Erkrankung damals nicht erkannt worden war. Scott erklaerte die Erkrankung im Jahre $189 \mathrm{I}$ als erster fuer Krebs, ohne ihre Beziehung zur Schilddruese zu erkennen. Ihr Entstehen in der Schilddruese wurde zuerst von Plehn im Jahre 1902 behauptet, welcher die Krankheit als ein Adeno-Carcinom diagnostizierte. Pick veroeffentlichte als erster im Jahre 1905 eine eingehende Erforschung der Struktur dieser Neubildungen und erklaerte sie absolut fuer Krebs-Tumoren. Gilruth beschrieb dieselben in 1902 als Epitheliom der Kiemenboegen und wies nach, das sie in den Fisch-Brutanstalten Neu-Seelands sehr verbreitet waren. 
Gaylord began das Studium der Erkrankung im Jahre 1908 und berichtete Tatsachen, welche auf eine Infektion als Ursache hinwiesen. Marine und Lenhart behaupteten im Jahre 1909 und spaeter als das Resultat ihrer Untersuchungen, dass die Krankheit ein endemischer Kropf waere. Sie konnten in ihren Praeparaten keinen Krebs feststellen.

Die Erkrankung ist in den Vereinigten Staaten weit verbreitet und kommt wahrscheinlich mehr oder weniger ueberall vor, wo die $Z$ üchtung von Salmoniden ueber das frueheste Stadium hinaus fortgefuehrt wird.

II. Die Follikel der normalen Schilddruese in der Lachs-Gruppe aehneln denen der Saeugetier-Schilddruese, aber die Druese ist nicht eingekapselt und nicht so scharf abgegrenzt. Bei der wilden Bach-Forelle sind die groessten Häufchen der Follikel makroskopisch eben wahmehmbar, und das gesammte Schilddruesengewebe ist in der Naehe der Ventral-Aorte hauptsaechlich dorsalwaerts derselben gelagert zwischen dem ersten und dritten Kiemenbogen. Sie dehnen sich nicht lateralwaerts längs den Kiemenboegen aus. Die Lage is mehr beschraenkt als nach der Angabe von Gudernatsch. Haeufig sieht man anomale Follikel-Anhaeufungen unter dem Epithel der Jugular-Vertiefung, aber kaum irgend wo anders. Die Schilddruesen-Follikel der wilden Forelle sind von regelmaessiger Gestalt, gewoehnlich kugelig oder länglichrund, in der typischen oder einfachsten Form haben sie ein flaches, jedenfalls nie hoeher als würfelförmiges Epithel.

III. Einfache Hyperplasie der Schilddruese findet man bei der wilden Forelle. Die Follikel sind zahlreicher, unregelmässiger in Form, das Colloid ist vermindert und das Epithel ist zum grossen Teil säulenförmig. Solch eine Hyperplasie kommt auch beider zahmen Forelle vor, und dieselbe lässt sich nicht von dem frühsten Stadium des Schilddruesen-Krebses unterscheiden. Die immune See-Forelle (Salmo trutta) zeigt gelegentlich im ersten Jahr diese einfache Hyperplasie und im ausgewachsenen Zustand findet man einzelne mit colloidem Kropf. Spontanheilung des SchilddrüsenKrebses beim Fisch zeigt nicht dieses Bild des colloiden Kropfes.

IV. Das erste makroskopische Anzeichen der Erkrankungen ist gewöhnlich ein hyperämischer Fleck in dem Boden der Mundhöhle (red floor). Das erste Zeichen einer sichtbaren Neubildung findet man an der Kiemenbogen-Vereinigung. Deutliche Tumoren können entweder hier oder auf dem Boden der Mundhöhle oder zu beiden Seiten der Kiemenbögen hervorwachsen. Selbständige Tumoren entwickeln sich in der JugularVertiefung, woselbst nicht selten Anhäufungen von normalem Schilddrüsen:Gewebe zu finden sind. Die ersten mikroskopischen Anzeichen der Erkrankung findet man in vereinzelten Follikeln, gewoehnlich denen welche einem grossen Blutgefäss benachbart sind. Eine kleine Gruppe von veränderten Follikeln sieht man oft im Frühstadium umgeben von normalem Gewebe. Das Epithel ist würfel-oder säulenförmig, das Protoplasma und die Kerne im gefärbten Präparat sind stark gefärbt. Colloid ist vermindert oder nicht vorhanden, die Gefässe des Stromas sind hyperämisch. Demnächst stellt sich Wucherung der Follikelwand ein, es bilden sich neue Follikel von unregelmässiger Gestalt und papillenartige Auswüchse in die Follikeln. Da die Drüse keine Kapsel hat, wächst das neugeformte Gewebe in die Muskelbündel hinein und füllt die Areolar-Räume. 
In diesem Stadium sind karyokinetische Bilder sehr gewöhnlich, das Epithel ist hochsäulenförmig, häufig findet man mehrere Epithel-Lagen in einem einzelnen Follikel. Die Wucherung kann jetzt so weit fortgeschritten sein, dass sie das "rote Boden" Stadium erreicht. Die Neubildung verfolgt nun nichtmehr den Weg des geringsten Widerstandes. In diesem Stadium des deutlich sichtbaren Tumors zeigt derselbe eine auffallende Character-Verschiedenheit im Wachstum. Sämmtliche Typen können in einem Tumor vorkommen. Man kann alveolare, tubulare und solide Formen unterscheiden, welche im Verein mit papillären und cystischen Typen auftreten können. Häufig findet man kleine adenomatöse Gewebshäufchen von bösartigem Aussehen, welche in das umgebende, weniger bösartig aussehende Schilddrüsengewebe hineinwachsen und dasselbe durchdringen. Manchmal fanden sich Inseln von normalem Schilddrüsengewebe in den Knochenräumen oder in den Knochenhöhlen, wo das gesammte umgebende Gewebe durch Schilddrüsen-Krebs ersetzt war. Es liess sich wirkliche Infiltration des Knochens, des Knorpels, der Gefäss-Wandung, des Muskels und der Haut nachweisen. Manchmal stösst man auf Tumoren, welche das Bild des sogenannten Sarco-Carcinom der SäugetierSchilddrüse geben; ein Hintergrund von Spindel-Zellen wie beim Sarkom mit einer Alveole hier und da. Tumoren an der Spitze des Unterkiefers sind entweder Implantationen oder Metastasen. Eine deutliche Ähnlichkeit des primären Tumors in der Schilddrüsen-Gegend mit der Wucherung an der Spitze des Kiefers, welche wir in einem Falle untersuchten, zeigte dass letztere wahrscheinlich eine Metastase an einer verletzten Stelle war. Einen unzweifelhaften Fall von Metastasis fanden wir in einer Neubildung in der Darm-Wandung am untern Ende des End-Darms. Dasselbe wuchs in die Muscularis mucosa des Darms, zeigte den typischen Schilddrüsen-Krebs-Bau, grosse unregelmässige Follikel gesäumt mit säulenartigem Epithel, hier und da etwas Colloid. Teile der Geschwulst sehen aus wie die am wenigsten bösartig aussehenden primären Tumoren. Der Character dieser Neubildung und die Localität beweisen deutlich dass es eine Metastase ist. Eine Vergleichung der verschiedenen Formen des Schilddrüsenkrebses in den Salmoniden zeigt, dass sie im Grossen und Ganzen den drei Gruppen entsprechen, welche Langhans fuer den Schilddrüsenkrebs bei Säugetieren aufstellt, nämlich: Wuchernder Kropf, krebsartiger Kropf und bösartiges Papillom.

V. Drei Fälle der Erkrankung haben wir in den Vereinigten Staaten beim-Fisch im Wildzustand gefunden, einen bei einer Bach-Forelle, welche vielleicht aus einer FischZüchterei verpflanzt worden war. Die zwei andere betraf einen "Weissfisch" (Coregonus) und ein Lachs (Salmo sebago). Bei dem Coregonus findet weder künstliche Fütterung noch Züchtung statt.

VI. Die Erkrankung wurde in I6 Arten der Familie "Lachs" beobachtet oder in deren Kreuzungsformen. Die geologische Formation des Bodens in der Umgebung der Gewässer und ihrer Quellen, in denen die Krankheit an Fischen beobachtet worden ist, hat wahrscheinlich nichts mit ihrem Ursprung zu thun, ebenso wenig die im Wasser gelösten Bestandteile. Die Erkrankung ist gewöhnlich endemisch, zuweilen epidemisch. Sie kommt vor in Teichen und Wasserbehältern, was immer auch die Construction sein mag, in welchen Fische gehalten, gezüchtet und mit der gebräuchlichen Proteinhaltigen Nahrung gefüttert werden: Roher Leber, Herz, Lunge und anderen animalen Bestandteilen. Beim Verfolgen eines Flussgebiets stromabwärts sieht man 
eine Zunahme in der Affektion. Kreuzungen mit dem Lachs des Stillen Oceans sind besonders emfänglich und zeigen eine hohe Krankheits-Ziffer. Die endemische Form verläuft langsam, chronisch mit einer niedrigen Sterberate, welche selbst sicherer festzustellen ist wegen der Complication mit intercurrenten Affektionen und der schliesslichen Infektion. Das Vorkommen deś Tumors schwankt sehr und nimmt mit dem Alter des Fisches zu. Makroskopisch sichtbare Neubildungen waren erst nach dem fünften Lebensmonat des Fisches bemerkbar. Anämie und Cachexie, zuweilen sehr hochgradig, waren eine häufige aber nicht constante Begleit-Erscheinung. Immunität zeigt sich in auffallender Weise nicht nur bei einzelnen Arten wie bei der See-Forelle, sondern auch bei Arten welche für die Erkrankung empfänglich sind. Heilung oder Rückbildung kommt vor, wenn die erkrankten Individuen in Verhältnisse absoluten Naturzustandes übergef ührt werden und auch wenn Fische in Teichen weiter gehalten werden, in welchen sie erkrankten.

VII. Füttern von Bachforellen mit Fisch-Tumoren oder mit Krebs vom Menschen während einer Periode von meheren Monaten gab nicht den geringsten Beweis, dass eine Erkrankung solchem Füttern zuzuschreiben sei. Innige Berührungen von empfänglichen Forellen mit Forellen-Tumor-Material in stagnierendem Wasser oder mit tumorbehafteten Fischen in circulierendem unverändertem Wasser brachte uns nur negative Resultate. Der Fischtumor hat sich noch nicht mit Erfolg transplantieren lassen, aber Implantationen gelangen bis zu einem gewissen Grade, und dieselben waren nach Verlauf von 3 Monaten lebensfähig. Der Tumor-Extract ist hochgradig giftig für die Forelle, wenn derselbe in die Schilddrüse oder subcutan injiciert wird. Wilde Forellen wurden aus ihrer natürlichen Umgebung in Cement-Behälter gebracht und mit ungekochter Leber and Herz gefüttert. Dieselben zeiten die mikroskopisch nachweisbare Erkrankung am Ende des ersten Jahres und sichtbaren Krebs zwischen dem ersten und zweiten Jahr. Fütterung mit gekochter Leber verzögerte den Prozess. Spontane Rückbildung war in einem grossen Prozentsatz der fleischgefütterten Fische am Ende des zweiten Jahres nachweisbar. Forellen derselben Art mit Salzwasser-Fisch, Vegetabilien oder einer Mischung von Muscheln und lebenden Würmern genährt behielten ihre normale Schilddrüse.

VIII. Jod, Quecksilber und Arsen in ihren Salzverbindungen im Wasser gelöst, in welchem die Fische leben, unterbrechen das Fortschreiten der Erkrankung und stellen beinahe den Normal-Zustand des Schilddrüsen-Epithels wieder her. Ein deutlicher Einfluss ist schon nach wenigen Tagen bemerkbar. Sichtbare Tumoren werden wahrnehmlich beeinflusst und können beträchtlich schrumpfen. Jod und Quecksilber sind schon im millionenfacher Verdünnung wirksam. Jod ist wirksam, wenn in den Verdauungstractus gebracht und durch die Vermittlung des Wassers. Nach beiden Richtungen hin waren Versuche mit Thymol ohne Einfluss.

IX. Schlamm und Wasser von Fischteichen, in welchen Schilddrüsenkrebs endemisch war, wurde an Hunde verfüttert. Es zeigte sich, dass das Wasser ein Agens enthielt, welches imstande war, deutliche Veränderungen in der Schilddrüse zu verursachen. Material, welches von der Innenseite alter Fischbehälter abgekratzt worden war, in denen beständig Schilddrüsenkrebs produciert worden war, gab positive Resultate 
Vier Hunde wurden 6 Monate lang mit Wasser getränkt, dem dieses Material beigesetzt war. Sie zeigten sämmtlich ausgesprochene Hyperplasie der Schilddrüse, und drei hatten vergrösserte Schilddrüsen. Die Schilddrüsen der 3 Control-Tiere blieben normal in Grösse. Zwei davon waren normal in Bau, während eine leichte Hyperplasie zeigte, wahrscheinlich aus Gründen eines früheren Experiments. Ratten wurden 6 Monate lang mit Schlamm und Wasser aus Teichen gefüttert, in denen Schilddrüsenkrebs vorherrschend war. Dies Wasser musste mehrere hundert Meilen transportiert werden. Das Resultat war negativ. Das obenerwähnte abgekratzte Fischbehälter material wurde 4 Monate lang in Wasser an Ratten verfüttert. Das Wasser wurde ebenfalls einige hundert Meilen transportiert. Das Resultat war ähnlich wie bei den Hunden, nur nicht so ausgesprochen.

$\mathrm{X}$. In den hyperplastischen Schilddrüsen von drei jungen und einem atusgewachsenen Hund, welche mit Wasser und Schlamm aus Fischteichen und Kratzmaterial aus Fischtrögen getränkt wurden, fanden wir kleinste Nematoden unmittelbar unter der Kapsel oder in der Substanz der Schilddrüse. Die Würmer waren von Anhäufungen von Bindegewebe eingeschlossen. In zwei Fällen wurden nur Überreste von kleinen Nematoden in der Schilddrüsengegend bei Bachforellen gefunden mit einem Schilddrüsenkrebs, der sich in der Rückbildung befand. Wenn diese Nematoden eine aetiologische Bedeutung haben, so kann es nur die sein, dass sie Träger eines ursächlichen Agens sind.

\section{SCHLUSSFOLGERUNGEN.}

r. Die Krankheit, welche unter dem Namen Kiemen-Krankheit, Schilddrüsentumor, endemischer Kropf oder Krebs der Schilddrüse bei der Lachs-Familie bekannt ist, ist eine bösartige Neubildung.

2. Die Krankheit findet sich bei Fischen, dic unter natürlichen Bedingungen in bewohnten Gebieten leben.

3. In Fisch-Züchtereien eingeführt wird sie endemisch und bricht zuweilen in Epidemien aus.

4. Normale Fische der Wildnis entnommen können an der Affektion erkranken, wenn sie in Fisch-Anstalten gebracht werden, in welchen dieselbe endemisch ist

5. Die Fütterung mit ungekochtem Proteid Material vom Tier begünstigt, die mit gekochtem verzögert den Ausbruch der Krankheit. Fütterung allein ist nicht eine wirksame Ursache. Es muss dazu kommen ein anderes Agens, das wahrscheinlich durch Wasser oder durch Nahrung oder durch beides übermittelt wird.

6. Durch Ausschaben der Innenfläche hölzerner wasserdurchtränkter FischBottiche, in welchen die Krankheit endemisch ist, erhält man ein Agens, welches nach der Wirkung auf die Säugetier-Schilddrüse durch Vermittlung von Trinkwasser zu urteilen ohne $Z$ weifel die Ursache der Erkrankung der Fische ist, wclche in diesen Behältern gehalten werden.

7. Durch Kochen wird dasselbe zerstört.

8. In allen Stadien der Erkrankung werden Fische günstig beeinflusst, wenn man dern Wasser in gewisser Verdünnung Quecksilber, Arsen oder Jod zusetzt. 
9. Die Wirkung des Quecksilbers, Arsens und Jods auf Schilddrüsenkrebs beim Fisch und die daraufhin vorgenommenen erfolgreichen Versuche mit Metallen an Säugetieren sind wahrscheinlich der Ausdruck einer Heilwirkung dieser Elemente beim Krebs.

Io. Gewisse Arten der Salmóniden haben beinahe eine völlige natürliche Widerstandsfähigkeit gegen die Erkrankung.

I I. Manche Fische von empfänglichen Arten zeigen einen hohen Grad vom Immunität gegen die Krankheit.

12. Spontanheilung kommt in einer beträchtlichen Anzahl von Individuen vor.

13. Übertragung aus Teichen mit endemischer Erkrankung in natürliche Umgebung oder Übergang zu mehr natürlicher Nahrung vermehrt den Prozentsatz der Spontanheilungen.

I4. Spontan-Heilung scheint einen gewissen Grad von Schutz gegen Rückfall zu. verleihen.

15. Der Prozentsatz der Spontan-Heilungen in den Frühstadien der Krankheit scheint höher zu sein als in den späteren Stadien.

16. Das Vorkommen der Krankheit nimmt mit dem Alter des Fisches zu wenigstens. bis zum 5 ten Jahr.

I7. Schilddrüsen-Vergrösserung und Veränderungen, welche nach Verlauf von 5 Monaten das Bild eines diffusen parenchymatösen Strumas darboten, wurden bei Säugetieren erzeugt, wenn man ihnen Wasser zu trinken gab mit ausgeschabtem Material von Fischbottichen, in welchen die Krankheit endemisch war. Controll-Tiere, welche dasselbe Wasser gekocht erhielten, zeigten keinerlei Veränderungen an der Schilddrüse. Dass diese Vergrösserungen und Veränderungen an Säugetier-Schilddrüsen die ersten Stadien derselben Erkrankung sind, welche bei Fischen vorkommen, welche die obenerwähnten Bottiche bewohnt haben, ist ein Schluss, welchen nach unserer Überzeugung weitere Versuche rechtfertigen werden.

18. Die Erkrankung ist zu einem hohen Prozentsatz in allen Forellen-Züchtereien der Vereinigten Staaten endemisch.

19. Das Vorkommen der Krankheit beim wilden Fisch, ihre Einführung in FischZüchtereien, ihre Localisation in gewissen Bottichen oder Wasserläufen, die Methode ihrer Verbreitung, ihre Übertragung auf Säugetiere, die Wirksamkeit von 3 wohlbekannten Germiciden inorganischer Natur bei der Behandlung der Krankheit, die Zerstörung des Agens durch Kochen, die Erscheinungen der Spontan-Heilung und der Immunität, weisen dringend darauf hin, dass das ursächliche Moment der Krankheit ein lebender Organismus ist.

20. Es ist bisher kein Nachweis geliefert, dass die Krankheit von einem Individuum auf das andere übertragen wird.

21. In einer Reihe von Entwicklungs-Phasen ist die Krankheit identisch mit endemischem Kropf. Da sich eine scharfe Grenze zwischen sogenanntem endemischem Kropf und dem was wir als Krebs der Schilddrüse auffassen und bewiesen zu haben glauben, nicht ziehen lässt, so behaupten wir, dass endemischer Kropf und SchilddrüsenKrebs bei den Salmoniden ein und dieselbe Krankheit ist. 


\section{RÉSUMÉ.}

L'investigation, dont les pages suivantes sont un compte-rendu, du carcinome de la glande thyroïdienne chez les poissons a été entreprise par le directeur du Gratwick Laboratory dans le cours des recherches du laboratoire sur la nature du cancer chez l'homme. Le Président des Etats-Unis ayant eu son attention appelée sur ce travail a instruit le bureau des poissons d'y prêter son concours, de sorte que les ressources des Etats-Unis et de l'Etat de New York, representées par ce bureau et le Gratwick Laboratory, étant réunies, il en a résulté une investigation plus étendue de grand intérêt et de grande importance autant pour la pisciculture que pour les recherches sur le cancer.

Bonnet, en I 883 , décrit une maladie des branchies chez la truite, laquelle est sans doute identique avec le sujet de ce travail. Cette description est donc la première publication sur ce sujet, quoique la nature de la maladie ne fút pas alors reconnue. Scott en i 89i fut le premier à reconnaître la maladie comme carcinomateuse sans toutefois reconnaître sa relation avec la glande thyroïde. Son origine dans la glande thyroïde fut avancée en premier lieu par Plehn en 1902, elle en fit le diagnostic de l'adéno-carcinome. Pick publia en I 905 la première étude un peu complète sur la structure de ces tumeurs et insista sur leur nature cancéreuse. Gillruth en 1902 le décrit comme une épithéliome ayant siège dans les arcs branchiaux et dit qu'on le trouvait dans la. plupart des établissements de pisciculture de la Nouvelle-Zélande. Gaylord commença son étude de la maladie en 1908 et fit un rapport dans lequel il attira l'attention sur la nature infectieuse de la cause. Marine et Lenhart comme résultat de leurs études. commencées en 1909 considèrent la mala die comme étant un goître endémique et disent qu'ils n'ont pas trouvé de sujets dans lesquels ils ont trouvé aucun symptôme de cancer.

La maladie est grandement répandue à travers les Etats-Unis et existe probablement plus ou moins partout où l'élevage artificiel des salmonidées est continué plus loin que dans leur état primitif.

II. Les follicules thyroïdiens chez les salmonidées ressemblent à ceux des mammaliens, mais la glande n'est pas encapsulée ni si limitée dans sa situation. Chez les truites de ruisseaux sauvages les plus grandes collections de follicules sont à peine macroscopiquement visibles, et tout le tissu thyrö̈dien est placé aux alentours de l'aorte ventrale du côté dorsal entre les premier et troisième ares branchiaux et ne s'étend pas latéralement le long de ces arcs. Leur distribution est quelque peu moins restreinte que ne l'indique Gudernatsch. On trouve souvent des dépôts irréguliers sous l'épithélium de la fosse jugulaire, mais ils sont rares autre part. Les follicules thyroïdiens des truites sauvages sont de forme régulière, généralement sphériques ou un peu allongés, dans les conditions types et normales ils sont composés d'épithélium généralement aplati, mais dans aucun cas plus haut que cuboïde.

III. Une simple hyperplasie de la thyroïde chez la truite existant dans des conditions sauvages se rencontre assez souvent. Les follicules sont augmentés en nombre, leur forme est plus irrégulière, la substance colloïdale est diminuée, l'épithélium est pour la plupart columnaire. La même hyperplasie existe aussi chez la truite d'élevage et ne peut être distinguée des premiers développements du carcinome de la thyroïde. 
La truite de mer (Salmo trutta) dans ses premières années présente aussi quelquefois cette simple hyperplasie, et on trouve même quelques adultes avec un goître colloïdal. La guérison spontanée du carcinome chez le poisson ne résulte pas en goître colloïdal.

IV. On trouve généralement comme première évidence macroscopique de la maladie un foyer d'hyperhémie sur le plancher de la bouche (plancher rouge). Le premier signe visible de tumeur se voit généralement à la jonction des ares branchiaux. Les tumeurs peuvent s'étendre dans différentes directions, soit vers le plancher de la bouche, soit de chaque côté des ouies. Des tumeurs indépendantes peuvent se développer dans la fosse jugulaire, région qui contient souvent des dépôts de tissu thyroïdien normal. On trouve la première évidence microscopique de la maladie dans lesfollicules individuels, généralement dans ceux proches d'un grand vaisseau. Souvent il se fait qu'on trouve à ce degré un petit groupe de follicules altérés entourés par des follicules normaux. L'épithélium est composé de hautes cellules cuboïdes ou en colonnes, le protoplasme et les noyaux prennent un coloris profond. La substance colloïdale est diminuée ou manque complètement, les vaisseaux du stroma sont hyperhémiques. Ceci est suivi par un bourgeonnement de la paroi du follicule, formant de nouveaux follicules isolés, de type irrégulier, et aussi des projections papillaires dans les follicules. Comme la glande n'est pas encapsulée, il se développe un tissu de formation nouvelle entre les plans musculaires et qui remplit aussi les espaces aréolaires. A cette époque on trouve souvent des formes karyokinétiques, l'épithéliuın est en colonnes hautes; le même follicules contenant souvent plusieurs couches d'épithélium. A ce moment il se peut que la prolifération soit assez developpée pour donner lieu à la condition reconnue comme celle du plancher rouge. L'os, le cartilage et le muscle, tout est envahi. La tumeur ne cherche plus le chemin de moindre résistance. Dans la période où la tumeur est visible les variations dans le caractère de la prolifération sont remarquables. Tous les différents types peuvent exister dans la même tumeur. On peut les diviser en alvéolaires, tubulaires et solides, ainsi que combinées avec les types papillaires et cystiques. On voit souvent de petites masses adénomateuses d'apparence maligne envahissant et infiltrant le tissu thyroïdien qui apparaît moins malin aux alentours. Il arrive quelquefois qu'on trouve des ilots de tissu thyroïdien normal dans les espaces et cavités des os, tandis que le tissu environnant a été complètement remplacé par le thyroïde carcinomateux. Une infiltration vraie de l'os, du cartilage, de la paroi vasculaire, du muscle et de la peau a été démontrée. Parfois on trouve des tumeurs qui présentent l'apparence des soi-disant tumeurs sarco-carcinomateuses de la thyroïde chez les mammifères; un arrière-plan de cellules en fuseau ressemblant à un sarcome avec, ça et là, des alvéoles. Les croissances sur la pointe de la mâchoire sont soit des implantations, soit des métastases. Ayant trouvé une tumeur de la pointe de la mâchoire pareille à une tumeur thyroïdienne primaire, nous en avons fait une étude spéciale, dont il résulte que cette formation métastatique a probablement lieu à un point blessé. Dans un cas de tumeur trouvée dans la paroi intestinale nous avons un cas certain de tumeur métastatique, cette tumeur fut trouvée à l'extrémité inférieure des intestins, elle infiltrait d'un vrai tissu carcinomateux thyroïdien le tissu "muscularis mucosa" de la paroi intestinale. Ce tissu se composait de grands follicules irréguliers doublés d'épithélium en colonne, 
contenant parfois de la substance colloïde. Il y avait des parties de la tumeur qui présentaient l'apparence des tumeurs primaires les moins malignes. Le caractère de cette tumeur et la région où on la trouva démontra sans aucun doute qu'elle était de caractère métastatique. Une comparaison des différents types de thyroïde carcinomateuse chez les salmonidées nous démontra qu'on peut les classer approximativement sous les trois groupes proposés par Langhans pour le carcinoma de la thyroïde chez les mammifères, c'est-à-dire struma proliférant, struma carcinomateux, et papillome malin.

V. Trois cas de la maladie ont été trouvés chez les poissons sauvage aux EtatsUnis. (I) Chez une truite de ruisseau qui peut avoir été distribuée par un établissement de pisciculture; (2) chez un Laveret (Coregonus) qui ne peut être élevé ni nourri artificiellement; (3) chez un saumon de lac (Salmo sebago).

VI. La maladie a été observée chez 16 espèces ou hybrides des salmonidées.

La formation géologique aux sources des eaux dans lesquelles on trouve la maladie semble n'avoir rien à faire avec son origine, de même que le contenu dissous dans l'eau.

La maladie est généralement endémique, rarement épidémique. On la trouve dans les viviers et bassins, quelle que soit leur construction, où les poissons sont gardés, élevés et nourris avec la nourriture protéidienne ordinaire de la pisciculture, c'est à dire, foie, cœur, poumons et autres viandes crues. Elle paraît avoir une tendance à augmenter en descendant un cours d'eau. Les hybrides du saumon de la côte du Pacifique semblent spécialement susceptibles et présentent un grand pourcentage de cas. Quand la maladie est endémique son cours est lent et chronique, avec une mortalité difficile à déterminer à cause de complications avec des infections secondaires ou terminales at autres causes de mort. Le nombre des tumerus varie énormément et augmente avec l'âge du poisson. Des tumeurs visibles macroscopiquement n'ont pas été vues dans des poissons de moins de 5 mois. Une anémie et cachexie, souvent extrême, accompagne généralement la maladie, mais cette condition peut manquer complètement. L'immunité se voit d'une manière remarquable, non seulement parmi les espèces, comme chez les truites de mer (Salmo trutta), mais aussi parmi certaines bandes contenant des espèces susceptibles. Quand des poissons affectés sont déplacés, soit dans un autre vivier non infecté ou mis dans des conditions sauvages, un mouvement rétrograde et même une guérison a lieu assez souvent.

VII. Des truites de ruisseau, quoique ayant été nourries pendant plusieurs mois de tumeurs de poisson et même de cancer humain, n'ont présenté aucune évidence de maladie qu'on ait pu attribuer à cette nourriture. De même, des truites susceptibles quoiqu'ayant été gardées dans de l'eau stagnante contenant de la matière de tumeur de truite, ou avec des poissons infectés dans de l'eau circulant non renouvelée, ont, elles aussi, donné un résultat négatif. La tumeur de poisson n'a pas encore été transplantée avec succès, quoique des greffes ont un peu grandi et n'étaient pas encore nécrotiques au bout du troisième mois. L'extrait de la tumeur est très toxique quand on l'injecte dans la région thyroïdienne ou autre part. Des truites de ruisseau venues d'endroits non habités et enfermées dans des viviers de ciment et nourries avec du cœur et du foie crus ont développé la maladie de manière à ce qu'elle fût visible microscopiquement au bout de la première année et un carcinome visible macroscopiquement 
entre la première et deuxième année. La cuisson de la nourriture retarde la marche de la maladie. Une rétrogradation spontanée semble avoir lieu dans un grand pourcentage des poissons ainsi nourris au bout de la deuxième année. Des truites semblables nourries avec du poisson de mer, avec de la nourriture végétale ou avec une combinaison de moules et d'asticots vivants, retiennent leurs thyroïdes normaux.

VIII. Les sels de n'importe lequel des éléments suivants: iode, mercure ou arsenic dissous dans l'eau habitée par les poissons, interrompt le progrès de la maladie et ramène l'épithélium thyroïdien à une condition pour ainsi dire normale. Le résultat se produit d'une manière visible au bout de quelques jours. Ce traitement agit sur les tumeurs visibles de manière que leur grosseur peut être vite diminuée. L'iode et le mercure agissent même quand ils sont dilués dans des millions de parties d'eau. L'iode est effectif quand on l'introduit dans le système digestif aussi bien que dans l'eau. Des. résultats négatifs furent obtenus avec l'administration du thymol des deux manières.

IX. L'administration, à des chiens, de la boue et de l'eau des viviers où le carcinome était endémique, montra d'une manière suggestive que la boue et l'eau contenaient un agent capable de produire des changements bien marqués dans la thyrö̈de. Des raclures d'intérieur de vieux bassins à poisson dans lesquelles le carcinome de poisson a été continuellement reproduit donnèrent des résultats positifs. Pendant six mois on donna à boire à quatre chiens de l'eau dans laquelle ces raclures avaient été macérées. Tous développèrent une hyperplasie thyroïdienne marquée et trois d'entre eux des thyroïdes grossis. Les thyroïdes de trois autres animaux de contrôle à qui on donna la même eau, mais bouillie, restèrent de grandeur normale. Deux d'entre eux étaient normaux comme structure, tandis que le troisième montrait quelques traces d'hyperplasie probablement causées par une expérience antérieure.

Des rats qui avaient été nourris avec la boue et l'eau prises des viviers où il y avait le carcinome et qui avaient été transportés une journée entière en chemin de fer, donnèrent un résultat négatif. Tandis que d'autres auxquels fut donnée de l'eau avec raclures de bassins à poisson également transportée, produisirent des résultats semblables à ceux trouvés chez les chiens, mais à un degré moins marqué.

$\mathrm{X}$. Dans les thyroïdes hyperplastiques des quatre chiens dont trois étaient jeunes, auxquels fut donnée la boue et l'eau de vivier ou de l'eau contenant des raclures de bassins, on a trouvé des vers nématoïdes miniscules directement sous la capsule ou dans la substance du thyroïde. Les vers étaient entourés de tubercules de tissu conjonctif. Dans deux cas seulement des restes de vers nématoïdes furent trouvés dans: la région thyroïdienne de quelques truites, dans ces cas le carcinome était en état de rétrogradation. Si ces vers ont une signification étiologique, ce ne peut être que simplement comme porteurs de l'agent causatif.

\section{CONCLUSIONS.}

I. La maladie connue sous les noms de maladie des branchies, tumeur thyroïdienne, goître endémique ou carcinome de la thyroïde chez les salmonidées, est une tumeur maligne.

2. La maladie se présente chez les poissons vivant en liberté dans des régions peuplées. 
3. Quand elle s'introduit dans un établissement de pisciculture elle devient endémique et même quelquefois épidémique.

4. Des poissons normaux pris loin des habitations peuvent contracter la maladie quand on les place dans un vivier où elle est endémique.

5. Le nourrissage avec des produits animaux protéidiens non cuits accélère le développement, tandis que les mêmes produits cuits retardent sa production. Mais le nourrissage seul n'est pas une cause efficace. Il faut le combiner avec un agent transmis probablement par la nourriture ou l'eau, ou peut-être par les deux.

6. En raclant la surface intérieure des bassins en bois dans lesquels la maladie est endémique, on peut acquérir un agent qui, par son action sur la thyroïde des mammifères quand on l'administre dans l'eau potable, est très probablement la cause de la maladie chez les poissons gardés dans ces bassins.

7. On peut détruire l'agent en le bouillant.

8. L'état des poissons, dans n'importe quel degré de la maladie, est amélioré favorablement par l'addition à l'eau, de mercure, d'iode, ou d'arsenic en quantité nécessaire.

9. L'effet du mercure, de l'arsenic et de l'iode sur le carcinome de la thyroïde chez les poissons, et subséquemment les résultats positifs de cet usage de métaux dans le cancer des mammifères, font croire à une relation thérapeutique entre les métaux et le carcinome.

ı. Certaines espèces de salmonidées offrent une résistance naturelle presque complète à la maladie.

I . Certains groupes de poissons d'espèces susceptibles montrent un degré d'immunité très élevé contre la maladie.

I2. Une guérison spontanée a lieu dans un pourcentage considérable de sujets.

13. Quand on change les sujets du local où la maladie est endémique à des conditions naturelles, ou quand on leur donne une nourriture plus naturelle, on remarque également une augmentation du pourcentage des guérisons spontanées.

14. La guérison spontanée semble accorder un certain degré d'immunité contre la récidive.

15. Le pourcentage des guérisons spontanées semble être plus grand dans les premiers degrés de la maladie que plus tard.

16. La susceptibilité à la maladie semble augmenter avec l'âge du poisson au moins jusqu'à l'âge de cinq ans.

I7. Au bout de cinq mois on a remarqué un développement thyroïde et autres changements qui présentent un tableau type de goître parenchymateux diffus chez les mammifères auxquels on a donné à boire de l'eau dans laquelle avaient été suspendues des raclures de bassins dans lesquelles la maladie était endémique. Les animaux employés comme contrôle qui recevaient la même eau bouillie n'ont pas développé de changements thyroïdiens. Que ces développements et changements sont les premiers degrés chez les mammifères de la même maladie qui a lieu chez les poissons habitant les bassins d'où les raclures ont été prises, voilà une déduction que nous croyons que des expériences plus étendues justifieront. 
18. La maladie est endémique dans un grand pourcentage des établissements de pisciculture aux Etats-Unis.

19. Que la maladie se présente chez le poisson sauvage, qu'on peut l'introduire dans des établissements de pisciculture, qu'elle se localise dans certains bassins ou cours d'eau, la manière dont elle se répand, sa transmission aux mammifères, le bon résultat obtenu dans le traitement de la maladie avec les trois germicides inorganiques bien connus, la destruction de l'agent par la chaleur, le phénomène de la guérison spontanée et de l'immunité, tout semble indiquer que l'agent provocateur de la maladie est un organisme vivant.

20. Jusqu'à présent rien n'indique que la maladie peut être transmise directement d'individu à individu.

2r. Dans beaucoup de ses phases la maladie est identique avec le goître endémique. Comme il ne semble pas y avoir de point de démarcation entre le goître endémique ct ce que nous croyons avoir demontré être un cancer de la thyroïde, il nous semble que nous pouvons dire que le goître endémique et le carcinome chez les salmonidées sont la même maladie. 


\section{BIBLIOGRAPHY}

ADAM, TH.

1876. Ueber das enzootische Vorkommen des Kropfes bei Pferden in Augsburg. Wochenschrift für Tierheilkunde und Viehzucht, jahrg. $x x, n r .2, p .13$.

Ascuorf, $\mathrm{L}$.

1912. Demonstrationen von Präparaten des Prof. Gaylord betreffend die künstliche Erzeugung von Kropfen bei Fischen und Hunden. Freiburger Medizinische Gesellschaft, Sitzung vom 3. Juni r912. Deutsche medizinische Wochenschrift, jahrg. 38, nr. 25, p. 1214.

BASHFORD, E. F., AND MURRAY, J. A.

1904. The zoological distribution, the limitations in the transmissibility, and the comparative histological and cytological characters of malignant new growths. Scientific Reports on the Investigations of the Cancer Research Fund, London, no. I.

BIRCHER, EUGEN.

Igroa. Zur experimentellen Erzeugung der Struma, zugleich ein Beitrag zu deren Histogenese. Deutsche Zeitschrift für Chirurgie, bd. 103, p. 276.

rgrob. Die kretinische Degeneration. (Kropf, Endemischer Kretinismus und Taubstumheit.) Fortschritte der naturwissenschaftlichen Forschung, bd. 2, p. 273.

19r 1a. Weitere Beiträge zur experimentellen Errzeugung des Kropfes. Die Kropfätiologie ein colloidchemisches Problem. Zeitschrift für experimentelle Pathologie und Therapie, Berlin, bd. 9, p. I.

I I rb. Weitere histologische Befunde bei durch Wasser erzeugten Rattenstrumen und Kropfherzen.

BIRCHER, H.

Deutsche Zeitschrift für Chirurgie, I,eipzig, bd. 112, p. 368 .

1883. Der endemische Kropf und seine Bezichung zur Taubstummheit und zum Kretinismus. Basel.

BONNET, R.

1883. Studien zur Physiologie und Pathologie der Fische. Bayerische Fischerei-Zeïtung, München, nr. 6, p. 79 .

BORREL, A.

I906. Tumeurs cancéreuses et helminthes. Reported by E. Roux in Bulletin de l'Académie de Médecine, 3 me série, t. 56 , p. $14 \mathrm{r}$.

rgro. Parasitisme et tumeurs. Travaux de la deuxième Conférence internationale pour l'Etude du Cancer, Paris, p. 193.

BREITNER.

1912. Ueber die Ursache und das Wesen des Kropfes. Wiener klinische Wochenschrift, jahrg. 25, nr. 2, p. 82 .

CARLE.

1888. La Riforma medica, p. I9r.

Ciingas, Cartos.

igr r. Ein neuentdeckter Krankheitsprozess des Menschen. Memorias do Instituto Oswaldo Cruz. Rio de Janeiro, Manguinhos, I911, t. III, p. 219.

Clowes, G. H. A.

1908. Action of chemical compounds on cancer in mice. In report of New York State Cancer Laboratory, 29th Annual Report of Department of Health of the State of New York, vol. I. Also in: Ueber die therapeutische Wirkung der Metalle auf Krebs. Berliner klinische Wochenschrift, r912, nr. 43 . 
DigTERLE, HirSChFELD, KLINGER.

1913. Studien über den endemischen Kropf. Münchener medizinische Wochenschrift, jg. 6o,

EWALD, C. A. nr. 33, p. 1813 .

1909. Die Erkrankungen der Schilddrüse, Myxödem und Kretinismus, 2te aufl. Nothnagels HandFibiger, Johannes. buch der speziellen Pathologie und Therapie, bd. 22. Wien und Leipzig.

1913. Ueber ein durch Nematoden (Spiroptera sp. n.) hervorgerufene papillomatöse und carcinomatöse Geschwulstbildung im Magen der Ratte. Berliner klinische Wochenschrift, Feb. 17,1913, nr. 7, p. 289.

GAYLORD, H. R.

I909. An epidemic of cancer of the thyroid in brook trout in a fish hatchery. Journal American Medical Association, Jan. 30, 1909, vol. 52, no. 5, p. 4II. (American Association for Cancer Research, meeting Nov. 27, Ig08.)

rgroa. An epidemic of carcinoma of the thyroid gland among fish. Ibid., Jan. 15, I9ro, vol. 54, no. 3, p. 227. (American Association for Cancer Research, meeting Nov. 27, 1909.)

Igrob. Discussion of paper by Dr. M. Plehn, Ueber Geschwülste bei niederen Wirbeltieren. Travaux de la deuxième Conférence internationale pour 1'Etude du Cancer, Paris, 2me partie, p. 787 .

19I2a. Ueber die therapeutische Wirkung der Metalle auf Krebs. Berliner klinische Wochenschrift, nr. 43.

1912b. The production of thyroid hyperplasia in dogs from water associated with thyroid hyperplasia in fish. Zeitschrift für Krebsforschung, bd. 12, heft 2, p. 439.

Gaylord, H. R., AND Clowes, G. H. A.

1906. On spontaneous cure of cancer. Surgery, Gynecology and Obstetrics, vol. 2, no. 6, p. 4I.

GAYLORD, H. R., and MARSII, M. C.

1912a. The action of iodine and mercury on thyroid hyperplasia and carcinoma in fish. Abstract. Zeitschrift für Krebsforschung, bd. II, p. I50. (American Association for Cancer Research, meeting Apr. 12, 1911.)

1912b. Relation of feeding to thyroid hyperplasia in Salmonidæ. Ibid., bd. 12, heft 2, p. 436 . (Ibid., Apr. 3-4, Igr2.)

Gaylord, H. R., Marsi, M. C., and Busch, F. C.

1912. Effect of iodine, mercury, and arsenic on thyroid hyperplasias and tumors in fish. Ibid., bd. 12 , heft 2, p. 437 .

GILRUTII, I. A.

rgo2. Epithelioma affecting the branchial arches of salmon and trout. Report of the New Zealand Department of Agriculture, Division of Veterinary Science.

Gudernatschi, J. F.

I909. The structure, distribution, and variation of the thyroid gland in fish. Journal of the American Medical Association, vol. 54, no. 3, Jan. 15, 1910, p. 227. (American Association for Cancer Research, meeting Nov. 27, 1909.)

19ria. The thyroid gland of the teleosts. Journal of Morphology, vol. 21, no. 4, supplement, Feb., IgIr, p. 709, 2 I text fig., 5 pl.

19r rb. The relationship between the normal and pathological thyroid gland of fish. Johns Hopkins HAAL,AND, M. Hospital Bulletin, vol. xxIr, no. 242, May, I9II, p. 152 .

19r. Spontaneous tumors in mice. 4th Scientific Report on the Investigations of the Imperial Cancer Research Fund, p. I.

HALSTED, WiLLiam S.

1888. Report at the Association of American Physicians by Dr. W. H. Welch of Dr. Halsted's experiments relating to the thyroid gland of the dog. The New York Medical Record, vol. 34, p. 368 . 
HALSTEE, WILLIAM S.-Continued.

r 896 . An experimental study of the thyroid gland of dogs, with especial consideration of hypertrophy of this gland. The Johns Hopkins Hospital Reports, vol. 1, p. 373 .

1913. Hypertrophy of the thyroid gland. Revision of experiments made 25 years ago. Proceed-

HANCKE. ings of the Society for Experimental Biology and Medicine, vol. $x$, no. 3 , p. II 1 .

1819. Beobachtungen über den Kropf, dessen ungewöhnlich häufige und rasche Entwicklung, sowie über dessen erfolgreiche Behandlung. C. W. Hufelands Neues Journal der praktische Arzneikunde und Wundarzneikunst, bd. 3 , stück 5, p. 77 .

HESSE, E.

I9II. Die Verbreitung des Kropfes im Königreich Sachsen mit besondcrer Berïcksichtigung der geologischen Verhältnisse. Archiv für klinische Medicin, bd. 102, p. 2 I 7 .

HrRsch, August.

1883. Handbuch der historisch-geographischen Pathologie, 2te aufl, bd. 2. p. 83 . Stuttgart.

HrtzIG.

1894. Beiträge zur Histologie und Histogenesis der Struma. Archiv für klinische Chirurgie, bd. XLVIr, $x 894$.

HOFER, BRUNO. 1904. Handbuch der Fischkrankheiten, p. Ig1. Stuttgart.

JABOULAX.

Igo8. Poissons atteints de goitres malins héréditaires et contagieux. Journal de Médecine et de

Chirurgie pratiques, t. 79, p. 239.

JORDAN, D. S., and EVERMANN, B. W.

r896. The fishes of North and Middle America, part I. Bulletin No. 47 of the U. S. National Museum.

rgo3. American food and game fishes. 573 p., illus. New York.

KOCHER, THEODOR.

1889. Vorkommen und Verteilung des Kropfes im Kanton Bern u.s.w. Bern

KRÄMER.

19ro. Uber die Rückbildungsvorgänge in den Schilddrüsenadenomen. Inaugural-Dissertation. Freiburg in Breisgau, I910.

KOLLE, W.

1909. Ueber Ziele, Wege und Probleme der Erforschung des endemischen Kropfes. Korrespondenzblatt für schweizerische Ärzte, nr. I7.

LANGHANS; THEODOR.

1907. Ueber die epithelialen Formen der malignen Struma. Virchow's Archiv, bd, 189, p. 69.

LEVIN, ISAAC.

19ro. Cancer among the American Indians and its bearing upon the ethnological distribution of the disease. Zeitschrift für Krebsforschung, bd. 9, heft 3 .

19r2. Studies in cancer and allied subjects. Pathology. Conducted under the George Crocker Special Research Fund. New York, p. 57.

LEWIN, CARL.

r9r3. Die Wirkung von Schwermetallen auf die bösartigen Tiergeschwülste. Berliner klinische Wochenschrift, nr. I2.

Looss, A.

19:1. The anatomy and life history of Ancylostoma duodenale, part 2. Record of the Egyptian Government School of Medicine, Cairo, vol. 4, p. 163-6r3.

LUSTIG

1890. Ueber die Ätiologie des endemischen Kropfes. Verhandlungen des X. internationalen Kongresses in Berlin, bd. 2.

$8207^{\circ}-14-\mathrm{II}$ 
Marine, David, ANd Lenhart, C. H.

Igro a. On the occurrence of goitre (active thyroid hyperplasia) in fish. Jolıns Hopkins Hospital Bulletin, vol. XxI, no. 229, April, rgro, p. 95.

rgrob. Observations and experiments on the so-called thyroid carcinoma of brook trout (Salvelinus fontinalis) and its relation to ordinary goitre. Journal of Experimental Medicine, vol. 12, p.311. Under same title á similar issue, Bulletin No. 7, Department of Fisheries of Pennsylvania, Harrisburg.

Igr ra. Further observations and experiments on the so-called thyroid carcinoma of the brook trout (Salvelinus fontinalis) and its relation to endemic goitre. Journal of Experimental Medicine, vol. I3, p. 455 .

rgrrb. Continued observations and experiments on the so-called thyroid carcinoma of brook trout (Salvelinus fontinalis) and its relation to ordinary goitre. Bulletin No. 8, May I, Igrr, Department of Fisheries of Pennsylvania, Harrisburg. Similar to the preceding with the addition of "Practical suggestions" as part $\mathrm{m}$.

rgrrc. On certain limitations in interpreting thyroid histology. Johns Hopkins Hospital Bulletin,

MARSH, M. C. July, I9II, vol. 22, no. 244, p. 217 .

1902. Hemoglobin estimations and blood counts in fishes. Washington Medical Annals, vol. $\mathrm{r}$, no. 5 , p. 397 .

rg03. Epithelioma in trout. Washington Medical Annals, vol. 2, no. I, p. 59.

rgro. Thyroid tumor in salmonoids. Transactions American Fisheries Society, 19ro, p. 377, I pl.

MAURER, FriEdRTCh.

1886. Schilddrüse und Thymus der Teleostien. Morphologisches Jahrbuch, bd. II, p. r29.

MCCARRISON, ROBERT.

1906. Observations on endemic goitre in the Chitral and Gilgit valleys. Medico-Chirurgical Transactions, London, vol. 89 , p. 437.

1909. Further researches on the etiology of endemic goitre. Quarterly Journal of Medicine, vol. 2, no. 7, p. 279.

Igrr. The experimental transmission of goitre from man to animals. Proceedings of the Royal Society, ser. B, vol. 84 , I912, p. 155 .

MCCLELLAND, JoHN.

r837. Inquiry into the nature and causes of goitre. Dublin Journal of Medical Science, vol. XI, p. 295 .

Mrchaud.

1906. Die Histogenesis der Struma nodosa. Archiv für pathologisclie Anatomie, bd. I86.

MURRAY, J. A.

1908. The zoological distribution of cancer. Third Scientific Report on the Investigations of the Imperial Cancer Research Fund, London, p. $4 \mathrm{r}$.

Neuberg, C., Caspari W., und Löhe, H.

19r2. Weiteres üeber Heilversuche an geschwulstkranken Tieren snittels tumoraffinen Substanzen. Berliner klinische Wochenschrift, bd. 49, nr. 30, p. 1405.

Parker, T. Jerthery, and Haswell, W. A.

1897. A text-book of zaology, vol. ri.

Prek, L.

1905. Der Schilddrüsenkrebs der Salmoniden. Aus dem I,aboratorium der L. und Th. Landau'schen Frauenklinik, Berlin. Berliner klinische Wochenschrift, I905, nr. 46-49, p. I435-1542.

Pick, L., UND POLL, H.

1903. Ueber einige bemerkenswerte Tumorbildungen aus der Tierpathologie, insbesondere tiber gutartige und krebsige Neubildungen bei Kaltblütern. Berliner klinische Wochenschrift, nr. 23-25. Abstract in Journal American Medical Association, Aug. 8, 1903, p. 4 or. 
PLEKN, MarianNe.

1902. Bösartiger Kropf (Adeno-Carcinom der Thyreoidea) bei Salmoniden. Allgemeine FischereiZeitung, München, Apr. 1, 1902, nr. 7, p. I17-1 18.

I g06. Ueber Geschwülste bei Kaltblütern. Zeitschrift für Krebsforschung, Berlin, bd. 4, p. 525.

r9o9. Fische als Uebertrager der Krebskrankheit. Allgemeine Fischerei-Zeitung, r. Juli, I909, nr. 13, p. $290-292$.

19ro. Ueber Geschwülste bei niederen Wirbeltieren. Travaux de la deuxième Conférence internationale pour l'Etude du Cancer, Paris, p. 221 . Discussion, p. 787 .

1912. Ueber Geschwülste bei Kaltblütern. Wiener klinischen Wochenschrift, xxv. jahrg., nr. rg, p. $69 \mathrm{I}$.

DE QUERVAIN, F.

ro04. Die akute, nicht eiterige Thyreoiditis und die Beteiligung der Schildrüse an akuten Intoxi-

REGAUD, C. kationen und Infektionen überhaupt. Mitteilungen aus den Grenzgebieten. II. sup.-bd.

1907. Helminthiase extra-intestinal et néoplasmes malins chez le rat. Comptes rendus des

RÉprN, CH. Séances et Mémoires de la Société de Biologie, t. I, p. 194.

1911. Goitre expérimental. Comptes rendus hebdomadaires des Séances et Mémoires de la Société de Biologie, t. 2, I9Ir, p. 225-227.

Rous, PeyTon.

1910. A sarcoma of the fowl transmissible by an agent separable from the tumor cells. Joumal of Experimental Medicine, vol. xiIr, p. 397.

Rous, Peyton, Murphy, James B., ANd TyTLER, W. H.

I912. A filterable agent the cause of a second chicken tumor, an osteochondrosarcoma. Joumal American Medical Association, vol. L1x, no. 20, p. 1793.

Rous, Peyton, AND LANGe, Linda.

1913. A hitherto undescribed transplantable tumor of the fowl. American Association of Pathologists and Bacteriologists, $3^{\text {th }}$ annual meeting. In press, Journal of Experimental Medicine.

SCHÖNE, GeORG.

1910. Versuche über die Beeinflussung der Wundheilung und des Geschwulstwachstums durch Stoffwechselstörungen und Vergiftungen. Archiv für klinische Chirurgie, bd. 93, heft 2,

Scotr. p. 369 .

I891. Note on the occurrence of cancer in fish. Transactions and proceedings of the New Zealand Institute, Wellington, N. Z., vol. 24 (issued May, 1892), p. 201 , I plate.

SEURAT, I. G.

1912. Sur la quatrième mue des nématodes parasites. Comptes rendus hebdomadaires des Séances

Srmon, J. et Mémoires de la Société de Biologie, t. 2, 1912, p. 279-28r.

1814. On the comparative anatomy of the thyroid gland. Philosophical Transactions of the Royal Society of London, vol. I34, p. 295.

Simpson, B. T.

I9I3. Growth centers of the benign blastomata with especial reference to thyroid and prostatic adenomata. Journal of Medical Research. vol. Xxv11, no. 3, p. 269.

SLYE, MAUD.

1913. The incidence and inheritability of cancer in mice. Meeting of American Association for Cancer Research, May 5, I913. Zeitschrift \{ür Krebsforschung, vol. I3, p. 500, I9I3.

Smrrн, H. M.

rgog. Case of epidemic carcinoma of thyroid in fishes. Washington Medical Annals, vol. 8 , no. 5 , p. $3 I_{3}$.

SzÉCSI, StEphan.

Iو12. Ueber die Wirkung von Cholinsalzen auf das Blut und über die Beeinflussung von Mäusetumoren durch kolloidale Metalle. Merizinische Klinik, nr. 28, p. I162. 
THompson, F. D.

I9Ir. The thyroid and parathyroid glands throughout vertebrates, with observations on some other closely related structures. Philosophical Transactions of the Royal Society of London, series B, vol. 20I, p. 9 r.

TYZZER, E. E.

1907. A study of heredity in relation to the development of tumors in mice. Journal of Medical Research, vol. I7 (n. s., vol. 12), p. I99.

VIRCHOW, RUDOLF.

r863. Die krankhaften Geschwülste, bd. m. 496 p.

WiLMs, M.

19ro. Experimentelle Erzeugung und Ursache des Kropfes. Deutsche medizinische Wochenschrift, xxxv1. jg., I910, no. $1_{3}$, p. 604-606.

WÖLFLER, ANTON.

1883. Ueber die Entwicklung und den Bau des Kropfes. Archiv für klinische Chirurgie, bd. $\mathrm{xxIx}, \mathrm{x}^{8} 3$, heft $3, \mathrm{p} .754-866$, xo pl. 


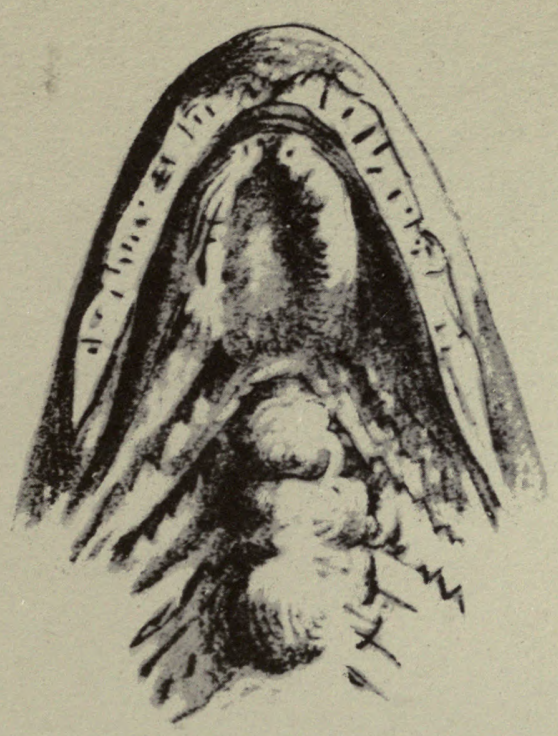

FIG. 1.-From Scott's "Cancer in Fish," 1891. Floor of mouth of Salmo fontinalis, showing protrusion of tumor in pharyngeal floor.

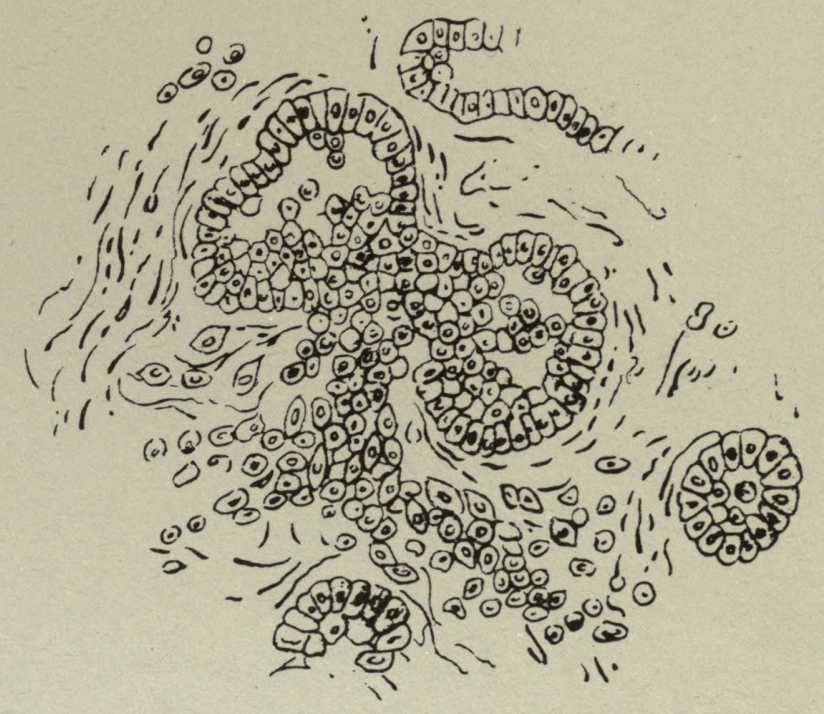

FIG. 2.- Drawing from microscopic section showing acini with infiltration of surrounding structure of individual
cells. After cells. After Scott. 



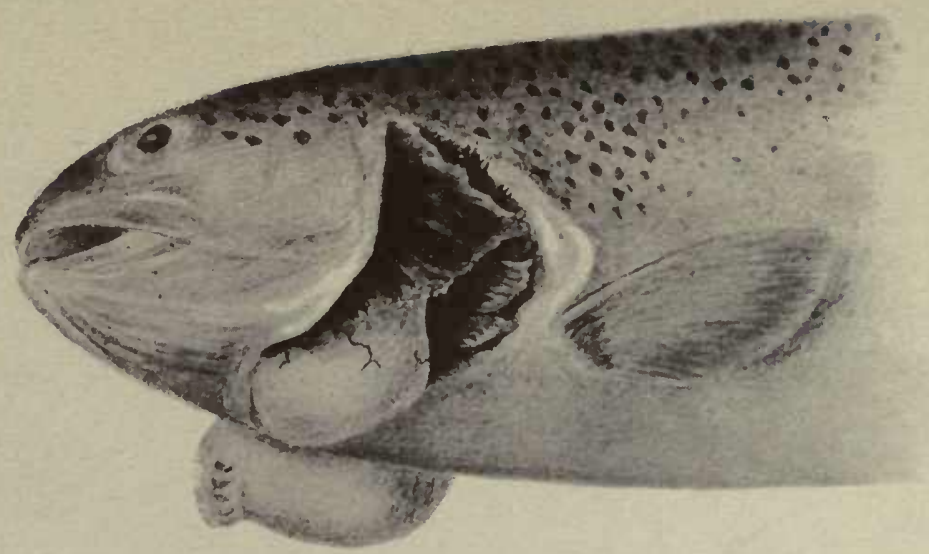

Fic. 3. - Rainbow tront. Redrawn from Gilruth's colored original, 1902. Large tumor on each side of branchial junction. Gill fringe distended on surface of lower one.

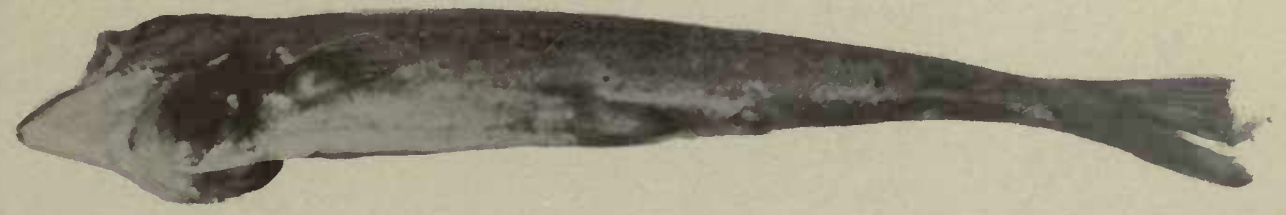

FIG. 4a.-Yearling hybrid salmon. Massive tumors and marked emaciation. 1,ot 1988 .

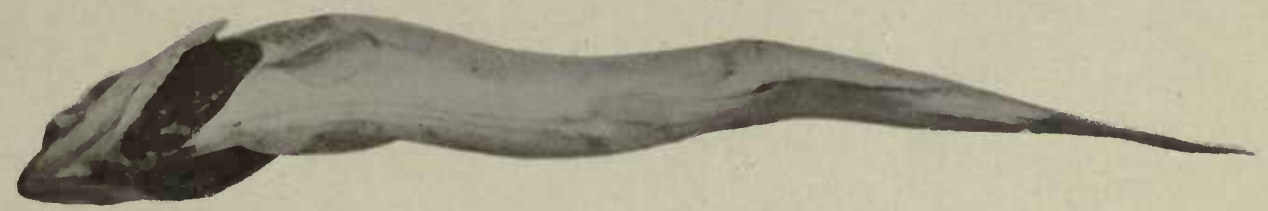

Fig. 41).-Two year old Salmo sebago, extreine eniaciation. I,ot 1950.

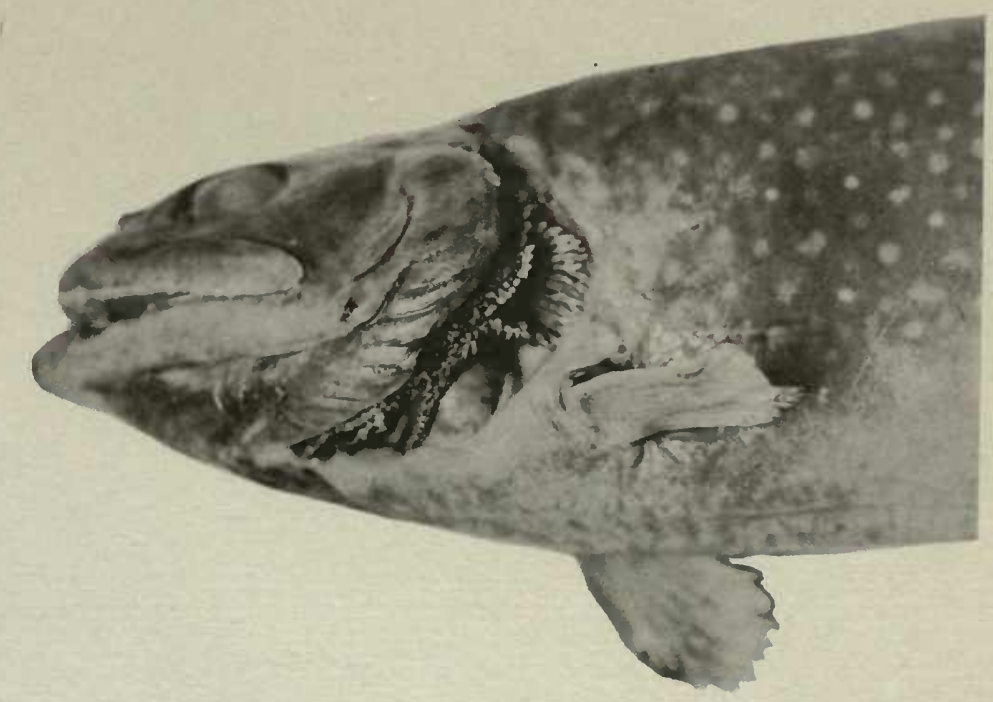

Frg. 4.- Salmo fontinal is 2 vears old. First external evidence of tumor in base of muscular structure of isthmus. showing marked infiltrative tendency of growtl. 



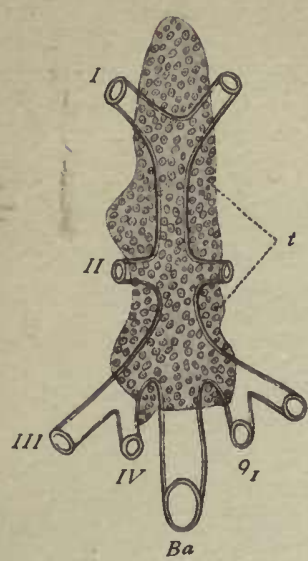

5

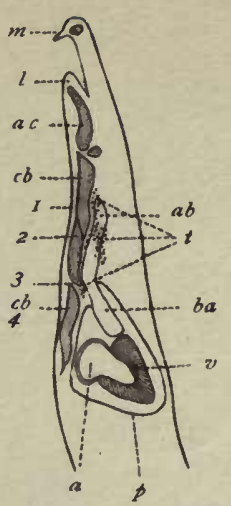

6

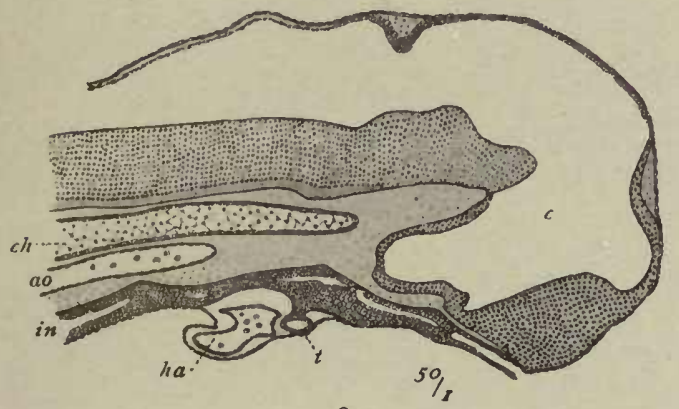

8

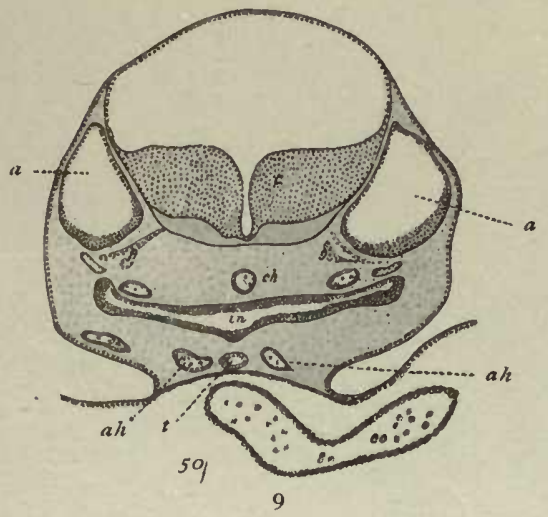

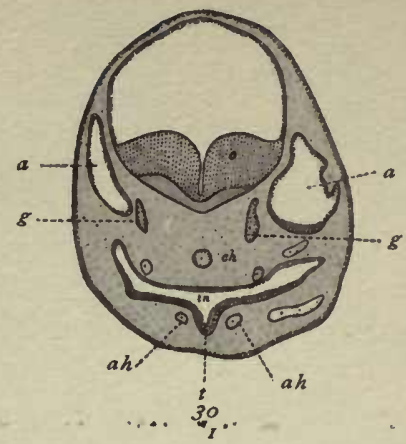

7

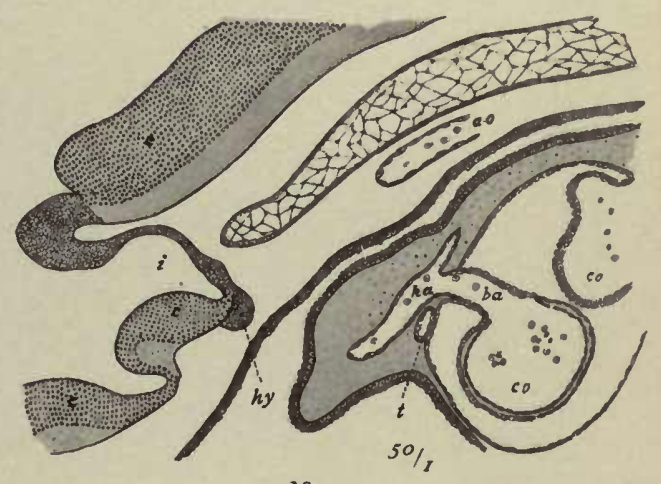

10

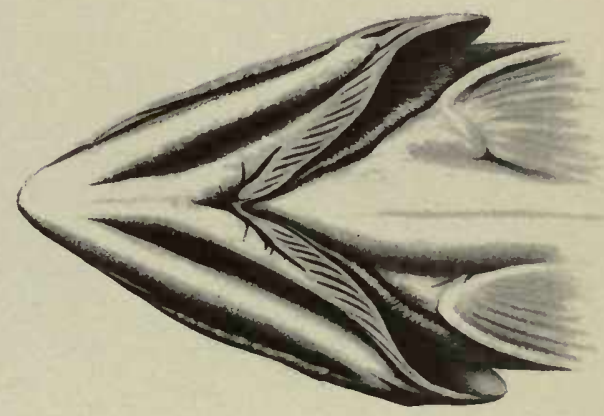

11

F1G. 5.-Redrawn from Maurer, 1886. Thyroid of a trout $20 \mathrm{~cm}$. long; shown in its relation to the branclial arteries. seen from the ventral side.

Fig. 6.-Redrawn from Manrer. Median section to show distribution of thyroid about the ventral aorta in a trout 2.5 c1in. long.

F1G. 7.- Redrawn from Maurer. Cross section of the head of a trout embryo of 30 days, showing earliest evagination of pharyngeal epitheliunt to form the thy roid.

FIG. 8.-Redrawn from Maurer. Median section through head of trout embryo of 35 days. Primary thyroid resicle (t) still attaclied to parent epithelium by pedicle.

F1G. 9.- Redrawn from Maurer. Cross section of a trout embryo of 35 days. Primary thyroid vesicle ( $t$ ) separated from parent epithelitum.

Fig. 10.- Redrawn from Maurer. Median section through head of tront embryo of 41 days. Compared with figure 8 , it shows thint the elongated prinary thy roid vesicle $(t)$ has moved backward and now lies veintral to the aorta.

F1(i, 11,-Drawing showing gross appearance of jugular pit from below. 



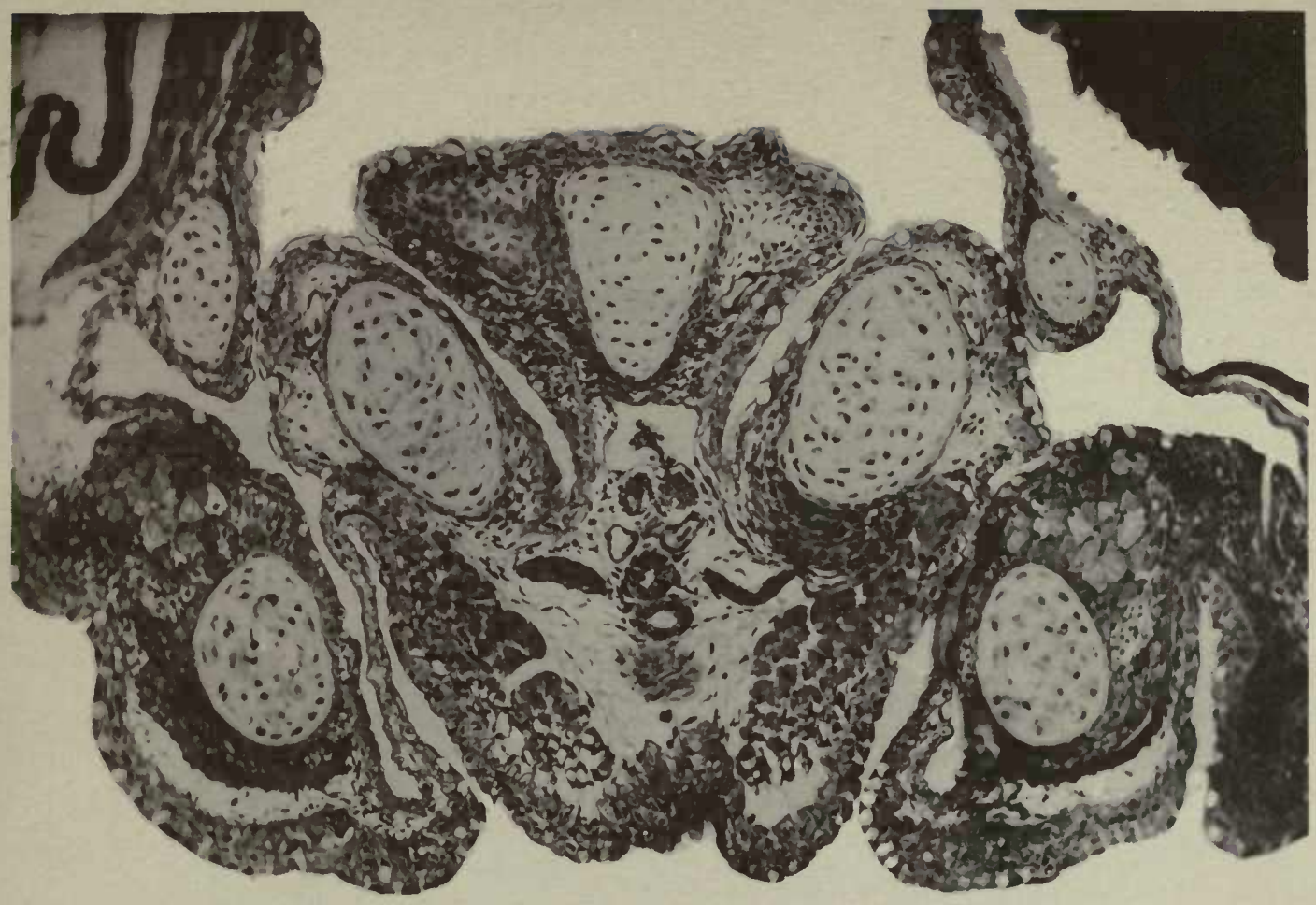

Fig. 12.-Salvelinus fontinalis in sac stage, hatched a few days: showing relation of thyroid follicles to invagination which becomes jugular pit. $\times 86$.

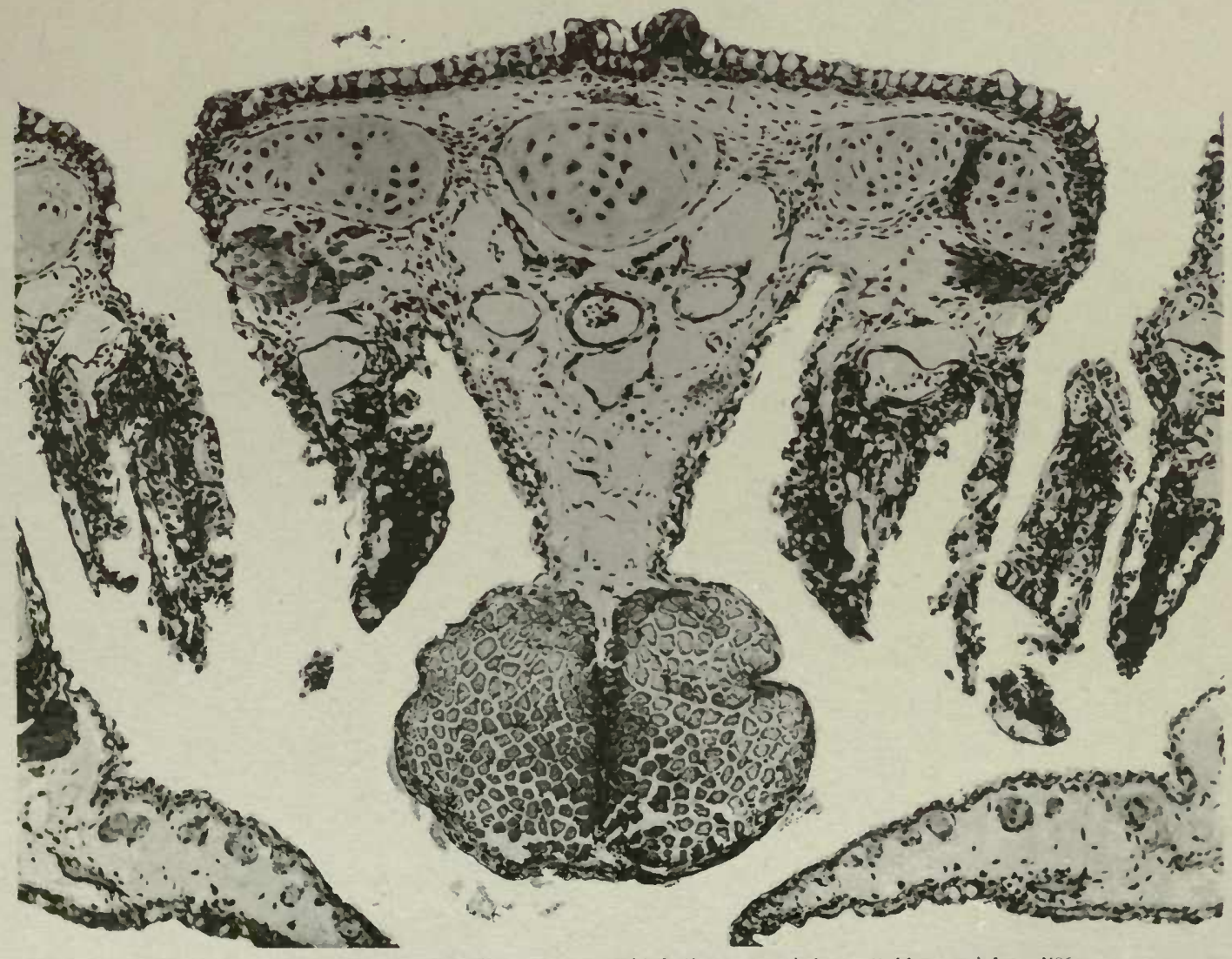

Fis: 13.-Brook tront fry showing early thyroid follicles contaning colloid material. $\quad$ X86. 



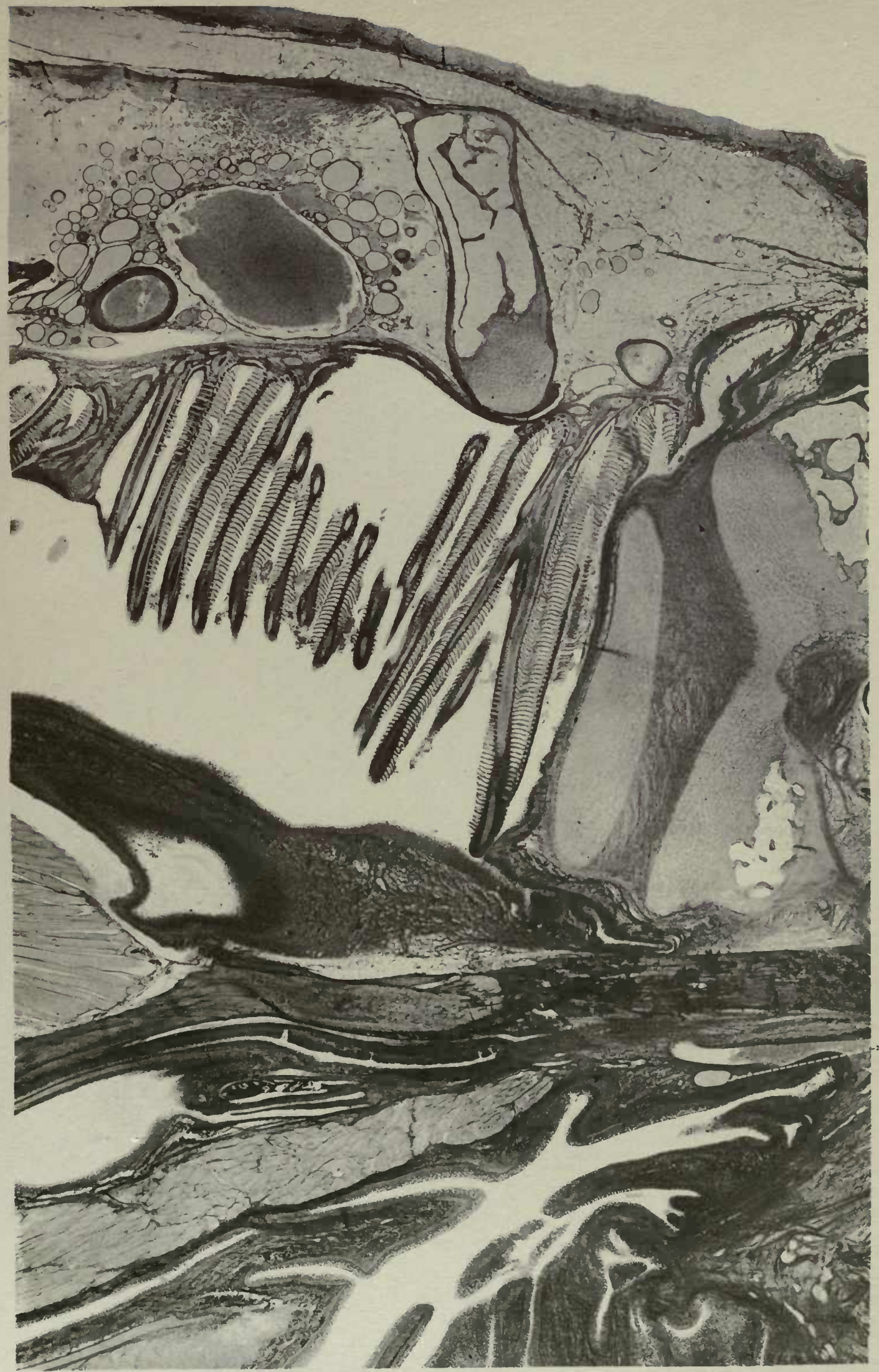





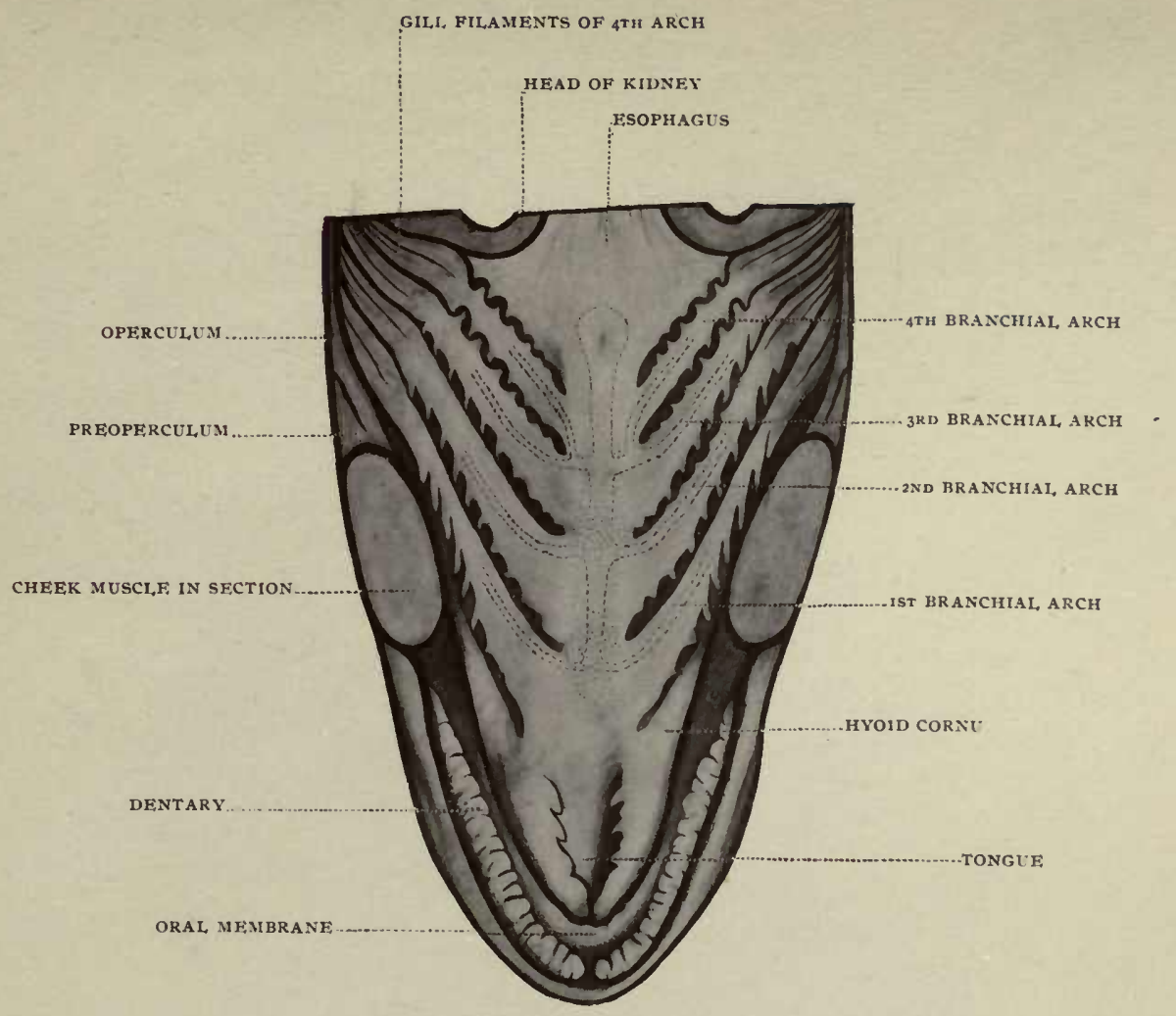

FIG. 15.-Composite picture of lateral and longitudinal distribution of normal thyroid in the Salmonidæ, with vessels.

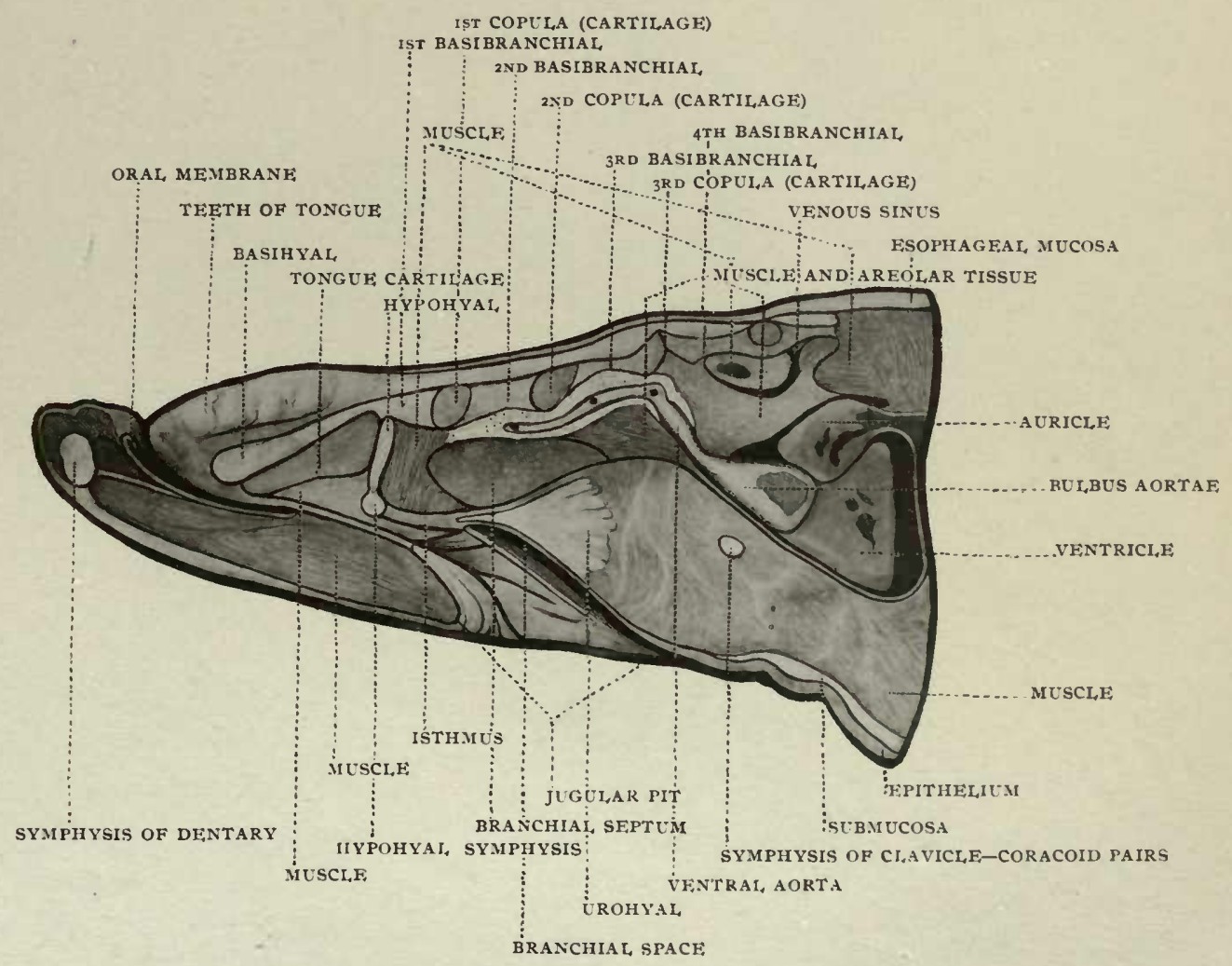

FIG. 16.-I,ongitudinal and dorso-ventral distribution of thyroid in the salnonidæ. 



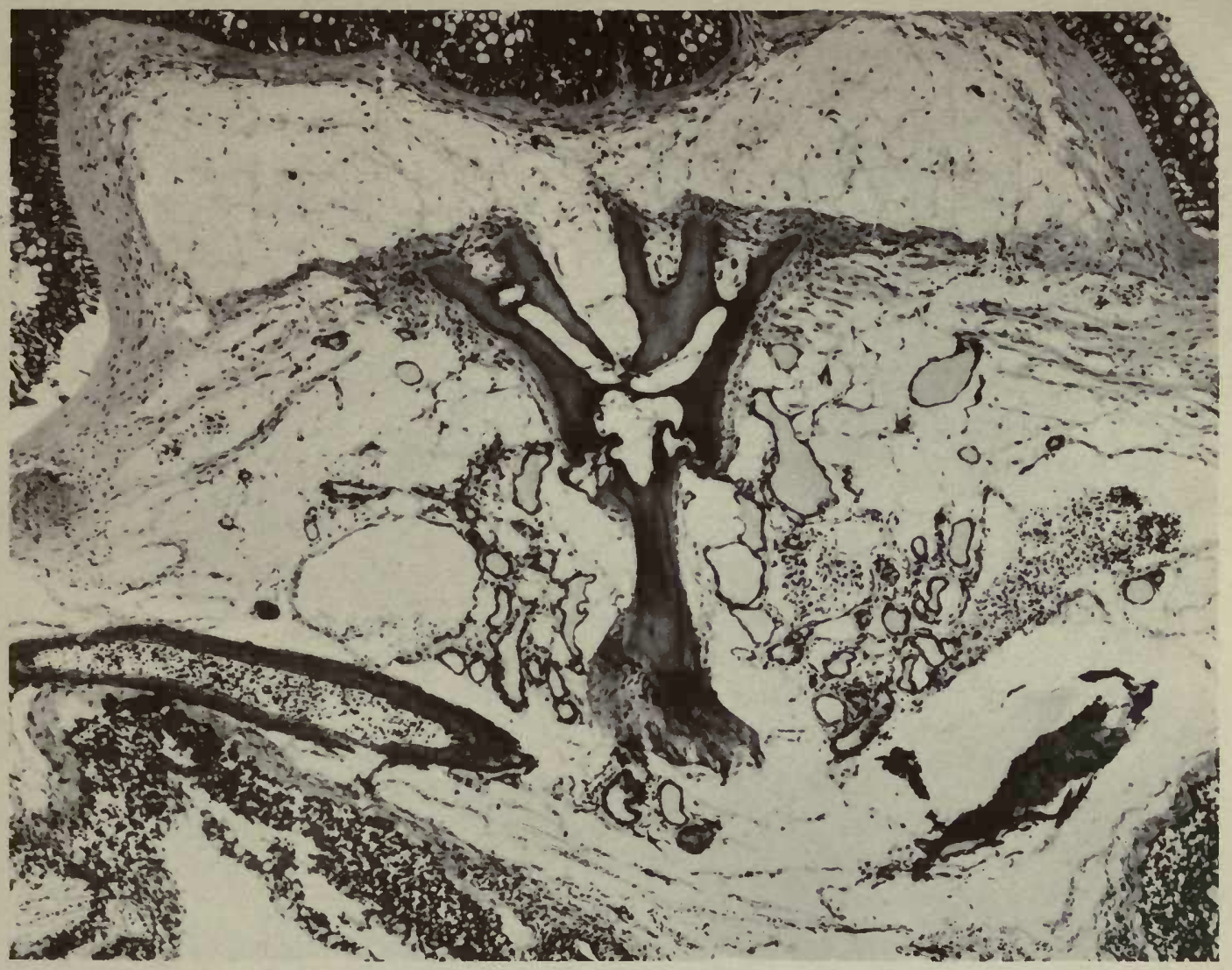

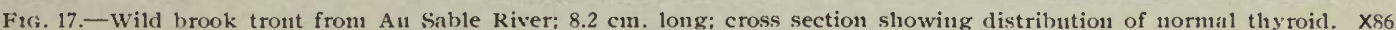

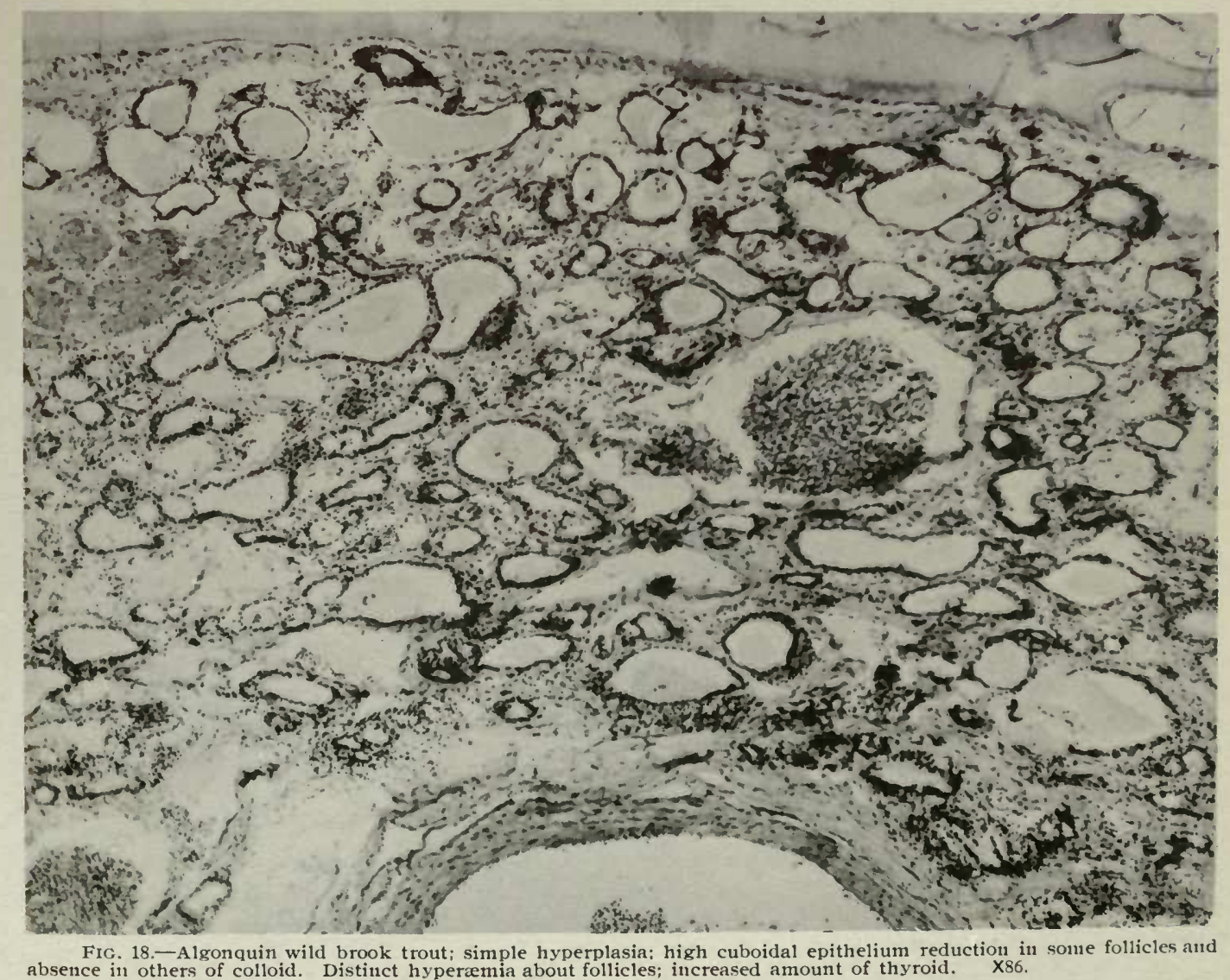





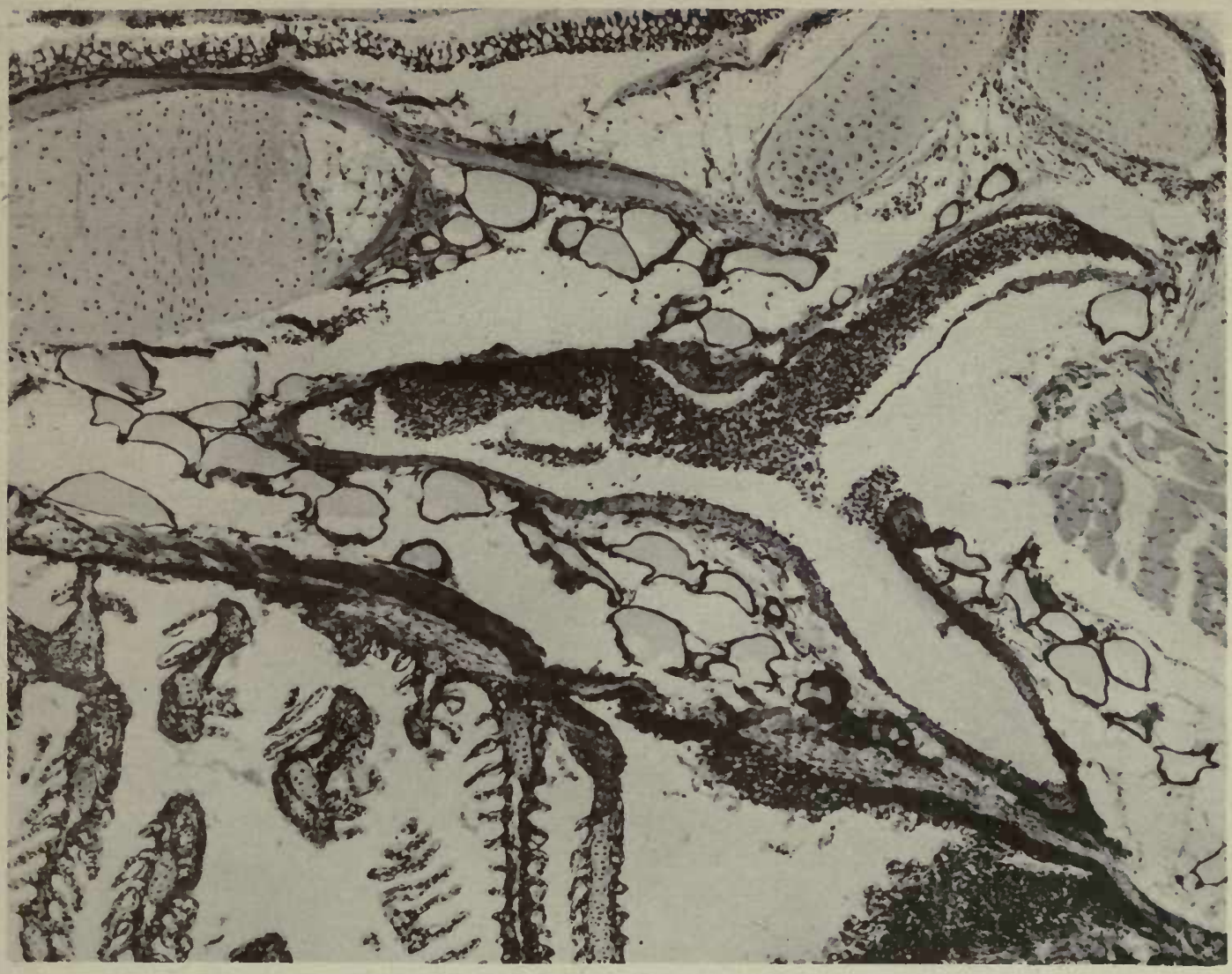

F16. 19.-Domesticated Scotch sea trout fingerling; normal thy roid structure. $\quad \times 86$

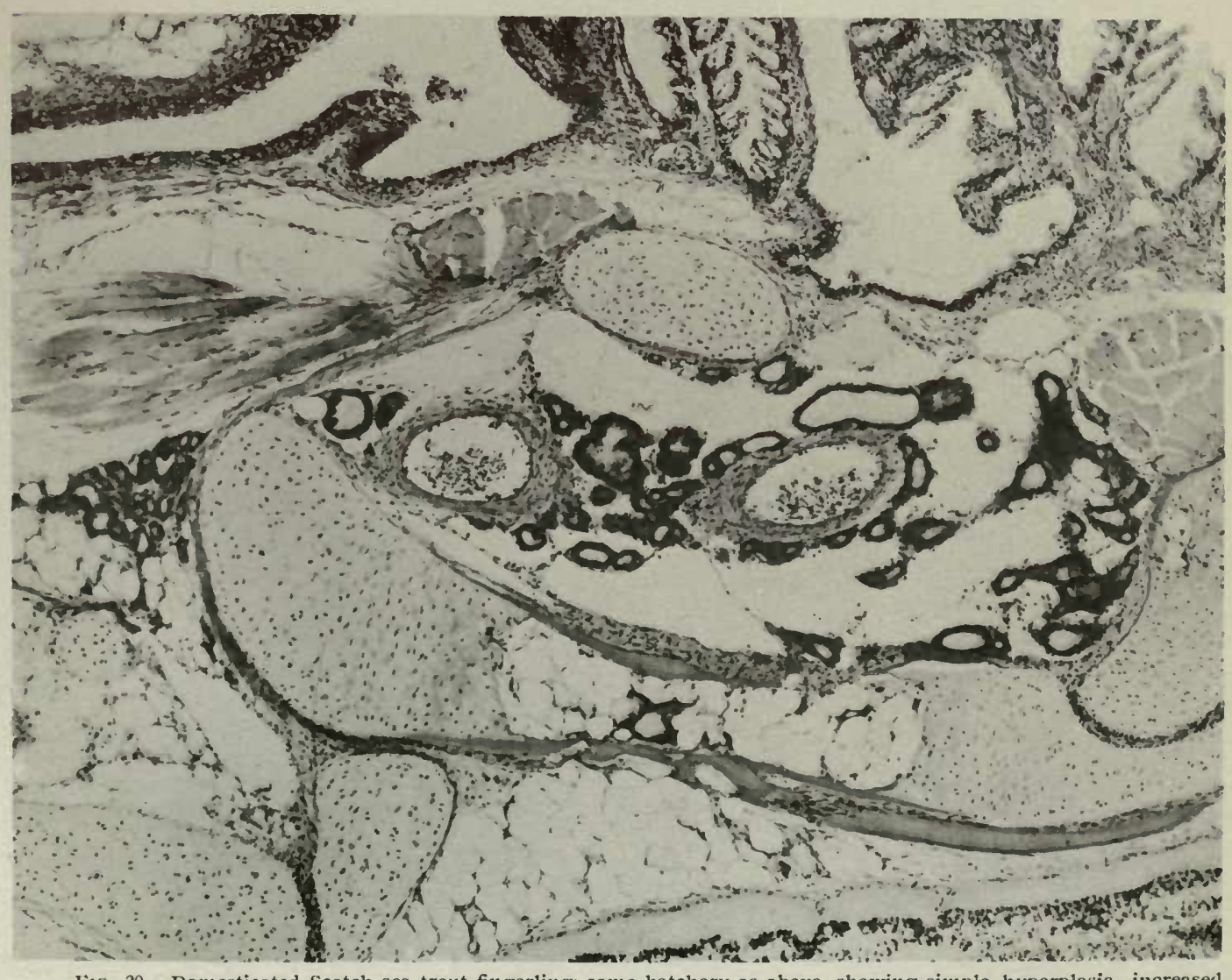





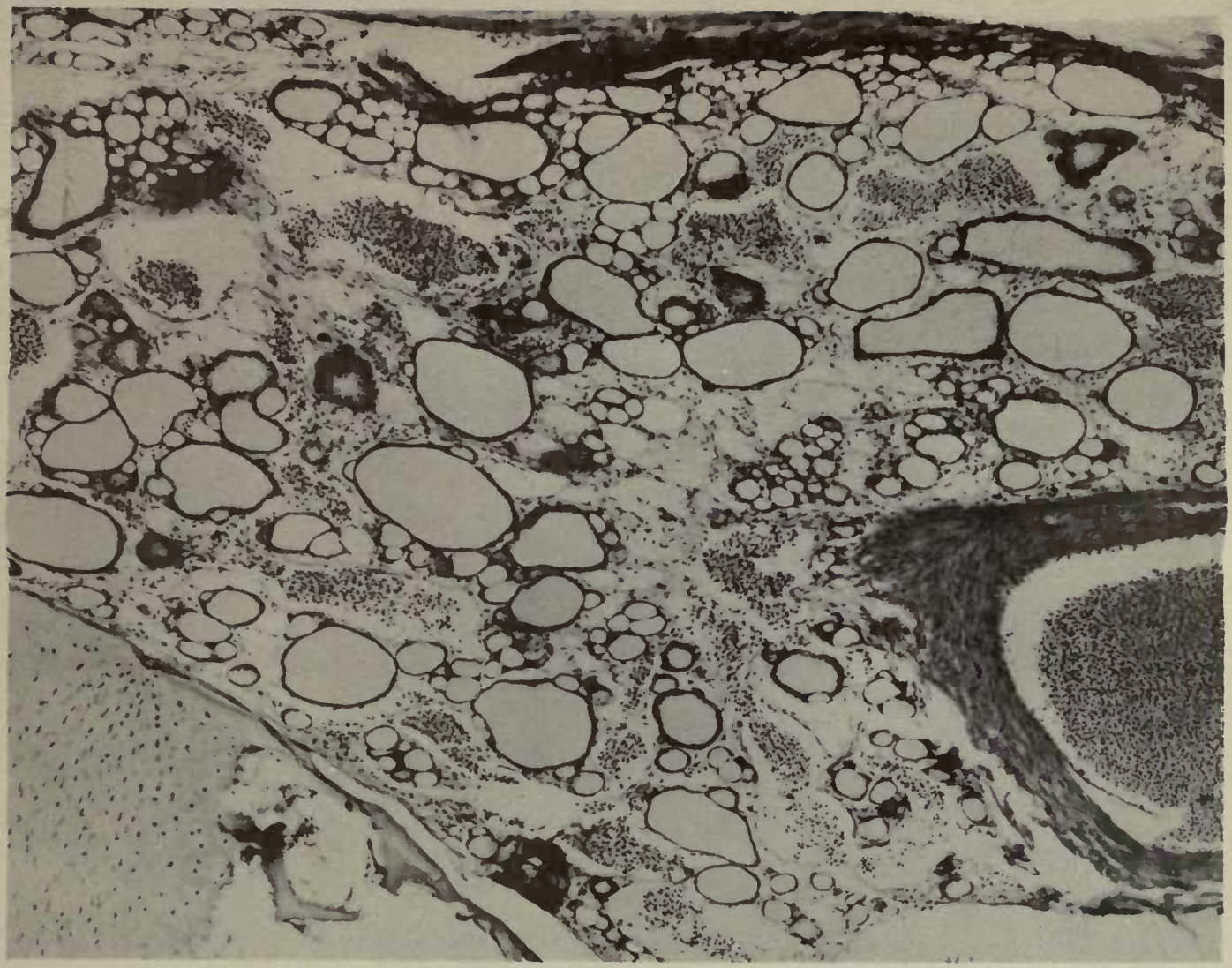

Fig. 21.-Adult domesticated sen trout, normal thyroid structure. $\mathbf{X} 86$.

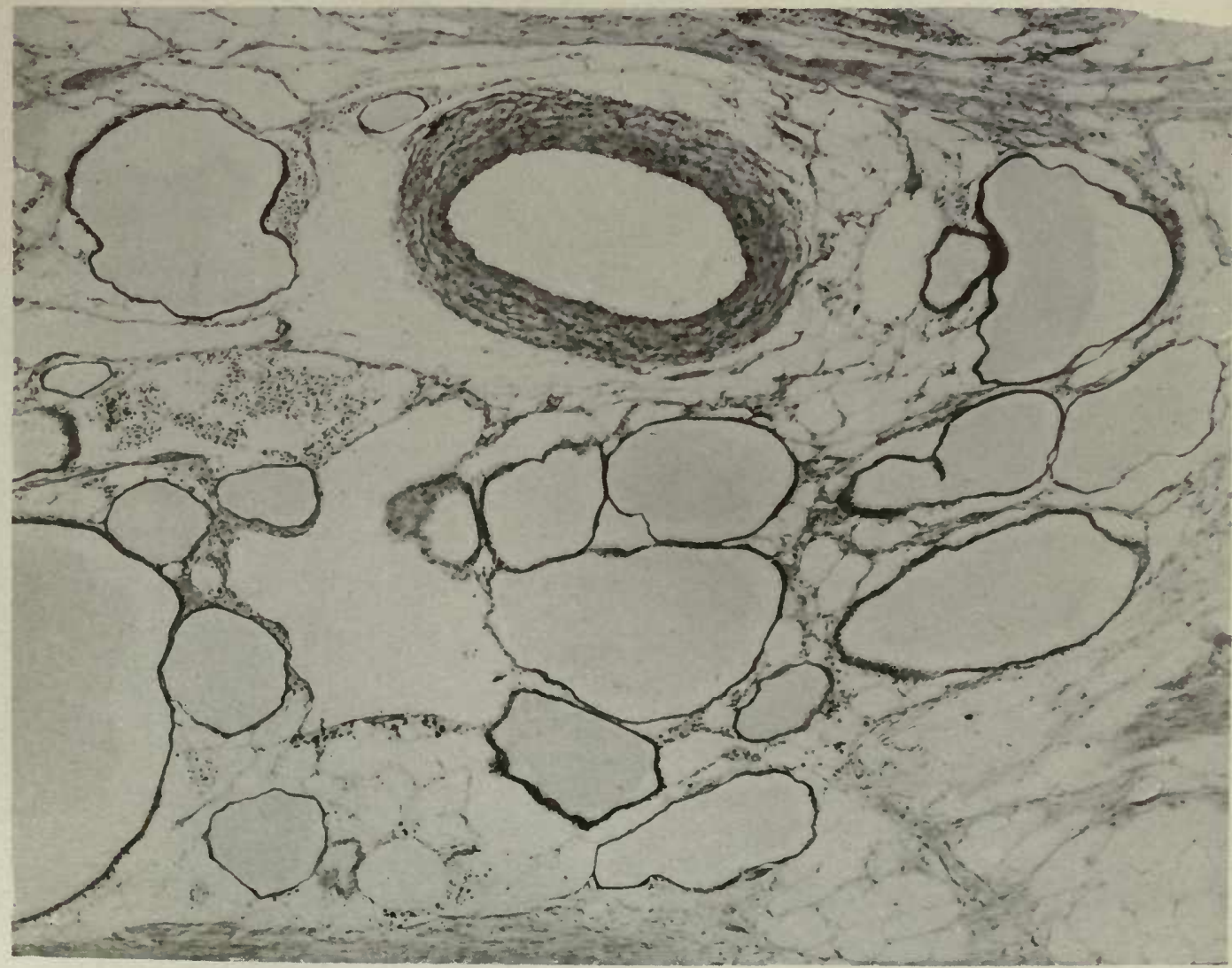





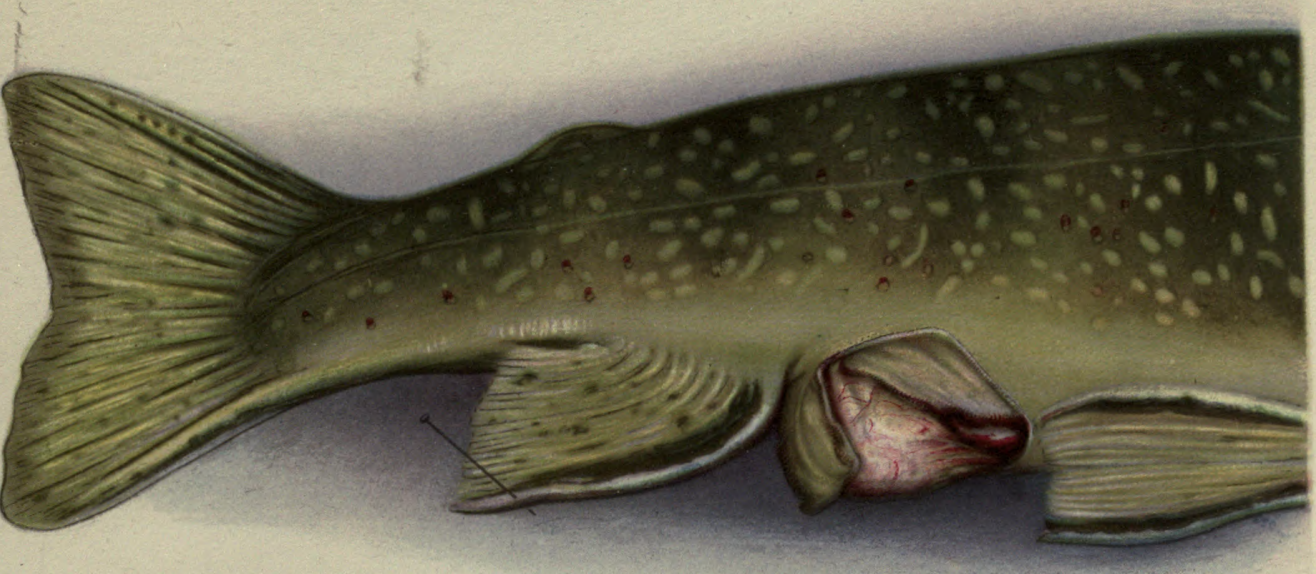

Fig. 25.-Brook trout, showing rectal metastasis of thyroid origin (Anal fin pinned back to show tumor.)

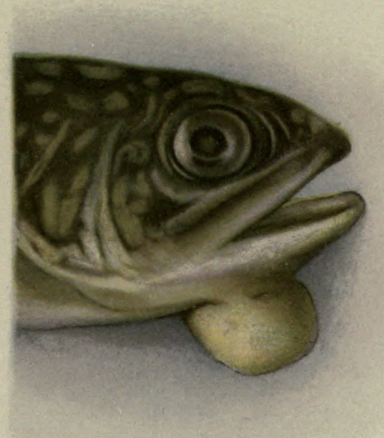

Fig, 24.-Brook trout. showing large round tumor springing from the jugular pit.

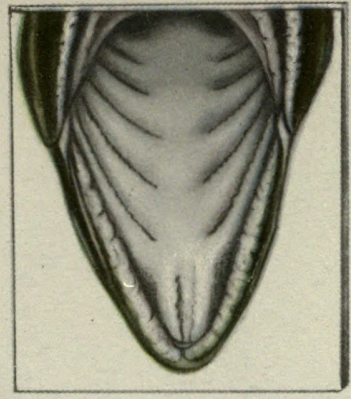

FIG. 23a.-A view of normal floor of mouth of adult brook trout.

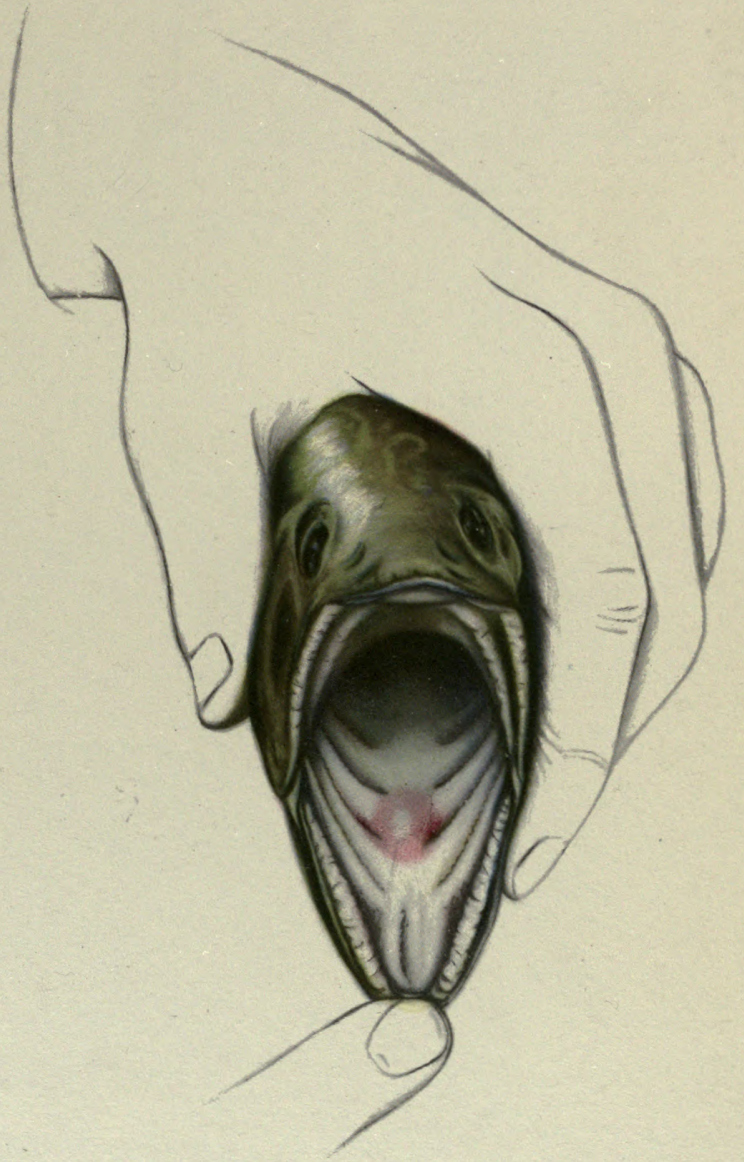

Fig. 23-Hyperemia of floor of mouth of adult brook trout. so-called red floor. First macroscopic evidence of hyperplasia or carcinoma of thyroid. 

BULL. U. S. B. F. I912.

PLATE LIXVI.

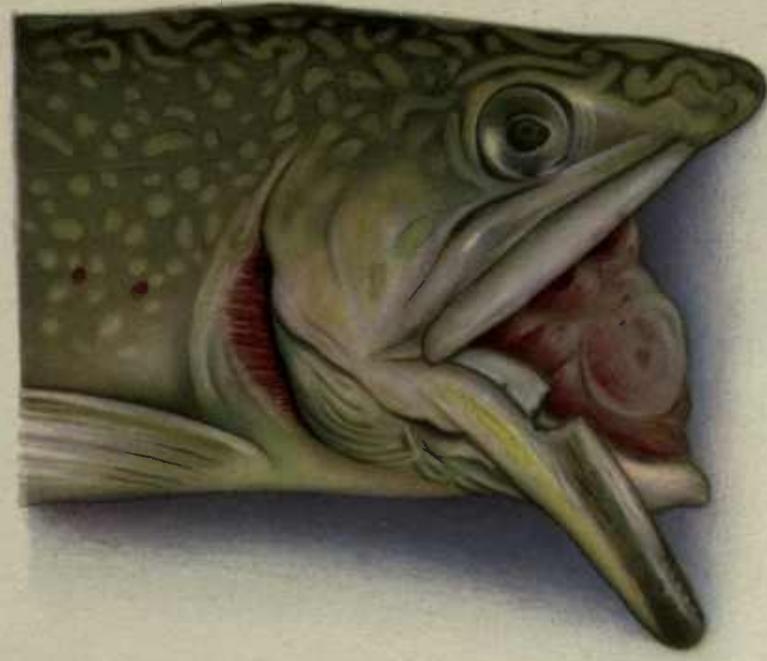

FIG. 26.-Brook tront, showing massive thyroid tumor in the mouth cavity, springing fronir the floor of the mouth.

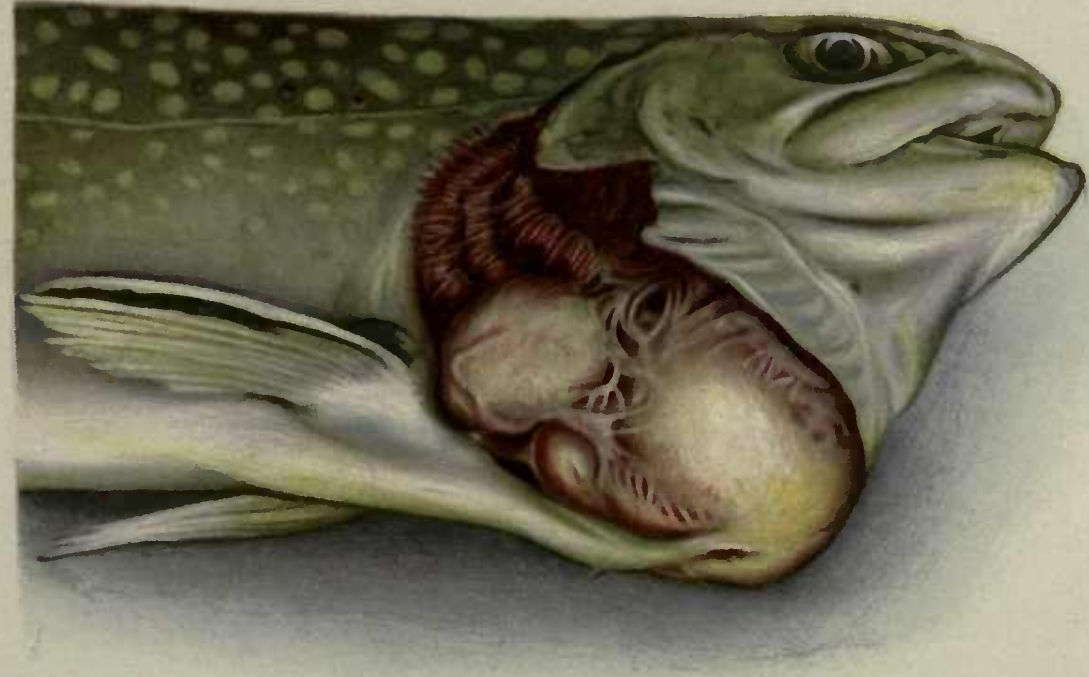

FIG. 27. -Two year old brook trout, showing massive tumor filling the entire gill space.

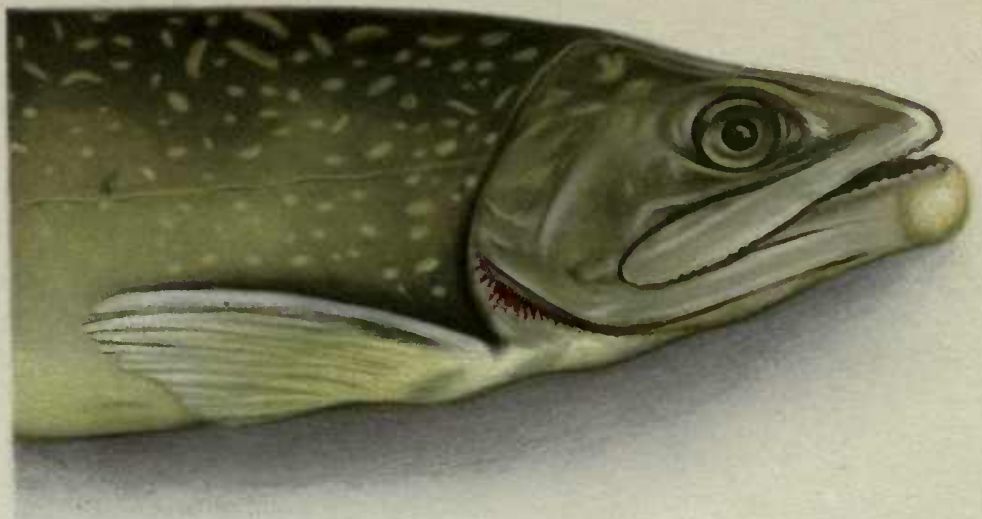

FIG: 28. - Brook trout. showing tumor mass at the tip of the lower jaw. 



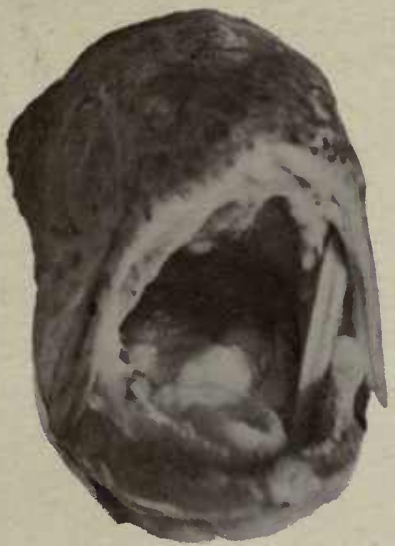

FIG. 29.-Brook trout showing nodular growths in floor of mouth.

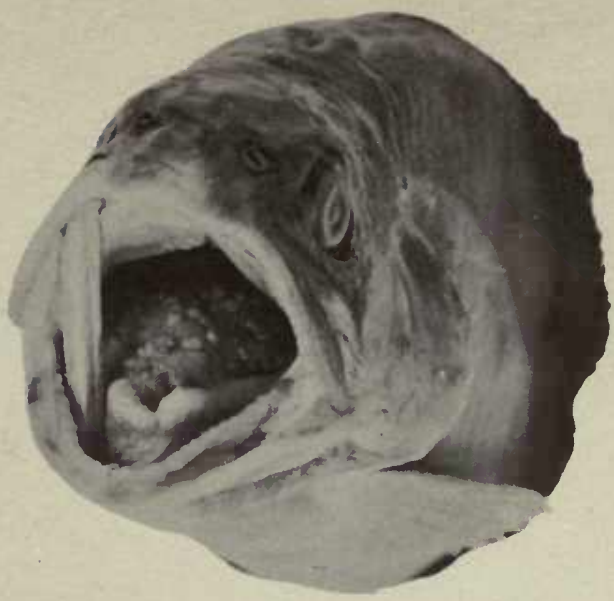

Fici. 30.-Brook trout showing numerous tumor vegetations in floor of month.

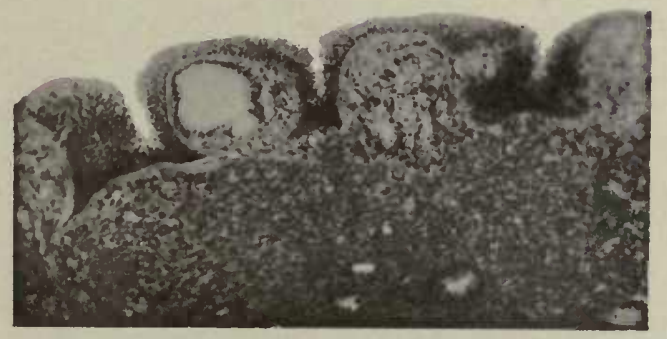

FIG. 31. - Section of floor of month showing thyroil follicles growing in epithelium above basal menthrane.

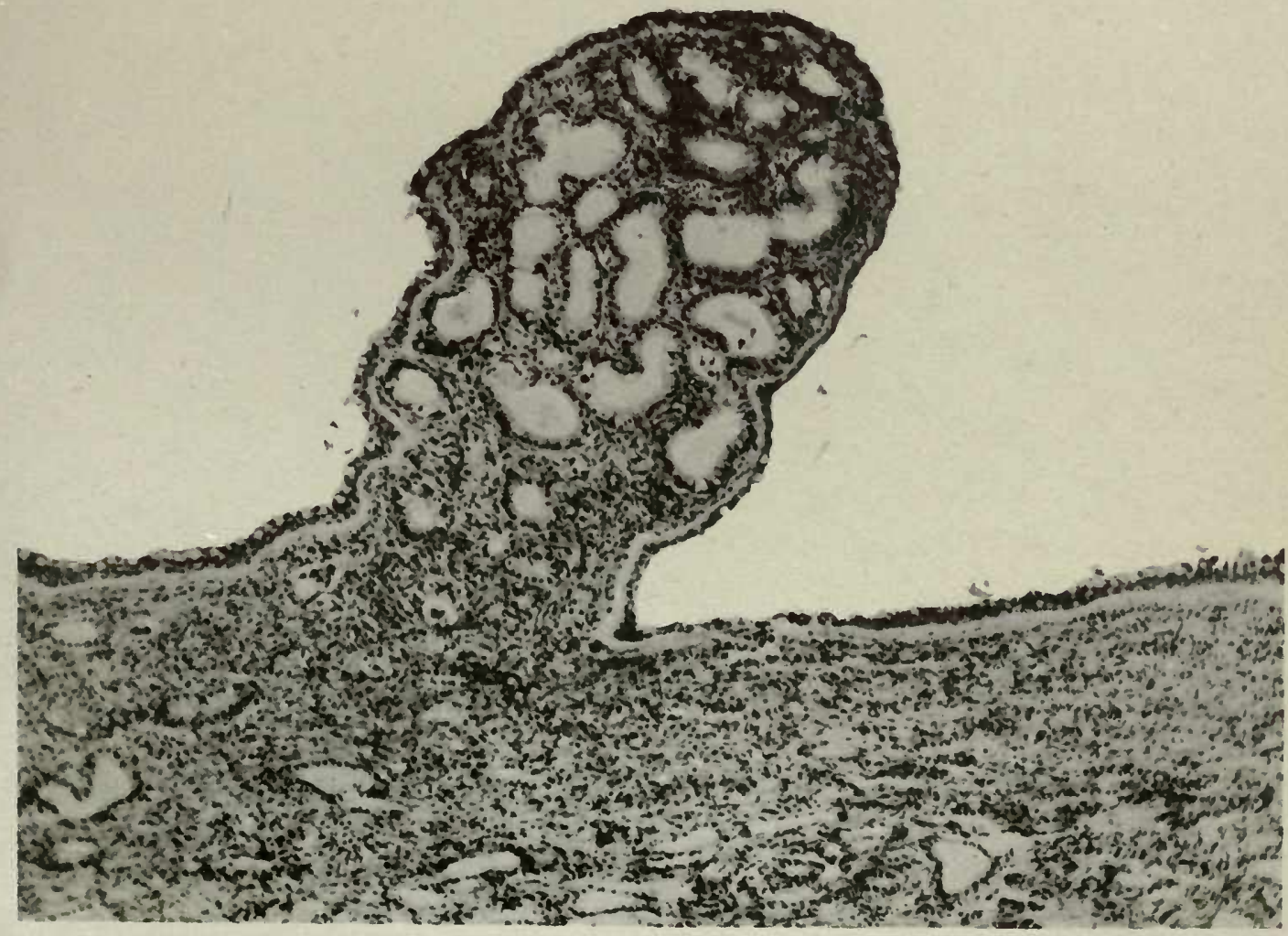

HiG 32-Section from floor of mouth showing listologicil structure of pupillary grouths fonul in foor of mouth illustrated macroscopically by figure $30 . \quad$ x 94. 



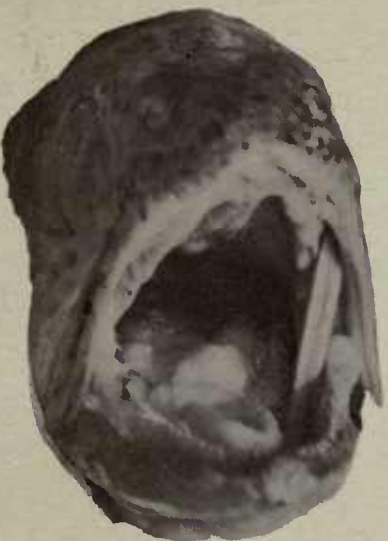

FIG. 29.-Brook trout showing nodular growths in floor of mouth.

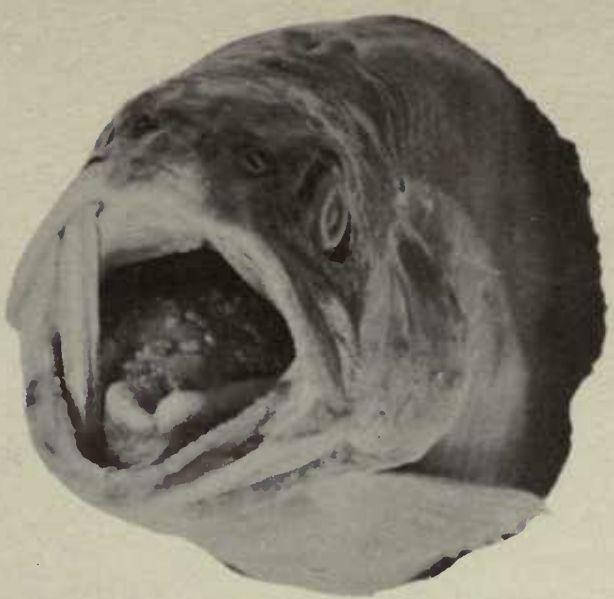

FIG. 30--Brook tront showing nunnerous tumor vegetations in floor of moutl.

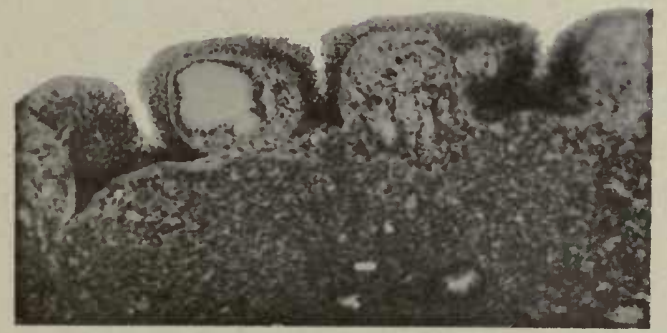

Frg. 31. - Section of floor of month showing thyroid follicles growing in epithelium above basal membrane.

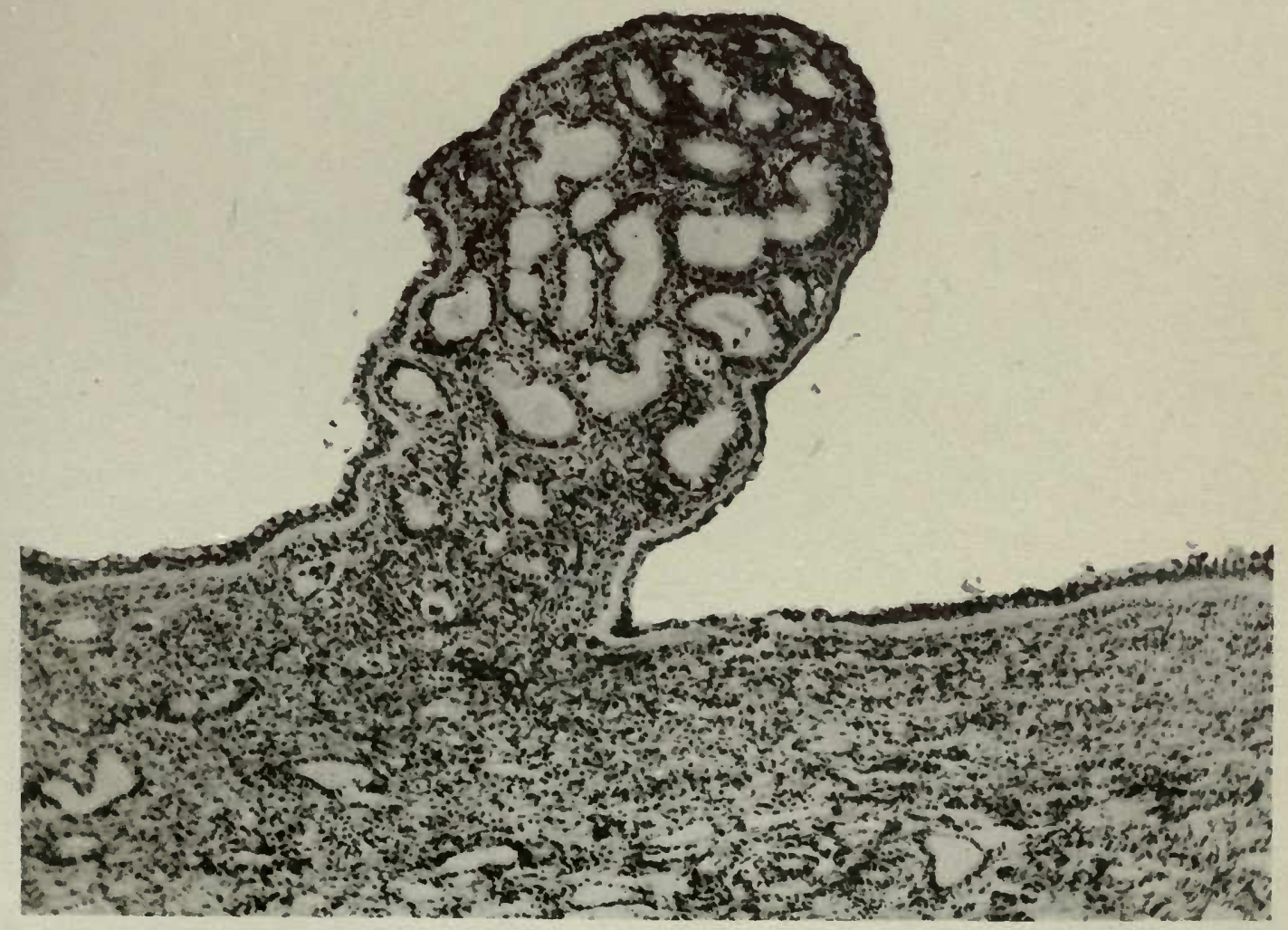

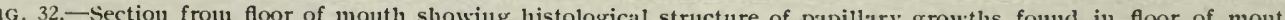
illustrated macroscopicilly by figure 30 . $\times 94$. 


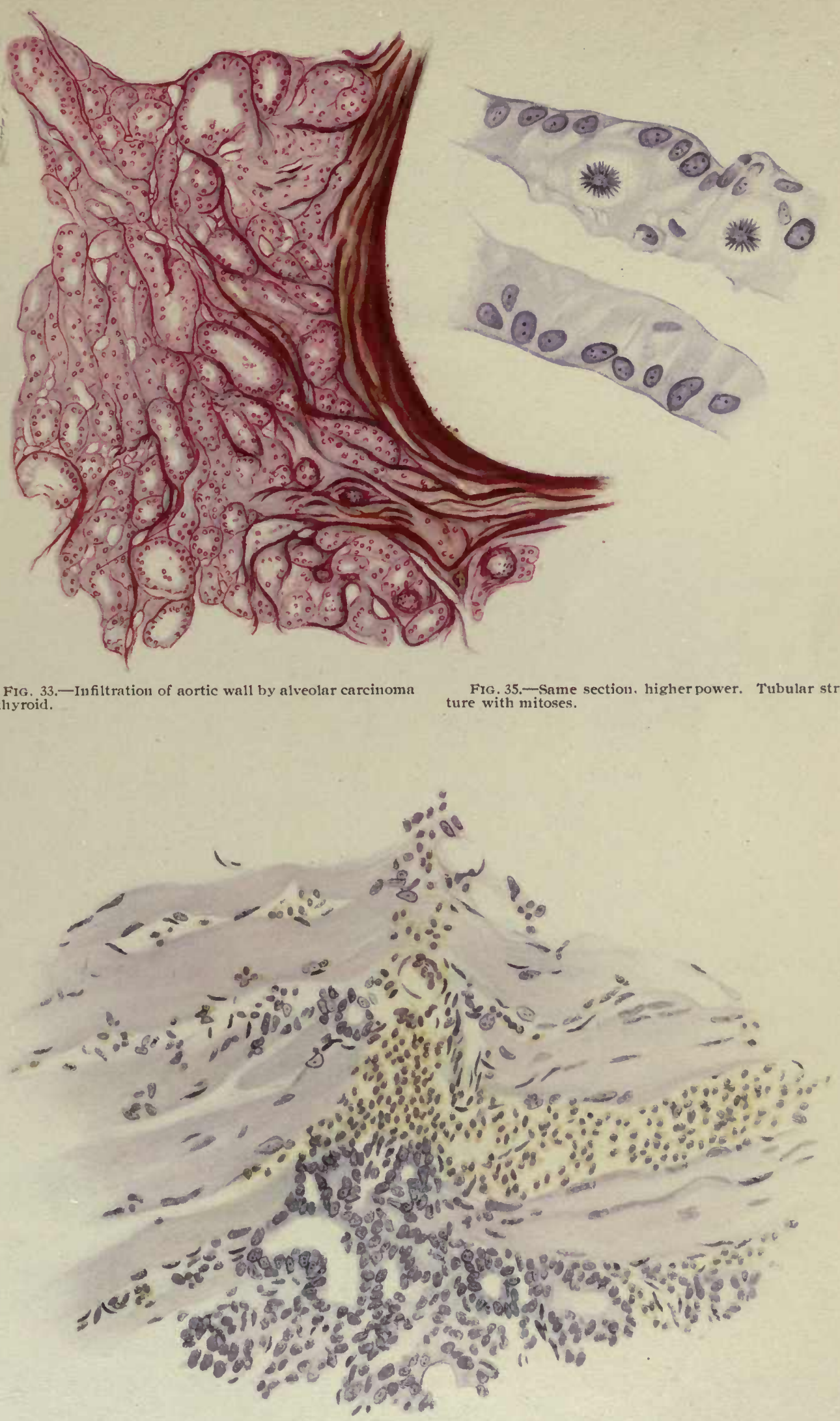

Fis. 34,-Drawing show̌ing infiltration of surrounding structures in the enrly stage of carcinonna of thyroid. 



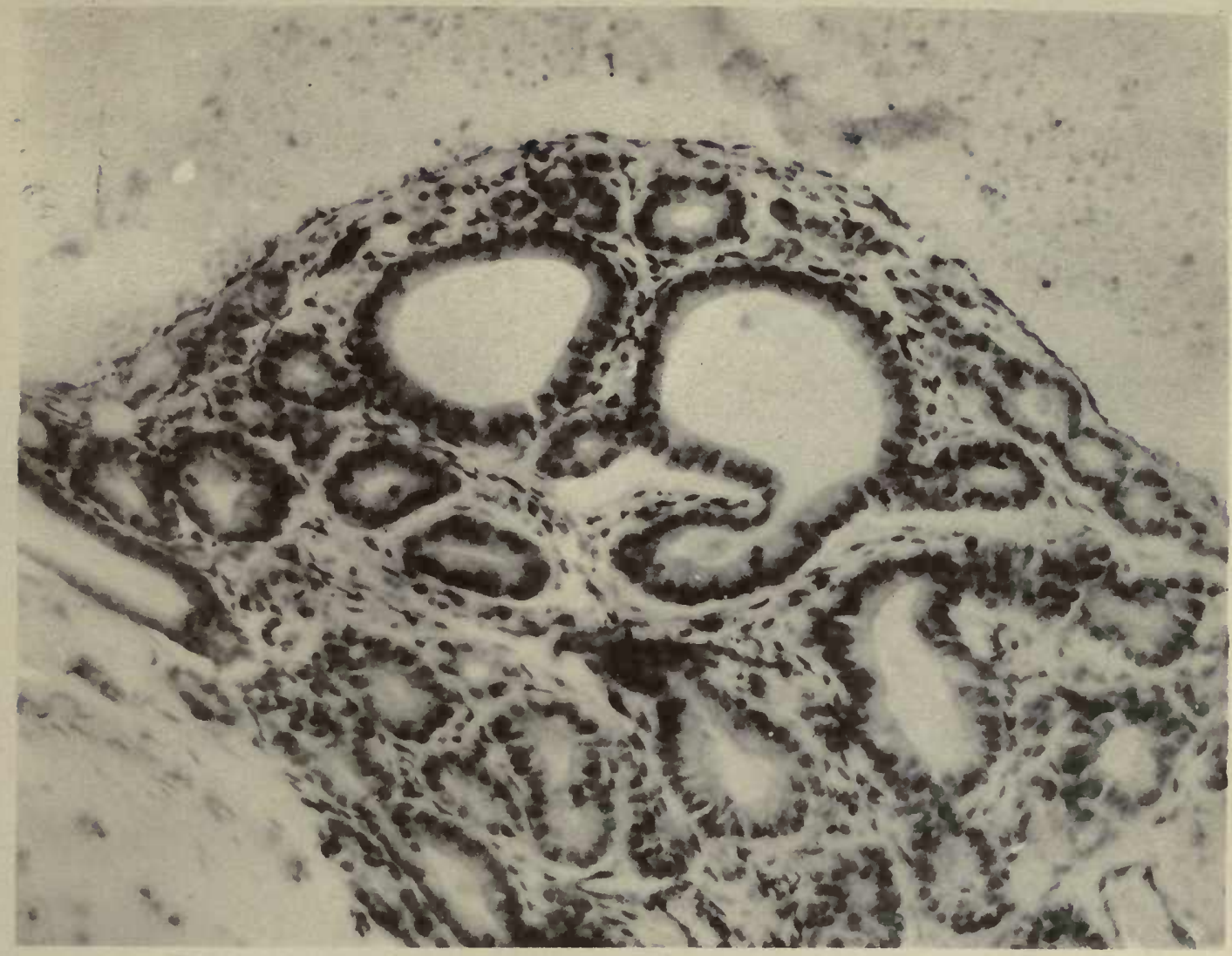

Fig. 36. - High power section of the early stages of the disease showing formation of new follicles by budding of the alveoli with subsequent splitting off. Note karyokinetic figures. X200.
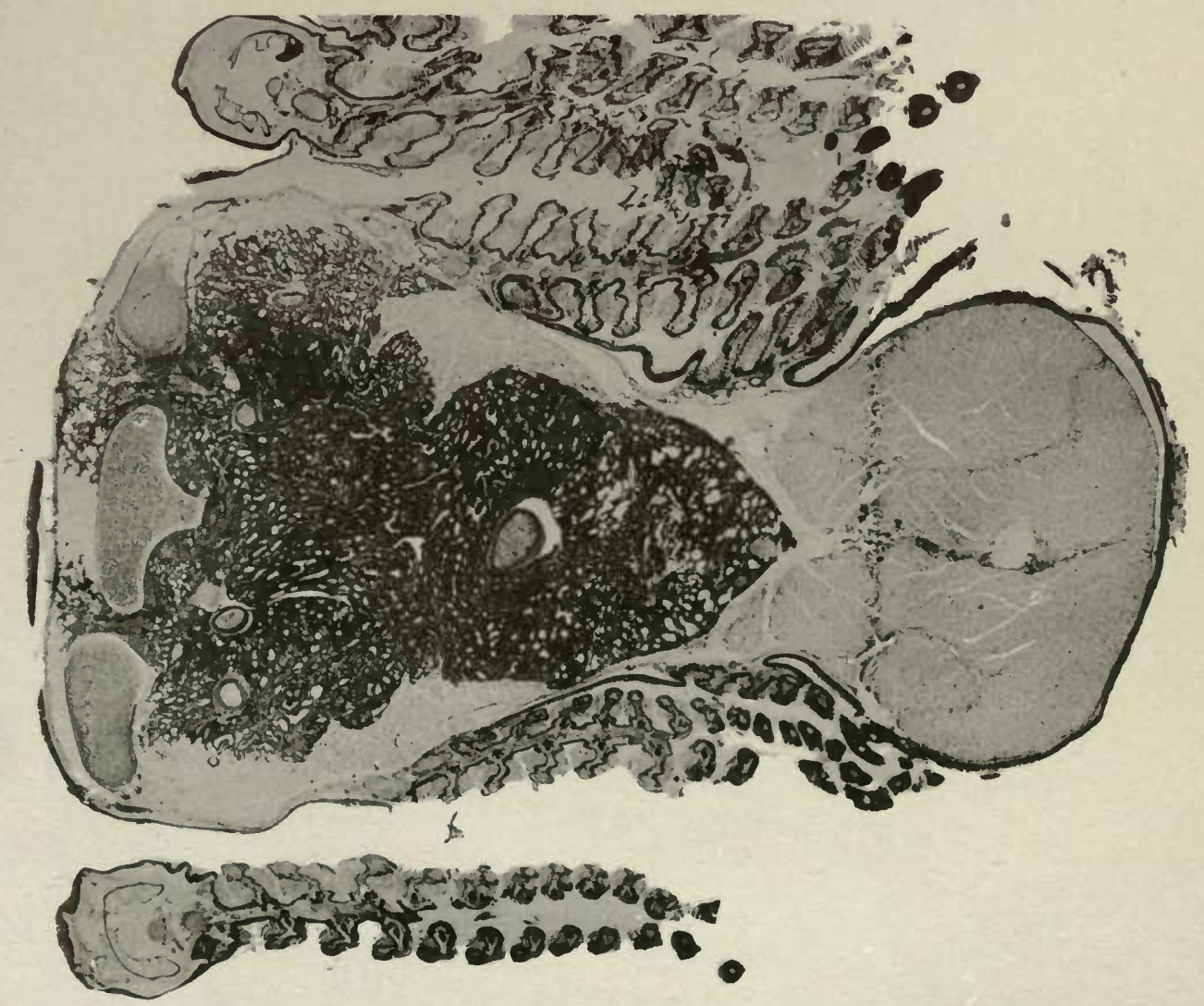

FIG. 37.-Cross section of the lower jaw showing growth infiltrating the surrounding structures.

$\times 10^{1 / 2}$. 



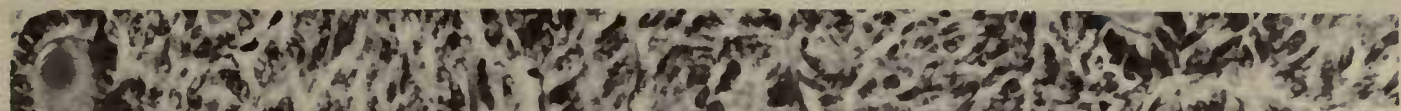

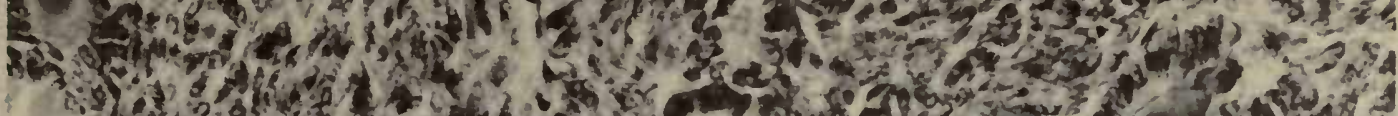

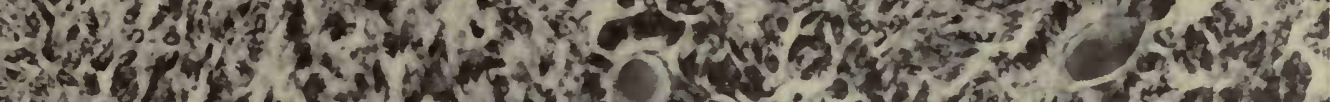

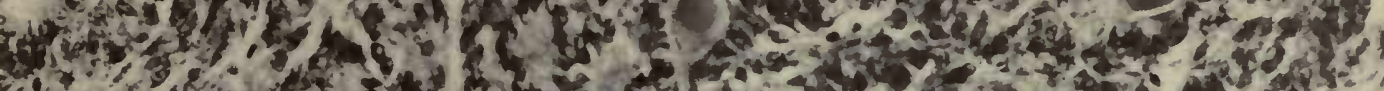

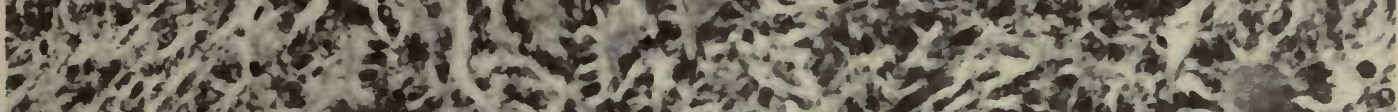

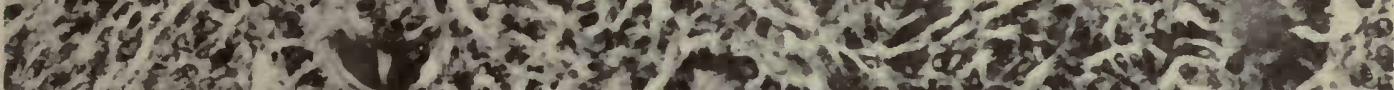

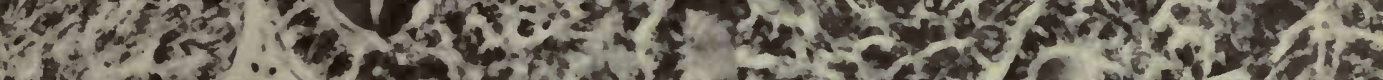

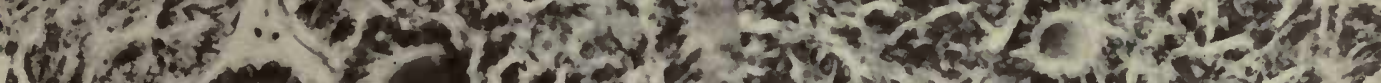

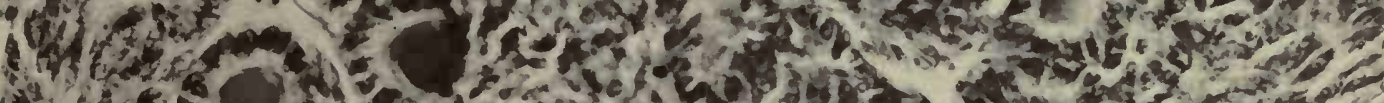

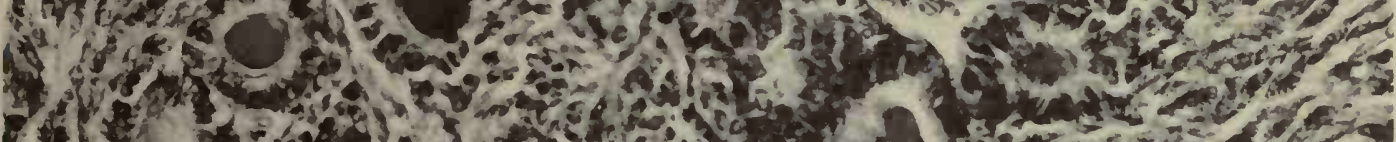

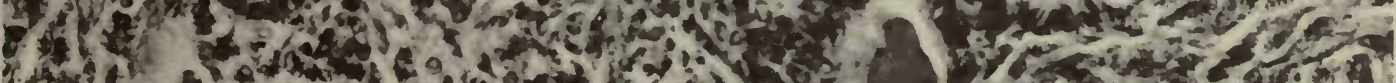

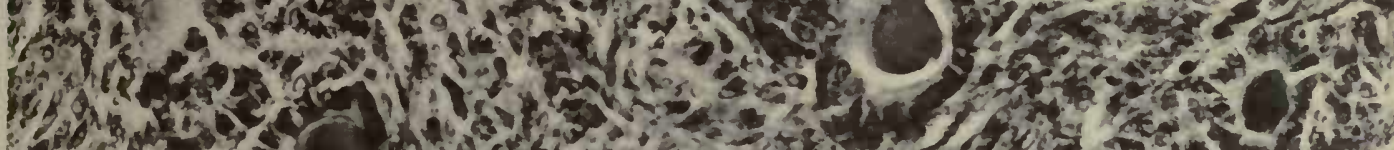

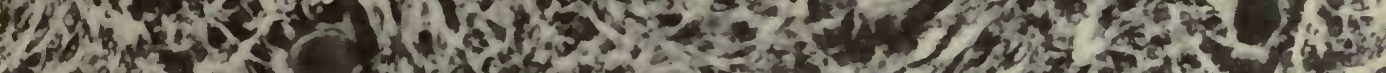
on

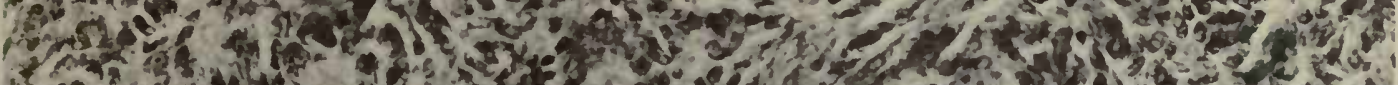

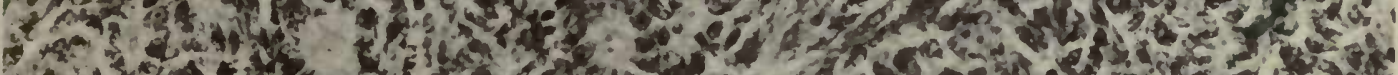
- Nont P.t. cells $F_{11}$. 38.

He.

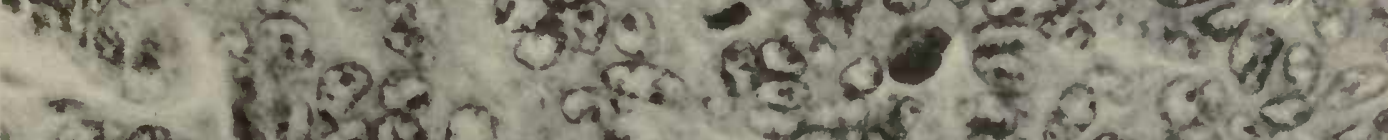

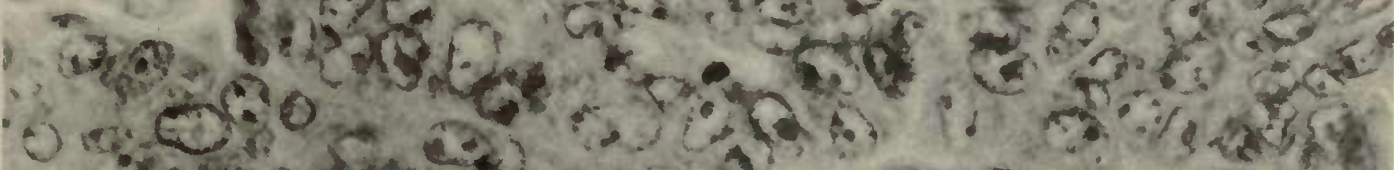

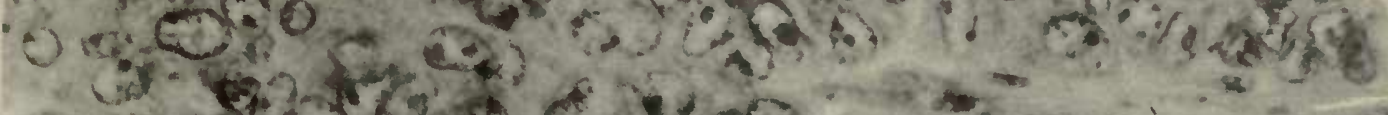
30 -

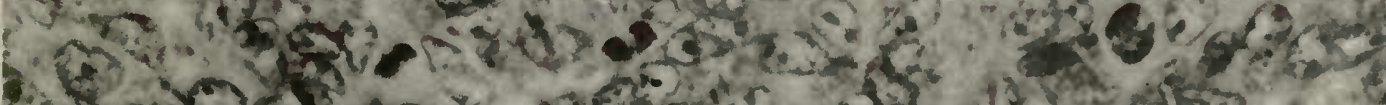

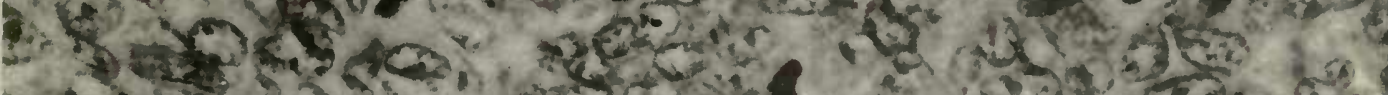
a.

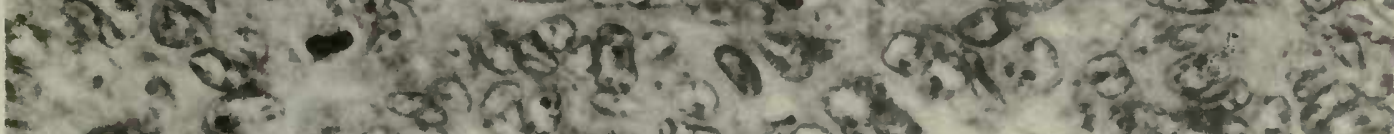

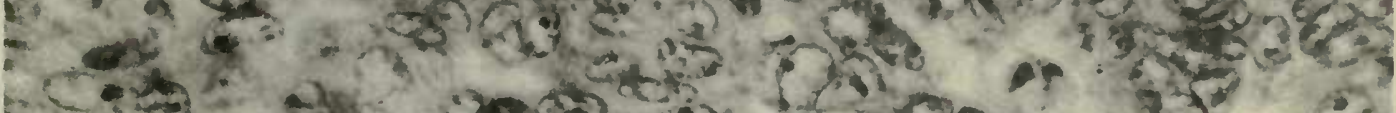

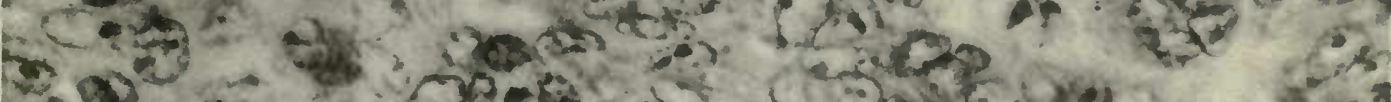

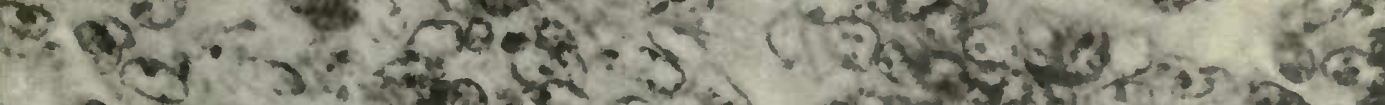

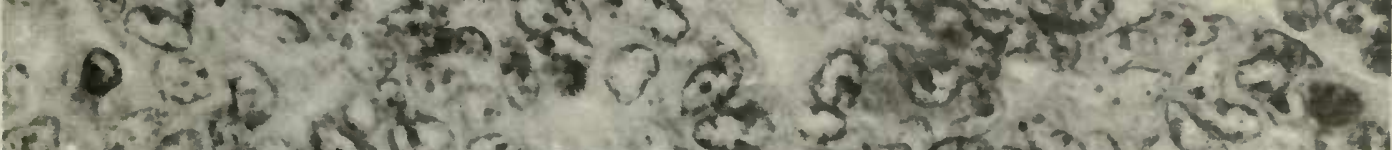

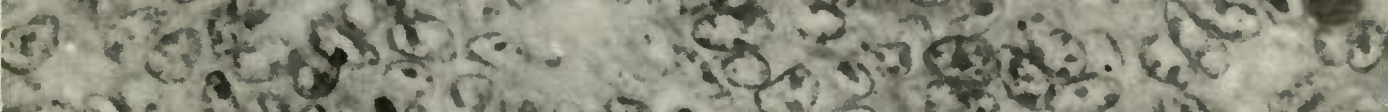

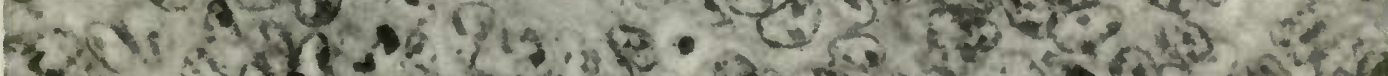

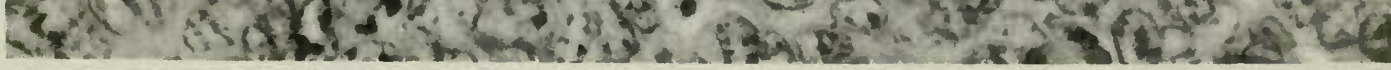





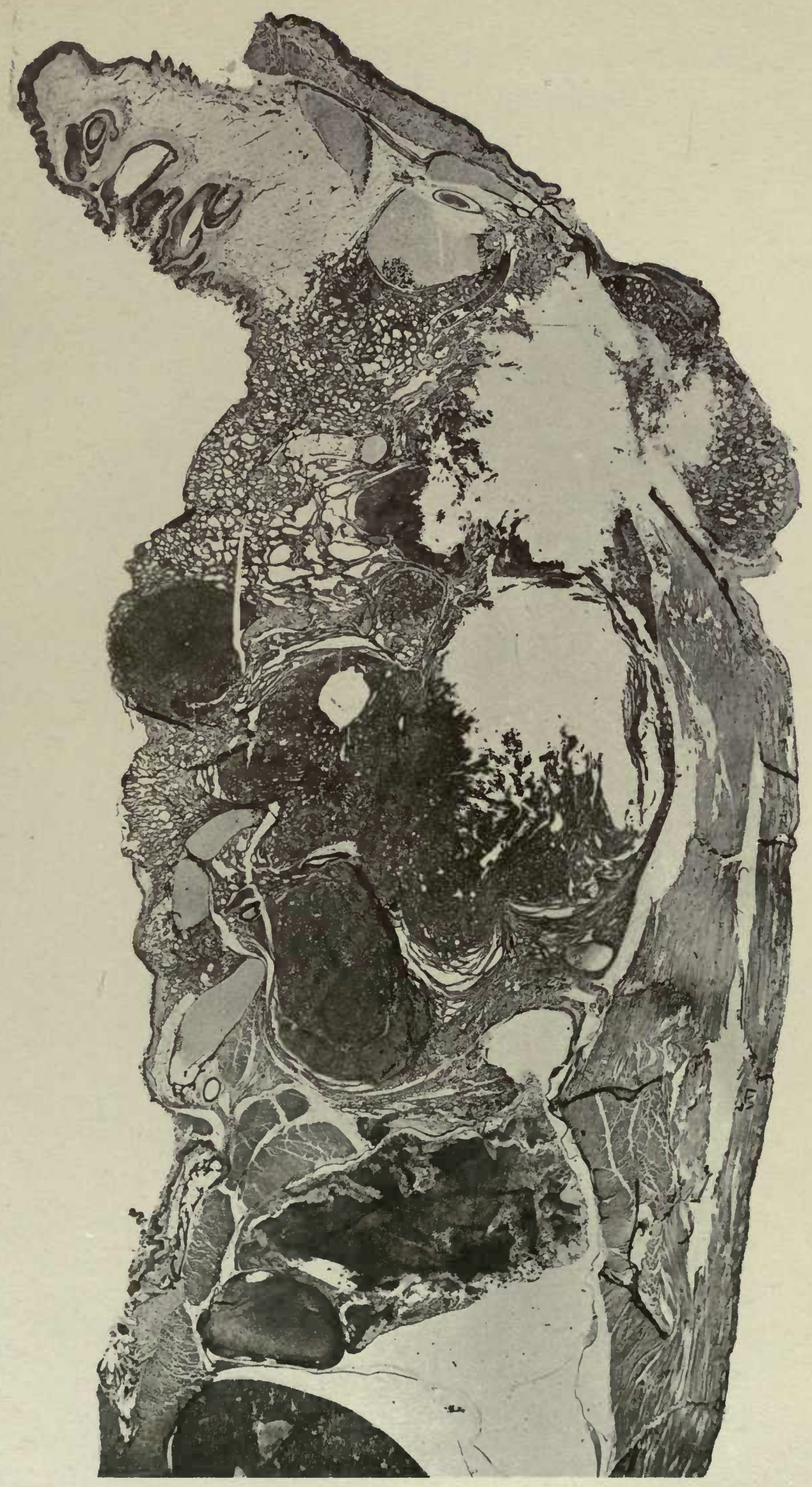

Fig. 40.-Section of lower jaw showing nodulat development in various portions of the tumor mass. 



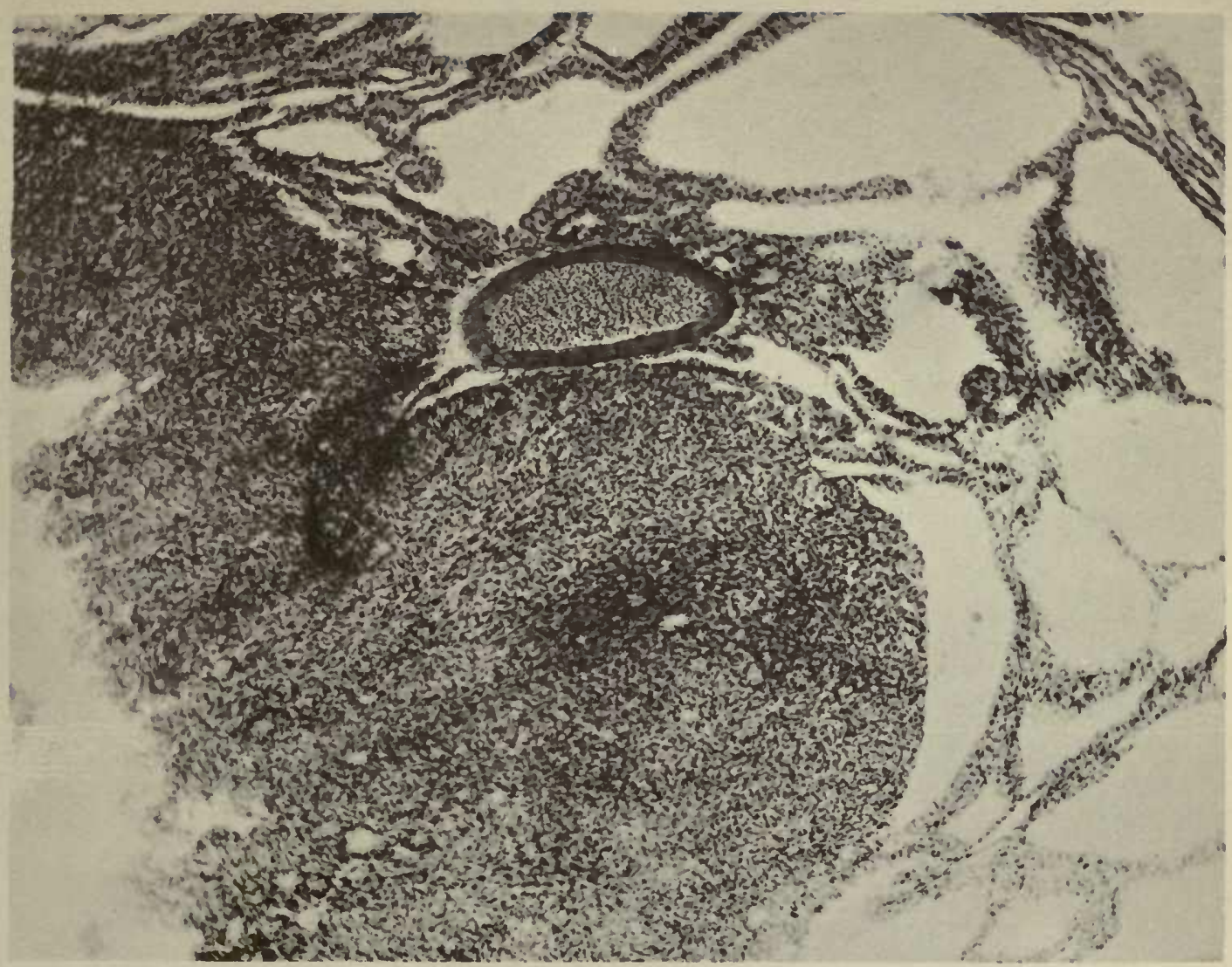

Fig. 41.-Figh power section from figure 39 of a nodule showing closely packed spinclle and oval cells with deeply staining. nuclei, with here and there in attempt at alvelar arrangentient. $\mathrm{X} 94$.

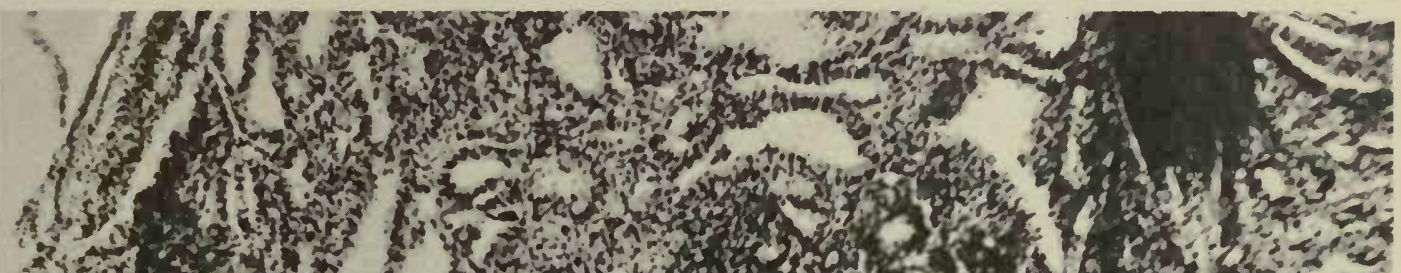

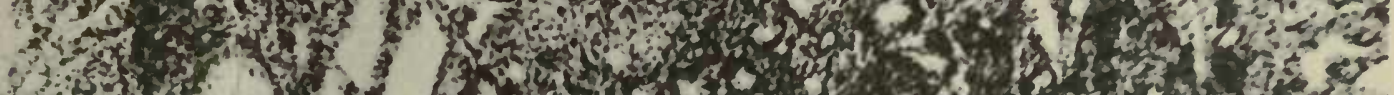

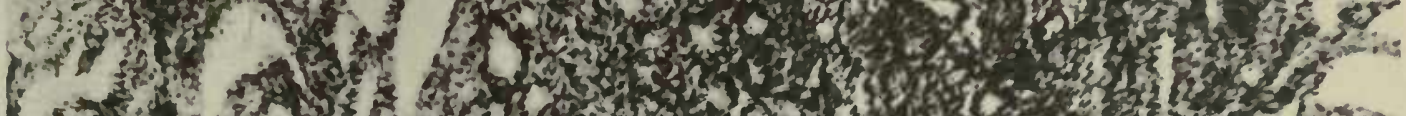

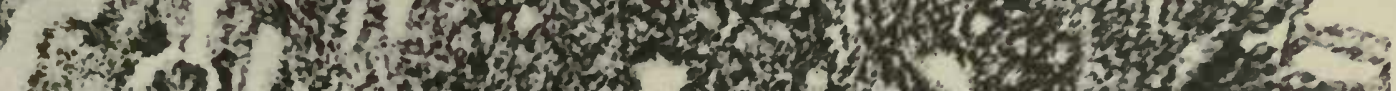

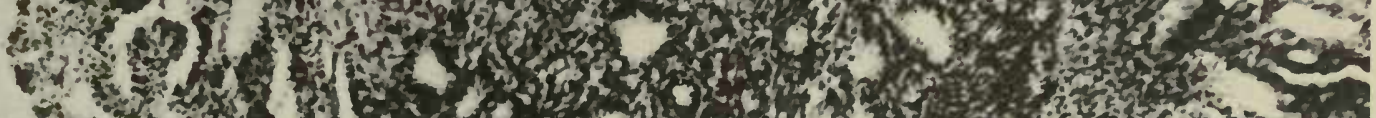

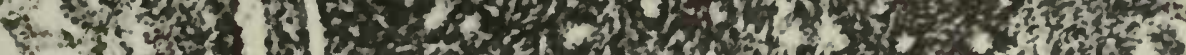

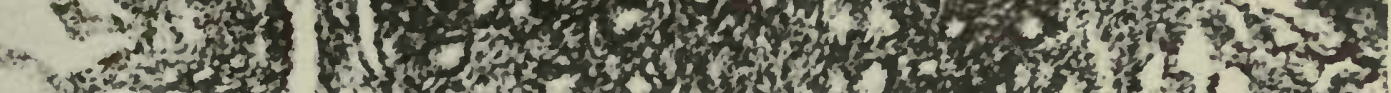

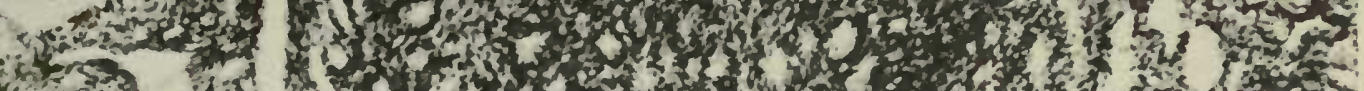
arins Fon

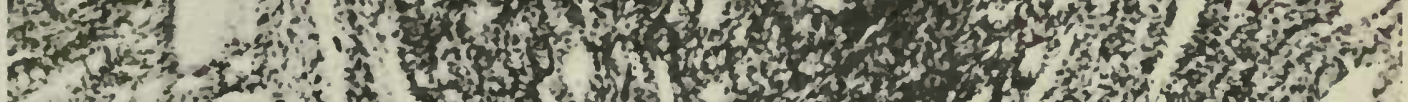
ato and 3 - 3

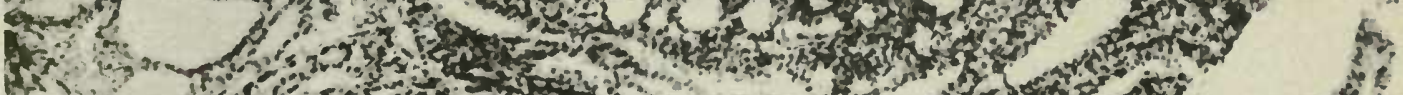
(17, $175^{3}$ (3)

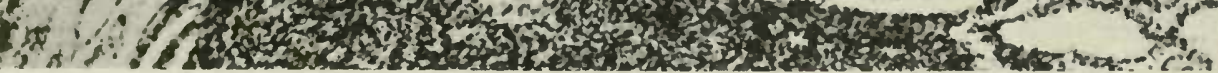





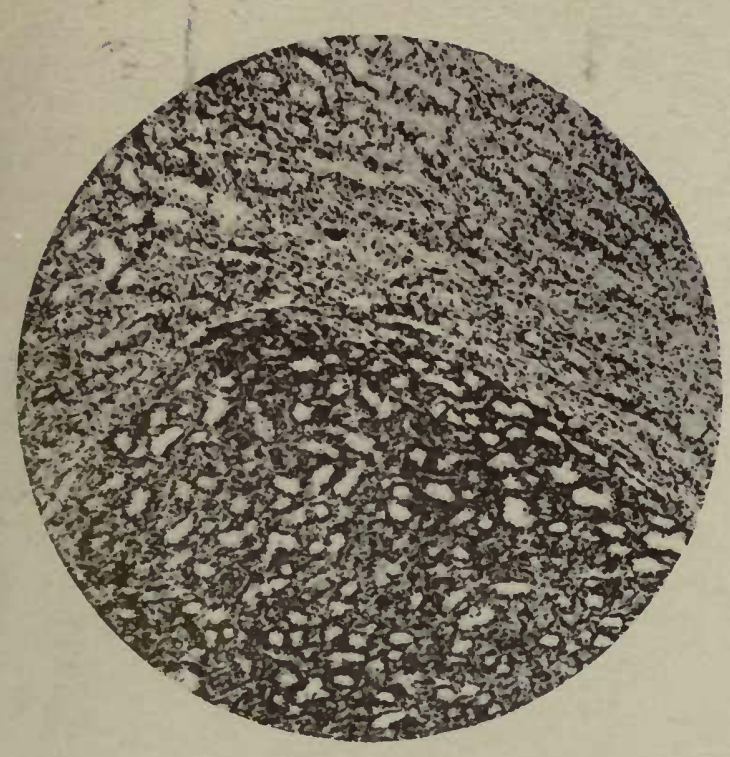

FIG. 43.- Sections showing intensive nodular growth with concentric compression of the surrounding tumor tissue. $\times 40$.

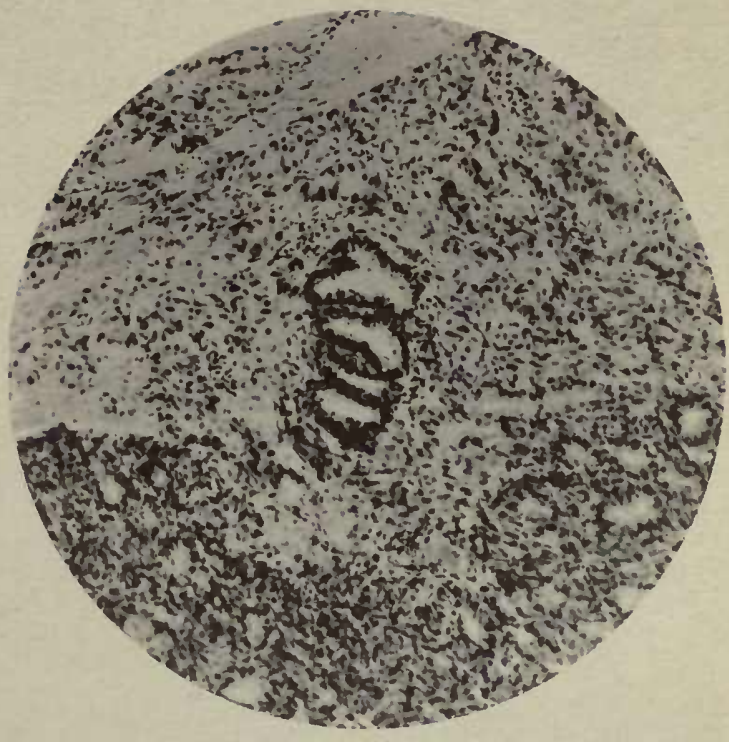

Fig. 44--Section showing individual follicles of more malignant type infiltrating surrounding tumior tissue. X130.

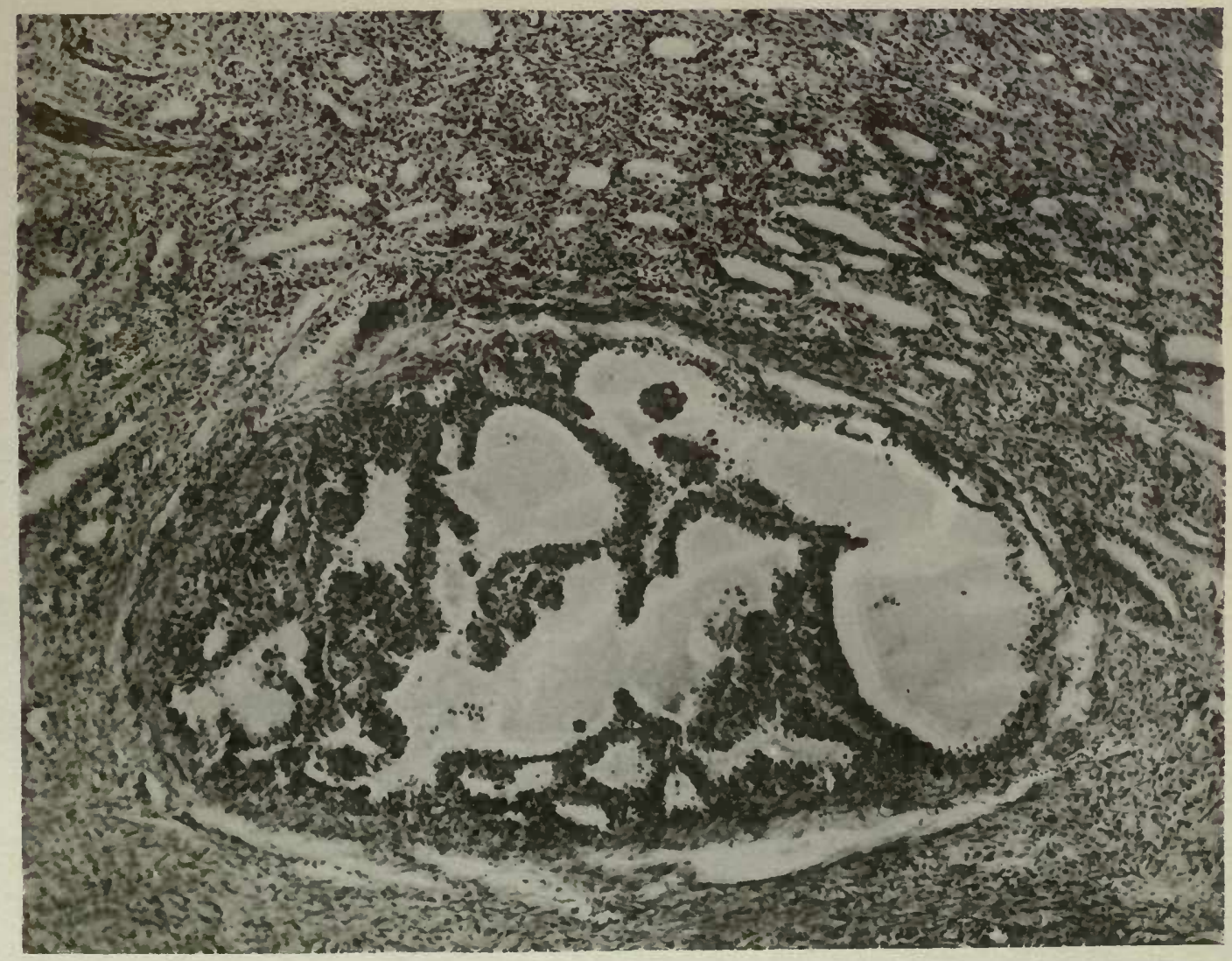

Fig. 45.-Section showing encapsulated nodnle of papillar type lying in tumor tissue of alveolar type. $\quad$ X94. 



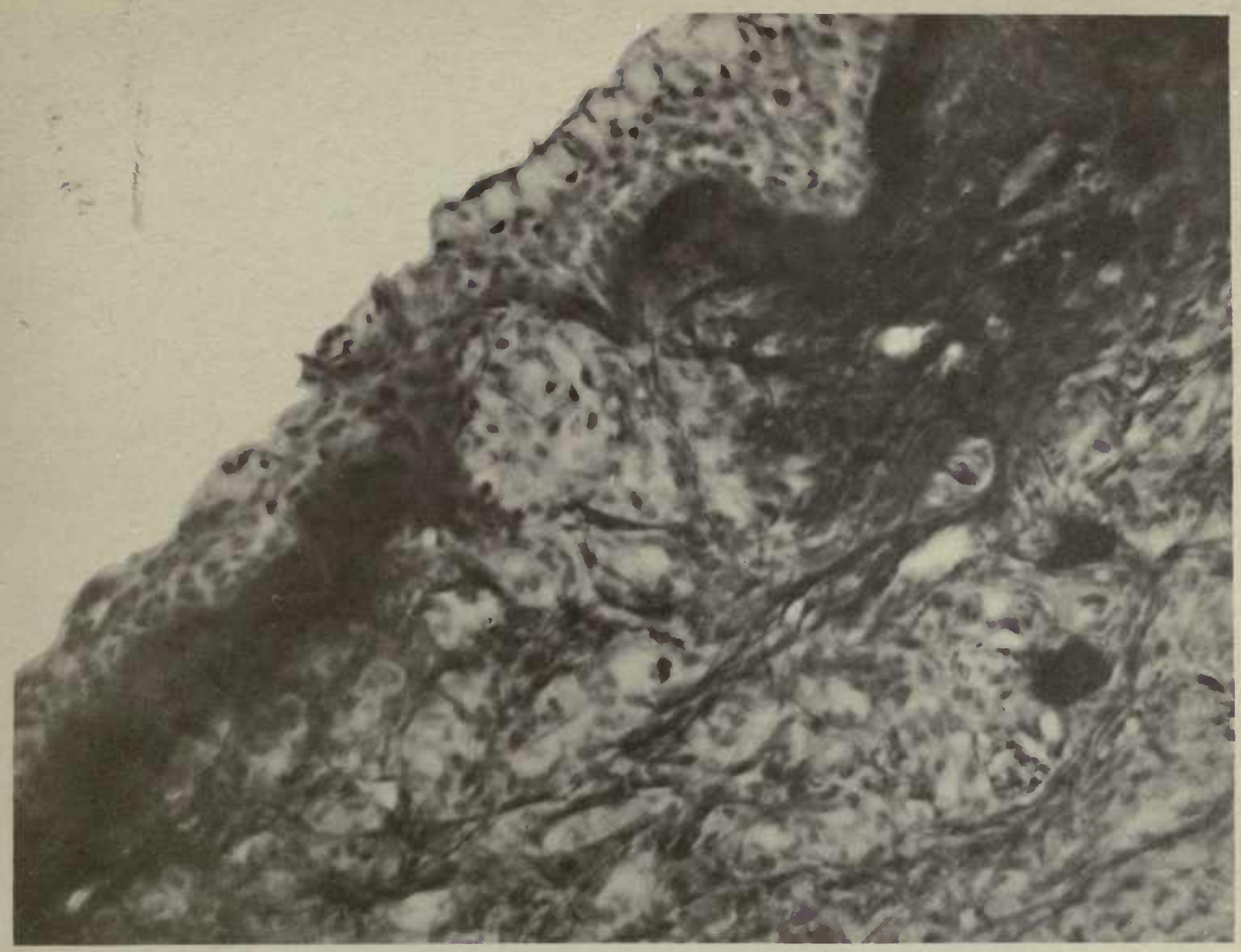

Fig. 46. - Section of floor of the mouth showing tumor cells infiltrating and destroying basal membrane. Splitting of elastica. $\times 260$.

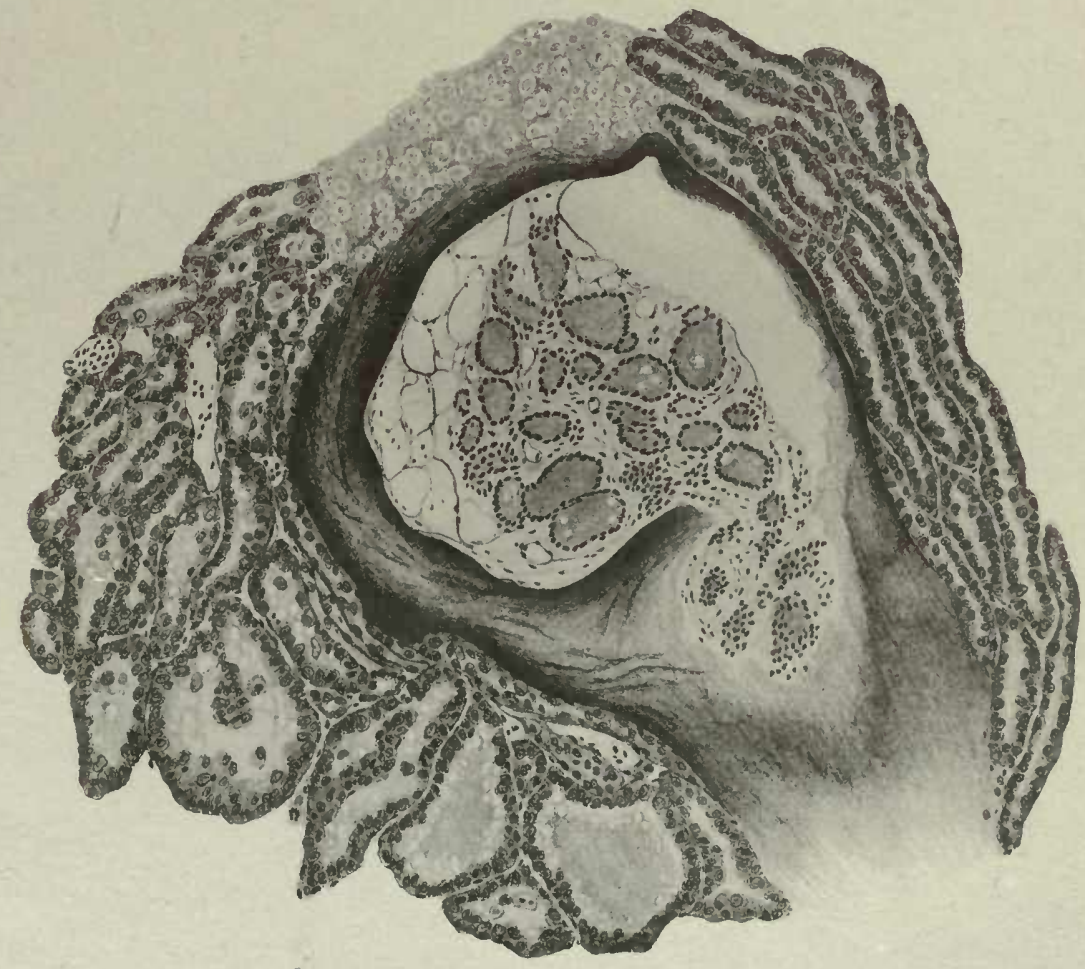





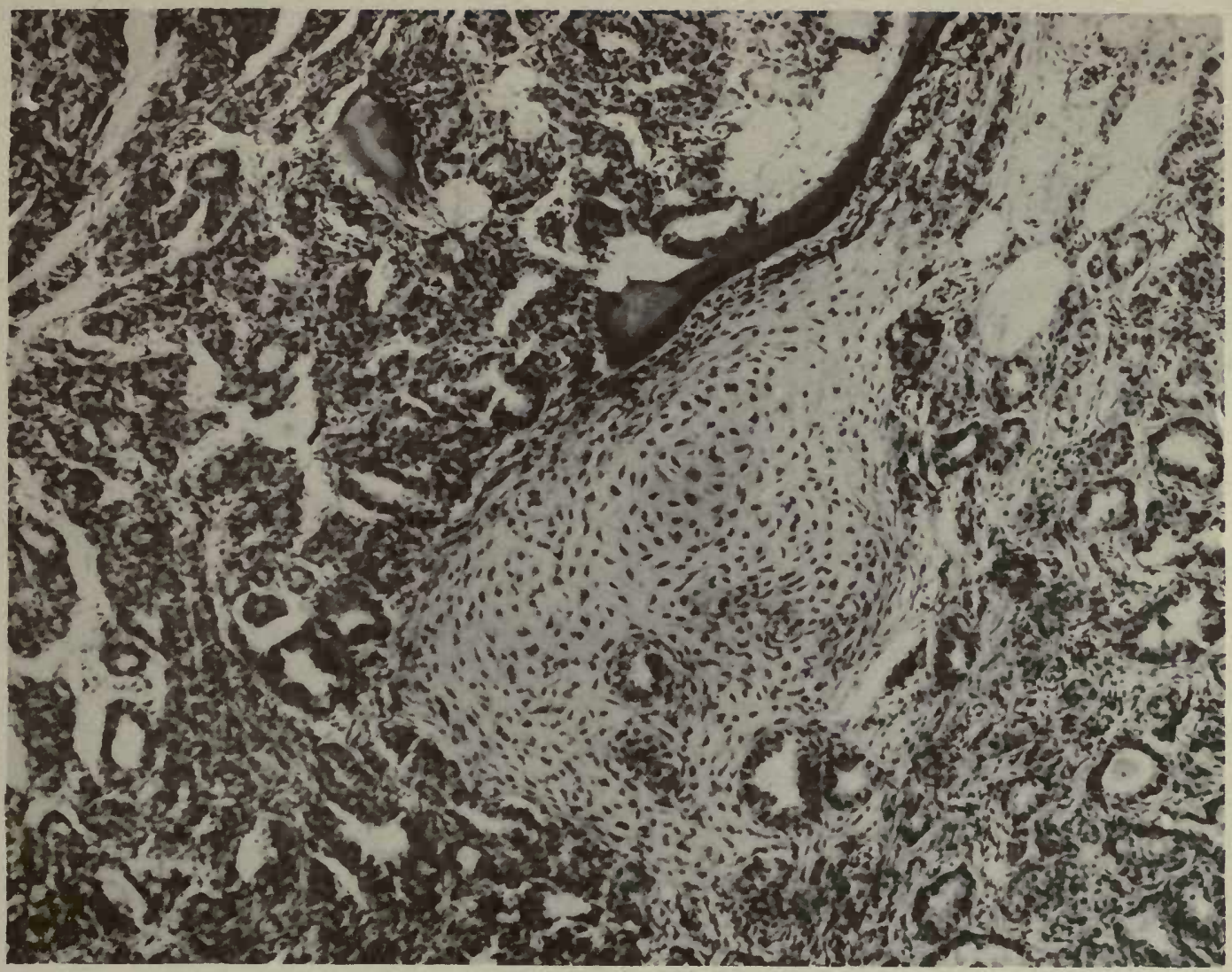

Fig. 48.-Section showing infiltration and destruction of cartilage. $\times 136$.

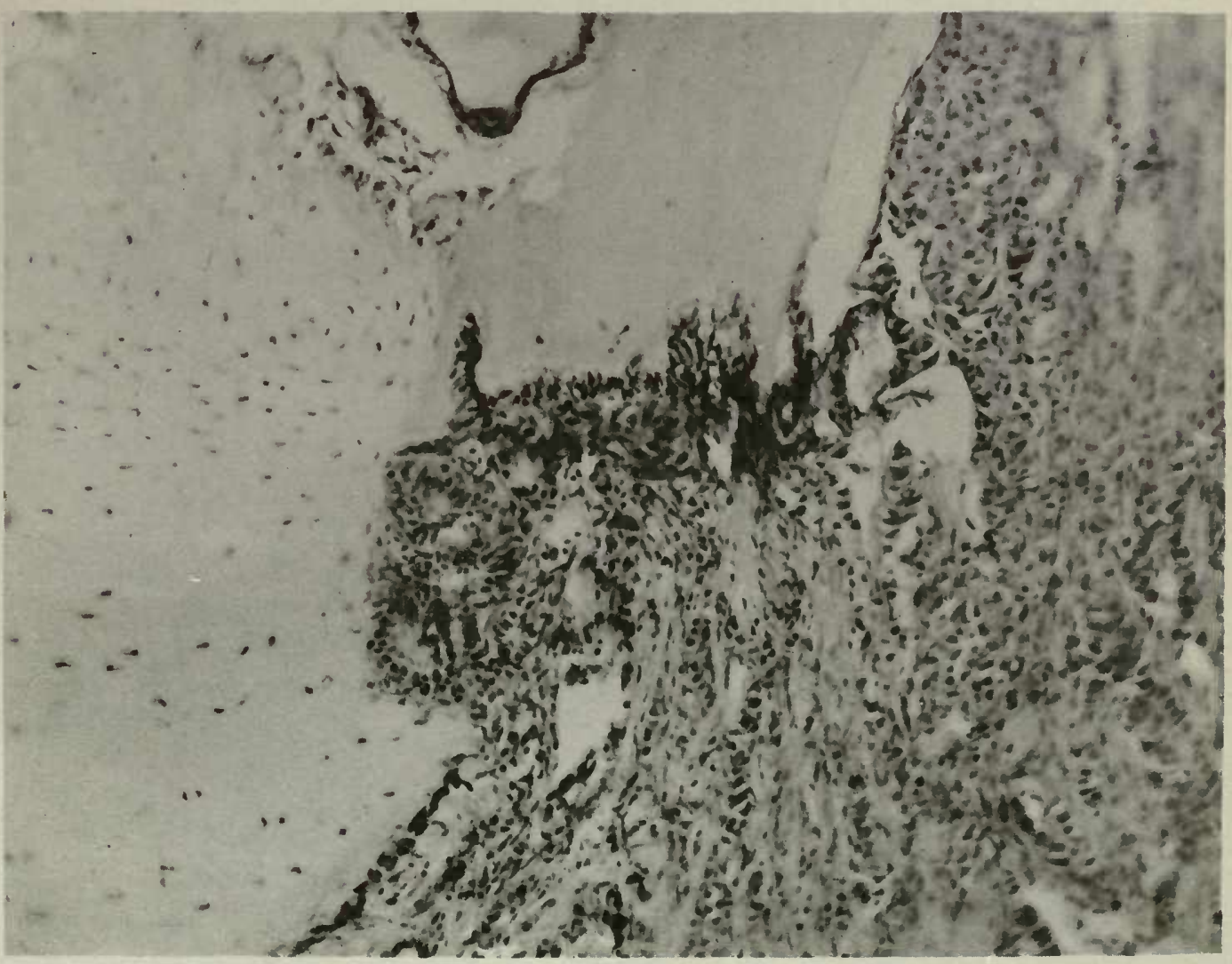



BULL. U. S. B. F. I9I2.

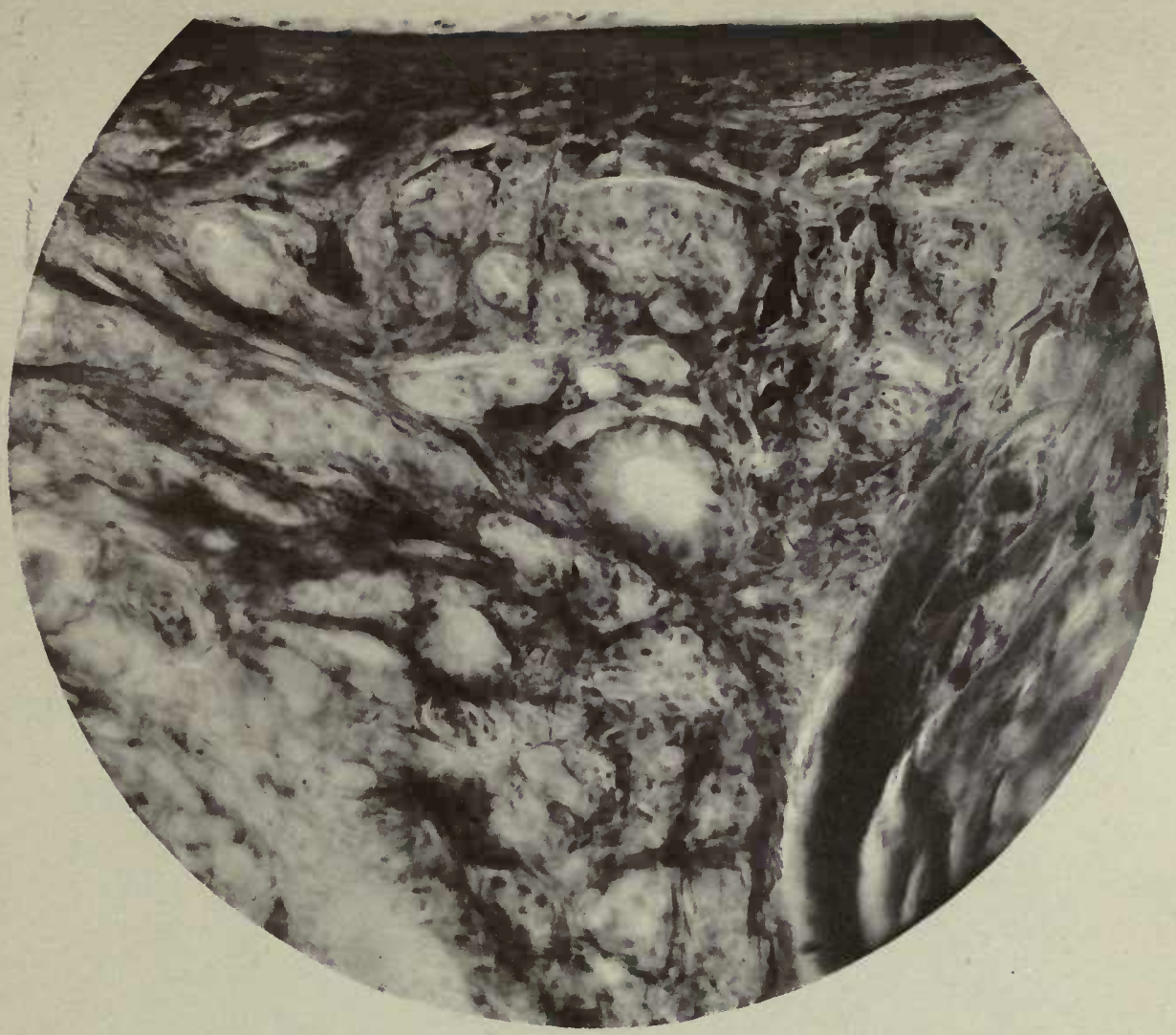

FIG. 50.-Section showing involvement of aortic wall. Tumor alveoli between elastic lamellæ of media. X260.

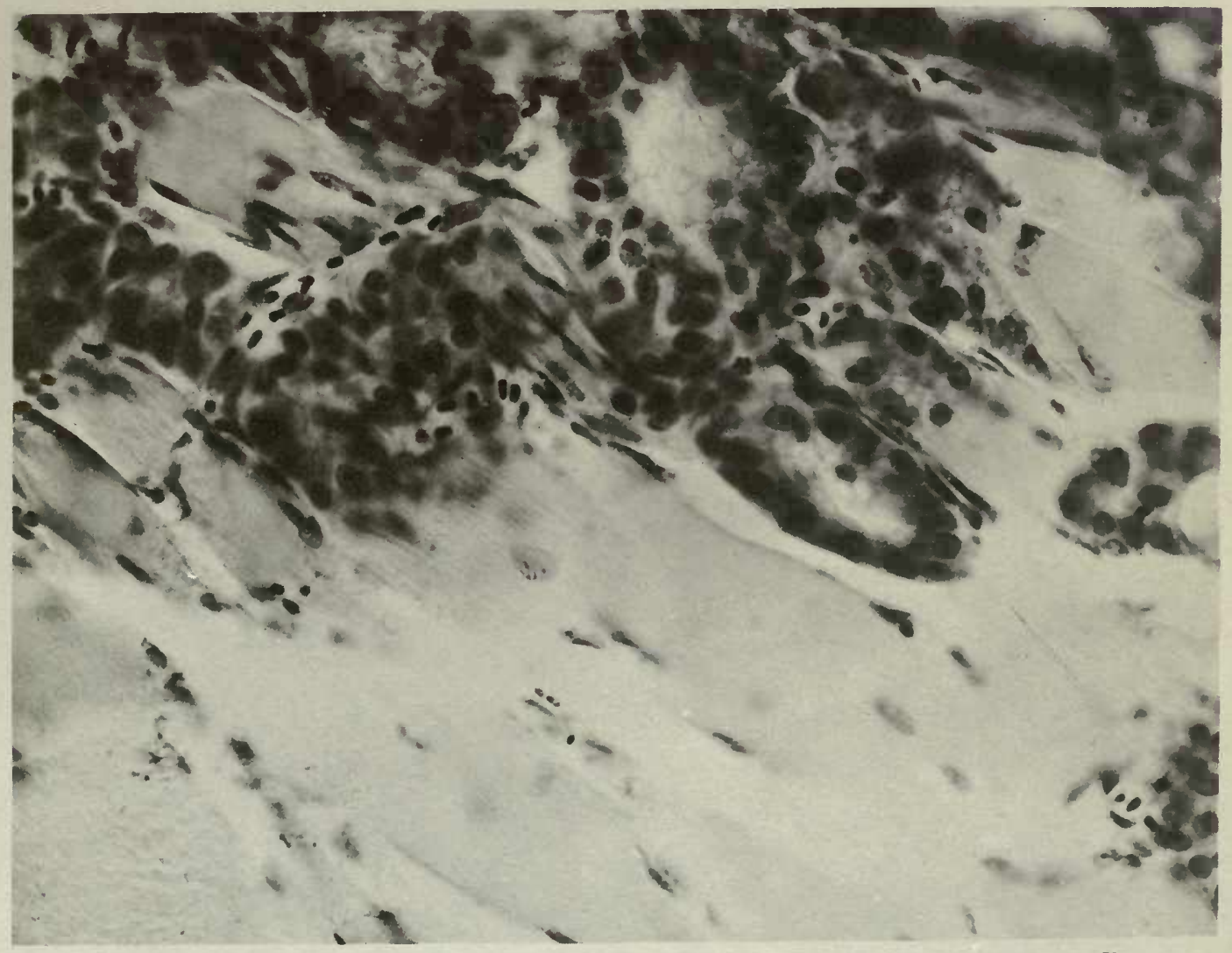

Fic. 51.-Section showing infiltration of individual muscle fibres. Cells within the sarcolemma. $\times 500$. 



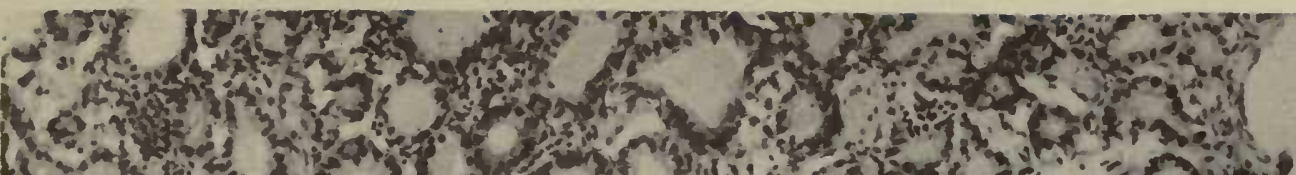

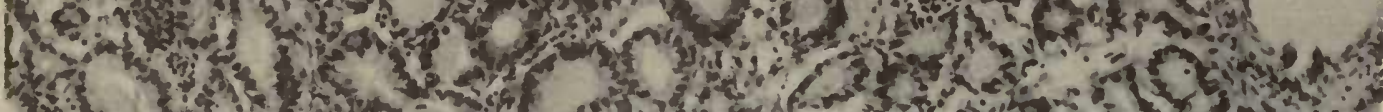

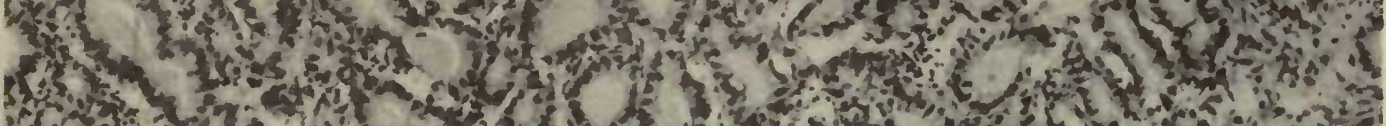
Pif

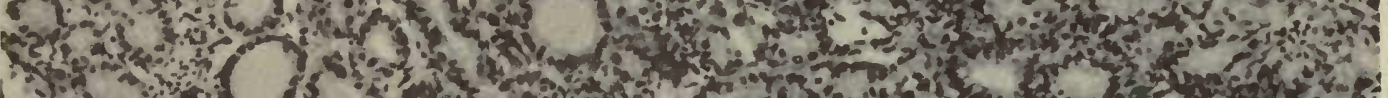
T. 4 ing

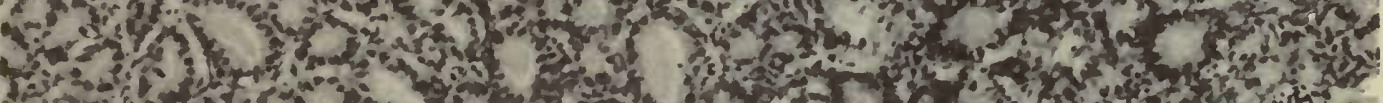

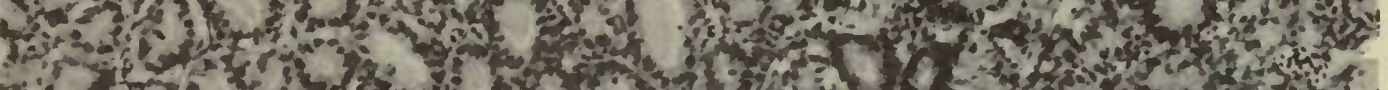

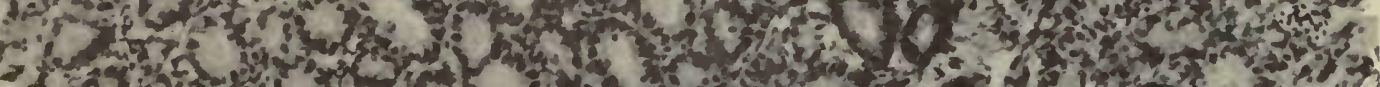

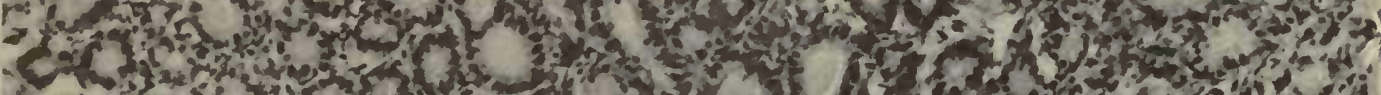

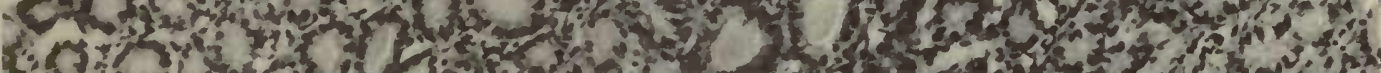

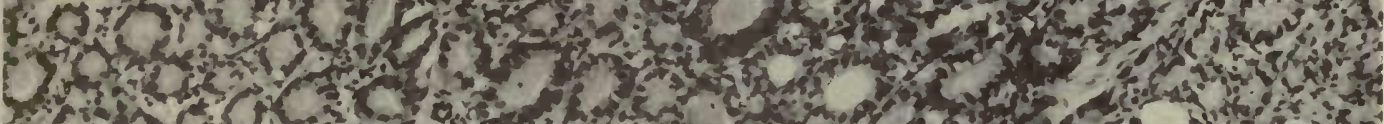

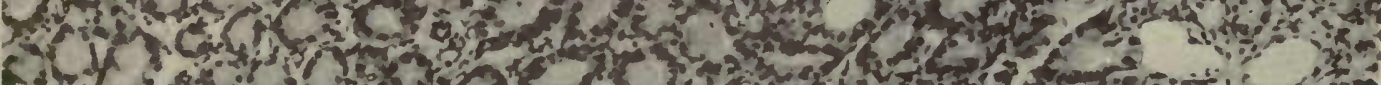

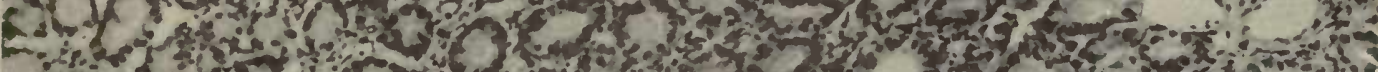

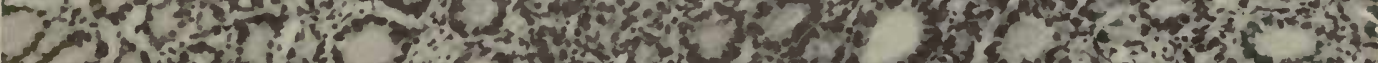

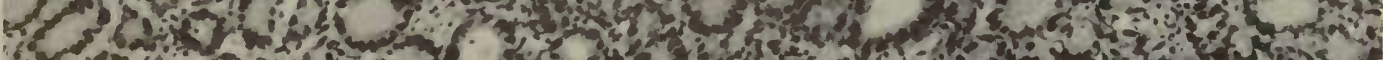
R.

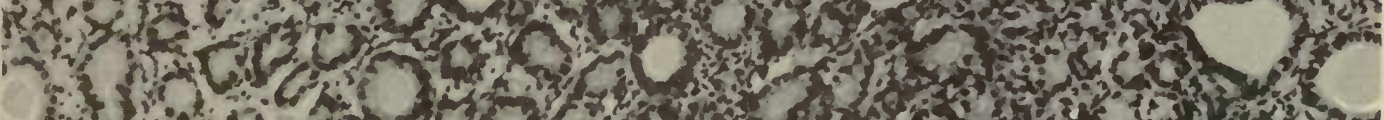

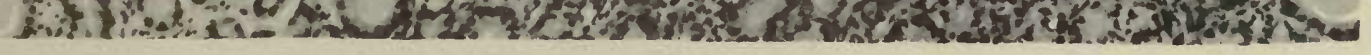

Fis. 52.-Primary tumor of thyroid region, Alveolar type. X136.

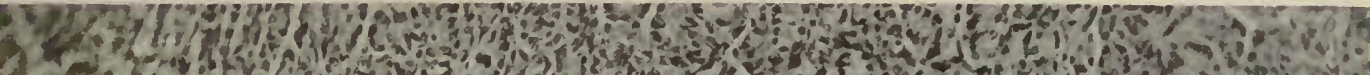

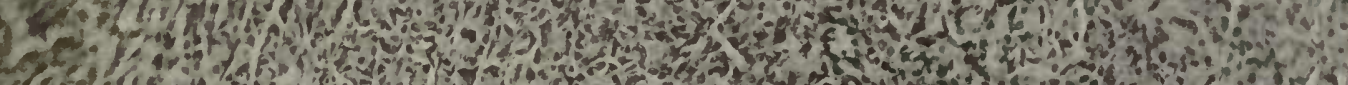

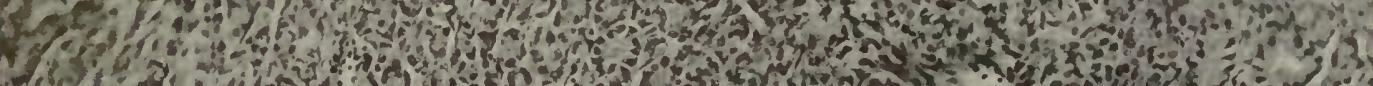

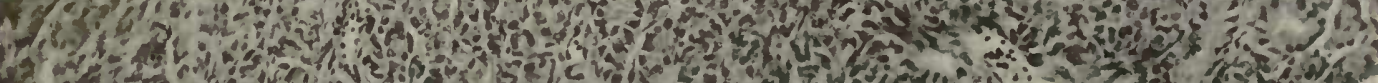

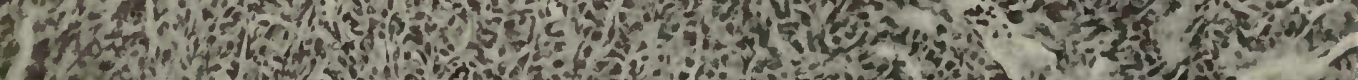

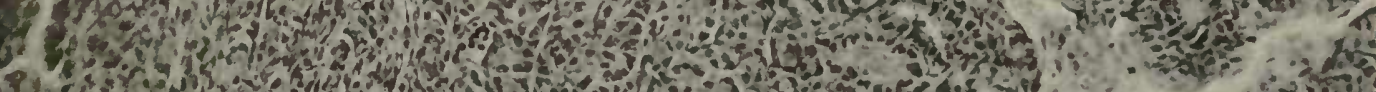
3.

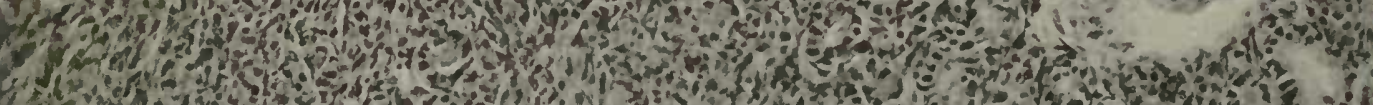

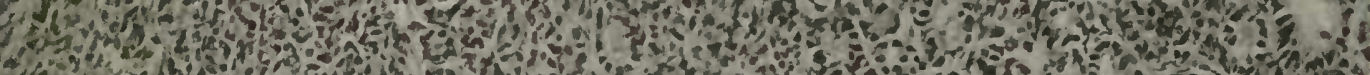

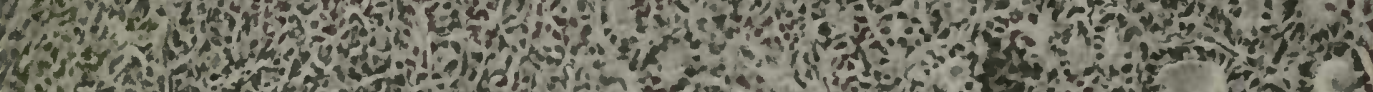
21. - 50,30 .

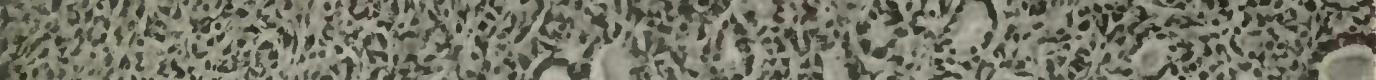

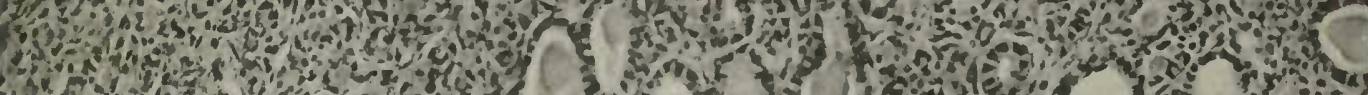
15

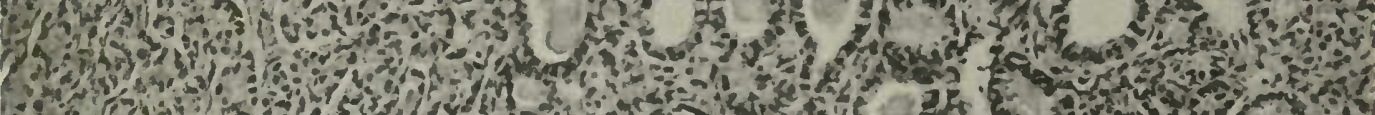

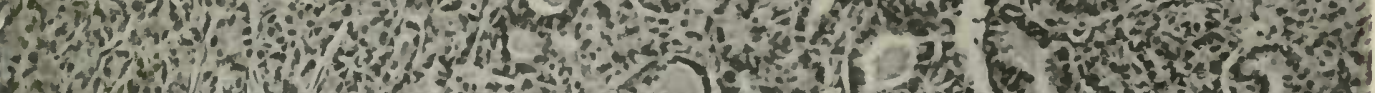

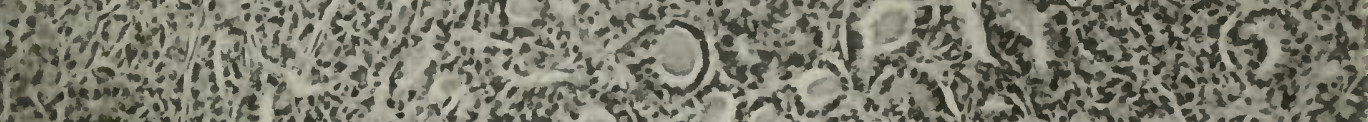

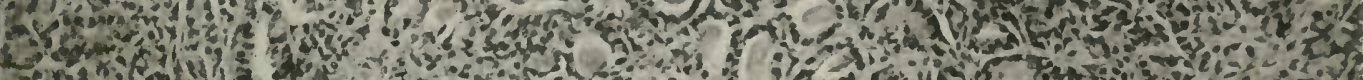

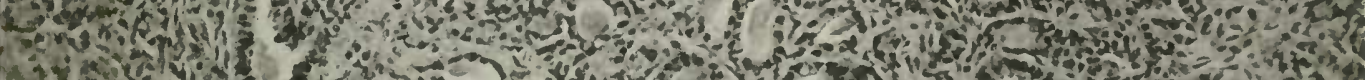

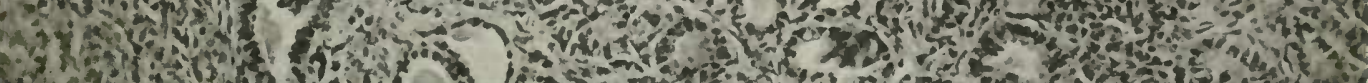

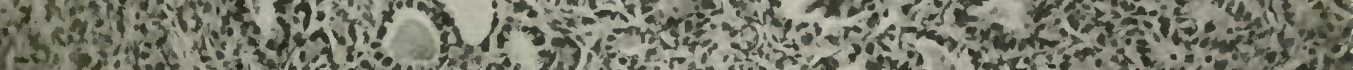

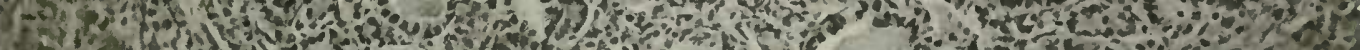

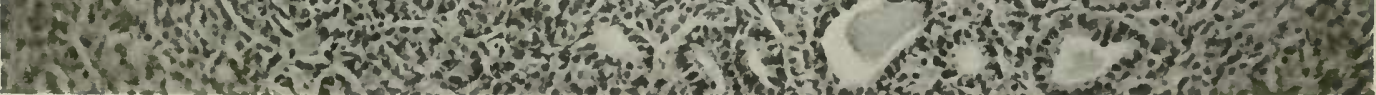





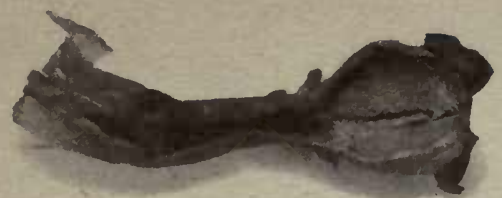

FIs. 54.-Pliotograph of metastatic tumor in the rectal wall. Normal size.

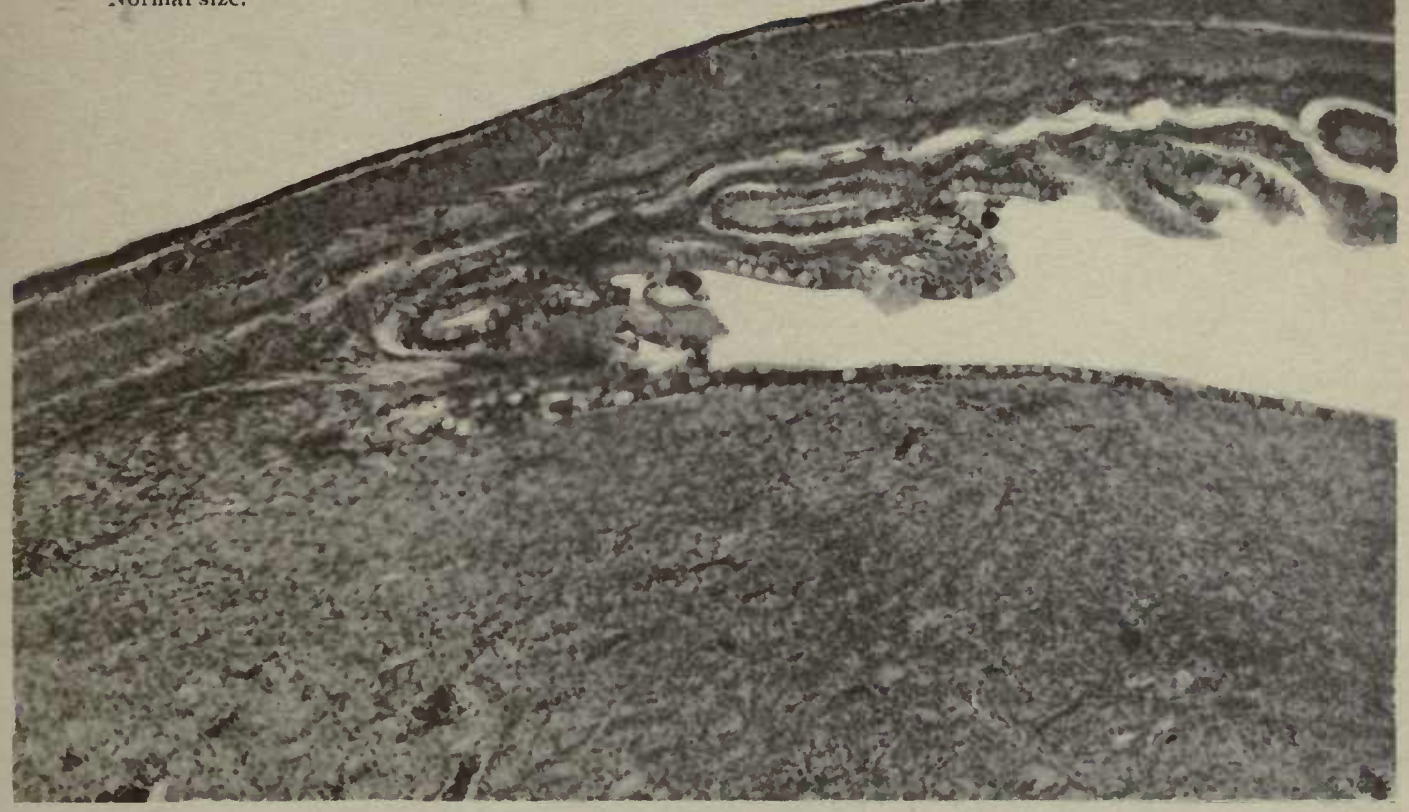

Frg. 55.-Microscopic section of rectal metastasis showing attachment to the intestinal wall; with extension of rectal inticosa over surface of tumor. $\quad X 86$.

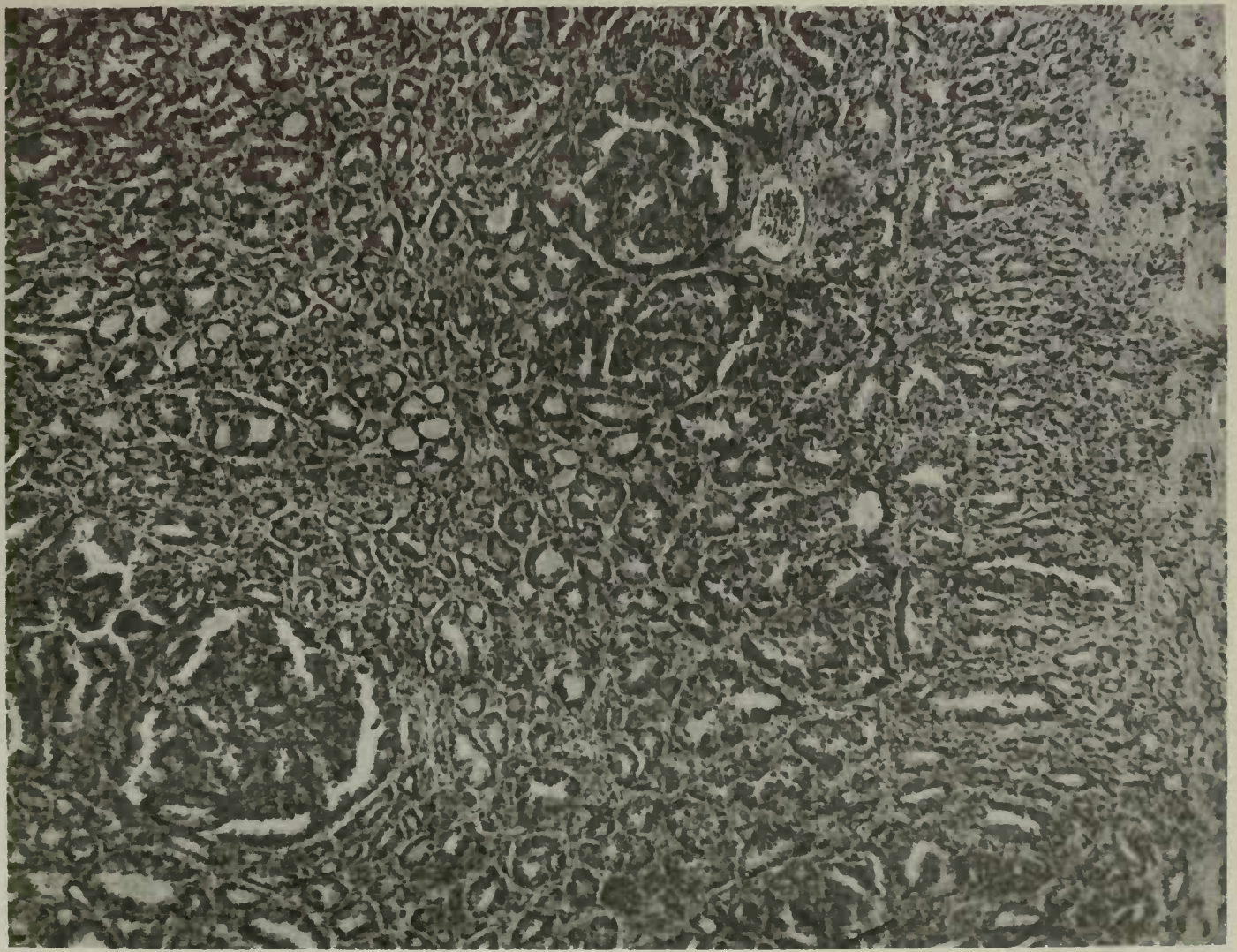





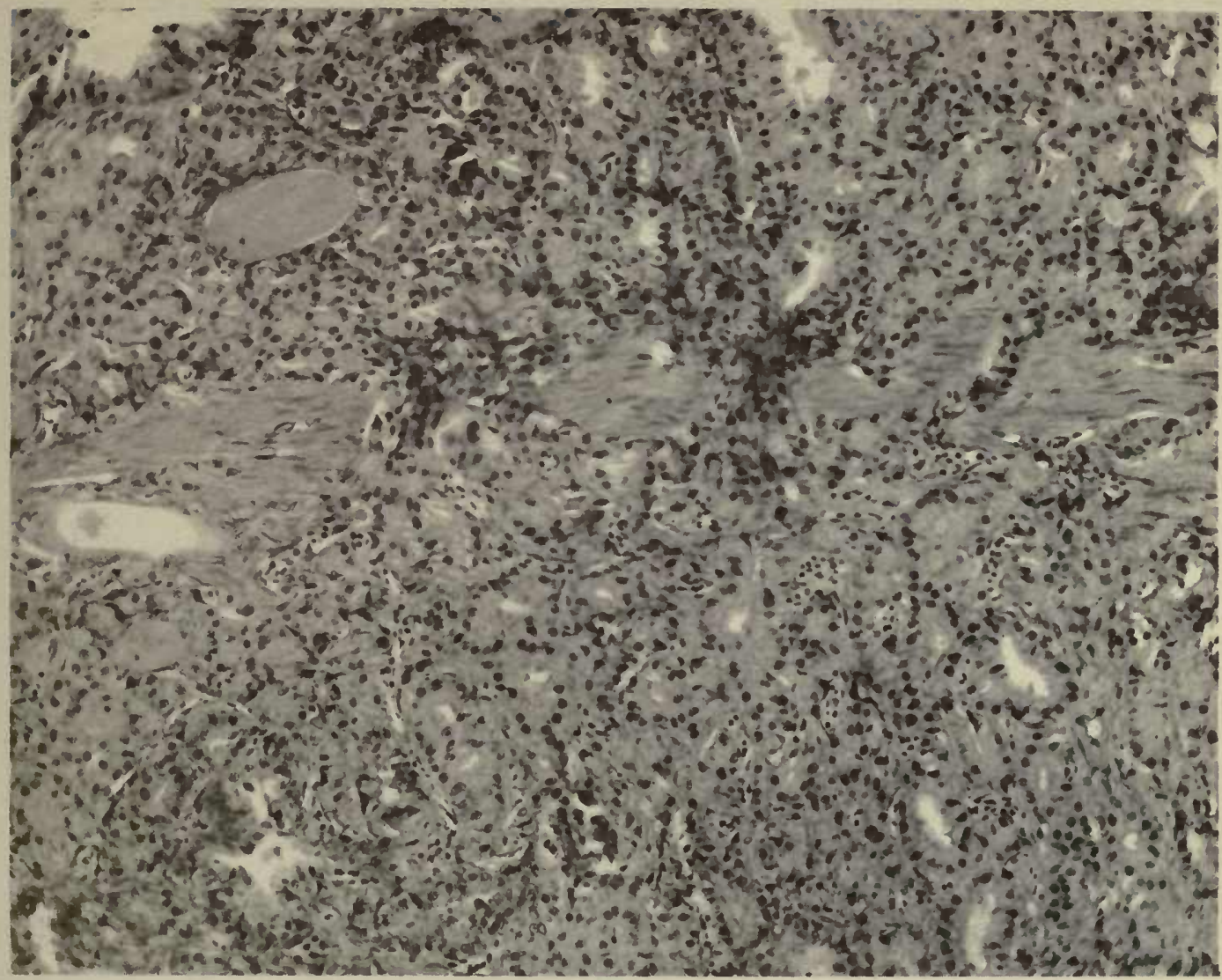

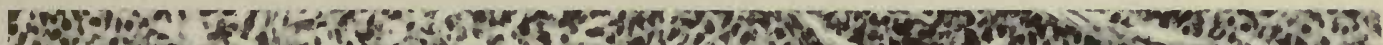
fusootis. 14.

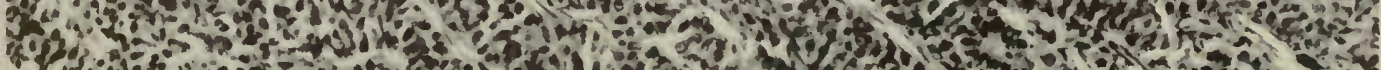

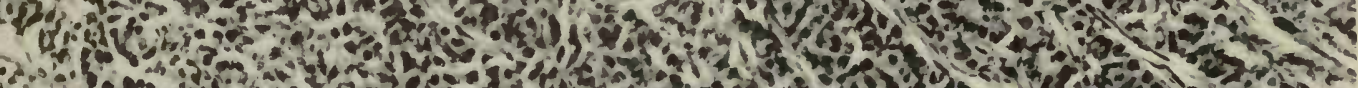
3.0.6.

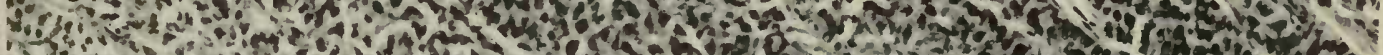
A.

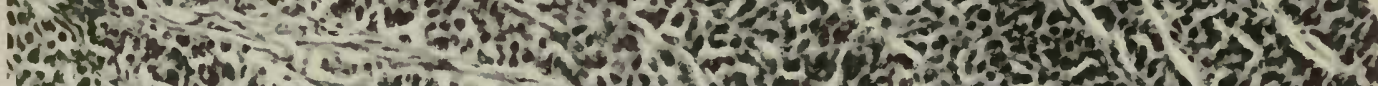
Ho (c) P. 25 . 10.

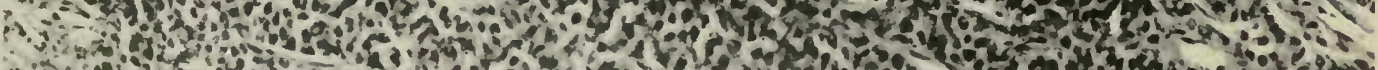

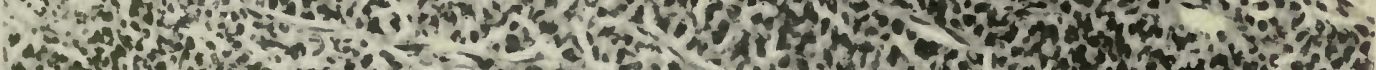

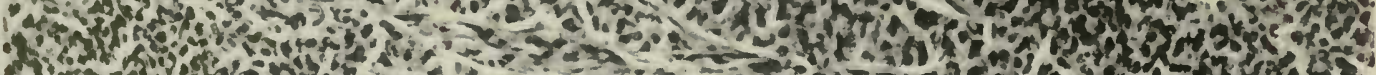

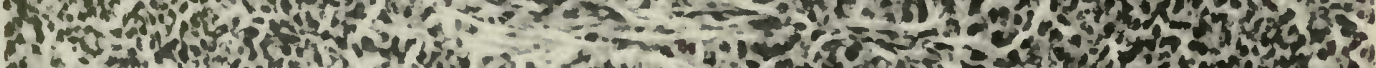
4. - En Hif

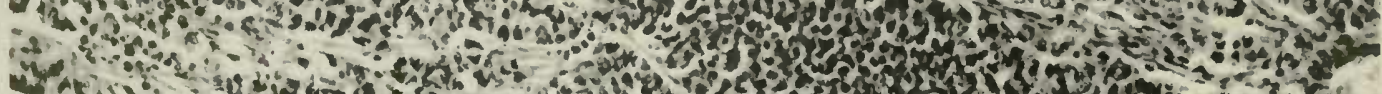

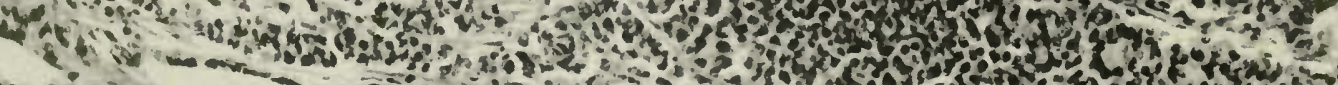

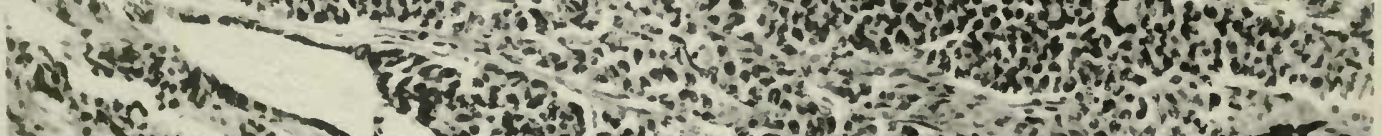
Lit 



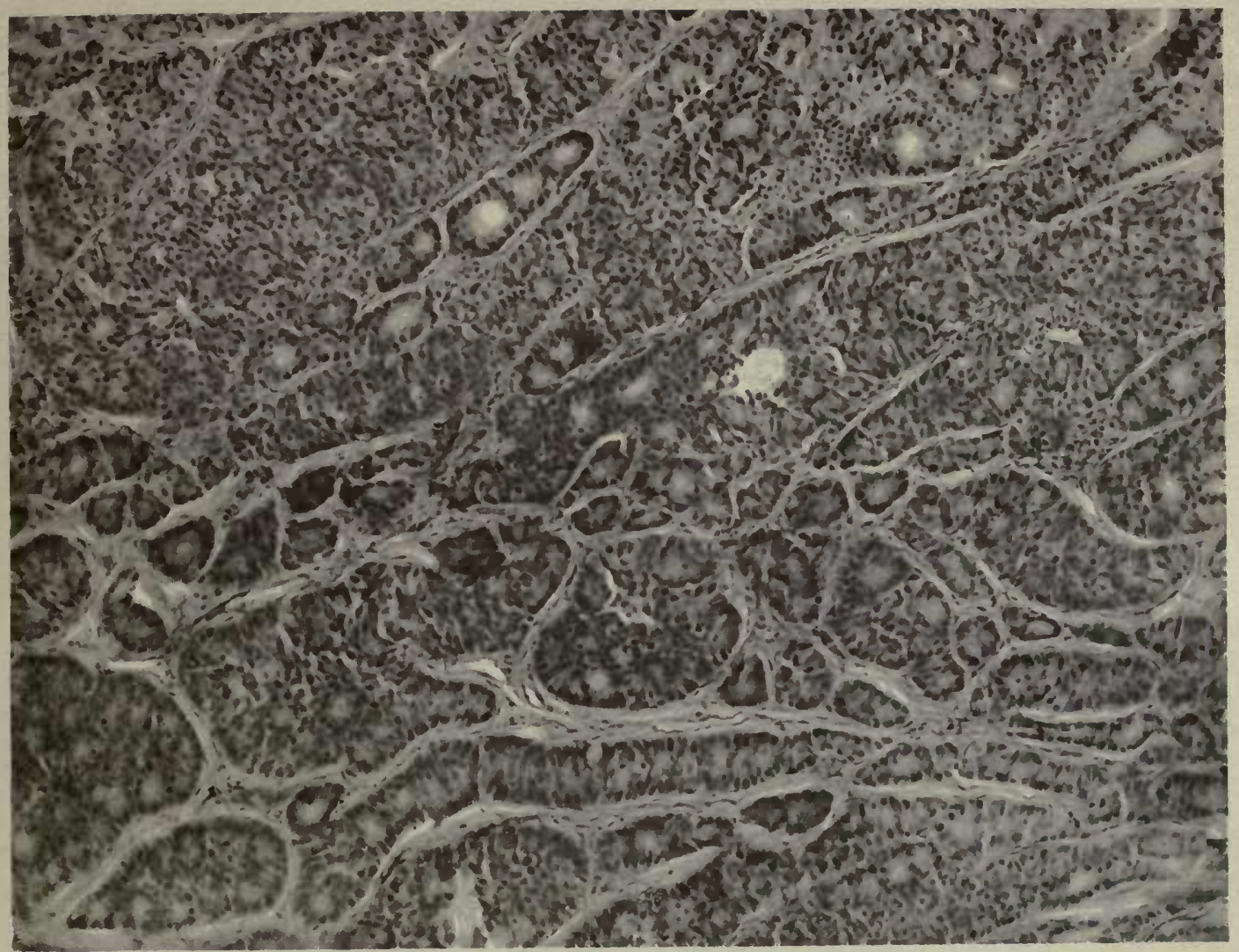

Fig. 59.-Section of fish thyroid tumor resembling the proliferating struma of Langhans as illustrated in plate 2, figure 12 , of his article. $\times 160$.

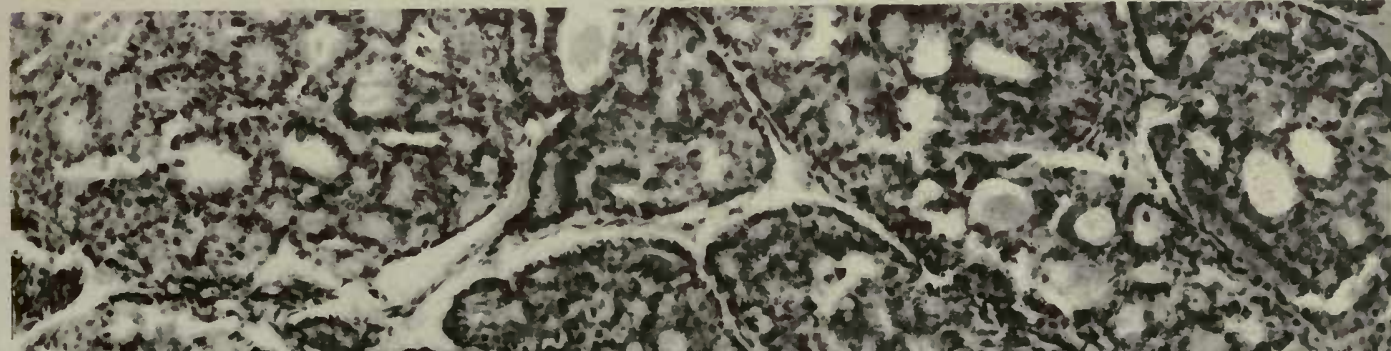

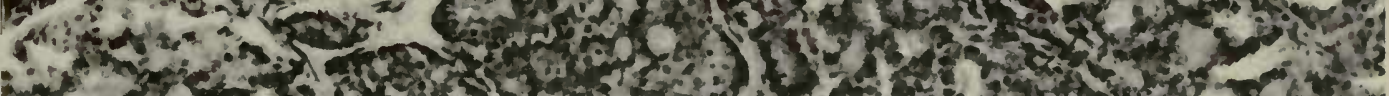
H.m.

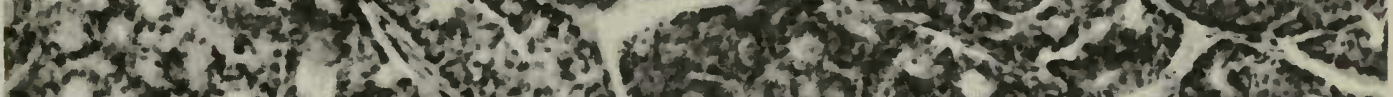

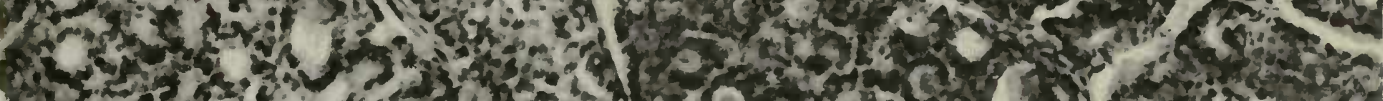

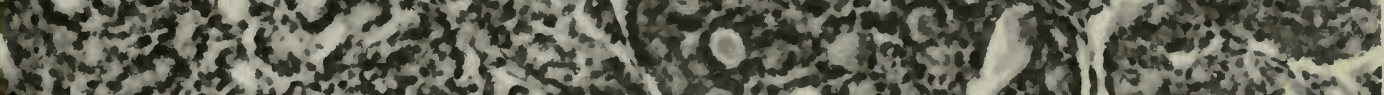

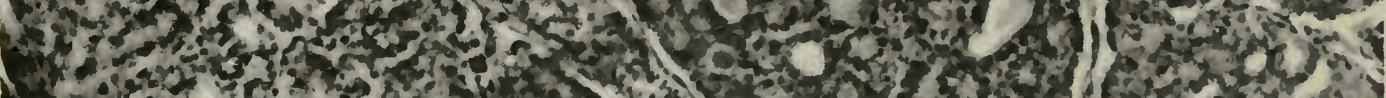

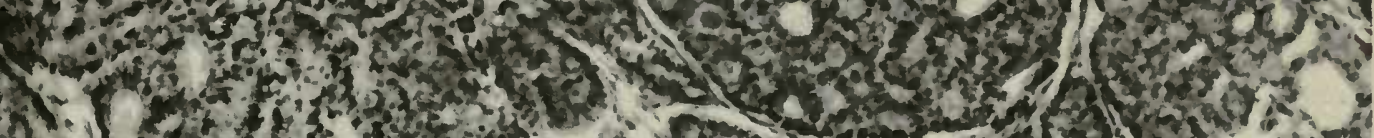

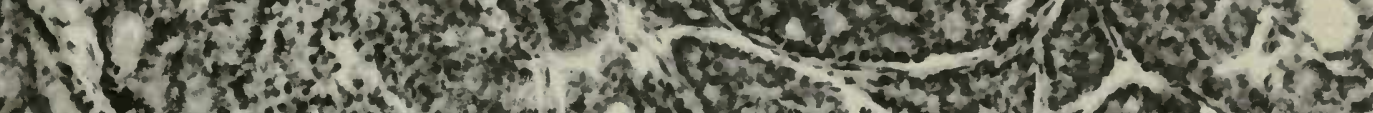

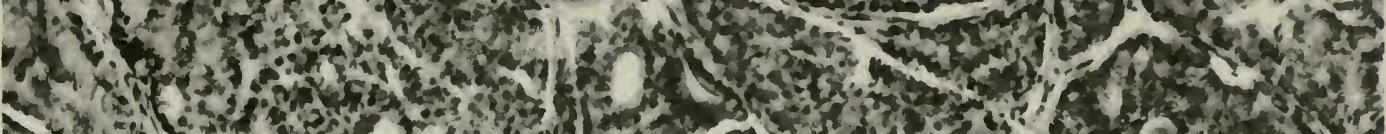
n.m. If Trom 



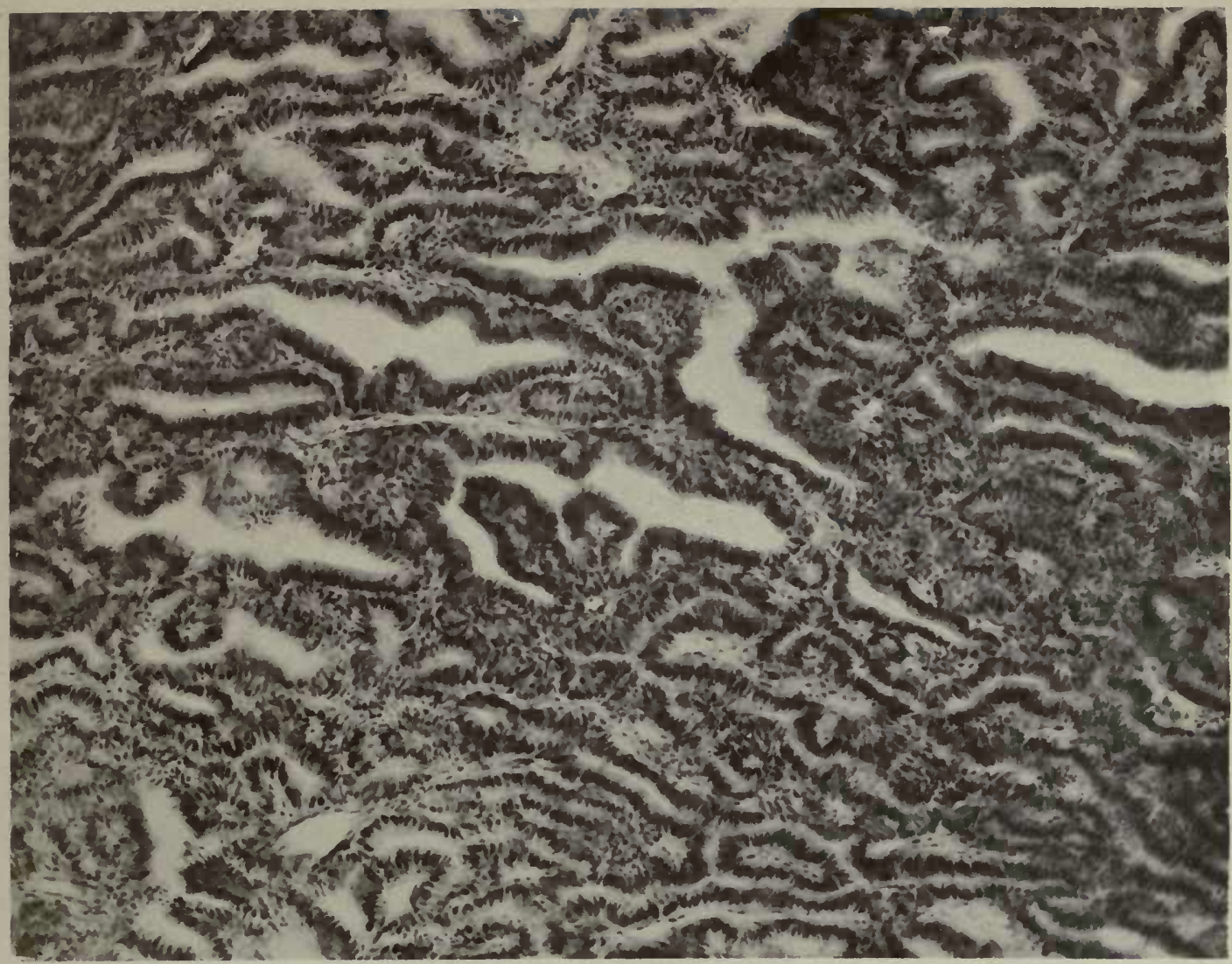

FIG. 61.-Papillar type in fish thyroid tumor resenıbling malignant papillar type in man, as illustrated in I,anghans article, plate 7 , figure $32 . \quad \times 160$.

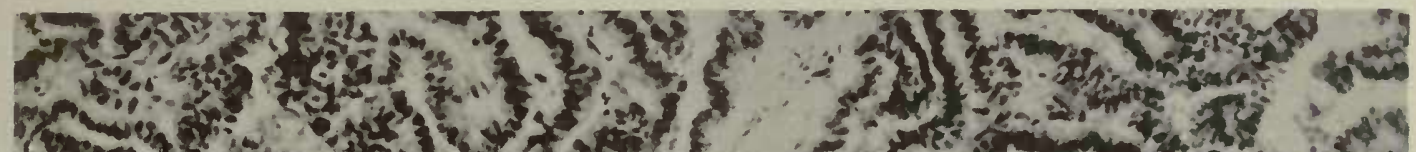

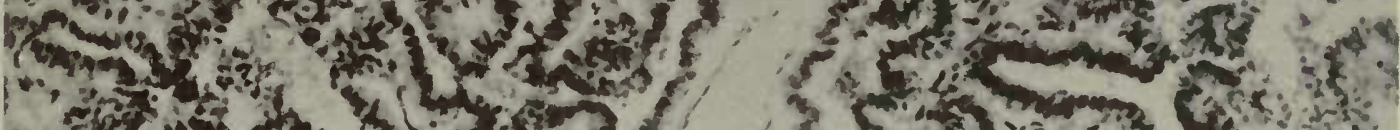

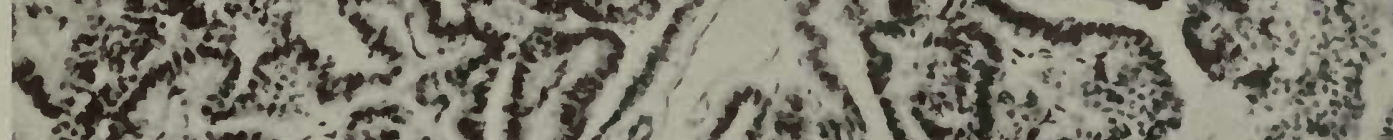

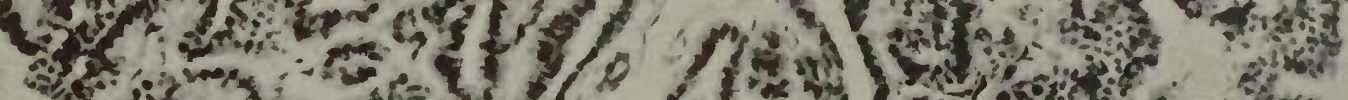

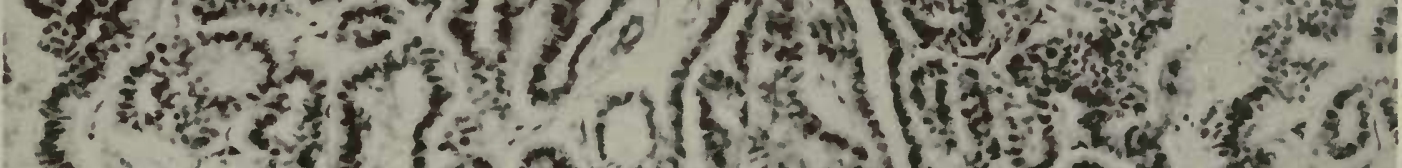

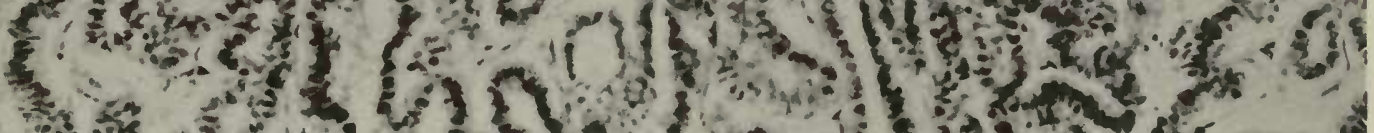

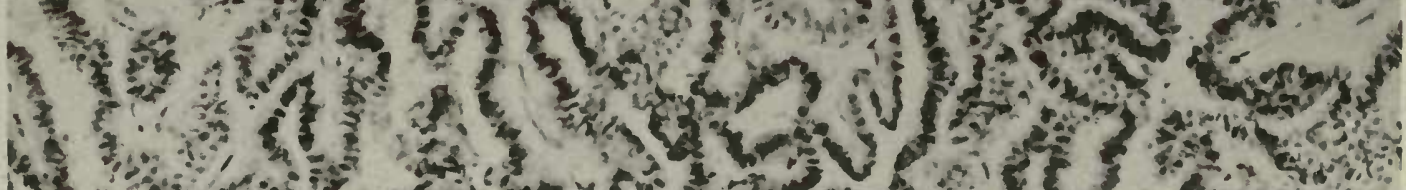
14.

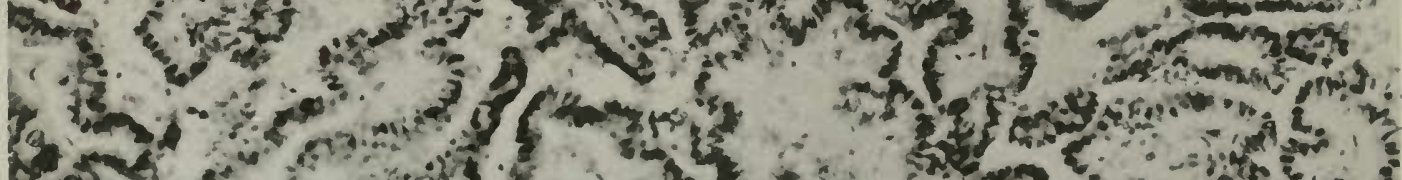

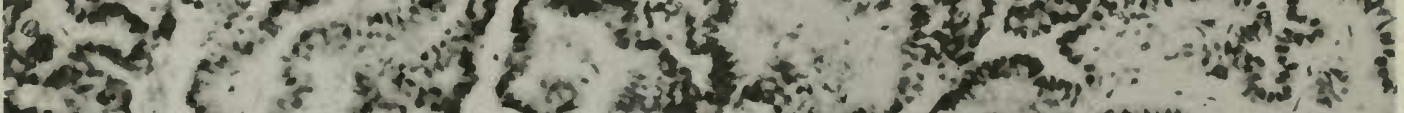

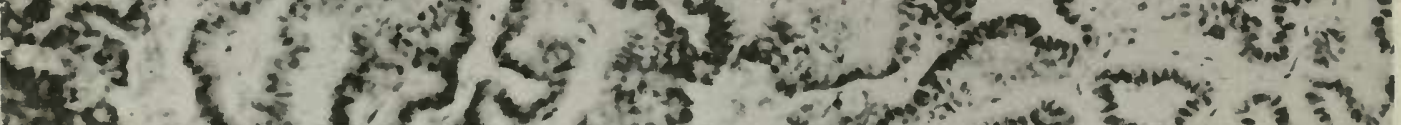

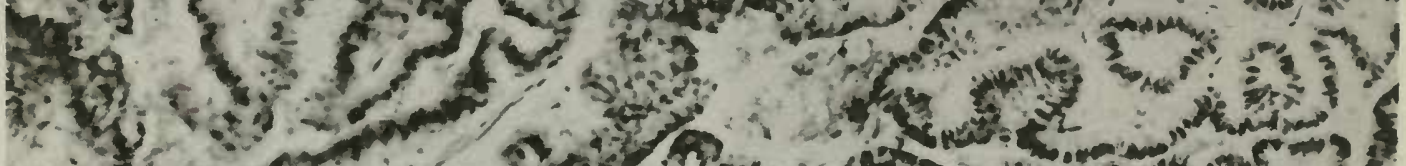

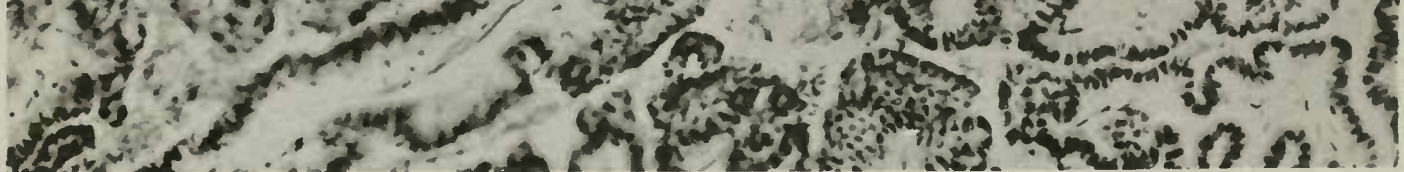
(to be compared with

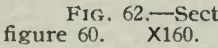





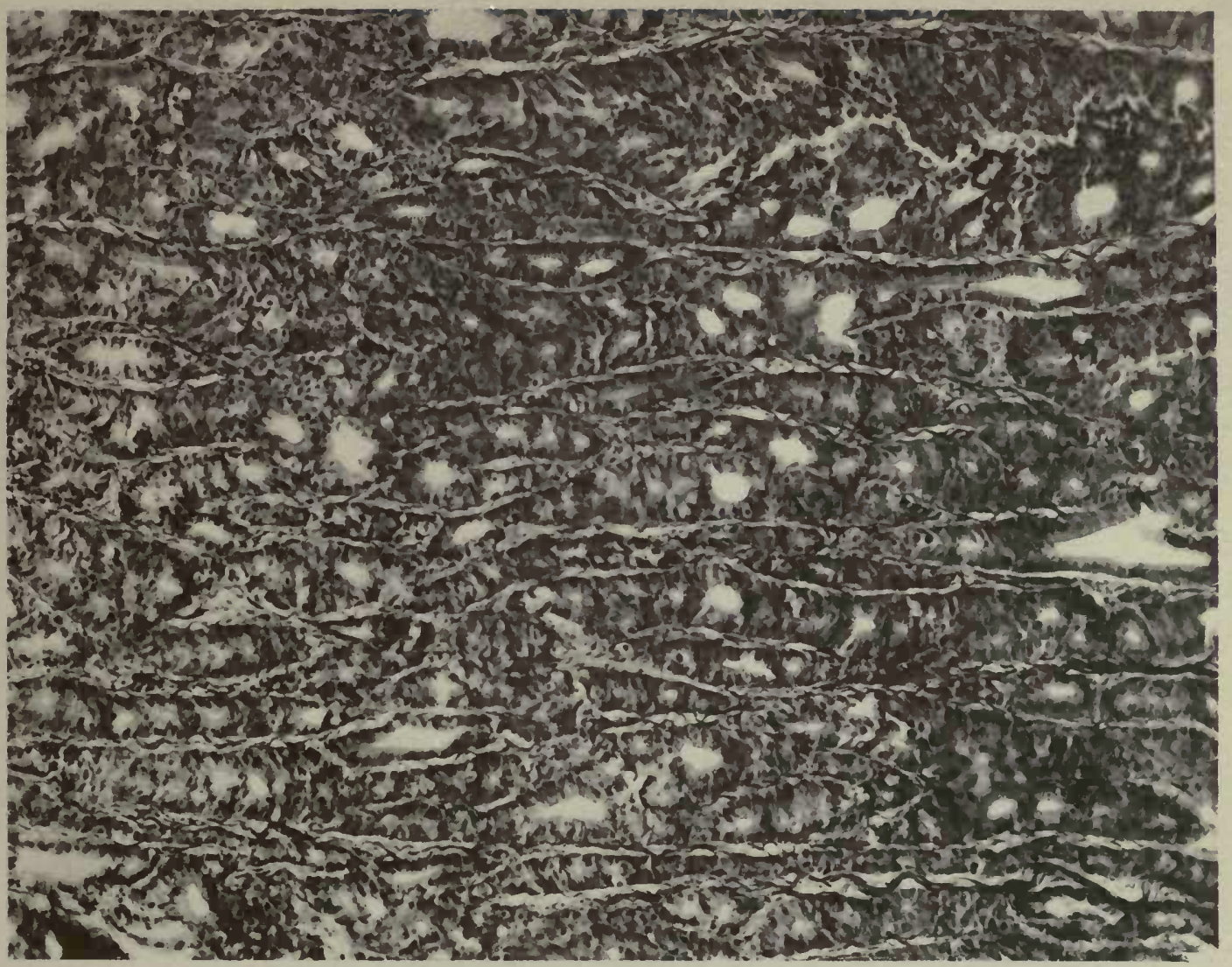

FIG. 63.-Fish thyroid tumor showing tubular type resembling the struna of Geisslar, as illustrated in plate 6 , figure 27 of Langhan's' article. $\times 160$

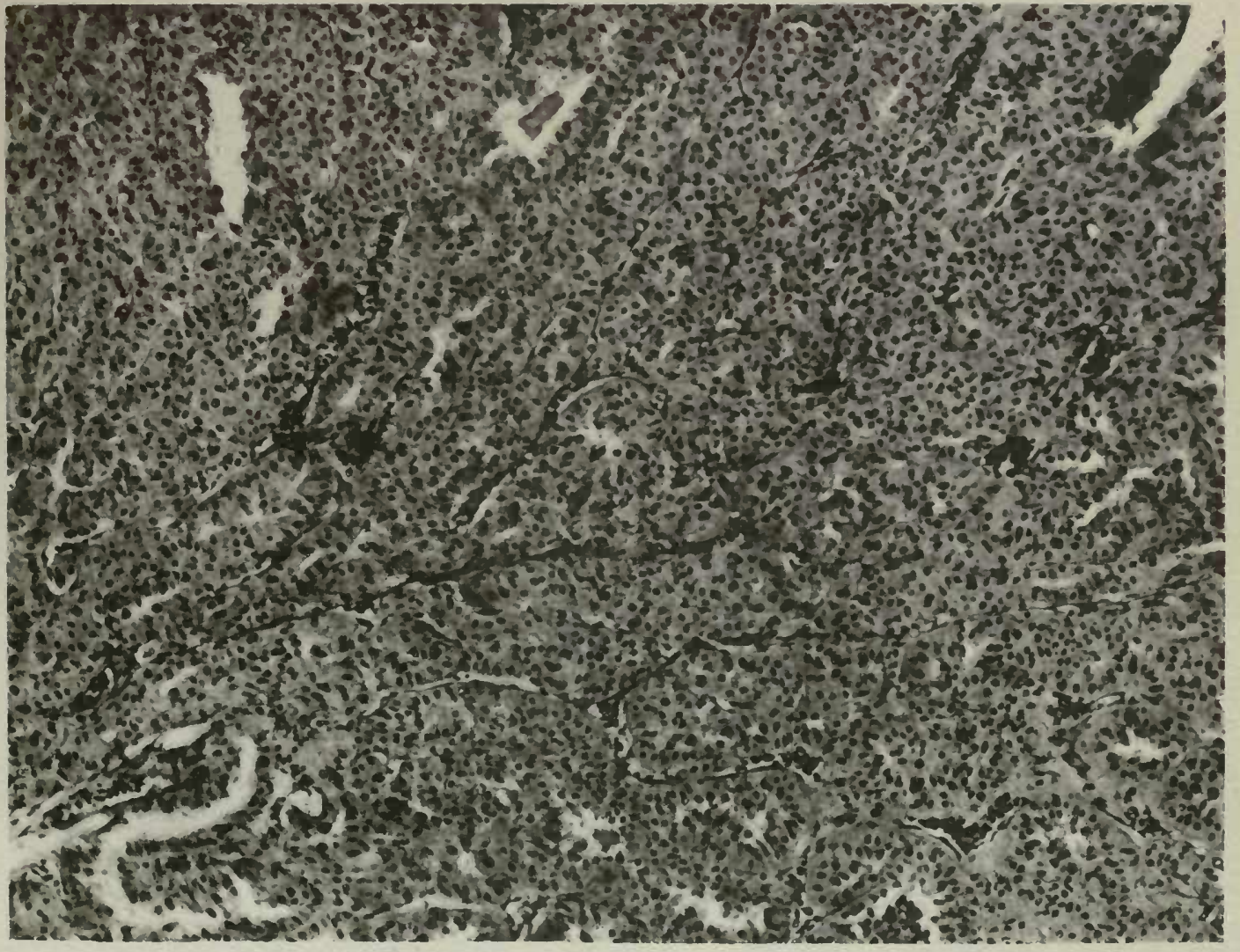





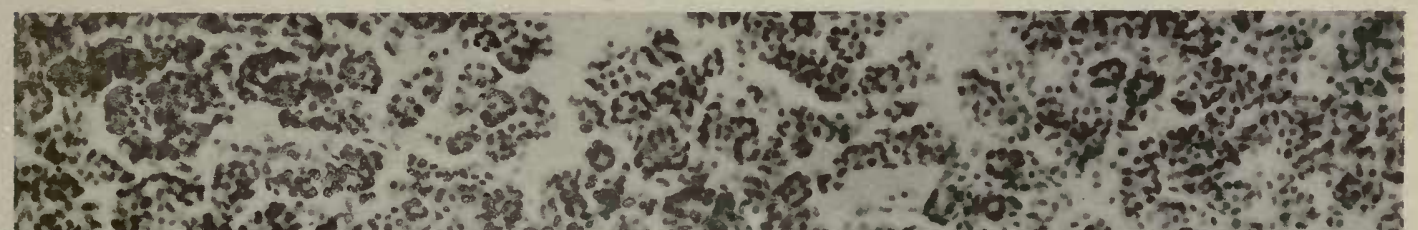
foro to 1 (f) 1.

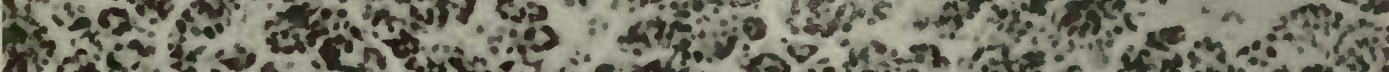

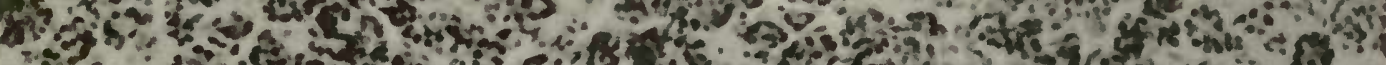

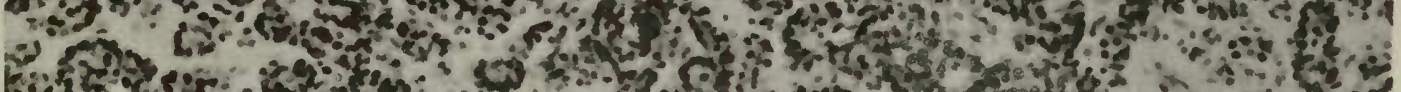

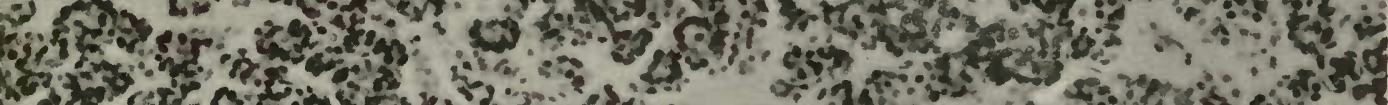

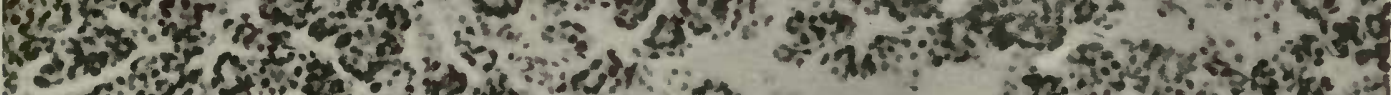

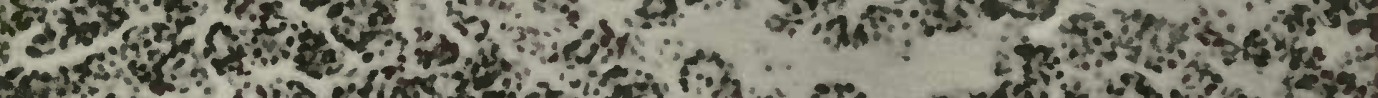

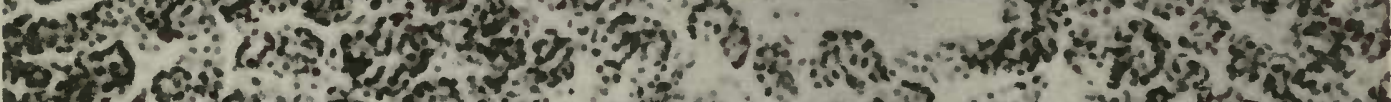

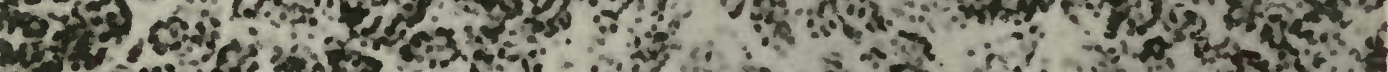

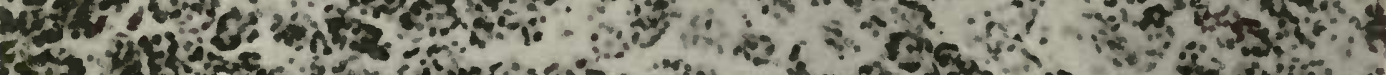

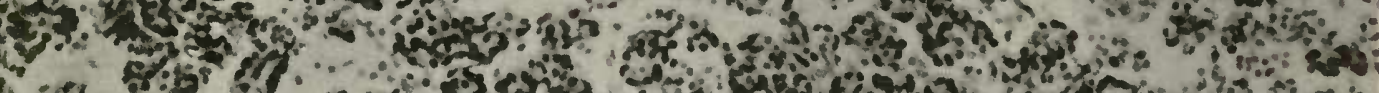

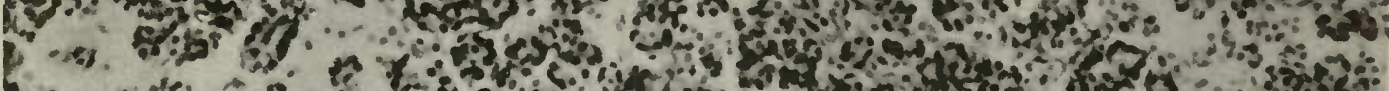

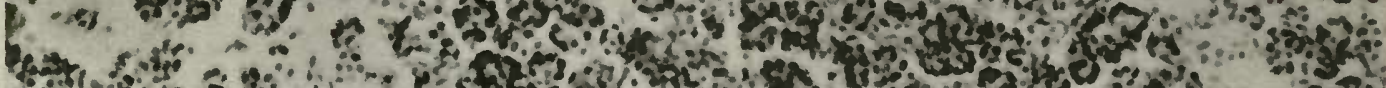
for

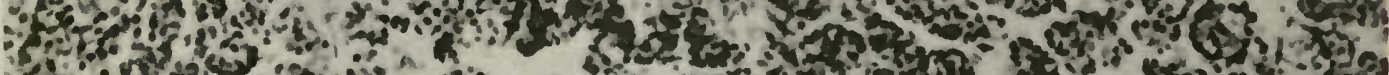
Fine

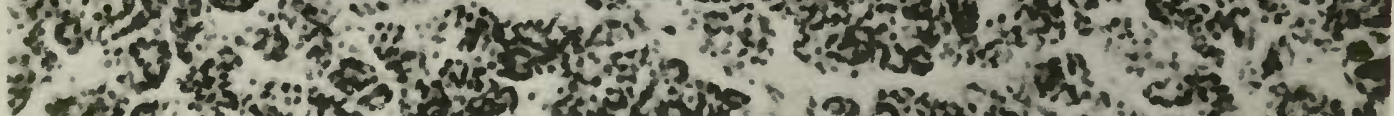

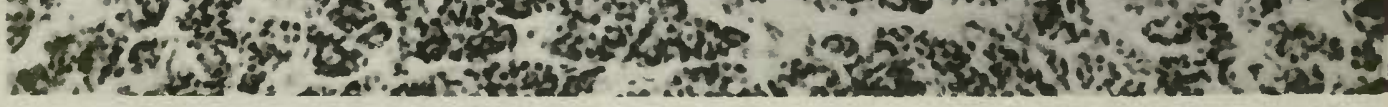





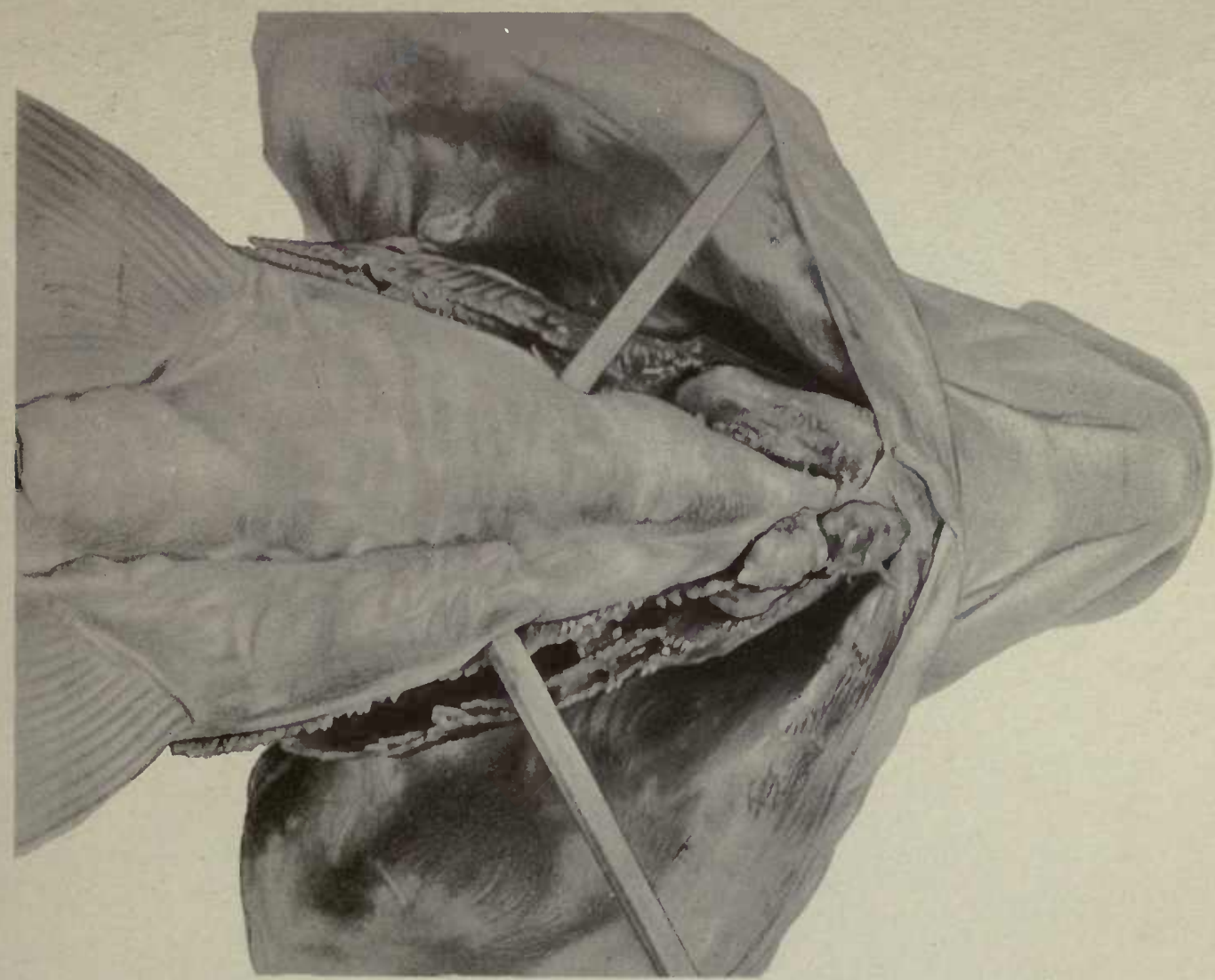

FIG. 67.-Infiltrating thyroid tumors in the gill region of a wild white fish (Coregonus clupeiformis.)

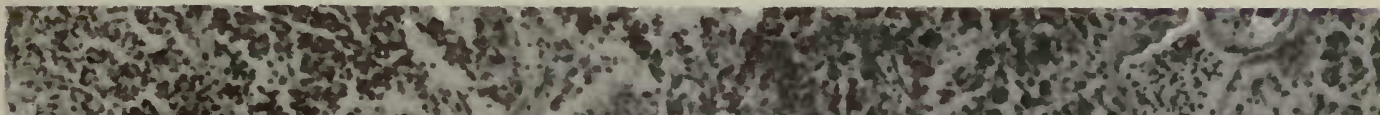

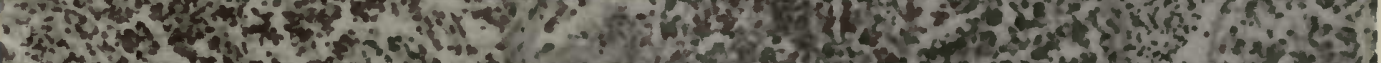

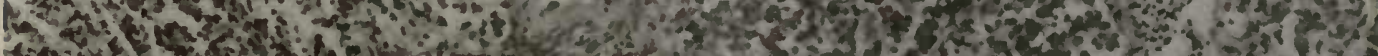

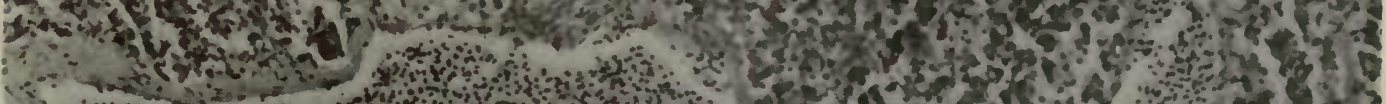

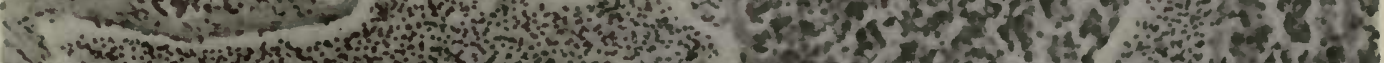
s.

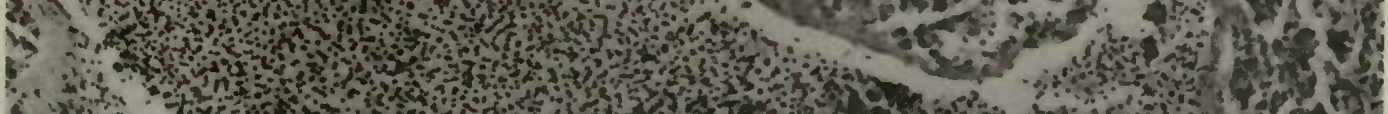

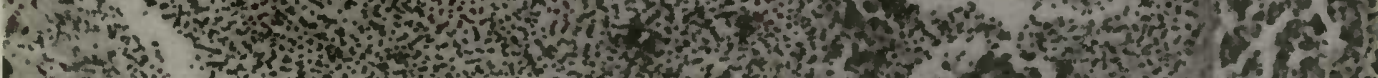

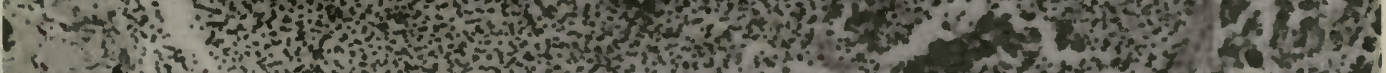

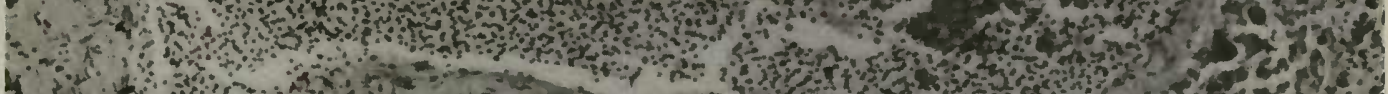

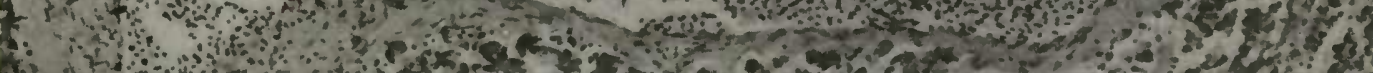

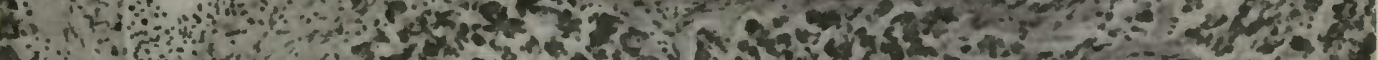

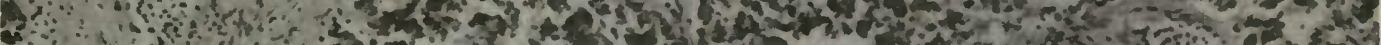

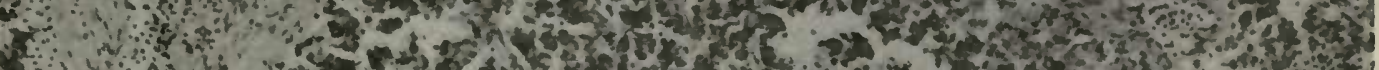

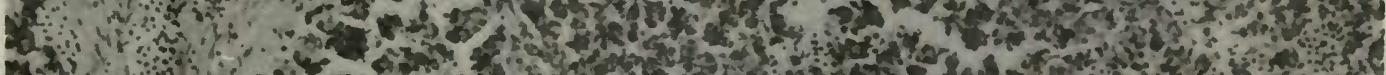

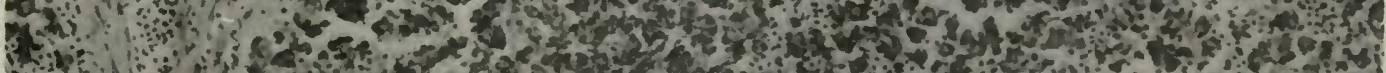

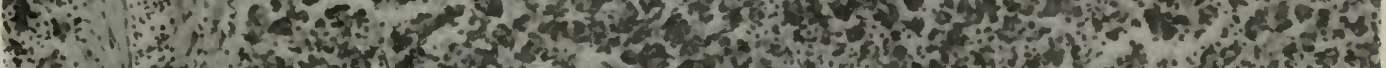

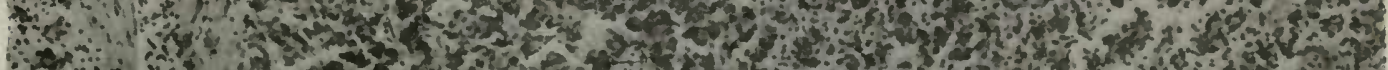
- bi

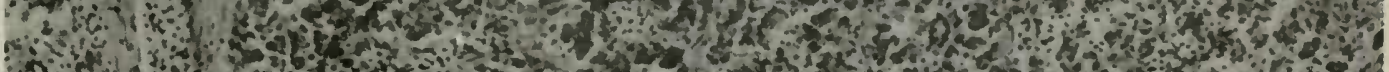

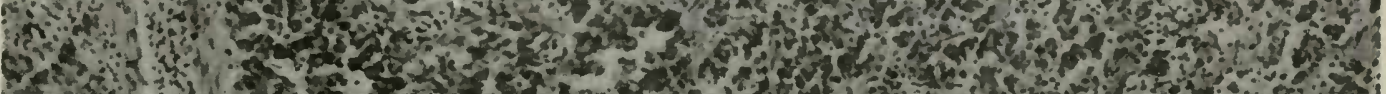

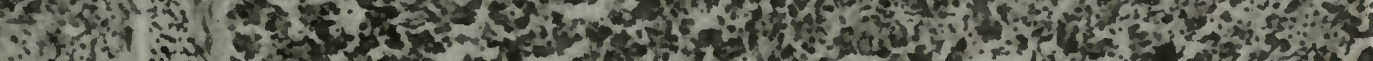

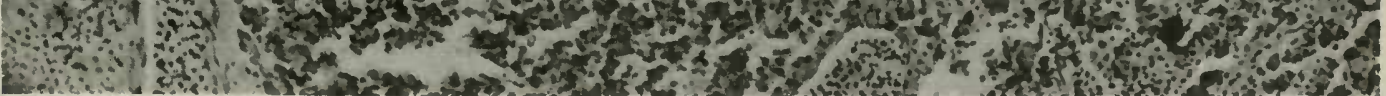
FIG. 68.-Microscopic section of the tumor shown in figure 66. Infiltration of wall of vein. Cell nests in luneen. $X 136$. 



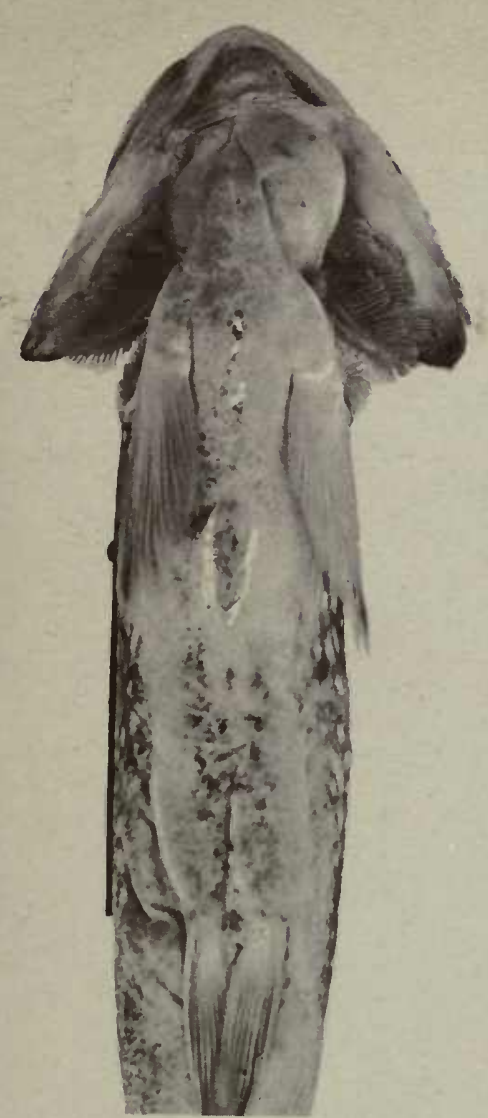

FIG. 69.- Photograph showing tumor in a wild brook tront (Salzelinus fonlinalis.)

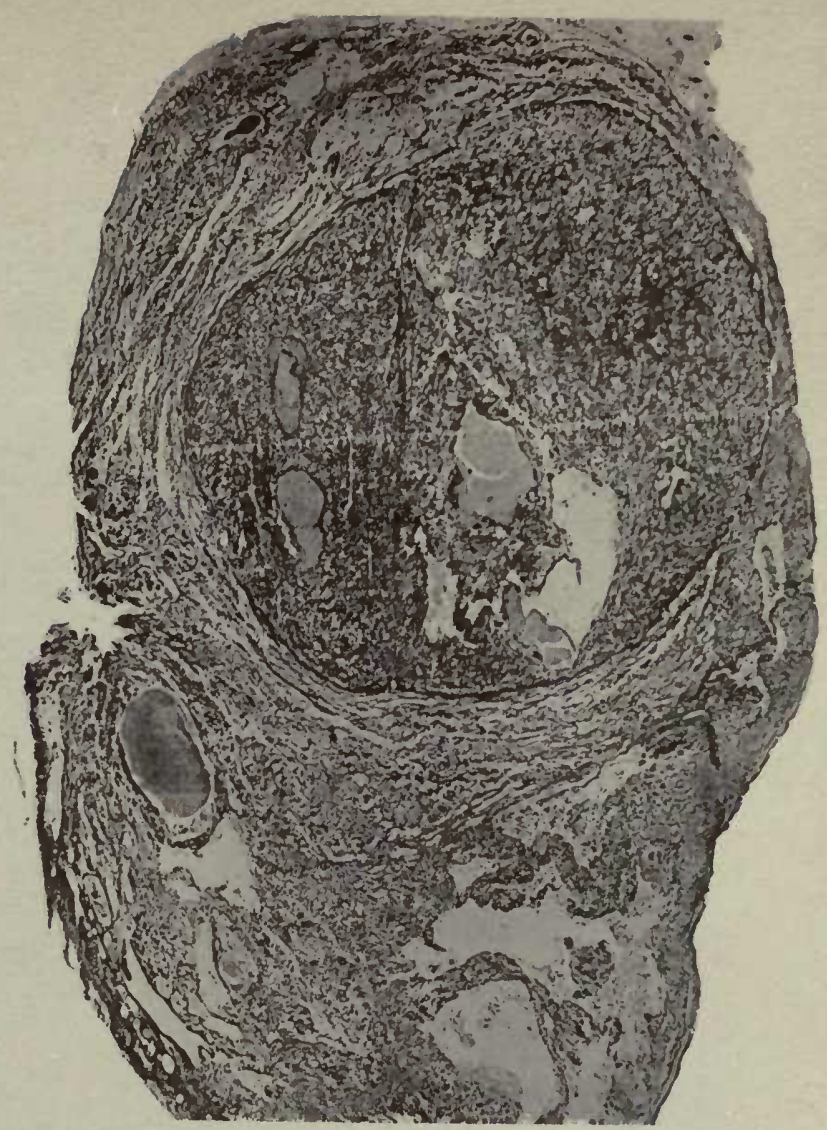

FIG. 70 - Low power photomicrograph of the tumor of
figure 68 . Note the large nodule within the tumor mass.
X $91 / 2$.

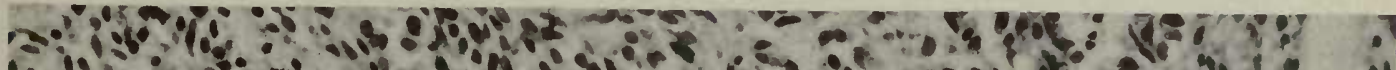

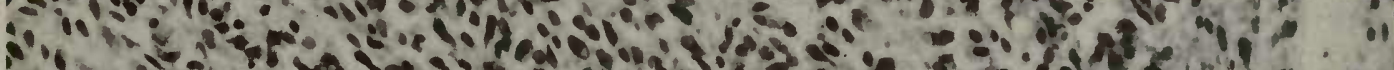

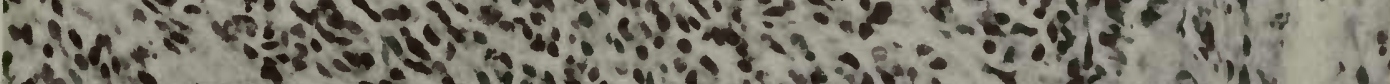

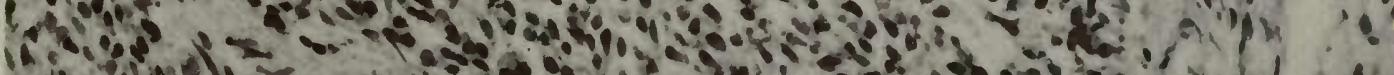

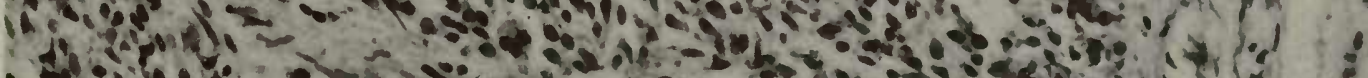

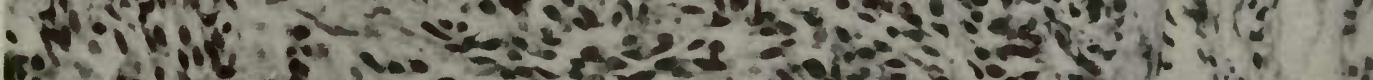

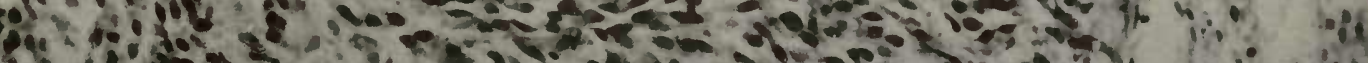

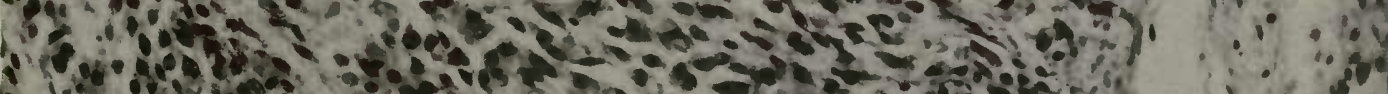

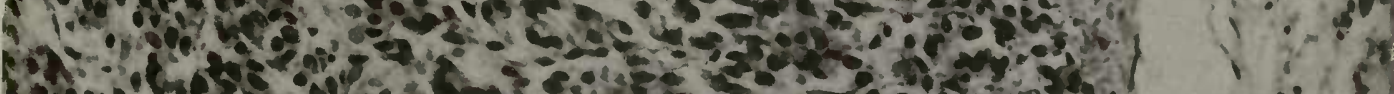

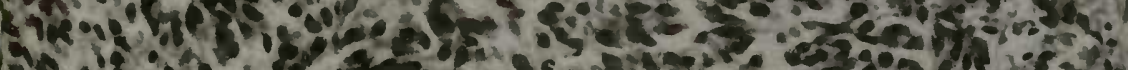

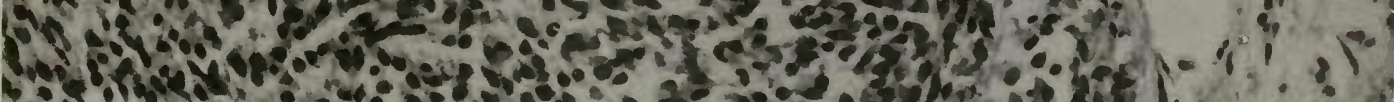

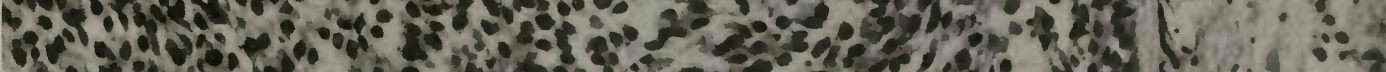

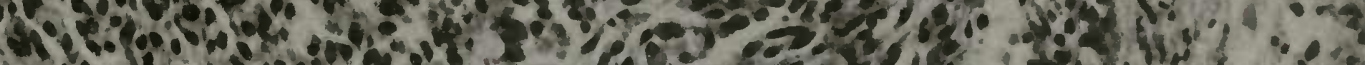

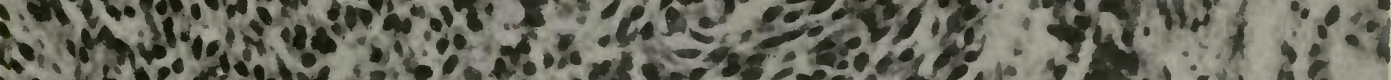

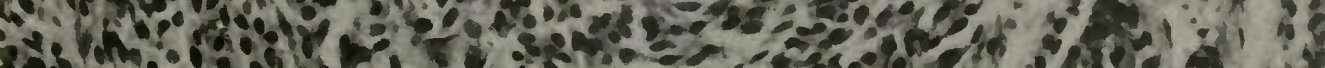

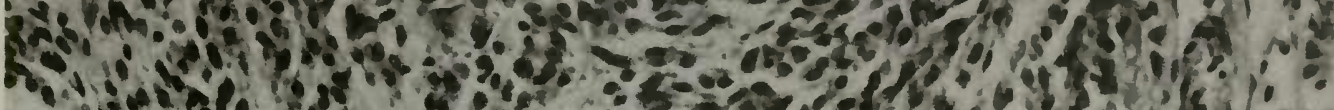
If

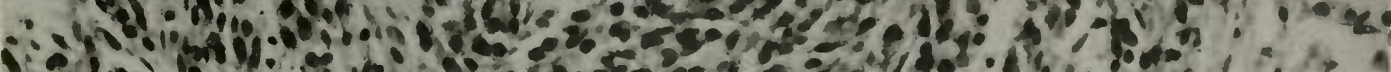

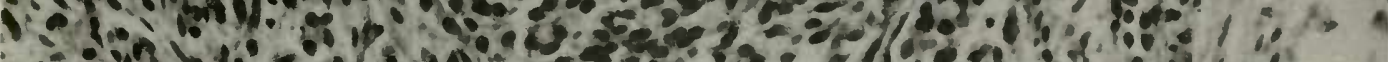

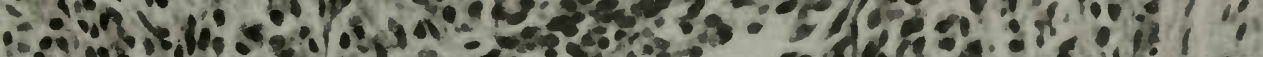

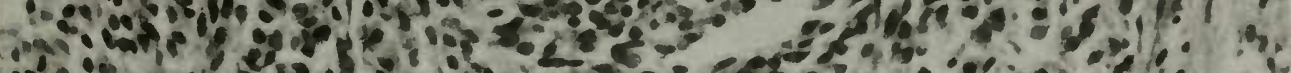
1060 in

Fig. 71.-High power photonicrograph of the tumor in figure 68 . Note the spindle cell character of the tumior 



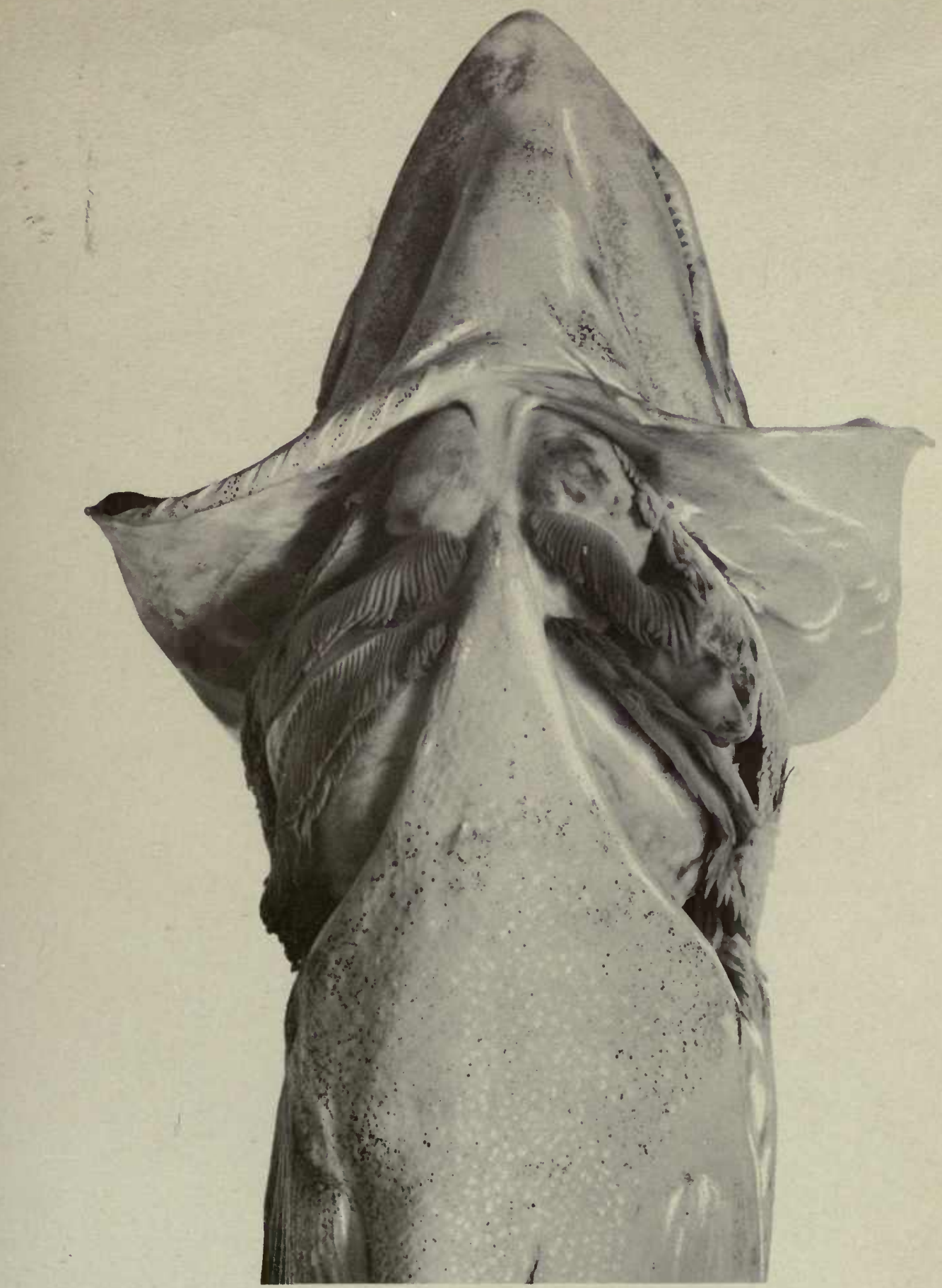

F1G, 72.-Massive thyroid tumors in wild Salmo sebago 4 years old, caught in Sebago I,ake, Maine. I,argest fish observed with tumors. Natural size.

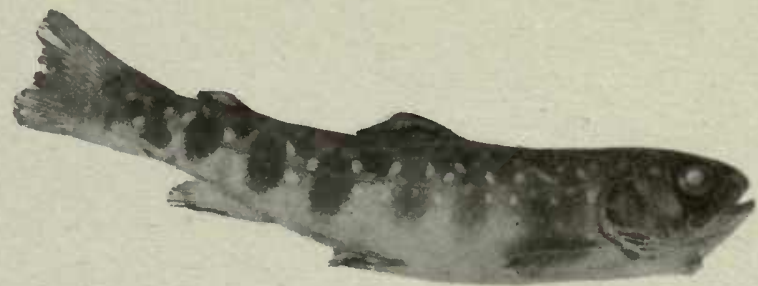

Fig. 73.--Smallest tumor fish, domesticated brook trout 5 months old. Natural size. 



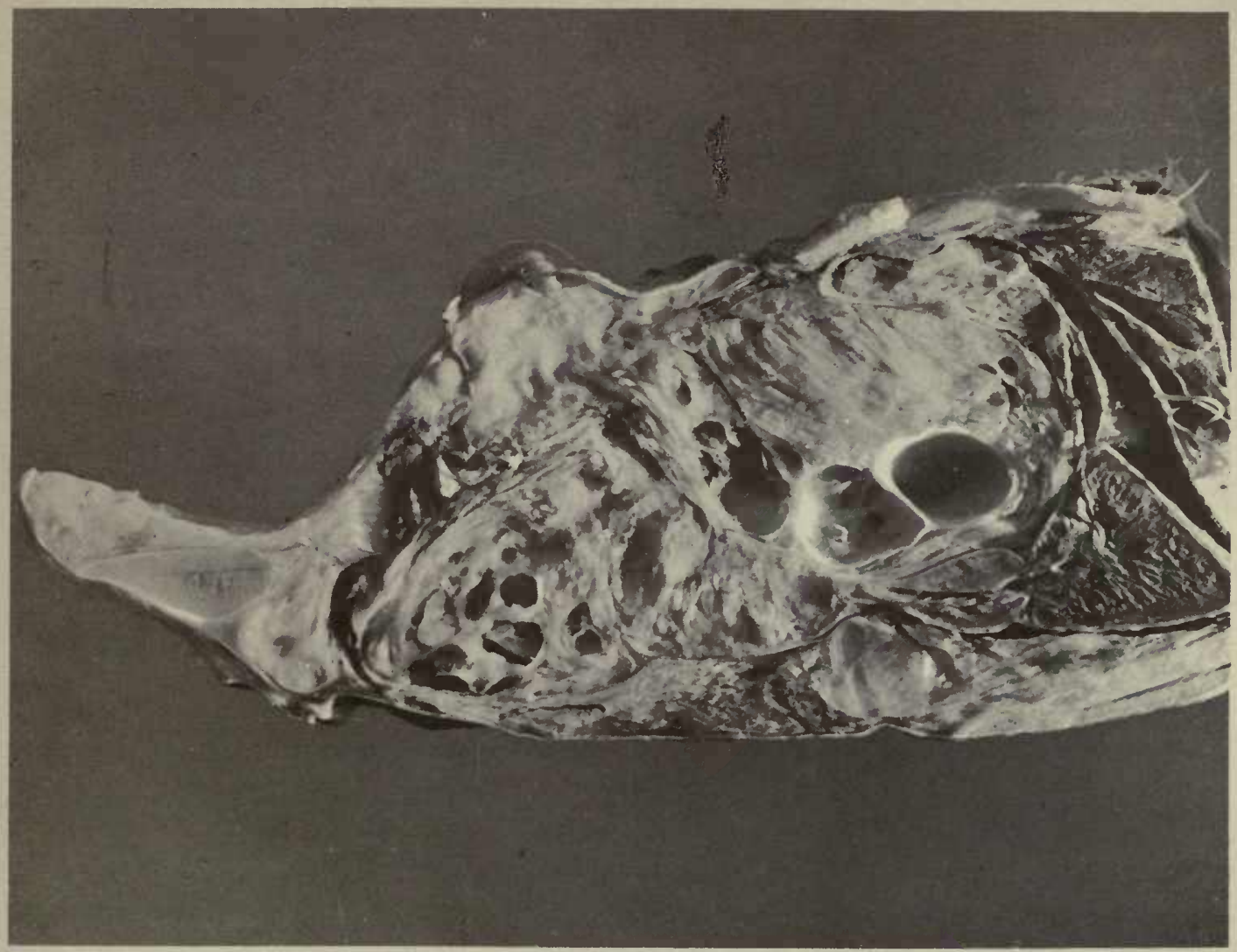

Fic. 74.-Photograpli of longitudinal section of lower jaw of landlocked salmon; illustrated by figure 72 .

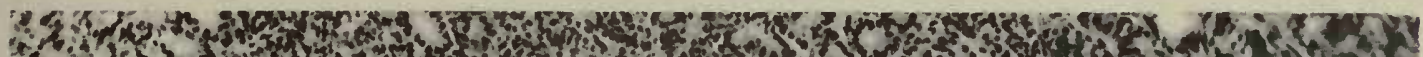

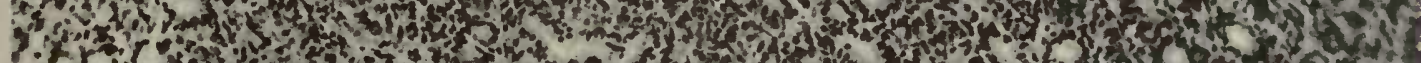

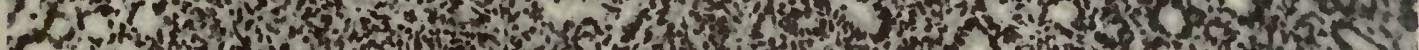

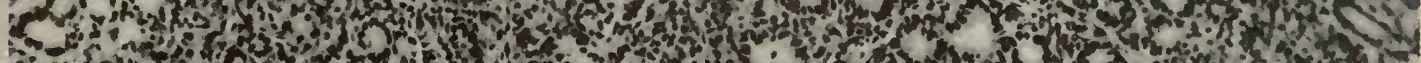

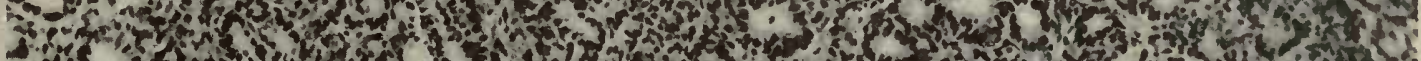

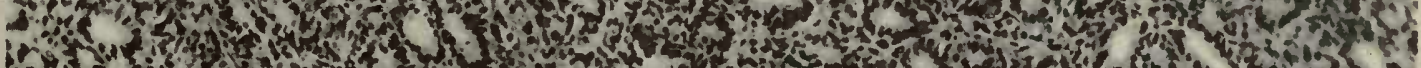

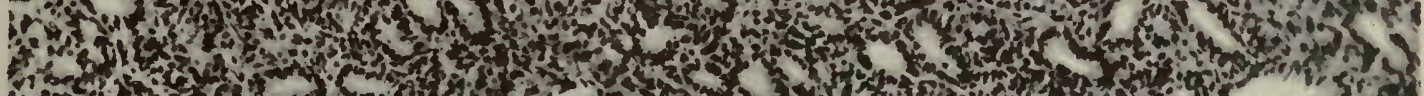

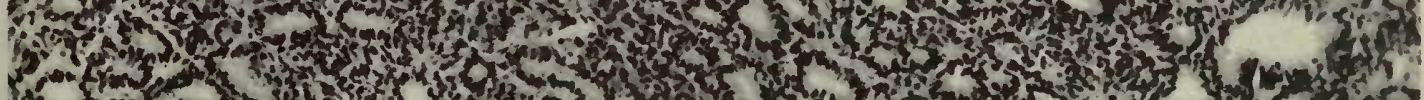

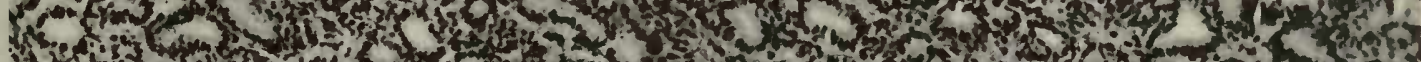

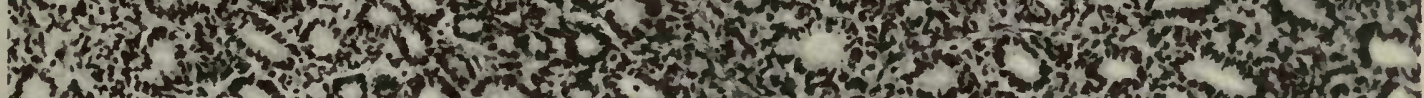

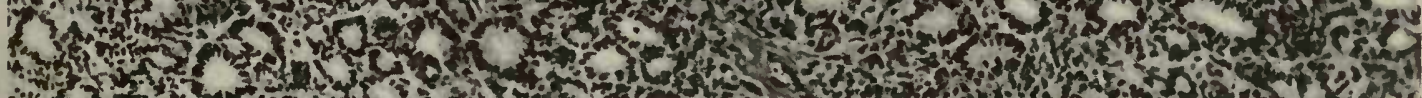

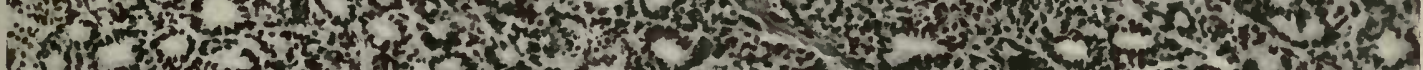

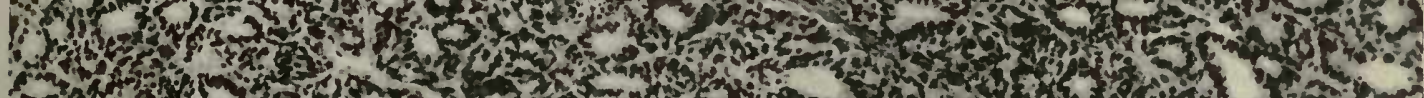

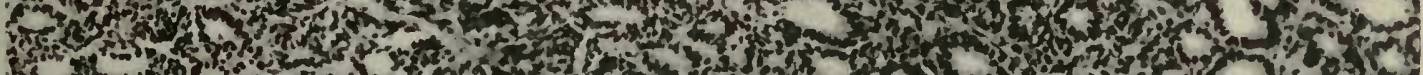
1. 19 enf 60.

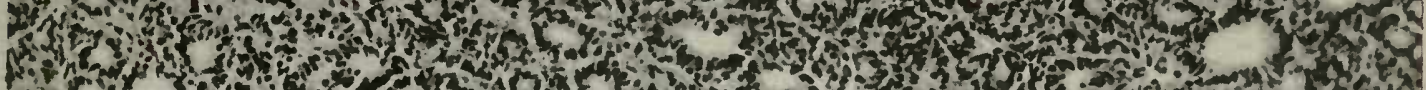

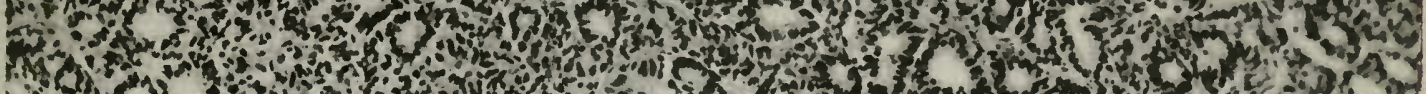

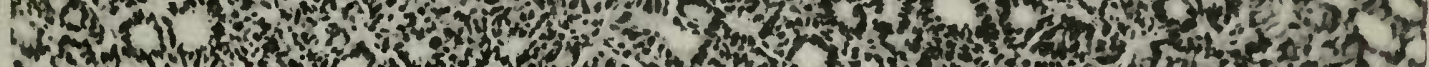
1.6. 7 m

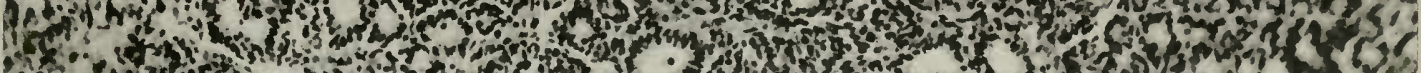

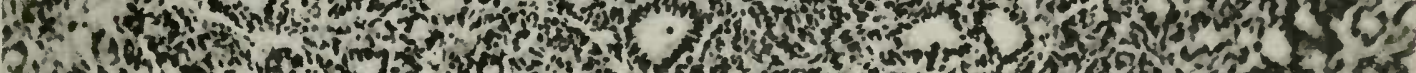
Fig. 75.-Section showing alveolar type of tumor. Wild landlocked salmon. Illustrated by figure 71 . $\times 160$. 



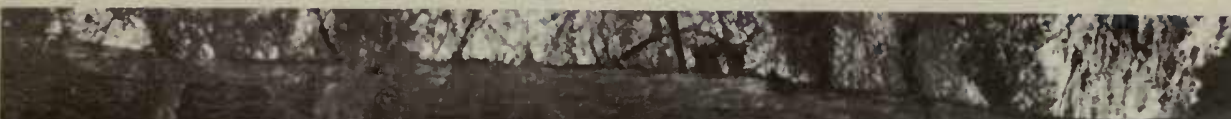

\section{Merk}

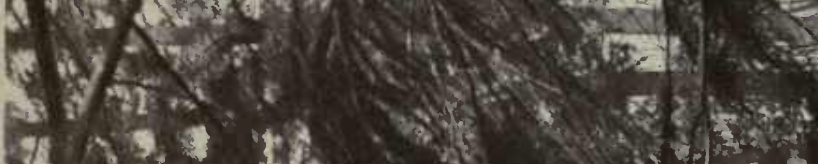

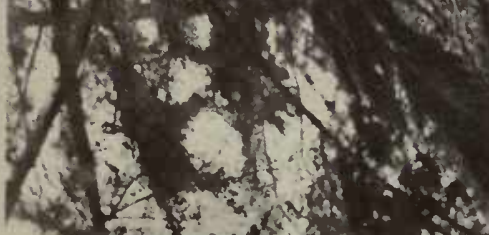

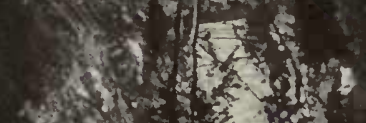

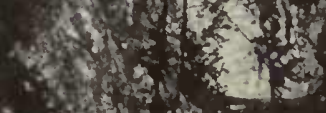

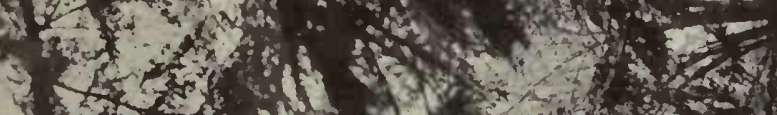

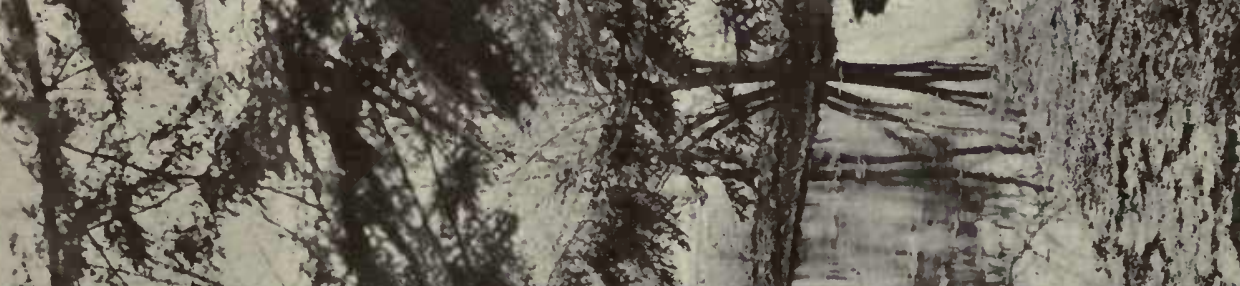

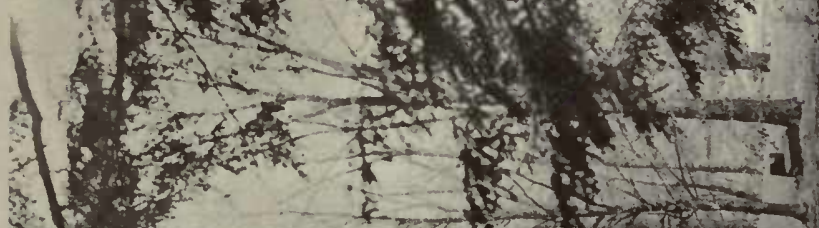

(4) 5 , 3

$4 x^{2}+2$

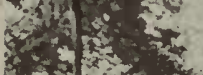

$+x^{2}+x^{2}$

$\rightarrow+\infty$ तो

$\int_{i=0}$

sor

in $x^{2} \mathrm{k}$

$\cos$

$\therefore 1$
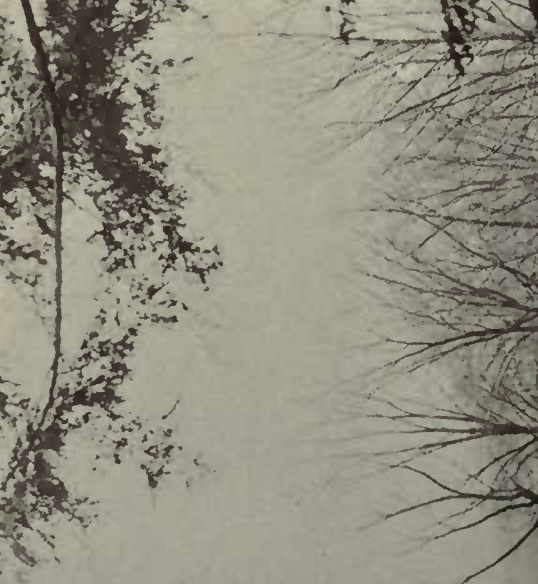

2.

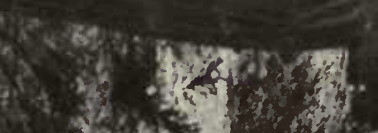

9.

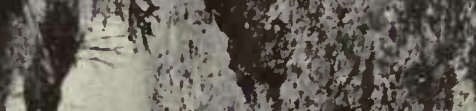

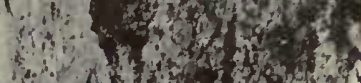

or and on

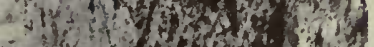
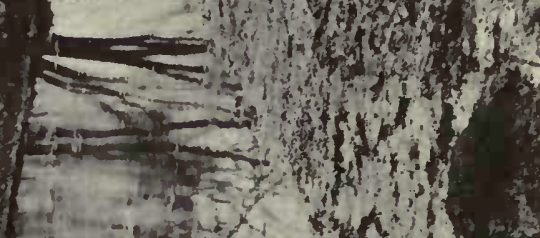



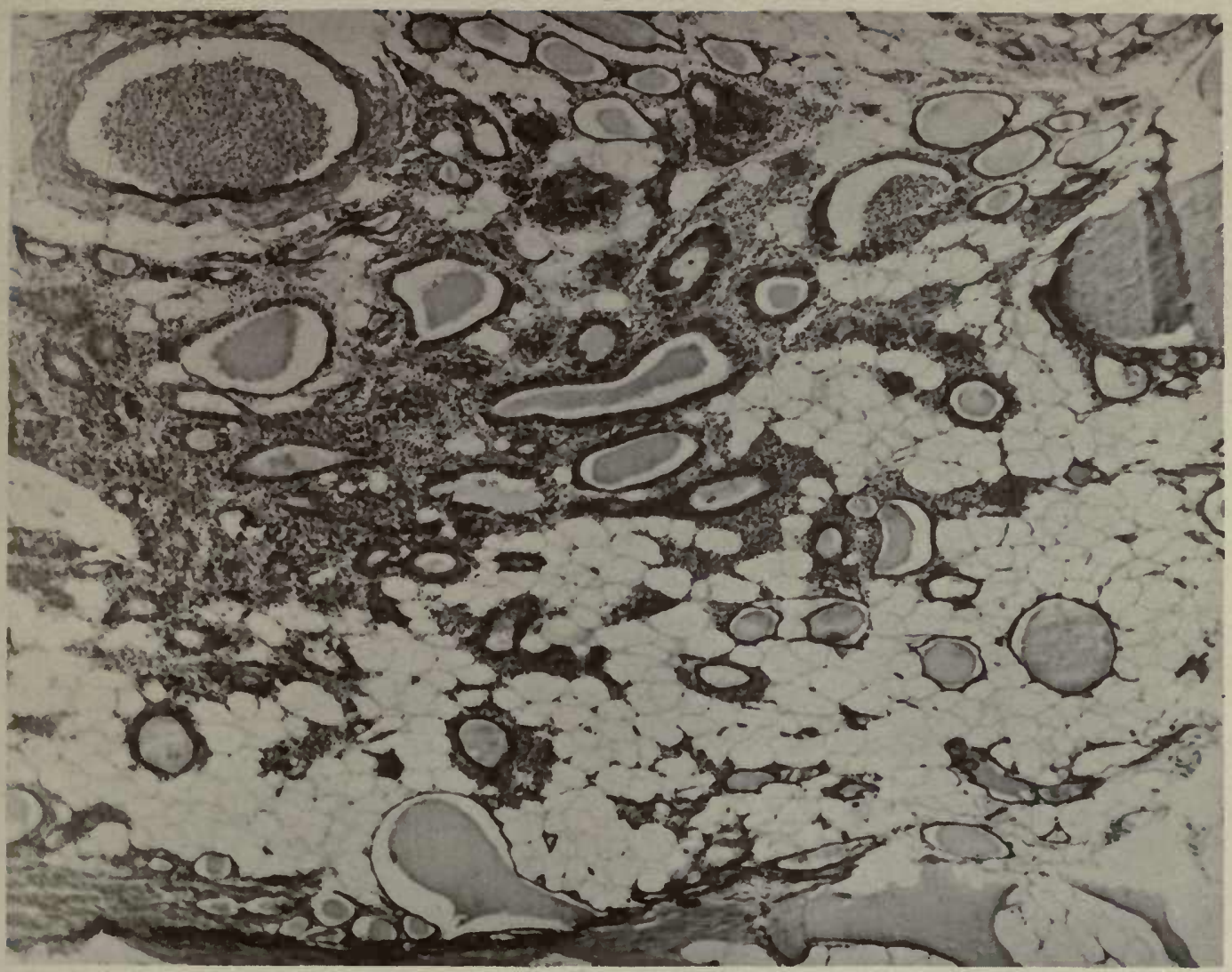

Fig. 84. - Section of wild Wisconsin brook trout. Raw liver feeding 12 months. Focal development carcinoma of the thy roid. Sinall group of follicles with columnar epithelium. Reduced colloid. Hyperæmia about follicles. At periphery (1)

Hor

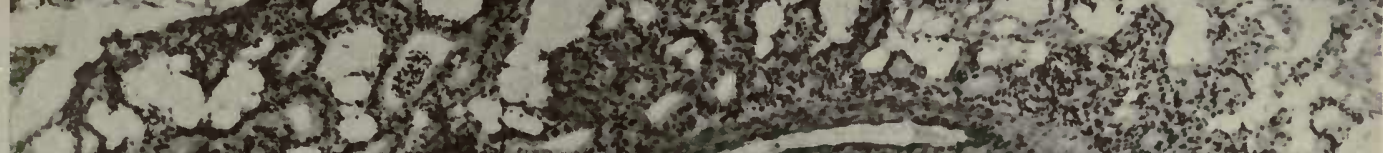
If If

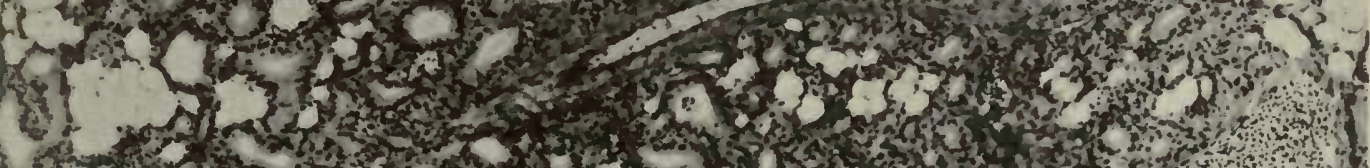

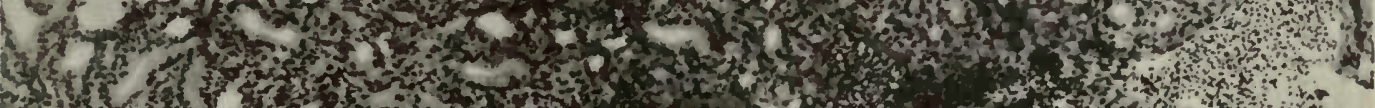

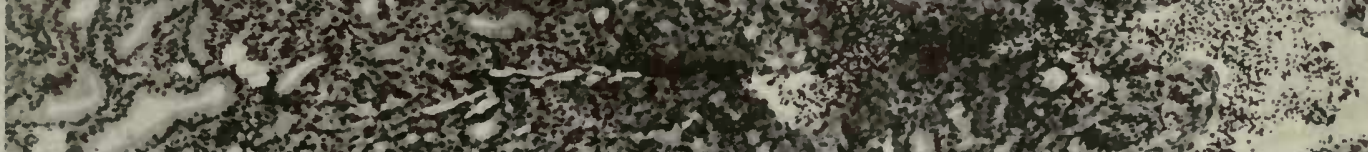
(1)

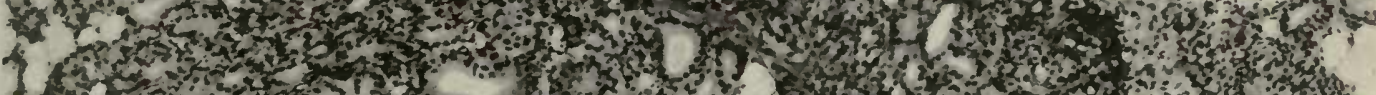

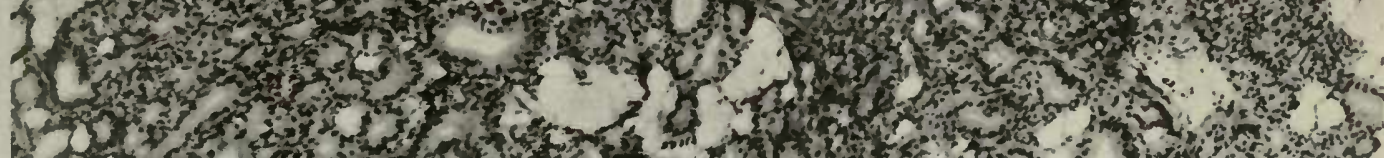

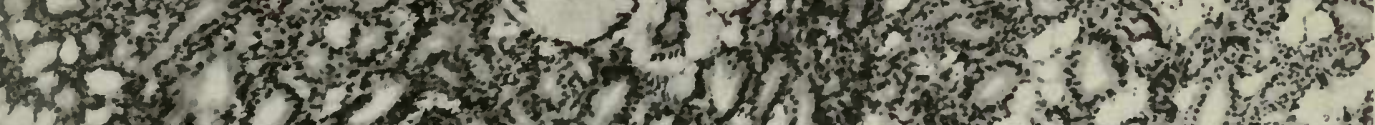

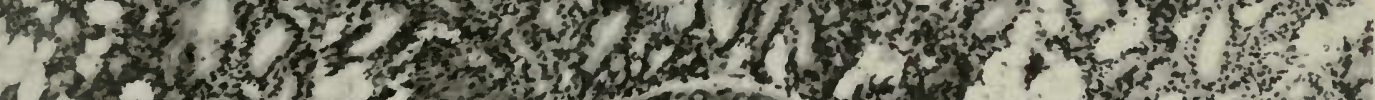

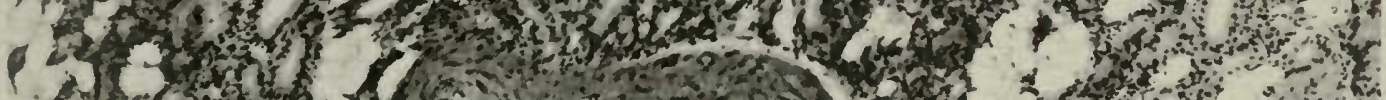

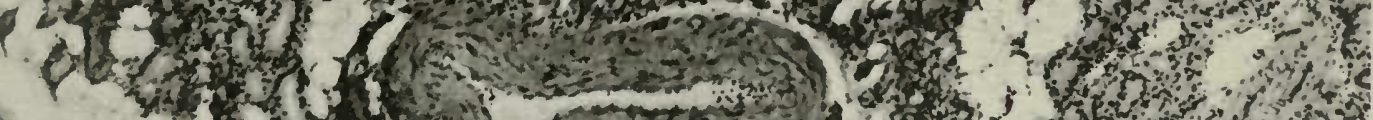

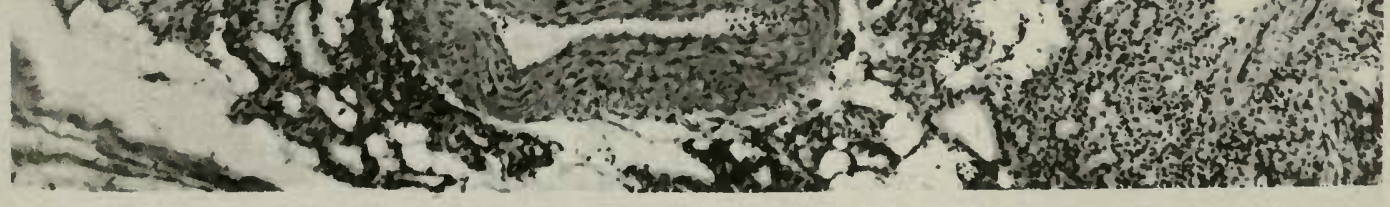

FIG. 85. -Wild Wisconsin brook trout. Raw heart feeding 12 months. Beginning carcinoma of the thy roil. Xs6. 



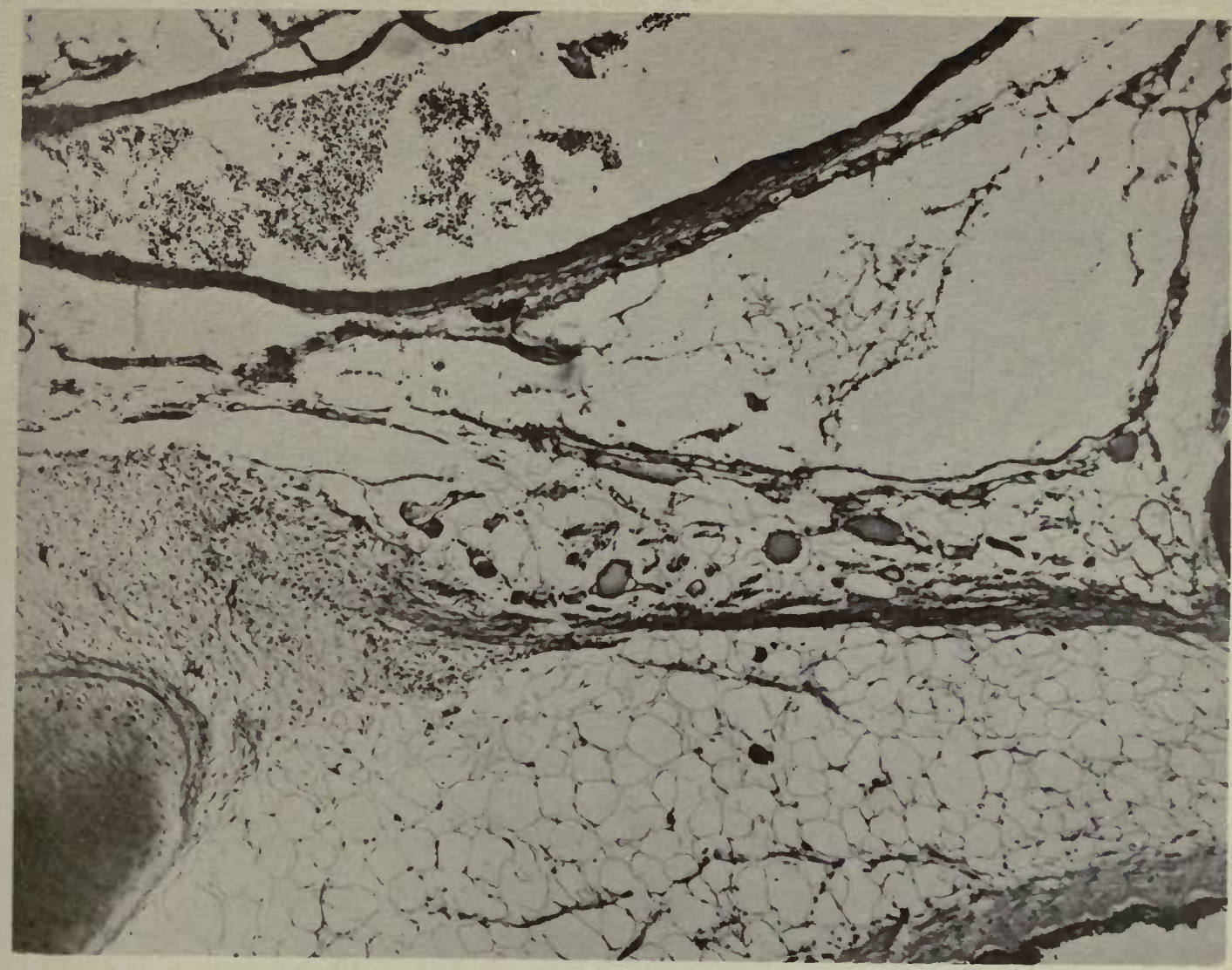

Fis: 86. - Section of wild Wisconsin brook tront from sanse experiment. Natural food 12 montlss. Normal thyroid. X86.

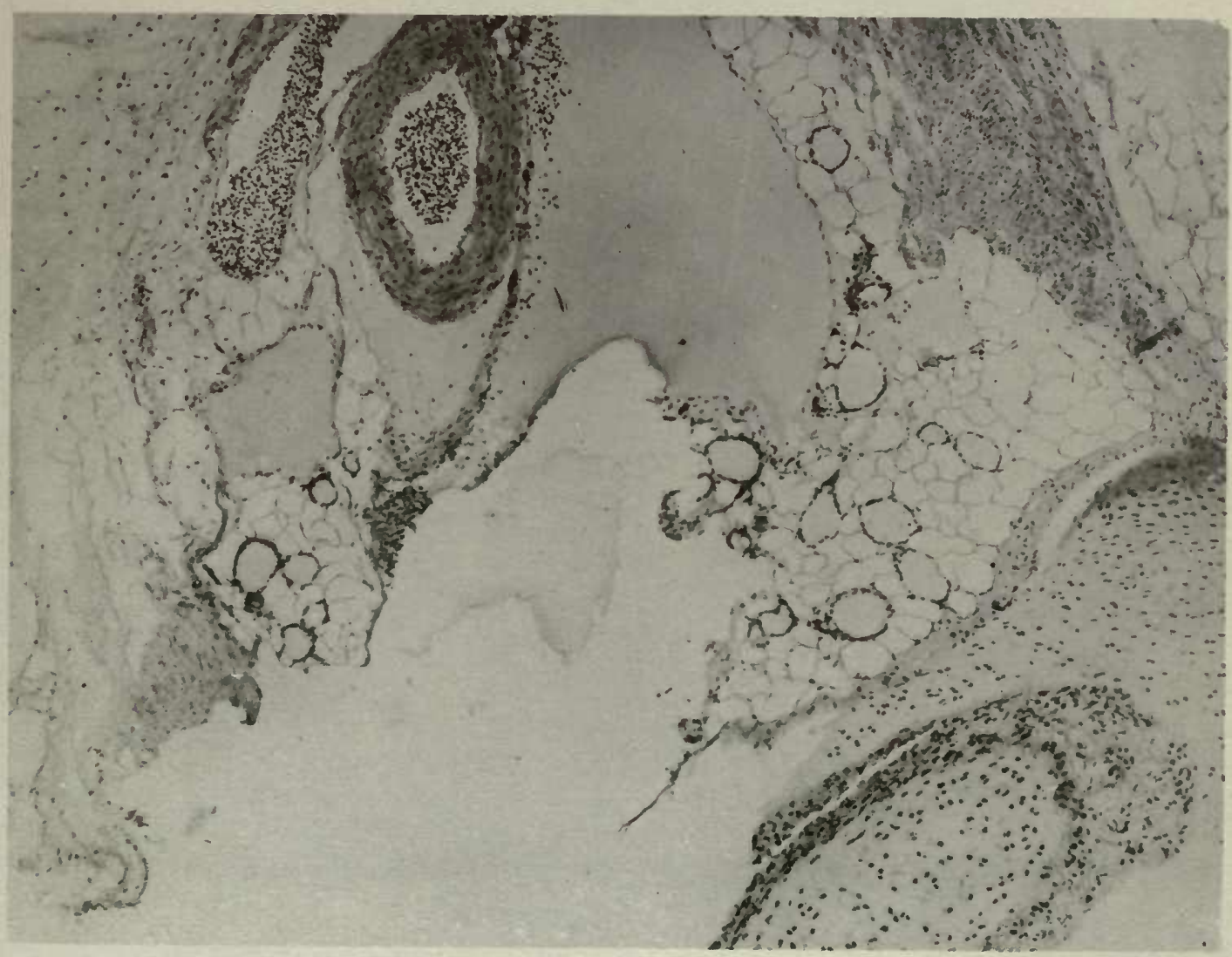

FIG. 87.-Section of wild Wisconsin brook tront. Cooked liver feeding 12 months. Normal thyroid. X86. 



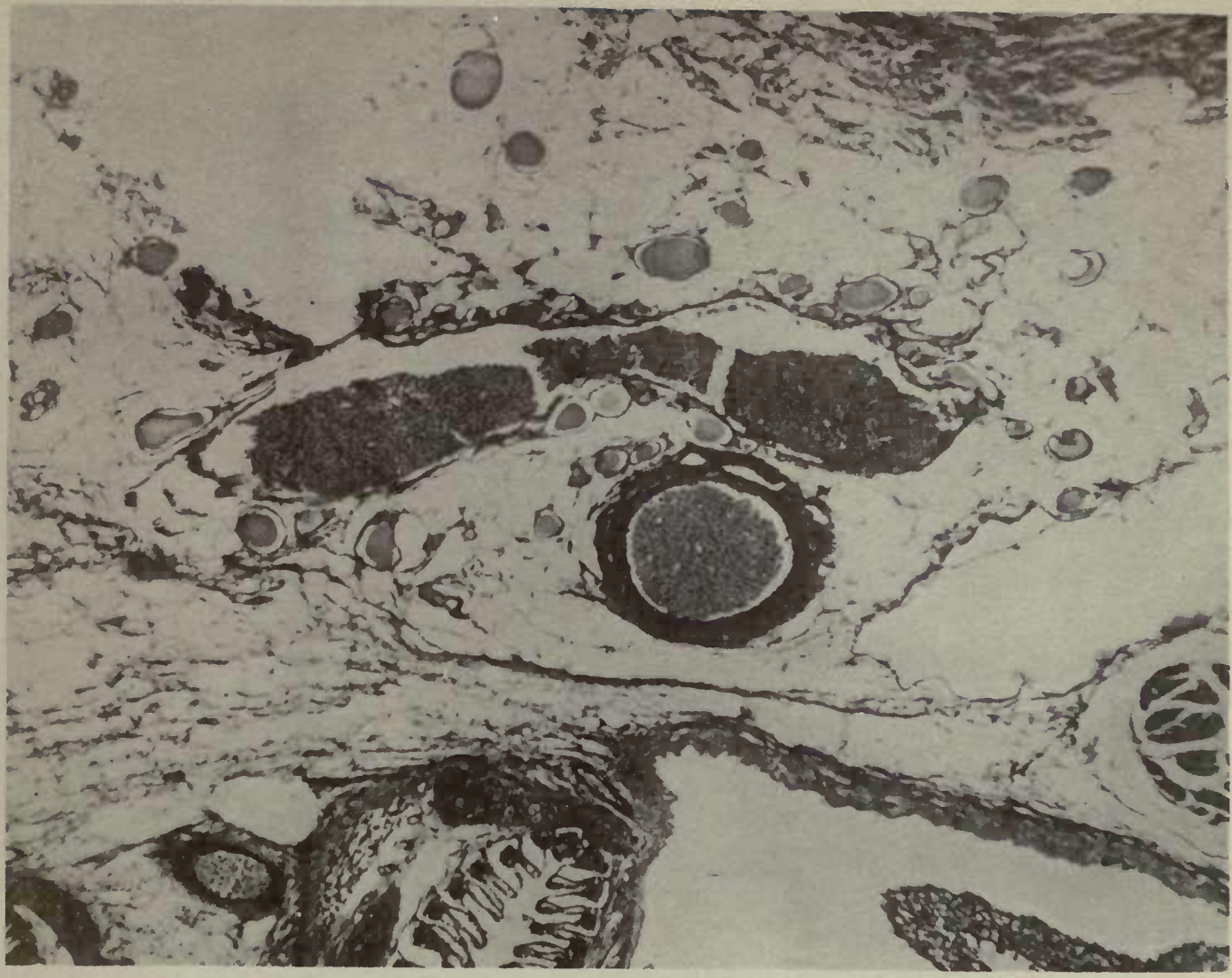

Fig. 88. -Wild Wisconsin brook tront. Fed marine fish 12 months. Normal thyroid. $x 86$.

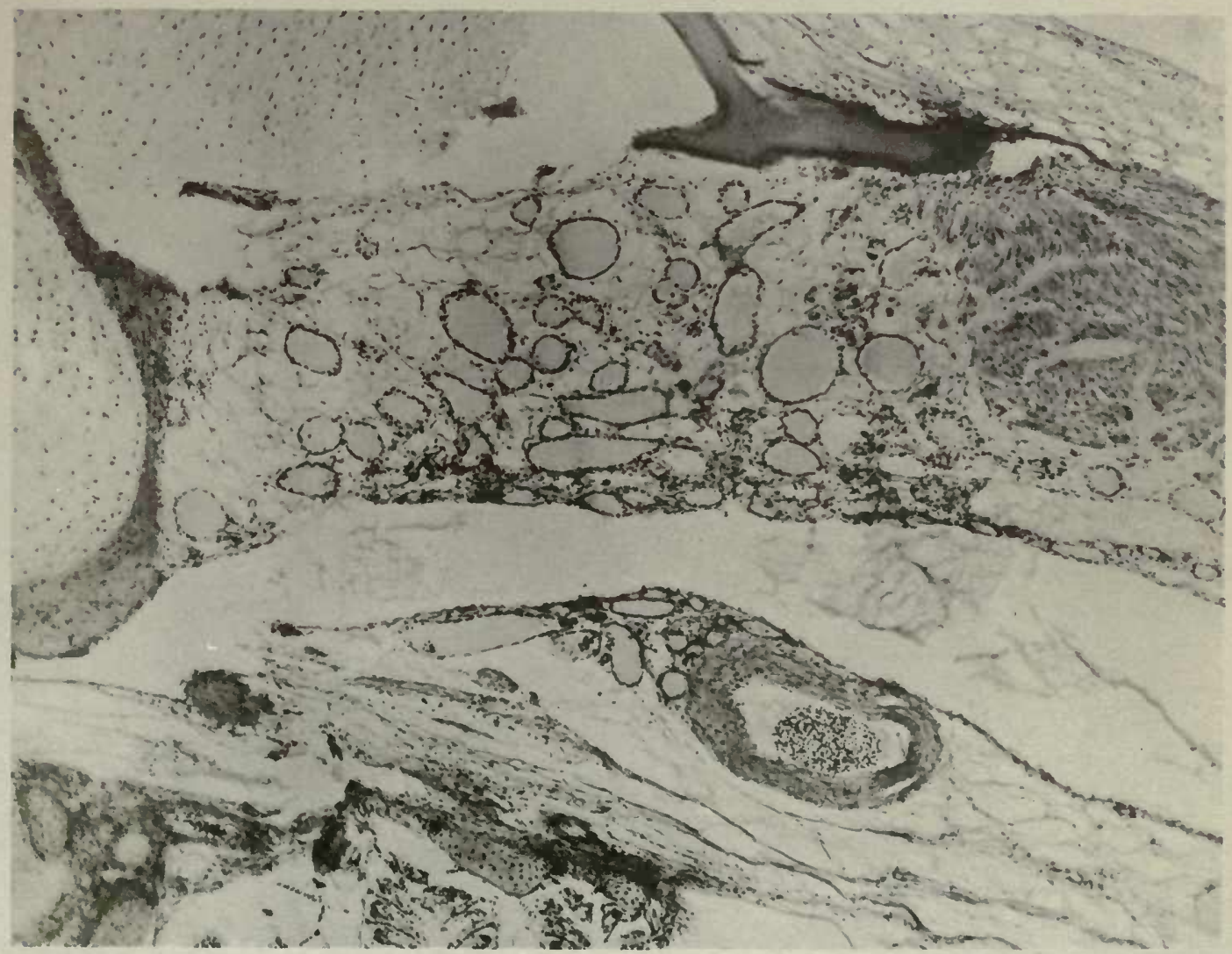

\footnotetext{
Fis. 89.-Wild Wisconsin brook tront. Vegetable food 12 months. Normal thyroid. X86.
} 



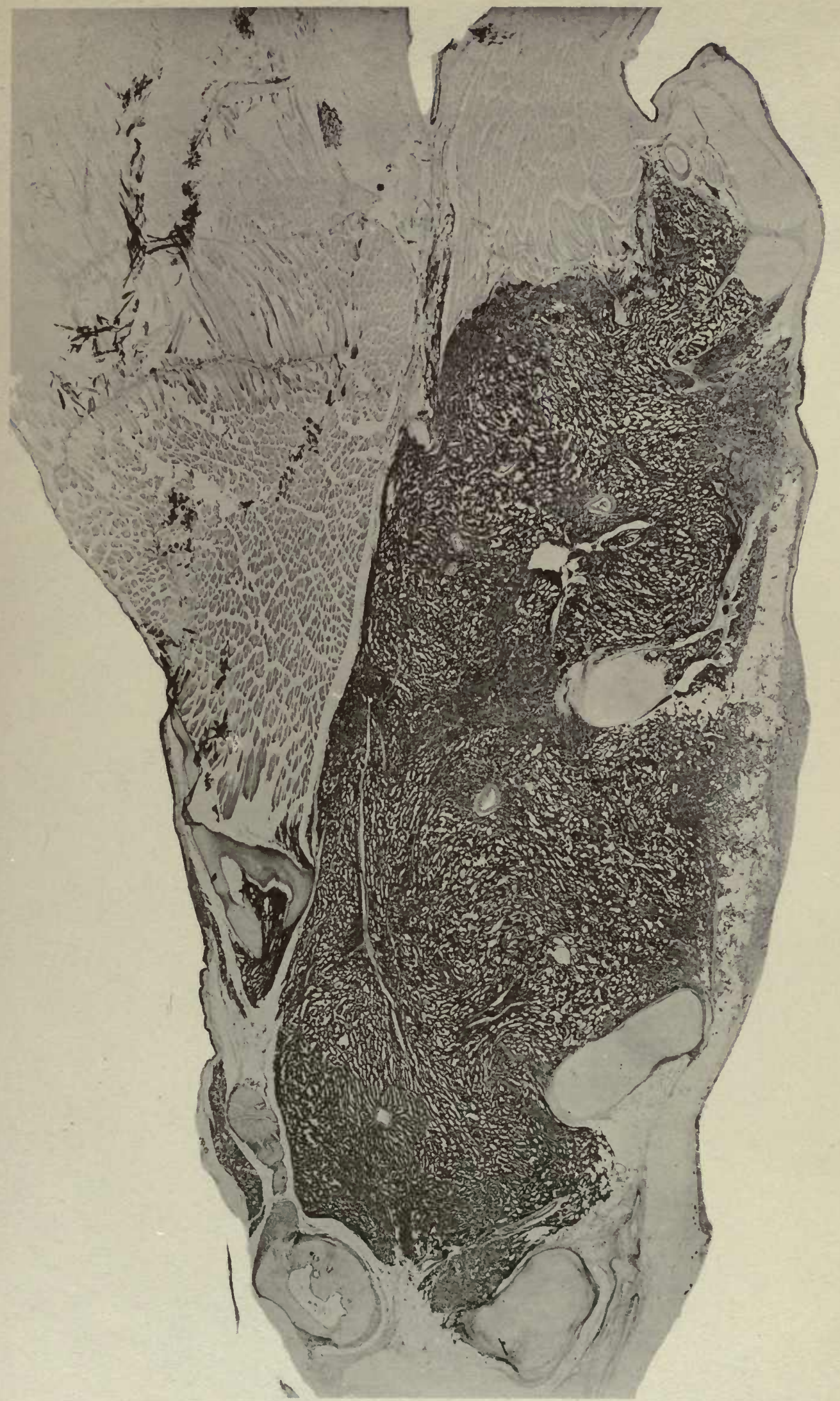

FIG. 90.- I.Ow power section at median line through thy roid region of wild wisconsin brook trout, showing welldeveloped carcinoma of the thyroid infiltrating surrounding structures, bone and cartilage. After 18 months raw liver feeding at Craig Brook. Fxperimental induction of carcinoma of the thyroid. $\times 13$. 



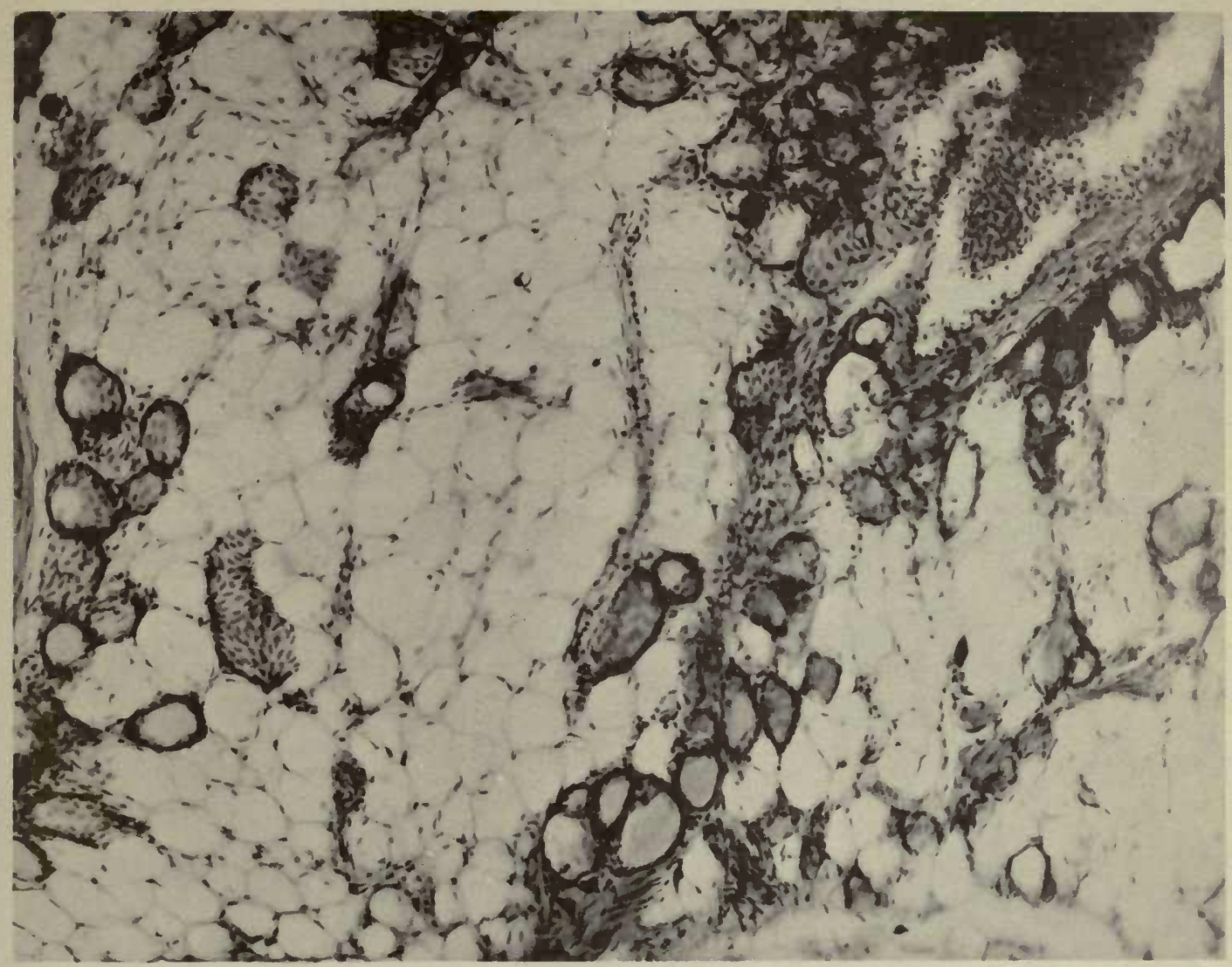

Fig. 91.- Section of thyroid showing spontaneous recovery from carcinoma of the thyroid. Early stage. Wild
Wisconsin brook trout. Fish No. 2099 A. X86.

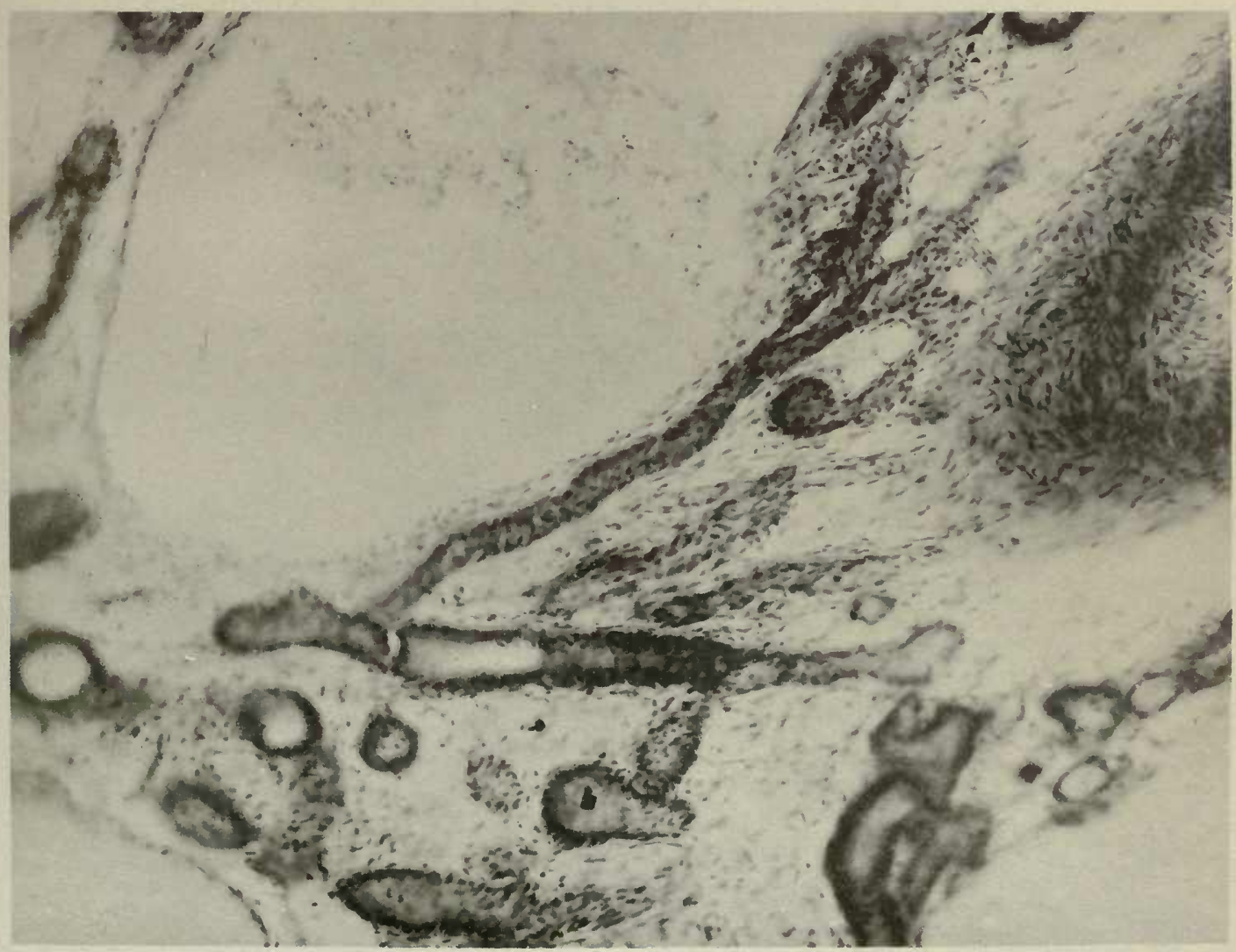

Frg. 92.-Section showing spontaneous recovery from experimentally induced carcinoma of the thyroid in wild Wisconsin brook trout. Fish No. $2099 \mathrm{~B}$. X86. 



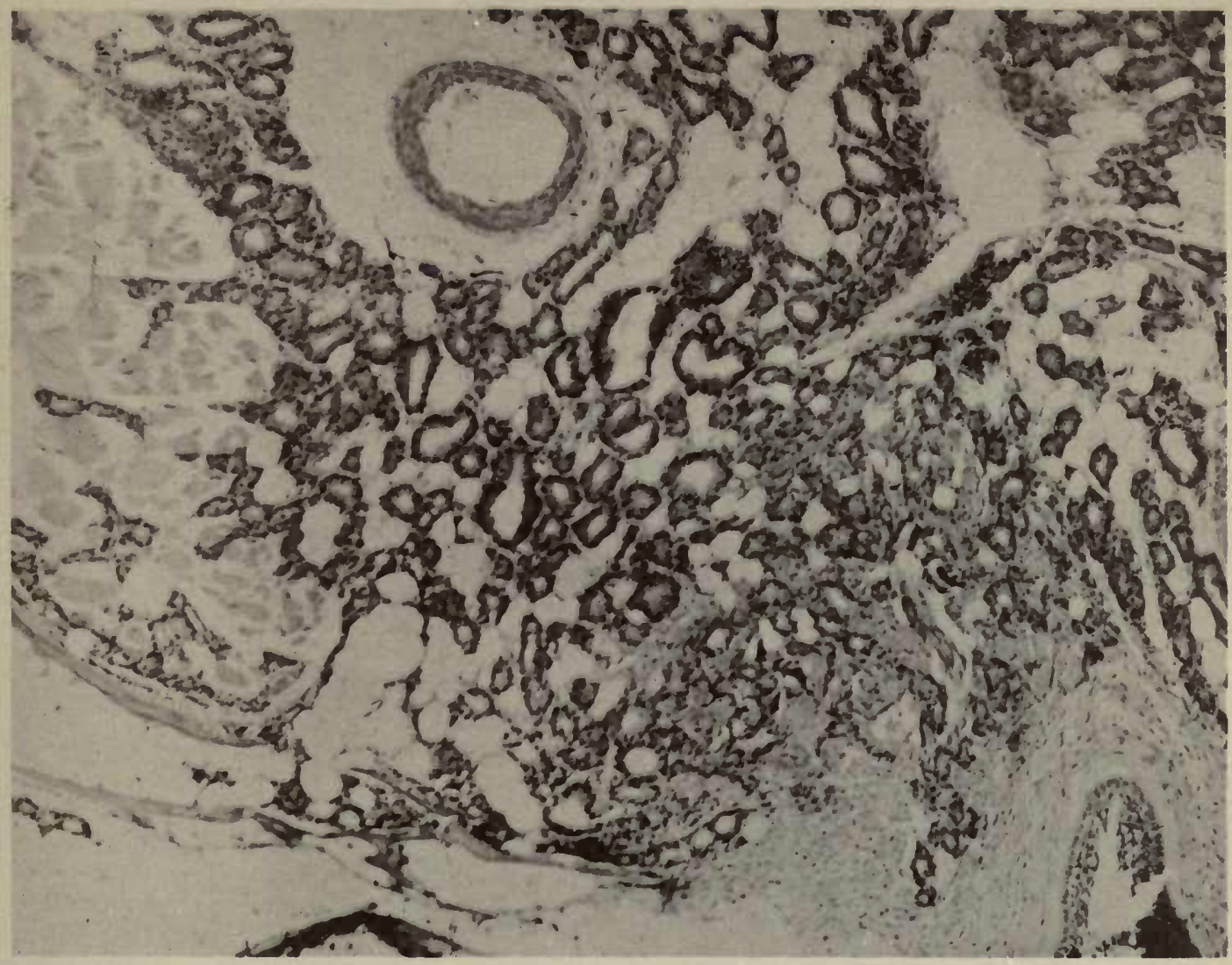

FIG. 93.-Section thyroid region domesticated yearling, Cold Spring Harbor hatchery, kept in old troughs. Raw liver and heart feeding. Well developed hyperplasia. $\times 86$.

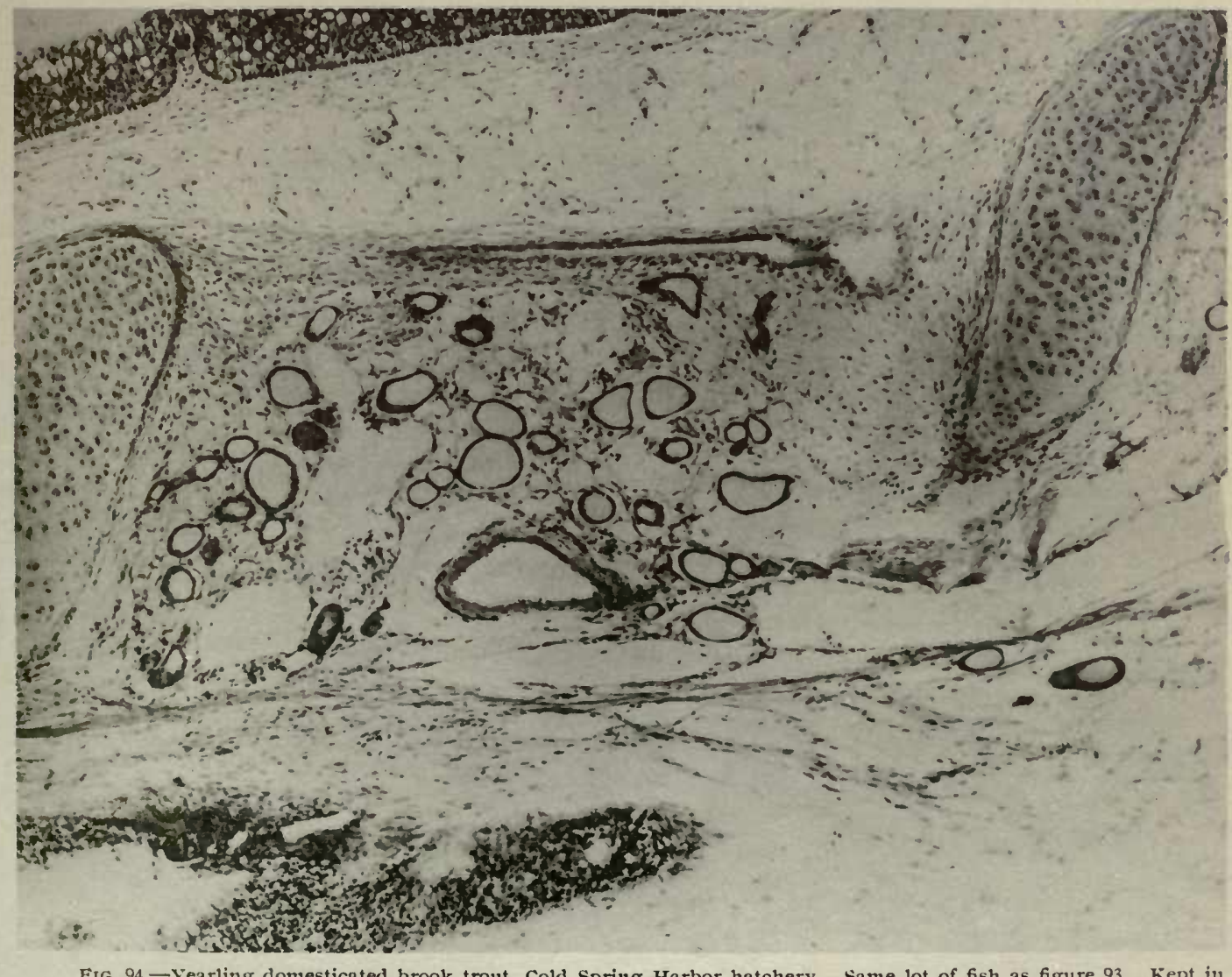





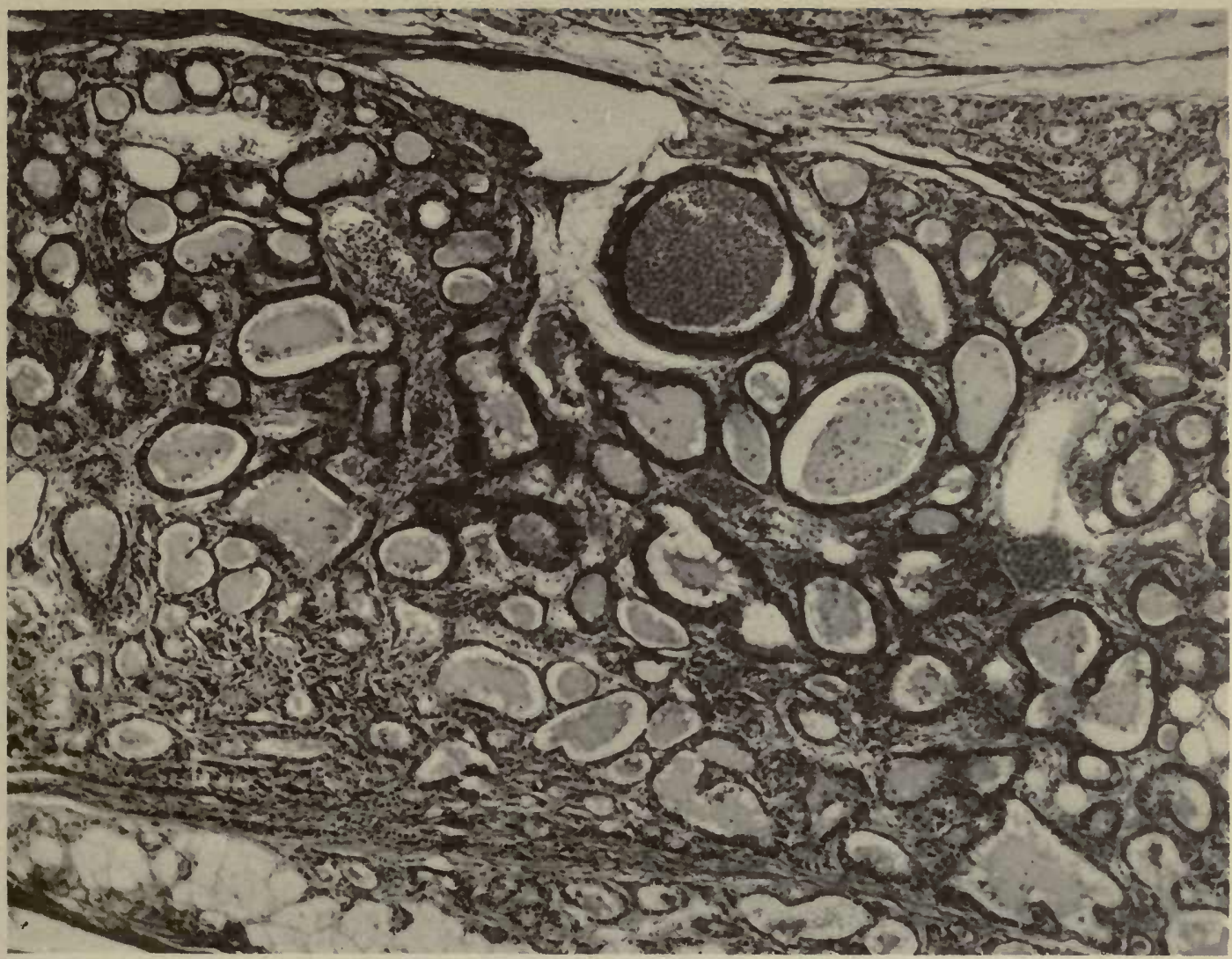

FIG. 96.-Marked hyperplasia domesticated brook trout used as control for figure 97. Fish 1040 , table IX. $X 86$.

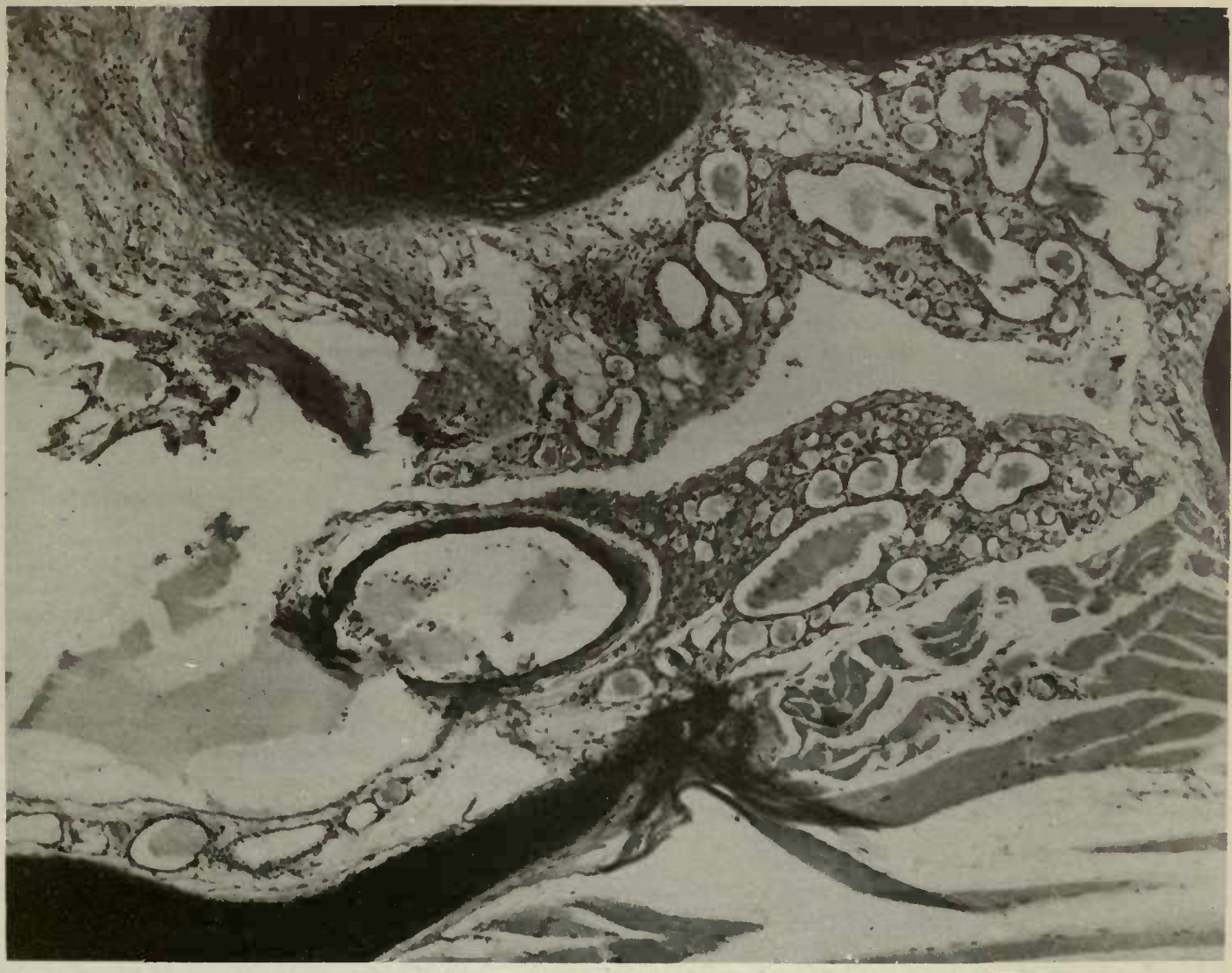

Fig. 97.-Fish from same lot treated by adding in continuous concentration potassium iodide in the water $1: 5,000,000$. Marked regression of hyperplasia at the end of 13 days. Fish 1039, table IX. X86. 

BULL. U. S. B. F. I912.

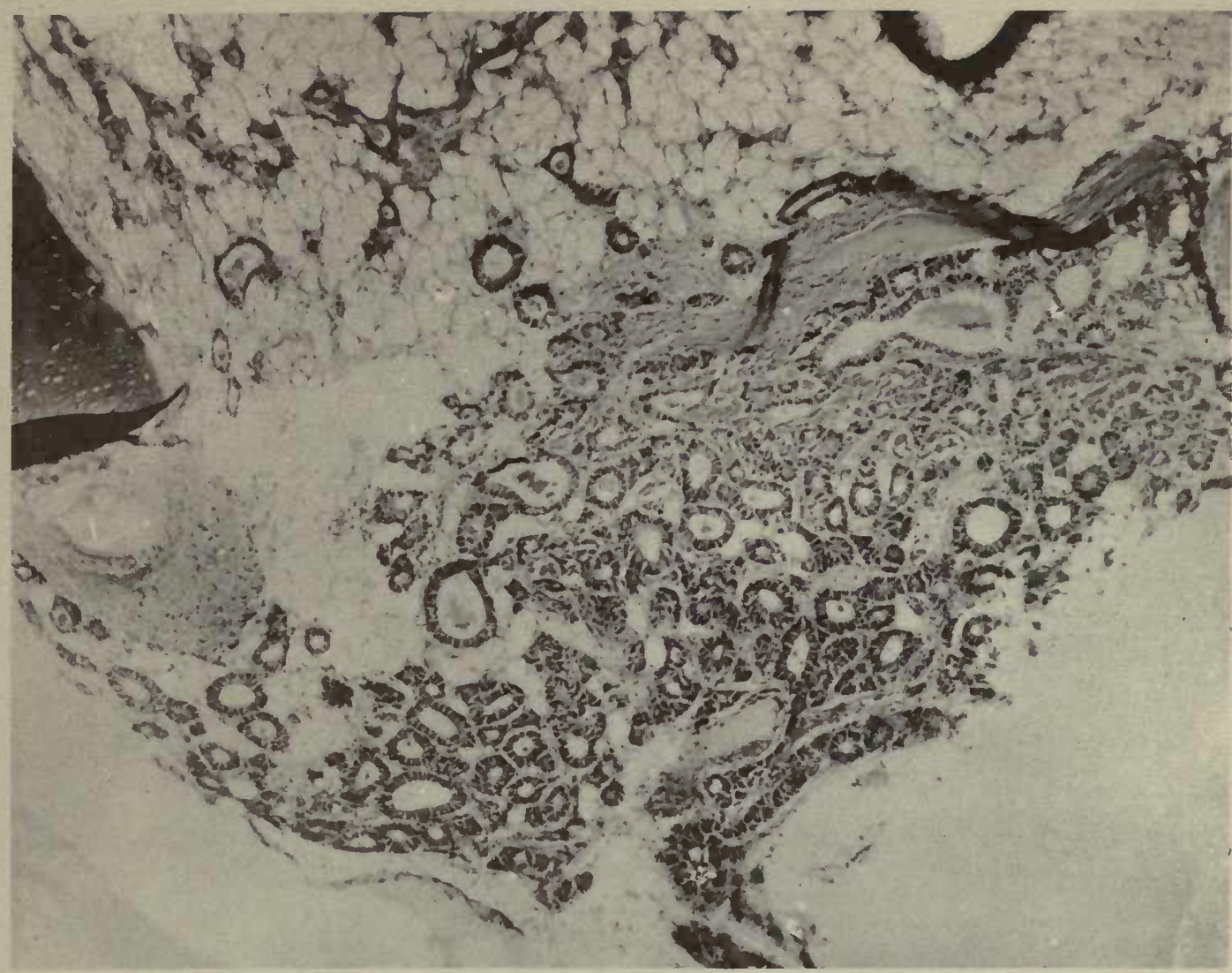

F1(i. 98.- Marked hyperplasia domesticated brook trout used as control for figure $99 . \quad$ Fish 1070, table 1X. $\quad$ X86.

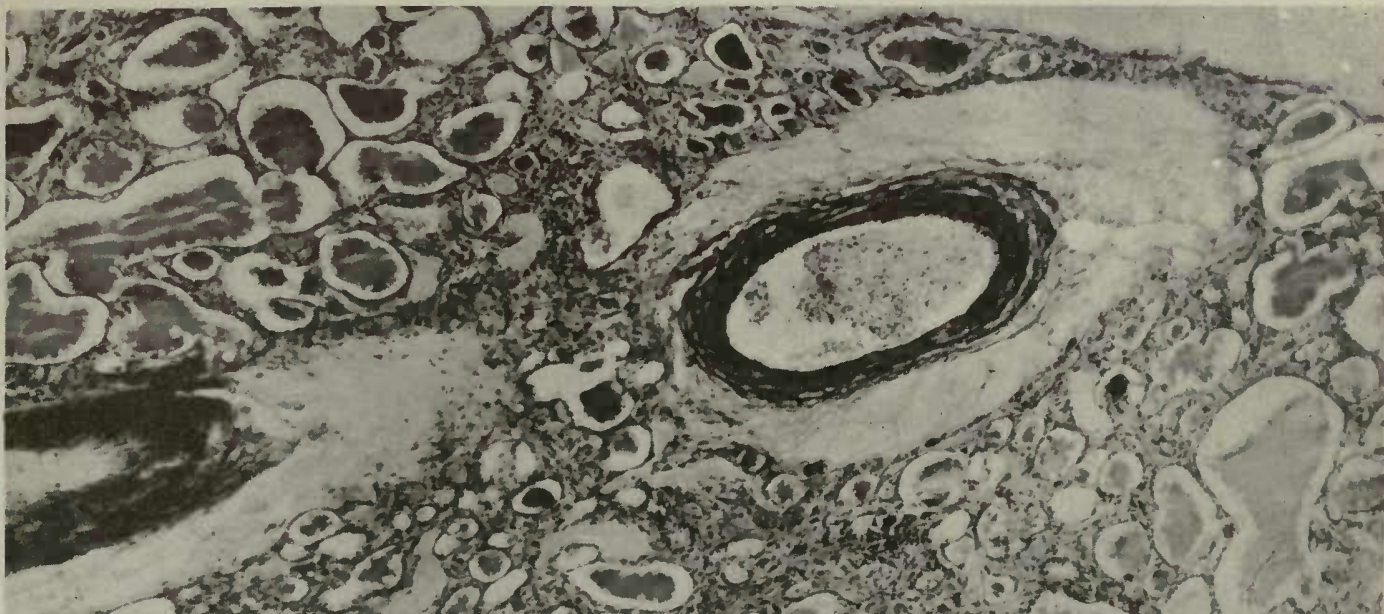
$-105.650 .005$

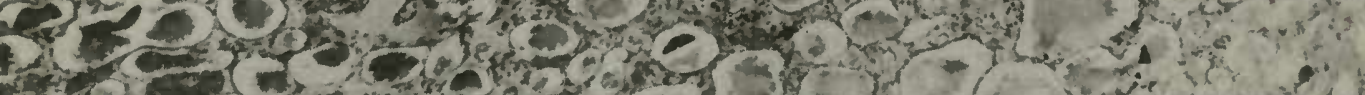

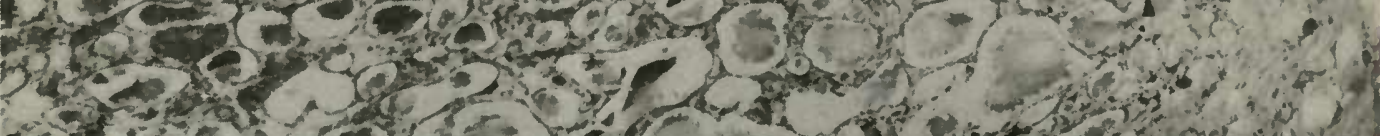

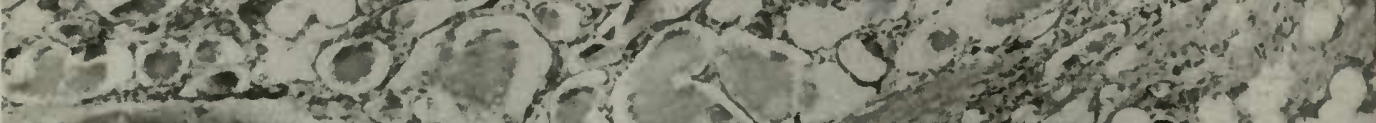

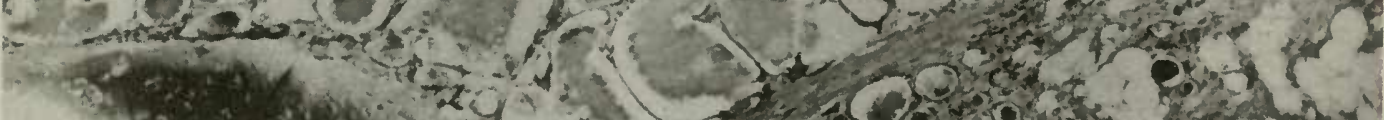

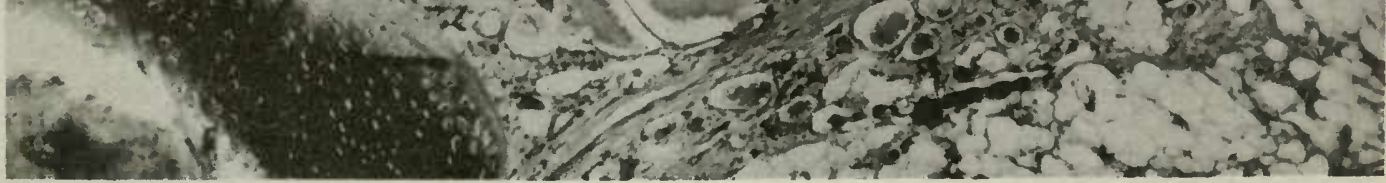
Fis. 99.-Fish from same lot treated by adding in continuons concentration potassium iodide in the water $1: 5,000.000$. Marked regression of hyperplasia at the end of 27 days. Fish 1069, table 1x. X86. 

Fig. 100-Hybrid yearling salmon. Iarge protruding tumor showing narked change with reversion toward normal type is the result of treatment with jodine added to the water by continuous flow in the proportion of $1: 5,000,000$ for 24 days. Great visible reduction in size of tumor. Fish 1083, table ix. $\quad$ X86.

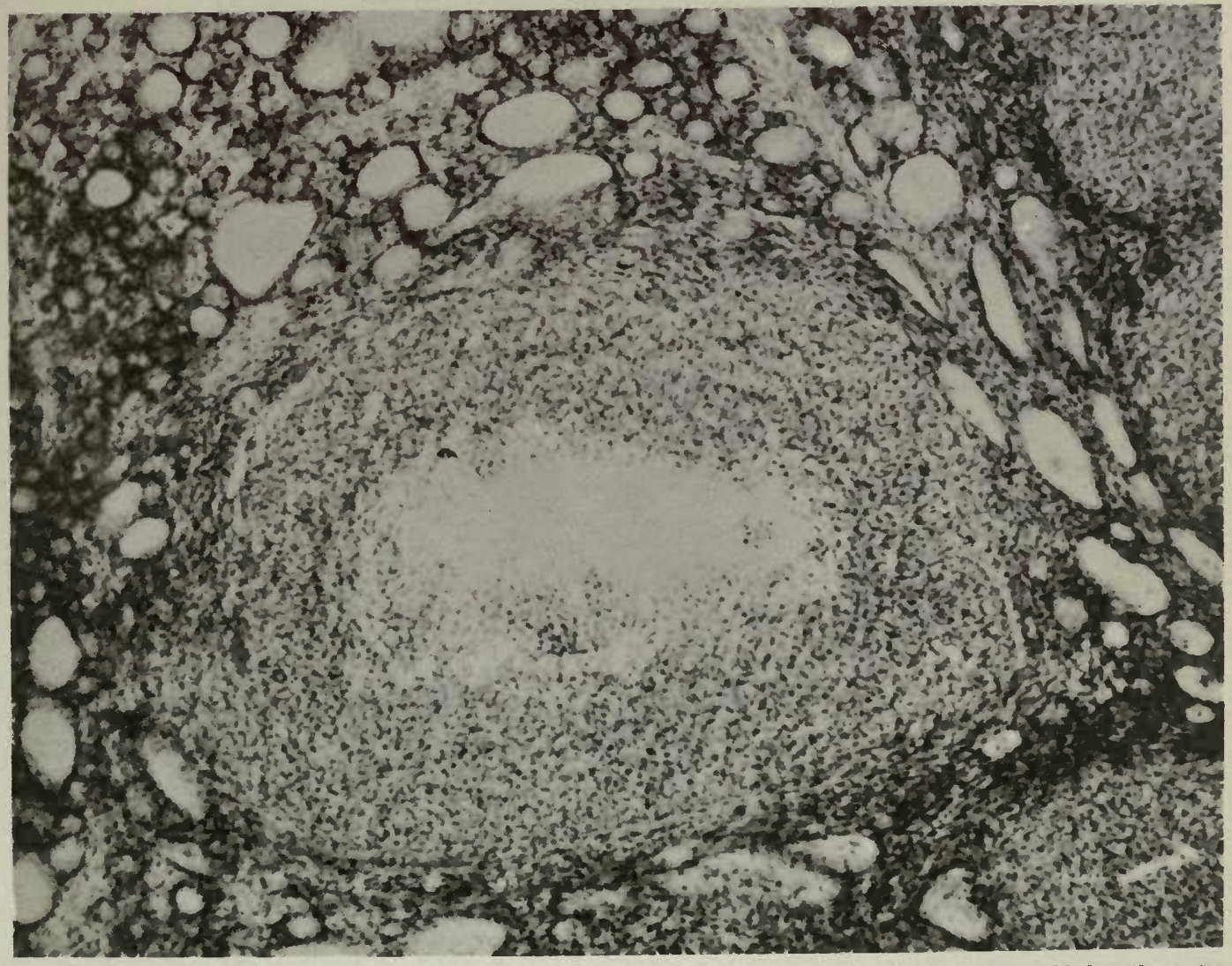

(he wate tissue. previous hemorrhage in substance of tumor induced by treatment. Great reduction in size of tumor. Fisll 1060 . table tx. X136. 



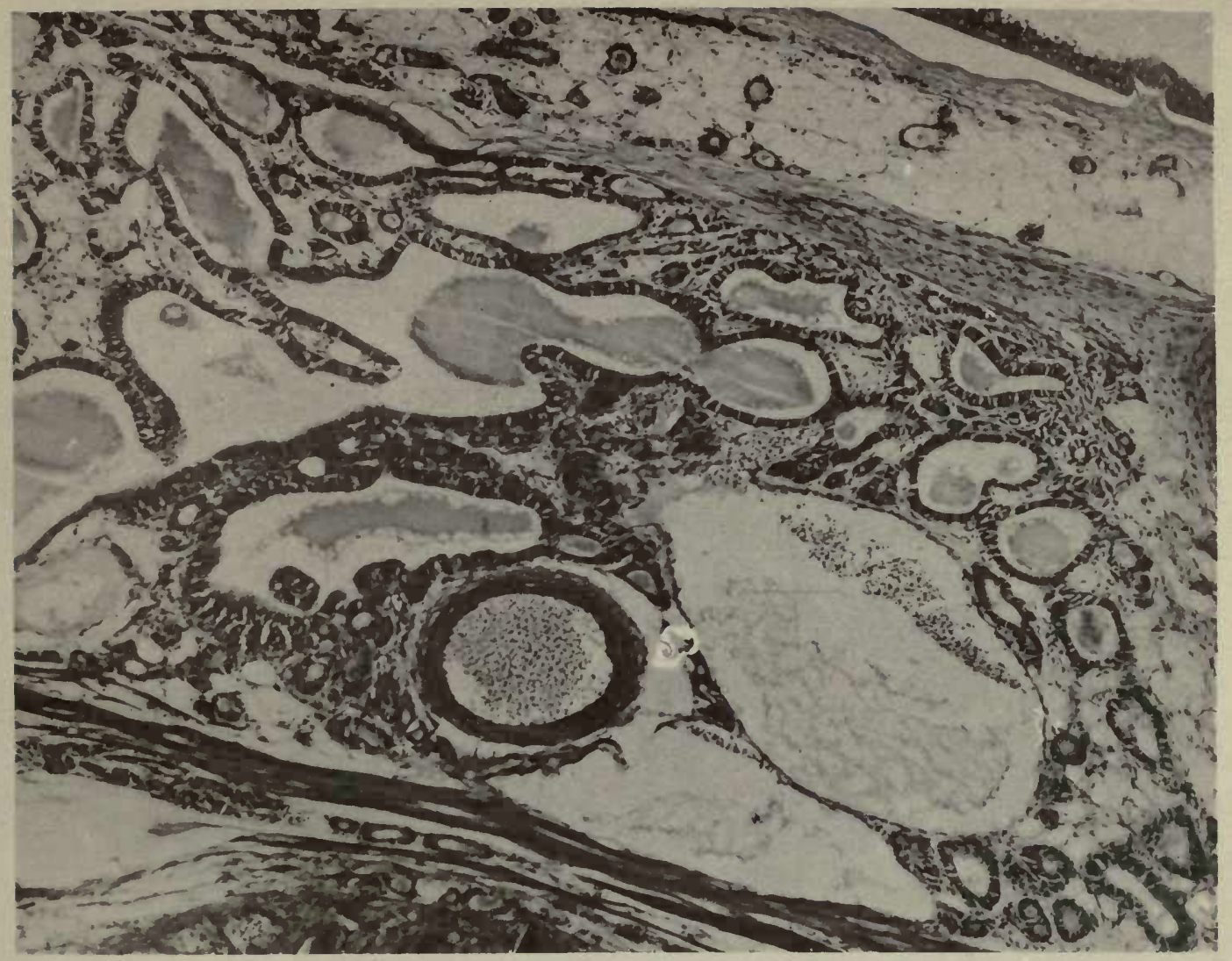

Fici, 102,-Control for figure 103. Fisil 1090, table $\mathrm{x} 11 . \quad \times 86$

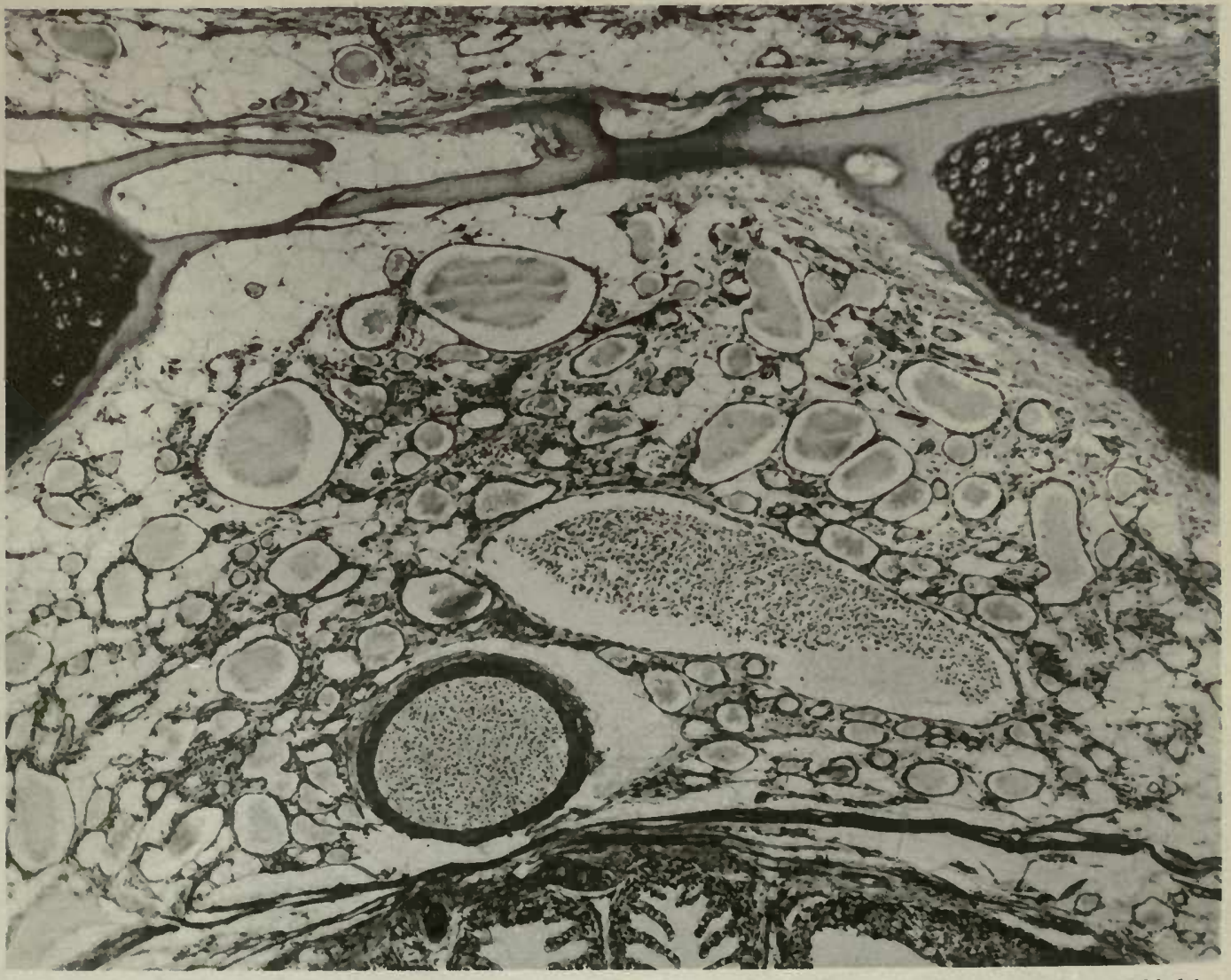




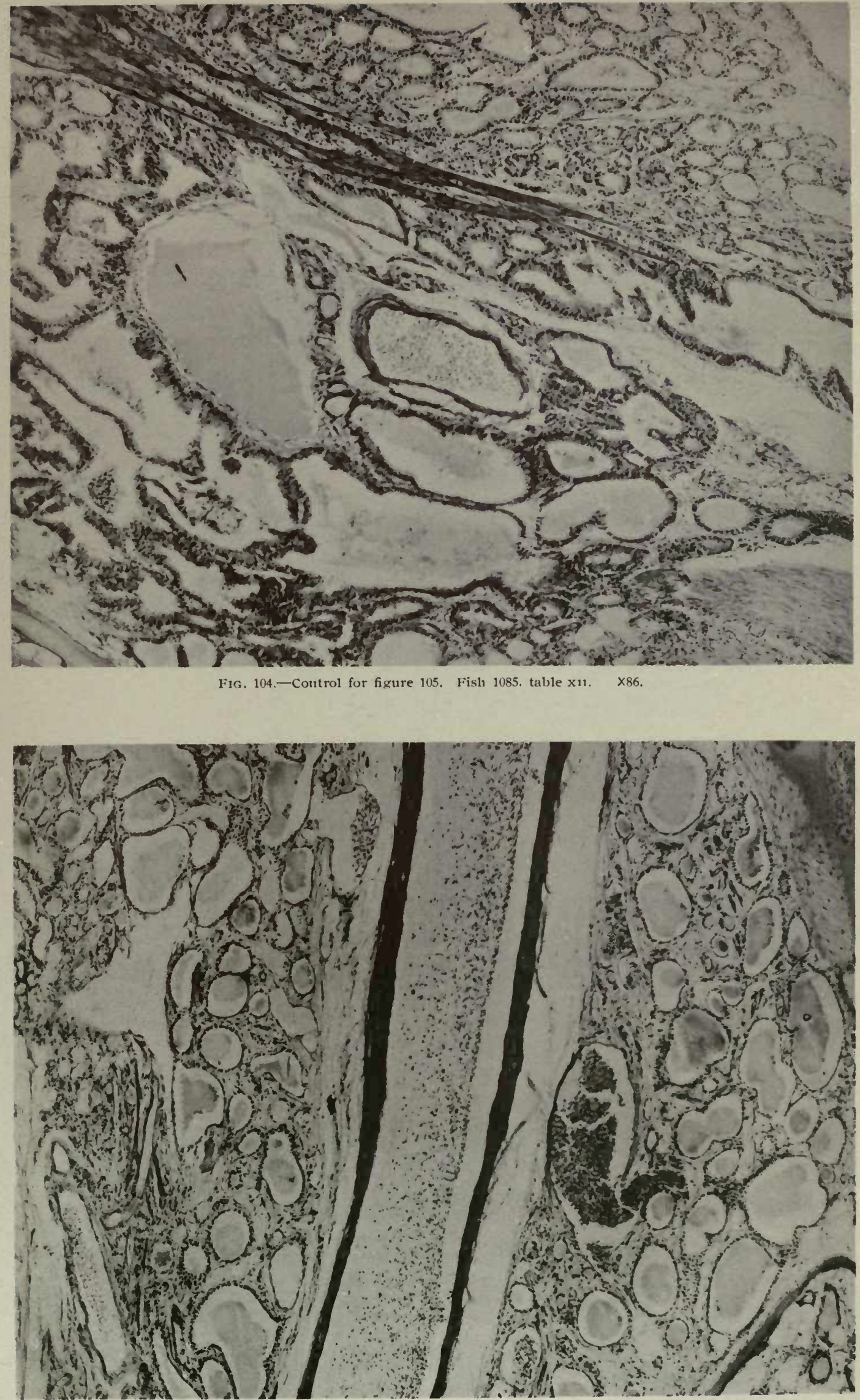

Fic 105-Domesticated brook trout from the same lot as figure 104. treated with bicliloride of mercury added by contininous flow to the water in the proportion of $1: 5,000.000$ for 14 days. Disappearence of layperplasia. Marked reversion to the normal type. Fish 1084. table xil. X86. 



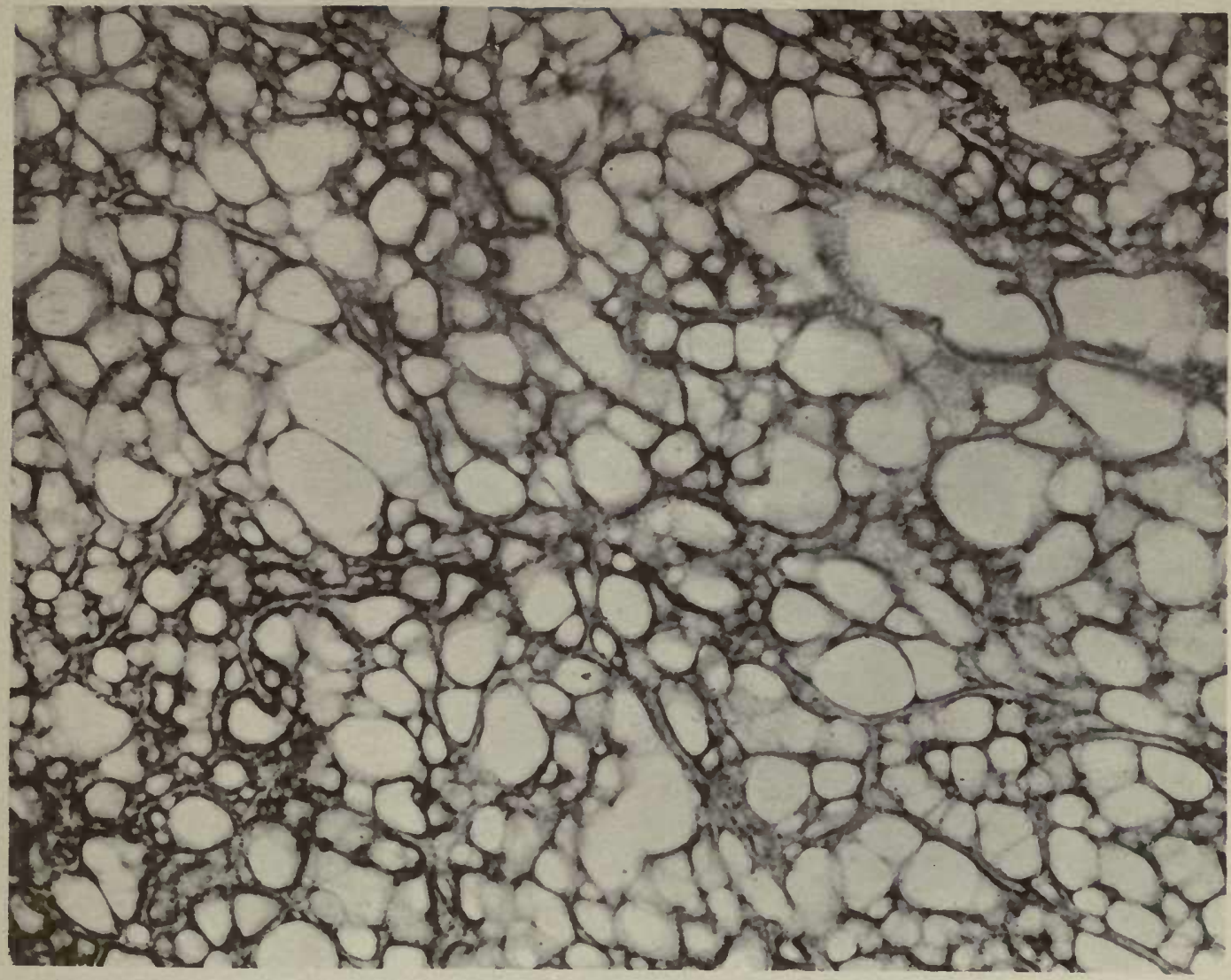

FIG. 106.- Section through large tumor domesticated brook trout which under treatment with bichloride added to the running water in the proportion of $1: 5,000,000$ for 3 days and then placed in standing bichloride solution $1: 300,000$

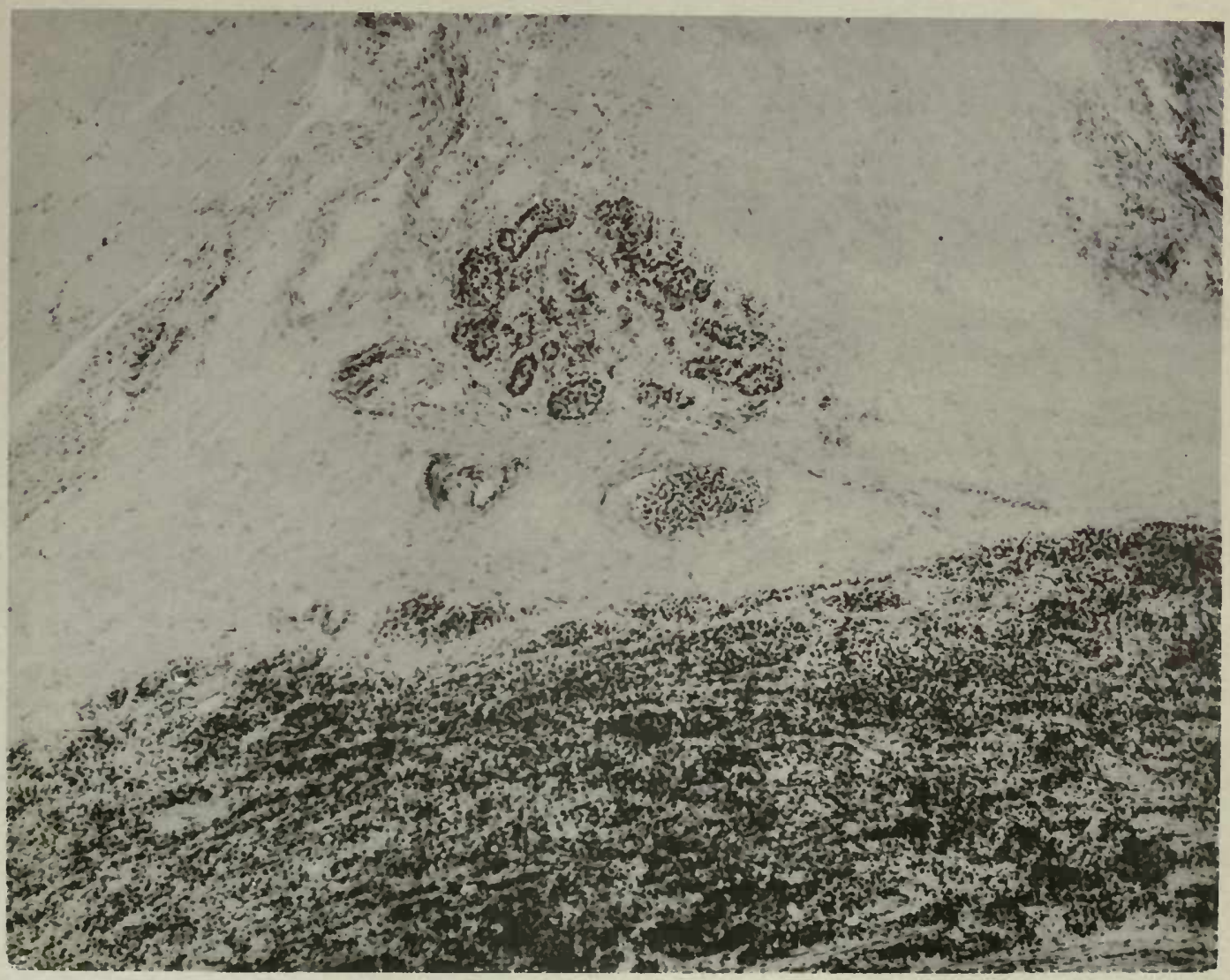

Fic 107 - - Section through margin of large tumor added to the water for 18 days. Marked atrophy of tumor celis, remnants of nests of cells in marginal connective tissue presenting a picture similar to regression of carcinoma in mammals. Fish 1065, table X11. X86. 



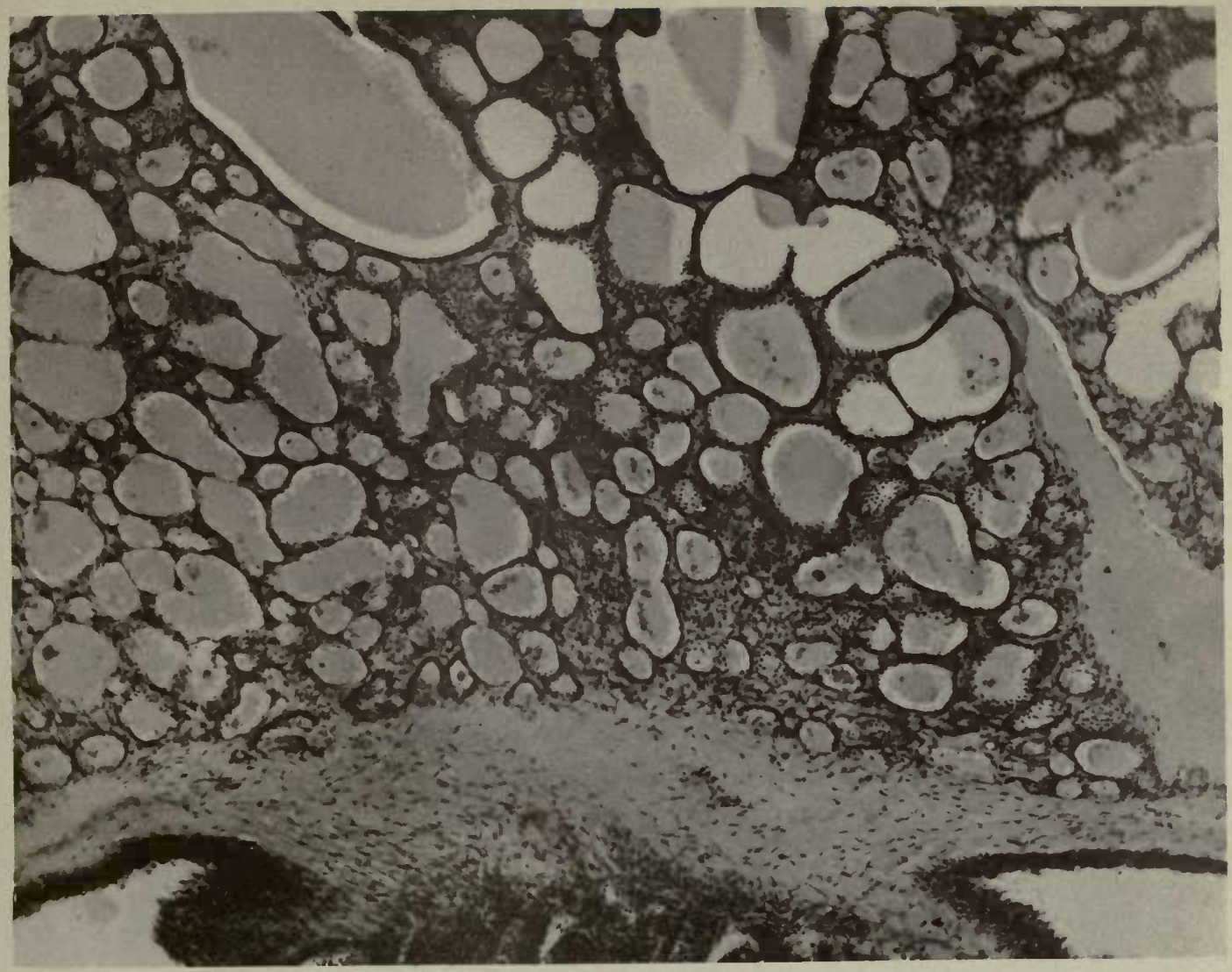

Fig, 108-Section throngls tumor of two-yenr old brook trout treated with bichloride of mercury added by continuous flow to the water in proportion of 1:5,000.000. Result at the end of 11 days. Great reduction in size of tunnor. Reversion of tumor tissue to the normal type. Fish 1144. table xn1. X86.

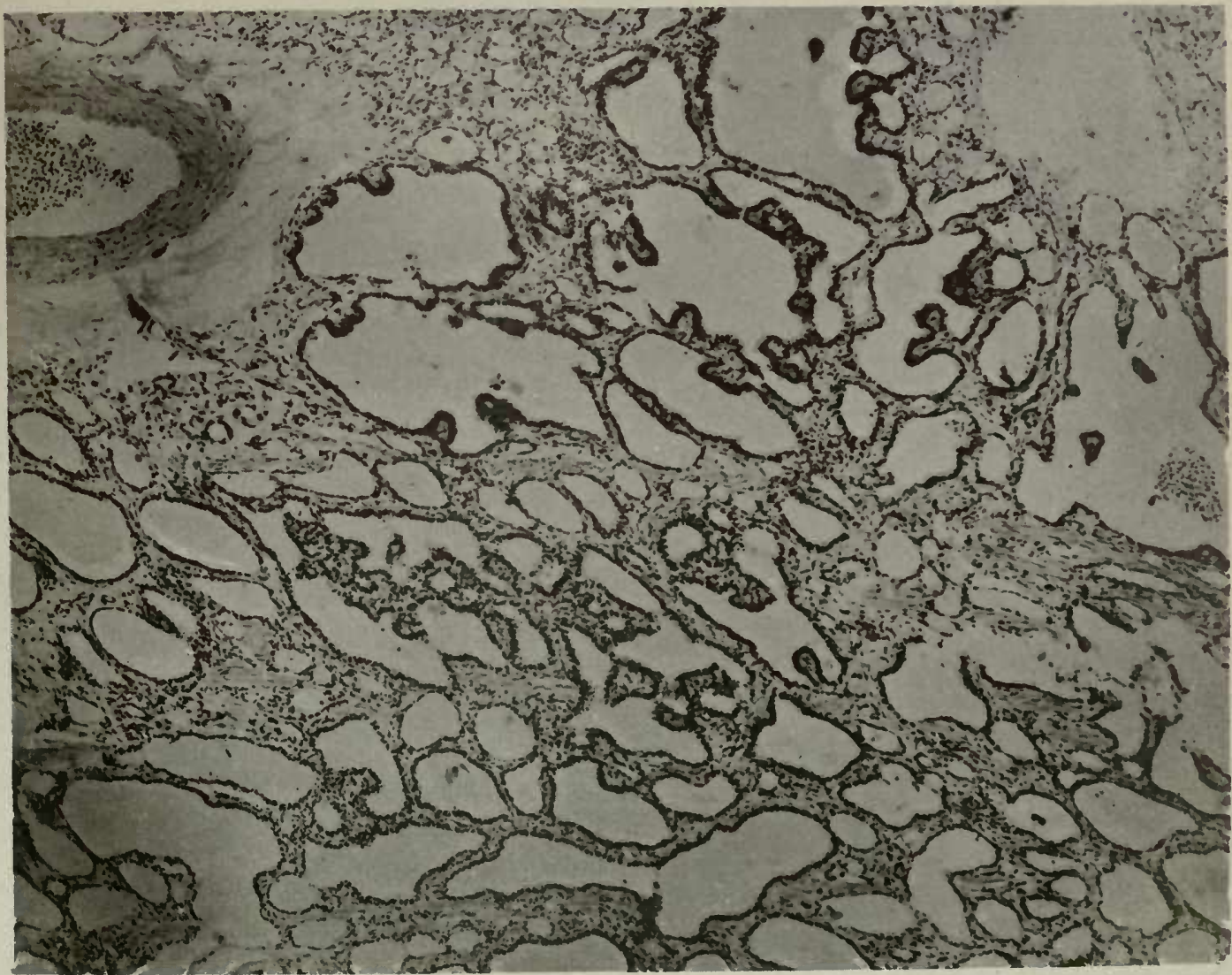





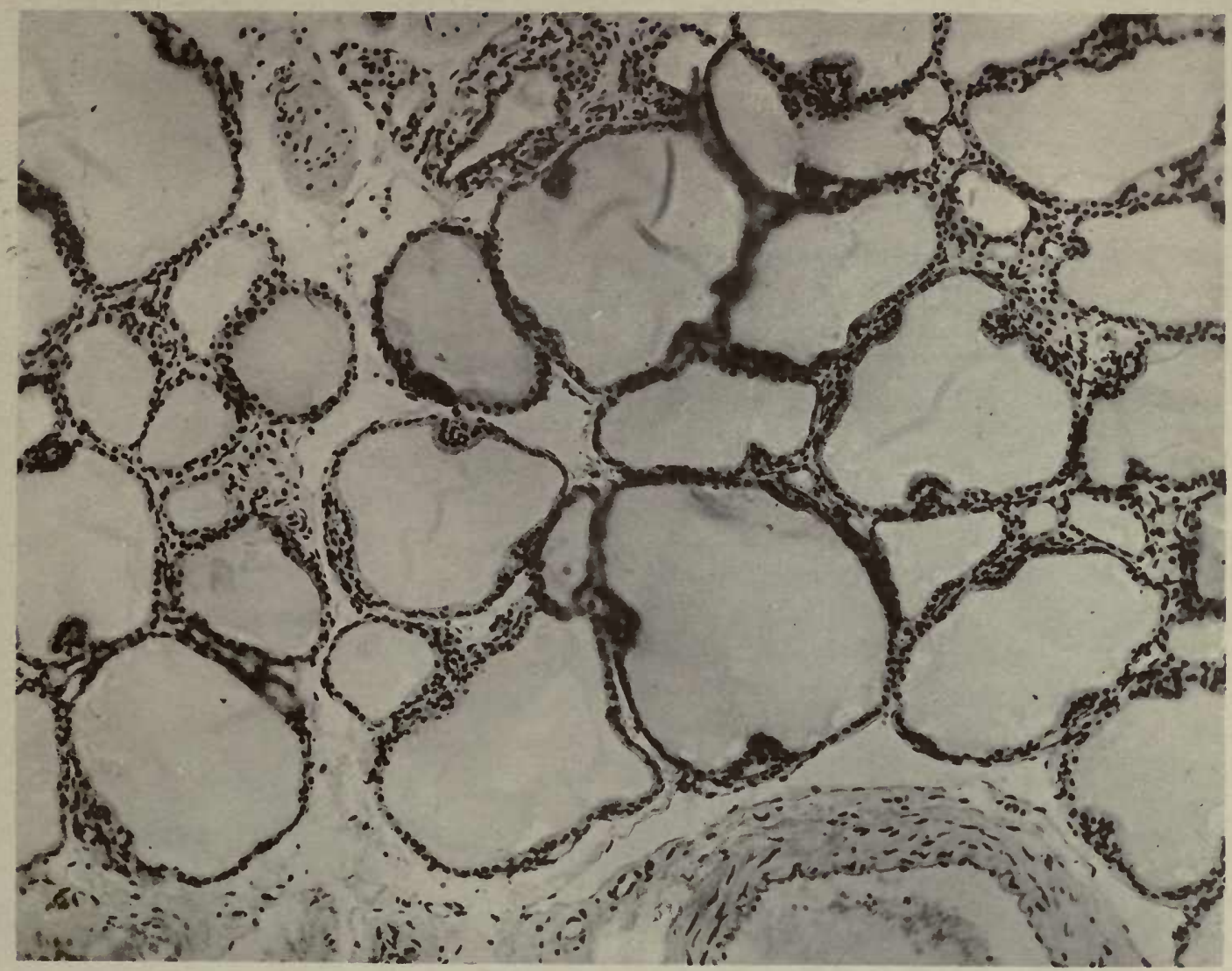

FIG. 110.- Section of thy roid of $\operatorname{dog} 21$ used as control for $\operatorname{dog} 16$, figure 111 . Received same water as dog 16 but

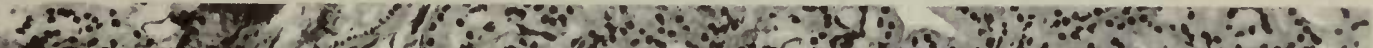

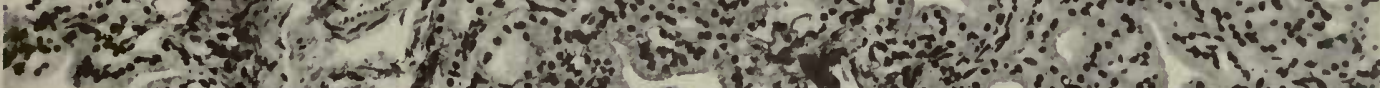
45 the

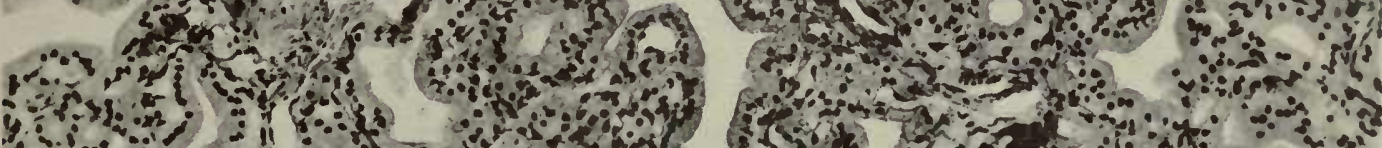

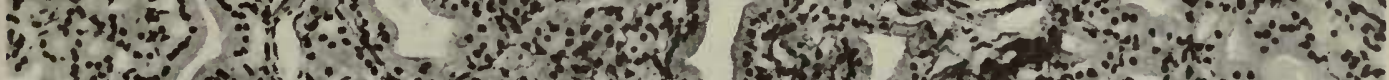

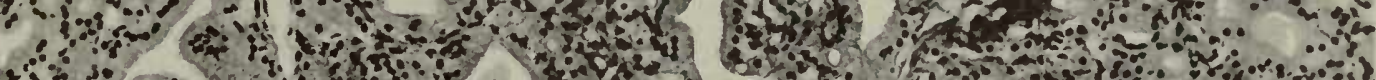
r.

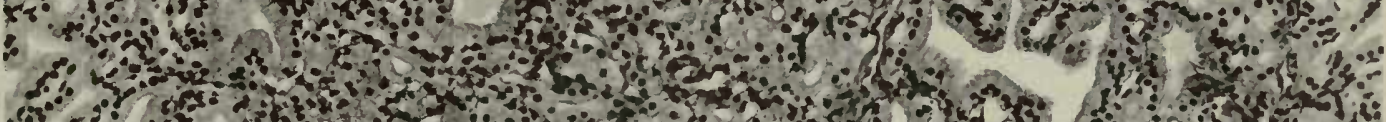

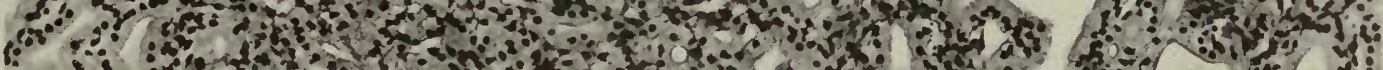

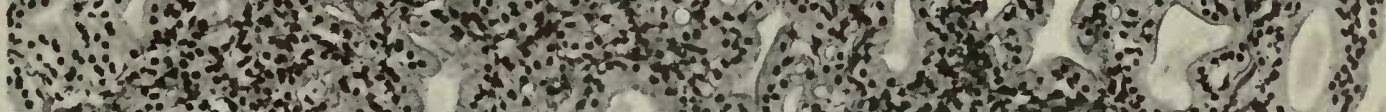

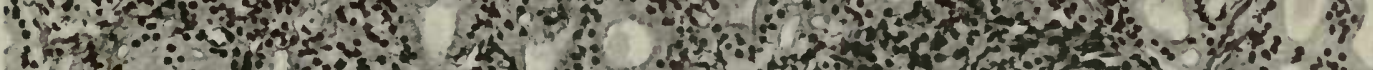

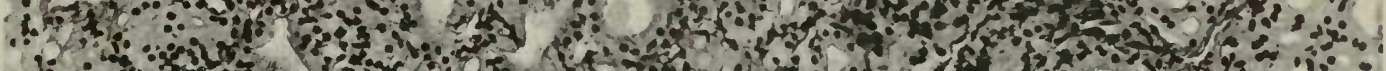

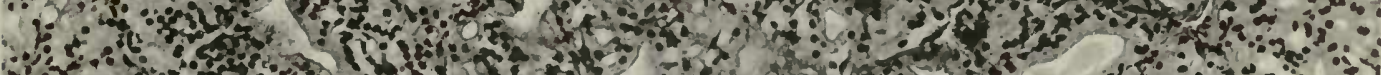

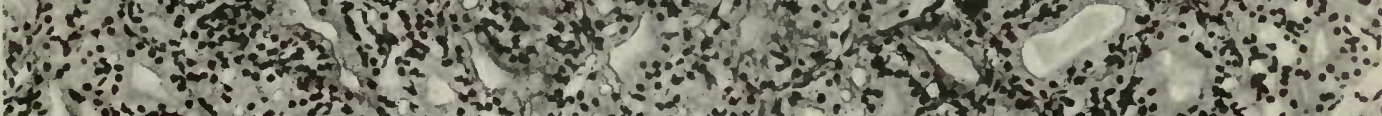
5.

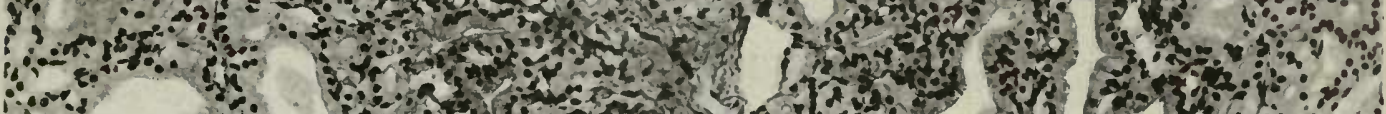

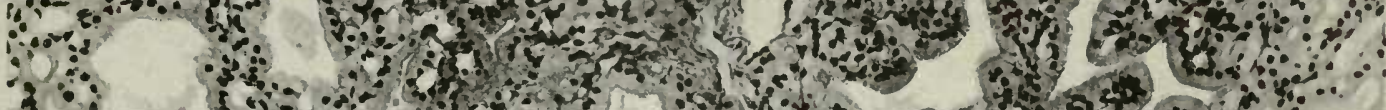
Ti:

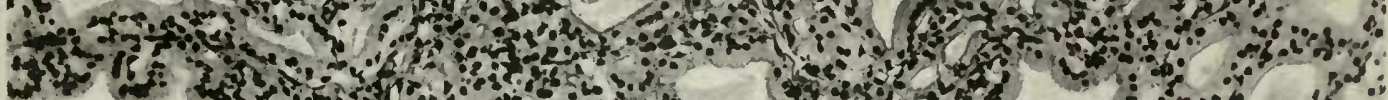

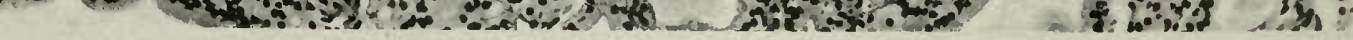
FIG. 111.- Section of thy roid of dog 16. Marked enlargement of the thy roid, well developed hyperplasia as the result prevalent. $\times 160$ 



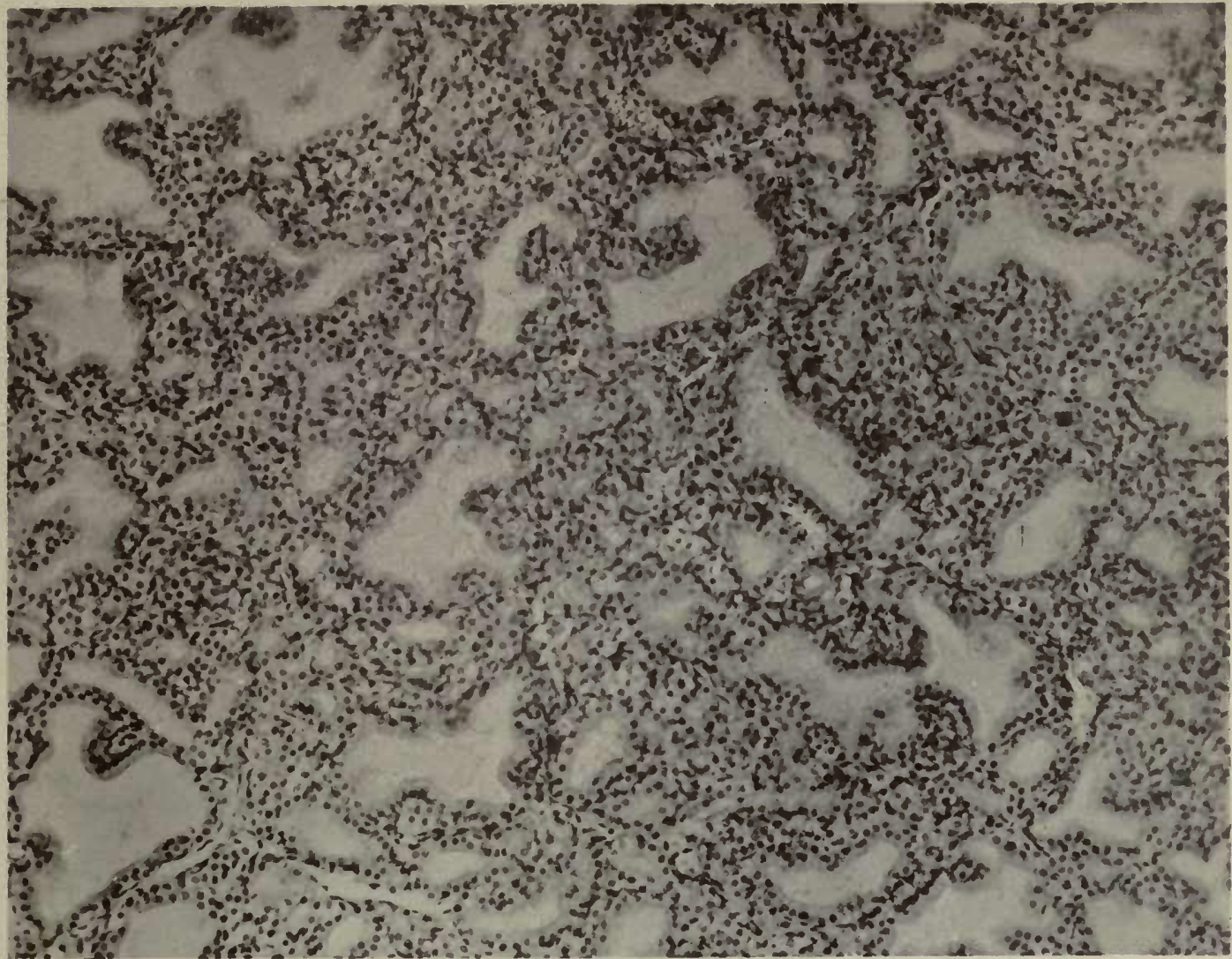

FIG. 112.-Dog. 17. Hyperplasia of the thyroid at the end of five months, from drinking water in which were suspended scrapings taken from fish troughs in which carcinoma of the thyroid was prevalent. The same experinelit as dog 6, figure 111 . $\times 160$.

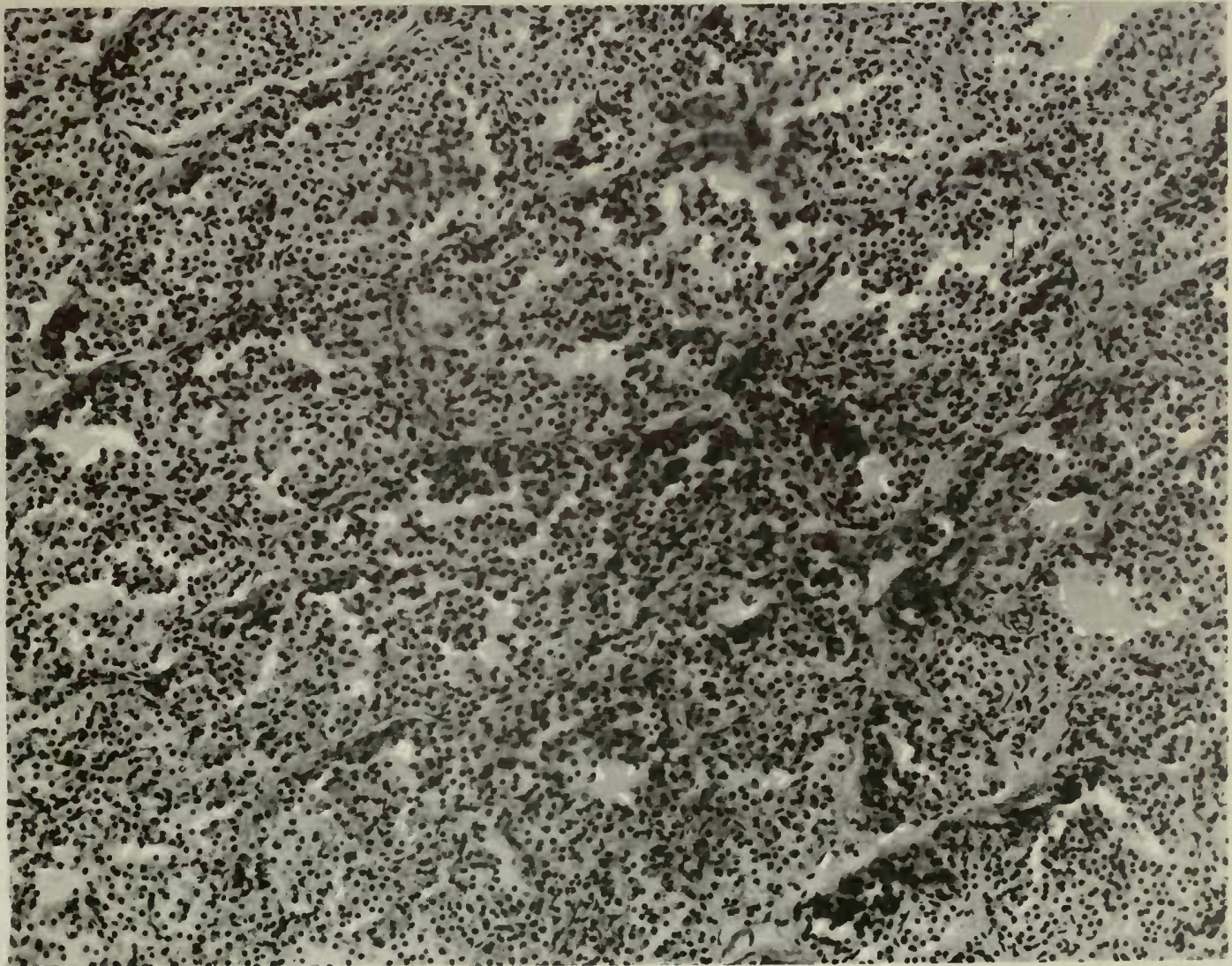
F1s. 113 - Section of enlarged thy roid of dog 15. Marked hyperplasia of the thy roid with desquanation and degenerative changes in dog drinking water with nund from pond 10 . Craig Brook. $\quad \times 160$ 



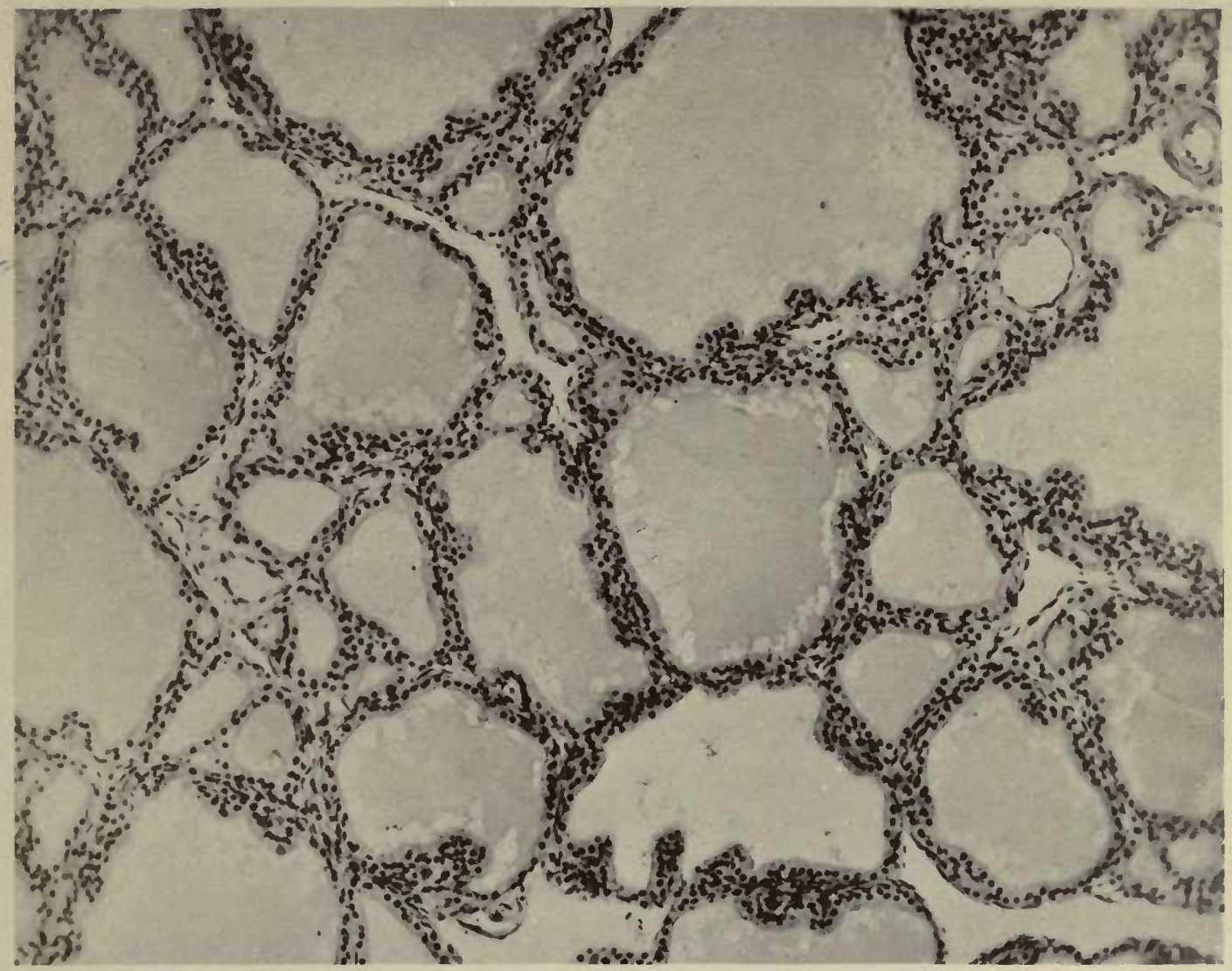

Fig. 114 - Section of thyroid of dog 20 used as control for dogs 22,16 and 17. Received the same water as dogs 16, 17 and 22 , but, like control dog 21 , boiled before drinking. $\times 160$.

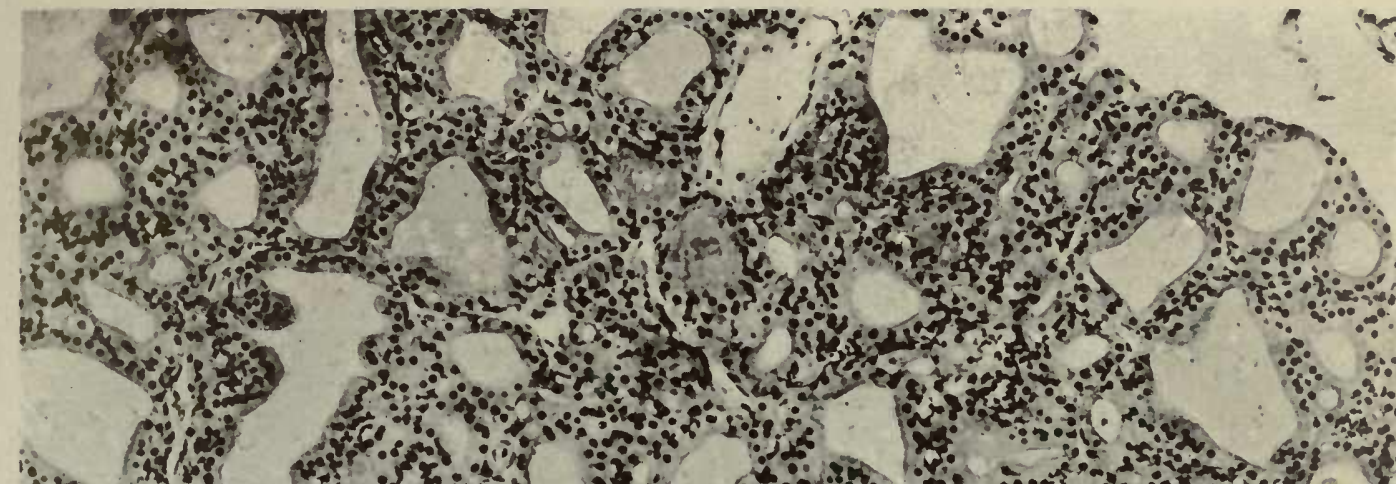
3. $\therefore$ S O

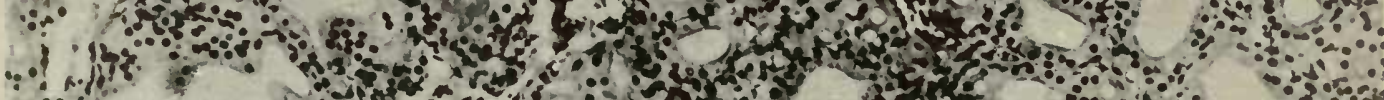
3 (1)

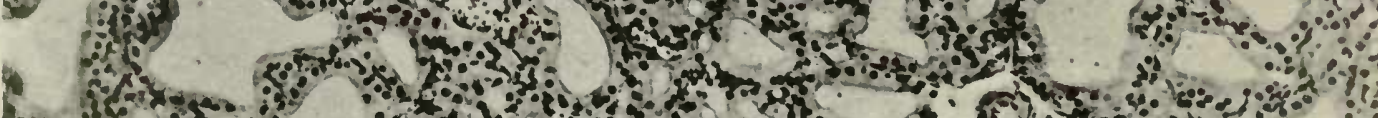
6.

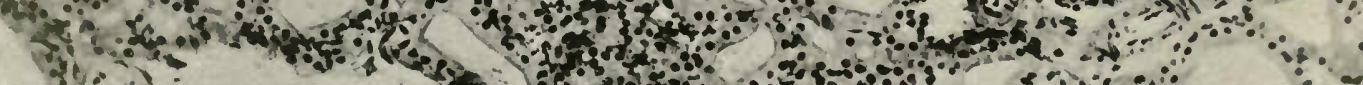
Ylo

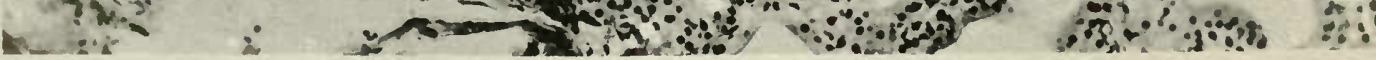
F1: 115.-Dog 22. Section of enlarked thyroid. Well developed hyperplasia after drinking water five nonths with suspended scrapings from infected fish trouglis. The same experiment and result as dog 16. figure 111 , and dog 17,
figure 112 . X160. 



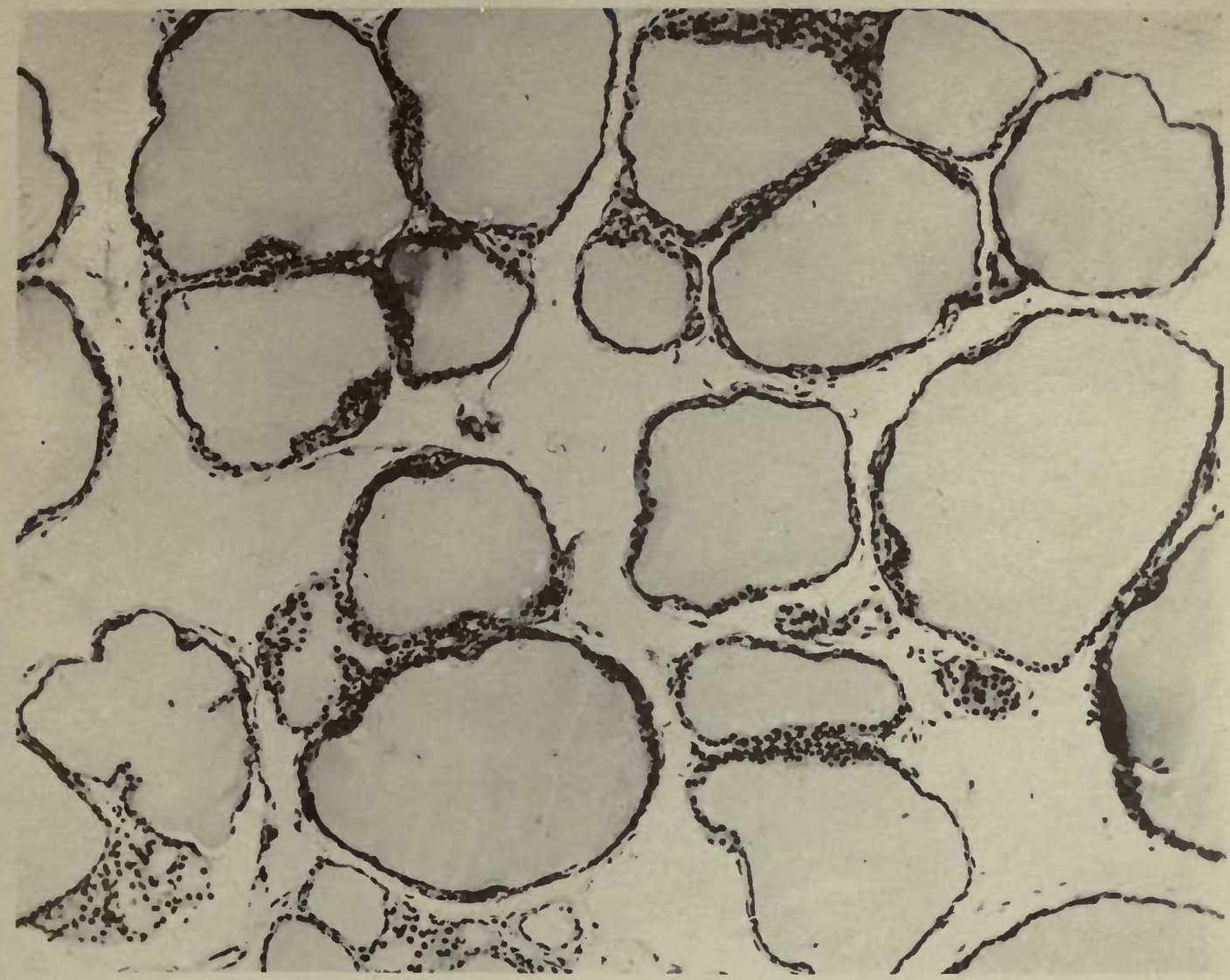

F1c, 116. - Section of normal thyroid of adult female dog, mother of dogs 15, 16, 17, 20, 21 and 22, used as control for dog 18, figure 117. Received same water but boiled before drinking. $\times 160$.

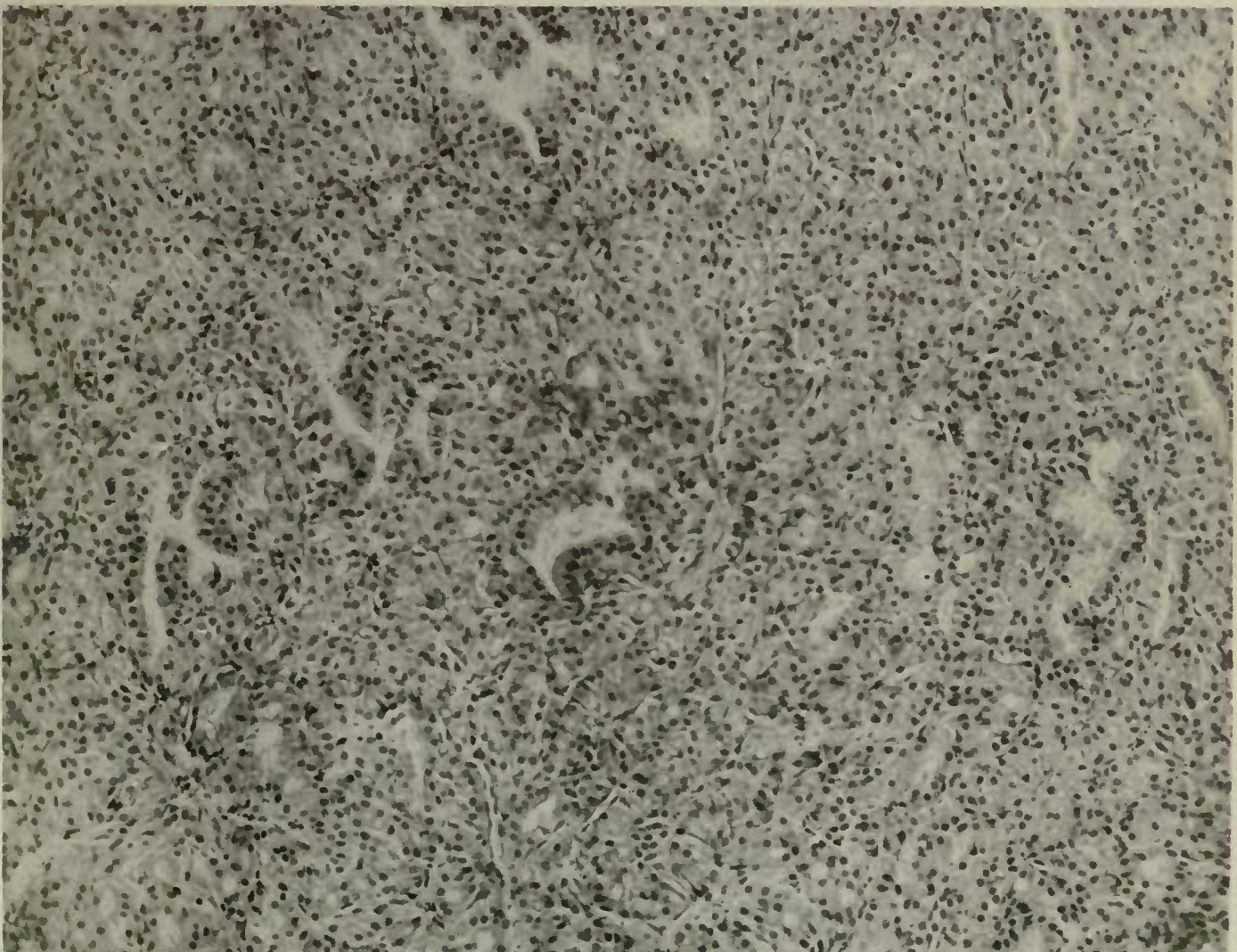

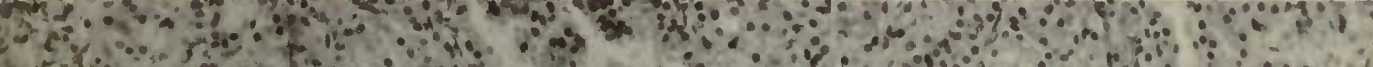

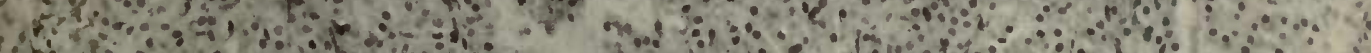

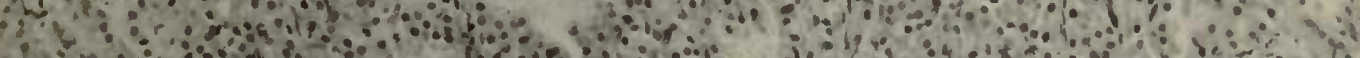

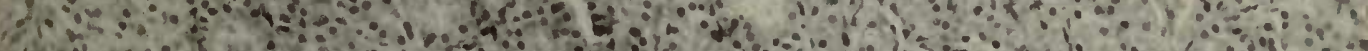

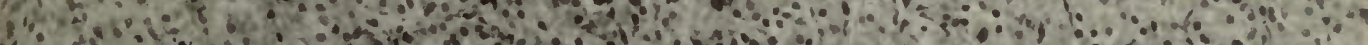
A

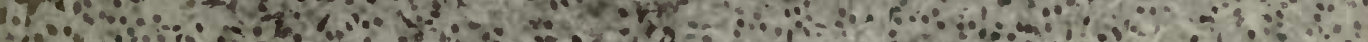

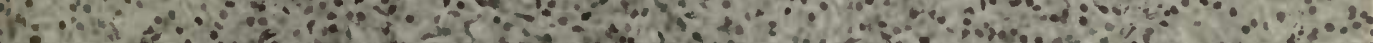

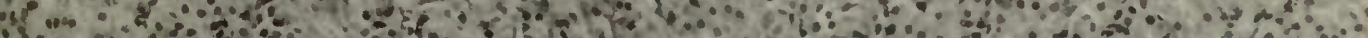

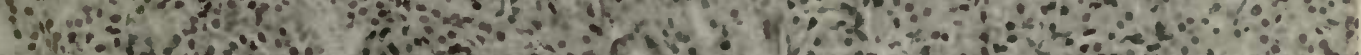

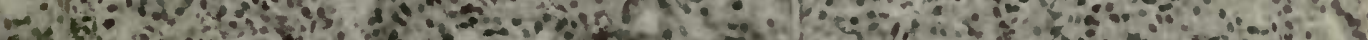

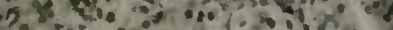

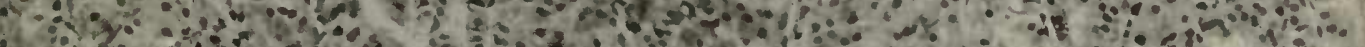

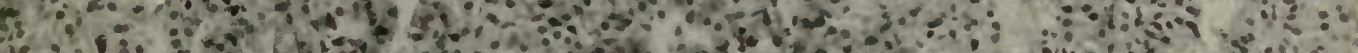

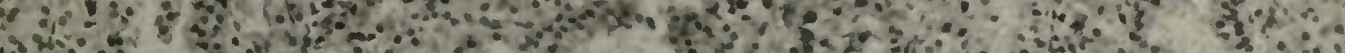

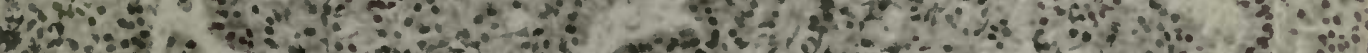

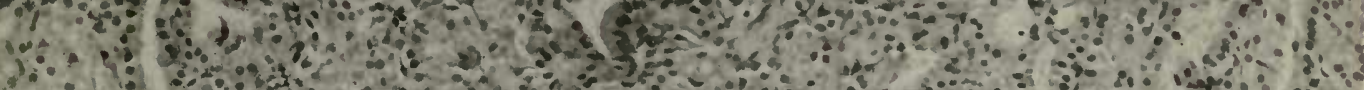

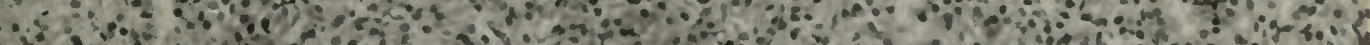

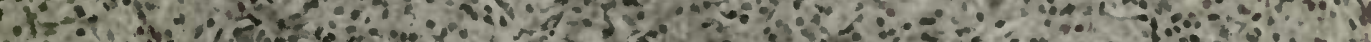

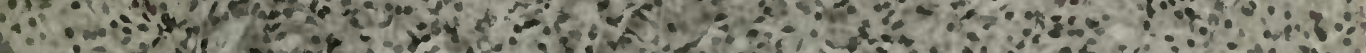

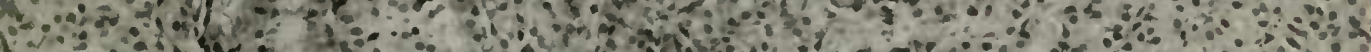

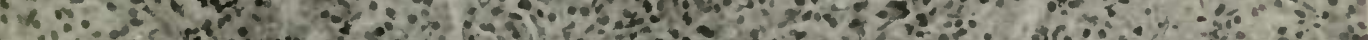

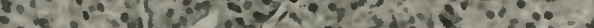

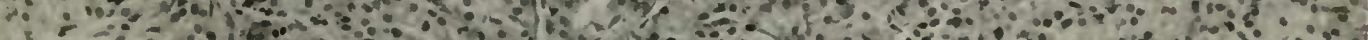

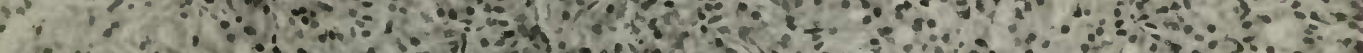

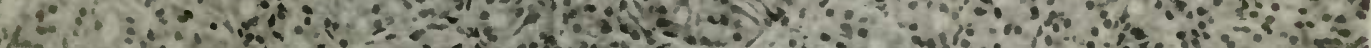

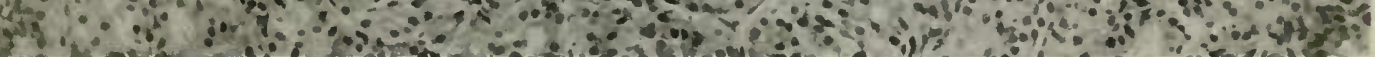

Fig. 117. - Section of markedly enlarged thyroid of adult dog 18. Result after five months drinking water in which were suspended scrapings from fish troughs in which carcinoma of the thy roid in trout was continually developing. $\mathrm{X} 160$. 



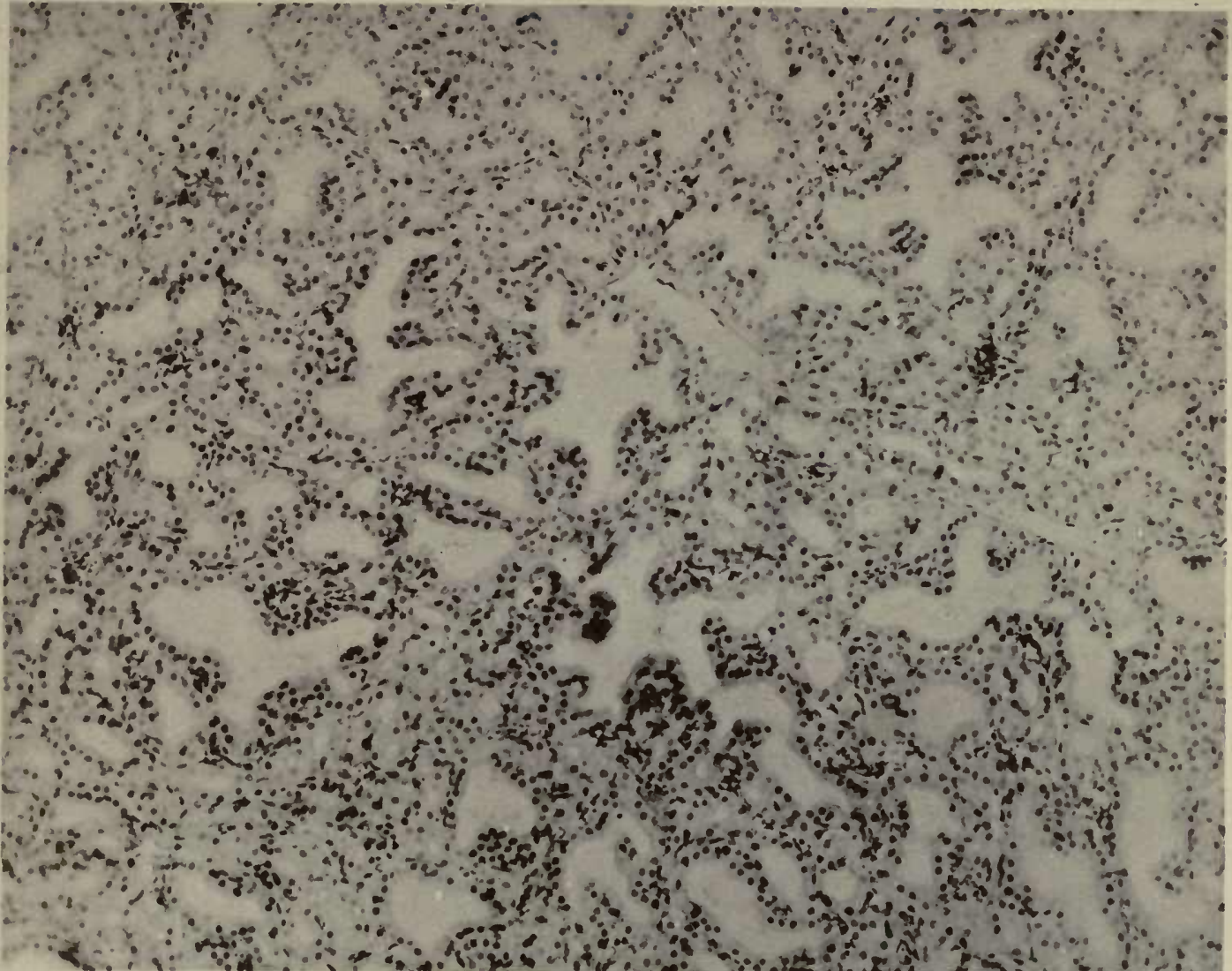

Fra. 118.- Section near periphery of enlarged thyroid of dog 18. The process is less intensive than near the center. as illustrated in figure 117 and 119. Columnar epithelium, marked papillary growths into distorted alveoli. Colloid absent. $\quad$ X160.

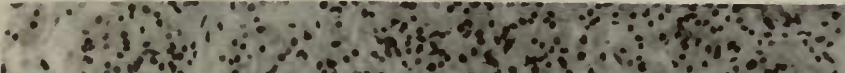

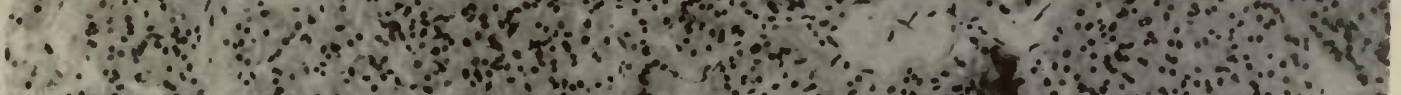
年

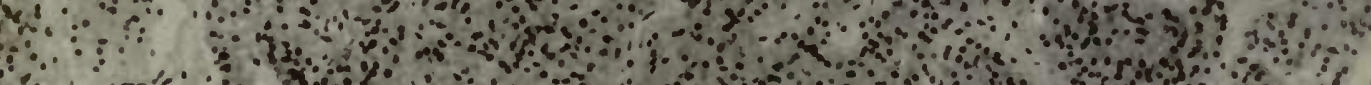

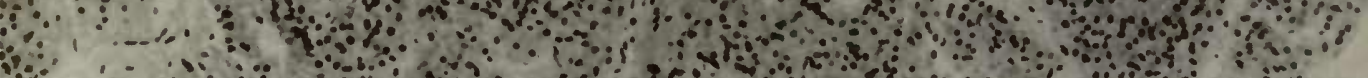

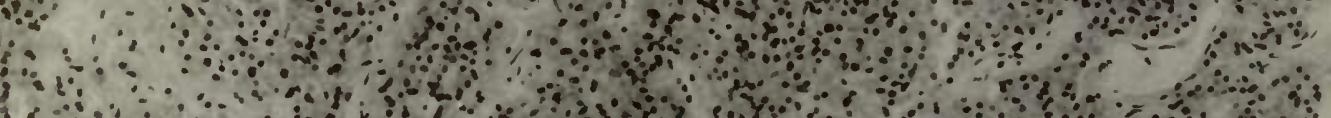
\%

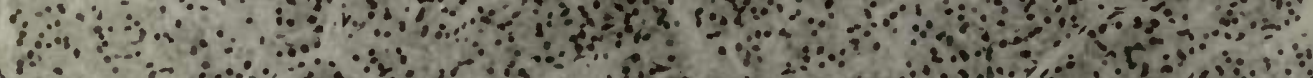

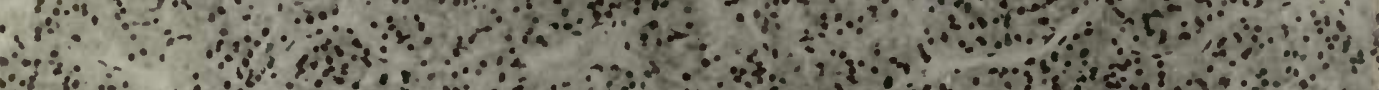

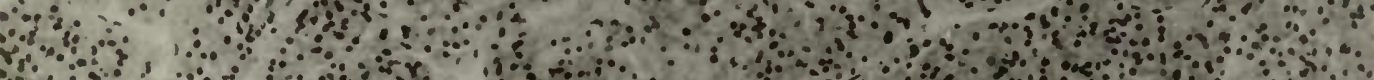

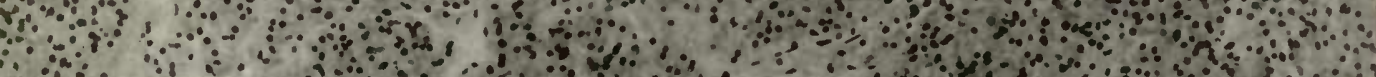
$\therefore \quad \therefore \quad \cdots$

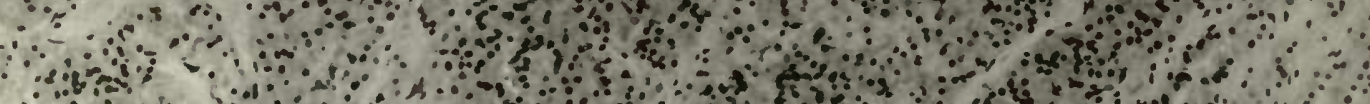

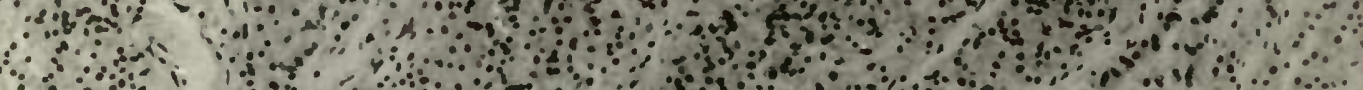

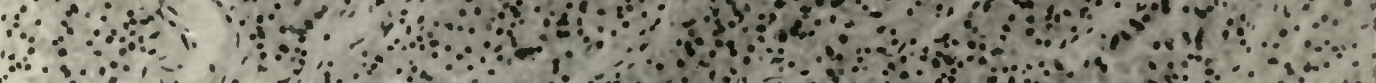

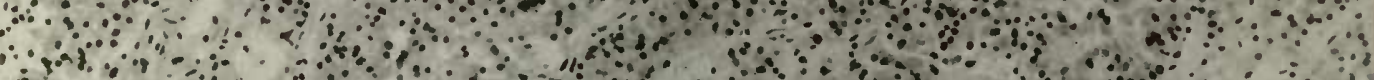

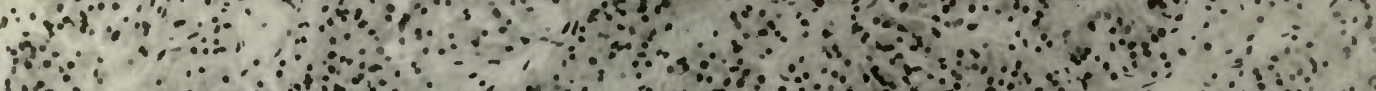

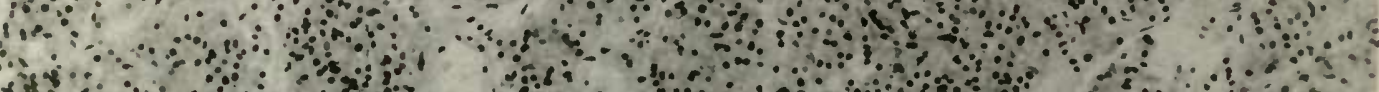
+

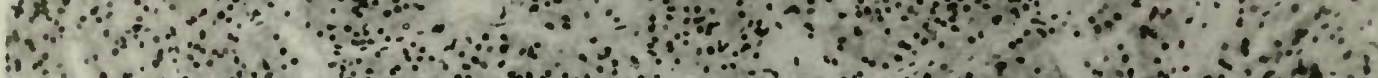

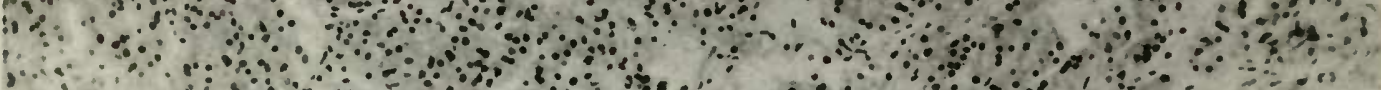

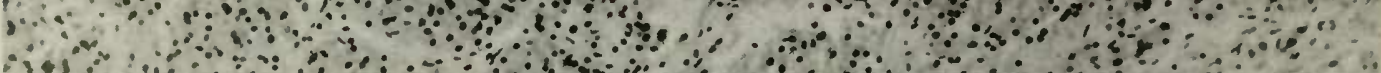

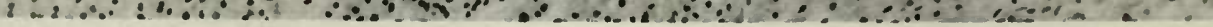





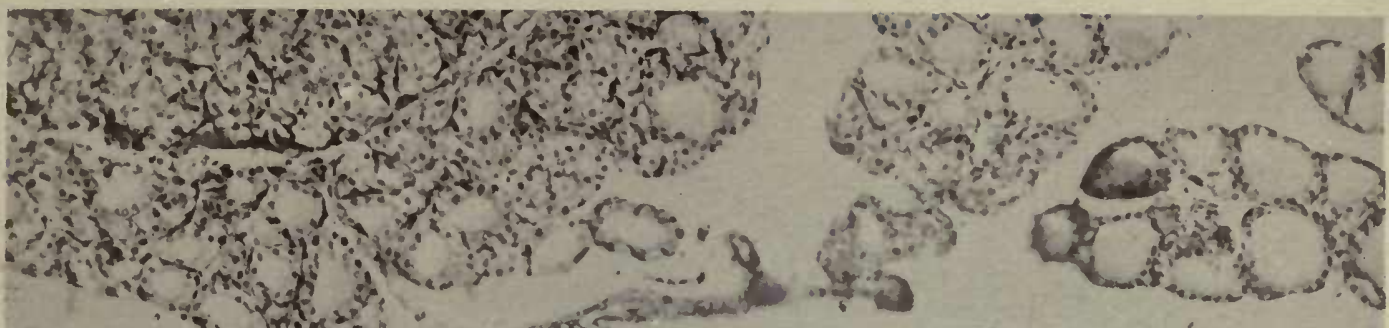
1.7.

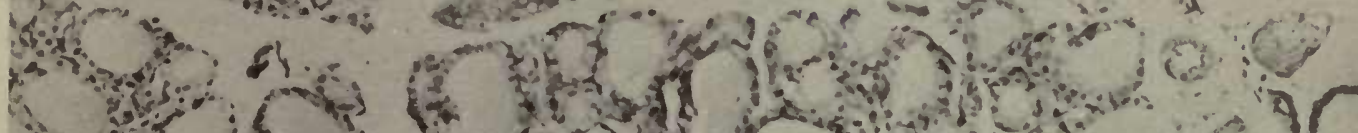

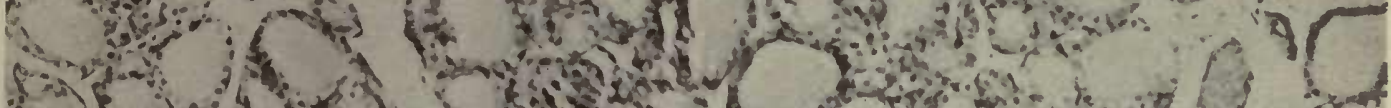

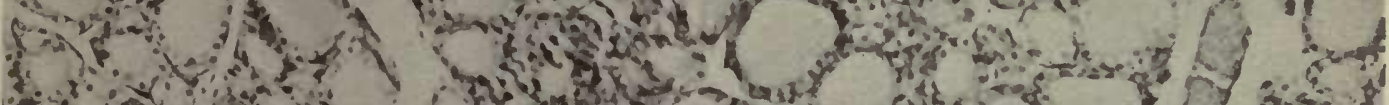
y. 1.

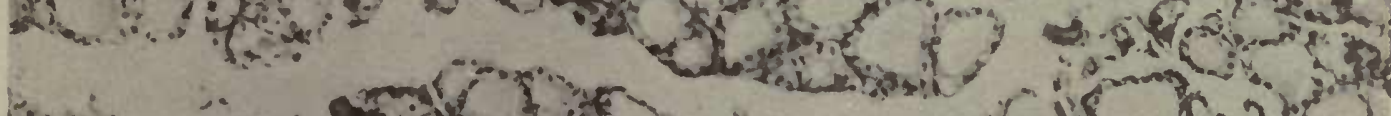
Fin

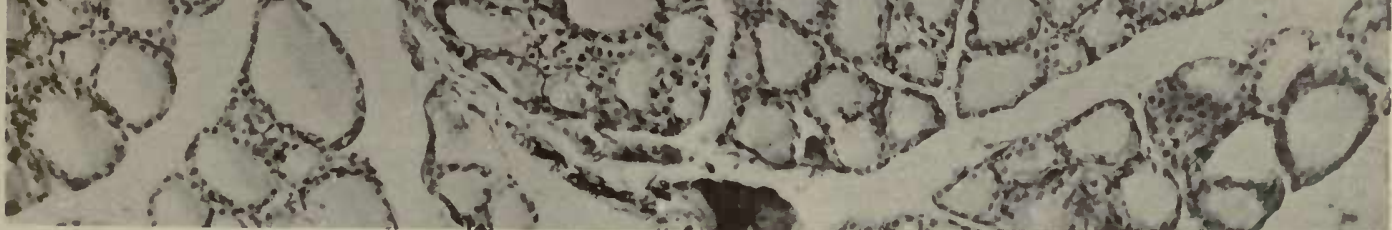

Hig. 120.- Normal thy roid gland of rat 32 used as control for rat 115, figure $121 . \quad \times 160$.

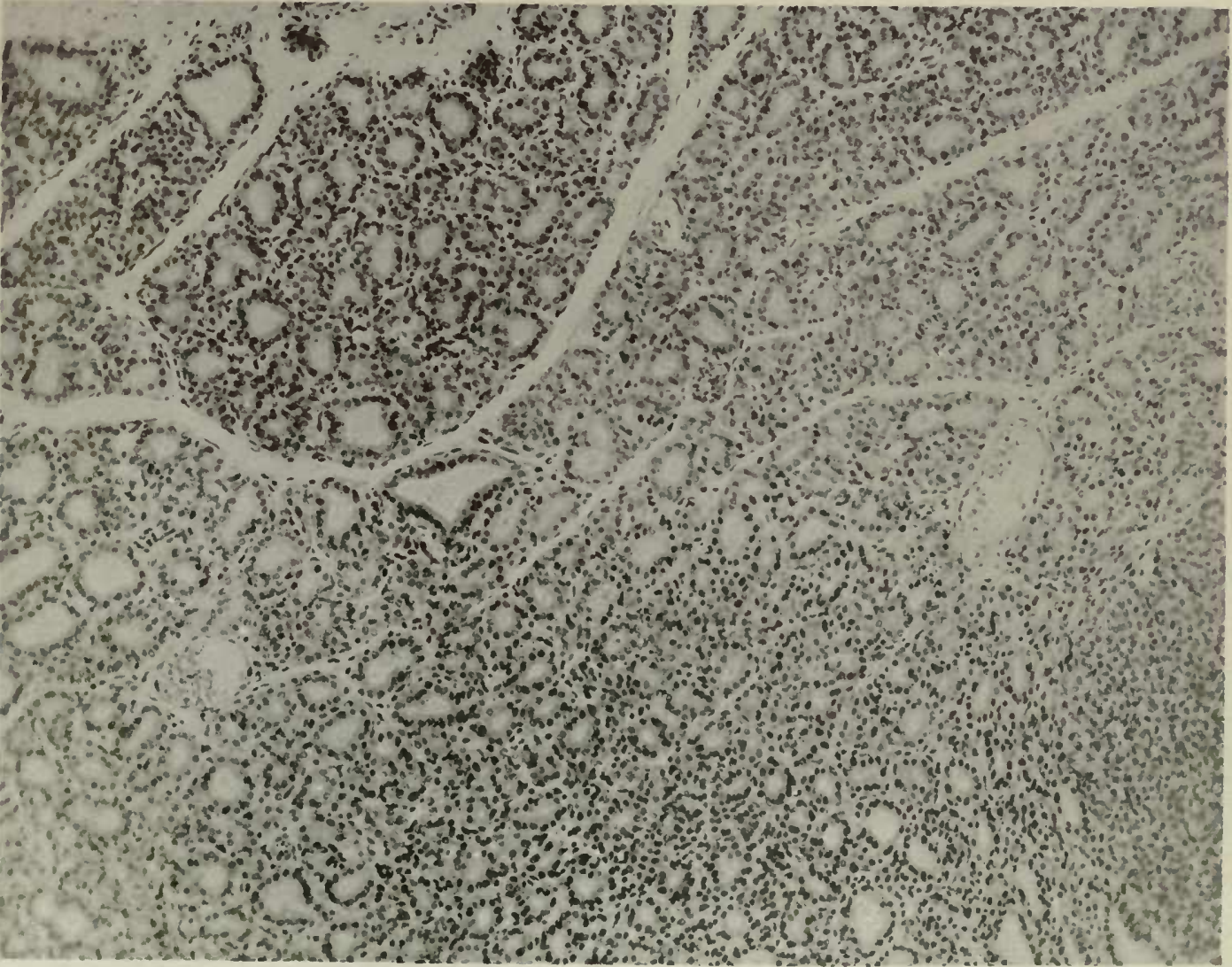





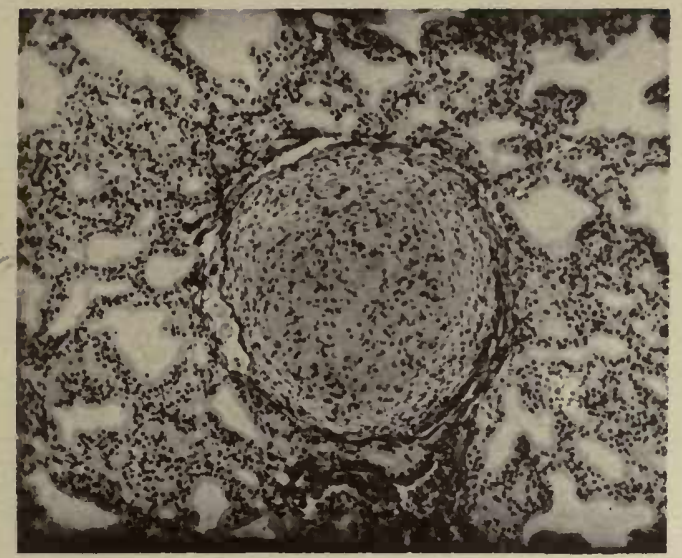

Fisc. 122.-Section of dog's thyroid showing tubercle with cross section of nematode in capsule. $\times 70$.

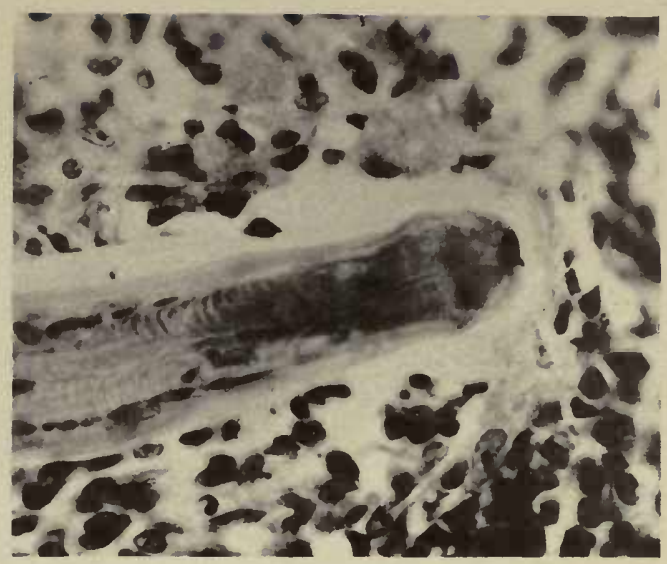

Frg. 123.- Section showing head of nematode inclosed in tubercle. $\times 550$.

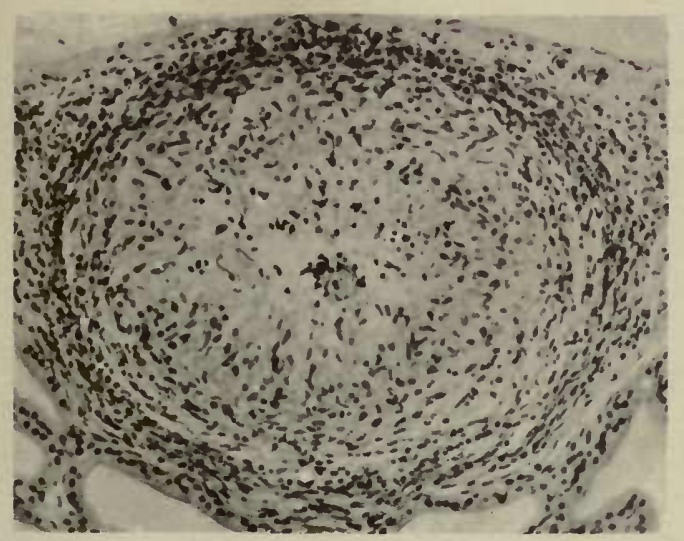

FIG. 124.-Cross section of nematode in center of tubercle. F1G. 124. Cross sectio
in dog's thyroid. $\times 130$.

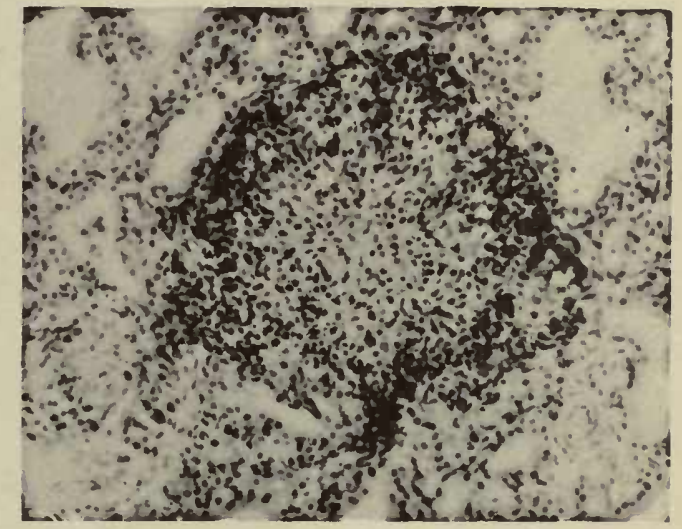

Fjg. 125. - Healed tubercle showing no evidence of
nematode. $\times 130$.

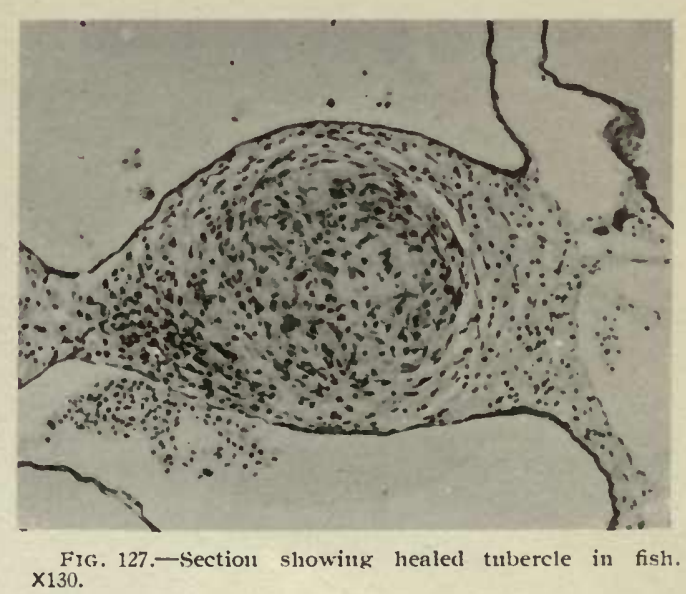

Fig. 127.-Section showing healed tubercle in fish. $\times 130$.

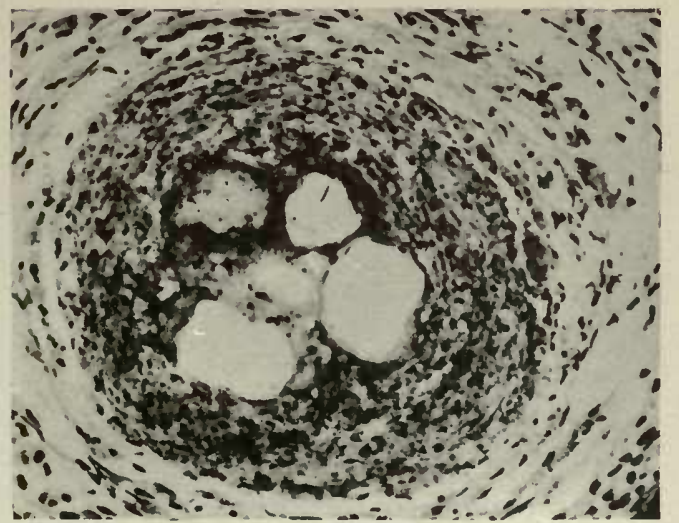

FIG. 126.- Section of tubercle in fish showing spaces evidently occupied by nematode. $\times 240$. 



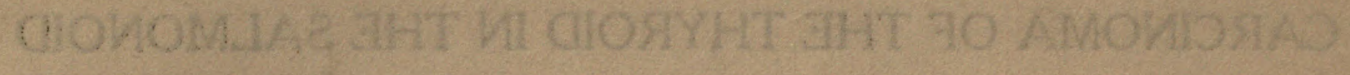

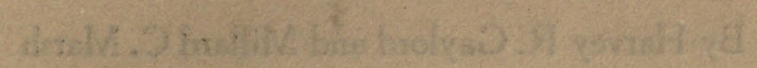

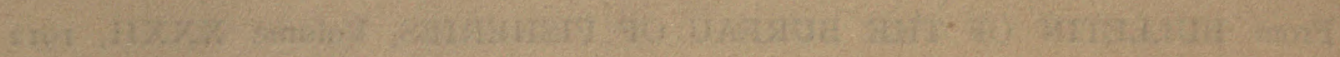

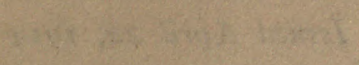
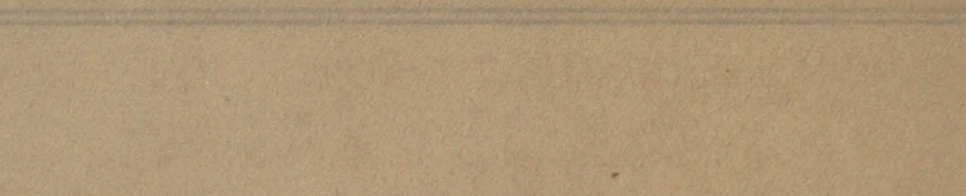

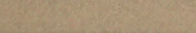




\section{CARCINOMA OF THE THYROID IN THE SALMONOID FISHES : : : By Harvey R. Gaylord and Millard C. Marsh \\ From BULLETIN OF THE BUREAU OF FISHERIES, Volume XXXII, I9I2 \\ Document No. $790::::::::::: \quad:$ Issued April 22, r914 \\ Document No. $790:::::::::::$ Issued April 22, r9I4 \\ $\underline{\text { FISHES }}$}

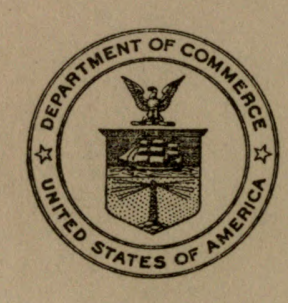

WASHINGTON $: \quad: \quad: \quad: \quad:$ GOVERNMENT PRINTING OFFICE $: \quad: \quad: \quad: \quad: \quad: \quad: \quad: \quad: 1914$ 


\section{UNIVERSITY OF CALIFORNIA LIBRARY BERKELEY}

Return to desk from which borrowed.

This book is DUE on the last date stamped below.

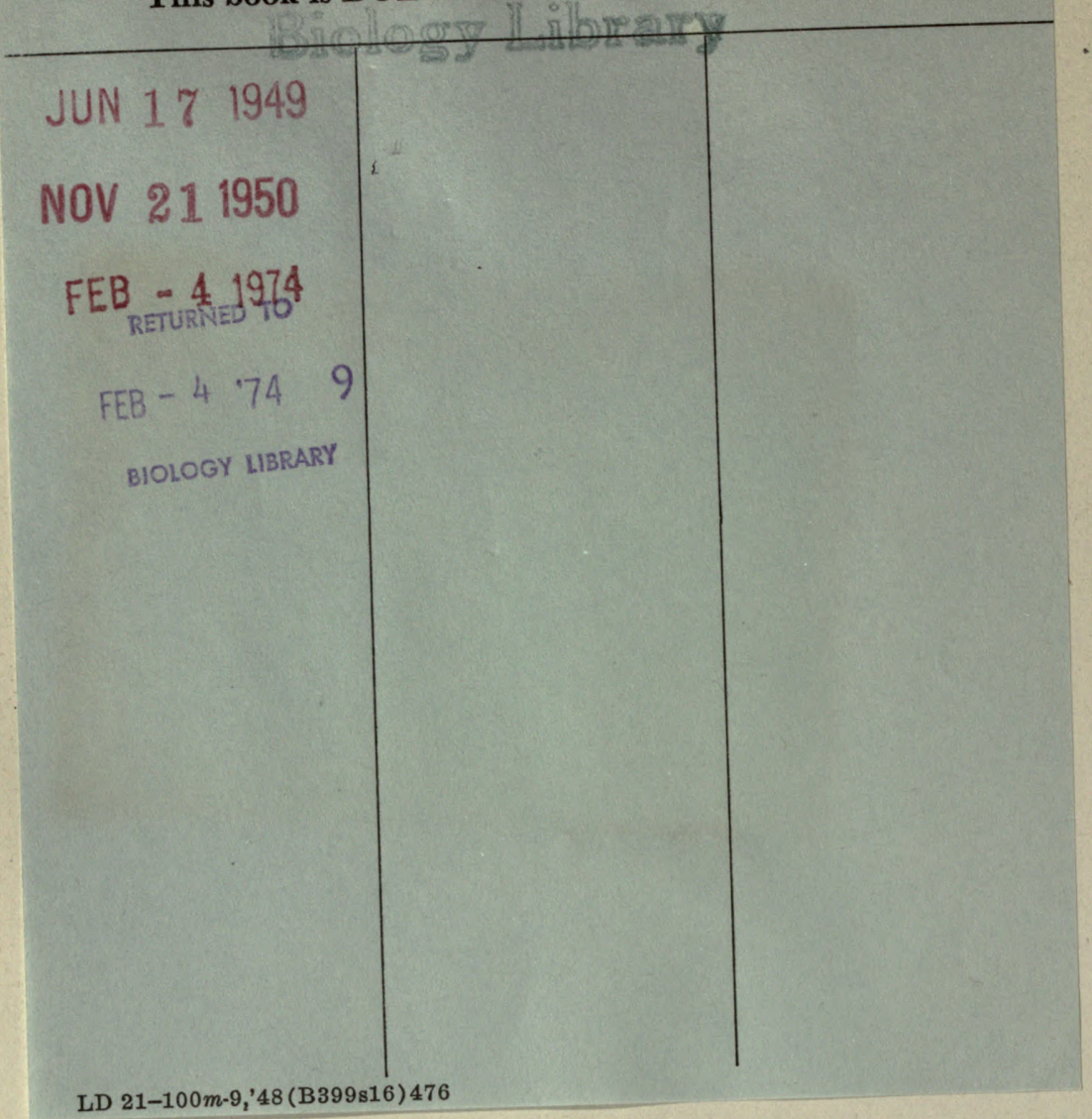


U. C. BERKELEY LIBRARIES

|||||||||||||||||||||||||||||||||||||||||

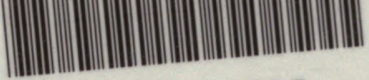

C04583831]

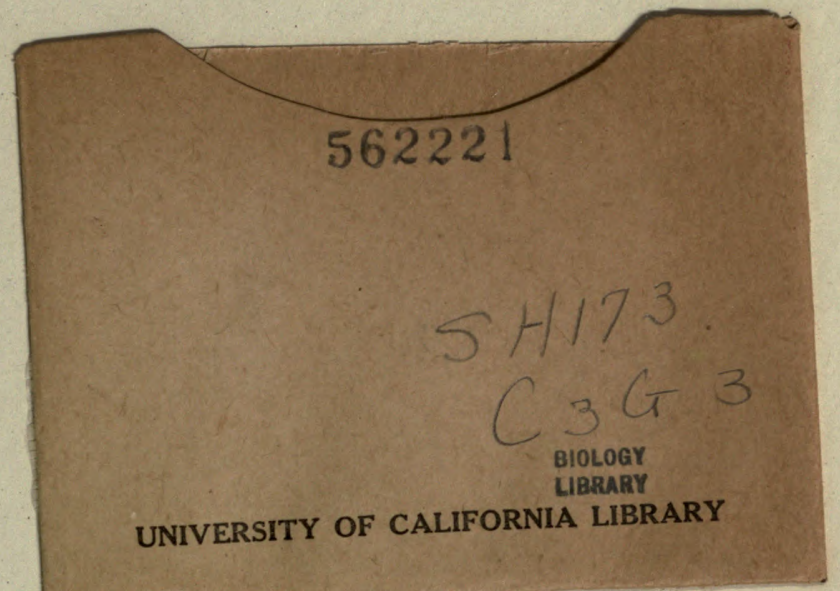


